\title{
INTRODUCTION
}

As a preface to the contents of this volume there is given the following historical sketch of the instrument used before and after modification. The prime vertical transit instrument which was mounted at the old Observatory was purchased upon the recommendation of Lieut. JAMES M. GILLISs, United States Navy, in February, 1844. The instrument was constructed by Pistor \& Martins, of Berlin, Germany, at a cost of $\$ 1,750$. An illustrated description of it will be found in United States Naval Observatory Publications for 1845 .

The instrument was first used for the purpose of obtaining declinations of stars located in the region just south of the zenith of the Observatory. In a large degree the stars observed were at that time lacking in accurately known positions, and the observations were made to improve those places, rather than to use the declinations in ascertaining corrections needed to the Aberration and Nutation Constants that entered into the reduction of the stars from observed to mean place.

The material thus accumulated has been published in the Catalogue of Stars observed at the Naval Observatory during the years 1845 to 1877 prepared by Prof. M. Yarnall, United States Navy.

In 1862 Prof. J. S. Hubbard, United States Navy, assumed charge of the prime vertical transit, and with it commenced a series of observations of the declination of $\alpha$ Lyræ for the purpose of securing material with which to determine corrections to the Constants of Aberration and Nutation, and also to obtain the absolute parallax of that star.

Professor Hubbard died in 1863, and after his death he was succeeded in charge of the instrument by Prof. S. Newcomв, United States Navy, who had as assistants Prof. A. Hall and Prof. WM. Harkness, United States Navy.

Later Professor HaLl was placed in charge of the instrument. It was the intention in the plan of work laid down to continue the observations of $\alpha$ Lyræ long enough to determine a correction to the Nutation Constant, but that intention was not carried out.

In the Astronomical Journal (Vol. 8, Nos. 1 and 2) Professor Hall discusses the material obtained in 1863-1867, and from it obtains a value of the Constant of Aberration. At the close of his paper he states that he considers the observations made of $\alpha$ Lyræ with the prime vertical transit have produced the most accurate declinations ever obtained in this country. •

After 1867 the prime vertical transit was not in use again until 1882. In that year, by direction of Commander W. T. SAmpson, United States Navy, assistant superintendent, observations of selected stars, including $\alpha$ Lyræ, were commenced.

About this time correspondence had passed between the Superintendent of the Naval Observatory and the Director of the Lisbon Observatory, F. A. Oom, captain, Portuguese Navy, with the object of formulating a plan by which simultaneous 
observations would be carried on at both observatories, the latitudes being nearly the same, Lisbon $+38^{\circ} 42^{\prime} .5$ and Washington $+38^{\circ} 53^{\prime} .6$, and both equipped with prime vertical transits. This method had been suggested by the International Geodetic Society.

The observations were commenced at Washington in 1882 and continued until July, 1884. Three observers engaged in the work, namely, Lieuts. Bowman and Ingersoll and Ensign TaYlor, United States Navy. The observations made by them have been published in Volume 3, Second Series, Publications United States Naval Observatory.

In the fall of 1892 and winter of 1893 the removal from the old to the new Naval Observatory was progressing. Advantage was taken of that opportunity to make alterations in the form of the prime vertical transit, and it was sent to FaUth \& Co., instrument makers, Washington, D. C., for that purpose. An appropriation of $\$ 2,500$ to cover the expense had been granted by Congress.

In April, 1893, the remodeled instrument was returned to the Naval Observatory and mounted in its present position. On May 10, 1893, the Superintendent of the Observatory issued an order placing the prime vertical transit in charge of Prof. Edgar Frisby, United States Navy, with Computer George A. Hill as assistant. On May 17, 1893, Mr. Hill was promoted to be an assistant astronomer. He was ordered to supervise the installing of the illuminating apparatus, for this was the first instance in which electric illumination had been attached to an astronomical instrument at the Naval Observatory.

In the latter part of July, 1893, regular observations were begun, and the instrument was in constant use from that time until the end of December, 1912, except for two periods. The first was when the instrument was dismounted in the fall of 1903 for cleaning and repairs, and the second was in 1905, when the observer was away for four months as a member of an eclipse expedition.

Practically all the observations which appear in this volume were made by Astronomer George A. Hill. Computer E. I. Yowell made three observations of $\alpha$ Lyræ in the fall of 1902, and Mr. C. W. FredERICK was assigned to the instrument as an assistant from November 1, 1908, until September 1, 1909, when he resigned his position to accept an appointment at the Naval Academy, Annapolis, Md.

Astronomer George A. HiLl assumed full charge of the instrument on December 9,1893 , in accordance with the following order:

Assistant Astronomer George A. HiLL.

Naval Observatory, December 9, 1893.

Sir:

You are hereby appointed as Chief of Department, Prime Vertical Transit Instrument, from this date:

Very respectfully,

$$
\begin{gathered}
\text { F. V. McNaIr, } \\
\text { Captain, U. S. Navy, } \\
\text { Superintendent, Naval Observatory. }
\end{gathered}
$$

The foregoing historical sketch covers the operation of the prime vertical transit instrument from 1845 down to 1893 , when it was replaced by a remodeled instrument. 
Since the small personnel of the Observatory in 1893 did not permit of assigning more than one observer to the instrument, a careful study was made of the program of work which would, under those circumstances, give the maximum results. It was predicated on the importance of two things:

First, to carry on observations with which to secure corrections to the Aberration Constant.

Second, to continue them over the period of the revolution of the Moon's Node. These studies led to the following conclusions:

1. The observer should make a continuous series of observations of $\alpha$ Lyræ to cover a Dracontic Cycle. The star is bright enough to be seen with the aid of the telescope at any moment on a clear day as it crosses the east or the west vertical.

Moreover, the star's position in right ascension is favorable to a relatively large numerical value, either positive or negative, of the coefficient introduced in an equation of condition to solve for a correction to the Aberration Constant that has been used in reducing the observed declination to its mean place.

2. A study was then made of what other stars, favorably situated, could be used in a similar manner. The study immediately disclosed the absence of a star sufficiently bright to be seen when it crosses the east and west vertical within two hours before or two hours after noon.

3. Attention was then directed to the selection of other stars, 6 hours apart in right ascension, and favorably placed, and to the time of year when they should be observed. Those dates should fall near the positive and negative maxima of aberration for each star. A star at 0 hours of right ascension would have a range of 1.4 in the aberration coefficient; at 6 hours right ascension, 0.5 ; and at 12 hours right ascension the same as at 0 hours.

4. After further study, though its coefficient would not be as large as desired, it was decided to observe $\theta$ Aurigæ, R. A. $5^{\mathrm{h}} 52^{\mathrm{m}}$, from as near August 15 as possible until November 1, and from February 1 until April 15.

The following stars were also tried in this scheme, namely, $\mu$ Andromedæ, $\mathrm{R}$. A. $0^{\mathrm{h}} 51^{\mathrm{m}} ; \alpha$ Canum Venaticorum, R. A. $12^{\mathrm{h}} 51^{\mathrm{m}} ; \gamma$ Bootis, R. A. $14^{\mathrm{h}} 28^{\mathrm{m}}$; and $\tau$ Cygni, R. A. $21^{\mathrm{h}} 10^{\mathrm{m}}$. However, it was found the program was too heavy for one observer.

The plan of observing as outlined above was prepared before the real nature of the variation of latitude had been established. It was continued until about 1900 , although the major portion of the observations were confined to $\alpha$ Lyræ and $\theta$ Aurigæ.

In the spring of 1900 a list of about 360 close zenith stars was placed upon the observing program. The most of these stars are relatively faint, and the purpose in observing them was to improve their declinations. At the same time the program of observing $\alpha$ Lyræ for its special purpose was continued.

It was the intention to secure five observations of each of these zenith stars, and that was done except in two or three cases. Observations of the list were finished in the spring of 1904, and immediately thereafter the polygon method of observing groups of stars with the instrument was commenced. The details of that plan will be mentioned later.

The program of observing $\alpha$ Lyræ was continued until the close of 1912. There have been secured 1,867 observed declinations of that star. 
The building in which the prime vertical transit is mounted is situated about 50 feet north of the clock house. The structure, an entirely detached building, is an iron frame resting on a stone foundation. The sides of the building are covered with a double sheathing, on the outside corrugated galvanized iron and on the inside corrugated zinc.

The space between the inner and outer sheathing is 8 inches, and along the lower portion of the building, on the outside, are louver openings which permit ventilation between the sheathing. On the inside, near the floor line, are small swinging doors, which also serve the same purpose.

The photographs of the building, both inside and outside (Plates I and II) will show its form of construction.

The building, inside measurement east and west, is 17 feet 10 inches; and north and south it is 19 feet 10 inches. The upper shutters are divided in the middle for ease in raising and lowering. They are opened and closed by means of a very excellent system of gearing and counterpoises, and in the many years the house has been in use the gearing has never been out of order or in need of repairs, other than an occasional painting to preserve the iron of which it is made.

The distance from the peak of the upper shutters to the floor is 20 feet 6 inches. The slit when opened is 2 feet 6 inches wide. The side shutters operate in a similar manner, and have the same width of opening as the upper shutters. Plate I shows the handwheels with which both the upper and side shutters are opened and closed.

In designing this type of building the aim was to obtain a form of structure which would respond quickly to changes of temperature. This has in a great measure been accomplished, and the possibility of the material out of which the building is constructed retaining heat and slowly radiating it at night has been reduced to practically a minimum.

On the north side of the building there are two large windows which give additional opportunity to adjust the temperature of the room to that of the outside air.

There is a thermometer shelter attached to the north side of the building, but it has not been used.

\section{THE PIERS OF THE INSTRUMENT}

The large pier, upon which are placed the two upright stone piers supporting the instrument, is massive. It is made of concrete, without reenforcing by means of iron rods or bars. The large pier is built upon a footing of concrete embedded in the ground. It is 10 feet 4 inches from the ground to the top of the pier. At its base the large pier is 9 feet, 11 inches north and south, and 7 feet 11 inches east and west. At the top it is 8 feet north and south, and 5 feet east and west. This pier is capped with a granite slab 12 inches thick.

The two stone piers that support the instrument are each 5 feet 6 inches high. At their bases they are 2 feet 5 inches by 1 foot 4 inches. At their tops they are 2 feet 3 inches by 1 foot 2 inches. They were both cut from the same piece of stone, and weigh approximately 2.26 tons each. 


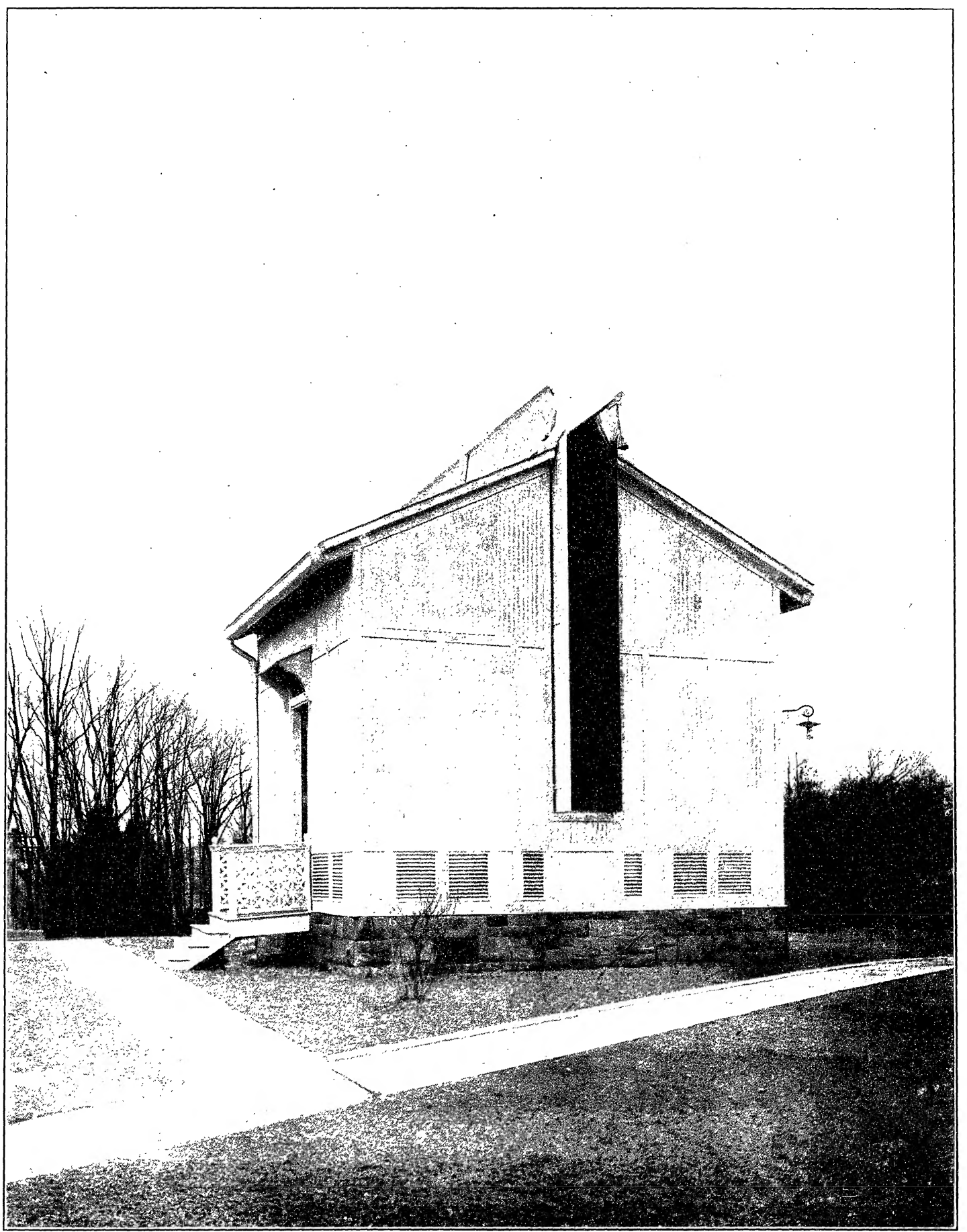

THE PRIME VERTICAL TRANSIT HOUSE 
REMODELING PRIME VERTICAL TRANSIT

When the prime vertical transit was dismounted in 1892, preparatory to its removal to the site of the new Naval Observatory, it was decided to change its general form into a symmetrical type. In its original form (see Naval Observatory Publications, Vol. 1) the cube of the instrument was fastened to one end of an axis that rested in two Y's, and was counterpoised at the opposite end by a weight equal to that of the telescope. In that form there is no question but that an unsymmetrical condition of the instrument prevails.

Therefore specifications to cover the remodeling of the instrument were prepared by Prof. William Harkness, United States Navy, a copy of which follows:

SPECIFICATIONS FOR REPAIRING AND REMOUNTING THE PRIME VERTICAL TRANSIT INSTRUMENT, NAVAL OBSERVATORY

The work of repairing and remounting the prime vertical transit instrument shall include the following particulars:

Telescope.-The present unsymmetrical axis shall be removed, and a new symmetrical axis shall be provided, to the center of which the two halves of the present telescope tube shall be attached. The said axis shall be of the best phosphor bronze, properly turned and finished, with a central cube measuring about 10 inches on each side. The length of the axis between the centers of the $Y$ 's shall be not less than 40 inches, and the telescope tube shall be placed midway between the two Y's.

Four new positive Kellner eyepieces, with sunshades, shall be provided, their equivalent focal distances being respectively 1 inch, $3 / 4$ inch, $1 / 2$ inch, and $1 / 3$ inch, and special care shall be taken to make them achromatic and to have their fields of view as large and flat as possible.

Pivots, Y's and striding level.-The pivots shall be of hardened steel, properly turned and polished, and each about $2 \frac{1}{4}$ inches in diameter. The Y's shall be of the ordinary $\mathbf{V}$ shape, and shall be provided with the usual adjustments in azimuth and level. The present striding level shall be altered to conform to the new mounting of the instrument, and shall be provided with suitable apparatus for mechanically placing it upon the pivots, and making the necessary reversals to determine the inclination of the axis, and removing it out of the way after the required readings have been obtained. Said level shall be furnished with a new chambered bubble tube of the best quality, ground to such a radius that a change of inclination of 15 seconds of arc will cause the bubble to move through a space of not less than 1 inch.

Illumination.-Means shall be provided for illuminating the field of the telescope both by incandescent electric lamps and by gas or oil, so that either can be used at will. Said illumination shall be arranged to give dark wires upon a bright field, and suitable means shall be provided for modifying both the color and intensity of the light, and giving the peculiar illumination required in making nadir observations.

Reversing apparatus and counterpoises. - New reversing apparatus shall be provided, arranged to always remain in position, and capable of reversing the instrument in 45 seconds or less. All counterpoises shall be so constructed as not to interfere with the rapid reversal of the instrument.

Reflection apparatus.-A suitable mercury basin for obtaining the nadir shall be provided beneath the floor of the observing room, and an apparatus at least as good as that usually furnished with the Repsold transit circles shall be provided for observing stars by reflection.

Observing couch.-An observing couch of suitable height, and similar in design to that now used with the transit circle of the Naval Observatory, shall be furnished.

Finish.-All parts of the instrument shall be refinished and relacquered, all missing parts shall be supplied, and everything needful to restore the instrument to perfect condition shall be done, notwithstanding any omissions in these specifications. 
Remounting of instrument.-After the repairs specified above have been executed, the prime vertical transit instrument, together with everything pertaining to it, shall be transported to the Naval Observatory, Georgetown Heights, Washington, D. C., and shall there be remounted and put in order for immediate use. Two new piers shall be provided for supporting the instrument, together with all necessary platforms and steps, and the said piers shall consist of a single block of solid marble of such dimensions and finish as the Superintendent of the Naval Observatory shall direct.

This work shall be set up in place designated for it at the Naval Observatory, Georgetown Heights, Washington, D. C., completed and ready for use, on or before March 1, 1892, and subject to the approval of a board of naval officers to be appointed by the Secretary of the Navy.

\section{THE REMODELED INSTRUMENT}

A description of the remodeled instrument, as mounted by the instrument makers, is as follows:

The telescope.-The object glass has a clear aperture of 4.86 inches and is 77 inches in focal length. No change was made in the object glass, or the cell in which it is placed, except to clean the glass and relacquer the cell. As a matter of information it is stated that the object glass cell is not provided with a spring.

The length of the axis of the instrument, from the outside edge of each pivot, is 43 inches, and the sides of the cube are 10 inches. The pivots are $2 \frac{1}{4}$ inches in diameter, pierced through their centers by a hole 1 inch in diameter, which permits light to pass into the cube for the purpose of illuminating the transit threads.

Two small setting circles, divided into degrees and 10 minute spaces, and read by verniers to 10 seconds, are fastened on opposite sides of the telescope tube near the eye end. They are graduated to read zenith distances. They are supplied with small level tubes, for the purpose of defining the plane of the horizon.

The need for two circles is due to the fact that when the observer is about to note transits of a star he sets the circle on the side of the telescope corresponding to the first appearance of the star in the field of view, at a zenith distance equal to that of the object about one minute of time before it will reach the first transit thread. The other circle is set to the zenith distance the star will have, after the first tally of transits has been recorded and the instrument reversed.

Leveling apparatus.-By consulting Plate I, an iron post will be seen on the top of the north pier, the one on the left as seen in the photograph. To this post an arm is fastened, the function of which is to support the level frame. Engaging in this arm is a round piece of steel, one-half inch in diameter, 10 inches long, and cut its entire length with a screw of a very coarse pitch. This screw passes through the arm and is held in place by a gear wheel in pitch with it. Another gear wheel is fastened to a rod running along the top of the frame, and is in gear with the one just mentioned. At the opposite end of the rod is a handle, which when turned revolves the rod, and by the system of gears just mentioned the level frame is elevated or lowered.

The long screw just described is securely fastened to the center of a flat iron bar which is directly over the level frame. At the ends of this bar two pieces of metal in the shape of a hook are bolted. It is the duty of these two hooks to raise the level frame from the pivots, and when the apparatus is not in use to support the same. 


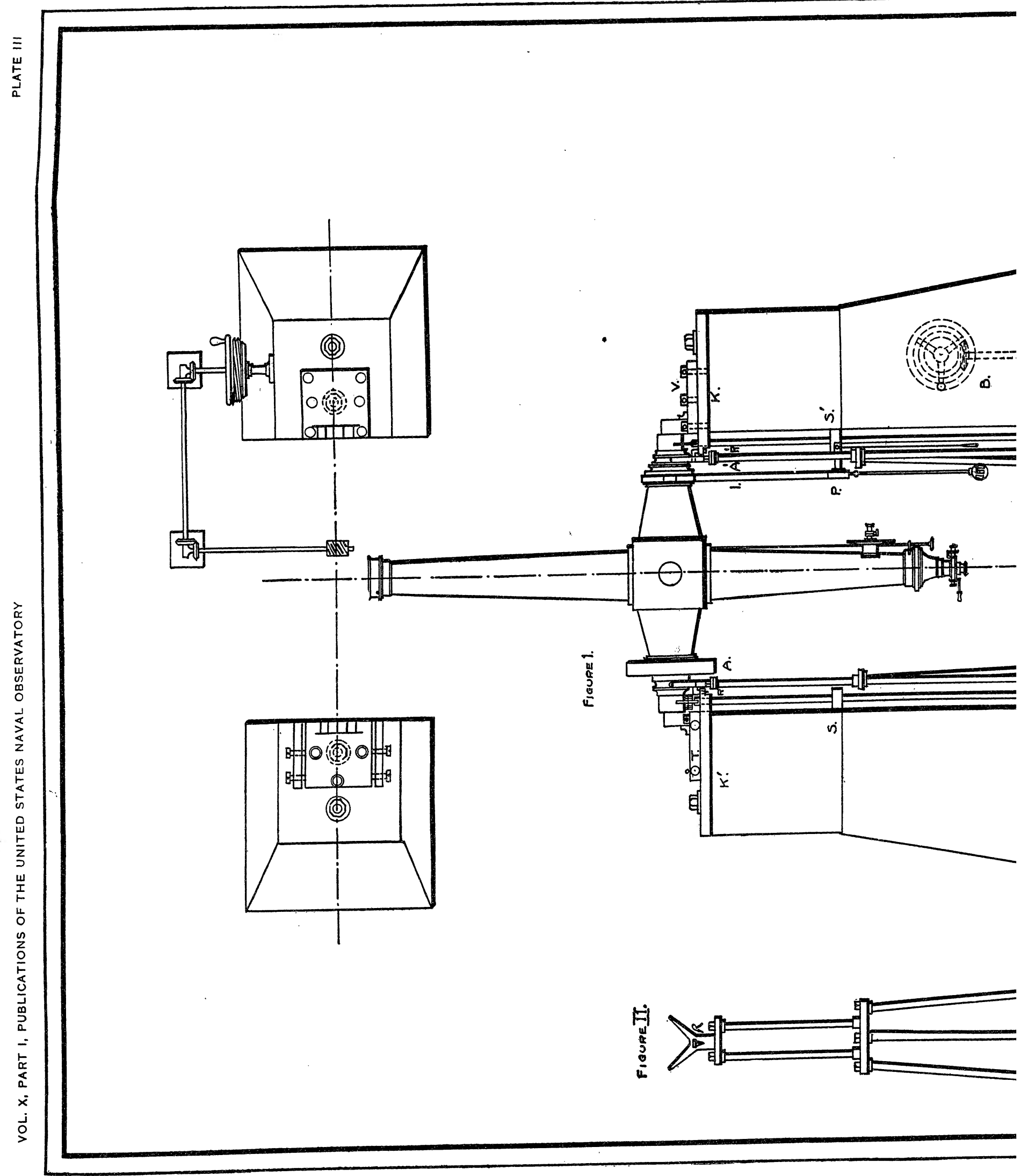




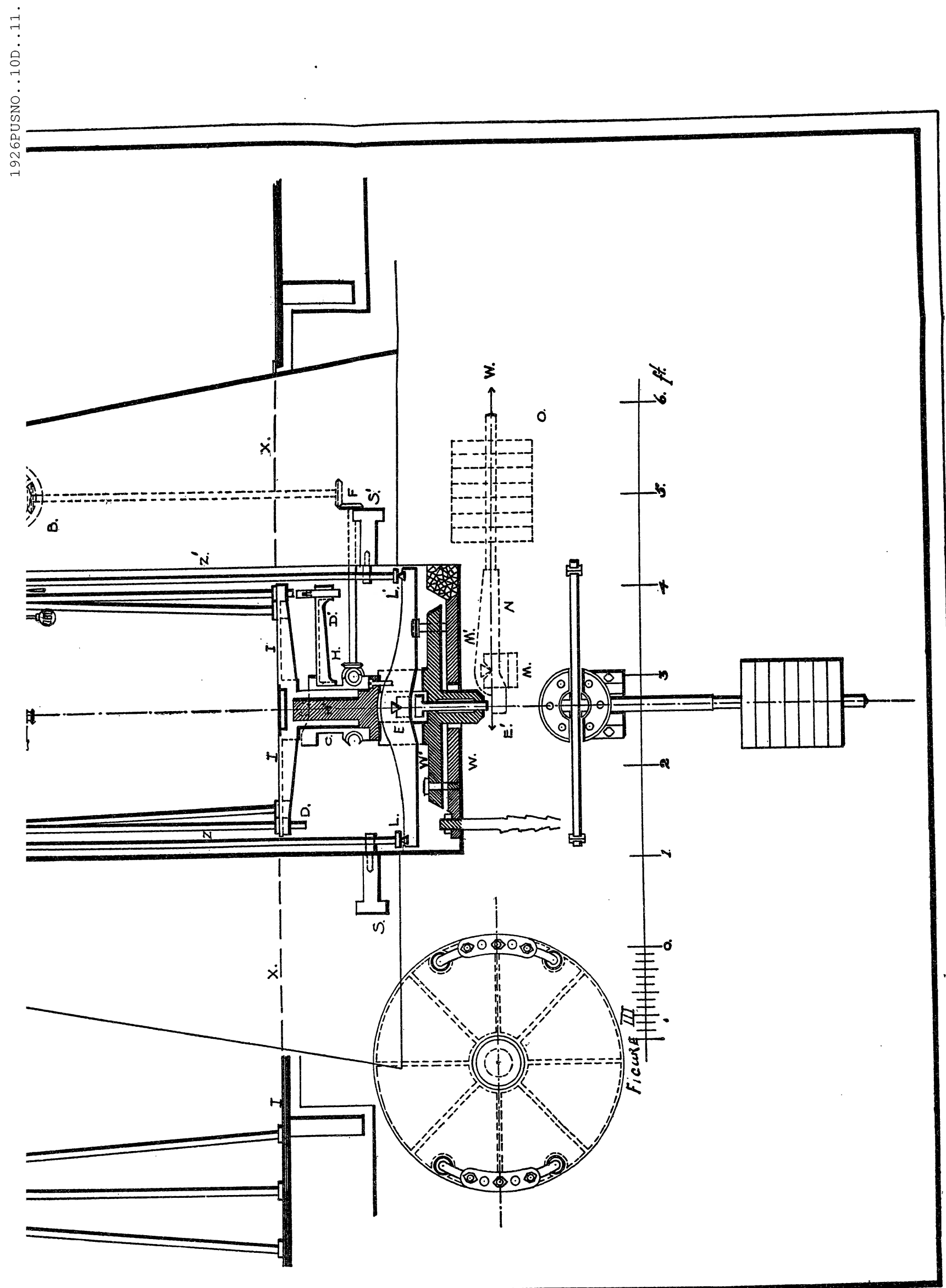

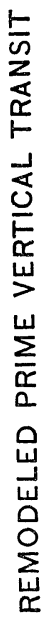




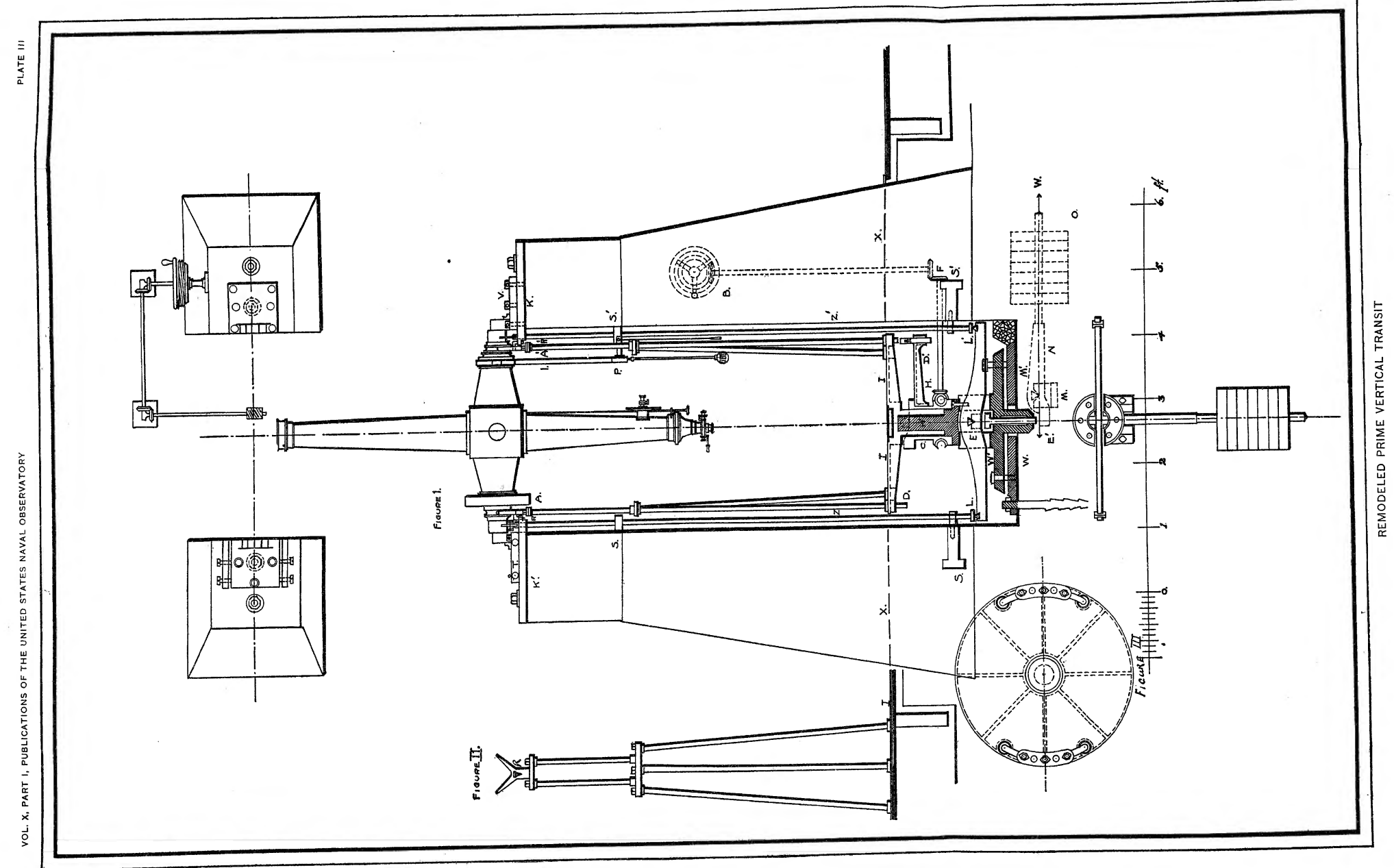

John G. Wolbach Library, Harvard-Smithsonian Center for Astrophysics • Provided by the NASA Astrophysics Data System 
Attached to the upper surface of these two hooks are two pins, three-sixteenths of an inch in diameter and one-half of an inch in length. In the center of the bearing surface of the level frame as it rests in these two hooks are two holes, slightly larger than the pins. Their purpose is to prevent any side thrust of the level frame on the pivots when the frame is lowered on or raised from the pivots.

In other words, the mechanical placing of the level Y's on the pivots or elevating them therefrom is done automatically, no matter how many times the apparatus is reversed.

The crane supporting the leveling apparatus is placed over the pivots of the instrument, or removed therefrom, by meáns of a handle fastened to the upright. post just mentioned. This post is in two parts. That portion just below the handle is bolted to the pier, and does not move. The portion above the handle revolves on a pivot placed in the middle of the lower section of the post. There are two stops, one fastened to the movable part, and the other to the fixed part of the post.

When the observer turns the crane so as to bring the projecting arm supporting the leveling apparatus over the instrument, and it has reached a plane passing through the center of the level box and the pivots of the instrument, the two stops meet, and prevent the crane from passing beyond that point.

Attached to the right-hand end of the arm extending over the instrument, and in pitch with the large screw, is a device called a dog. At one end of this dog a $\sqcap$-shaped spring is fastened.

With this explanation of the several parts of the leveling apparatus, we will point out the steps taken in obtaining a level reading.

The apparatus having been moved over the instrument, the observer turns the handle that operates the gear wheels in the proper direction, and the level frame is lowered on the pivots. The two hooks which had supported it, as soon as relieved of the weight of the frame, because this operation places the Y's of the level on the pivots, descend sufficiently to be free from contact with the frame.

To reverse the level the observer turns the handle in the opposite direction. This motion raises the hooks which in turn elevate the frame from the pivots. This is continued until the large screw has raised the support for the level frame far enough to permit the $\Pi$-shaped spring to extend its sides around a short piece of steel fastened to the support. This piece of steel can be seen in Plate I just to the right of the point on the support where the screw is fastened to it.

A clutch is now secured between the level frame which it is desired to turn half way around, and the device for doing so. This mechanical contrivance permits the level frame to make a half revolution without handling by the observer. As soon as a half turn has been made reversing the motion of the handle releases the $\neg$-shaped spring from its grip on the piece of steel, and the level frame is lowered on the pivots.

In the middle of the arm supporting the level frame (see Plate I) there will be seen projecting downward what may be termed another form of stop. One end of this is bolted to the arm, and at the opposite end is fastened a brass tube, 4 inches long and $1 / 2$ inch in diameter. Inclosed in the tube is a round piece of steel rod, that rests on a short spiral spring at the bottom of the tube. A slit has been cut in

$$
101141^{\circ}-26 \text { † }
$$


the brass tube and to prevent the spring from pushing the steel rod out of the tube, a small screw is tapped into the rod, and moves up and down within the limits of the slit just mentioned.

There are openings at each end of the cross bar to which the hooks supporting the level frame are bolted. When the level frame is reversed, and as it approaches a half turn, the end of the bar presses down on the steel rod. until the bar has advanced far enough to permit the tension of the spring to push the steel rod up through the opening, thus preventing the level frame from passing beyond a plane through the pivots and the Y's of the level frame.

By the operation of the several devices just described the striding level is always placed on the pivots in an automatic manner, without jarring the level tube or necessity of operating the leveling apparatus through the medium of the hands of the observer.

Moreover, the points of contact of the Y's of the level frame with the surfaces of the pivots must necessarily, under conditions explained, be the same every time a level determination is obtained.

A movable weight fastened to a rod on the opposite side of the arm supporting the leveling apparatus acts as a counterpoise.

A thermometer is suspended directly over the instrument, and its readings recorded every time a level reading is made.

The illumination.-On the top of each stone pier has been placed what may be termed hoods. They are made of tin, and painted a dark color. Each covers an electric lamp of 16 candlepower and 110 volts. The lamps are placed in sockets attached to blocks of wood upon which the tin hoods rest. At the top and bottom of each hood holes have been made in the tin, to permit a circulation of air inside the hood so as to avoid an accumulation of heat therein. The electric current is conveyed to these lamps by wires attached to a side of each of the piers.

The electric current having been turned on, the illumination from one of the lamps passes through an extension of the hood, through the axis of the instrument, to a small mirror three-fourths of an inch in diameter placed in the cube. From the mirror the illumination is reflected symmetrically on to the transit threads.

In Plate I a small cap will be seen in the center of the cube of the instrument. This covers a hole in the cube. In the center of this cap an opening has been made, and in this opening a piece of round brass rod, painted a dead black color, fits snugly. On the end of this rod, and in the center of the interior of the cube, the mirror is fastened. The metal part holding the mirror is also painted a dead black. A short piece of brass rod is fastened to the rod extending into the cube, and by turning the former a proper angle can be given to the mirror to reflect the illumination on to the transit threads.

Along the side of the telescope tube, extending from the eye end to the central portion of one face of the cube, is a brass rod. This rod connects with a disk on the inside of the cube. This disk is placed at right angles to one of the openings through the pivots.

Around the circumference of it fo'ur circular openings have been cut, each about an inch in diameter. One of the openings permits the illumination from 
the lamp to pass through the disk without interference. The space covered by another opening in the disk is filled with small holes that permit only about 50 per cent of the illumination to pass through. The third, fourth, and fifth openings are covered with light red, deep red, and blue colored glass, respectively. By turning the rod, at the eye end, it revolves the disk and any of these colors or any intensity of illumination can be obtained. By properly combining both it is possible with bright field illumination, under ordinary conditions of seeing, to observe transits of an 8.0 magnitude star with the instrument.

The adjustment for level and azimuth.-The adjusting screws by which the instrument is leveled are tapped into the left-hand $Y$, as shown in Plate I. The base of the $Y$ is fastened to the pier by the aid of four bolts. Four holes were drilled in the pier, slightly larger than the bolt, and after the base of each $Y$ was placed in position, the space around the bolts was filled with plaster of Paris.

The upper part of the $Y$ by which the instrument is leveled is accurately fitted into the lower part, so that the former may slide up and down in the latter. On either side of the $Y$ there are two bolts with relatively large heads, but with screws of fine pitch. These are tapped into the lower section of the $Y$, and the upper section rests upon the heads of these bolts. In the lower section of the $Y$, and between the two bolts just mentioned, is a third, tapped into the upper section of the $Y$. The instrument is made horizontal by elevating or depressing these screws, and after the adjustment has been made, two set screws on the north face of the $Y$ firmly hold the upper to the lower part.

The adjustment in azimuth is made by a transverse motion of the $Y$ on the south pier, the right-hand one as seen in the illustration. The upper part of the $Y$ is dovetailed into the lower part. Tapped into the east and west faces of the $Y$ are two opposing bolts the duty of which is to move the $Y$ in azimuth. Two bolts tapped into the south face of the $Y$ serve, after the adjustments have been made, to clamp the upper part of the $Y$ to the lower part.

The reversing apparatus.-In Plate III at $\mathrm{Z}$ and $\mathrm{Z}^{\prime}$ are shown two rods made of iron tubing, $1 \frac{1}{2}$ inches in diameter. In the upper end of each a short piece of steel is fastened, polished to a blunt point and made glass hard. Two blocks of metal, flat on top and curved underneath are placed on these two blunt points. On the under side of each a depression has been countersunk, and in these depressions the blunt points of the rods $\mathrm{Z}$ and $\mathrm{Z}^{\prime}$ fit.

In each block are placed friction rollers, and on these the instrument is supported. The rods $\mathrm{Z}$ and $\mathrm{Z}^{\prime}$ extend from the axis of the instrument downward beneath the floor at $X$, and rest on steel knife edges at $L$ and $L^{\prime}$. The guides at $S$ and $S^{\prime}$ keep them in alignment.

The heavy iron casting at $\mathrm{W}$ is placed on the top of the large pier, to which it is bolted. This casting, which is in the form of a triangle, does not touch either of the two piers placed on the large one. A large steel bolt passes up through the casting and supports the knife edge at $\mathrm{E}$.

At $M$ is a block of metal supporting another knife edge at $\mathbf{M}^{\prime}$, and on this the weight of the counterpoise arm $\mathrm{N}$, for the whole instrument, is balanced. At $\mathrm{E}^{\prime}$ a hole is countersunk into the arm, and the end of the bolt that fits into it has been 
finished so as to be similar to the points in the upper part of the rods supporting the two friction rollers that relieve the weight of the instrument from the pivots.

The weight at $O$ can be increased or decreased at pleasure, and the amount of weight carried by the pivots in the Y's regulated to suit the observer. It has been found, after long use with the instrument, that a weight of about 10 pounds gives the best results, and prevents the instrument from moving up along the edges of the Y's as it is revolved on the pivots.

The blunt points upon which the two blocks at $Z$ and $Z^{\prime}$ are balanced are practically an open ball and socket joint. It is impossible, when the telescope is resting on them, for the friction rollers to assume any other than a direct upward bearing. These rollers are 3 inches in diameter, their faces planed to a smooth surface, and the bearing surface is three-fourths of an inch wide.

At $\mathrm{A}$ and $\mathrm{A}^{\prime}$ are supports that elevate and hold the telescope when it is to be reversed. Figure II of Plate III shows a side view of these. In the normal position of the instrument they are entirely free from contact with it. They are fastened to the floor at I.

On top of the casting, at $\mathrm{W}^{\prime}$, is placed a cylinder $\mathrm{C}$, into which a smaller cylinder $\mathrm{H}^{\prime}$ is fitted. At this point in the construction of the reversing apparatus there is an important detail to which attention is called. When the supports, A and $A^{\prime}$, and the circular floor I are elevated, for the purpose of reversing the instrument, it is absolutely necessary that the motion shall be exactly vertical; otherwise there will be a side thrust of the pivots in the Y's. The cylinders are therefore made very rigid, about 10 inches in diameter, and both turned to a true bearing. These cylinders are made so true that a very small inequality of level of the circular floor will make them bind, and prevent the instrument from being reversed.

At $\mathrm{H}$ is a worm screw in pitch with a wide thread on the outside of the outer cylinder. A rod runs from $\mathrm{H}$ to $\mathrm{F}$, and then to $\mathrm{B}$. This rod ends in a handle fastened to a bracket near the right-hand pier, as seen in Plate I. When the handle is turned, the motion revolves the screw at $\mathrm{H}$, and that elevates the cylinder $\mathrm{C}$. The turning of the handle also moves the two supports $\mathrm{A}$ and $\mathrm{A}^{\prime}$ upward, and the telescope is lifted from the $Y^{\prime}$ 's. The arm at $\mathrm{D}^{\prime}$, which is bolted to the cylinder $\mathrm{C}$, also revolves. As the telescope, by turning the handle, is elevated sufficiently to be free from interference with the Y's, the arm just mentioned has also been elevated enough to come into contact with the device at $\mathrm{D}$ called a dog. Continuing to turn the handle presses the arm against the dog and the telescope is given a half turn.

Fastened to the left-hand pier in Plate I, near the floor line but not shown in the drawing, is a stop. This prevents the telescope from passing beyond a half turn. After the telescope has been reversed, changing the motion of the handle reverses the motion of the gears just explained, the pivots of the instrument are lowered into the Y's, the friction rollers taking up the weight of the telescope, and the two supports are depressed to free them from contact with the instrument. At $R$ and $R^{\prime}$ are two perpendicular stops which act as guides to the telescope as it is coming into a position of rest in the $Y$ 's.

The under surface of the turntable at I (also shown in Plate III, Fig. III) is that upon which the telescope is revolved. The turntable is made of cast iron, 
and the under surface of the casting has been planed smooth to provide a proper rolling surface.

The turntable rests upon four antifriction wheels (not shown in the drawing). These wheels turn on spindles in four metal pieces called supports. These supports are fastened to the iron frame resting on the top of the large pier W. In addition, each support is a section of an endless screw. On the circumference of the turntable is fastened a gear wheel which is in pitch with the screws on the friction roller supports.

Assuming the telescope is to be reversed, the gear in pitch with the screw on the cylinder is made to revolve by turning the handle near the right-hand pier. That elevates the cylinder, and as it moves upward each of the friction rollers follows, thus keeping the turntable level.

As will be seen in Plate III, Figure III, the frame of the turntable resembles a wheel with its hub, spokes, and rim. In the spaces between what appear as spokes pieces of boards are fastened. When it is necessary to inspect or clean the portion of the reversing apparatus beneath the floor these boards can be removed.

The specifications under which the prime vertical transit was repaired stipulated that the reversing apparatus should permit the instrument to be reversed in a maximum limit of 45 seconds. It is practicable to reverse the instrument, reset it, in zenith distance, and place the observing couch under it, in approximately 25 seconds.

The reflection apparatus. - The prime vertical transit is supplied with two pieces of apparatus by which reflection observations may be made. In the center of the frame of the turntable that has been described is a circular iron basin. In this is placed a copper basin, the entire inner surface of which has been amalgamated. This copper basin contains the mercury by which adjustments of the collimation and of the circles may be made. The basin is provided with an iron cap to prevent foreign matter from falling onto the surface of mercury.

The other basin is for the purpose of obtaining transits by reflection. The apparatus is in the form of an iron box, 7 inches wide; 32 inches long, in which has been placed a copper basin that has been amalgamated. The two basins rest on a low carriage mounted on four wheels. This is for ease in placing the basin under the instrument, and after use moving it away.

In the frame of the carriage there are three screws, two in one end and one in the other. The purpose of these screws is to make approximately level the mercury in the basin. When it is desired to observe a star by reflection the carriage is rolled onto floor of the turntable. This floor is entirely free from contact with the floor of the transit house.

The surface of mercury in the basin is of sufficient length, counting from its center over the nadir of the instrument, to permit a star falling within the maximum zenith distance adopted in this work to be observed by reflection. The minimum zenith distance, based upon the height of the object glass from the surface of mercury, and the diameter of the object-glass cell, that a star can be observed by reflection with the instrument is just over $4^{\circ}$. The maxiumm zenith distance is about $25^{\circ}$. All stars in this volume have been observed at less than $18^{\circ}$ zenith distance in the prime vertical. 
The eyepiece and reticule.-The box containing the transit threads is attached firmly to a piece of brass tubing, 15 inches long and $1 \frac{1}{2}$ inches in diameter. This piece of tubing fits into the tail end of the telescope. Along the surface of the tubing a piece of steel is fastened. When the tubing is pushed into the tail end, this piece of steel slides into an indentation cut into the end of the telescope. Two opposing screws are tapped into the tail end of the telescope, and their ends press against the piece of steel. The steel strip has sufficient motion in the identation to permit the transit threads to be adjusted to a true vertical position. When that adjustment has been accomplished, as well as the stellar focus of the instrument determined, the two opposing screws clamp the tailpiece to the telescope. This adjustment is made without the aid of a focusing screw, as none was provided.

The eyepiece that has been used with the instrument has an equivalent focal length of $1 / 2$-inch, and a magnifying power of about 155 . There is attached to the box a slide, into which the eyepiece holder is screwed. The slide, by the aid of a short screw, can be moved at right angles to the axis of the telescope.

The system of transit threads that was first used is shown in the accompanying illustration Plate IV. In the center is indicated the vertical fixed middle thread, with the movable one, indicated by a dotted line, adjacent to it. On either side of the middle thread there are two groups of seven threads each. Over these the transits were recorded, except in the case of one star which will be explained later. The threads are spaced about three seconds of time, equatorial interval.

As the STRUve method of observing with the prime vertical transit, avoids the necessity of an accurate knowledge of thread intervals, those intervals have not been determined, except as will be explained in the paragraph under the micrometer. The space in the field of view of the eyepiece between which transits are recorded is indicated by the two horizontal lines shown in the illustration.

The motion of a star, as is well known, across either the east or the west vertical is not at right angles to the transit threads, as it is when a star crosses the meridian. The apparent motion of the star is in an oblique direction. On the east vertical it is increasing its altitude, and 'on the west vertical it is decreasing its altitude.

Therefore as the star transits each thread the object glass must in one case be moved toward the zenith to bring the star between the horizontal threads, and in the other case moved from the zenith. This change of zenith distance which is necessary, for the group of threads spaced as those shown in the illustration, is between $15^{\prime}$ and $1^{\circ}$ of arc on each vertical.

The micrometer.-The use of a micrometer screw with a prime rertical transit is for three purposes. The first is when a star passes the east and west verticals within a short distance of the zenith. Its motion then is so slow that to observe transits over threads as they are ordinarily placed would consume considerable time. In fact, the declination being nearly equal to or slightly greater than the latitude, the star would not pass out of the field of view during the time that it is crossing from the east to the west vertical.

A method is given in almost every textbook on practical astronomy by which, knowing the angular value of one revolution of the micrometer screw, and by setting the thread at either whole or half turns of the screw in the direction the star is mov- 


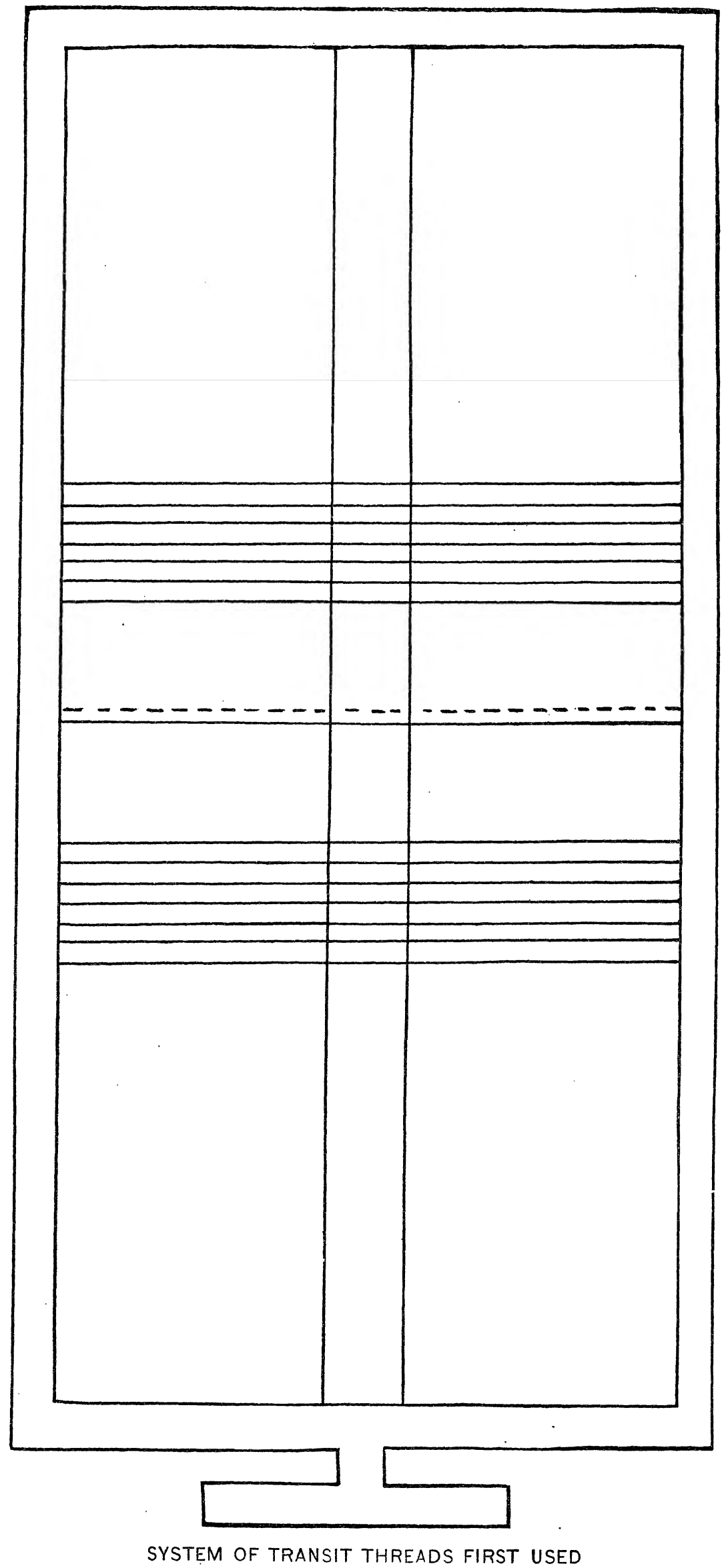


ing, and noting the times of transit at these successive settings, the difference between the latitude and the declination of the star can be obtained. In the observations included in this volume only one star was observed in accordance with this method, the details of which will be mentioned in another paragraph.

The second use of the micrometer is to measure changes of azimuth of the instrument by making readings on the mark.

The third use is to point the telescope vertically downward toward a surface of mercury, and measure with the micrometer the distances of the middle thread from its image, in both positions of the clamp. The measurements will give both the collimation and the level of the instrument. This third method has only been used to adjust the instrument for collimation.

The method by which the angular value of one revolution of the micrometer screw is ascertained in the case of a transit instrument placed in the prime vertical is as follows:

The value of the screw can be obtained from the observations made to determine the declination of the star.

Let $c$ equal the distance of any thread in a group from the collimation axis positive when north. Let $t$ equal one-half of the elapsed time between the transit of a star across a thread on the east vertical, and its transit across the same thread on the west vertical, the clamp of the instrument being north. In a similar manner let $t^{\prime}$ equal one-half of the elapsed time of a transit across the same thread, the clamp being south.

Let the symbols $\varphi$ and $\delta$ represent the latitude and the declination of the star, respectively; then,

$$
\begin{aligned}
-\sin c & =\cos \varphi \sin \delta-\sin \varphi \cos \delta \cos t \\
\sin c & =\cos \varphi \sin \delta-\sin \varphi \cos \delta \cos t^{\prime}
\end{aligned}
$$

Their difference is,

$$
\sin c=-\sin \varphi \cos \delta \sin 1 / 2\left(t+t^{\prime}\right) \sin 1 / 2\left(t-t^{\prime}\right) .
$$

If we represent by $S, 1 / 2\left(t+t^{\prime}\right)$, and by $U, 1 / 2\left(t-t^{\prime}\right)$, we have,

$$
\sin c=-\sin S \cdot \sin U \cdot \cos \delta \sin \varphi
$$

Since $c$ will be a small angle, we can write,

$$
c=-\sin S \cdot \sin U \cdot \cos \delta \sin \varphi \operatorname{cosec} 1^{\prime \prime} \text {. }
$$

The last formula will not only give the distance of each thread from the collimation axis, but also the distance between them.

The next step is to measure in terms of the micrometer screw the distances between threads. Calling these distances, $a, b, c, d, e$, and $f$, and the corresponding angular differences between the threads $1,2,3,4,5$, and 6 , the value, $R$, of one revolution of the micrometer screw, expressed in arc, is

$$
R=\frac{1+2+3+4+5+6}{a+b+c+d+e+f}
$$

By the above method the value of a revolution of the screw of the first micrometer was obtained, and from the commencement of observations until March 6, 1910 , the adopted value was

$$
R=26.050^{\prime \prime}
$$




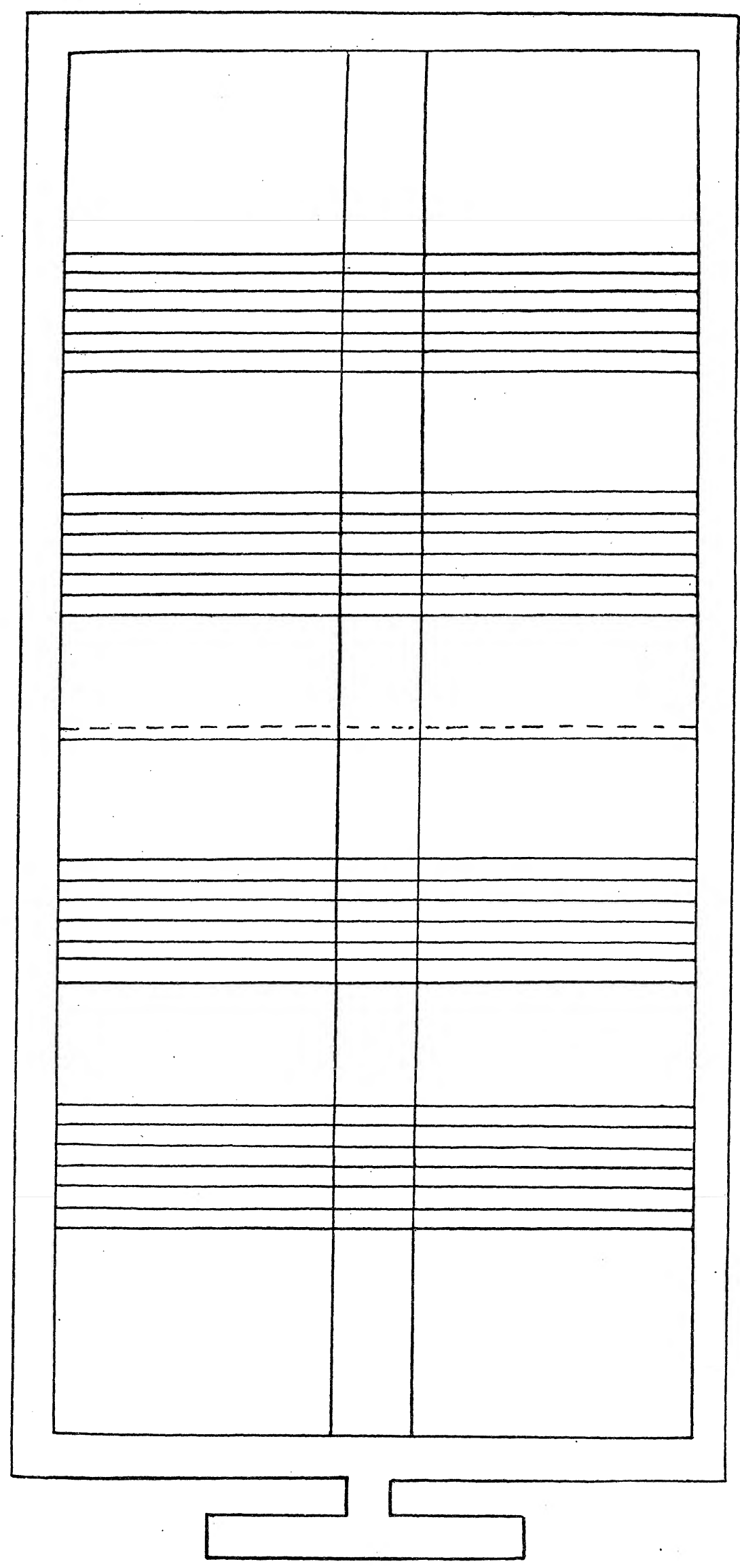

DRAWING OF THE SET OF TRANSIT THREADS ADOPTED IN 1903 
Provision has been made for moving the lens transversely with respect to the object glass of the telescope by the aid of a long screw passing through a nut fastened to the lens cell.

Attached to one end of the screw is a knob to be used in turning the screw. A divided head is also fastened to the screw and adjacent to the knob. The other end of the screw revolves in a nut attached to the mounting. On the front face of the mounting a piece of brass has been attached, which is graduated into intervals corresponding to one turn of the screw. A line cut in the center of the sliding plate is a reference point from which to measure changes of the lens with respect to the mark. Once the lens has been adjusted, a lock nut attached to the screw prevents any accidental change.

The pier upon which the base of the mark is placed is made of brick. Its dimensions are 3 by 3 feet. It is 3 feet above and 2 feet in the ground. The top is finished off with a cap made of concrete. On this is placed an iron base which is securely fastened to it by bolts embedded in the concrete. Integral with the base is an upright extension to which is attached a thin piece of metal painted a dead black color. In the center of this plate is a small hole, about one two-hundredths of an inch in diameter. On the opposite side of the plate as seen from the transit instrument the metal immediately around the hole has been reamed away so that a ray of light passing through the hole is not disturbed by reflection of light from the interior of the hole.

An electric lamp of $\mathbf{1 6}$ candlepower is placed behind the hole in the plate, and when the telescope is turned toward the mark and the current is on an artificial star of about the sixth magnitude is seen.

The depression of the mark below the horizontal plane of the instrument is $4^{\circ} 24^{\prime}$. The line of sight from the telescope to the mark passes over a lawn covered with grass.

To provide a means by which to convey an electric current for illuminating purposes to the mark house there has been laid under the ground a terra-cotta pipe, 3 inches in diameter, extending from the transit house to the mark house. In this pipe is placed a lead cable containing two copper wires.

At the mark house the two terminals are attached to a lamp socket, placed just behind the hole in the plate previously mentioned. At the transit house the two terminals are attached to the feed wires that carry the electric current to different parts of the room. A switch is attached to the south wall of the building which is in circuit with the wires running to the mark house, thus permitting the current to be turned off or on without leaving the building. In addition, a rheostat has been placed in the circuit just described, by means of which the intensity of the illumination behind the mark can be increased or decreased.

\section{THE CHRONOGRAPH}

The times of transit of all stars published in this volume have been recorded on a chronograph, and not by the eye-and-ear method. The chronograph was placed on a stand located on the south side of the transit building, during that portion of the year when the temperature remains above $32^{\circ} \mathrm{F}$. During the winter 
months it was placed in the east observer's room, located about 50 feet south of the transit building. This room is heated by steam.

The first chronograph was a modified form of the HIPf, in which the speed of the train of wheels that propel the chronograph barrel is controlled by a spring making 132 vibrations per second. The barrel is 6.4 inches in diameter, 13.5 inches long, and when the apparatus is running makes one revolution per minute.

A sheet of white paper is wrapped around the barrel, and held in place by two brass clips. The length of the barrel is sufficient to give two hours of continuous record on the sheet. The record is made by the aid of a fountain pen, carried by an arm attached to the armature of the magnet. The magnet is mounted on a carriage which is moved parallel to the barrel by means of a screw. The above-described chronograph was one of eight designed by the late Prof. WM. Harkness, United States Navy, for use on the Transit of Venus Expeditions.

In July, 1906, the chronograph which had been in use for 13 years was replaced by one purchased from the Bausch, Lomb, SAegmüller Co., of Rochester, N. Y. The speed of the train of wheels of the SAEGMüLleR type of chronograph is controlled by means of a double conical pendulum governor. The chronograph has operated in a satisfactory manner and was used until the close of the series of observations.

The method of connecting the chronograph magnets to an observing clock is practically the same in both of these types of chronograph. Two posts on the pen carriage are connected by copper wires, one with the secondary terminal of a relay in circuit with the clock, and the other to a battery. Another wire completes the circuit from the opposite pole of the battery to the other secondary terminal of the relay.

One of the wires just mentioned is extended to the instrument in the shape of a loop. This loop in the wire is fastened to a side of one of the piers. At a proper place on the pier the wire is separated and the two ends attached to what is termed a "key," an auxiliary apparatus to break the circuit between the clock and the chronograph.

The key is made of hardwood. It is 5 inches long and $2 \frac{1}{2}$ inches wide. Extending nearly the length of the key, and fastened to one of its sides, is a piece of brass, three-fourth of an inch wide and one-sixteenth of an inch thick. This piece of brass permits the electric current from the battery to pass through it. One end of the brass strip is fastened to the key by a screw, and it is also one of the terminals of the separated wire just mentioned. At the other end of the spring a circular rubber button is fastened. Near the button end of the key a piece of brass in the shape of an inverted $U$ straddles the spring, but does not touch it. The U-shaped piece of brass is fastened to the key by two screws, one of which is the other terminal of the separated wire.

A brass screw has been tapped into the upper face of the U-shaped piece, the end of which is tipped with a piece of platinum wire. In a similar manner a piece of platinum has been attached to the brass spring. directly under the screw in the U-shaped piece. In the normal state of the key these two platinum points are touching and the current is not interrupted except by the beat of the clock. 
If, however, the button is pressed downward a separation of the two platinum points occurs, the current is broken, and its effect will be registered on the sheet of white paper placed on the barrel of the chronograph.

The method of installation described above is the so-called "break-circuit" system, and is the one that has been used in securing a record of times of transit of all stars that appear in this volume.

After the sheet is removed from the chronograph barrel the record of transits, by the aid of a graduated scale, is read and transcribed to the observing books. The scale is $233 / 4$ inches long, and is divided to read seconds and tenths of seconds of time.

THE CLOCKS, CLOCK CORRECTIONS, AND RATES

With the exception of the RIEFLER clocks, the clocks which have been used in observing transits are provided with a wheel the duty of which is to break the electric current every second, except the sixtieth. That second is omitted so that the beginning of each minute may be identified.

Suspended just in front of this wheel is a delicate spring. At the end of the spring. is a platinum point which touches another platinum point fastened to the frame holding the spring. The frame and spring are both insulated from each other by a block of rubber. At the upper end of the spring provision has been made for attaching a small copper wire, and a similar provision has been provided at the upper end of the frame.

A jewel is fastened to the spring and so adjusted that, as the wheel revolves, its teeth will touch the jewel as each passes it, and press the jewel outward.

The impulse of the tooth moving the jewel outward breaks contact between the two platinum points, and after the tooth has past the circuit is closed.

The two copper wires mentioned are extended, one to a battery and the other to a primary point on a relay. A wire from the other primary point to the battery completes the circuit. A switch is placed in the circuit, and opened when the clock is not in use.

The same description is applicable to the electric contact in a chronometer except that on account of the compactness of that time piece, the apparatus for breaking the circuit is very much smaller.

The RIEFLER clocks are provided with a mechanism the duty of which is to break the electric current every two seconds except between the fifty-eighth and second when the signal is omitted.

The names of the several clocks and chronometers that have been used in observing are listed below. They have been, except for the RIEFLER clocks, installed either in the clock room or the observers' waiting room. In cold weather both of these rooms are heated.

A hack chronometer is kept on the observer's desk in the transit house. It is corrected each observing tour to agree with the face of the observing clock.

In the early part of the work the time pieces used in observing were compared with the observing clock of the south transit, to obtain clock corrections and rates. Later, when the RIEFLER clocks had been installed in the clock vault, clock corrections and rates were obtained from the Time Service Department, and were based upon time sights made with either the 6 -inch or the 9-inch transit circle. 
The Observatory is supplied with a large switchboard, to which all clocks, chronographs, and batteries used by the several astronomical instruments are connected. By means of plugs in the board any clock may be made to record its beat on any chronograph, or two clocks made to record their respective beats on the same chronograph.

In this way the clock comparisons were made, and corrections to the prime vertical observing clock were obtained.

The following clocks and chronometers have been used in the interval of time covered by the observations printed in this volume:

NEGUS break-circuit chronometer No. 1518, from July 24, 1893, to No vember 16, 1895.

NEgus break-circuit chronometer No. 1527, from November 18 to November $30,1895$.

Negus break-circuit chronometer No. 1295, from December 3, 1895, to . May 21, 1896.

Howard clock No. 404, from May 27 to June 30, 1896.

Negus break-circuit chronometer No. 1585, from July 1 to August 4, 1896.

Negus break-circuit chronometer No. 1518 from August 4, 1896, to August 2, 1897.

Howard clock No. 404, from August 6, 1897, to February 8, 1898.

Negus break-circuit chronometer No. 1520 from February 8 to February $10,1898$.

Howard clock No. 404, February 12, 1898.

Negus break-circuit chronometer No. 1520 from February 14 to February $23,1898$.

Charles Frodsham clock from February 23 to May 25, 1898.

NEgus break-circuit chronometer No. 1518 from May 25, 1898, to July 9, 1899.

Charles Frodsham clock from July 9 to November 2, 1899.

NEgus break-circuit chronometer No. 1518 from November 27 to December $31,1899$.

Parkinson \& Frodsham clock No. 611 from January 21 to October 16, 1900.

HowaRd clock No. 404 from October 18, 1900 to April 28, 1901.

Parkinson \& Frodsham clock No. 611 from April 29 to August 19, 1901.

Charles Frodsham clock from August 20 to August 22, 1901.

Parkinson \& Frodsham clock No. 611 from August 22 to October 19, 1901.

Howard clock No. 404 October 20, 1901.

Parkinson \& Frodsham clock No. 611 from October 21 to October 24, 1901.

HowaRD clock No. 404 from October 26, 1901, to January 18, 1903.

NEGUs break-circuit chronometer No. 1295 from January 30 to March 4, 1903.

Howard clock No. 404 from March 12 to May 5, 1903.

Parkinson \& Frodsham clock No. 611 from May 7 to May 22, 1903. 
Howard clock No. 404 from May 28 to July 20, 1903.

Parkinson \& Frodsham clock No. 611 from July 21 to July 27, 1903.

Howard clock No. 404 from August 5 to August 12, 1903.

Riefler clock No. 70 from December 3, 1903, to May 19, 1904.

Riefler clock No. 60 from May 19 to July 17, 1904.

Riefler clock No. 82 from July 17 to October 10, 1904.

RIEFLER clock No. 70 from October 13, 1904, to January 18, 1906.

RIEFLER clock No. 82 from January 18 to April 14, 1906.

Riefler clock No. 70 from April 15, 1906, to May 30, 1907.

RIEFLER clock No. 151 from June 3, 1907, to July 1, 1908.

Riefler clock No. 70 from July 1 to July 20, 1908.

RIEFLER clock No. 151 from July 28 to September 2, 1908.

Riefler clock No. 70 from September 3, 1908, to June 11, 1909.

RiefLer clock No. 151 from June 14 to August 24, 1909.

Riefler clock No. 70 from August 26, 1909, to March 8, 1910.

Riefler clock No. 151 from March 13, 1910, to April 20, 1911.

RIEFLER clock No. 60 from April 24, 1911, to December 30, 1912.

Table I contains the adopted clock corrections and rates, and the headings indicate with sufficient clearness the nature of the data.

TABLE I.-The Adopted Clock Corrections and Rates

\begin{tabular}{|c|c|c|c|c|c|c|c|}
\hline Date & $\begin{array}{l}\text { Sid. } \\
\text { hour }\end{array}$ & $\begin{array}{c}\text { Clock } \\
\text { correction }\end{array}$ & $\begin{array}{c}\text { Hourly } \\
\text { rate }\end{array}$ & Date & $\begin{array}{l}\text { Sid. } \\
\text { hour }\end{array}$ & $\begin{array}{l}\text { Clock } \\
\text { correction }\end{array}$ & $\begin{array}{l}\text { Hourly } \\
\text { rate }\end{array}$ \\
\hline 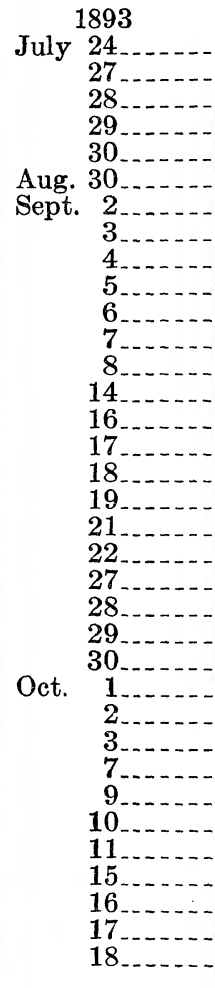 & $\begin{array}{l}\text { h. } \\
\text { 15. } 49 \\
\text { 16. } 11 \\
\text { 17. } 86 \\
\text { 17. } 94 \\
\text { 17. } 92 \\
\text { 17. } 82 \\
18.22 \\
\text { 17. } 90 \\
17.88 \\
17.88 \\
17.90 \\
17.91 \\
17.86 \\
17.90 \\
17.90 \\
17.86 \\
18.01 \\
17.88 \\
17.88 \\
17.84 \\
17.88 \\
17.88 \\
17.89 \\
17.89 \\
17.91 \\
17.94 \\
17.94 \\
17.94 \\
17.94 \\
17.92 \\
17.89 \\
18.88 \\
18.89 \\
18.89 \\
17.90\end{array}$ & $\begin{aligned} & s \\
&+ 7.87 \\
&+11.31 \\
&+11.71 \\
&+12.46 \\
&+13.44 \\
&+28.30 \\
&+28.61 \\
&+28.54 \\
&+28.56 \\
&+28.70 \\
&+29.13 \\
&+29.60 \\
&+29.65 \\
&+30.90 \\
&+31.88 \\
&+31.99 \\
&+31.98 \\
&+32.04 \\
&+32.57 \\
&+33.27 \\
&+33.33 \\
&+34.06 \\
&+34.40 \\
&+34.97 \\
&+35.14 \\
&+35.33 \\
&+35.51 \\
&+35.45 \\
&+35.82 \\
&+35.83 \\
&+36.12 \\
&+36.11 \\
&+37.20 \\
&+38.98 \\
&+40.04\end{aligned}$ & $\begin{array}{l}s \\
+0.048 \\
+0.017 \\
+0.031 \\
+0.041 \\
+0.004 \\
+0.003 \\
+0.001 \\
+0.006 \\
+0.018 \\
+0.020 \\
+0.002 \\
+0.009 \\
+0.020 \\
+0.005 \\
0.000 \\
+0.002 \\
+0.011 \\
+0.029 \\
0.000 \\
+0.030 \\
+0.014 \\
+0.024 \\
+0.007 \\
+0.008 \\
+0.008 \\
0.000 \\
+0.008 \\
0.000 \\
+0.012 \\
0.000 \\
+0.045 \\
+0.074 \\
+0.044 \\
+0.009\end{array}$ & 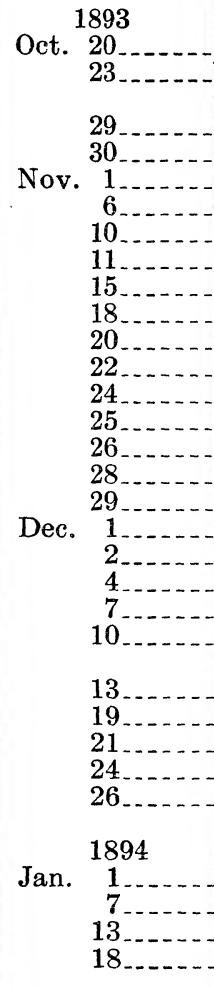 & $\begin{array}{l}h \\
\text { 17. } 92 \\
\text { 17. } 89 \\
\text { Clock set } \\
19.04 \\
19.06 \\
18.05 \\
18.05 \\
18.06 \\
18.06 \\
1.76 \\
1.77 \\
19.04 \\
19.04 \\
19.04 \\
19.03 \\
19.03 \\
1.90 \\
1.75 \\
1.73 \\
18.86 \\
1.69 \\
1.72 \\
1.71 \\
\text { Clock se } \\
1.76 \\
1.68 \\
18.88 \\
18.88 \\
18.90\end{array}$ & $\begin{array}{r}s \\
+40.49 \\
+40.43 \\
\text { ahead 1m. } \\
-18.53 \\
-16.16 \\
-11.81 \\
-5.40 \\
-0.51 \\
+1.76 \\
+9.60 \\
+15.69 \\
+19.55 \\
+24.71 \\
+28.83 \\
+32.91 \\
+37.56 \\
+41.07 \\
+41.67 \\
+43.75 \\
+44.60 \\
+46.17 \\
+49.40 \\
+52.31 \\
\text { ahead } 1 \mathrm{~m} . \\
-4.38 \\
+2.49 \\
+4.15 \\
+8.62 \\
+12.18\end{array}$ & $\begin{array}{l}+0.091 \\
+0.091 \\
+0.053 \\
+0.051 \\
+0.095 \\
+0.075 \\
+0.085 \\
+0.088 \\
+0.108 \\
+0.086 \\
+0.170 \\
+0.194 \\
+0.064 \\
+0.025 \\
+0.043 \\
+0.050 \\
+0.029 \\
+0.045 \\
+0.040 \\
+0.046 \\
+0.048 \\
+0.048 \\
+0.040 \\
+0.062 \\
+0.050 \\
+0.063\end{array}$ \\
\hline
\end{tabular}


TABLE I.-The Adopted Clock Corrections and Rates-Continued

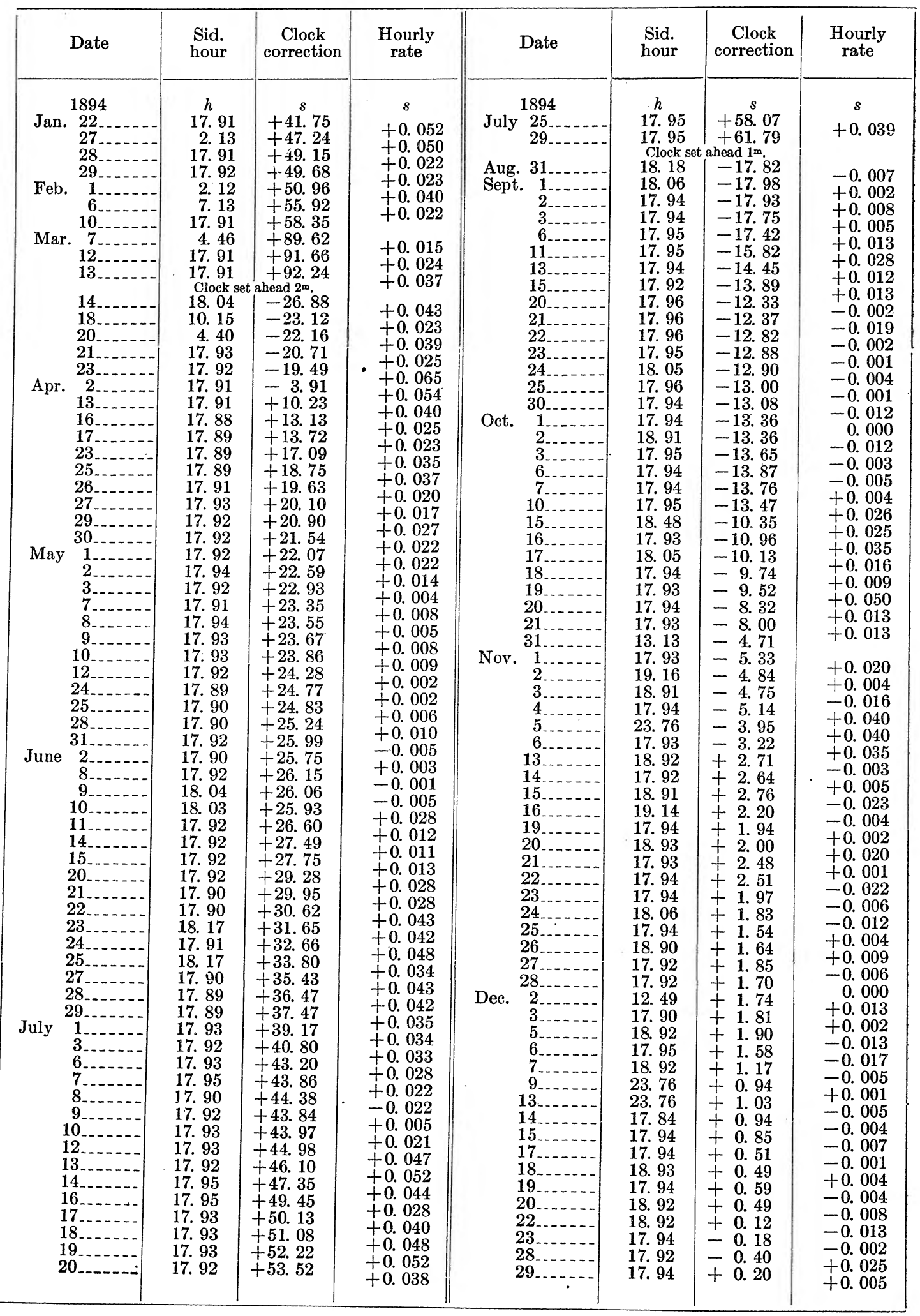


INTRODUCTION.

TABLE I.-The Adopted Clock Corrections and Rates-Continued

\begin{tabular}{|c|c|c|c|c|c|c|c|}
\hline Date & $\begin{array}{l}\text { Sid. } \\
\text { hour }\end{array}$ & $\begin{array}{c}\text { Clock } \\
\text { correction }\end{array}$ & $\begin{array}{l}\text { Hourly } \\
\text { rate }\end{array}$ & Date & $\begin{array}{l}\text { Sid. } \\
\text { hour }\end{array}$ & $\begin{array}{c}\text { Clock } \\
\text { correction }\end{array}$ & $\begin{array}{l}\text { Hourly } \\
\text { rate }\end{array}$ \\
\hline 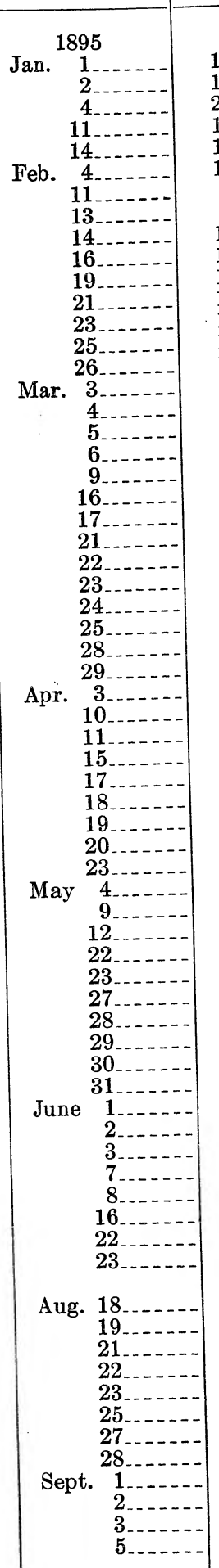 & $\begin{array}{r}h \\
17.92 \\
17.92 \\
23.74 \\
12.55 \\
17.94 \\
17.93 \\
4.48 \\
4.48 \\
17.94 \\
17.94 \\
17.94 \\
17.94 \\
17.95 \\
17.94 \\
17.94 \\
4.47 \\
17.94 \\
17.94 \\
17.94 \\
17.94 \\
17.94 \\
17.94 \\
17.94 \\
17.94 \\
17.92 \\
17.92 \\
17.92 \\
17.92 \\
17.92 \\
17.93 \\
17.92 \\
17.94 \\
17.94 \\
17.93 \\
17.93 \\
17.93 \\
17.93 \\
17.92 \\
17.93 \\
17.92 \\
17.93 \\
17.92 \\
17.92 \\
17.93 \\
17.93 \\
17.93 \\
17.93 \\
17.93 \\
17.93 \\
17.93 \\
17.93 \\
19.92 \\
17.93 \\
17.94 \\
17.93 \\
17.93\end{array}$ & 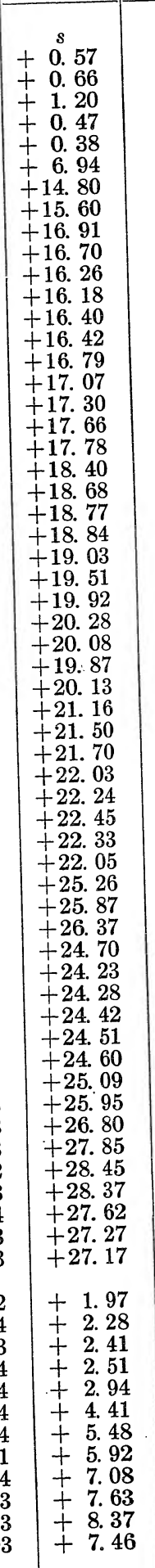 & 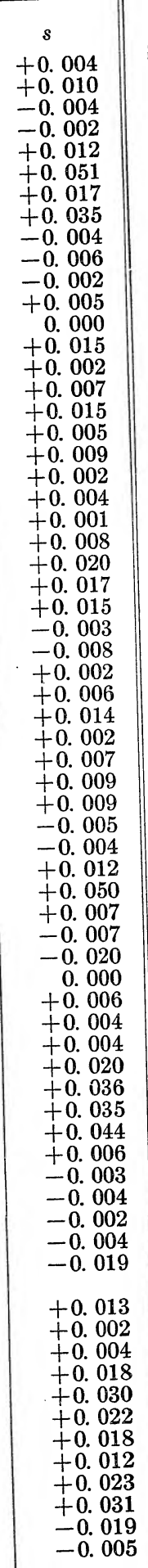 & 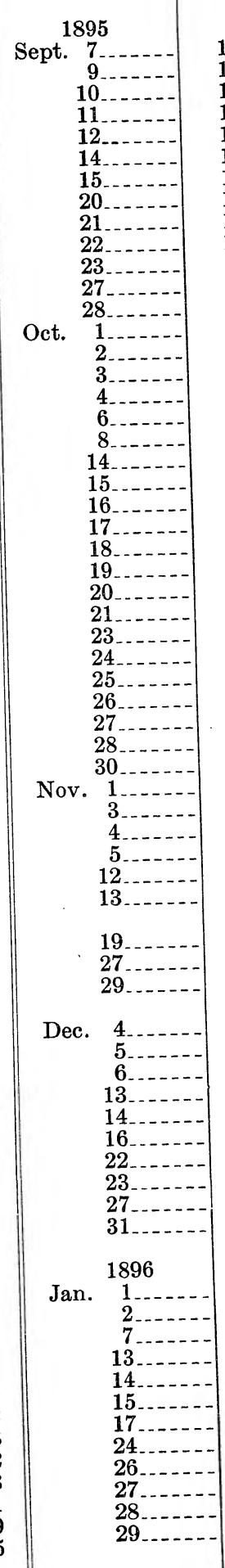 & 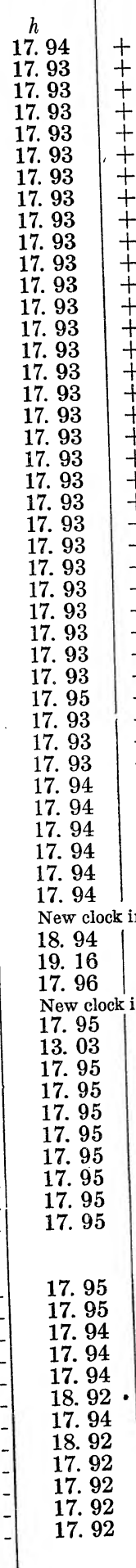 & 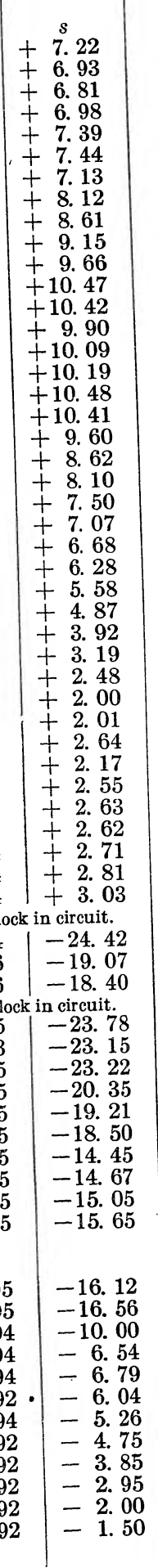 & $\begin{array}{r}s \\
-0.006 \\
-0.005 \\
+0.007 \\
+0.017 \\
+0.001 \\
-0.013 \\
+0.008 \\
+0.020 \\
+0.022 \\
+0.021 \\
+0.008 \\
-0.002 \\
-0.007 \\
+0.008 \\
+0.004 \\
+0.012 \\
-0.001 \\
-0.017 \\
-0.007 \\
-0.022 \\
-0.025 \\
-0.018 \\
-0.016 \\
-0.017 \\
-0.029 \\
-0.030 \\
-0.020 \\
-0.030 \\
-0.030 \\
-0.020 \\
+0.000 \\
+0.026 \\
-0.010 \\
+0.008 \\
+0.002 \\
0.000 \\
+0.004 \\
0.000 \\
+0.009\end{array}$ \\
\hline
\end{tabular}


PRIME VERTICAL TRANSIT INSTRUMENT.

TABLE I.-The Adopted Clock Corrections and Rates-Continued

\begin{tabular}{|c|c|c|c|c|c|c|c|}
\hline Date & $\begin{array}{l}\text { Sid. } \\
\text { hour }\end{array}$ & $\begin{array}{c}\text { Clock } \\
\text { correction }\end{array}$ & $\begin{array}{l}\text { Hourly } \\
\text { rate }\end{array}$ & Date & $\begin{array}{l}\text { Sid. } \\
\text { hour }\end{array}$ & $\begin{array}{c}\text { Clock } \\
\text { correction }\end{array}$ & $\begin{array}{l}\text { Hourly } \\
\text { rate }\end{array}$ \\
\hline 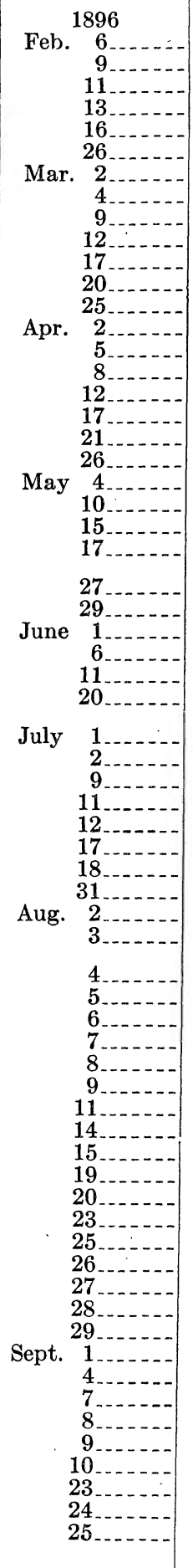 & 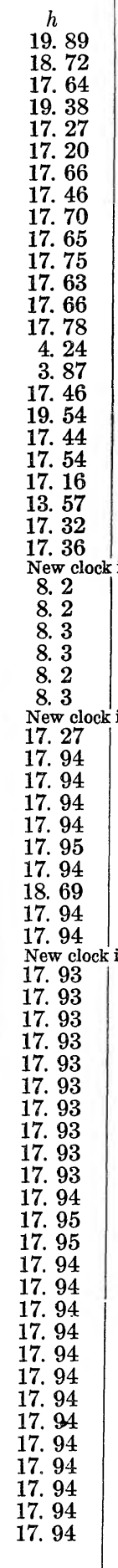 & $\begin{array}{l}\text { s } \\
-0.40 \\
=0.37 \\
0.11 \\
+0.37 \\
+1.01 \\
+7.40 \\
+8.04 \\
+9.37 \\
+11.32 \\
+12.24 \\
+13.94 \\
+14.75 \\
+17.68 \\
+20.03 \\
+21.65 \\
+22.90 \\
+24.81 \\
+25.42 \\
+27.60 \\
+29.59 \\
+29.81 \\
+28.72 \\
+26.82 \\
+26.28 \\
+7.5 \\
+7.9 \\
+6.0 \\
+6.0 \\
+4.8 \\
+4.3 \\
+0.6 \\
+ \text { ircuit. } \\
+18.68 \\
+18.47 \\
+16.27 \\
+15.99 \\
+15.59 \\
+15.32 \\
+14.80 \\
+12.79 \\
+12.23 \\
+12.19 \\
+ \text { incuit. } \\
+34.41 \\
+35.40 \\
+37.19 \\
+38.60 \\
+40.10 \\
+41.66 \\
+44.97 \\
+49.35 \\
+50.08 \\
+51.52 \\
+51.55 \\
+52.74 \\
+53.82 \\
+53.94 \\
+53.96 \\
+53.88 \\
+53.63 \\
+53.78 \\
+54.94 .95 \\
+55.45 \\
+54.53 \\
+54.37 \\
+54.30 \\
+55\end{array}$ & $\begin{array}{l}s \\
0.000 \\
+0.005 \\
+0.010 \\
+0.009 \\
+0.027 \\
+0.007 \\
+0.028 \\
+0.016 \\
+0.013 \\
+0.014 \\
+0.011 \\
+0.024 \\
+0.012 \\
+0.027 \\
+0.017 \\
+0.017 \\
+0.005 \\
+0.022 \\
+0.017 \\
+0.001 \\
+0.008 \\
-0.016 \\
-0.011 \\
\\
-0.012 \\
-0.012 \\
-0.010 \\
-0.004 \\
-0.017 \\
\\
-0.009 \\
-0.013 \\
-0.006 \\
-0.017 \\
-0.002 \\
-0.022 \\
-0.006 \\
-0.012 \\
-0.002 \\
\end{array}$ & 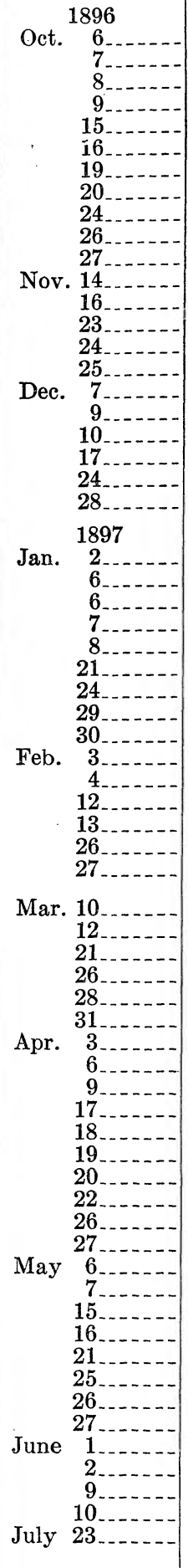 & 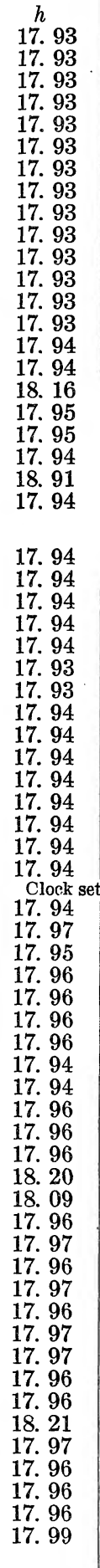 & 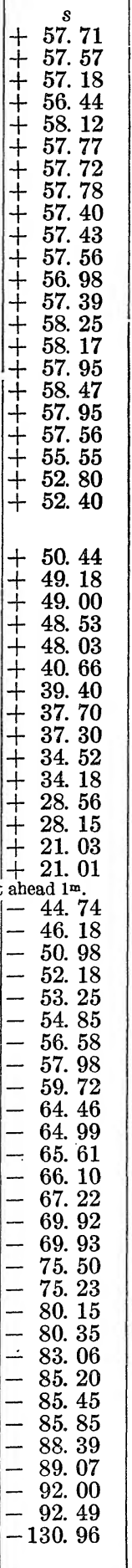 & 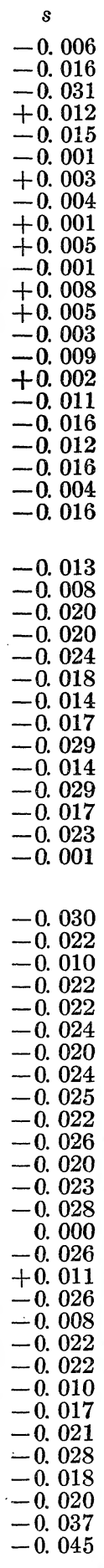 \\
\hline
\end{tabular}


INTRODUCTION.

A XXXIII

TABLE I.-The Adopted Clock Corrections and Rates-Continued

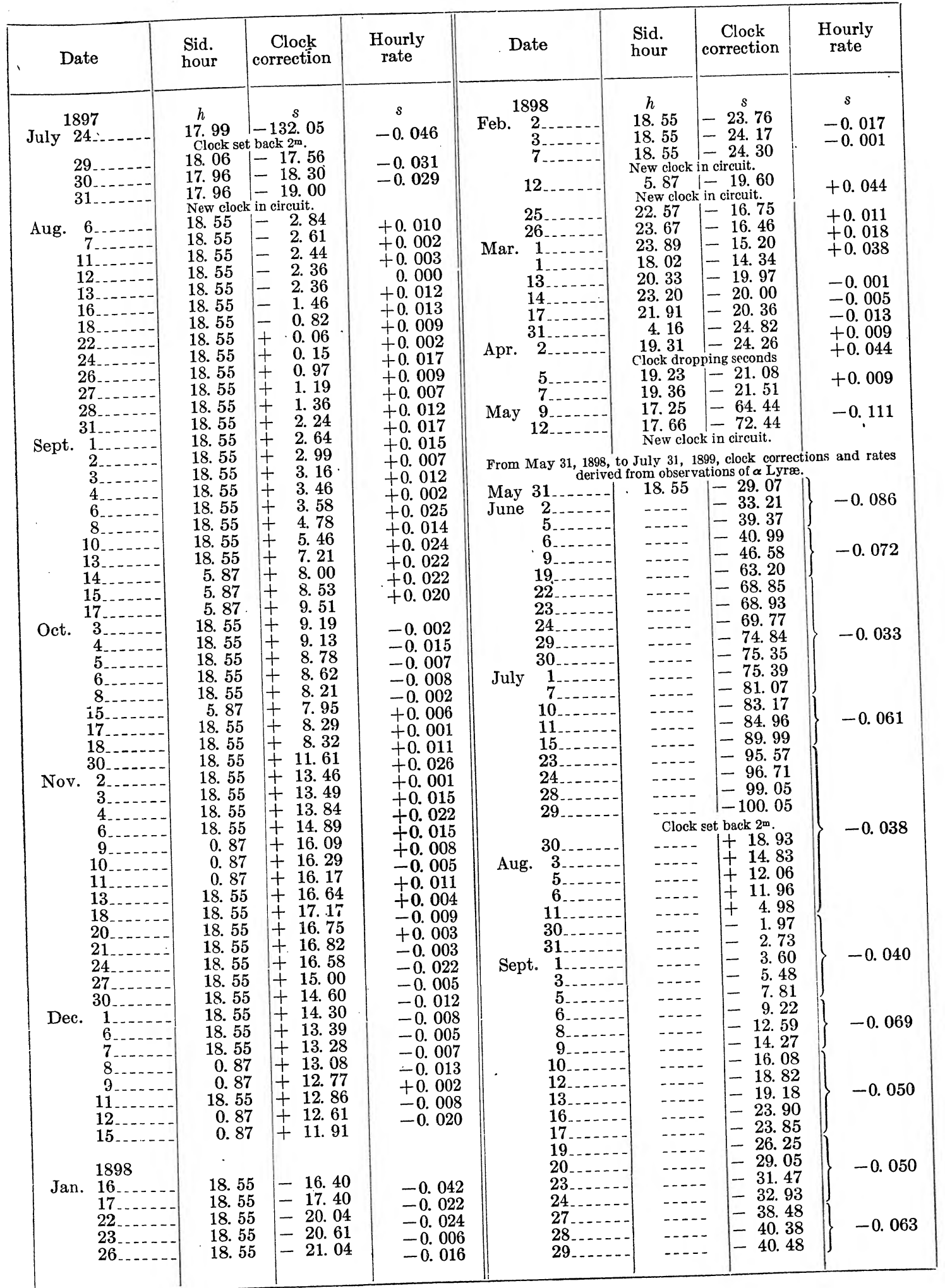

$101141^{\circ}-26 \div-P T I-3$ 
TABLE I.-The Adopted Clock Corrections and Rates-Continued

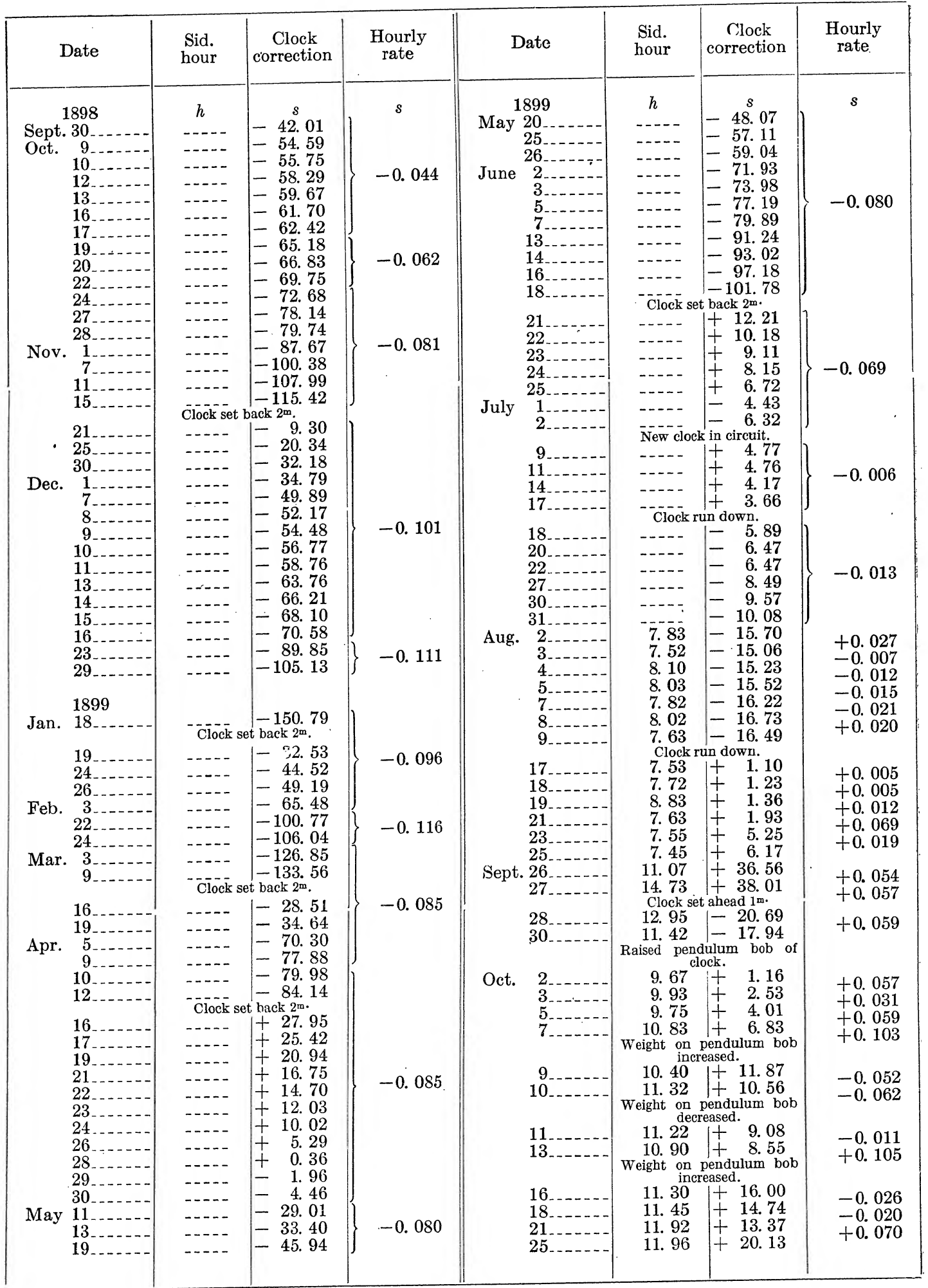


INTRODUCTION.

A XXxv

TABLE I.-The Adopted Clock Corrections and Rates-Continued

\begin{tabular}{|c|c|c|c|c|c|c|c|}
\hline Date & $\begin{array}{l}\text { Sid. } \\
\text { hour }\end{array}$ & $\begin{array}{c}\text { Clock } \\
\text { correction }\end{array}$ & $\begin{array}{l}\text { Hourly } \\
\text { rate }\end{array}$ & Date & $\begin{array}{l}\text { Sid. } \\
\text { hour }\end{array}$ & $\begin{array}{c}\text { Clock } \\
\text { correction }\end{array}$ & $\begin{array}{l}\text { Hourly } \\
\text { rate }\end{array}$ \\
\hline 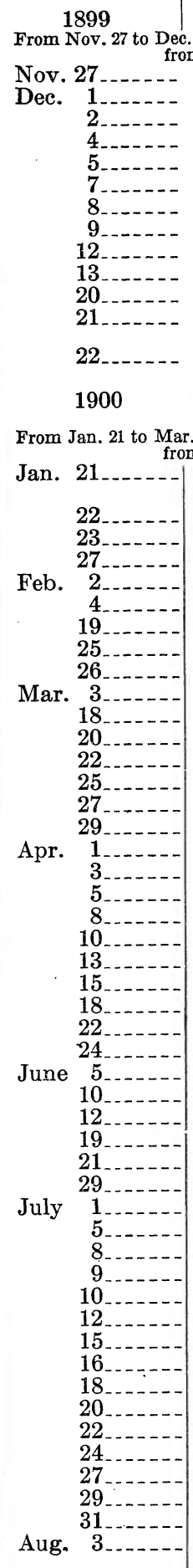 & 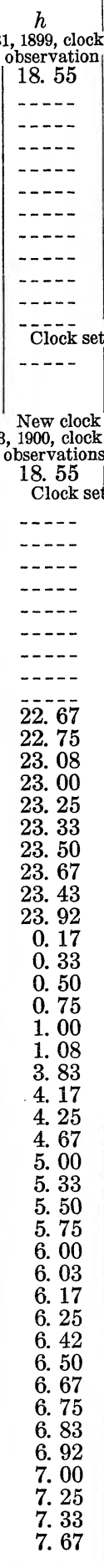 & 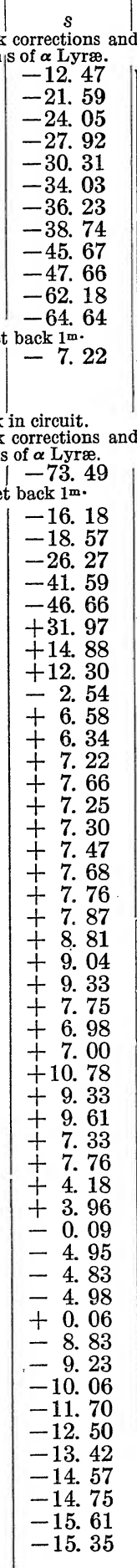 & $\begin{array}{l}-0.116 \\
\\
-0.005 \\
+0.018 \\
+0.006 \\
+0.008 \\
+0.001 \\
+0.002 \\
+0.004 \\
+0.002 \\
+0.002 \\
+0.020 \\
+0.003 \\
+0.006 \\
-0.021 \\
-0.008 \\
0.000 \\
-0.012 \\
+0.006 \\
+0.014 \\
+0.009 \\
-0.019 \\
-0.005 \\
-0.042 \\
-0.068 \\
+0.005 \\
+0.006 \\
+0.105 \\
-0.124 \\
-0.017 \\
-0.017 \\
-0.034 \\
-0.017 \\
-0.019 \\
-0.016 \\
-0.004 \\
-0.018 \\
+0.003 \\
-0.003\end{array}$ & 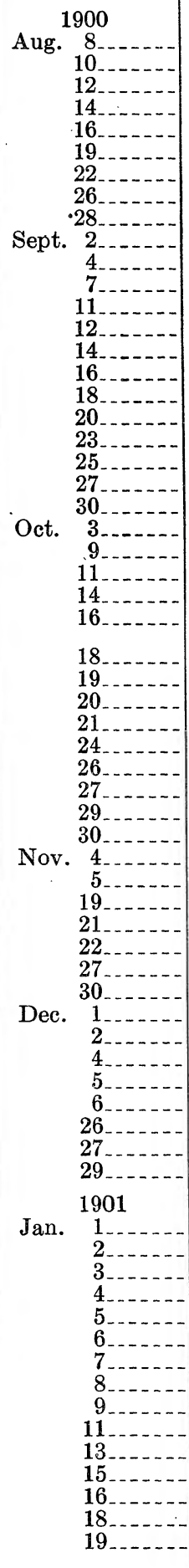 & $\begin{array}{c}h \\
8.00 \\
8.17 \\
8.25 \\
8.42 \\
8.50 \\
8.67 \\
9.00 \\
9.08 \\
9.25 \\
9.50 \\
9.83 \\
10.00 \\
10.25 \\
10.33 \\
10.50 \\
10.58 \\
10.67 \\
10.83 \\
11.00 \\
11.17 \\
11.25 \\
11.33 \\
11.50 \\
12.00 \\
12.25 \\
12.33 \\
12.42 \\
\text { New clock } \\
10.64 \\
1.03 \\
1.03 \\
1.03 \\
1.03 \\
1.03 \\
1.03 \\
1.03 \\
0.85 \\
0.97 \\
1.03 \\
0.85 \\
1.03 \\
1.03 \\
1.03 \\
1.03 \\
0.90 \\
1.41 \\
3.41 \\
3.16 \\
3.16 \\
1.04 \\
1.04 \\
19.92 \\
\text { 10 }\end{array}$ & \begin{tabular}{|c} 
s \\
-15.77 \\
-15.11 \\
-15.51 \\
-15.91 \\
-16.35 \\
-17.01 \\
-17.38 \\
-17.11 \\
-16.94 \\
-16.82 \\
-16.73 \\
-16.84 \\
-21.71 \\
-21.07 \\
-20.71 \\
-19.79 \\
-18.76 \\
-16.03 \\
-12.70 \\
-10.96 \\
-9.99 \\
-8.89 \\
-7.80 \\
-3.98 \\
-1.11 \\
+2.15 \\
+5.04 \\
+5 circuit. \\
-25.12 \\
-25.40 \\
-25.56 \\
-25.69 \\
-25.12 \\
-24.54 \\
-24.19 \\
-23.98 \\
-23.57 \\
-22.32 \\
-22.38 \\
-26.68 \\
-26.87 \\
-26.27 \\
-26.26 \\
-27.31 \\
-28.05 \\
-28.37 \\
-29.21 \\
-2.29 .53 \\
-30.00 \\
-42.87 \\
-43.07 \\
-43.66 \\
-44.98 \\
-4.98 \\
-45.43 \\
-45.45 \\
-46.14 \\
-46.75 \\
-47.16 \\
-47.12 \\
-47.49 \\
-47.82 \\
-48.40 \\
-48.80 \\
-49.02 \\
-49.29 \\
-49.67
\end{tabular} & $\begin{array}{c}s \\
+0.014 \\
+0.008 \\
-0.008 \\
-0.009 \\
-0.009 \\
-0.005 \\
+0.003 \\
+0.003 \\
+0.001 \\
+0.002 \\
+0.001 \\
+0.051 \\
+0.027 \\
+0.008 \\
+0.019 \\
+0.022 \\
+0.057 \\
+0.046 \\
+0.036 \\
+0.022 \\
+0.014 \\
+0.015 \\
+0.026 \\
+0.060 \\
+0.045 \\
+0.050 \\
\end{array}$ \\
\hline
\end{tabular}


TABLE I.-The Adopted Clock Corrections and Rates-Continued

\begin{tabular}{|c|c|c|c|c|c|c|c|}
\hline & $\begin{array}{l}\text { Sid. } \\
\text { hour }\end{array}$ & $\begin{array}{c}\text { Clock } \\
\text { correction }\end{array}$ & $\begin{array}{c}\text { Hourly } \\
\text { rate }\end{array}$ & Date & $\begin{array}{l}\text { Sid. } \\
\text { hour }\end{array}$ & $\begin{array}{c}\text { Clock } \\
\text { correction }\end{array}$ & $\begin{array}{l}\text { Hourly } \\
\text { rate }\end{array}$ \\
\hline $\begin{array}{r}\text { Jan. } \\
\text { Feb. } \\
\\
\\
\\
\\
\\
1 \\
1 \\
1 \\
1 \\
2 \\
2 \\
2 \\
\text { Mar. } \\
\\
1 \\
1 \\
1 \\
2 \\
2 \\
2 \\
2\end{array}$ & $\begin{array}{c}h \\
1.99 \\
3.96 \\
1.99 \\
\text { Clock set } \\
\text { 19. } 34 \\
18.86 \\
19.18 \\
18.92 \\
\text { 19. } 06 \\
19.34 \\
13.86 \\
15.15 \\
19.48 \\
19.96 \\
19.74 \\
20.02 \\
20.01 \\
21.40 \\
10.00 \\
10.11 \\
13.32 \\
21.17 \\
6.34 \\
21.24 \\
21.86 \\
21.39 \\
21.40 \\
13.11 \\
8.03 \\
8.09 \\
23.03 \\
9.10 \\
12.89 \\
17.11 \\
23.31 \\
24.07 \\
24.07 \\
12.50 \\
13.03 \\
13.03 \\
13.03 \\
\text { New clock } \\
0.57 \\
0.43 \\
0.78 \\
1.26 \\
17.18 \\
18.93 \\
17.93 \\
22.36 \\
1.16 \\
0.38 \\
13.02 \\
13.16 \\
13.03 \\
9.31 \\
13.30 \\
13.88 \\
14.96 \\
15.52 \\
17.06 \\
17.06 \\
19.58 \\
22.83 \\
23.55 \\
0.54 \\
1.60 \\
11.23 \\
11.82 \\
\text { 1. }\end{array}$ & 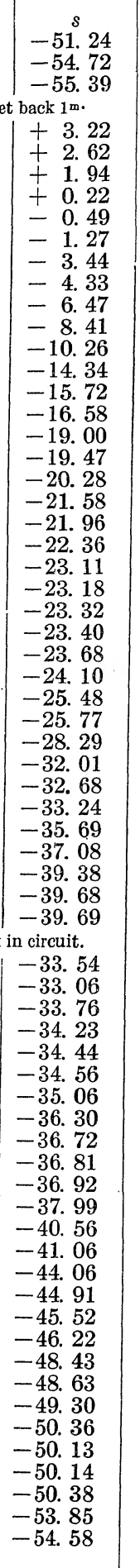 & $\begin{array}{c}s \\
-0.024 \\
-0.030 \\
-0.033 \\
-0.025 \\
-0.028 \\
-0.024 \\
-0.029 \\
-0.032 \\
-0.033 \\
-0.035 \\
-0.028 \\
-0.040 \\
-0.036 \\
-0.028 \\
-0.029 \\
-0.034 \\
-0.020 \\
-0.020 \\
-0.030 \\
-0.010 \\
-0.004 \\
-0.010 \\
-0.010 \\
-0.004 \\
-0.006 \\
-0.001 \\
-0.007 \\
-0.017 \\
-0.022 \\
-0.033 \\
-0.033 \\
-0.030 \\
-0.022 \\
-0.023 \\
-0.026 \\
-0.038 \\
-0.012 \\
-0.006 \\
0.000\end{array}$ & 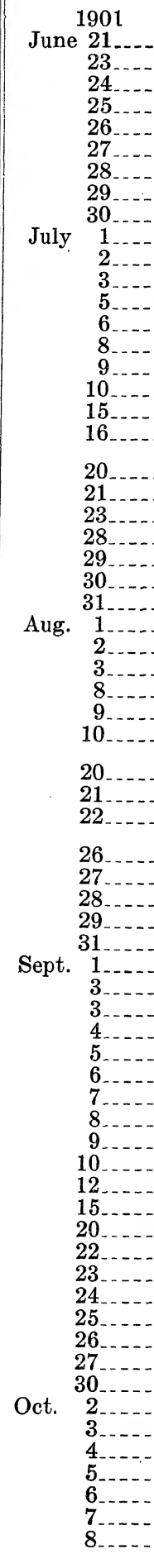 & $\begin{array}{l}\text { h } \\
11.20 \\
12.04 \\
12.98 \\
13.81 \\
\text { 14. } 47 \\
15.46 \\
16.22 \\
16.90 \\
\text { 17. } 55 \\
17.82 \\
\text { 19. } 46 \\
19.66 \\
22.54 \\
7.58 \\
4.98 \\
18.82 \\
17.25 \\
17.56 \\
9.27 \\
\text { Clock set } \\
11.63 \\
12.55 \\
14.22 \\
18.27 \\
19.49 \\
18.24 \\
21.10 \\
22.08 \\
9.85 \\
10.16 \\
11.34 \\
10.68 \\
10.81 \\
\text { New clock } \\
7.59 \\
7.48 \\
22.49 \\
\text { New clock } \\
20.03 \\
21.03 \\
21.80 \\
22.70 \\
0.55 \\
1.63 \\
0.09 \\
8.33 \\
9.64 \\
9.60 \\
9.43 \\
7.42 \\
8.61 \\
0.76 \\
10.16 \\
9.48 \\
9.60 \\
10.16 \\
19.47 \\
20.45 \\
21.12 \\
22.19 \\
23.20 \\
23.40 \\
3.20 \\
10.31 \\
10.48 \\
\text { 10. } 46 \\
9.32 \\
9.90 \\
2.59\end{array}$ & 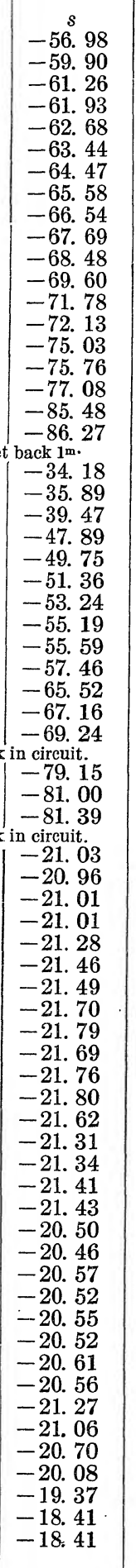 & $\begin{array}{r}+0.003 \\
-0.002 \\
0.000 \\
-0.005 \\
-0.008 \\
-0.001 \\
\\
-0.003 \\
+0.004 \\
-0.003 \\
-0.002 \\
+0.007 \\
+0.018 \\
+0.001 \\
-0.002 \\
0.000 \\
+0.008 \\
+0.001 \\
+0.004 \\
+0.002 \\
-0.001 \\
+0.001 \\
-0.004 \\
0.000 \\
-0.013 \\
+0.009 \\
+0.015 \\
+0.029 \\
+0.027 \\
+0.040 \\
0.000 \\
+0.015\end{array}$ \\
\hline
\end{tabular}


INTRODUCTION.

A XXXVII

TABLE I.-The Adopted Clock Corrections and Rates-Continued

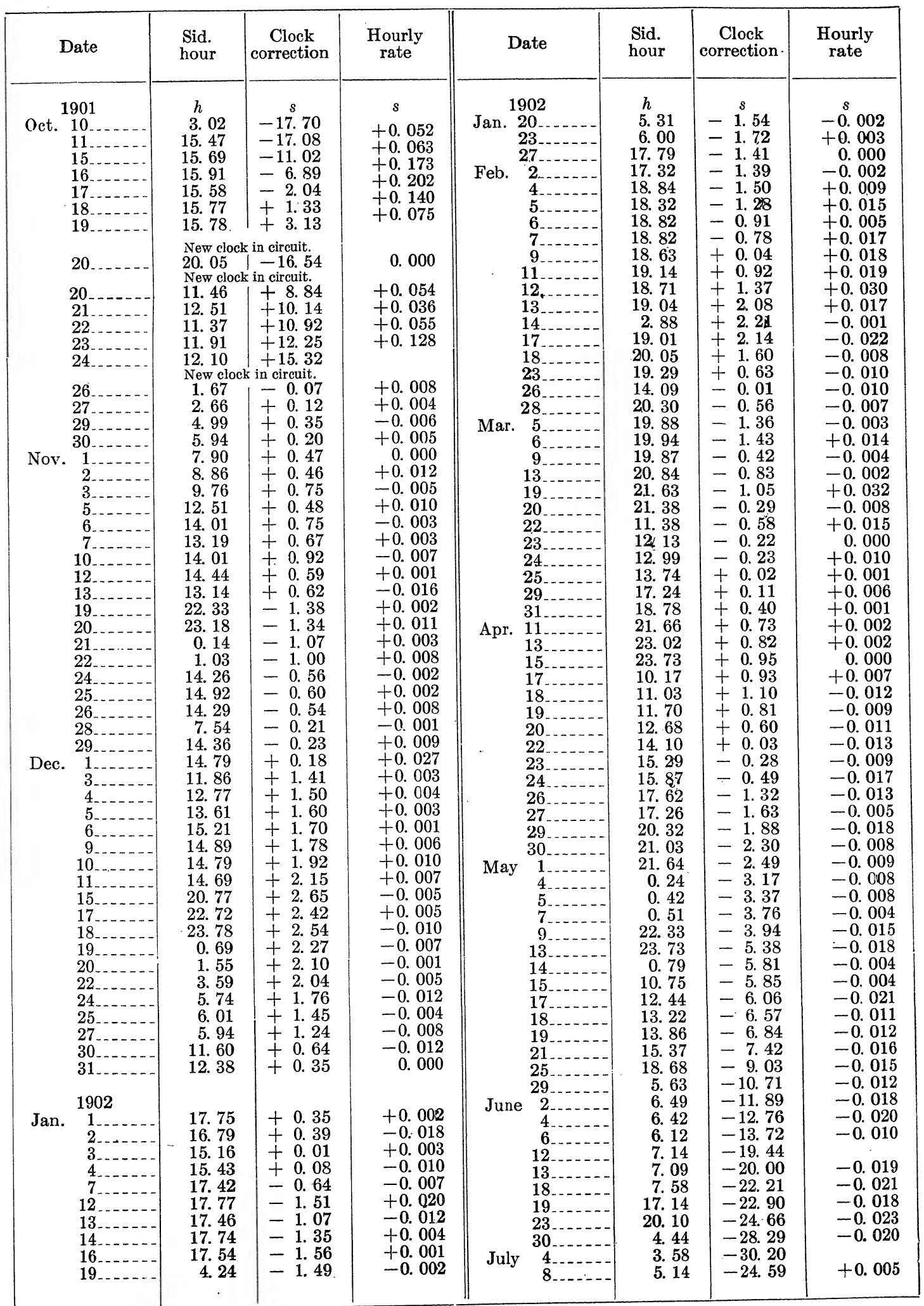


TABLE I.-The Adopted Clock Corrections and Rates-Continued

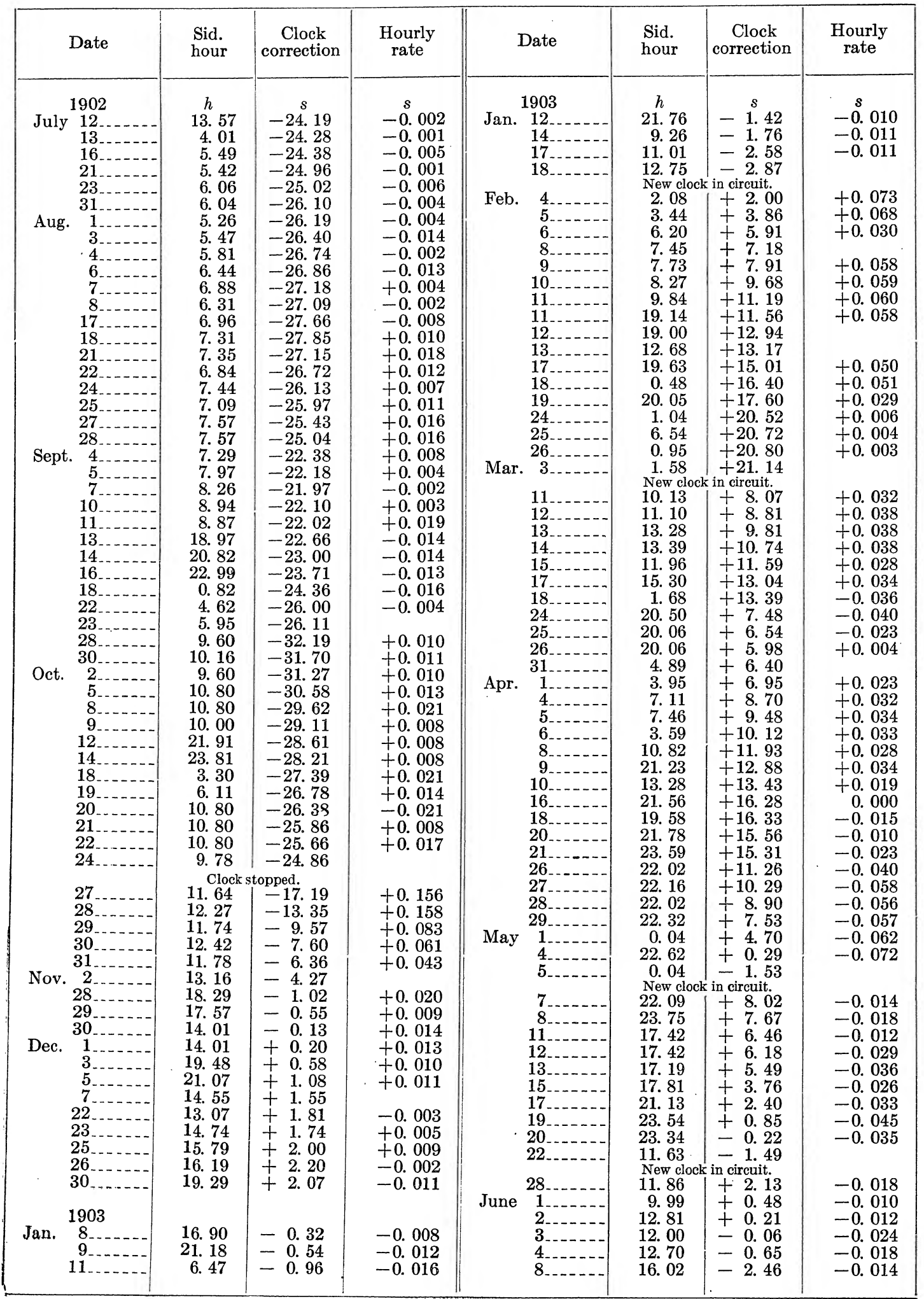


INTRODUCTION.

Table I.-The Adopted Clock Corrections and Rates-Continued

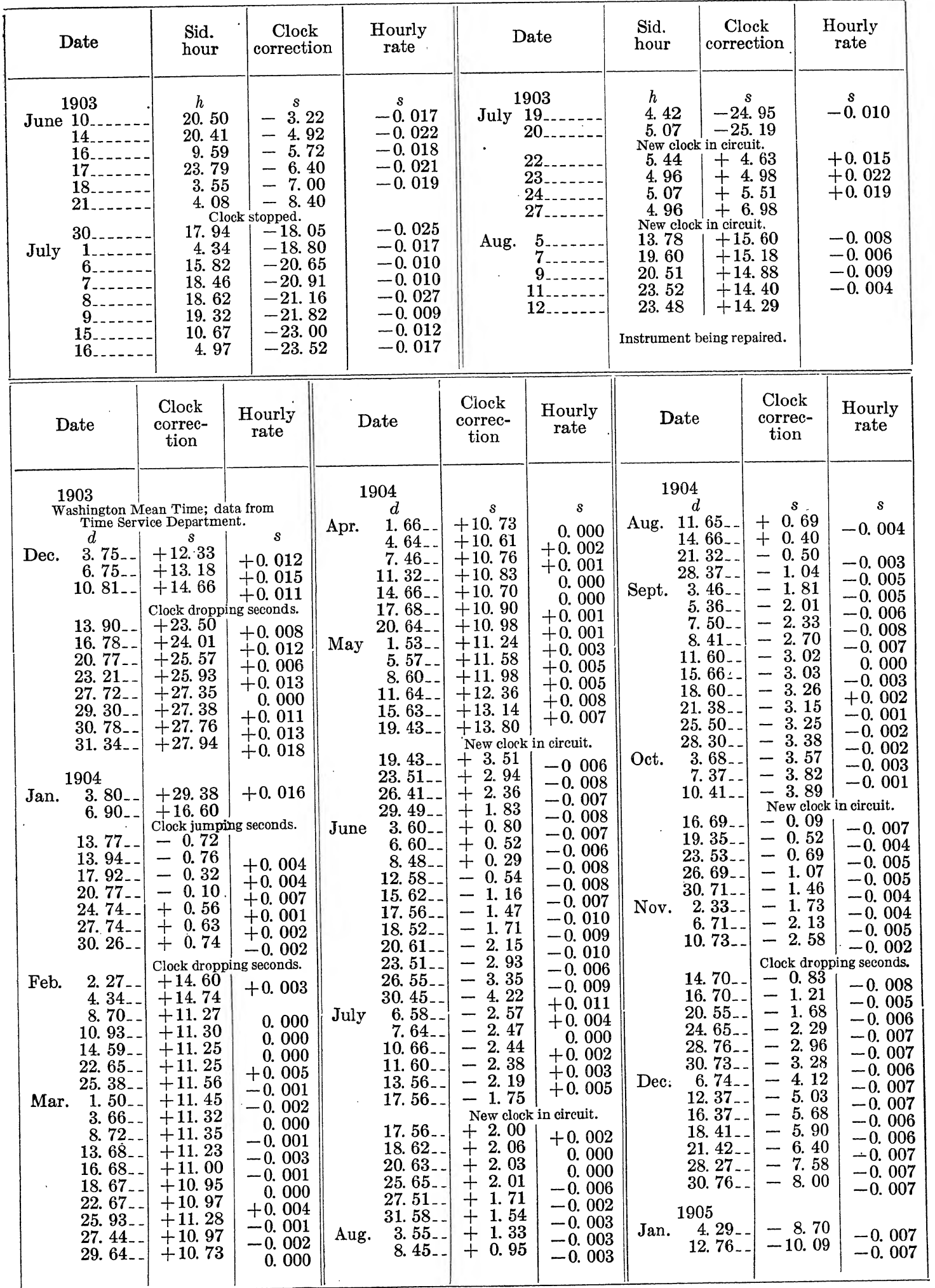




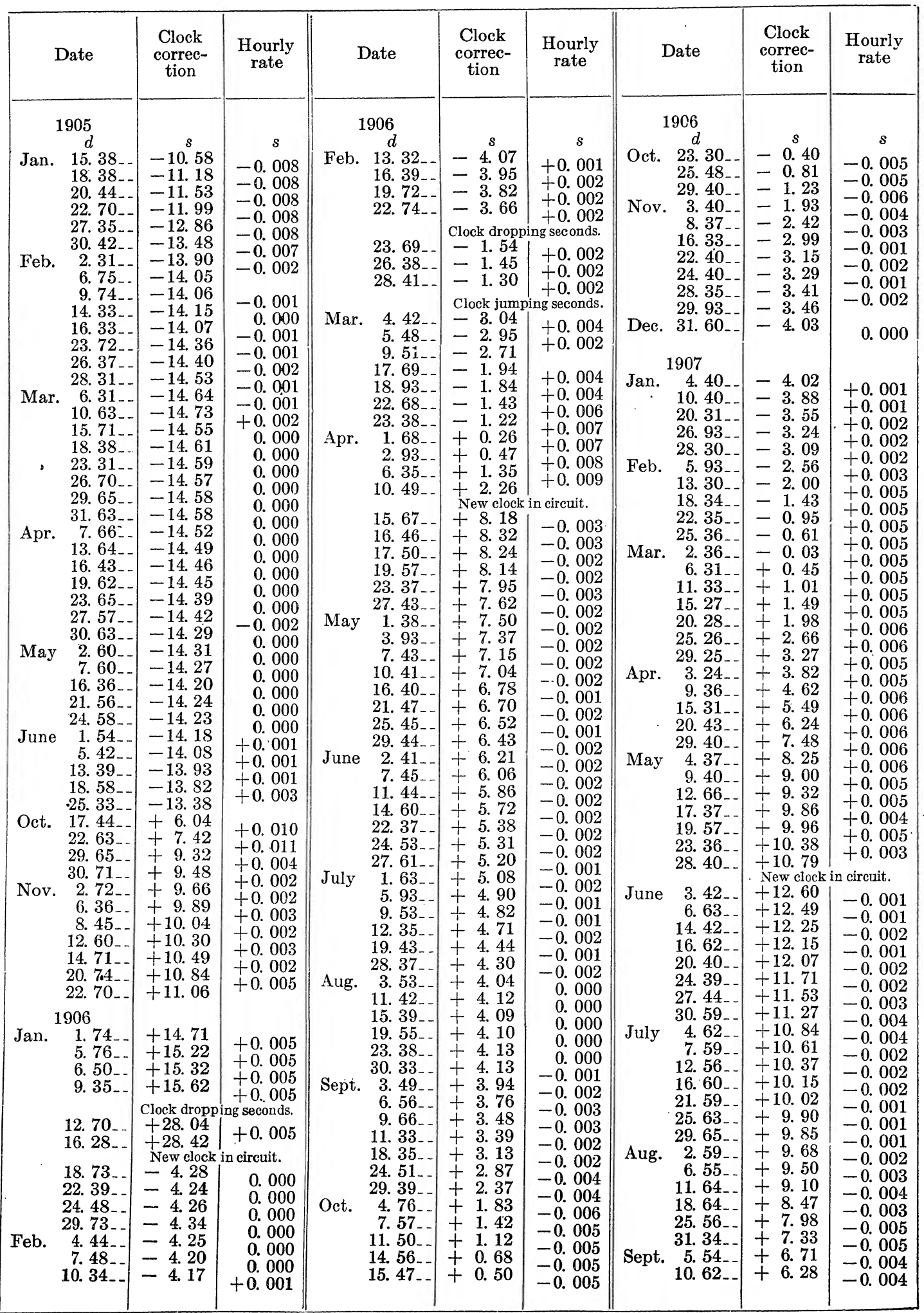


INTRODUCTION.

TABLE I.-The Adopted Clock Corrections and Rates-Continued

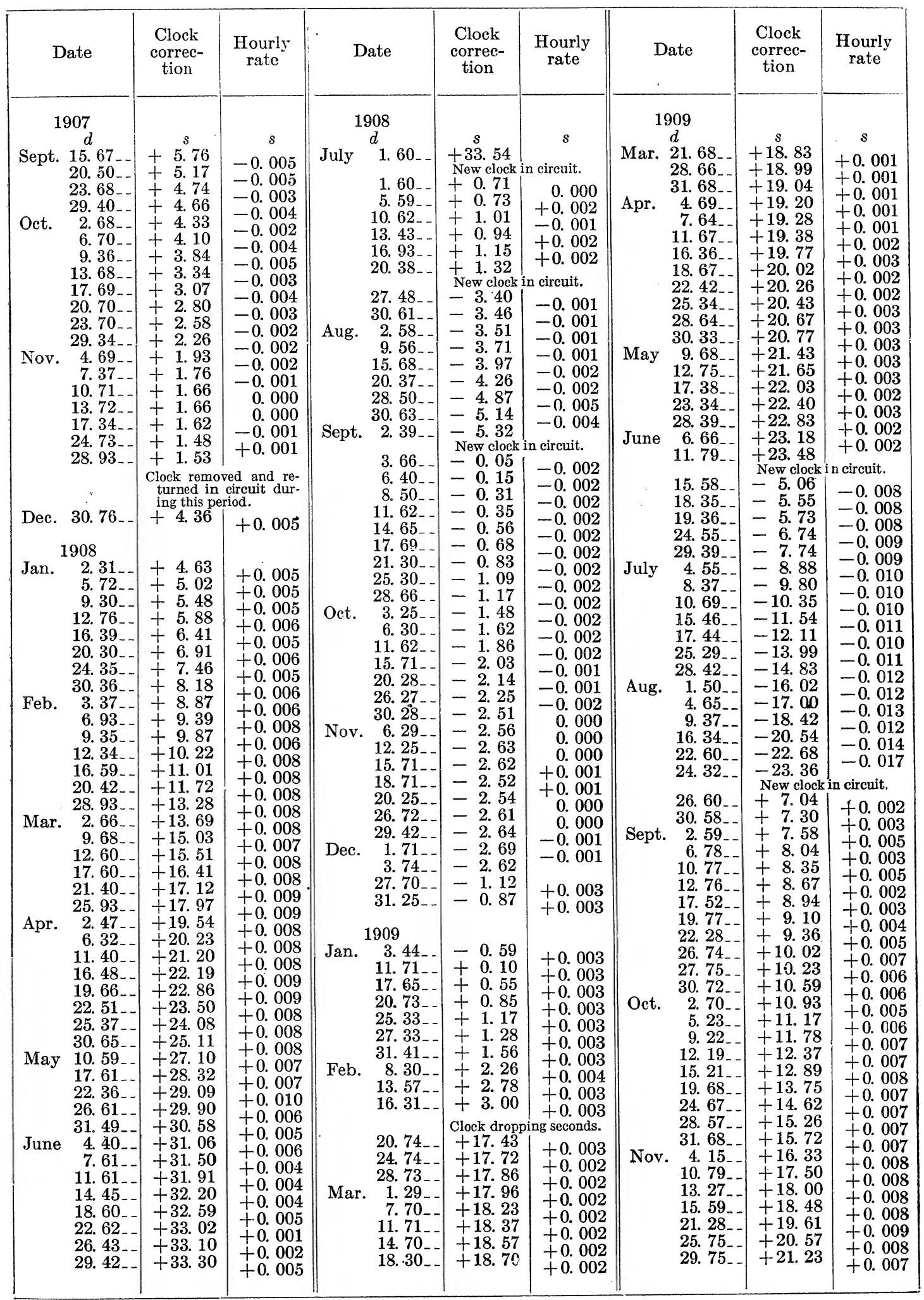


TABLE I.-The Adopted Clock Corrections and Rates-Continued

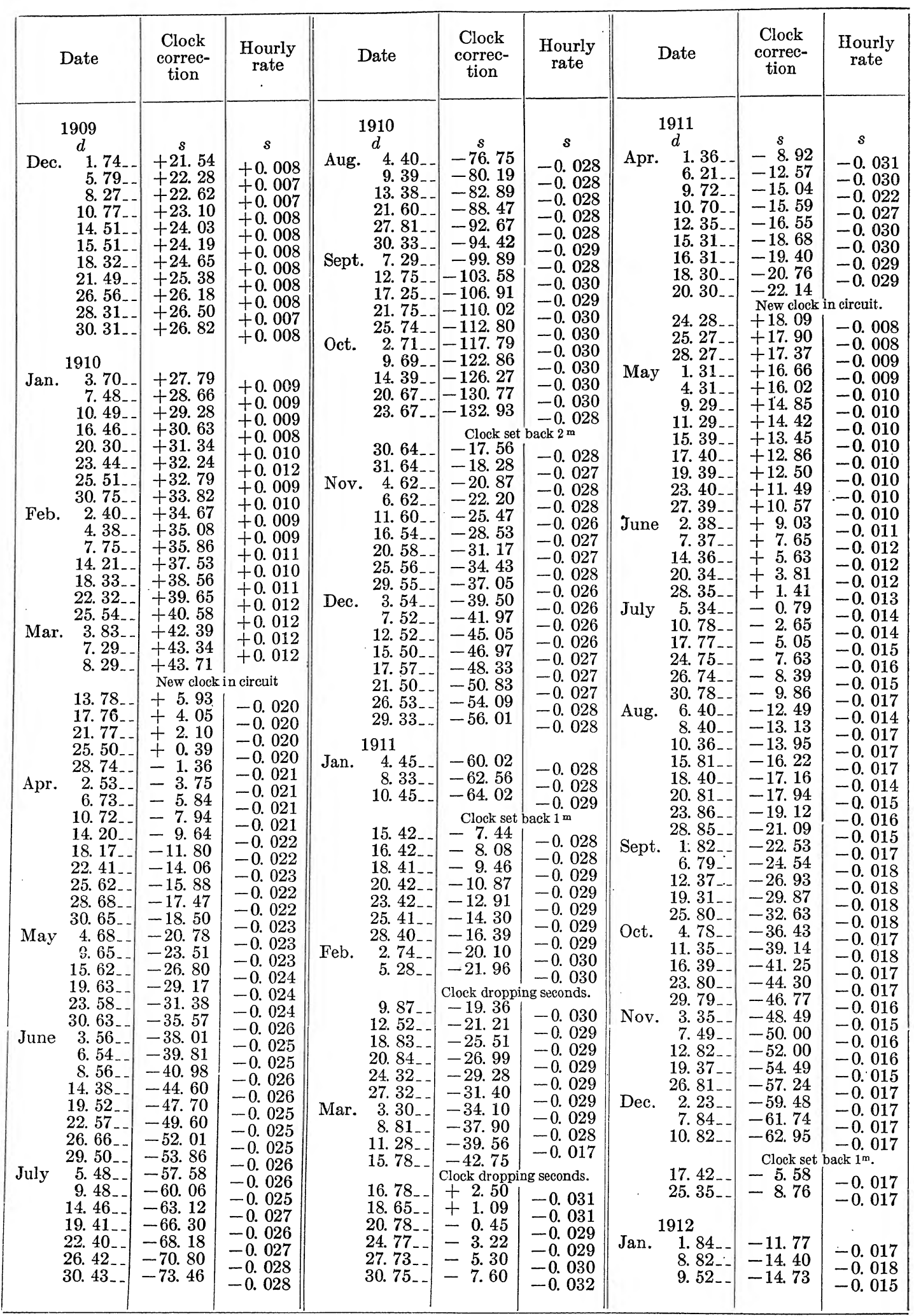


INTRODUCTION.

TABLE I.-The Adopted Clock Corrections and Rates-Continued

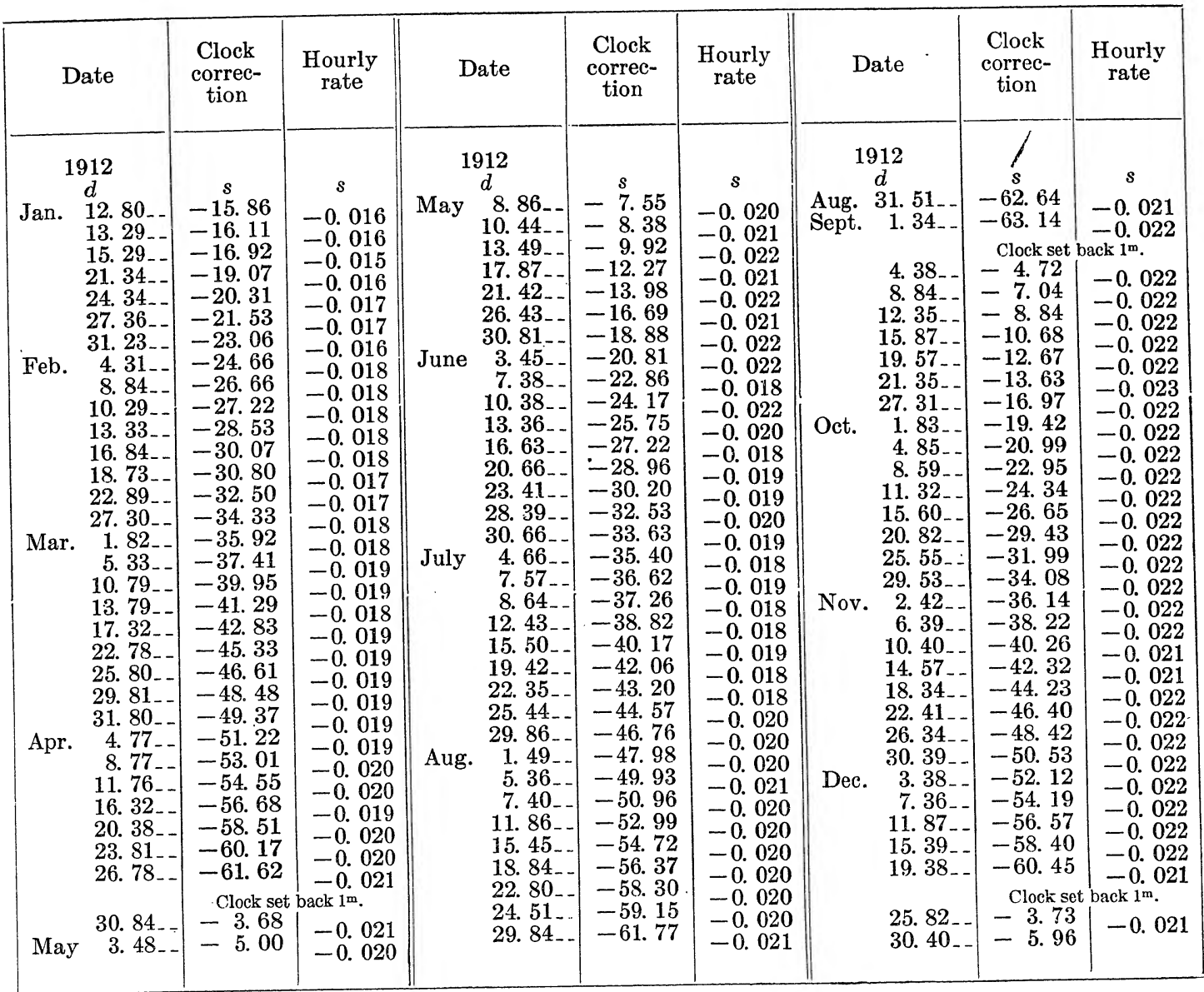

THE LEVEL VIAL

The level vial which has been used in measuring the inclination of the axis of the instrument was made by Adolph Pessler, of Freiburg, Saxony. It is $7 \frac{1}{2}$ inches in length, three-fourths of an inch in diameter, and chambered. The lines indicating divisions are etched on the vial. There are 70 of them, and they are numbered from one end of the vial toward the other.

The level vial is inclosed in a piece of brass tubing, 11 inches in length and 1 inch in diameter. On the lower inside surface of the tubirg four projections have been fastened. They extend upward from the tubing one-fourth of an inch and are one-half an inch wide. Two are placed near one end of the tubing, opposite each other, and two placed in a similar manner at the other end. The level vial is laid on these projections and their purpose is to raise the vial from contact with the tubing, except at the four points.

Directly over these projections two pieces of brass are fastened to the tubing. They are each one-fourth of an inch wide. The ends of these are tipped with cork. Their purpose is to press lightly on the level vial, merely to keep it in position. 
In each end of the brass tubing are fitted two lugs, made of the same material as the tubing. In one lug a long screw is tapped perpendicularly and is threaded into the level frame. Its purpose is to raise or depress the level box with respect to the level frame.

The other lug fits between two screws tapped into a projection on the level frame. Its purpose, by adjustment of the two screws, is to move the level tube into the vertical plane passing through the pivots of the instrument.

As the brass tubing is 11 inches long and the level vial $7 \frac{1}{2}$ inches, and since each of the lugs occupies a space of one-fourth of an inch in the tubing, there remain 3 inches of vacant space in the tubing. This space, $1 \frac{1}{2}$ inches at each end of the level vial, is filled with cotton, to prevent the vial from moving in a direction parallel to the tubing, and to avoid the possibility of any unyielding substance coming in contact with the ends of the vial.

The brass tubing, between the limits of the divisions on the level vial, is cut away, so as to expose to view the upper surface of the vial.

A box $83 / 8$ inches long, $1 \frac{1}{2}$ inches wide, and 2 inches high surrounds the tubing containing the level. The box is made of brass, except the two ends, which are hard rubber. The tubing, including the lugs in the ends of the tubing, projects through the box $1 \frac{3}{8}$ inches. As the ends of the box are composed of rubber, there is practically an air-tight joint at each end through which the tubing projects.

On the sides of the box are hermetically sealed two pieces of glass. Readings of the level are made through these glass sides. In other words, the level vial is inclosed in a practically air-tight box. Any sudden changes of temperature that may take place near the vial will, in a large degree, be controlled by radiation of its effect on the vial and not by direct contact.

This detailed description of the level vial and the box containing it has been deemed necessary because the accuracy of a declination secured through an observation made on the prime vertical depends in a large degree on the level determinations.

When the prime vertical transit was remodeled in 1893, three level vials of good workmanship were sent with it. Each was tested on a level trier, and the one that gave the most accordant distances between divisions was selected. It has proved to be an excellent one.

When the instrument was remounted in 1893 a short-focus telescope was attached to the post on the left-hand pier (see Plate I) for the purpose of reading the ends of the bubble at a distance of 5 feet from the level box. Two mirrors were fastened to the horizontal arm over the level frame. They also can be seen in Plate I. Their purpose was to reflect the image of the bubble into the field of view of the short-focus telescope. The above apparatus did not prove satisfactory, and except for a few readings made at the commencement of the work, it has not been used.

Readings of the level have always been made by direct vision, those made in the daytime by daylight, and those at night by the aid of an electric lamp held in the hand. 


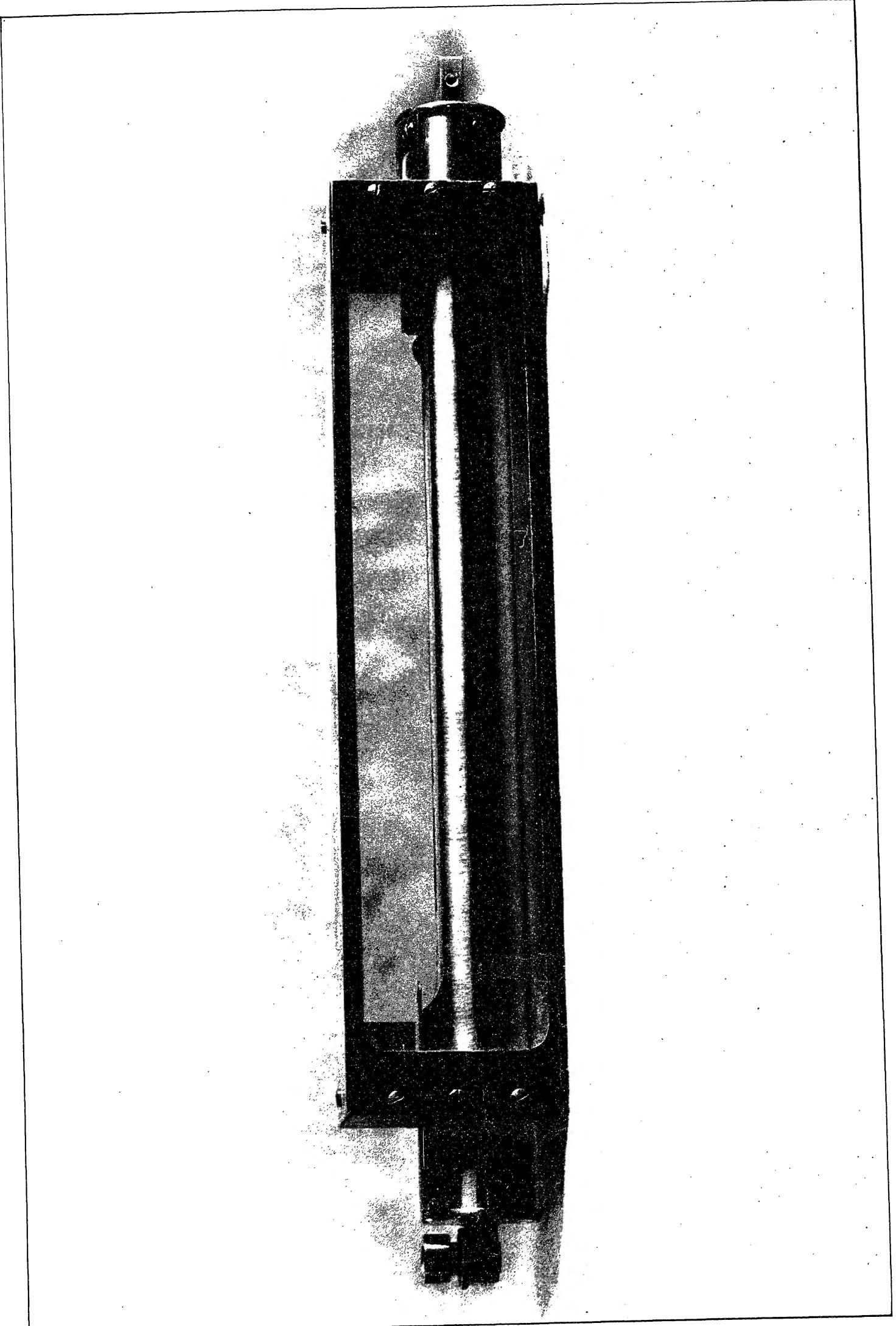

LEVEL AND BOX OF THE PRIME VERTICAL TRANSIT 
Throughout the series the value of one division of the level vial has been determined by readings made on three different level triers. The values are as follows:

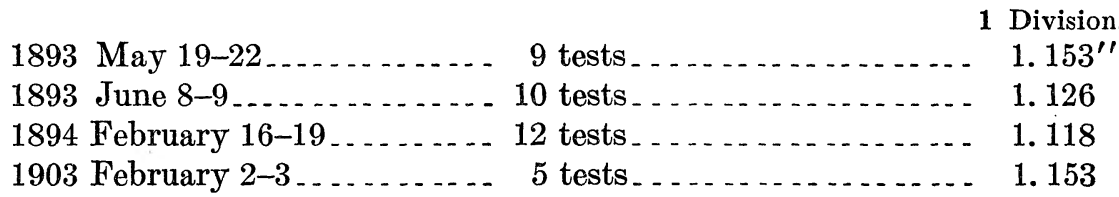

The adopted value of 1 division of the level vial is

$$
\text { 1. } 138^{\prime \prime} \text {. }
$$

About March 12, 1894, it was discovered that the level readings which had been made at the time certain stars had been observed just prior to that date gave an erroneous value to the resulting level correction. It was reported at once and instructions were given to make observations of transits, both direct and reflected, so as to learn what the cause might be.

An examination of the level vial in its mounting did not indicate that anything was wrong with it or that too much pressure was placed upon it. This condition continued until about September 24, 1894, when it ceased to show itself.

The observations made in the above period, when they were reduced brought to light a systematic difference between those made direct and those made reflected. From the material accumulated it was found that the application of a correction of $-1.20^{\prime \prime}$. to a direct observation and $+1.20^{\prime \prime}$ to a reflected one would bring the two declinations into agreement.

Therefore all observed declinations secured between March 12 and September 24,1894 , have been so corrected in the journal.

\section{THE PIVOTS, THEIR FORM AND INEQUAIITY}

The form of the pivots of a prime vertical transit is a very important matter to be investigated; first, to ascertain if each pivot is a true cylinder, and second, whether they are equal in diameter. In the first case if either or both are not true cylinders there exists what is termed an irregularity of pivots. In the second case there is an inequality of pivots.

By the STRUve method of observing with a prime vertical transit it follows that should the pivots of the instrument be not equal in diameter, although both are true cylinders, a reversal of the instrument in its $Y$ 's will eliminate the inequality of the pivots from the mean of level readings made before and after reversal.

But if one or both of the pivots are not true cylinders, then that effect is not eliminated by a reversal of the instrument, and there exists what is termed an irregularity of pivots.

The polished surface of each of the pivots is 1 inch wide, but the actual contact between pivot and $Y$ is but one-tenth of an inch wide. The angle between the surfaces of the level $Y$ 's is $82^{\circ} 48^{\prime}$, and the angle between the surfaces of the $Y$ 's of the instrument is $82^{\circ} 50^{\prime}$.

The Y's of the instrument are $1 \frac{1}{4}$ inches wide in a direction parallel to the pivots. Moreover, the polished surface of each $Y$ is not flat, but convex, the 
curvature commencing at the north and south edges of each $\mathrm{Y}$, respectively, and reaching a maximum in the center of the surface of each $Y$. Consequently the width of the bearing surface of each pivot in the $Y$ of the instrument is very small.

Early in the work a test was made to ascertain if the leveling apparatus placed the Y's of the level frame on the same portion of the pivots each time it was lowered thereon. The test consisted in lowering the level 'Y's on the pivots 50 consecutive times, and measuring by the aid of a rule graduated to one-sixty-fourth of an inch the distance from the north edge of the level $Y$ to the north face of the north $Y$ of the instrument. The readings were made on the rule by aid of a magnifying glass, and they did not differ by one division on the rule.

Inequality.-A discussion of the inequality of the pivots of the instrument has been considered so important that figures are given to illustrate the subject matter that follows.

These figures have been reproduced from Chauvenet's Spherical and Practical Astronomy (Vol. II, page 153), but similar figures are given in other books dealing with Practical Astronomy, for example, in Rev. RoBert MaIN's Spherical and Practical Astronomy, page 26, published in 1863, and in Dr. A. Sawrisch's Abriss der Practischen Astronomie, Tafel 1, published in 1850.

As is well known, when the Y's of a frame to which a level vial is attached, be it either a hanging or a striding level, are placed in a vertical plane passing through the axis of the two pivots, the true inclination of the axis of the instrument is not determined unless the pivots are equal in diameter.

It is for the purpose of discussing this particular condition, and to illustrate it, that Figures 1, 2, and 3 are shown, Plate VII. In each figure the letters $A$ and $A^{\prime}$ indicate the vertex of the level $Y$, and $C$ and $C^{\prime}$ the vertex of the $Y$ of the pivot. Using the letters of the figures,

Let $2 I=$ the angle of $Y$ of level frame $=82^{\circ} 48^{\prime}$

$2 I^{1}=$ the angle of $Y$ of instrument $=82^{\circ} 50^{\prime}$

$R$ =the radius of one pivot

$D=$ the vertical distance of $A$ above $O$

$D_{1}=$ the vertical distance of $O$ above $C$,

then $\quad D=R \operatorname{cosec} I$

$D_{1}=R \operatorname{cosec} I^{1}$.

For the other pivot, by making $R^{\prime}$ equal to its radius, we have,

$D^{\prime}=R^{\prime} \operatorname{cosec} I$

$D_{1}^{\prime}=R^{\prime} \operatorname{cosec} I^{1}$.

Let $N$ and $S$ equal the inclination of the axis of the instrument found by level readings, clamp north and clamp south,

$P$ and $P^{\prime}$ equal the true inclination for clamp north and clamp south, a equal the constant inclination of the line $C C_{1}{ }^{\prime}$

$L$ equal the distance between the $Y$ 's of the level frame, $=40.19$ inches.

In Figure 1 the line $G O$ is parallel to the line $A A^{\prime}$, and the line $H O$ is parallel to the line $C C^{\prime}$. 
PLATE VII
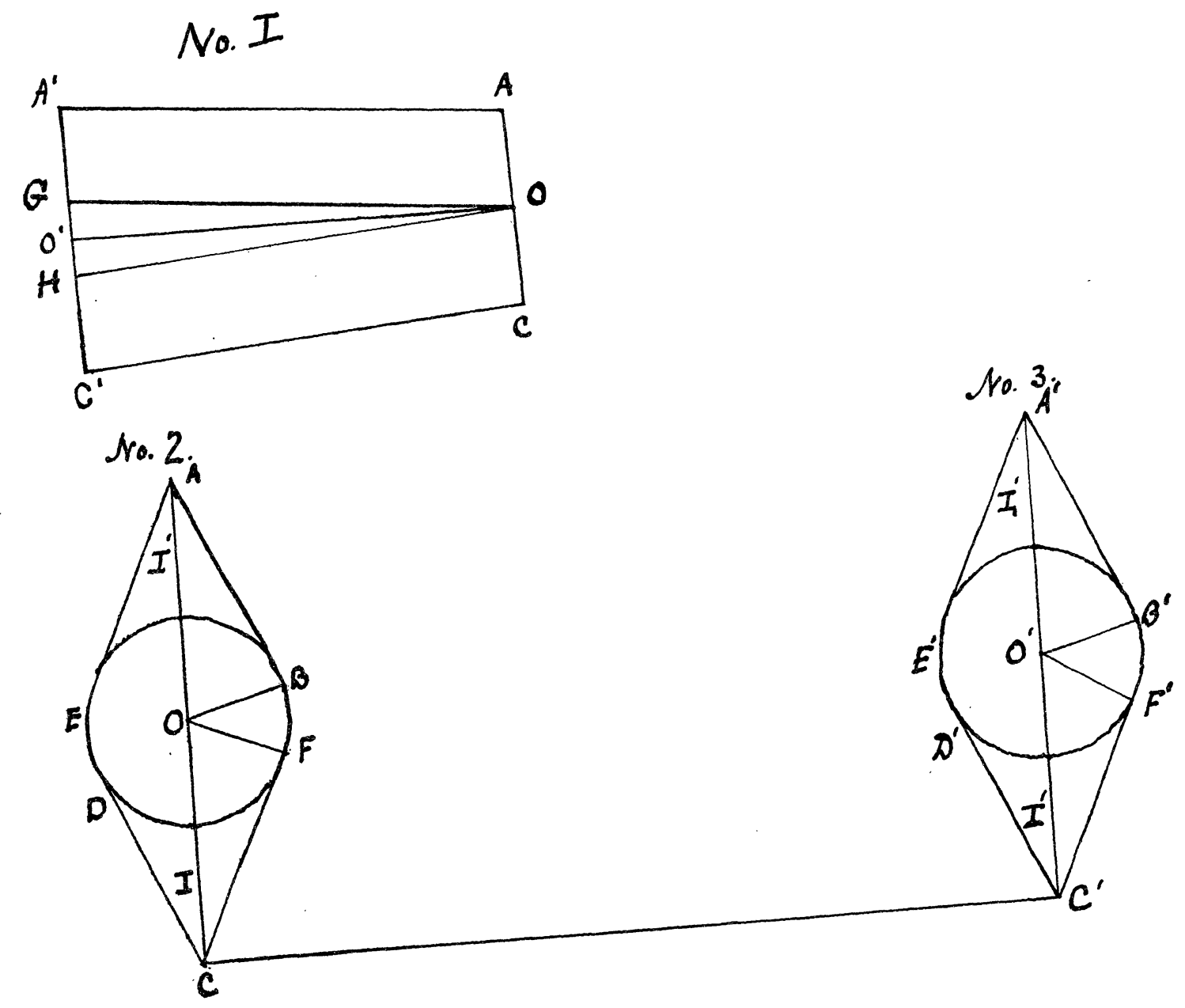
We will first suppose the clamp of the instrument is north, and afterwards south, and that the inclination of the axis in both positions has been obtained from level readings.

In Figure 1 put

$$
\begin{aligned}
y=G O O^{\prime}, y_{1} & =H O O^{\prime} . \\
\text { Then } \sin y & =\frac{D^{\prime}-D}{L}=\frac{R^{\prime}-R}{L \sin I} \\
\sin y_{1} & =\frac{D_{1}^{\prime}-D_{1}}{L}=\frac{R^{\prime}-R}{L \sin I^{1}},
\end{aligned}
$$

or if $y$ and $y_{1}$ are small angles,

$$
y=\frac{R^{\prime}-R}{L \sin I \sin 1^{\prime \prime}} \quad y_{1}=\frac{R^{\prime}-R}{L \sin I^{1} \sin 1^{\prime \prime}} \text {. }
$$

For clamp north we have, $P=N+y=a-y_{1}$.

For clamp south, $\quad P^{1}=S-y=a+y_{1}$.

Hence

$$
\begin{aligned}
& P^{1}-P=S-N-2 y=2 y_{1} . \\
& \text { and } \\
& \frac{S-N}{2}=y+y_{1}=y \cdot \frac{\sin I+\sin I^{1}}{\sin I^{1}}, \text { or } \\
& y=\frac{S-N}{2} \cdot \frac{\sin I^{1}}{\sin I+\sin I^{1}}
\end{aligned}
$$

As has been stated, the angles between the $Y$ 's of the level frame and those of the instrument, have been measured and are $82^{\circ} 48^{\prime}$ and $82^{\circ} 50^{\prime}$, respectively. Therefore, $I$ is equal to $41^{\circ} 24^{\prime}$, and $I^{1}$ is equal to $41^{\circ} 25^{\prime}$. Hence the value of $\frac{\sin I^{1} \cdot}{\sin I+\sin I^{1}}$ is 0.50008 , and

$$
y=\frac{0.50008(S-N)}{2}
$$

The factor in the first part of this equation is so near one-half that it can be adopted without any appreciable error in the value of $y$.

Therefore,

$$
y=\frac{S-N}{4}
$$

It has not been the intention to compute the inequality of pivots to be used as a correction to either a north or a south level reading, but rather from a large mass of material, collected over a long period of time, to study the amount of wear of the pivots.

Below is given an example of the method used in computing the inequality of pivots from level readings. These readings were taken from an observation of a Lyræ made on January 21, 1900. 
The numbers $261.6,240.8,242.3$, and 256.0 are the sums, respectively, of two readings of the north and south ends of the level bubble, before and after reversal of the level, for both clamp north and clamp south.

The value of the level correction in each clamp has been obtained by the following formula:

$$
\Delta \delta=d \cdot \frac{\sin 2 \delta \cdot \operatorname{cosec} 2 \varphi}{16} \text {, in which }
$$

$d=$ the value of 1 division of level vial $=1.138^{\prime \prime}$, $\delta=$ the declination of the star,

$\varphi=$ the latitude of instrument.

The algebraic sign of the level correction is found by taking the difference between level readings reversed and level readings direct, as in the following example. The level correction is positive when the south end of the axis of the instrument is too high, when that correction is to be applied to an observed declination.

Example:

Sum of level readings direct, east vertical, clamp north . . . . . . . . . . . . . . . 2 261. 6

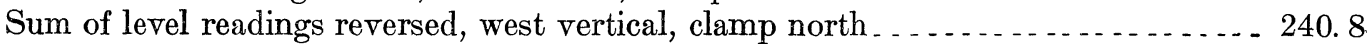

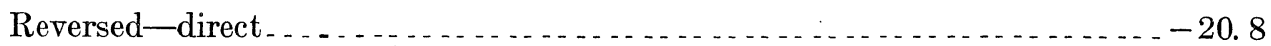

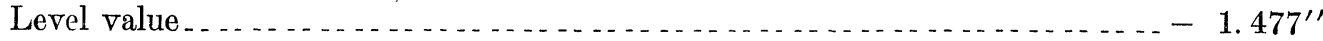

Sum of level readings direct, east vertical, clamp south . . . . . . . . . . . . . . . . . 2 242. 3

Sum of level readings reversed, west vertical, clamp south . . . . . . . . . . . . 256. 0

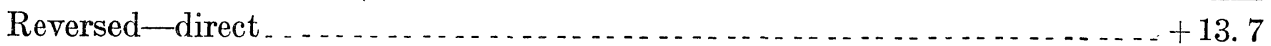

Level value... . . . . . . . . . . . . . . $0.973^{\prime \prime}$

Clamp north - clamp south $\div 4=$ inequality of pivots $=-0.61^{\prime \prime}$.

In accordance with the above, the values of the inequality of pivots shown in Table II have been obtained.

In Table III are given values of the inequality formed into means based upon 50 individual values, together with the dates between which each mean was obtained.

An examination of the data shows a certainty of wear of the pivots. Taking these values as they stand, the change of the inequality of the pivots, from July 1893 , to July, 1903, appears to be about $0.24^{\prime \prime}$. The change, after the pivots were refigured, namely, from the end of 1903 to the end of 1912 , appears to be about $0.11^{\prime \prime}$. 
INTRODUCTION.

A XLIX

TABLE II.-Inequality of Pivots Obtained from Individual Observations

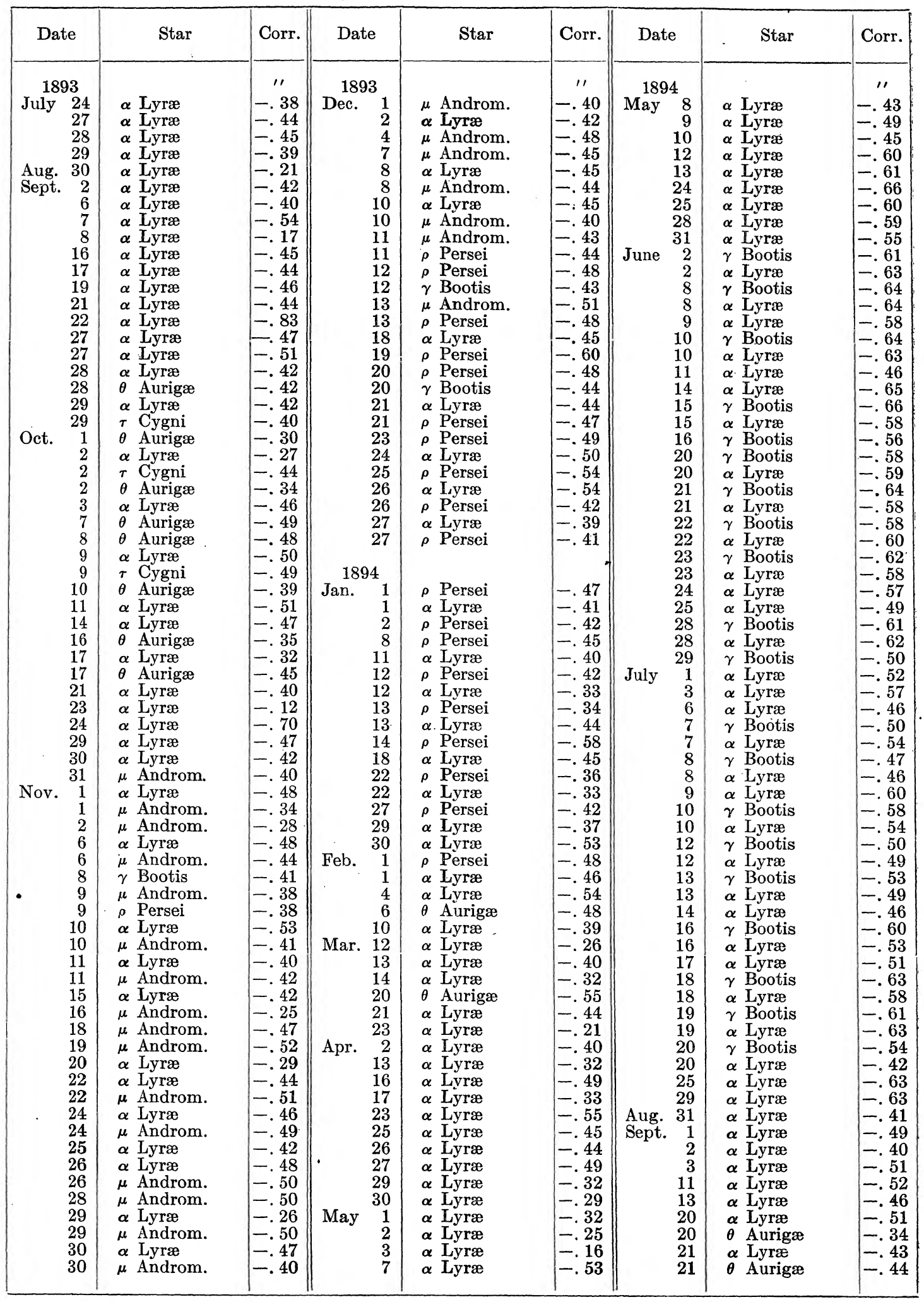

$101141^{\circ}-26 \dagger$ †T I -4 
TABLE II.-Inequality of Pivots Obtained from Individual Observations-Continued

\begin{tabular}{|c|c|c|c|c|c|c|c|c|c|}
\hline \multicolumn{2}{|c|}{ Date } & Star & Corr. & Date & Star & Corr. & Date & Star & Corr. \\
\hline $\begin{array}{r}180 \\
\text { Sept. }\end{array}$ & $\begin{array}{r}94 \\
22 \\
22 \\
23 \\
23 \\
24 \\
25 \\
30 \\
1 \\
2 \\
3 \\
5 \\
6 \\
7 \\
7 \\
10 \\
10 \\
11 \\
12 \\
13 \\
14 \\
15 \\
16 \\
16 \\
17 \\
17 \\
18 \\
19 \\
19 \\
20 \\
21 \\
31 \\
1 \\
2 \\
3 \\
3 \\
4 \\
4 \\
5 \\
6 \\
13 \\
14 \\
15 \\
15 \\
16 \\
16 \\
19 \\
19 \\
20 \\
21 \\
22 \\
22 \\
23 \\
24 \\
24 \\
25 \\
26 \\
27 \\
27 \\
28 \\
3 \\
3 \\
4 \\
5 \\
5 \\
6 \\
6 \\
9 \\
13 \\
14 \\
14\end{array}$ & $\begin{array}{ll}\alpha & \text { Lyræ } \\
\theta & \text { Aurigæ } \\
\alpha & \text { Lyræ } \\
\theta & \text { Aurigæ } \\
\alpha & \text { Lyræ } \\
\theta & \text { Aurigæ } \\
\alpha & \text { Lyræ } \\
\alpha & \text { Lyræ } \\
\alpha & \text { Lyræ } \\
\alpha & \text { Lyræ } \\
\theta & \text { Aurigæ } \\
\alpha & \text { Lyræ } \\
\alpha & \text { Lyræ } \\
\theta & \text { Aurigæ } \\
\alpha & \text { Lyræ } \\
\theta & \text { Aurigæ } \\
\alpha & \text { Lyræ } \\
\alpha & \text { Lyræ } \\
\alpha & \text { Lyræ } \\
\theta & \text { Aurigæ } \\
\theta & \text { Aurigæ } \\
\alpha & \text { Lyræ } \\
\theta & \text { Aurigæ } \\
\alpha & \text { Lyræ } \\
\theta & \text { Aurigæ } \\
\alpha & \text { Lyræ } \\
\alpha & \text { Lyræ } \\
\theta & \text { Aurigæ } \\
\alpha & \text { Lyræ } \\
\alpha & \text { Lyræ } \\
\mu & \text { Androm. } \\
\alpha & \text { Lyræ } \\
\alpha & \text { Lyræ } \\
\alpha & \text { Lyræ } \\
\mu & \text { Androm. } \\
\alpha & \text { Lyræ } \\
\mu & \text { Androm. } \\
\mu & \text { Androm. } \\
\alpha & \text { Lyræ } \\
\alpha & \text { Lyræ } \\
\alpha & \text { Lyræ } \\
\alpha & \text { Lyræ } \\
\mu & \text { Androm. } \\
\alpha & \text { Lyræ } \\
\mu & \text { Androm. } \\
\alpha & \text { Lyræ } \\
\mu & \text { Androm. } \\
\alpha & \text { Lyræ } \\
\alpha & \text { Lyræ } \\
\alpha & \text { Lyræ } \\
\mu & \text { Androm. } \\
\alpha & \text { Eyræ } \\
\alpha & \text { Lyræ } \\
\mu & \text { Androm. } \\
\mu & \text { Androm. } \\
\alpha & \text { Lyræ } \\
\alpha & \text { Lyræ } \\
\mu & \text { Androm. } \\
\alpha & \text { Lyræ } \\
\alpha & \text { Lyræ } \\
\mu & \text { Androm. } \\
\mu & \text { Androm. } \\
\alpha & \text { Lyræ } \\
\mu & \text { Androm. } \\
\alpha & \text { Lyræ } \\
\mu & \text { Androm. } \\
\mu & \text { Androm. } \\
\mu & \text { Androm. } \\
\alpha & \text { Lyræ } \\
\mu & \text { Androm. }\end{array}$ & 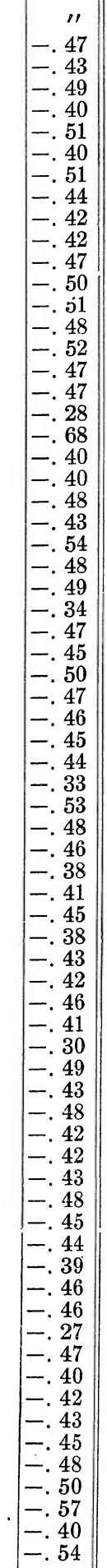 & $\begin{aligned} 1894 \\
\text { Dec. } 15 \\
15 \\
17 \\
17 \\
18 \\
18 \\
19 \\
19 \\
20 \\
20 \\
22 \\
22 \\
23 \\
23 \\
27 \\
28 \\
29 \\
1895 \\
1 \\
\text { Jan. } \\
1 \\
4 \\
13 \\
14 \\
14 \\
\text { Feb. } 4 \\
5 \\
11 \\
13 \\
13 \\
14 \\
15 \\
16 \\
17 \\
19 \\
21 \\
23 \\
23 \\
24 \\
25 \\
26 \\
26 \\
3 \\
\text { Mar. } \\
4 \\
55 \\
6 \\
6 \\
9 \\
9 \\
5 \\
10 \\
10\end{aligned}$ & $\begin{array}{ll}\alpha & \text { Lyræ } \\
\mu & \text { Androm. } \\
\alpha & \text { Lyræ } \\
\mu & \text { Androm. } \\
\alpha & \text { Lyræ } \\
\mu & \text { Androm. } \\
\alpha & \text { Lyræ } \\
\mu & \text { Androm. } \\
\alpha & \text { Lyræ } \\
\mu & \text { Androm. } \\
\alpha & \text { Lyræ } \\
\mu & \text { Androm. } \\
\alpha & \text { Lyræ } \\
\mu & \text { Androm. } \\
\mu & \text { Androm. } \\
\alpha & \text { Lyræ } \\
\alpha & \text { Lyræ } \\
& \\
\alpha & \text { Lyræ } \\
\mu & \text { Androm. } \\
\mu & \text { Androm. } \\
\alpha & \text { Lyræ } \\
\mu & \text { Androm. } \\
\alpha & \text { Lyræ } \\
\theta & \text { Aurigæ } \\
\theta & \text { Aurigæ } \\
\theta & \text { Aurigæ } \\
\theta & \text { Aurigæ } \\
\alpha & \text { Lyræ } \\
\alpha & \text { Lyræ } \\
\theta & \text { Aurigæ } \\
\alpha & \text { Lyræ } \\
\theta & \text { Aurigæ } \\
\alpha & \text { Lyræ } \\
\alpha & \text { Lyræ } \\
\theta & \text { Aurigæ } \\
\alpha & \text { Lyræ } \\
\theta & \text { Aurigæ } \\
\alpha & \text { Lyræ } \\
\theta & \text { Aurigæ } \\
\alpha & \text { Lyræ } \\
\theta & \text { Aurigæ } \\
\alpha & \text { Lyræ } \\
\theta & \text { Aurigæ } \\
\theta & \text { Aurigæ } \\
\alpha & \text { Lyræ } \\
\theta & \text { Aurigæ } \\
\alpha & \text { Lyræ } \\
\theta & \text { Aurigæ } \\
\alpha & \text { Lyræ } \\
\theta & \text { Aurigæ } \\
\alpha & \text { Lyræ } \\
\theta & \text { Aurigæ } \\
\theta & \text { Aurigæ } \\
\alpha & \text { Lyræ } \\
\theta & \text { Aurigæ } \\
\alpha & \text { Lyræ } \\
\theta & \text { Aurigæ } \\
\alpha & \text { Lyræ } \\
\theta & \text { Aurigæ } \\
\alpha & \text { Lyræ } \\
\theta & \text { Aurigæ } \\
\theta & \text { Aurigæ } \\
\alpha & \text { Lyræ } \\
\alpha & \text { Lyræ } \\
\alpha & \text { Lyræ } \\
\theta & \text { Aurigæ } \\
\theta & \text { Aurigæ } \\
\alpha & \text { Lyræ } \\
\end{array}$ & 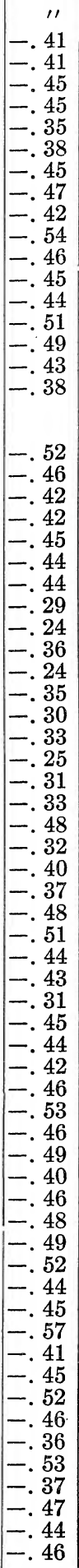 & 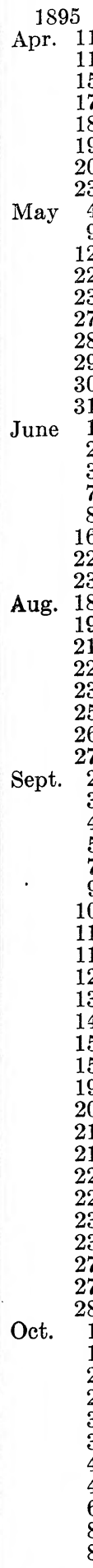 & 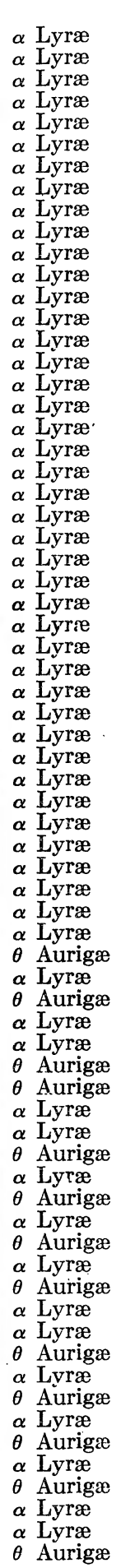 & $\begin{array}{l}11 \\
-.49 \\
-.42 \\
-.46 \\
-.44 \\
-.46 \\
-.46 \\
-.42 \\
-.48 \\
-.48 \\
-.48 \\
-.53 \\
-.44 \\
-.48 \\
-.40 \\
-.41 \\
-.58 \\
-.55 \\
-.60 \\
-.50 \\
-.47 \\
-.45 \\
-.55 \\
-.51 \\
-.52 \\
-.53 \\
-.46 \\
-.49 \\
-.51 \\
-.47 \\
-.35 \\
-.49 \\
-.55 \\
-.54 \\
-.59 \\
-.58 \\
-.58 \\
-.54 \\
-.55 \\
-.69 \\
-.57 \\
-.48 \\
-.53 \\
-.50 \\
-.52 \\
-.43 \\
-.45 \\
-.46 \\
-.52 \\
-.52 \\
-.45 \\
-.45 \\
-.47 \\
-.59 \\
-.50 \\
-.56 \\
-.46 \\
-.47 \\
-.42 \\
-.43 \\
-.46 \\
-.44 \\
-.46 \\
-.52 \\
-.47 \\
-.45 \\
-.45 \\
-.44 \\
-.63 \\
-.43 \\
-.42 \\
\end{array}$ \\
\hline
\end{tabular}


INTRODUCTION.

TABLE II.-Inequality of Pivots Obtained from Individual Observations-Continued

\begin{tabular}{|c|c|c|c|c|c|c|c|c|}
\hline Date & Star & Corr. & Date & Star & Corr. & Date & Star & Cors. \\
\hline $\begin{array}{rr}1895 \\
\text { Oct. } \\
9 \\
13 \\
14 \\
15 \\
16 \\
16 \\
17 \\
17 \\
18 \\
19 \\
20 \\
20 \\
21 \\
21 \\
22 \\
23 \\
23 \\
24 \\
25 \\
25 \\
26 \\
26 \\
27 \\
28 \\
28 \\
30 \\
1 \\
\text { Nov. } \\
3 \\
4 \\
5 \\
5 \\
\text { Jan. } \\
189 \\
12 \\
12 \\
12 \\
13 \\
2 \\
4 \\
73 \\
13 \\
18 \\
13 \\
19 \\
14 \\
15\end{array}$ & $\begin{array}{ll}\theta & \text { Aurigæ } \\
\theta & \text { Aurigæ } \\
\alpha & \text { Lyræ } \\
\alpha & \text { Lyræ } \\
\alpha & \text { Lyræ } \\
\theta & \text { Aurigæ } \\
\alpha & \text { Lyræ } \\
\theta & \text { Aurigæ } \\
\alpha & \text { Lyræ } \\
\alpha & \text { Lyræ } \\
\alpha & \text { Lyræ } \\
\theta & \text { Aurigæ } \\
\alpha & \text { Lyræ } \\
\theta & \text { Aurigæ } \\
\alpha & \text { Lyræ } \\
\alpha & \text { Lyræ } \\
\alpha & \text { Lyræ } \\
\alpha & \text { Lyræ } \\
\alpha & \text { Lyræ } \\
\theta & \text { Aurigæ } \\
\alpha & \text { Lyræ } \\
\theta & \text { Aurigæ } \\
\alpha & \text { Lyræ } \\
\alpha & \text { Lyræ } \\
\theta & \text { Aurigæ } \\
\alpha & \text { Lyræ } \\
\alpha & \text { Lyræ } \\
\alpha & \text { Lyræ } \\
\alpha & \text { Lyræ } \\
\alpha & \text { Lyræ } \\
\mu & \text { Androm. } \\
\alpha & \text { Lyræ } \\
\mu & \text { Androm. } \\
\alpha & \text { Lyræ } \\
\mu & \text { Androm. } \\
\mu & \text { Androm. } \\
\alpha & \text { Lyræ } \\
\mu & \text { Androm. } \\
\alpha & \text { Lyræ } \\
\mu & \text { Androm. } \\
\alpha & \text { Lyræ } \\
\mu & \text { Androm. } \\
\alpha & \text { Lyræ } \\
\alpha & \text { Lyræ } \\
\mu & \text { Androm. } \\
\mu & \text { Androm. } \\
\alpha & \text { Lyræ } \\
\mu & \text { Androm. } \\
\alpha & \text { Lyræ } \\
\mu & \text { Androm. } \\
\mu & \text { Androm. } \\
\alpha & \text { Lyræ } \\
\mu & \text { Androm. } \\
\alpha & \text { Lyræ } \\
\mu & \text { Androm. } \\
\alpha & \text { Lyræ } \\
\alpha & \text { Lyræ } \\
\mu & \text { Androm. } \\
& \\
\end{array}$ & $\begin{array}{l}\text { ". } \\
-.35 \\
-.47 \\
-.45 \\
-.50 \\
-.54 \\
-.70 \\
-.52 \\
-.53 \\
-.52 \\
-.55 \\
-.31 \\
-.46 \\
-.48 \\
-.42 \\
-.50 \\
-.43 \\
-.52 \\
-.44 \\
-.48 \\
-.50 \\
-.47 \\
-.55 \\
-.54 \\
-.47 \\
-.46 \\
-.48 \\
-.48 \\
-.51 \\
-.47 \\
-.42 \\
-.48 \\
-.46 \\
-.49 \\
-.53 \\
-.49 \\
-.49 \\
-.57 \\
-.54 \\
-.50 \\
-.59 \\
-.32 \\
-.64 \\
-.46 \\
-.43 \\
-.48 \\
-.47 \\
-.54 \\
-.39 \\
-.62 \\
-.56 \\
-.47 \\
-.36 \\
-.48 \\
-.53 \\
-.43 \\
-.60\end{array}$ & $\begin{array}{rr}1896 \\
\text { Jan. } \\
17 \\
24 \\
26 \\
27 \\
28 \\
29 \\
\text { Feb. } \\
6 \\
7 \\
10 \\
10 \\
11 \\
11 \\
13 \\
14 \\
14 \\
15 \\
16 \\
17 \\
17 \\
18 \\
19 \\
19 \\
25 \\
27 \\
\text { Mar. } \\
2 \\
2 \\
3 \\
3 \\
4 \\
4 \\
5 \\
7 \\
7 \\
7 \\
8 \\
9 \\
9 \\
9 \\
12 \\
10 \\
11 \\
15 \\
12 \\
17 \\
29 \\
13 \\
30\end{array}$ & $\begin{array}{ll}\alpha & \text { Lyræ } \\
\alpha & \text { Lyræ } \\
\alpha & \text { Lyræ } \\
\alpha & \text { Lyræ } \\
\alpha & \text { Lyræ } \\
\alpha & \text { Lyræ } \\
\alpha & \text { Lyræ } \\
\theta & \text { Aurigæ } \\
\theta & \text { Aurigæ } \\
\alpha & \text { Lyræ } \\
\theta & \text { Aurigæ } \\
\alpha & \text { Lyræ } \\
\alpha & \text { Lyræ } \\
\theta & \text { Aurigæ } \\
\alpha & \text { Lyræ } \\
\theta & \text { Aurigæ } \\
\theta & \text { Aurigæ } \\
\theta & \text { Aurigæ } \\
\alpha & \text { Lyræ } \\
\alpha & \text { Lyræ } \\
\theta & \text { Aurigæ } \\
\alpha & \text { Lyræ } \\
\theta & \text { Aurigæ } \\
\theta & \text { Aurigæ } \\
\theta & \text { Aurigæ } \\
\alpha & \text { Lyræ } \\
\theta & \text { Aurigæ } \\
\alpha & \text { Lyræ } \\
\theta & \text { Aurigæ } \\
\alpha & \text { Lyræ } \\
\theta & \text { Aurigæ } \\
\theta & \text { Aurigæ } \\
\alpha & \text { Lyræ } \\
\alpha & \text { Lyræ } \\
\theta & \text { Aurigæ } \\
\theta & \text { Aurigæ } \\
\alpha & \text { Lyræ } \\
\theta & \text { Aurigæ } \\
\alpha & \text { Lyræ } \\
\theta & \text { Aurigæ } \\
\theta & \text { Aurigæ } \\
\alpha & \text { Lyræ } \\
\theta & \text { Aurigæ } \\
\alpha & \text { Lyræ } \\
\theta & \text { Aurigæ } \\
\theta & \text { Aurigæ } \\
\alpha & \text { Lyræ } \\
\alpha & \text { Lyræ } \\
\alpha & \text { Lyræ } \\
\theta & \text { Aurigæ } \\
\alpha & \text { Lyræ } \\
\theta & \text { Aurigæ } \\
\alpha & \text { Lyræ } \\
\theta & \text { Aurigæ } \\
\alpha & \text { Lyræ } \\
\alpha & \text { Lyræ } \\
\alpha & \text { Lyræ } \\
\alpha & \text { Lyræ } \\
\alpha & \text { Lyræ } \\
\alpha & \text { Lyræ } \\
\alpha & \text { Lyræ } \\
\alpha & \text { Lyræ } \\
\alpha & \text { Lyræ } \\
\alpha & \text { Lyræ } \\
\alpha & \text { Lyræ } \\
\alpha & \text { Lyræ } \\
\alpha & \text { Lyræ } \\
\alpha & \text { Lyrææ } \\
\alpha & \text { Lyrææ } \\
\alpha & \text { Lyrræ }\end{array}$ & \begin{tabular}{|l} 
\\
-.45 \\
-.50 \\
-.49 \\
-.46 \\
-.45 \\
-.44 \\
-.48 \\
-.54 \\
-.50 \\
-.48 \\
-.46 \\
-.35 \\
-.47 \\
-.45 \\
-.50 \\
-.50 \\
-.58 \\
-.39 \\
-.38 \\
-.53 \\
-.43 \\
-.39 \\
-.60 \\
-.42 \\
-.53 \\
-.48 \\
-.40 \\
-.33 \\
-.44 \\
-.43 \\
-.47 \\
-.53 \\
-.51 \\
-.55 \\
-.48 \\
-.52 \\
-.39 \\
-.48 \\
-.67 \\
-.49 \\
-.45 \\
-.58 \\
-.44 \\
-.44 \\
-.51 \\
-.58 \\
-.41 \\
-.54 \\
-.45 \\
-.35 \\
-.45 \\
-.53 \\
-.53 \\
-.53 \\
-.51 \\
-.52 \\
-.47 \\
-.50 \\
-.52 \\
-.58 \\
-.43 \\
-.54 \\
-.64 \\
-.63 \\
.- .44 \\
-.61 \\
-.55
\end{tabular} & 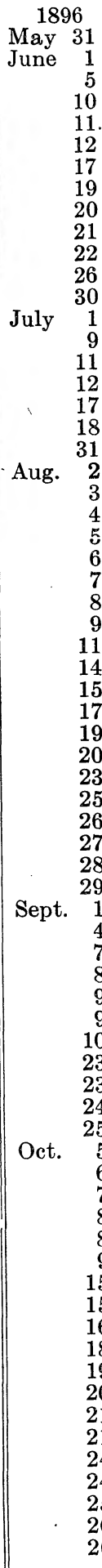 & $\begin{array}{ll}\alpha & \text { Lyræ } \\
\alpha & \text { Lyræ } \\
\alpha & \text { Lyræ } \\
\alpha & \text { Lyræ } \\
\alpha & \text { Lyræ } \\
\alpha & \text { Lyræ } \\
\alpha & \text { Lyræ } \\
\alpha & \text { Lyræ } \\
\alpha & \text { Lyræ } \\
\alpha & \text { Lyræ } \\
\alpha & \text { Lyræ } \\
\alpha & \text { Lyræ } \\
\alpha & \text { Lyræ } \\
\alpha & \text { Lyræ } \\
\alpha & \text { Lyræ } \\
\alpha & \text { Lyræ } \\
\alpha & \text { Lyræ } \\
\alpha & \text { Lyræ } \\
\alpha & \text { Lyræ } \\
\alpha & \text { Lyræ } \\
\alpha & \text { Lyræ } \\
\alpha & \text { Lyræ } \\
\alpha & \text { Lyræ } \\
\alpha & \text { Lyræ } \\
\alpha & \text { Lyræ } \\
\alpha & \text { Lyræ } \\
\alpha & \text { Lyræ } \\
\alpha & \text { Lyræ } \\
\alpha & \text { Lyræ } \\
\alpha & \text { Lyræ } \\
\alpha & \text { Lyræ } \\
\alpha & \text { Lyræ } \\
\alpha & \text { Lyræ } \\
\alpha & \text { Lyræ } \\
\alpha & \text { Lyræ } \\
\alpha & \text { Lyræ } \\
\alpha & \text { Lyræ } \\
\alpha & \text { Lyræ } \\
\alpha & \text { Lyræ } \\
\alpha & \text { Lyræ } \\
\alpha & \text { Lyræ } \\
\alpha & \text { Lyræ } \\
\alpha & \text { Lyræ } \\
\alpha & \text { Lyræ } \\
\alpha & \text { Lyræ } \\
\theta & \text { Aurigæ } \\
\alpha & \text { Lyræ } \\
\alpha & \text { Lyræ } \\
\theta & \text { Aurigæ } \\
\alpha & \text { Lyræ } \\
\alpha & \text { Lyræ } \\
\theta & \text { Aurigæ } \\
\alpha & \text { Lyræ } \\
\alpha & \text { Lyræ } \\
\alpha & \text { Lyræ } \\
\theta & \text { Aurigæ } \\
\alpha & \text { Lyræ } \\
\alpha & \text { Lyræ } \\
\theta & \text { Aurigæ } \\
\alpha & \text { Lyræ } \\
\theta & \text { Aurigæ } \\
\alpha & \text { Lyræ } \\
\alpha & \text { Lyræ } \\
\alpha & \text { Lyræ } \\
\theta & \text { Aurigæ } \\
\alpha & \text { Lyyræ } \\
\theta & \text { Aurigæ } \\
\theta & \text { Aurigæ } \\
\alpha & \text { Lyræ } \\
\theta & \text { Aurigæ }\end{array}$ & \begin{tabular}{|l}
$\prime \prime$ \\
-.65 \\
-.60 \\
-.51 \\
-.51 \\
-.63 \\
-.57 \\
-.62 \\
-.55 \\
-.64 \\
-.61 \\
-.69 \\
-.63 \\
-.59 \\
-.57 \\
-.62 \\
-.67 \\
-.66 \\
-.54 \\
-.62 \\
-.62 \\
-.59 \\
-.57 \\
-.61 \\
-.58 \\
-.53 \\
-.60 \\
-.67 \\
-.56 \\
-.66 \\
-.58 \\
-.62 \\
-.62 \\
-.47 \\
-.54 \\
-.54 \\
-.56 \\
-.62 \\
-.50 \\
-.61 \\
-.57 \\
-.70 \\
-.57 \\
-.61 \\
-.57 \\
-.63 \\
-.66 \\
-.60 \\
-.548 \\
-.58 \\
-.57 \\
-.45 \\
-.47 \\
-.56 \\
-.62 \\
-.52 \\
-.48 \\
-.52 \\
-.58 \\
-.56 \\
-.58 \\
-.61 \\
-.56 \\
-.55 \\
-.57 \\
-.57 \\
-.57 \\
-.54 \\
-.54 \\
.57
\end{tabular} \\
\hline
\end{tabular}


TABLE II.-Inequality of Pivots Obtained from Individual Observations-Continued

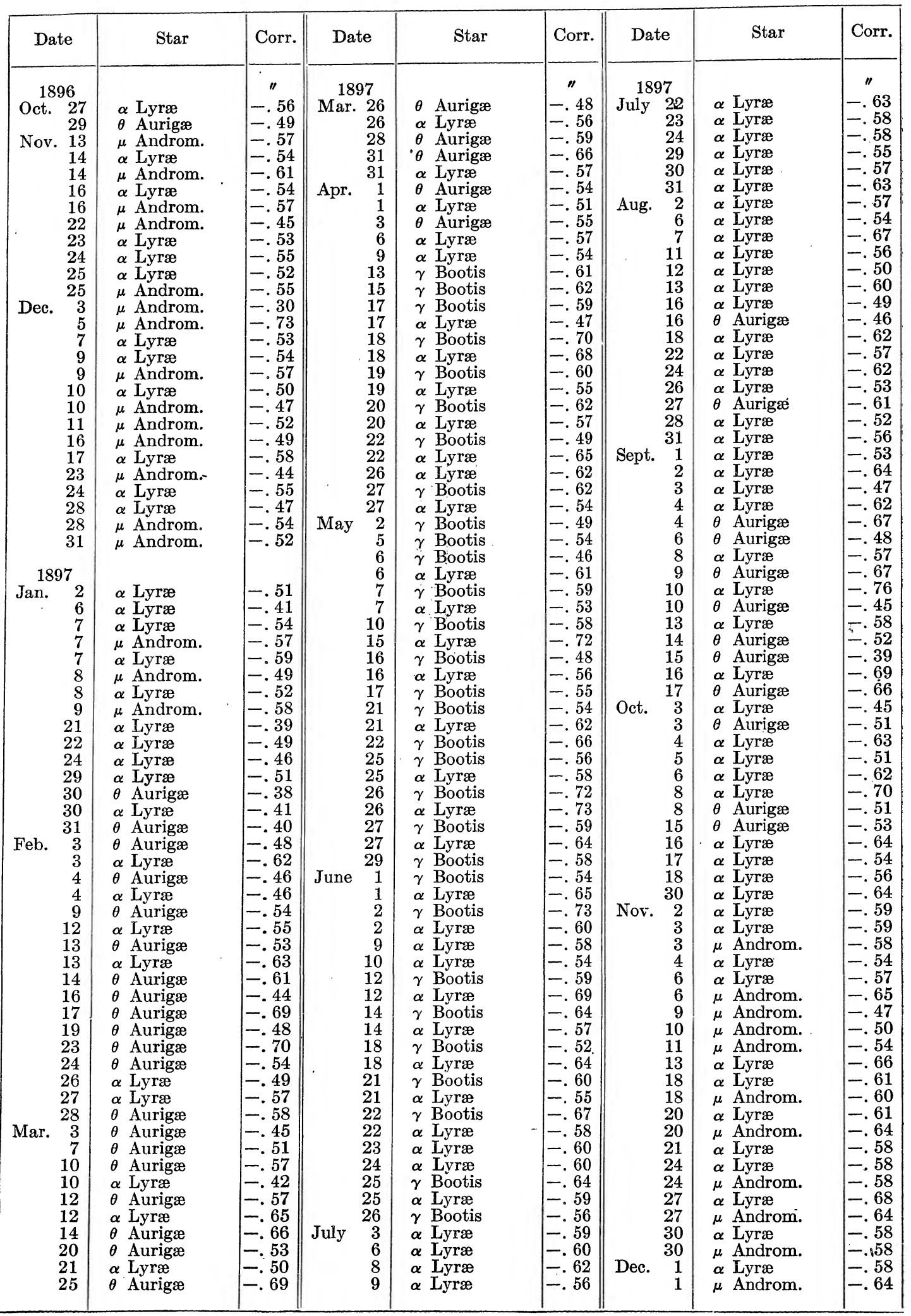


INTRODUCTION.

A LIII

TABLE II.-Inequality of Pivots Obtained from Individual Observations-Continued

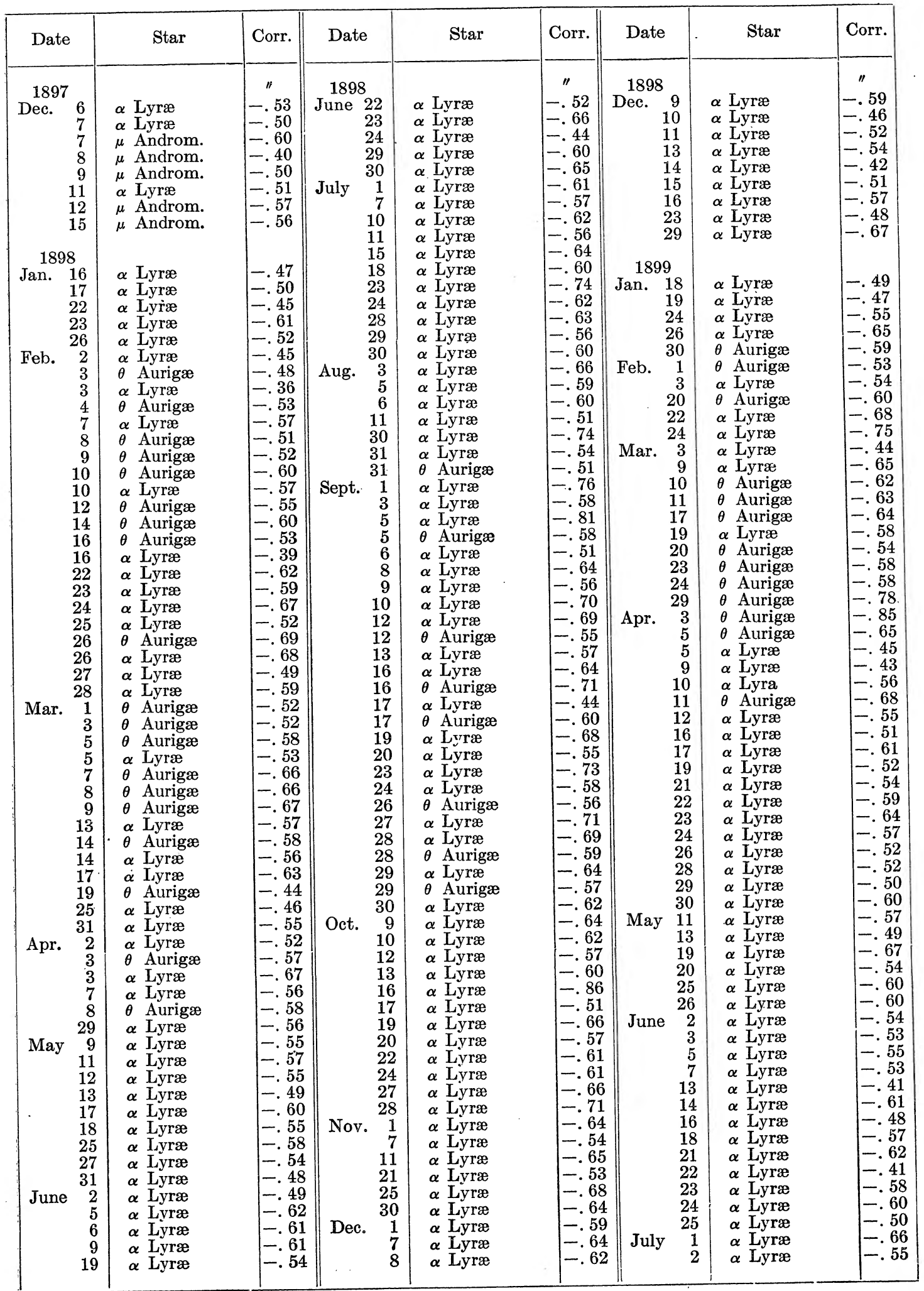


PRIME VERTICAL TRANSIT INSTRUMENT.

TABLE II.-Inequality of Pivots Obtained from Individual Observations-Continued

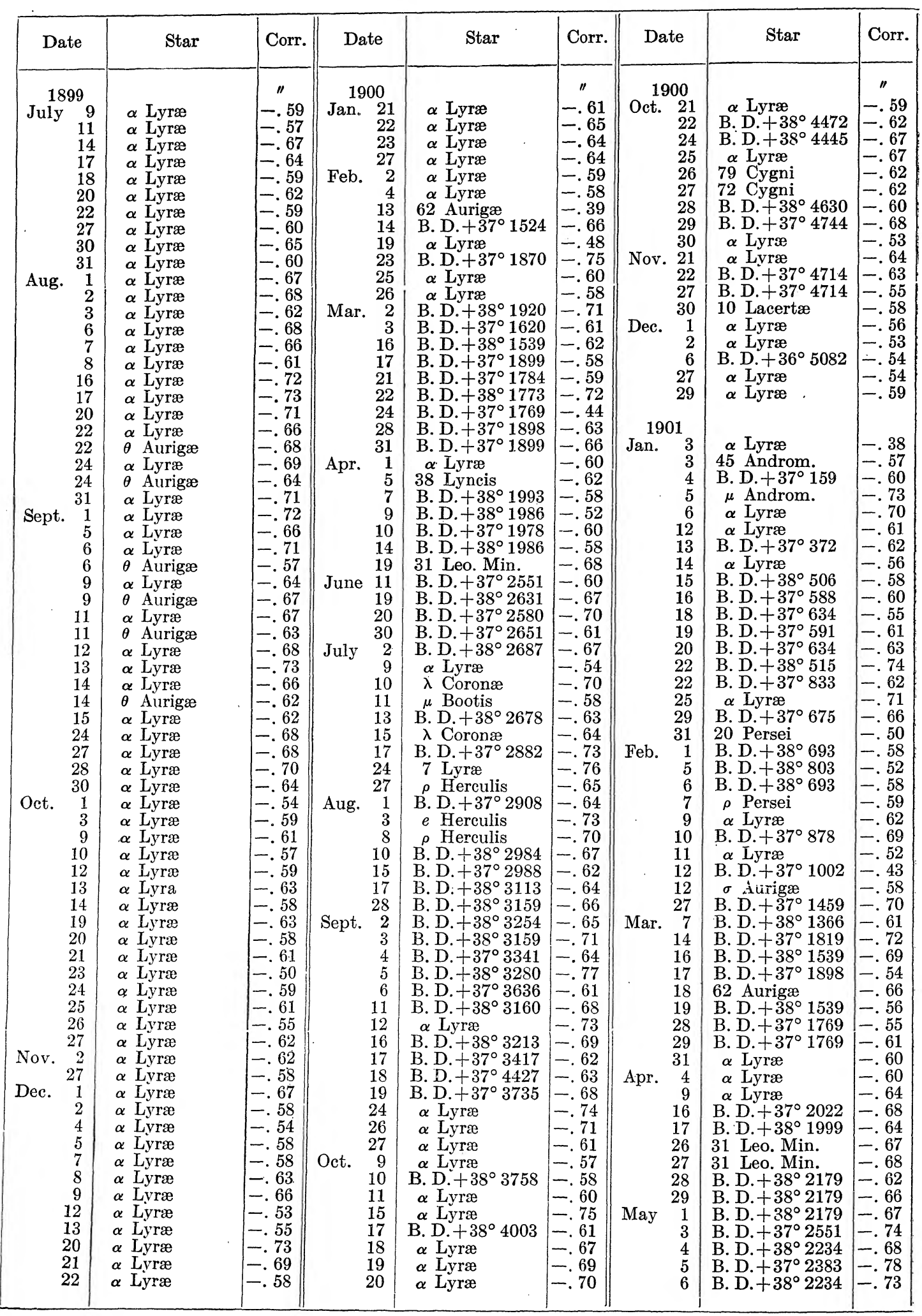


TABLE II.-Inequality of Pivots Obtained from Individual Observations-Continued

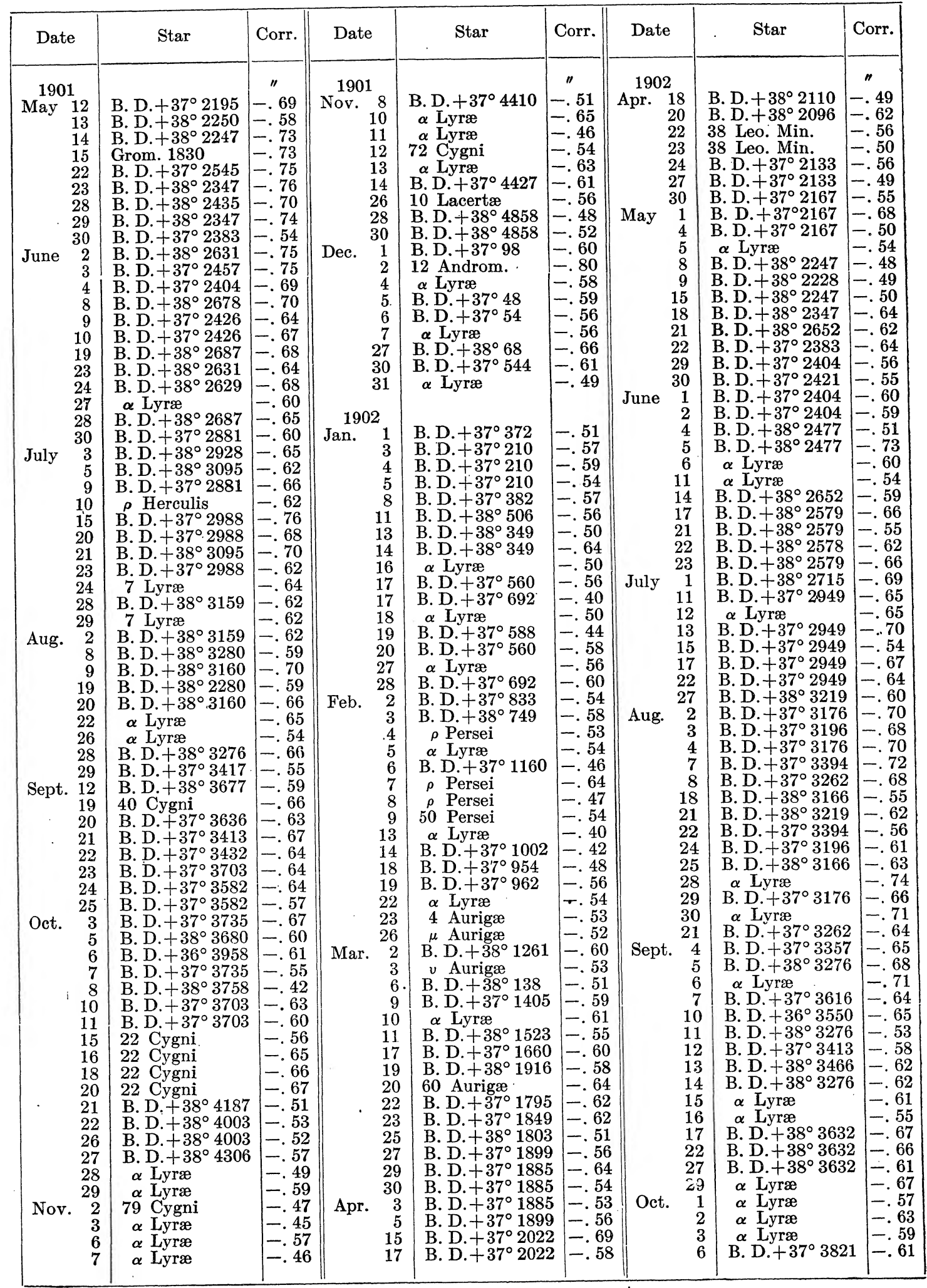


TABLE II.-Inequality of Pivots Obtained from Individual Observations-Continued

\begin{tabular}{|c|c|c|c|c|c|c|c|c|}
\hline Date & Star & Corr. & Date & Star & Corr. & Date & Star & Corr. \\
\hline \begin{tabular}{|rr}
\multicolumn{2}{|c}{1903} \\
Jan. \\
9 \\
10 \\
12 \\
14 \\
18 \\
19 \\
21 \\
22 \\
22 \\
23 \\
28 \\
30 \\
Feb. 4 \\
4 \\
5 \\
6 \\
6 \\
9 \\
12 \\
17 \\
18 \\
20 \\
22 \\
23 \\
25 \\
26 \\
Mar. 1 \\
3 \\
3 \\
4 \\
12 \\
13 \\
17 \\
18 \\
19 \\
24 \\
25 \\
26 \\
27 \\
31 \\
4 \\
4 \\
6 \\
9 \\
10 \\
17 \\
18 \\
21 \\
27 \\
29
\end{tabular} & 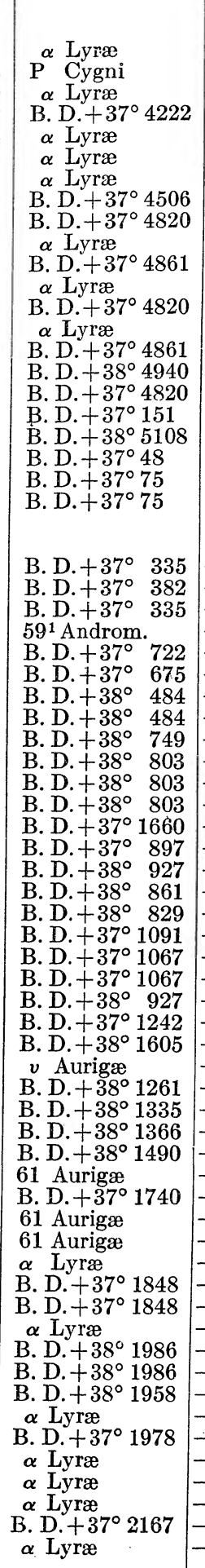 & 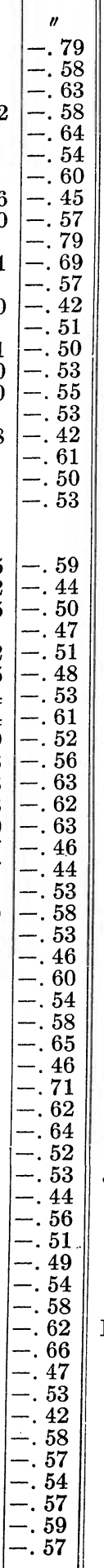 & \begin{tabular}{|rr}
\multicolumn{1}{|c}{1903} \\
May & 1 \\
4 \\
5 \\
7 \\
9 \\
11 \\
12 \\
15 \\
19 \\
21 \\
28 \\
June 2 \\
2 \\
3 \\
8 \\
10 \\
14 \\
18 \\
21 \\
30 \\
1 \\
July \\
6 \\
7 \\
8 \\
9 \\
15 \\
18 \\
19 \\
21 \\
23 \\
24 \\
25 \\
27 \\
Aug. \\
7 \\
9 \\
9 \\
11 \\
12 \\
6 \\
6 \\
Dec. \\
11 \\
13 \\
14 \\
15 \\
17 \\
22 \\
23 \\
26 \\
28 \\
29 \\
30
\end{tabular} & 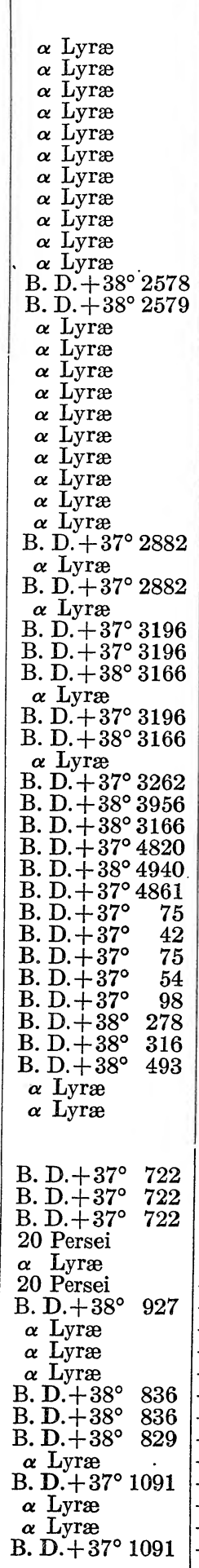 & 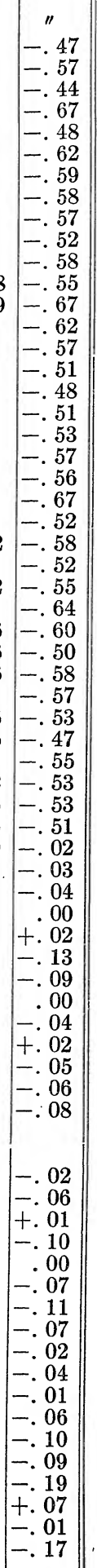 & \begin{tabular}{|rr}
1904 \\
Feb. 20 \\
22 \\
24 \\
25 \\
Mar. \\
3 \\
4 \\
8 \\
9 \\
16 \\
16 \\
23 \\
28 \\
29 \\
Apr. \\
1 \\
2 \\
3 \\
4 \\
5 \\
14 \\
16 \\
17 \\
17 \\
18 \\
19 \\
20 \\
21 \\
1 \\
May \\
2 \\
4 \\
5 \\
5 \\
8 \\
11 \\
12 \\
15 \\
20 \\
21 \\
23 \\
24 \\
25 \\
27 \\
28 \\
3 \\
June \\
8 \\
13 \\
14 \\
15 \\
17 \\
18 \\
22 \\
23 \\
23 \\
24 \\
25 \\
2 \\
6 \\
6 \\
11 \\
13 \\
13 \\
14 \\
17 \\
17 \\
25 \\
20 \\
26 \\
27 \\
29 \\
29 \\
3 \\
6 \\
11 \\
14 \\
15 \\
23 \\
July
\end{tabular} & 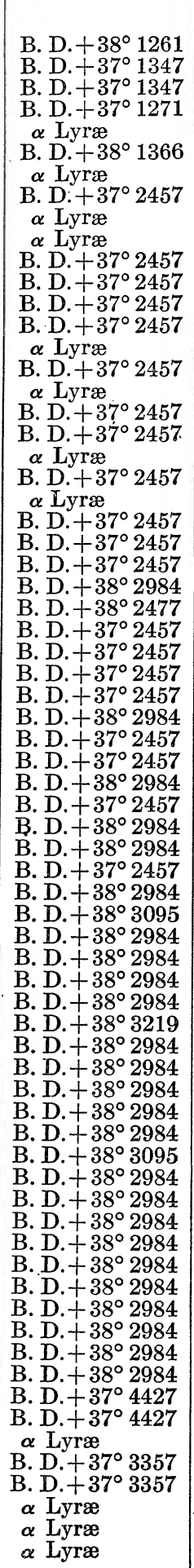 & $\begin{array}{l}+.01 \\
+.07 \\
+.03 \\
+.04 \\
+.11 \\
-.14 \\
.03 \\
+.01 \\
+.06 \\
+.06 \\
+.02 \\
+.03 \\
+.07 \\
+.04 \\
+.06 \\
+.04 \\
+.07 \\
+.04 \\
+.02 \\
+.05 \\
+.04 \\
+.04 \\
+.03 \\
+.04 \\
+.05 \\
+.01 \\
.02 \\
+.09 \\
+.07 \\
+.03 \\
+.09 \\
+.01 \\
+.06 \\
+.08 \\
.03 \\
.03 \\
+.11 \\
+.02 \\
+.02 \\
+.09 \\
+.08 \\
+.04 \\
.01 \\
+.04 \\
+.04 \\
.01 \\
+.08 \\
+.03 \\
+.05 \\
+.10 \\
+.02 \\
+.05 \\
+.06 \\
+.06 \\
+.01 \\
+.15 \\
+.04 \\
+.03 \\
+.01 \\
+.01 \\
+.04 \\
+.08 \\
+.04 \\
+.10 \\
+.07 \\
+.01 \\
+.01 \\
+.02 \\
+.04 \\
\end{array}$ \\
\hline
\end{tabular}


TABLE II.-Inequality of Pivots Obtained from Individual Observations-Continued

\begin{tabular}{|c|c|c|c|c|c|c|c|c|c|}
\hline Date & Star & Corr. & \multicolumn{2}{|l|}{ Date } & Star & Corr. & Date & Star & Corr. \\
\hline \multirow{2}{*}{$\begin{array}{c}1904 \\
\text { Sept. } 10\end{array}$} & & $" \prime$ & 1905 & & & 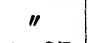 & 1906 & & \\
\hline & B. D. $+37^{\circ} 4427$ & +.04 & Mar. 1 & & B. D. $+37^{\circ} 2457$ & +.07 & Feb. 1 & B. D. $+38^{\circ} 1382$ & +.03 \\
\hline & B. D. $+38^{\circ} 3680$ & -.02 & & 12 & $\alpha$ Lyræ & +.08 & & B. D. $+38^{\circ} 1382$ & +.02 \\
\hline & B. D. $+37^{\circ} 3821$ & $\begin{array}{l}-.01 \\
+\quad 02\end{array}$ & & 13 & B. D. $+37^{\circ} 1740$ & $\begin{array}{l}+.11 \\
+13\end{array}$ & 1 & B. D. $+38^{\circ} 1382$ & $\begin{array}{r}+.04 \\
0\end{array}$ \\
\hline 21 & B. D. $+37^{\circ} 3867$ & $\begin{array}{l}+.02 \\
+.05\end{array}$ & & 16 & B. D. $+37^{\circ} 1849$ & $\begin{array}{l}+.10 \\
+.07\end{array}$ & & B. D. $+37^{\circ} 2457$ & -.01 \\
\hline & B. D. $+37^{\circ} 4427$ & +.03 & & 18 & B. D. $+37^{\circ} 1848$ & +.05 & & B. D. $+38^{\circ} 1382$ & +.04 \\
\hline 23 & B. D. $+37^{\circ} 4427$ & +.06 & & 25 & B. D. $+37^{\circ} 2457$ & +.02 & & B. D. $+38^{\circ} 1382$ & +.04 \\
\hline 26 & B. D. $+37^{\circ} 4427$ & -.01 & & 27 & 51 Urs. Maj. & +.07 & & B. D. $+38^{\circ} 1382$ & +.04 \\
\hline & $\alpha$ Lyræ & +.01 & & 28 & 51 Urs. Maj. & +.08 & 2 & B. D. $+38^{\circ} 1382$ & -.02 \\
\hline Oct. 1 & B. D. $+37^{\circ} 4427$ & +.03 & & 29 & 51 Urs. Maj. & +.06 & Mar. & B. D. $+38^{\circ} 1382$ & -.02 \\
\hline & B. D. $+37^{\circ} 4427$ & +.04 & & 30 & & $\begin{array}{l}+.07 \\
+.09\end{array}$ & & B. D. $+37^{\circ} 2457$ & $\begin{array}{r}0 \\
+\quad 01\end{array}$ \\
\hline & $\begin{array}{l}\text { B. D. }+37^{\circ} 4427 \\
\text { B. D. }+37^{\circ} 4427\end{array}$ & $\begin{array}{l}+.06 \\
+.04\end{array}$ & Apr. & $\begin{array}{r}31 \\
2\end{array}$ & $\begin{array}{l}\text { B. D. }+37^{\circ} 2457 \text { Lyræ } \\
\text { Ly }\end{array}$ & $\begin{array}{l}+.09 \\
+.08\end{array}$ & & $\begin{array}{l}\text { B. D. }+37^{\circ} 2457 \\
\text { B. D. }+37^{\circ} 2457\end{array}$ & $\begin{array}{l}+.01 \\
-.07\end{array}$ \\
\hline & B. D. $+38^{\circ} 1539$ & $\begin{array}{l}1.01 \\
+.01\end{array}$ & & 7 & B. D. $+37^{\circ} 2457$ & +.13 & & B. D. $+37^{\circ} 2457$ & +.03 \\
\hline 10 & B. D. $+37^{\circ} 4427$ & +.09 & & 8 & 51 Urs. Maj. & +.08 & Apr. & B. D. $+37^{\circ} 2457$ & 0 \\
\hline 14 & B. D. $+37^{\circ} 4427$ & +.02 & & 9 & $\alpha$ Lyræ & +.10 & & B. D. $+37^{\circ} 2457$ & +.07 \\
\hline 15 & B. D. $+37^{\circ} 4427$ & +.05 & & 13 & $\alpha$ Lyræ & +.12 & & B. D. $+38^{\circ} 2477$ & -.04 \\
\hline 16 & B. D. $+38^{\circ} 1382$ & +.08 & & 14 & B. D. $+37^{\circ} 2457$ & +.04 & & B. D. $+37^{\circ} 2457$ & +.01 \\
\hline 18 & B. D. $+37^{\circ} 4427$ & +.09 & & 17 & B. D. $+39^{\circ} 2418$ & +.08 & & B. D. $+37^{\circ} 2457$ & -.02 \\
\hline 19 & $\alpha$ Lyræ & +.08 & & 18 & $\alpha$ Lyræ & +.06 & & B. D. $+39^{\circ} 2418$ & \\
\hline 21 & B. D. $+38^{\circ} 1357$ & +.13 & & 19 & B. D. $+39^{\circ} 2418$ & +.08 & & B. D. $+37^{\circ} 2457$ & +.01 \\
\hline 22 & B. D. $+37^{\circ} 4427$ & +.03 & & 24 & B. D. $+37^{\circ} 2457$ & +.05 & & B. D. $+38^{\circ} 2477$ & 0 \\
\hline 24 & B. D. $+37^{\circ} 4427$ & +.04 & & 27 & B. D. $+38^{\circ} 2984$ & +.05 & & B. D. $+37^{\circ} 2457$ & 0 \\
\hline 27 & B. D. $+37^{\circ} 4427$ & +.04 & & 30 & B. D. $+39^{\circ} 2418$ & & & B. D. $+38^{\circ} 3113$ & +.02 \\
\hline 28 & B. D. $+36^{\circ} 4902$ & -.02 & May & 1 & B. D. $+39^{\circ} 2418$ & +.04 & & B. D. $+37^{\circ} 2457$ & +.01 \\
\hline 2 & B. D. $+37^{\circ} 4714$ & +.10 & & 2 & B. D. $+39^{\circ} 2418$ & +.07 & & B. D. $+38^{\circ} 3113$ & +.04 \\
\hline 31 & B. D. $+37^{\circ} 4427$ & .00 & & 7 & B. D. $+38^{\circ} 2477$ & +.10 & & B. D. $+37^{\circ} 2457$ & 0 \\
\hline Nov. & B. D. $+37^{\circ} 4427$ & +.05 & & 8 & B. D. $+37^{\circ} 2457$ & +.05 & May & B. D. $+38^{\circ} 2984$ & -.02 \\
\hline & $\alpha$ Lyræ & & & 12 & B. D. $+38^{\circ} 3095$ & +.01 & & B. D. $+37^{\circ} 2457$ & +.07 \\
\hline & B. D. $+37^{\circ} 4427$ & -.02 & & 19 & B. D. $+37^{\circ} 2457$ & +.07 & & B. D. $+37^{\circ} 2457$ & +.02 \\
\hline & B. D. $+37^{\circ} 4427$ & +.11 & & 20 & B. D. $+37^{\circ} 2457$ & +.04 & & B. D. $+37^{\circ} 2457$ & +.01 \\
\hline & $\alpha$ Lyræ & -.02 & & 21 & B. D. $+37^{\circ} 2426$ & +.03 & & B. D. $+38^{\circ} 2984$ & +.03 \\
\hline 11 & B. D. $+36^{\circ} 4902$ & +.05 & & 23 & B. D. $+37^{\circ} 2457$ & +.03 & & B. D. $+37^{\circ} 2457$ & +.05 \\
\hline 14 & B. D. $+37^{\circ} 4427$ & +.06 & & 24 & B. D. $+37^{\circ} 2457$ & +.09 & & B. D. +3 & +.04 \\
\hline 15 & B. D. $+37^{\circ} 4427$ & +.05 & & 27 & B. D. $+38^{\circ} 2984$ & +.06 & & B. D. $+37^{\circ} 2457$ & \\
\hline 16 & $\alpha$ Lyræ & +.07 & June & & B. D. $+38^{\circ} 2984$ & +.07 & & B. D. $+37^{\circ} 2457$ & +.07 \\
\hline 17 & B. D. $+37^{\circ} 4427$ & +.05 & & 3 & B. D. +38 & +.08 & & B. D. $+38^{\circ} 2477$ & +.08 \\
\hline 19 & B. D. $+38^{\circ} 1382$ & +.07 & & 8 & B. D. $+37^{\circ} 288$ & +.07 & & $3^{\circ} 2477$ & +.07 \\
\hline & 16 Persei & -.01 & Oct. & 23 & 10 Lacertæ & +.02 & June & B. D. $+37^{\circ} 2457$ & 0 \\
\hline & $\alpha$ Lyræ & +.15 & & 28 & 40 Aurig. & 00 & & B. D. +38 & \\
\hline Dec. & 20 Persei & +.05 & & 29 & B. D. $+37^{\circ} 4427$ & -.01 & & $-38^{\circ} 2984$ & -.01 \\
\hline & $\alpha$ Lyræ & +.05 & & 30 & B. D.t & .00 & & B. D. +3 & -.02 \\
\hline 29 & B. D. $+37^{\circ} 786$ & +.06 & Nov. & & B. D. $+38^{\circ} 1382$ & -.01 & & B. D. $+38^{\circ} 2984$ & \\
\hline 30 & $\alpha$ Lyræ & +.09 & & & $\alpha$ Lyræ & +.02 & & B. D. $+38^{\circ} 2984$ & -.01 \\
\hline & B. D. $+38^{\circ} 1382$ & +07 & & 4 & $\alpha$ Lyræ & +.07 & & B. D. $+38^{\circ} 2984$ & +.02 \\
\hline & & & & 8 & B. D. $+38^{\circ} 861$ & +.02 & July & B. D. $+38^{\circ} 2994$ & +.07 \\
\hline 1905 & & & & 10 & B. D. $+37^{\circ} 947$ & +.01 & & B. D. $+38^{\circ} 2984$ & +.01 \\
\hline Jan. & B. D. $+37^{\circ} 794$ & +.08 & & 11 & $\alpha \mathrm{Lys}$ & +.09 & & B. D. $+38^{\circ} 3095$ & \\
\hline & B. D. $t$ & +.08 & & 12 & B. D. $+38^{\circ} 1382$ & +.04 & & B. D. $+38^{\circ} 2984$ & +.03 \\
\hline 13 & $\alpha$ Lyræ & +.09 & & 14 & B. D. $+38^{\circ} 1382$ & & & B. D. $+38^{\circ} 29$ & \\
\hline 14 & $38^{\circ} 682$ & +.02 & & 17 & $\alpha$ Lyræ & +.04 & & B. D. $+38^{\circ} 29$ & +.01 \\
\hline 15 & B. D. $+38^{\circ}$ & +.07 & & 21 & B. D. $+38^{\circ} 1382$ & -.04 & & 71 & +.02 \\
\hline 16 & B. D. $+37^{\circ} 794$ & +.06 & & 22 & B. D. $+38^{\circ} 4940$ & -.02 & & B. D. $+38^{\circ} 3095$ & +.05 \\
\hline 18 & B. D. $+37^{\circ} 786$ & -.02 & & 23 & $\boldsymbol{\alpha}$ Lyræ & +02 & & B. D. $+38^{\circ} 2984$ & +.03 \\
\hline 19 & $\alpha$ Lyræ & -.03 & & & & & Aug. & B. D. $+38^{\circ} 2$ & +.01 \\
\hline 20 & B. D. $+37^{\circ} 786$ & +.06 & 1906 & & & & & B. D. $+37^{\circ} 4$ & -.05 \\
\hline 27 & B. D. $+38^{\circ} 1382$ & +.02 & Jan. & 5 & B. D. $+38^{\circ} 1382$ & +.06 & & B. D. & +.07 \\
\hline 28 & B. D. $+38^{\circ} 1382$ & +.08 & & 6 & B. D. +3 & $\begin{array}{l}+.09 \\
+\end{array}$ & & B. D. & -.01 \\
\hline 30 & B. D. $+38^{\circ} 1382$ & +.10 & & 9 & B.D. $+38^{\circ} 1382$ & +.02 & Sept. & B. D. $+38^{\circ} 3213$ & -01 \\
\hline Feb. & $\alpha$ Lyræ & +.09 & & 10 & B. D. $+38^{\circ} 1382$ & +.01 & & B. D. $+38^{\circ} 3213$ & -.01 \\
\hline & B. D. $+38^{\circ} 1382$ & +.06 & & 18 & B. D. $+38^{\circ} 689$ & -.01 & & B. D. $+38^{\circ} 3213$ & -.01 \\
\hline & $\alpha$ Lyræ & & & 24 & B. D. $+38^{\circ} 682$ & +.04 & & $\alpha$ Lyræ & \\
\hline g & $\alpha$ Lyræ & +.08 & & 28 & B. D. $+38^{\circ} 827$ & -.03 & & $\alpha$ Lyra & +.03 \\
\hline 10 & B. D. $+38^{\circ} 1382$ & +.06 & & 29 & B. D. $+37^{\circ} 1347$ & +.02 & & $\alpha \mathrm{Ly}$ & +.01 \\
\hline 14 & B. D. $+38^{\circ} 1382$ & +.05 & & 31 & B. D. $+38^{\circ} 1382$ & +.03 & & $\alpha$ Lyræ & +.05 \\
\hline 17 & B. D. $+38^{\circ} 1382$ & +.01 & Feb. & 2 & $\alpha$ Lyræ & +.05 & & $\alpha$ Lyræ & +.03 \\
\hline 18 & B. D. $+38^{\circ} 1382$ & +.03 & & 3 & B. D. $+38^{\circ} 1382$ & +.07 & & $\alpha$ Lyræ & +.07 \\
\hline 2 & B. D. $+38^{\circ} 1382$ & +.11 & & 4 & B. D. $+38^{\circ} 1382$ & +.08 & & $\alpha$ Lyræ & -.01 \\
\hline 26 & B. D. $+38^{\circ} 1382$ & +.04 & & 5 & B. D. $+38^{\circ} 1$ & +.04 & & $\alpha$ Lyræ & -.02 \\
\hline & B. D. $+38^{\circ} 1382$ & +.04 & & 9 & B. D. $+38^{\circ} 1382$ & +.04 & & $\alpha$ Lyræ & -.06 \\
\hline
\end{tabular}


TABLE II.-Inequality of Pivots Obtained from Individual Observations-Continued

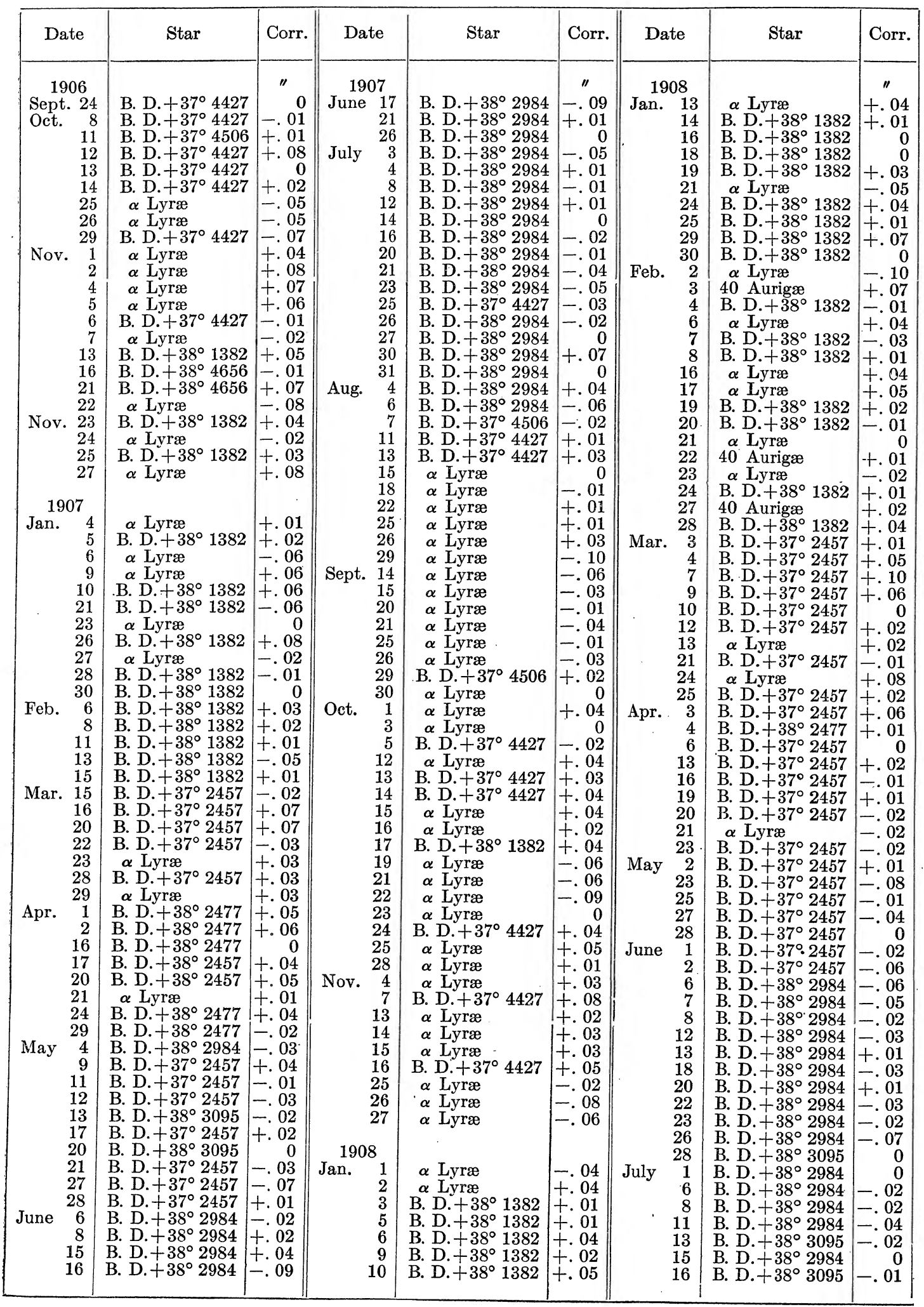


INTRODUCTION.

A LIX

TABLE II.-Inequality of Pivots Obtained from Individual Observations-Continued

\begin{tabular}{|c|c|c|c|c|c|c|c|c|c|}
\hline Date & Star & Corr. & Date & & Star & Corr. & Date & Star & Corr. \\
\hline 1908 & & $"$ & $\begin{array}{l}1909 \\
\text { n. }\end{array}$ & & & 1 & $\begin{array}{c}1909 \\
\end{array}$ & $\mathrm{P} D+2000084$ & 01 \\
\hline $\begin{array}{ll}\text { July } & 20 \\
& 28\end{array}$ & $\begin{array}{l}\text { B. D. }+38^{\circ} 2984 \\
\text { B. D. }+38^{\circ} 2984\end{array}$ & $\begin{array}{l}-.03 \\
-.01\end{array}$ & Jan. & 20 & $\begin{array}{l}40 \text { Aurigæ } \\
\alpha \text { Lyræ }\end{array}$ & $\begin{array}{l}+.02 \\
+.08\end{array}$ & 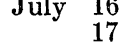 & $\begin{array}{l}\text { B. D. }+38^{\circ} 2984 \\
\text { B. D. }+38^{\circ} 2984\end{array}$ & $\begin{array}{l}-.01 \\
-.06\end{array}$ \\
\hline $\begin{array}{l}20 \\
29\end{array}$ & B. D. $+38^{\circ} 2984$ & +.01 & & 26 & B. D. $+38^{\circ} 1382$ & $\begin{array}{l}+.02 \\
+.02\end{array}$ & 19 & B. D. $+38^{\circ} 2984$ & $\begin{array}{l}-.00 \\
-.02\end{array}$ \\
\hline Aug. 1 & B. D. $+38^{\circ} 2984$ & -.04 & & 27 & $\alpha$ Lyræ & -.09 & 20 & B. D. $+38^{\circ} 2984$ & -.12 \\
\hline & B. D. $+38^{\circ} 2984$ & -.01 & & 31 & $\alpha$ Lyræ & +.02 & 24 & B. D. $+38^{\circ} 2984$ & -.05 \\
\hline $\begin{array}{r}3 \\
18\end{array}$ & B. D. $+38^{\circ} 2984$ & +.01 & Feb. & 1 & 40 Aurigæ & -.04 & 25 & B. D. $+37^{\circ} 4427$ & -.04 \\
\hline $\begin{array}{l}18 \\
19\end{array}$ & $\alpha$ Lyræ & -.03 & & 2 & B. D. $+38^{\circ} 1382$ & +.02 & 27 & B. D. $t$ & -.07 \\
\hline $\begin{array}{l}19 \\
20\end{array}$ & $\begin{array}{ll}\alpha & \text { Lyræ } \\
\alpha & \text { Lyræ }\end{array}$ & $\begin{array}{l}-.04 \\
-.04\end{array}$ & & $\begin{array}{l}4 \\
6\end{array}$ & B. D. $+38^{\circ} 1382$ & $\begin{array}{r}-.02 \\
+\quad 06\end{array}$ & Aug $\begin{array}{r}28 \\
1\end{array}$ & $\begin{array}{l}\text { B. D. }+38^{\circ} 2984 \\
\text { B.D }+38^{\circ} 2984\end{array}$ & $\begin{array}{l}-.04 \\
-.05\end{array}$ \\
\hline 29 & $\alpha$ Lyræ & $\begin{array}{l}-.04 \\
-.04\end{array}$ & & 7 & $\alpha$ Lyræ & -.04 & Aus. 2 & B. D. $+38^{\circ} 2984$ & -.02 \\
\hline $\begin{array}{l}30 \\
31\end{array}$ & $\alpha$ Lyræ & +.05 & & 8 & B. D. $+38^{\circ} 1382$ & +.04 & 6 & $\alpha$ Lyræ & -.04 \\
\hline $\begin{array}{r}31 \\
\text { Sept. }\end{array}$ & $\alpha$ Lyræ & -.01 & & 10 & $\alpha$ Lyræ & -.03 & 7 & $\alpha$ Lyræ & +.03 \\
\hline $\begin{array}{ll}\text { Sept. } & 2 \\
& 3\end{array}$ & B. D. $+37^{\circ} 4427$ & $\begin{array}{l}-.04 \\
+.01\end{array}$ & & 11 & $\begin{array}{l}\text { B. D. }+38^{\circ} 1382 \\
\text { B. D. }+38^{\circ} 1382\end{array}$ & $\begin{array}{l}+.12 \\
-.02\end{array}$ & $\begin{array}{r}8 \\
10\end{array}$ & $\alpha$ Lyræ & $\begin{array}{l}-.01 \\
-.02\end{array}$ \\
\hline $\begin{array}{l}3 \\
6\end{array}$ & $\begin{array}{l}\text { B. D. }+37^{\circ} 4427 \\
\alpha \text { Lyræ }\end{array}$ & $\begin{array}{l}+.01 \\
-.02\end{array}$ & & $\begin{array}{l}16 \\
17 \\
17\end{array}$ & B. D. $+38^{\circ} 1382$ & +.01 & 11 & $\alpha$ Lyræ & -.03 \\
\hline 7 & $\alpha$ Lyræ & -.02 & & 24 & $\alpha$ Lyræ & -.02 & 19 & $\alpha$ Lyræ & -.02 \\
\hline $\begin{array}{l}8 \\
9\end{array}$ & $\alpha$ Lyræ & -.06 & & 25 & B. D. $+38^{\circ} 1382$ & +.07 & 21 & $\alpha$ Lyræ & -.06 \\
\hline 9 & $\alpha$ Lyræ & +.02 & & 26 & B. D. $+33^{\circ} 1382$ & -.02 & 22 & $\alpha$ Lyræ & -.04 \\
\hline $\begin{array}{l}12 \\
15\end{array}$ & $\alpha$ Lyræ & -.03 & & 28 & B. D. $+38^{\circ} 1382$ & -.08 & 23 & $\alpha$ Lyræ & -.06 \\
\hline $\begin{array}{l}15 \\
16\end{array}$ & $\begin{array}{l}\alpha \text { Lyræ } \\
\alpha \text { Lyræ }\end{array}$ & $\begin{array}{l}-02 \\
-03\end{array}$ & Mar. & 7 & $\alpha$ Lyræ & +.01 & 24 & a Lyræ. & -.03 \\
\hline $\begin{array}{l}10 \\
22\end{array}$ & $\begin{array}{l}\alpha \text { Lyræ } \\
\alpha \text { Lyræ }\end{array}$ & $\begin{array}{r}-.03 \\
0\end{array}$ & & 10 & 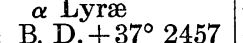 & $\begin{array}{l}+.08 \\
-.03\end{array}$ & $\begin{array}{l}26 \\
27\end{array}$ & $\alpha$ Lyræ & $\begin{array}{l}-.12 \\
-.03\end{array}$ \\
\hline 23 & $\alpha$ Lyræ & -.06 & & 17 & B. D. $+37^{\circ} 2457$ & -.04 & 29 & $\alpha$ Lyræ & -.01 \\
\hline 24 & $\alpha$ Lyræ & -.01 & & 19 & B. D. $+37^{\circ} 2457$ & -.05 & 30 & $\alpha$ Lyræ & \\
\hline 29 & $\alpha$ Lyræ & +.01 & & 21 & B. D. $+37^{\circ} 2457$ & -.01 & Sept. 1 & $\alpha$ Lyræ & +.01 \\
\hline 30 & $\alpha$ Lyræ & +.07 & & 22 & B. D. $+37^{\circ} 2457$ & -.04 & 7 & $\alpha$ Lyræ & -.07 \\
\hline Oct. & $\alpha$ Lyræ & -.08 & & 23 & B. D. $+37^{\circ} 2457$ & -.03 & 8 & $\alpha$ Lyræ & -.07 \\
\hline 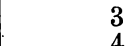 & $\alpha$ Lyræ & 0 & & 26 & B. D. $+37^{\circ} 2457$ & 0 & 11 & $\alpha$ Lyræ & -.08 \\
\hline $\begin{array}{l}4 \\
5\end{array}$ & $\alpha$ Lyra & +.01 & & 28 & B. D. $+37^{\circ} 2457$ & -.01 & 12 & B. D. $+37^{\circ} 4427$ & -.01 \\
\hline $\begin{array}{l}5 \\
6\end{array}$ & $\alpha$ Lyræ & +.01 & & 30 & B. D. $+37^{\circ} 2457$ & -.02 & 13 & $\alpha$ Lyræ & -.05 \\
\hline $\begin{array}{r}6 \\
11\end{array}$ & $\alpha$ Lyræ & +.01 & & 31 & B. D. $+37^{\circ} 2457$ & +.01 & 14 & $\alpha$ Lyræ & -.07 \\
\hline $\begin{array}{l}11 \\
12\end{array}$ & B. D. $+37^{\circ} 4427$ & -.04 & Apr. & 3 & B. D. $+37^{\circ} 2457$ & +.01 & 28 & $\alpha$ Lyræ & +.03 \\
\hline $\begin{array}{l}12 \\
13\end{array}$ & $\alpha$ Lyræ & +.01 & & 6 & B. D. $+38^{\circ} 2477$ & -.02 & 29 & $\alpha$ Lyræ & -.06 \\
\hline $\begin{array}{l}13 \\
14\end{array}$ & $\alpha$ Lyræ & +.12 & & 10 & $\begin{array}{l}\text { B. D. }+37^{\circ} 2457 \\
\text { B }\end{array}$ & $\begin{array}{l}+.04 \\
-01\end{array}$ & Oct. & $\alpha$ Lyræ & -.20 \\
\hline $\begin{array}{l}14 \\
15\end{array}$ & $\alpha$ Lyræ & & & 11 & $\begin{array}{l}\text { B. D. }+37^{\circ} 2457 \\
\text { B. D }+37^{\circ} 2457\end{array}$ & $\begin{array}{l}-.01 \\
-.02\end{array}$ & & ${ }^{\alpha}$ Lyræ & -.02 \\
\hline $\begin{array}{l}15 \\
16\end{array}$ & 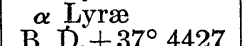 & & & $\begin{array}{l}10 \\
16\end{array}$ & $\begin{array}{l}\text { B. D. }+37^{\circ} 2457 \\
\text { B. D. }+37^{\circ} 2457\end{array}$ & -.02 & & B. D. $+37^{\circ} 4427$ & $\begin{array}{l}+.05 \\
-10\end{array}$ \\
\hline 18 & $\begin{array}{l}\text { B. D. + 37 } 4427 \\
\alpha \text { Lyræ }\end{array}$ & $\begin{array}{r}0 \\
-.09\end{array}$ & May & 1 & $\begin{array}{l}\text { B. D. }+37^{\circ} 2457 \\
\text { B. D. }+37^{2457}\end{array}$ & -.05 & 7 & $\begin{array}{l}\alpha \text { Lyræ } \\
\alpha \text { Lyræ }\end{array}$ & $\begin{array}{l}-.10 \\
-08\end{array}$ \\
\hline 26 & $\alpha$ Lyræ & & & 2 & B. D. $+37^{\circ} 2457$ & -.04 & 9 & B. D. $+37^{\circ} 4427$ & $\begin{array}{l}-.08 \\
-.02\end{array}$ \\
\hline 30 & $\alpha$ Lyræ & -.02 & & $\overline{5}$ & B. D. $+37^{\circ} 2457$ & -.05 & 12 & $\alpha$ Lyræ & -.02 \\
\hline 31 & $\alpha$ Lyræ & +.02 & & 6 & B. D. $+37^{\circ} 2457$ & -.03 & 13 & $\alpha \mathrm{Ly}$ & -.01 \\
\hline Nov. 1 & $\alpha$ Lyræ & -.08 & & 8 & B. D. $+37^{\circ} 2457$ & +.01 & & B. D. $+37^{\circ} 4427$ & +.03 \\
\hline & $\alpha$ Lyræ & +.02 & & 10 & B. D. $+38^{\circ} 2984$ & -.11 & 19 & B. D. $+37^{\circ} 4427$ & -.01 \\
\hline & $\alpha$ Lyræ & -.02 & & 11 & B. D. $+37^{\circ} 2457$ & -.06 & 22 & $\alpha$ Lyræ & -.15 \\
\hline $\mathbf{5}$ & B. D. $+37^{\circ} 4506$ & +.04 & & 12 & B. D. $+37^{\circ} 2457$ & -.11 & 25 & $\boldsymbol{\alpha}$ Lyræ & -.01 \\
\hline 6 & $\alpha$ Lyræ & -.05 & & 14 & B. D. $+37^{\circ} 2457$ & -.12 & 26 & B. D. $+37^{\circ} 4427$ & \\
\hline 7 & $\alpha \cdot$ Lyræ & +.01 & & 15 & B. D. $+37^{\circ} 2457$ & -.10 & 28 & $\alpha$ Lyræ & -.10 \\
\hline 8 & B. D. $+38^{\circ} 1382$ & +.05 & & 16 & B. D. $+37^{\circ} 2457$ & -.13 & 29 & B. D. $+37^{\circ} 4427$ & -.06 \\
\hline 12 & $\alpha$ Lyræ & +.04 & & 17 & B. D. $+38^{\circ} 2984$ & -.10 & 30 & B. D. $+37^{\circ} 4427$ & +.12 \\
\hline 13 & $\alpha$ Lyræ & +.03 & & 18 & B. D. $+38^{\circ} 2477$ & -.02 & 31 & $\boldsymbol{\alpha}$ Lyræ & +.06 \\
\hline 16 & B. D. $+38^{\circ} 1382$ & +.03 & & 24 & B. D. $+37^{\circ} 2457$ & -.06 & Nov. 1 & $\alpha \operatorname{Lyr}$ & \\
\hline 17 & $\alpha$ Lyræ & +.04 & & 29 & B. D. $+37^{\circ} 2457$ & +.05 & & $\alpha$ Lyræ & -.04 \\
\hline 18 & B. D. $+37^{\circ} 4427$ & 0 & June & 6 & B. D. $+38^{\circ} 2984$ & -.06 & 5 & $\alpha \mathrm{Lyr}$ & -.10 \\
\hline 19 & $\alpha$ Lyræ & +.04 & & 15 & B. D. $+38^{\circ} 2984$ & -.03 & 8 & $\alpha \mathrm{Ly}$ & -.04 \\
\hline 20 & B. D. $+38^{\circ} 1382$ & -.06 & & 16 & B. D. $+38^{\circ}$ & -.04 & 10 & $37^{\circ} 4506$ & +.04 \\
\hline 21 & $\alpha$ Lyræ & 0 & & 18 & B. D. $+38^{\circ}$ & -.01 & 1 & B. D. $+37^{\circ} 4427$ & -.02 \\
\hline 25 & $\alpha$ Lyræ & -.04 & & 19 & B. D. $+38^{\circ} 2984$ & -.03 & 12 & $\alpha$ Lyræ & -.06 \\
\hline 26 & B. D. $+38^{\circ} 1382$ & -.01 & & 20 & B. D. $+38^{\circ} 2984$ & -.0 & 1 & $\alpha \mathrm{Ly}$ & +.03 \\
\hline & $\alpha$ Lyræ & -.02 & & 24 & B. D. $+38^{\circ} 2984$ & -.07 & 18 & $\alpha$ Lyræ & -.03 \\
\hline Dec. 2 & $\alpha$ Lyræ & +.07 & & 25 & B. D. $+38^{\circ} 2984$ & -.06 & 19 & B. D. $+38^{\circ} 1382$ & -.03 \\
\hline 31 & $\alpha$ Lyræ & & & 29 & B. D. $+38^{\circ} 2984$ & -.17 & 2 & $\alpha$ Lyræ & -.08 \\
\hline & & & & 30 & B. D. $+38^{\circ} 2984$ & -.04 & & B. D. $+38^{\circ} 1382$ & +.07 \\
\hline 1909 & & & July & 1 & B. D. $+38^{\circ} 2984$ & -.06 & 26 & $\alpha$ Lyræ & -10 \\
\hline Jan. 1 & B. D. $+38^{\circ} 1382$ & +.02 & & 2 & B. D. $+38^{\circ} 2984$ & +.01 & Domet & B. D. $+38^{\circ} 1382$ & +.06 \\
\hline & $\alpha$ Lyræ & +.02 & & 3 & B. D. $+38^{\circ} 2984$ & -.05 & Dec. & $\alpha$ Lyræ & \\
\hline $\begin{array}{r}3 \\
10\end{array}$ & $\alpha$ Lyræ & -.01 & & 6 & $8^{\circ} 2984$ & -.08 & & $\alpha \mathrm{Lj}$ & +.01 \\
\hline $\begin{array}{l}10 \\
17\end{array}$ & $\alpha$ Lyræ & +01 & & 7 & B. D. $+38^{\circ} 2984$ & $\begin{array}{l}+.03 \\
-\quad 02\end{array}$ & & $\alpha$ Lyræ & $\begin{array}{l}-.01 \\
-.03\end{array}$ \\
\hline $\begin{array}{l}17 \\
18\end{array}$ & $\begin{array}{l}\text { B. D. }+38^{\circ} 1382 \\
\text { B. D. }+38^{\circ} 1382\end{array}$ & $\begin{array}{l}+.01 \\
-.01\end{array}$ & & $\begin{array}{l}8 \\
9\end{array}$ & $\begin{array}{l}\text { B. D. }+38^{\circ} 2984 \\
\text { B. D. }+38^{\circ} 2984\end{array}$ & $\begin{array}{l}-.02 \\
-.13\end{array}$ & . & $\begin{array}{l}\text { B. D. + } 38^{\circ} 1382 \\
\alpha \text { Lyræ }\end{array}$ & $\begin{array}{r}-.00 \\
0\end{array}$ \\
\hline 19 & $\alpha$ Lyræ & +.01 & & 15 & B. D. $+38^{\circ} 2984$ & -.03 & 10 & $\alpha$ Lyræ & -.06 \\
\hline
\end{tabular}


TABLE II.-Inequality of Pivots Obtained from Individual Observations-Continued

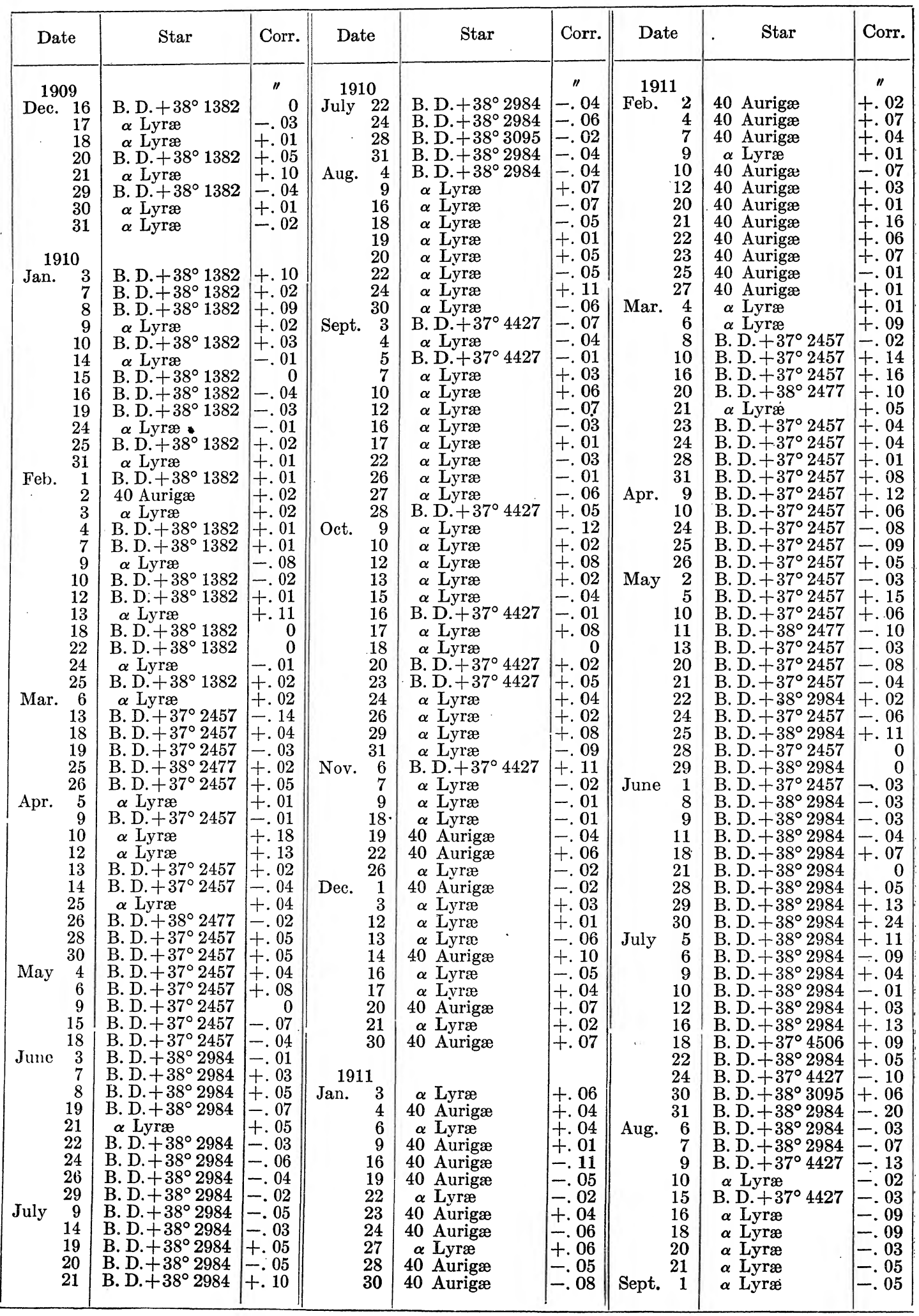


INTRODUCTION.

A LXI

TABLE II.-Inequality of Pivots Obtained from Individual Observations-Continued

\begin{tabular}{|c|c|c|c|c|c|c|c|c|c|c|}
\hline Date & Star & Corr. & Date & & Star & Corr. & \multicolumn{2}{|l|}{ Date } & Star & Corr. \\
\hline \multirow{2}{*}{$\begin{array}{l}1911 \\
\text { Sept. }\end{array}$} & & " & \multirow{2}{*}{\multicolumn{2}{|c|}{$\begin{array}{c}1912 \\
\text { Jan. }\end{array}$}} & \multirow[b]{2}{*}{$\alpha$ Lyræ } & " & \multicolumn{2}{|c|}{1912} & \multirow[b]{2}{*}{ B. D. $+38^{\circ} 2984$} & ${ }^{\prime \prime}$ \\
\hline & $\alpha$ Lyræ & -.12 & & & & +.05 & \multicolumn{2}{|c|}{ July 8} & & -.07 \\
\hline $\begin{array}{r}7 \\
11\end{array}$ & $\alpha$ Lyræ & -.10 & \multicolumn{2}{|c|}{$\begin{array}{l}\text { Feb. } 2 \\
4\end{array}$} & B. D. $+38^{\circ} 1382$ & $\begin{array}{l}+.06 \\
-16\end{array}$ & & 3 & B. D. $+38^{\circ} 2984$ & -.04 \\
\hline 16 & B. D. $+37^{\circ} 4427$ & -.05 & & $\begin{array}{l}4 \\
5\end{array}$ & B.D. $+38^{\circ} 1382$ & $\begin{array}{l}-.16 \\
-.04\end{array}$ & & 2 & $\begin{array}{l}\text { B.D. }+37^{\circ} 4427 \\
\text { B. D. }+38^{\circ} 3095\end{array}$ & $=.09$ \\
\hline 23 & $\alpha$ Lyræ & -.10 & & 6 & B. D. $+38^{\circ} 1382$ & -.06 & & 6 & B. D. $+38^{\circ} 2984$ & -.02 \\
\hline 24 & $\alpha$ Lyræ & +.03 & & 8 & B. D. $+38^{\circ} 1382$ & -.06 & & & B. D. $+37^{\circ} 4427$ & +.11 \\
\hline Oct. 8 & $\alpha$ Lyræ & -.06 & & 9 & B. D. $+38^{\circ} 1382$ & -.01 & Aug. & & B. D. $+38^{\circ} 2984$ & -.09 \\
\hline 11 & $\alpha$ Lyræ & -.06 & & 11 & B. D. $+38^{\circ} 1382$ & -.03 & & 3 & B. D. $+38^{\circ} 3095$ & -.07 \\
\hline 12 & $\alpha$ Lyræ & +.04 & & 13 & B. D. $+38^{\circ} 1382$ & -.02 & & 5 & B. D. $+38^{\circ} 2984$ & -.02 \\
\hline 13 & $\alpha$ Lyræ & & & 16 & $\alpha$ Lyræ & -.12 & & 10 & $\alpha$ Lyræ & -.05 \\
\hline 16 & $\alpha$ Lyræ & & & 17 & B. D. $+38^{\circ} 1382$ & -.02 & & 11 & $\alpha$ Lyræ & -.07 \\
\hline 18 & $\alpha$ Lyræ & -.13 & & 22 & B. D. $+38^{\circ} 1382$ & -.12 & & 2 & $\alpha$ Lyræ & -.05 \\
\hline 23 & $\alpha$ Lyræ & +.13 & & 23 & B. D. $+38^{\circ} 1382$ & +.02 & & 22 & $\alpha$ Lyræ & -.10 \\
\hline 24 & $\alpha$ Lyræ & -.01 & & 27 & B. D. $+38^{\circ} 1382$ & -.07 & & 23 & $\alpha$ Lyræ & +.06 \\
\hline 25 & $\alpha$ Lyræ & -.05 & Mar. & & B. D. $+38^{\circ} 2477$ & -.02 & & 24 & $\alpha$ Lyræ & -.06 \\
\hline 29 & $\alpha$ Lyræ & +.03 & & 9 & B. $\bar{D} .+37^{\circ} 2457$ & -.02 & & 27 & $\alpha$ Lyræ & +.02 \\
\hline Nov. 2 & B. D. $+37^{\circ} 4427$ & -.04 & & 10 & $\alpha$ Lyræ & +.02 & & 88 & $\alpha$ Lyræ & -.05 \\
\hline & $\alpha$ Lyræ & -.14 & & 16 & B. D. $+37^{\circ} 2457$ & -.09 & Sept. & 5 & $\alpha$ Lyræ & -.12 \\
\hline 7 & $\alpha$ Lyræ & & & 17 & B. D. $+37^{\circ} 2457$ & +.01 & & & B. D. $+37^{\circ} 4427$ & -.01 \\
\hline 10 & $\alpha$ Lyræ & -.11 & & 18 & B. D. $+37^{\circ} 2457$ & -.19 & & 9 & $\alpha$ Lyræ & -.07 \\
\hline 11 & $\alpha$ Lyræ & -.02 & & 25 & B. $\mathrm{D} .+37^{\circ} 2457$ & -.05 & & 10 & $\alpha$ Lyræ & -.04 \\
\hline 13 & B. D. $+37^{\circ} 4427$ & -.02 & Apr. & 6 & $\alpha$ Lyræ & -.05 & & 12 & $\alpha$ Lyræ & -.04 \\
\hline 15 & $\alpha$ Lyræ & -.02 & & 8 & B. D. $+37^{\circ} 2457$ & -.05 & & 17 & B. D. $+37^{\circ} 4506$ & +.03 \\
\hline 16 & $\alpha$ Lyræ & -.01 & & 9 & B. D. $+38^{\circ} 2477$ & .00 & Oct. & & $\alpha$ Lyræ & -.13 \\
\hline 18 & $\alpha$ Lyræ & -.09 & & 10 & B. D. $+37^{\circ} 2457$ & -.11 & & 9 & $\alpha$ Lyræ & -.05 \\
\hline 21 & B. D. $+38^{\circ} 1382$ & +.11 & & 19 & B. D. $+37^{\circ} 2457$ & -.12 & & 10 & $\alpha$ Lyræ & +.10 \\
\hline 22 & B. D. $+38^{\circ} 1382$ & -.05 & & 20 & B. D. $+37^{\circ} 2457$ & -.02 & & 12 & $\alpha$ Lyræ & -.05 \\
\hline 25 & $\alpha$ Lyræ & -.10 & & 23 & B. $\bar{D} .+37^{\circ} 2457$ & +.07 & & 15 & $\alpha$ Lyræ & -.06 \\
\hline 26 & B. D. $+38^{\circ} 1382$ & -.05 & & 27 & B. D. $+37^{\circ} 2457$ & +.04 & & 16 & $\alpha$ Lyræ & -.09 \\
\hline Dec. & $\alpha$ Lyræ & +.01 & May & 1 & B. D. $+37^{\circ} 2457$ & -.12 & & 20 & $\alpha$ Lyræ & +.07 \\
\hline & $\alpha$ Lyræ & -.04 & & & B. D. $+37^{\circ} 2457$ & +.03 & & & $\alpha$ Lyræ & -.07 \\
\hline 5 & $\alpha$ Lyræ & +.01 & & 3 & B. D. $+38^{\circ} 2984$ & +.02 & & 26 & $\alpha$ Lyræ & -.10 \\
\hline 6 & $\alpha$ Lyræ & -.04 & & 10 & B. D. $+37^{\circ} 2457$. & -.12 & & 28 & B. D. $+37^{\circ} 4427$ & -.10 \\
\hline 7 & $\alpha$ Lyræ & +.01 & & 13 & B. D. $+37^{\circ} 2457$ & +.03 & & 30 & B. D. $+37^{\circ} 4427$ & -.01 \\
\hline 8 & $\alpha$ Lyræ & +.04 & & 17 & B. D. $+38^{\circ} 2984$ & -.10 & Nov. & & $\alpha$ Lyræ & -.13 \\
\hline 10 & B. D. $+38^{\circ} 1382$ & -.09 & & 18 & B. D. $+37^{\circ} 2457$ & -.10 & & & $\alpha$ Lyræ & +.05 \\
\hline 18 & B. D. $+38^{\circ} 1382$ & -.04 & & 20 & B. D. $+37^{\circ} 2457$ & +.14 & & 9 & B. D. $+38^{\circ} 1382$ & -.05 \\
\hline 19 & $\alpha$ Lyræ & -.04 & & 24 & B. D. $+37^{\circ} 2457$ & -.07 & & 11 & $\alpha$ Lyræ & -.06 \\
\hline & & & & 26 & B. D. $+37^{\circ} 2457$ & -.01 & & 16 & $\alpha$ Lyræ & -.06 \\
\hline 1912 & & & & 28 & B. D. $+37^{\circ} 2457$ & -.06 & & 21 & $\alpha$ Lyræ & -.04 \\
\hline Jan. & B. D. $+38^{\circ} 1382$ & & & 30 & B. D. $+37^{\circ} 2457$ & -.05 & & 22 & $\alpha$ Lyræ & -.12 \\
\hline & $\alpha$ Lyræ & & June & 1 & B. D. $+37^{\circ} 2457$ & -.06 & & 26 & B. D. $+38^{\circ} 1382$ & -.07 \\
\hline 7 & B. D. $+38^{\circ} 1382$ & -.03 & & 8 & B. D. $+38^{\circ} 2984$ & -.02 & & 27 & $\alpha$ Lyræ & +.03 \\
\hline 9 & B. D. $+38^{\circ} 1382$ & +.06 & & 9 & B. D. $+38^{\circ} 29$ & -.09 & & 29 & $\alpha$ Lyræ & -.02 \\
\hline 15 & B. D. $+38^{\circ} 1382$ & -.14 & & 10 & B. D. $+38^{\circ} 2984$ & +.01 & & 30 & $\alpha$ Lyræ & +.11 \\
\hline 19 & B. D. $+38^{\circ} 1382$ & +.02 & & 12 & B. D. $+38^{\circ} 2984$ & -.19 & Dec. & 3 & 40 Aurigæ & -.06 \\
\hline 20 & $\alpha$ Lyræ & +.01 & & 20 & B. D. $+38^{\circ} 2984$ & -.07 & & 9 & $\alpha$ Lyræ & +.03 \\
\hline 21 & B. D. $+38^{\circ} 1382$ & +.19 & July & 2 & B. D. $+38^{\circ} 2984$ & -.04 & & 10 & $\alpha$ Lyræ & +.05 \\
\hline 22 & B. D. $+38^{\circ} 1382$ & -.16 & & 5 & B. D. $+38^{\circ} 2984$ & -.03 & & 12 & $\alpha$ Lyræ & -.05 \\
\hline 24 & B. D. $+38^{\circ} 1382$ & -.09 & & 6 & B. D. $+38^{\circ} 2984$ & -.05 & & 14 & $\alpha \quad$ Lyræ & -.03 \\
\hline 20 & B. D. $+38^{\circ} 1382$ & -.12 & & 7 & B. D. $+38^{\circ} 2984$ & -.16 & & & & \\
\hline
\end{tabular}


TABLE III.-Inequality of Pivots of Instrument

[Nоте.-These means are based upon 50 individual observations, except the last one before the pivots were refigured, which is based upon 12 observations, and the last one after the pivots were refigured, which is based upon 27 observations.]

\begin{tabular}{|c|c|c|c|}
\hline \multicolumn{2}{|r|}{ Before pivots were refigured } & \multicolumn{2}{|r|}{ After pivots were refigured } \\
\hline 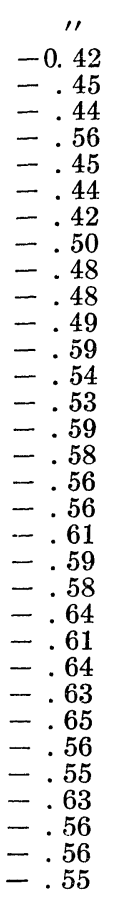 & 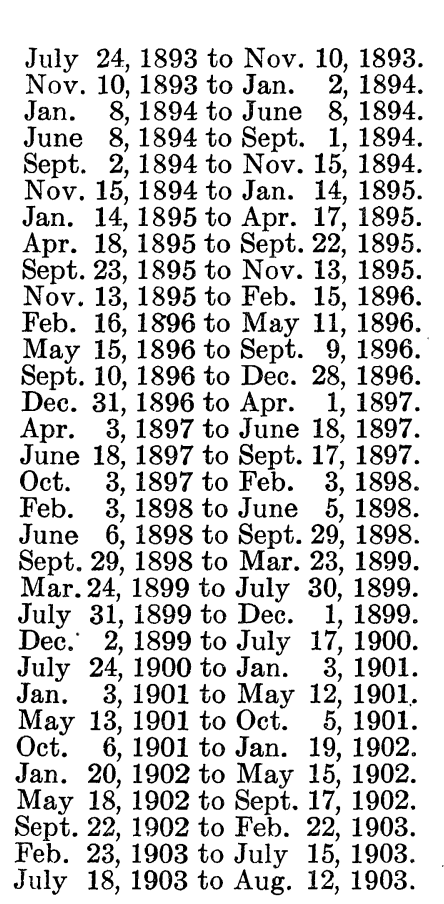 & $\begin{array}{r}\prime \prime \\
-0.03 \\
+.04 \\
+.05 \\
+.06 \\
+.03 \\
+.02 \\
+.01 \\
.00 \\
.00 \\
.00 \\
-.01 \\
.00 \\
-.04 \\
.04 \\
.00 \\
+.00 \\
+.01 \\
-.02 \\
-.03 \\
-.04 \\
-.03\end{array}$ & 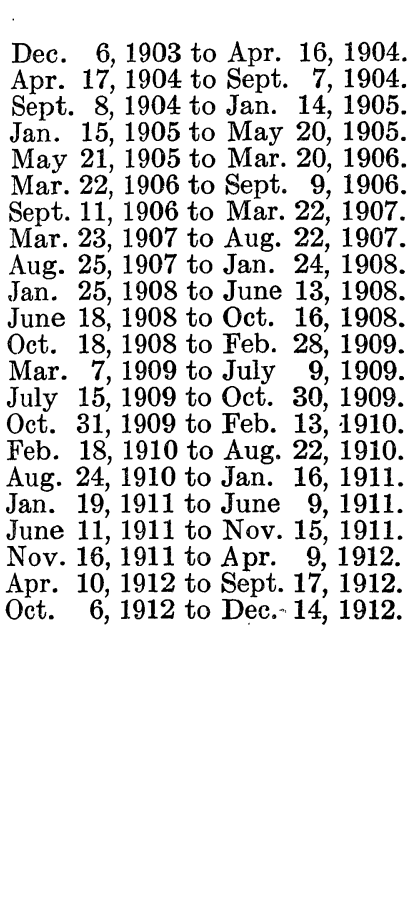 \\
\hline
\end{tabular}

By the use of formulæ already given we can ascertain what was the linear wear of one pivot with respect to the other, in each of these instances.

Let $R^{\prime}-R=y_{0} . L . \sin I . \sin 1^{\prime \prime}$, in which,

$$
\begin{aligned}
y_{0} & =0.24^{\prime \prime} . \\
L & =40.19 \text { inches. } \\
I & =41^{\circ} 25^{\prime} .
\end{aligned}
$$

From these data we find in the first period the relative change in the radii of the two pivots was $\frac{3}{100,000}$ of an inch, and in the second period it was $\frac{1}{100,000}$ of an inch.

As $R$ equals the radius of the pivot on the clamp side, and $R^{\prime}$ the radius of the pivot at the other end of the axis, the change in radii of the two pivots shows that the pivot opposite the clamp side was wearing more than was the clamp pivot.

We can secure an independent check on the difference of radii of the two pivots by measuring the linear difference between the radii of the two pivots.

With that end in view a piece of apparatus called a caliper has been made to fit the pivots. It was devised by the late Prof. William Harkness, United States Navy, and its general form is described by him in Monthly Notices (Vol. 38, page 487), with an accompanying drawing of both the caliper and the spherometer to be used with it.

To secure the most accurate results from the caliper it should be made to fit the diameter of the pivots which are to be measured, and for that reason the caliper 
here mentioned has been constructed especially for the prime vertical transit. It is not suitable to measure the diameter of pivots of other transit instruments or meridian circles, unless the pivots are of nearly the same diameter as those of the prime vertical.

The constants of the spherometer have the following values: The screw of the spherometer has 100 threads to the inch, and the head is divided into 100 parts. Consequently, as the distance between divisions was estimated in tenths, the unit value of the differences shown in the last column of Table IV is $\frac{1}{100.000}$ of an inch.

The instrument permits of being removed from the Y's upon which it rests through the aid of the reversing apparatus, and then turned out of the plane of the prime vertical so as to provide easy access to the two pivots. While so supported the telescope can be adjusted to any desired angle from the zenith, thus permitting as many measurements of the diameters of each pivot to be made as is desired.

In Table IV there is presented a tabulation of the results of these measurements. The reading in the table shown at $0^{\circ}$ was made with the telescope perpendicular, and the object glass up. In that position the caliper was adjusted on one of the pivots, and settings of the spherometer made and recorded. The caliper was then transferred to the other pivot and similar settings were made and recorded.

Following the above the telescope was turned from the perpendicular, so that the object-glass end was $45^{\circ}$ from the zenith. In that position similar settings were made and recorded. The above process was duplicated at each $45^{\circ}$ interval around the two pivots. These readings in the table are recorded in a decimal part of one revolution of the screw.

Each measured diameter of the two pivots is based upon 20 readings of the head of the spherometer, 10 with the caliper in one position and 10 with it reversed. The readings shown opposite $360^{\circ}$ are a duplicate of those made at the same position on each pivot, and shown opposite $0^{\circ}$. The last reading is a check on the first.

Moreover, the following should be noted: When the values of these several readings of the spherometer, as shown in either the second or third columns of the table, are numerically larger than a reading which is adjacent thereto, it indicates that the diameter of the pivot with the larger reading is less in amount than the one with the smaller reading and vice versa. The differences in the last column are so taken that the plus sign indicates that the pivot opposite the clamp has the greater diameter at each of the selected points shown in the table.

TABLE IV.-Pivot Irregularities Determined by the Spherometer-Caliper

\begin{tabular}{|c|c|c|c|}
\hline $\begin{array}{c}\text { Zenith } \\
\text { distance }\end{array}$ & $\begin{array}{c}\text { Clamp } \\
\text { pivot }\end{array}$ & $\begin{array}{c}\text { Opposite } \\
\text { pivot }\end{array}$ & Differences \\
\hline 0 & rev. & rev. & rev. \\
0 & 0.163 & 0.164 & +0.001 \\
45 & .163 & .165 & \pm .002 \\
90 & .164 & .163 & \pm .001 \\
135 & .161 & .163 & +.002 \\
180 & .163 & .164 & +.001 \\
225 & .162 & .163 & \pm .001 \\
270 & .164 & .162 & -.002 \\
315 & .163 & .163 & .000 \\
360 & .162 & .163 & +.001 \\
\hline
\end{tabular}


The resulting differences between the radii of the two pivots, for eight positions on each, are given in the table below.

The angle between the faces of the caliper $Y$ was measured, and found to be practically $90^{\circ}$.

Let $r=$ radius of clamp pivot,

$r^{\prime}=$ radius of other pivot,

$2 L=$ the angle between faces of caliper $Y$ 's.

$x=$ the differences between corresponding diameters expressed in decimals of an inch,

$$
\text { then, } r-r^{\prime}=\frac{x \sin L \text {. }}{1+\sin L}
$$

(Unit of $r-r^{\prime}$ is the millioneth of an inch.)

\begin{tabular}{|c|c|}
\hline Zenith Dist. & $r-r^{\prime}$ \\
\hline$\circ$ & \\
0 & -4 \\
45 & -8 \\
90 & \pm 4 \\
135 & -8 \\
180 & -4 \\
225 & -4 \\
270 & +8 \\
315 & 0 \\
\hline
\end{tabular}

From the above, it will be seen that readings made with the spherometer indicate that the clamp pivot is the smaller by about 0.000002 of an inch.

The difference in radii obtained from level readings, but only on one diameter of each pivot, indicates that the value is 0.00008 of an inch, and also that the clamp pivot is the smaller by that amount.

The latter value was derived from the mean inequality of the pivots, namely, $0.50^{\prime \prime}$, corresponding to the epoch when the spherometer readings were made. Changing that value from arc to linear difference gives the value as above expressed.

In August, 1903, the pivots of the instrument were refigured. In April, 1909, their form was measured by the aid of an axial microscope. The apparatus by which it was accomplished consisted of a microscope objective attached to a tube 39 inches long, and a filar micrometer.

The apparatus was mounted upon the south pier of the prime vertical transit, with its axis coincident with the axis of the telescope. Both pivots are hollow and into these openings are fitted brass caps, the outer ends of which are covered with glass.

The microscope was focused upon a minute globule of mercury deposited upon the face of the glass in the cap. This mercury globule was located as nearly as possible in the center of the glass. It was illuminated by the aid of an electric lamp placed on the north pier, the beam of light passing axially through the axis of the instrument.

If both pivots are true cylinders, and their axes lie along a straight line, revolving the instrument would cause the illuminated globule, as seen in the field of the microscope, to describe a true circle. 
However, if irregularities exist in the form of the pivots, the illuminated spot would not describe such a circle. This deviation can be measured in two coordinates, the horizontal, which would be a change of azimuth, and the vertical, which would be a change in level.

The microscope which was used magnified 300 diameters, and settings were made up on the spot at intervals of $10^{\circ}$ through a complete revolution of the instrument.

In the following table there is given the amount of the combined irregularities of the two pivots, in level and azimuth, expressed in arc.

The quantities given in the table have not been used in the reduction of the observations.

TABLE V.-Corrections to Level and Azimuth of Prime Vertical Transit Clamp North, Due to Irregularity of Pivots as Determined in April, 1909

\begin{tabular}{|c|c|c|c|c|c|}
\hline $\begin{array}{c}\text { Zenith } \\
\text { distance }\end{array}$ & Level & Azimuth & $\begin{array}{l}\text { Zenith } \\
\text { distance }\end{array}$ & Level & Azimuth \\
\hline 。 & 19 & '1 & 0 & "I & 11 \\
\hline 0 & -0.02 & +0.03 & 190 & -.02 & .00 \\
\hline 10 & -.04 & -.01 & 200 & .00 & -.02 \\
\hline 20 & +.03 & -.11 & 210 & -.05 & -.01 \\
\hline 30 & -.03 & -.01 & 220 & +.05 & -.04 \\
\hline 40 & -.01 & -.08 & 230 & +.05 & +.01 \\
\hline 50 & +.04 & -.03 & 240 & .00 & -.05 \\
\hline 60 & +.05 & +.01 & 250 & +.02 & -.07 \\
\hline 70 & +.05 & +.01 & 260 & .00 & -.06 \\
\hline 80 & +.05 & +.03 & 270 & -.03 & +.03 \\
\hline 90 & -.06 & +.03 & 280 & -.01 & +.04 \\
\hline 100 & -.05 & +.03 & 290 & +.05 & +.03 \\
\hline 110 & -.03 & +.08 & 300 & +.06 & +.01 \\
\hline 120 & -.07 & +.05 & 310 & +.09 & -.05 \\
\hline 130 & -.14 & +.06 & 320 & 11 & -.07 \\
\hline 140 & -.09 & +.07 & 330 & 01 & -.08 \\
\hline 150 & -.03 & +.04 & 340 & +.05 & -.06 \\
\hline 160 & -.05 & +.09 & 350 & +.03 & -.04 \\
\hline 170 & -.04 & +.04 & 360 & -.02 & +.03 \\
\hline 180 & -.02 & +.02 & & & \\
\hline
\end{tabular}

METHODS OF OBSERVING AND REDUCTION

There are several methods by which a star can be observed in the prime vertical for the purpose of obtaining its declination, or, if that be accurately known, to derive the latitude of the instrument.

The methods of observing by which the errors of the instrument are eliminated in the most complete manner from the observed position is that developed by the illustrious STRUVE, and his method has been used in this work.

He developed two methods of observing a star in the prime vertical. In one case the celestial body can be so close to the zenith that it is in the field of the eyepiece during the entire time of its passage from the east to the west vertical, and at approximately the same setting of the instrument. In this volume there is included but one star which was observed by that method, namely, a Canum Venaticorum. In the other case the zenith distance in the prime vertical of a star is such that separate settings of the instrument must be made for the transits over the east and west vertical.

$101141^{\circ}-26 \dagger-\mathrm{PT} \mathrm{I}-5$ 
In the discussion of the general repairs of the instrument (page A XXII) an illustration is given showing the group arrangement of the transit threads in the micrometer. That arrangement permits a sufficient interval of time to reverse the instrument in its Y's after a star has made a transit of the threads on one side of the field and before it would transit them again in reverse order.

In general, an observation of a star in the prime vertical made for the purpose of obtaining its declination or the latitude of the instrument is affected by errors, part of them instrumental and part due to the rate of the clock. They may be expressed as follows: The error of collimation of the instrument; the level error; the errors due to inequality or irregularity or pivots; a change in the rate of the clock; an error of azimuth, as well as a change in its value which might occur between the times the star was observed on the east and west verticals, respectively.

Selecting the STRUve method of observing because it does eliminate from an observation a number of these errors, although not all of them, the procedure in observing has been as follows:

The first step is to set the circles, one at the zenith distance the star will have when it is about a minute of time from the first thread of the group over which it is to be observed. The other circle is set at the zenith distance the star will have after the instrument.is reversed and it is approximately a minute of time from the same group of threads, but now in reverse order.

A few minutes before the time a star is in a position to be observed the level is moved over the axis of the instrument and placed on the pivots. After the bubble has come to a state of rest the divisions corresponding to its ends are read and recorded.

The level is then raised from the pivots by means of the automatic apparatus, reversed, and again placed on the pivots. The divisions corresponding to the ends of the level bubble are read and recorded. The level is then slightly raised from the pivots, so as to change the position of the bubble and replaced. After the bubble has come to a state of rest an independent reading is made and recorded. Following this the level is reversed back to its first position, and a fourth reading of the ends of the bubble is made.

The above explanation indicates that four readings of the level bubble are made before observing transits, two direct and two reversed. They are so timed as to be finished three or four minutes before the star transits a group of threads.

After the transits have been observed the instrument is immediately reversed and set to the zenith distance that corresponds to the time when the star will be near the first thread in the same group; that is, the one which was the last thread before reversal. After these transits are observed four level readings are made, precisely as has been explained.

A few minutes before the time when the star would cross the west vertical another set of level readings is recorded. The clamp of the instrument must at this time be in the same position as it was when an observation was finished on the east vertical for that particular star.

The circles are set, one to the zenith distance on the west vertical that will bring the star in the field about a minute of time before it will cross the first thread 
of the group, and the second circle to the zenith distance the star will have after the instrument has been reversed. After the transits are secured four more level readings are made.

The above explanation shows that each time a star is observed in the prime vertical for the purpose of obtaining its declination 16 independent level readings are made upon which to base the level correction. That is, four level readings are made before and four after reversal on the east and west verticals, respectively. The two reversals of the instrument eliminate the collimation error from the transits, as well as the effect of the inequality of the pivots.

Therefore each observed declination published in this volume has been corrected for level error, based upon 16 readings made as near the time of the transit of the star over each vertical as possible. No attempt has ever been made to interpolate level corrections to be applied to a declination for which a level correction was not obtained at the time the star was observed over either vertical.

Turning to the method of obtaining transits it will be noted that on the east vertical the star transits from the south side of the field toward the north and on the west vertical vice versa.

The interval of time that has elapsed between the star crossing any thread on the east and west verticals, respectively, in each position of the clamp, is in error by the amount of the collimation and the thread interval and by taking the mean of those times both are eliminated.

Some of the formulæ printed in this section for the reduction of a prime vertical observation made in the manner suggested by STRuve, are to be found in Observations de Poulkova (Vol. 3). Similar formulæ will also be found in Chauvenet's Practical Astronomy (Vol. 2). They may also be found in Dr. A. Sawitsch's Abriss der Practischen Astronomie, Band 1.

The formulæ of reduction are as follows:

Let $t$ equal one-half the elapsed sidereal time between transits of a star in one position of the clamp, as recorded by a clock with a zero rate; $t^{\prime}$ equal one-half the elapsed sidereal time in the reversed position of the clamp; $n$ equal the declination of the north end of the axis of the instrument; $\delta$ equal the declination of the star, and $c$ equal the distance of a transit thread from the optical axis of the instrument, positive when north of the collimation axis; then we have,

$$
\begin{aligned}
-\sin c & =\sin n \cdot \sin \delta-\cos n \cdot \cos \delta \cos t . \\
\sin c & =\sin n \cdot \sin \delta-\cos n \cdot \cos \delta \cos t^{\prime} .
\end{aligned}
$$

By addition $c$ is eliminated and we obtain,

$$
\cot n=\tan \delta \sec 1 / 2\left(t+t^{\prime}\right) \sec 1 / 2\left(t-t^{\prime}\right) \ldots \ldots \ldots \ldots \text { A. }
$$

STRuve deduces the following formulæ convenient for computation. Designating the four transit times over the same thread by $A, B, C$, and $D$, assuming that the clock has a zero rate, that the axis of the instrument is in the true meridian and that $\varphi$ equals the latitude then,

$$
\mathrm{O}=\cos \frac{D-A}{2}+\cos \frac{C-B}{2} \cos \delta \sin \varphi-2 \sin \delta \cos \varphi \ldots \ldots \ldots
$$


of the group, and the second circle to the zenith distance the star will have after the instrument has been reversed. After the transits are secured four more level readings are made.

The above explanation shows that each time a star is observed in the prime vertical for the purpose of obtaining its declination 16 independent level readings are made upon which to base the level correction. That is, four level readings are made before and four after reversal on the east and west verticals, respectively. The two reversals of the instrument eliminate the collimation error from the transits, as well as the effect of the inequality of the pivots.

Therefore each observed declination published in this volume has been corrected for level error, based upon 16 readings made as near the time of the transit of the star over each vertical as possible. No attempt has ever been made to interpolate level corrections to be applied to a declination for which a level correction was not obtained at the time the star was observed over either vertical.

Turning to the method of obtaining transits it will be noted that on the east vertical the star transits from the south side of the field toward the north and on the west vertical vice versa.

The interval of time that has elapsed between the star crossing any thread on the east and west verticals, respectively, in each position of the clamp, is in error by the amount of the collimation and the thread interval and by taking the mean of those times both are eliminated.

Some of the formulæ printed in this section for the reduction of a prime vertical observation made in the manner suggested by STRUVE, are to be found in Observations de Poulkova (Vol. 3). Similar formulæ will also be found in Chauvenet's Practical Astronomy (Vol. 2). They may also be found in Dr. A. SAwitsch's Abriss der Practischen Astronomie, Band 1.

The formulæ of reduction are as follows:

Let $t$ equal one-half the elapsed sidereal time between transits of a star in one position of the clamp, as recorded by a clock with a zero rate; $t^{\prime}$ equal one-half the elapsed sidereal time in the reversed position of the clamp; $n$ equal the declination of the north end of the axis of the instrument; $\delta$ equal the declination of the star, and $c$ equal the distance of a transit thread from the optical axis of the instrument, positive when north of the collimation axis; then we have,

$-\sin c=\sin n \cdot \sin \delta-\cos n \cdot \cos \delta \cos t$ $\sin c=\sin n \cdot \sin \delta-\cos n \cdot \cos \delta \cos t^{\prime}$.

By addition $c$ is eliminated and we obtain,

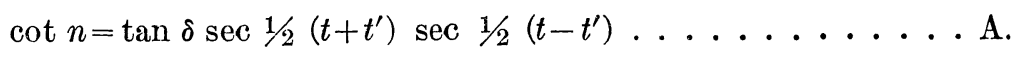

STRUve deduces the following formulæ convenient for computation. Designating the four transit times over the same thread by $A, B, C$, and $D$, assuming that the clock has a zero rate, that the axis of the instrument is in the true meridian and that $\varphi$ equals the latitude then,

$$
\mathrm{O}=\cos \frac{D-A}{2}+\cos \frac{C-B}{2} \cos \delta \sin \varphi-2 \sin \delta \cos \varphi \ldots \ldots \ldots
$$


which can be transformed to

$$
\tan \delta=\frac{\tan \varphi}{\sec \frac{(D-A)+(C-B) \sec }{4} \frac{(D-A)-(C-B)}{4}} \ldots \ldots \ldots . . . .
$$

Formula $\mathrm{C}$ is the one developed by Struve by which to determine either a latitude or a declination when a star is observed in accordance with his method.

Suppose we express by $b$ the inclination to the horizon of the axis of the instrument, positive when the north end is too high, by $a$, the azimuth of the axis, positive when east of north, by $\varphi$ the latitude of the instrument, by $\lambda$ the longitude of the meridian of the instrument, positive when west of the true meridian, then we will have the following equations:

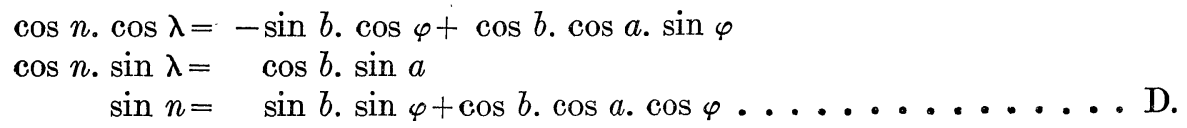

Assume that $h$ and $d$ satisfy the conditions,

$$
\begin{aligned}
& \hbar \sin d=\sin b \\
& h \cos d=\cos b \cos a .
\end{aligned}
$$

then equations $\mathrm{D}$ become,

$$
\begin{aligned}
\cos n \cos \lambda & =h \sin (\varphi-d) \\
\cos n \sin \lambda & =\cos b \sin a \\
\sin n & =h \cos (\varphi-d)
\end{aligned}
$$

From the first and third of these we derive,

$$
\cot n \cos \lambda=\tan (\varphi-d) \ldots \ldots \ldots \ldots \text {. . . . . }
$$

in which $d$ is the average of the level readings obtained in two positions of the instrument, both for the east transit and for the west transit, or

$$
d=\frac{\left(b+b^{\prime}\right) \cdot \text { east vertical }+\left(b+b^{\prime}\right) \text { west vertical }}{4}
$$

By reversal of the instrument the effect of the inequality of pivots is eliminated from the value of $d$, by taking the mean of level readings determined before and after reversing the instrument.

If we express $\varphi-d$ by $\varphi^{\prime}$ equation $\mathrm{A}$ can be written, $\tan \varphi^{\prime}=\tan \delta \sec 1 / 2\left(t+t^{\prime}\right) \sec 1 / 2\left(t-t^{\prime}\right) \cos \lambda$. . . . . . . F.

Transposing equation $\mathrm{F}$, so as to make $\delta$ the unknown quantity, we have,

$$
\tan \delta=\tan \varphi^{\prime} \cos 1 / 2\left(t+t^{\prime}\right) \cos 1 / 2\left(t-t^{\prime}\right),
$$

in which $\cos \lambda$ has been made equal to unity.

It would be possible to deduce $\delta$ directly from the above equation but it is more convenient to use a constant value of $\varphi$ and then apply a correction for the level as follows:

If $\delta^{\prime}$ expresses the instrumental declination and $\delta$ its true value, as well as $\varphi^{\prime}$ the instrumental latitude and $\varphi$ the true value we can write,

$$
\tan \delta \div \tan \delta^{\prime}=\tan \varphi^{\prime} \div \tan \varphi \text {. }
$$

From the above we derive,

$$
\sin \left(\delta-\delta^{\prime}\right)=\sin \left(\varphi^{\prime}-\varphi\right) \sin 2 \delta^{\prime} \operatorname{cosec} 2 \varphi \text {. }
$$


A fixed instrument can always be adjusted so that the quantity $\left(\varphi^{\prime}-\varphi\right)$ in the above equation is sufficiently small to be measured by the aid of the spirit level. If the value of $\left(\varphi^{\prime}-\varphi\right)$ is small then that of $\left(\delta-\delta^{\prime}\right)$ will also be small.

Hence in the above equation we may substitute $\Delta \delta^{\prime \prime}$ for $\sin \left(j-\delta^{\prime}\right)$ and $d^{\prime \prime}$ (the level error) for $\sin \left(\varphi^{\prime}-\varphi\right)$. We then have for deriving the declination the following, in which cosine $\lambda$ has been made equal to unity.

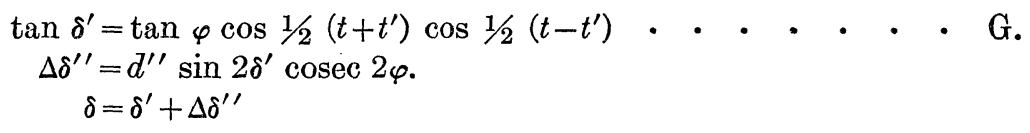

The quanity $\Delta \delta^{\prime \prime}$ is a correction to $\delta^{\prime}$, and is plus when $d$ indicates that the south end of the axis of the instrument is too high. The sign of $d$ in this case is the opposite to what it would have been as a correction to $\varphi^{\prime}$.

It has already been explained (see page A LxviI) that 16 level readings are made each time when an observed declination of a star was secured. Of these 8 were made with the clamp in one position, and 8 after reversal.

On the reduction sheets the sum of the readings corresponding to the divisions indicated by the north and south ends of the bubble are entered in one coiumn, and the sum of the readings made after the level tube is reversed, in another. The difference between these sums in the sense level reversed-level direct gives the proper sign for the level correction.

If the reading at the north end of the bubble is designated by $N$, and that at the south end by $S$; if the level tube is reversed and the reading of the north end expressed by $N^{\prime}$, and the one at the south end by $S^{\prime}$ and making $Z$ equal to the amount of the level error expressed in divisions of the level tube, we have,

$$
Z=\frac{\left(N^{\prime}+S^{\prime}\right)-(N+S)}{4} \text {. }
$$

However, as eight ends of the bubble were read in one position of the level and eight in the other, we have,

$$
Z_{0}=\Sigma\left(N^{\prime}-S^{\prime}\right)-\Sigma(N-S)
$$

To obtain $d$ from $Z_{0}$ the latter must be multiplied by the value of one division of the level tube. To facilitate the computations a table has been prepared which gives the factor

$$
\frac{\text { one division of level }}{32} \cdot \frac{\sin 2 \delta^{\prime}}{\sin 2 \varphi}
$$

When the approximate declination of a star is known, the proper factor taken from the table and multiplied by $Z_{0}$ will give $\Delta \delta^{\prime \prime}$. These multiplications are facilitated by the use of CRELLE's Rechentafeln.

The following table contains the values of $\frac{1 \text { division }}{32} \cdot \frac{\sin 2 \delta^{\prime}}{\sin 2 \varphi}$ for each $5^{\prime}$ from $37^{\circ} 00^{\prime}$ to $38^{\circ} 50^{\prime}$ north declination. The value of $\varphi$ used in computing the table is $+38^{\circ} 55^{\prime} 14^{\prime \prime}$. 
Table of Factors

[One division of level $=1.138^{\prime \prime}$ ]

\begin{tabular}{|c|c|c|c|c|c|c|c|c|}
\hline \multicolumn{2}{|c|}{ Declination } & Factor & \multicolumn{2}{|c|}{ Declination } & Factor & \multicolumn{2}{|c|}{ Declination } & Factor \\
\hline $\begin{array}{r}\circ \\
+37\end{array}$ & $\begin{array}{c}\prime \\
00 \\
05 \\
10 \\
15 \\
20 \\
25 \\
30 \\
35\end{array}$ & $\begin{array}{r}0.0350 \\
.0350 \\
.0350 \\
.0351 \\
.0351 \\
.0351 \\
.0352 \\
.0352\end{array}$ & $\begin{array}{r}\circ \\
+37 \\
38\end{array}$ & $\begin{array}{c}\prime \\
40 \\
45 \\
50 \\
55 \\
00 \\
05 \\
10 \\
15\end{array}$ & $\begin{array}{r}0.0352 \\
.0352 \\
.0353 \\
.0353 \\
.0353 \\
.0353 \\
.0354 \\
.0354\end{array}$ & $\begin{array}{r}\circ \\
+38\end{array}$ & $\begin{array}{l}\prime \\
20 \\
25 \\
30 \\
35 \\
40 \\
45 \\
50\end{array}$ & $\begin{array}{l}0.0354 \\
.0354 \\
.0355 \\
.0355 \\
.0355 \\
.0355 \\
.0356\end{array}$ \\
\hline
\end{tabular}

When a star transits across the prime vertical any error the observer makes in noting the time of transit has less effect upon the value of the declination which will be obtained, the closer the star is to the zenith. This may be shown as follows:

Consider the equation,

$$
\tan \delta=\tan \varphi \cos t
$$

If we differentiate this equation we have,

$$
d \delta^{\prime \prime}=-\frac{15}{2} \sin 2 \delta \tan t d t
$$

which indicates that an error $d t$ in the hour angle $t$, that may have been caused by the observer failing to note the true time when the star bisected the transit thread, has less effect on the declination as the hour angle itself diminishes.

The numerical value of the coefficient of $d t$ in the above equation, using the latitude of the prime vertical instrument, and hour angles for star at $+38^{\circ} 42^{\prime}$ and $+37^{\circ}$ declinations, respectively, is for the first declination 0.923 and for the second 2.776 .

Therefore mistakes made by the observer in recording transits of stars having the above declinations would cause errors in their observed declinations in the ratio of 0.923 to 2.776. That is, the effect on the object nearer the zenith is only one-third of that on the star at $+37^{\circ}$ declination, which is approximately the southern limit at which observations have been made.

The term $d t$ in the above equation might also represent the hourly rate of the clock, and substituted in the equation would yield a correction to the observed declination due to that cause. However, in the reductions another method of correcting for clock rates has been adopted.

The effect of the rate of the observing clock, when it is an appreciable quantity is allowed for in the hour angle by the following method:

The hourly rate is computed for the time corresponding to the hour in the day when the observation was made. This is written on the reduction sheet. When the double hour angle of the star has been found the clock rate is multiplied by it, and also written on the reduction sheet. This is applied as a correction to the double hour angle indicated by each thread over which a complete observation of the star has been made. The algebraic sign of this correction is plus when the clock is losing, 
and minus when it is gaining. If the clock is losing it indicates that the observed hour angle is less than it should be, and therefore must be increased over what it would have been had the clock been running without rate.

Explanations have now been made of the general method of observing a star in the prime vertical when its zenith distance in that vertical is such that it passes entirely across the field of view of the instrument. Also the methods adopted in reducing the observation have been explained.

STRUVE suggested another method by which a star that culminates near the zenith might be observed in the prime vertical, since for such a star the process already outlined would not be applicable. In this work only one star has been observed by this method, namely, $\alpha$ Canum Venaticorum.

The essential difference is that the movable thread is substituted for a fixed thread as the line over which transits are observed.

Let $M$ equal an assumed reading of the micrometer thread when it is approximately in the collimation axis and $M+c$ equal its true value. Let $m$ equal the micrometer reading at which an observed transit of a star has been noted. With our instrument, clamp south, the micrometer readings increase as the micrometer thread is moved toward the north. The thread is therefore $m-(M+c)$ north of the collimation axis.

The following fundamental equation can be adapted to solve for the quantities desired:

$$
\sin c=-\sin n \cdot \sin \delta+\cos n \cdot \cos \delta \cos t .
$$

If in this equation we put $90^{\circ}-\varphi=n$ and assume that both the level and azimuth are equal to zero, we derive,

$$
\begin{aligned}
\sin (m-M-c) & =-\cos \varphi \sin \delta+\sin \varphi \cos \delta \cos t . \\
& =\sin (\varphi-\delta)-2 \sin \varphi \cos \delta \sin ^{2} 1 / 2 t .
\end{aligned}
$$

For such stars $\varphi-\delta$ will be a small quantity. In the case of $\alpha$ Canum Venaticorum it was about $2^{\prime}$ of arc, therefore the equation may be written,

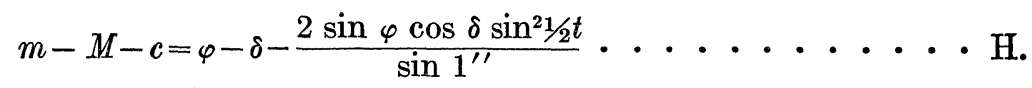

Equation $\mathrm{H}$, for easy computation, can be put in a more convenient form.

Let

$$
\begin{aligned}
e & =M-m \\
z & =\varphi-\delta \\
R & =\frac{2 \sin ^{2} 1 / 2 t}{\sin 1^{\prime \prime}} \sin \varphi \cos \delta
\end{aligned}
$$

As $e$ will be expressed in terms of the micrometer it must be multiplied by the value of one revolution of the screw, which for our instrument is $26.050^{\prime \prime}$. (See page A XXIII.) We then have

$$
z+c=R-e \text {. }
$$


When the instrument is reversed and the clamp is north, equation $\mathrm{H}$ becomes

$$
-m+M+c=\varphi-\delta-\frac{2 \sin \varphi \cos \delta \sin ^{2} 1 / 2 t}{\sin 1^{\prime \prime}} \cdots . . . . . \cdot \mathrm{I} \text {. }
$$

Putting $e^{\prime}=m-M$ then

$$
z-c=R-e^{\prime}
$$

In the method being considered the instrument is reversed but once. From observed transits the value of $z+c$ and $z-c$ for each thread is found, and combined into a general mean they give $z$ and $c$.

Level readings for this method of observing are made in the same manner as has already been explained. The plan of observing is as follows: After the first set of level readings has been made the movable micrometer thread is set eight half turns from the middle thread, toward the side of the field in which the star would appear. After noting the transit at this setting of the micrometer, it is moved one-half revolution in the direction of the motion of the star and another transit noted. This is repeated for seven half turns of the screw, which gives seven transits.

The instrument is now reversed on its axis and four level readings are made. As soon as they are finished the coincidence of the movable with the middle fixed thread is determined.

The movable thread is then turned to the position it occupied when the last transit was observed.

A few moments before the time for the star to reach the transit thread, after it has passed the meridian and is approaching the west vertical, a third set of level readings is made.

After the star passes the meridian it will have an opposite motion, as seen in the eye piece, from what it had when being observed on the east vertical. As soon as the first transit is recorded the micrometer is turned backward a half turn, and this is repeated until seven transits have been recorded, and the micrometer thread is in the same position which it had when the observation was begun on the east vertical.

After this the instrument is reversed back to its original clamp position and four level readings are made.

In the reductions it is necessary to determine $t$, the hour angle of the star from the meridian, corresponding to the time of transit across each of the seven threads. The apparent right ascension of the star for date of observation is taken from the American Ephemeris, and to this is applied the correction to the observing clock, with its sign changed, for what is wanted is the observing clock time the star reached the meridian.

The value of $t$ for each of the threads will have opposite signs, as derived from the two verticals.

If $T_{1}, T_{2}, T_{3} \cdots T_{7}$ represent the times of transit over each of the seven threads on the east vertical, $T_{7}{ }^{\prime}, T_{6}{ }^{\prime} \cdots T_{1}{ }^{\prime}$ the times of transit over the west vertical, and $\alpha$ equals the observed right ascension of the star, then the difference 
between $\alpha$ and the time expressed by each of the threads is the hour angle of the thread. There are numerous editions of tables containing both the natural number and the logarithm of

$$
\frac{2 \sin ^{2} 1 / 2 t}{\sin 1^{\prime \prime}}
$$

with the argument in time. One has been constructed to be used in reducing these observations, based upon Table VI found in the second volume of Chauvenet's Practical Astronomy.

After $z$ is derived from the mean of all the observed threads it is subtracted from the assumed latitude, $+38^{\circ} 55^{\prime} 14.70^{\prime \prime}$, which was used in the first reductions. To the declination thus obtained is applied the correction for level, secured in the same manner as has been explained for the other stars, from which results the observed declination of the star.

All declinations printed in this volume, with the exception of $\alpha$ Canum Venaticorum, have been reduced by the aid of equation G, given on page A LXIX, and changed to

$$
\delta=\delta^{\prime}+\Delta \delta^{\prime \prime}
$$

$$
\tan \delta^{\prime}=\frac{\tan \varphi}{\sec 1 / 2\left(t+t^{\prime}\right) \sec +1 / 2\left(t-t^{\prime}\right) \cos \lambda} \cdots \ldots \ldots .
$$

It was decided in the interest of economy in printing not to publish the observed times of transit on each vertical for each of the seven threads, but instead to print the differences in time of transit over threads. These are the quantities $2 t$ and $2 t^{\prime}$ in columns 3 to 9 , inclusive, of the journal of observations (pages A 54 to A 382) adjacent to the name of the star to which they correspond.

Before the values of $1 / 2\left(t+t^{\prime}\right)$ and $1 / 2\left(t-t^{\prime}\right)$ can be used in the above equation any appreciable hourly rate of the observing clock must be applied with the proper sign to the hour angle.

These hourly rates are to be taken from Table I in order to facilitate the reduction by formula $\mathrm{K}$.

$$
\text { Let } \begin{aligned}
4 \Delta t & =2\left(t+t^{\prime}\right) . \frac{\text { daily rate }}{24} \\
4 \Delta t & =2\left(t-t^{\prime}\right) . \frac{\text { daily rate }}{24}
\end{aligned}
$$

and let

$$
\begin{aligned}
& S=\frac{2\left(t+t^{\prime}\right)+4 \Delta t}{4} \\
& U=\frac{2\left(t-t^{\prime}\right)+4 \Delta t^{\prime}}{4}
\end{aligned}
$$

To avoid the necessity of making the divisions above indicated, STruve has prepared a table entitled "Tabulæ Auxiliares ad transitus per planum primum verticale reducendos inservientes." This table was published by the Pulkova Observatory in 1868, and copies of it are now becoming very scarce. It is a most useful adjunct in the reduction of prime vertical observations that are made in accordance with the methods developed. A computer using either $S$ or $U$ as an argument would take from the table the log. secant $1 / 2\left(t+t^{\prime}\right)$ or the log. secant $1 / 2\left(t-t^{\prime}\right)$ to be substituted in equation $\mathrm{K}$. 
That is to say, each log. secant in the table opposite a printed hour, minute, and second is the log. secant which corresponds to that hour, minute, and second divided by 4 . The table extends to six hours and gives the log. secant for each second of time in that interval. It will be seen how the use of this table very materially reduces the labor of computation in the reduction of prime vertical transit observations.

In columns 10 and 11 of the journal (pages A 47 to A 382) are printed the level sums, while in column 12 will be found the level corrections. On page A LxIX an explanation is made of the method by which the level corrections are derived from the level sums.

On page A XcIv is discussed the assumed latitude which was used as the value of $\varphi$ in equation $K$, and the two values given to it in the period covered by these observations.

The apparent declinations which appear in column 13 are the observed declinations which have resulted from substituting one of these values of $\varphi$ in the above equation. They are not corrected for the finally adopted value of the latitude of the instrument.

The reduction of the declinations to the beginning of the year, which appears in column 14, includes the proper motion for the following stars. It should also be noted that the proper motion of each of these stars has been included in the annual variation by which each observed declination has been deduced for 1900.0.

These stars are:

\begin{tabular}{|c|c|c|c|}
\hline . & R. A. 1900 & $\begin{array}{l}\text { Proper } \\
\text { motion }\end{array}$ & Authority \\
\hline 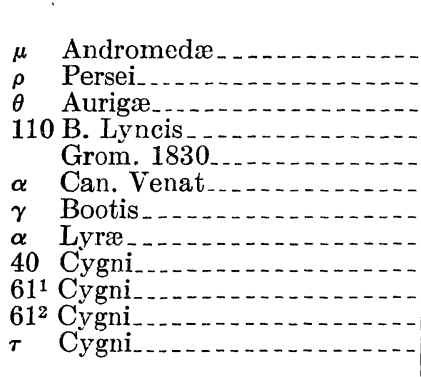 & \begin{tabular}{rr}
\multicolumn{1}{c}{$h$} & $m$ \\
0 & 51 \\
2 & 58 \\
5 & 53 \\
8 & 26 \\
11 & 47 \\
12 & 51 \\
14 & 28 \\
18 & 34 \\
20 & 24 \\
21 & 2 \\
21 & 3 \\
21 & 11
\end{tabular} & $\begin{array}{l}\quad l \\
+0.007 \\
-.113 \\
-.095 \\
=.175 \\
-5.782 \\
+.048 \\
+.142 \\
+.275 \\
.059 \\
+3.242 \\
+3.073 \\
+\quad .433\end{array}$ & $\begin{array}{l}\text { Boss, } 1875 . \\
\text { Boss, } 1875 . \\
\text { Boss, } 1875 . \\
\text { Boss, } 1900 . \\
\text { Newcomb, } 1900 . \\
\text { Boss, } 1875 . \\
\text { Boss, } 1875 . \\
\text { Boss, } 1875 . \\
\text { Newcomb, } 1900 . \\
\text { Boss, } 1900 . \\
\text { Boss, } 1900 . \\
\text { Boss, } 1875 .\end{array}$ \\
\hline
\end{tabular}

The proper motion is included in the reduction of the declinations of $\alpha$ Lyræ, for all years from 1893 to 1912. The declinations of all other stars which are printed in the journal have not been corrected for proper motion. This explanation is given here so as to make clear the nature of the data contained in the journal.

\section{REFLECTION OBSERVATIONS}

In the history of the operation of the prime vertical transit which was formerly installed at the old Naval Observatory the record shows but one attempt to make a reflection observation with it. This observation was made on June 15, 1846. However, mention of the method is contained in a brief suggestion in which it is proposed and in which its advantages are stated. (Astronomical Observations U. S. Naval Observatory, Vol. I, page LIX.) 
The writer, in connection with his work on the instrument, has examined and read numerous articles concerning the prime vertical transit instrument. The development of the method of observing by reflection with this type of astronomical instrument does not appear in any of the numerous books upon practical astronomy. To Prof. George C. Comstock, director of the Washburn Observatory, Madison, Wis., is due the credit of publishing the first article dealing with the subject. In a paper entitled "On a New Method of Observing with the Prime Vertical Transit". (Publications Washburn Observatory, Vol. II, page 279) he discusses this subject very completely and includes in his paper formulæ to be used in the reduction of such an observation. The volume containing his paper appeared about 1883 .

With the exception of observations made by Professor Comsтock with a transit mounted in the prime vertical, the writer has been unable to find any other series of reflected observations which have been made by the method suggested by him or by the method used in this series. The type of instrument used by Professor CoмsтосK was of the broken-back form, which did not permit of observing stars by reflection at less than $18^{\circ}$ zenith distance in the prime vertical. In our latitude at that zenith distance three hours would elapse between the transits of the star across the two verticals, and would call for a wide separation of the two groups of threads to permit transits both direct and reflected to be obtained. Those who may wish to review the developments Professor Comstock has made are referred to his article.

It has already been explained (see page A xxiv) that the reticule in the micrometer box was so designed by the writer that transits could be obtained both by direct pointing and by reflection, the two sets to be part of one observation of the star and at the same time strictly comply with the STRUVE method of observing. The level readings have always been made for a reflection observation in the same manner as for a direct pointing.

We will again consider equation $\mathrm{G}$ (page A LxIx). In that equation we have

$$
\begin{gathered}
\tan \delta^{\prime}=\tan \varphi \cos 1 / 2\left(t+t^{\prime}\right) \cos 1 / 2\left(t-t^{\prime}\right) \\
\Delta \delta^{\prime \prime}=d^{\prime \prime} \sin 2 \delta^{\prime} \operatorname{cosec} 2 \varphi
\end{gathered}
$$

It was pointed out that the value of $\varphi$ in the above equation has been adopted as a constant quantity instead of having the value of $d^{\prime \prime}$ applied to it before solving for the declination. It was also shown that the algebraic sign of $d^{\prime \prime}$ is to be taken as positive when the readings of the level indicate that the south end of the axis is too high.

We now wish to explain why the sign of $d^{\prime \prime}$ will be opposite when transits are observed by reflection, as compared to those made by a direct pointing, both methods of observing being used at practically the same time.

To fix our ideas, we will assume that the angle between the line of collimation of the instrument and the rotation axis is $90^{\circ}$. We will also assume that the telescope has been placed in a vertical position with the object glass at the upper end of the telescope. We will further assume that the south end of the axis is elevated by a quantity which we will designate by $d^{\prime \prime}$.

With these conditions existing, the line of collimation of the instrument, if projected upwards, would pierce the celestial sphere at the instrumental zenith which by definition is $d^{\prime \prime}$ north of the true zenith. If the instrument is now turned on 
its axis so that the object glaiss and the eye end have positions the exact opposite to those which they did have in the first instance, the angle between the line of collimation and the axis of rotation remaining equal to $90^{\circ}$, and no change having taken place in the numerical amount of $d^{\prime \prime}$, the following opposite conditions will be observed:

If a basin containing mercury is placed under the telescope the projected line of collimation will now intersect the reflecting surface of the mercury at a point which is south of the perpendicular from the zenith, and the projected line of collimation will be reflected from a point which is south of the zenith.

Therefore in all cases in which a star is observed by direct pointing and the south end of the axis is too high, $d^{\prime \prime}$ is plus. If a reflected observation of the same star is made simultaneously with the direct, then $d^{\prime \prime}$ is minus.

From what has just been explained it follows that if transits of a star are recorded over two independent sets of threads, both at the east and west verticals, respectively, one by direct pointing to the sky and the other by pointing the telescope downward toward a basin of mercury, and if the instrument is reversed at both verticals and similar transits secured, the errors of collimation, inequality of pivots, thread intervals, and level will be eliminated from the combination of the direct and reflected observations of the star thus observed.

Substituting the times thus secured in equation $G$ one will give $\delta^{\prime}{ }_{\mathrm{b}}$, the declination obtained by direct pointing, and the other $\delta^{\prime}{ }_{R}$ by reflection. The half sum of these two declinations will be free from the errors mentioned. Their half difference should produce the value of $d^{\prime \prime}$ obtained from readings of the level after $d^{\prime \prime}$ has been divided by $\sin 2 \delta^{\prime}$ cosec $2 \phi$.

To take advantage of this practically ideal method of obtaining declinations with a prime vertical transit such observations have been made in the period covered by the contents of this volume. They are indicated in the journal by a *.

However, it is self-evident that a star whose zenith distance in the prime vertical is small can not be observed by reflection, because of the interference of the objective end of the telescope with the direct ray of light from the star.

As was explained on page A xxI, the basin containing the reflecting material is placed upon the circular floor, directly beneath the instrument. This floor is not in contact with that of the transit house, and consequently vibrations are not conveyed from the latter to the former. When the telescope is pointed object glass downward, the eyepiece is about 9 feet above the level of the surface of mercury. When the observer is recording transits by reflection, he stands upon a stepladder placed beside the instrument, the feet of the ladder not touching the circular floor.

Another point developed by Professor Comstock is the limit of zenith distance at which a star can be observed by reflection, so as to have all the rays from the star fall upon the full aperture of the objective. The diameter of our objective is 4.85 inches. The vertical distance from the exterior face of the object glass to the surface of the mercury is 32 inches. If we let $a$ equal $4.85, d$ equal 32 inches, and $z$ equal the zenith distance, then, approximately,

$$
\sin z=\frac{a}{2 d}
$$

For the instrument as at present mounted $z=4^{\circ} .3$.

The star that has the least zenith distance of all that have been observed by reflection is a Lyræ. Assuming that its average declination in the period covered 
by these observations was $+38^{\circ} 41.4^{\prime}$, its zenith distance, when about to cross the prime vertical, would be $5^{\circ} 46^{\prime}$. The least zenith distance it will have as it transits the last thread after reversal of the instrument is $z-15 I \cos \phi$, in which $I$ is the interval of time between the star crossing the middle thread, which is practically in the plane of the prime vertical, and the last thread. This interval for this star is approximately 428 seconds of time. Substituting this value for $I$ in the above expression gives for $\Delta z=-1^{\circ} 23^{\prime}$.

Therefore the least zenith distance of a Lyræ, when it transits the last thread on the east vertical, and the first thread on the west vertical, is $4^{\circ} 23^{\prime}$. This is practically the same as the limit in zenith distance below which some of the rays of the light coming from the star would be cut off by interference of the objective end of the telescope for reflected observations. From this it follows that with this instrument these observations can not be made when $\phi-\delta$ is less than $14^{\prime}$.

In Table VI there are printed observed declinations of the star a Lyræ secured from the two methods of observing. The valuies of the observed declinations given in the third, fourth, fifth, seventh, and eighth columns, have been corrected for variation of latitude, and reduced to 1900.0, using the proper motion that has been found in these observations, namely, $+0^{\prime \prime} .294$ per year.

The values of declinations in the third column of the table, represented by the caption $\delta^{\prime}{ }_{\mathrm{R}}$ are those which have been obtained from transits observed by reflection, and those represented by the caption $\delta^{\prime}{ }_{\mathrm{p}}$, in the fourth column, have been obtained from transits observed direct. A correction for level error, as determined by the level vial, has not been applied to either $\delta^{\prime}{ }_{R}$ or $\delta^{\prime}{ }_{D}$.

TABLE VI.-A Comparison of Direct and Reflected Declinations of $\alpha$ Lyræ, 1900.0. Also a Comparison of Level Values Derived from Differences of these Declinations With those Derived from Spirit Level

$+38^{\circ} 41^{\prime}+$

\begin{tabular}{|c|c|c|c|c|c|c|c|c|c|}
\hline \multirow{2}{*}{ Date } & \multirow{2}{*}{$\begin{array}{c}\text { Level } \\
\text { re- } \\
\text { versed- } \\
\text { direct }\end{array}$} & \multicolumn{4}{|c|}{ Level correction not applied } & \multicolumn{2}{|c|}{$\begin{array}{l}\text { Level correction } \\
\text { applied }\end{array}$} & \multicolumn{2}{|c|}{ Level } \\
\hline & & $\delta^{\prime}{ }_{R}$ & $\delta^{\prime}{ }_{D}$ & $\frac{\delta_{\mathrm{R}}^{\prime}+\delta^{\prime} \mathrm{n}}{2}$ & $\delta^{\prime}{ }_{R}-\delta_{D}^{\prime}$ & $\delta^{\prime}{ }_{R}$ & $\delta^{\prime}{ }_{D}$ & $\begin{array}{c}\text { From } \\
\text { obser- } \\
\text { vations }\end{array}$ & $\begin{array}{l}\text { From } \\
\text { spirit } \\
\text { level }\end{array}$ \\
\hline 1904 & & "' & 'I & 11 & ' & " & 'I & 11 & 11 \\
\hline Apr. 5 & +11.8 & 26. 03 & 25. 20 & 25. 62 & +0.83 & 25.61 & 25. 62 & +0.41 & +0.42 \\
\hline 14 & +3.1 & 26. 02 & 25. 84 & 25. 93 & +.18 & 25. 91 & 25. 95 & +.09 & +.11 \\
\hline 17 & +1.6 & 25. 88 & 25. 79 & 25. 84 & +.09 & 25. 82 & 25. 85 & & -.06 \\
\hline Aug. 15 & +37.9 & 27. 20 & 24. 78 & 25. 99 & +2.42 & 25. 85 & 26. 13 & +1.21 & +1.35 \\
\hline & +5.4 & 26. 12 & 25. 68 & 25. 90 & +.44 & 25. 93 & 25. 87 & +.22 & -.19 \\
\hline Sept. 17 & +0.6 & 25. 43 & 25. 52 & 25. 48 & -.09 & 25. 41 & 25. 55 & .04 & +.02 \\
\hline 22 & +12.7 & 26. 21 & 25. 33 & 25. 77 & +.88 & 25.76 & 25. 78 & +.44 & 45 \\
\hline Oct. 1 & -12.7 & 25.45 & 26. 49 & 25. 97 & -1.04 & 25. 90 & 26. 04 & -.52 & -.45 \\
\hline & +30.1 & 26. 79 & 24. 82 & 25. 80 & +1.97 & 25. 72 & 25. 89 & +.98 & +1.07 \\
\hline 4 & +32.7 & 26. 75 & 24. 52 & 25. 64 & +2.23 & 25. 59 & 25. 68 & +1.12 & +1.16 \\
\hline 7 & +23.2 & 26. 49 & 24. 77 & 25. 63 & +1.72 & 25. 67 & 25. 59 & +.86 & +.82 \\
\hline 16 & +17.7 & 26. 63 & 25. 17 & 25. 90 & +1.46 & 26. 00 & 25.80 & +.73 & +.63 \\
\hline 18 & +55.9 & 27.22 & 22. 88 & 25. 05 & +4.34 & 25. 29 & 24.86 & +2.17 & +1.98 \\
\hline & +2.1 & 25.85 & 25.75 & 25. 80 & +.10 & 25.78 & 25.8 & +.05 & +.07 \\
\hline 27 & +31.9 & 26. 16 & 24. 58 & 25. 37 & +1.58 & 25. 03 & 25. 68 & & +1.13 \\
\hline 31 & +54.3 & 27. 21 & 23. 50 & 25. 36 & +3.71 & 25. 28 & 25. 43 & +1.86 & +1.93 \\
\hline Nov. 2 & +27.6 & 26. 40 & 24. 82 & 25.61 & +1.58 & 25. 42 & 25. 80 & +.79 & +.98 \\
\hline & +38.5 & 26. 49 & 24.21 & 25.35 & +2.28 & 25. 12 & 25. 54 & +1.14 & +1.37 \\
\hline 16 & +14.5 & 26. 16 & 24.82 & 25. 49 & +1.34 & 25. 64 & 25. 34 & +.67 & +.52 \\
\hline 17 & +3.8 & 25. 57 & 25. 06 & 25. 32 & +.51 & 25.44 & 25. 19 & +.26 & +.13 \\
\hline 19 & +29.6 & 26. 26 & 24. 61 & 25. 44 & +1.65 & 25. 21 & 25. 66 & +.82 & +1.05 \\
\hline 21 & +30.2 & 26. 29 & 24. 13 & 25. 21 & +2.16 & 25. 22 & 25. 20 & +1.08 & +1.07 \\
\hline Dec. 23 & +12.4 & 25. 96 & 24. 94 & 25.45 & +1.02 & 25. 52 & 25. 38 & +.51 & +.44 \\
\hline
\end{tabular}


A lxxvili $\quad$ Prime vertical transit instrument.

TABLE VI.-A Comparicon of Direct and Reflected Declinations of a Lyræ 1900.0. Also a Comparison of Levet Values Derived from Differences of these Declinations With those Derived from Spirit Level-Continued

\begin{tabular}{|c|c|c|c|c|c|c|c|c|c|}
\hline \multirow{2}{*}{ Date } & \multirow{2}{*}{$\begin{array}{c}\text { Level } \\
\text { re- } \\
\text { versed- } \\
\text { direct }\end{array}$} & \multicolumn{4}{|c|}{ Level correction not applied } & \multicolumn{2}{|c|}{$\begin{array}{l}\text { Level correction } \\
\text { applied }\end{array}$} & \multicolumn{2}{|c|}{ Level } \\
\hline & & $\delta^{\prime}{ }_{\mathrm{R}}$ & $\delta_{\mathrm{D}}^{\prime}$ & $\frac{\delta_{R}^{\prime}+\delta_{D}^{\prime}}{2}$ & $\delta_{R}^{\prime}-\delta_{D}^{\prime}$ & $\delta_{\mathrm{R}}^{\prime}$ & $\delta_{D}^{\prime}$ & $\begin{array}{c}\text { From } \\
\text { obser- } \\
\text { vations }\end{array}$ & $\begin{array}{l}\text { From } \\
\text { spirit } \\
\text { level }\end{array}$ \\
\hline 1905 & & "I & 11 & $\prime \prime$ & $\prime \prime$ & " & 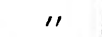 & 11 & "I \\
\hline Jan. 8 & -0.7 & 25. 23 & 25. 27 & 25. 25 & -0.04 & 25. 21 & 25. 20 & -.02 & -0.02 \\
\hline 14 & -21.8 & 24. 57 & 26. 08 & 25. 32 & -1.51 & 25. 34 & 25. 31 & -.76 & -.77 \\
\hline Feb. 9 & +56.7 & 27. 43 & 23.53 & 25. 48 & +3.90 & 25.42 & 25.54 & +1.95 & +2.01 \\
\hline Mar. 12 & +12.7 & 25.80 & 25. 08 & 25.44 & +.72 & 25. 36 & 25.53 & +.36 & +.45 \\
\hline 13 & -10.9 & 25. 07 & 26. 00 & 25. 54 & -.93 & 25.46 & 25. 61 & -.46 & -.39 \\
\hline 15 & 0. 0 & 25. 18 & 25.65 & 25. 42 & -.47 & 25. 18 & 25. 65 & -.24 & .00 \\
\hline 25 & -10.9 & 24. 83 & 26. 32 & 25.58 & -1.49 & 25. 22 & 25. 93 & -.74 & -.39 \\
\hline 27 & -16.7 & 24. 69 & 26.43 & 25. 56 & -1.74 & 25. 28 & 25. 84 & -.87 & -.59 \\
\hline Apr. 2 & +14.3 & 25. 94 & 25. 27 & 25.60 & +.67 & 25.43 & 25. 78 & +.34 & +.51 \\
\hline & +47.7 & 27. 21 & 24.14 & 25. 68 & +3.07 & 25. 52 & 25. 83 & +1.54 & +1.69 \\
\hline 13 & -15.6 & 24. 91 & 26. 42 & 25. 66 & -1.51 & 25.46 & 25. 87 & -.76 & -.55 \\
\hline 18 & -5.8 & 25. 52 & 25. 87 & 25. 70 & -.35 & 25. 73 & 25. 66 & -.18 & -.21 \\
\hline Oct. 30 & +4.8 & 25. 87 & 25. 29 & 25. 58 & +.58 & 25. 70 & 25. 46 & +.29 & +.17 \\
\hline Nov. 2 & -21.2 & 24. 43 & 25. 18 & 25. 30 & -1.75 & 25. 18 & 25.43 & -.88 & -.75 \\
\hline 11 & +15.4 & 25.74 & 25.16 & 25. 45 & +.58 & 25. 19 & 25. 71 & +.29 & +.55 \\
\hline 14 & $\div 4.4$ & 24.65 & 24.88 & 24. 76 & -.23 & 24. 81 & 24. 72 & -.12 & $-\therefore 16$ \\
\hline 17 & +52.3 & 27. 13 & 23. 39 & 25. 26 & +3.74 & 25.27 & 25. 25 & +1.87 & +1.86 \\
\hline 21 & +39.5 & 26. 16 & 23. 88 & 25. 02 & +2.28 & 24.76 & 25. 28 & +1.14 & +1.40 \\
\hline 22. & +9.5 & 25. 94 & 24.93 & 25. 44 & +1.01 & 25. 60 & 25. 27 & +.50 & +.34 \\
\hline 23 & +16.8 & 25. 96 & 24.60 & 25. 28 & +1.36 & 25. 36 & 25. 20 & +.68 & +.60 \\
\hline \multicolumn{10}{|l|}{1906} \\
\hline Jan. 6 & -31.8 & 24.40 & 26. 43 & 25. 42 & -2.03 & 25.53 & 25. 30 & -1.02 & -1.13 \\
\hline & -17.2 & 24. 54 & 26. 31 & 25. 42 & -1.77 & 25.15 & 25. 70 & -.88 & -.61 \\
\hline 18 & +22.1 & 25. 77 & 24. 68 & 25. 22 & +1.09 & 24. 99 & 25. 46 & +.54 & +.78 \\
\hline 28 & -2.6 & 24.55 & 25. 39 & 24.97 & -.84 & 24.64 & 25. 30 & -.42 & -.09 \\
\hline 29 & -10.3 & 25. 0 & 26. 02 & 25. 54 & -.97 & 25.42 & 25. 65 & -.48 & -.37 \\
\hline \multirow[t]{5}{*}{ Feb. } & +8.4 & 24. 82 & 24. 77 & 24. $80^{\circ}$ & +.05 & 24. 52 & 25. 07 & +.02 & +.30 \\
\hline & -3.0 & 25. 1 & 25.87 & 25. 48 & -.77 & 25.21 & 25. 76 & -.38 & -.11 \\
\hline & -6.9 & 24.6 & 25. 36 & 25. 0 & -.68 & 24.92 & 25. 12 & -.34 & -.24 \\
\hline & +2.8 & 24.82 & 25. 33 & 25.0 & -.51 & 24.72 & 25. 43 & -.26 & +.10 \\
\hline & -36.2 & 23.9 & 26. 86 & 25. 42 & -2.87 & 25. 28 & 25. 57 & -1.44 & -1.29 \\
\hline Mar. 5 & -9.1 & 24.8 & 25.83 & 25. 34 & -.97 & 25. 18 & 25. 51 & -.48 & -.32 \\
\hline 17 & -22.3 & 24.4 & 26. 64 & 25. 52 & -2.23 & 25.12 & 25.85 & -1.12 & -.79 \\
\hline 22 & -4.9 & 25. 46 & 26. & 25. 76 & -.60 & 25. 63 & 25. 89 & -.30 & -.17 \\
\hline \multirow{3}{*}{ Apr. 12} & -32.2 & 24.30 & 27.16 & 25. 73 & -2.86 & 25.44 & 26. 02 & -1.43 & -1.14 \\
\hline & -29.2 & 24.08 & 26.85 & 25. 46 & -2.77 & 25. 12 & 25. 81 & -1.38 & -1.04 \\
\hline & +7.8 & 25.9 & 25.94 & 25. 93 & +.02 & 25. 64 & 26. 22 & +.01 & +.28 \\
\hline 24 & +27.3 & 26.5 & 25.12 & 25.81 & +1.38 & 25.53 & 26. 09 & +.69 & +.97 \\
\hline Sept. 14 & +27.1 & 26. 43 & 24. 79 & 25. 61 & $\begin{array}{r}1.64 \\
+1.64\end{array}$ & 25. 47 & 25. 75 & +.82 & +.96 \\
\hline 18 & +28.4 & 26. 0 & 24.6 & 25. 3 & +1.40 & 25. & 25. & +.70 & +1.01 \\
\hline \multirow[b]{2}{*}{ Oct } & +10.4 & 25.43 & 25. 38 & 25. 40 & +.05 & 25. 06 & 25. 75 & +.02 & +.37 \\
\hline & +59.6 & 27. 32 & 23. 78 & 25.55 & +3.54 & 25. & 25. 90 & +1.77 & +2.12 \\
\hline Oct & +34.2 & 26.38 & 24.54 & 25.46 & $\begin{array}{r}1.84 \\
\end{array}$ & 25.1 & 25. 7 & +.92 & +1.21 \\
\hline 26 & +31.3 & 26. 34 & 24. 64 & 25. 49 & $\begin{array}{r}1.70 \\
\end{array}$ & 25. 33 & 25. 75 & +.85 & +1.11 \\
\hline \multirow[t]{2}{*}{ Nov. 4} & +18.6 & 25.73 & 24.71 & 25. 22 & +1.02 & 25. 09 & 25. 37 & +.51 & +.66 \\
\hline & +6.3 & 26. 00 & 25. 51 & 25. 76 & +.49 & 25.78 & 25. 73 & +.24 & +.22 \\
\hline 1907 & & & & & & & & & \\
\hline $\begin{array}{ll}\text { Jan. } & 4 \\
& 6\end{array}$ & $\begin{array}{l}+18.7 \\
+33.5\end{array}$ & $\begin{array}{l}25.78 \\
26.62\end{array}$ & 24.94 & 25. 36 & $\begin{array}{r}+.84 \\
+2.42\end{array}$ & 25. 12 & $\begin{array}{l}25.60 \\
25,39\end{array}$ & $\begin{array}{l}+.42 \\
+1.21\end{array}$ & $\begin{array}{l}+.66 \\
+1.19\end{array}$ \\
\hline & & & & & & & & & \\
\hline Jan. 1 & +35.0 & 26. 39 & 24. 04 & 25. 22 & +2.35 & 25.15 & 25. 28 & & \\
\hline Aug. 19 & +14.2 & 26. 01 & 25. 17 & 25. 59 & +.84 & 25. 51 & 25. 67 & +.44 & +.50 \\
\hline & +25.1 & 26. 39 & 25. 13 & 25. 76 & +1.26 & 25.50 & 26. 02 & & +.89 \\
\hline Sept. 8 & +5.2 & 25. 91 & 25.45 & 25.68 & +.46 & 25. 73 & 25. 63 & +.23 & +.18 \\
\hline & +14.7. & 26. 36 & 25.43 & 25. 90 & +.93 & 25. 84 & 25. 95 & +.46 & +.52 \\
\hline 1909 & & & & & & & & & \\
\hline Oct. 7 & +39.8 & 26. 61 & 24.47 & 25. 54 & +2.14 & 25. 20 & 25. 88 & +1.07 & +1.41 \\
\hline
\end{tabular}


In the fifth column are shown values of $1 / 2\left(\delta^{\prime}{ }_{R}+\delta^{\prime}{ }_{D}\right)$. These combined declinations have produced one which is free from the effect of the lack of horizontality in the axis of the instrument, at the time each observation was made.

In the sixth column will be found values of $\left(\delta^{\prime}{ }_{\mathrm{R}}-\delta^{\prime}{ }_{\mathrm{D}}\right)$. That difference divided by 2 represents in an independent manner what value of the level correction should be applied to each of these observed declinations to make them comparable to the same observed declinations to which has been applied the value of the level corrections as determined from readings of the spirit level.

For that reason if a number of individual observed values of $1 / 2\left(\delta^{\prime}{ }_{R}-\delta^{\prime}{ }_{D}\right)$ are combined into one sum, and that sum is divided by the sum of the differences of level readings, the quotient will be equal to one division of the level vial.

These differences expressed in terms of divisions of the level vial will be found in column 2 of the table. They have been obtained by taking the differences between the sums of level readings reversed and level readings direct, which are to be found in columns 10 and 11 of the pages of the journal of observations of $a$ Lyræ for dates given in Table VI.

As was explained on page A LXIx eight independent level readings have always been made at the time a star was observed with the instrument, or 32 readings of each end of the bubble. Therefore these differences in column 2 of Table VI should be divided by 32 to find the level error of the instrument in terms of divisions of the level vial.

From Table VI there have been taken 38 differences of $1 / 2\left(\delta^{\prime}{ }_{R}-\delta^{\prime}{ }_{\mathrm{D}}\right)$ and correspondingly 38 differences of level reversed - level direct, selecting those in which these differences are larger than 10 divisions of the level vial.

If we represent the sum of the 38 differences $1 / 2\left(\delta_{\mathrm{R}}^{\prime}-\delta^{\prime}{ }_{\mathrm{p}}\right)$ by $\Sigma d \delta$, and the sum of the 38 differences level reversed-level direct by $\Sigma d^{\prime}$, and if we let $d^{\prime \prime}$ equal one division of the level vial, we have,

$$
d^{\prime \prime}=\frac{\Sigma \Delta \delta}{\frac{\Sigma d^{\prime}}{32}} \div \sin 2 \delta^{\prime} \operatorname{cosec} 2 \varphi \text {. }
$$

the solution of which gives as the value of $d^{\prime \prime}, 1.110^{\prime \prime}$. The mean value used in the reduction of all observations was 1.138'". (See page A xLv.)

In the seventh and eighth columns of Table VI are tabulated the observed declinations to which level corrections have been applied, based upon $1.138^{\prime \prime}$ for the value of one division of the level vial.

In the ninth column will be found values of the level correction resulting from combined reflected and direct observations.

In the tenth column there are shown the numerical values of the correction for level which have resulted from readings of the bubble in the level vial taken in the usual manner. Their values are based upon $1.138^{\prime \prime}$ as the value of one division of the level vial.

The probable error of a single observation based upon $1 / 2\left(\delta_{\mathrm{R}}+\delta_{\mathrm{D}}\right)$ is $\pm 0.17 \mathrm{~d}^{\prime}$. The probable error similarly for $\delta_{\mathrm{R}}$ is $\pm 0.21^{\prime \prime}$ and for $\delta_{\mathrm{D}}$ is $\pm 0.20^{\prime \prime}$. 
A LXXX PRIME Vertical transit instrument.

THE AZIMUTH OF THE INSTRUMENT

The azimuth of the instrument has been obtained in the following manner: The half sum of the observed times of transit for each thread, clamp north and clamp south, respectively, is computed. The mean of these times is the sidereal time at which the star passed the meridian of the instrument. We will call that quantity $H$. To it must be applied two corrections, namely, the error of the clock on true sidereal time and any change in the level which may have taken place in the interval of time that has elapsed between the transits of the star over the two verticals. We will call the clock correction $\Delta C$, and indicate the correction for change in level of the axis of the instrument by $\Delta H$.

If we represent the apparent right ascension of the star for the date and time it was observed on the prime vertical by $a$, then

$$
\alpha-(H+\Delta H+\Delta C)=\lambda \ldots \ldots \ldots \ldots \ldots \text { L. . . }
$$

in which $\lambda$ indicates the deviation of the axis of the instrument from the plane of the true meridian. To reduce this to an azimuth deviation, which we will call $a$,

$$
a=\lambda \sin \varphi
$$

in which $\varphi$ is the latitude of the instrument.

The corrections to the observing clock used with the prime vertical have been obtained by comparisons with the observing clocks used by either the 6 -inch or the 9-inch transit circles. In later years these corrections have been obtained from the clock in circuit with the chronographs of the two transit circles and that. of the prime vertical transit.

Consider now a possible change in the level error of the instrument, determined at the time transits were observed over the east vertical, and again over the west. vertical. Let $b$ represent the level correction determined in the first instance, and $b^{\prime}$ in the second instance. Then $b-b^{\prime}$ indicates any change in the value of the level between times of the star passing the two verticals, and a correction for this must be applied to $H$ to obtain the meridian of the instrument.

In the formula $\cos t=\tan \delta \cot \varphi$ if we differentiate with respect to $t$ and $\varphi$, where $t$ is the hour angle at the west vertical, we have,

$$
15 \Delta t=\frac{\Delta \varphi \tan \delta}{\sin ^{2} \varphi \sin t}
$$

This reduces to

$$
15 \Delta t=\frac{\Delta \varphi \sin \delta}{\sin \varphi \sqrt{\sin (\varphi+\delta) \sin (\varphi-\delta)}}
$$

If the angle which the axis of the instrument makes with a plane passing through the horizon, which was measured by the level at the east vertical, has changed in amount when the star reaches the west vertical, then its effect is the same as that. of a difference of latitude, and $H$ will be increased by $1 / 2 \Delta t$.

- Therefore $\left(b-b^{\prime}\right)$ should be substituted in the above equation for $\Delta \varphi$, and we have,

$$
\Delta \mathrm{H}=\frac{\left(b-b^{\prime}\right) \sin \delta}{30 \sin \varphi \sqrt{\sin (\varphi+\delta) \sin (\varphi-\delta)}}
$$


The following table contains the factors computed from the above formula by which $\left(b-b^{\prime}\right)$ is to be multiplied to obtain $\Delta H$, between the limits of declination $+37^{\circ} 00^{\prime}$ to $+38^{\circ} 49^{\prime}$.

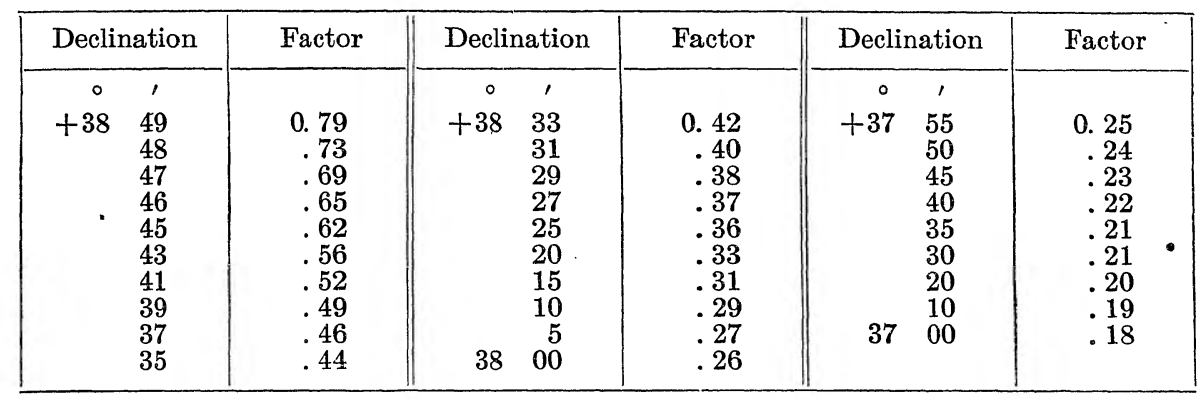

ERRORS IN OBSERVED DECLINATIONS DEPENDING UPON DISPLACEMENT OF INSTRUMENT' IN AZIMUTH

The error that affects an observed declination due to the axis of the instrument not being in the plane of the true meridian, is determined as follows:

Let $\delta$ represent a declination on the assumption that the axis of the instrument is in the meridian, or that the cosine of $\lambda$ is equal to 1 . Let $\delta_{0}$ represent the declination actually observed, then,

$$
\begin{aligned}
& \tan \left(90^{\circ}-\delta_{0}\right) \cos \lambda=\tan \left(90^{\circ}-\delta\right), \\
& \frac{\tan \delta}{\tan \delta_{0}}=\frac{1}{\cos \lambda}
\end{aligned}
$$

If unity is subtracted from both sides of this equation, we will obtain the following ratio:

$$
\sin \left(\delta-\delta_{0}\right)=\sin ^{2} 1 / 2 \lambda 2 \sin \delta_{0} \cos \delta
$$

The value of $\lambda$ in a well-adjusted instrument is usually a small quantity and if it is reduced to arc from time and substituted for the sine in the above equation we obtain with sufficient accuracy

$$
\delta=\delta_{0}+(1 / 2 \lambda)^{2} \sin 2 \delta \sin 1^{\prime \prime} .
$$

In the following table are arranged by declinations and for values of $\lambda$ from $1 \mathrm{~s}$. to $10 \mathrm{~s}$. the correction which it is necessary to apply to an observed declination

\begin{tabular}{|c|c|c|c|c|c|c|c|c|c|c|c|}
\hline \multicolumn{2}{|c|}{ Declination } & $1 \mathrm{~s}$. & $2 \mathrm{~s}$. & $3 \mathrm{~s}$. & $4 \mathrm{~s}$. & $5 \mathrm{~s}$. & $6 \mathrm{~s}$. & $7 \mathrm{~s}$. & $8 \mathrm{~s}$. & $9 \mathrm{~s}$. & $10 \mathrm{~s}$. \\
\hline 0 & , & $\prime \prime$ & 11 & 11 & 11 & 11 & $\prime \prime$ & 11 & 11 & 11 & $\prime \prime$ \\
\hline+38 & 45 & 0.000 & 0. 001 & 0.002 & 0. 004 & 0.007 & 0.010 & 0.013 & 0.017 & 0.022 & 0.027 \\
\hline 100 & 35 & .000 & & 2 & & 7 & 10 & 13 & 17 & 22 & 27 \\
\hline . & 25 & .000 & 1 & $\overline{2}$ & 4 & 7 & 10 & 13 & 17 & 22 & 27 \\
\hline & 15 & .000 & 1 & 2 & 4 & 7 & 10 & 13 & 17 & 22 & 26 \\
\hline & 5 & .000 & 1 & 2 & 4 & 7 & 10 & 13 & 17 & 21 & 26 \\
\hline 37 & 55 & .000 & 1 & 2 & 4 & 7 & 10 & 13 & 17 & 21 & 26 \\
\hline & 45 & .000 & 1 & 2 & 4 & 7 & 10 & 13 & 17 & 21 & 26 \\
\hline & 35 & .000 & 1 & 2 & 4 & 7 & 10 & 13 & 17 & 21 & 26 \\
\hline & 25 & .000 & 1 & 2 & 4 & 7 & 10 & 13 & 17 & 21 & 26 \\
\hline & 15 & .000 & 1 & 2 & 4 & 7 & 10 & 13 & 17 & 21 & 26 \\
\hline & 5 & .000 & 1 & 2 & 4 & 7 & 10 & 13 & 17 & 21 & 26 \\
\hline 37 & 00 & .000 & 1 & 2 & 4 & 7 & 10 & 13 & 17 & 21 & 26 \\
\hline
\end{tabular}
to free it from the error which has been caused by the axis of the instrument not being in the meridian at the time the observation was made.

TABLE VII, a.-Corrections to Declinations Depending on Azimuth

$101141^{\circ}--26 \dagger$ †T I-—6 
By the aid of formula $L$ on page A Lxxx and the following formulæ the longitude and azimuth of the instrument and the azimuth of the mark have been computed. The apparent right ascension of each star, represented by $a$ in formula L, has been taken from the American Ephemeris. The values of $\lambda$ and $a$ are tabulated in Table VII. Mention was made on page A xxiv that a meridian mark was established to be used in ascertaining the azimuth of the instrument at times when an Ephemeris star had not been observed.

TABLE VII.-The Azimuth of the Instrument and the Mark

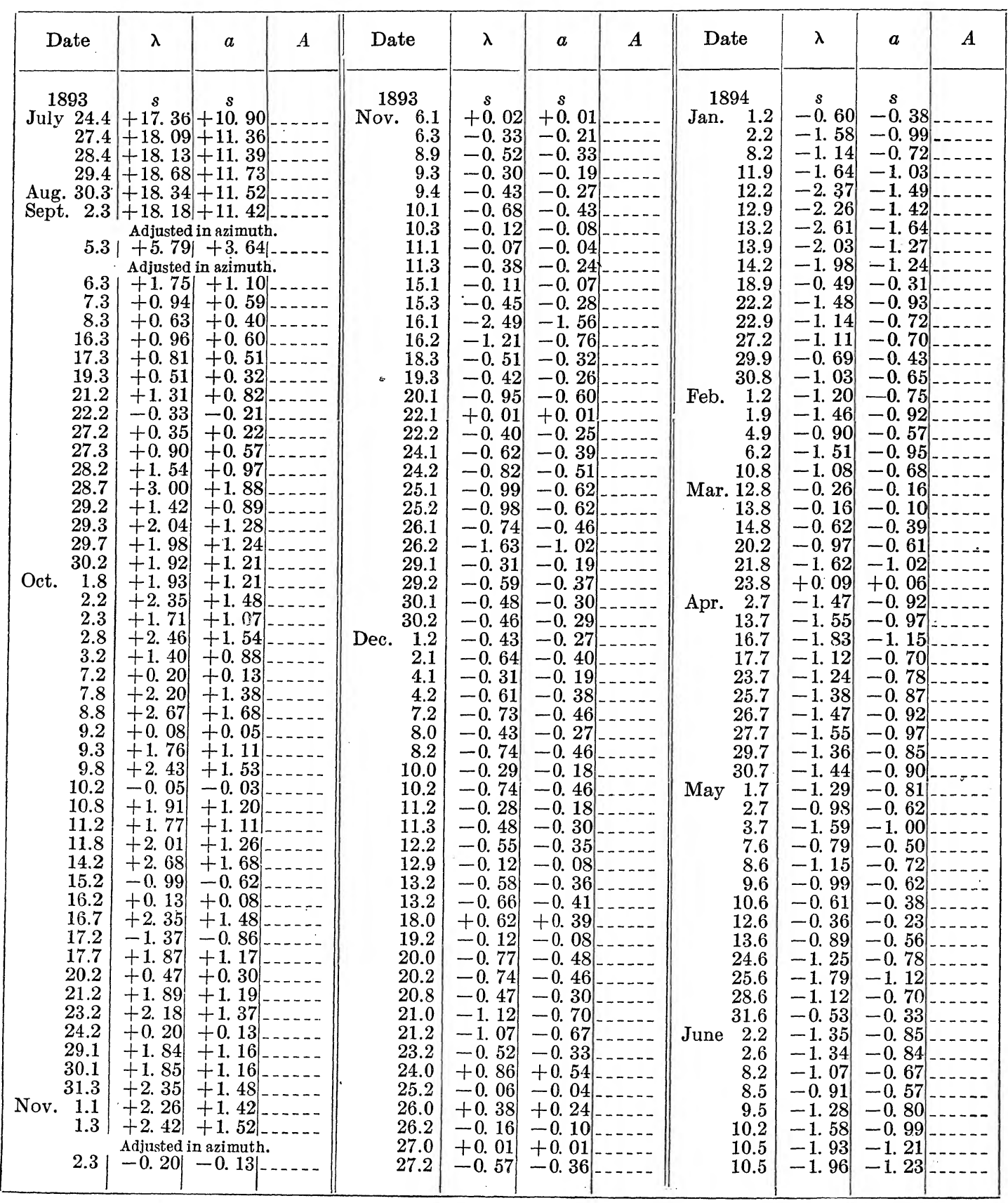


INTRODUCTION.

A LXXX.III

TABLE VII.-The Azimuth of the Instrument and the Mark-Continued

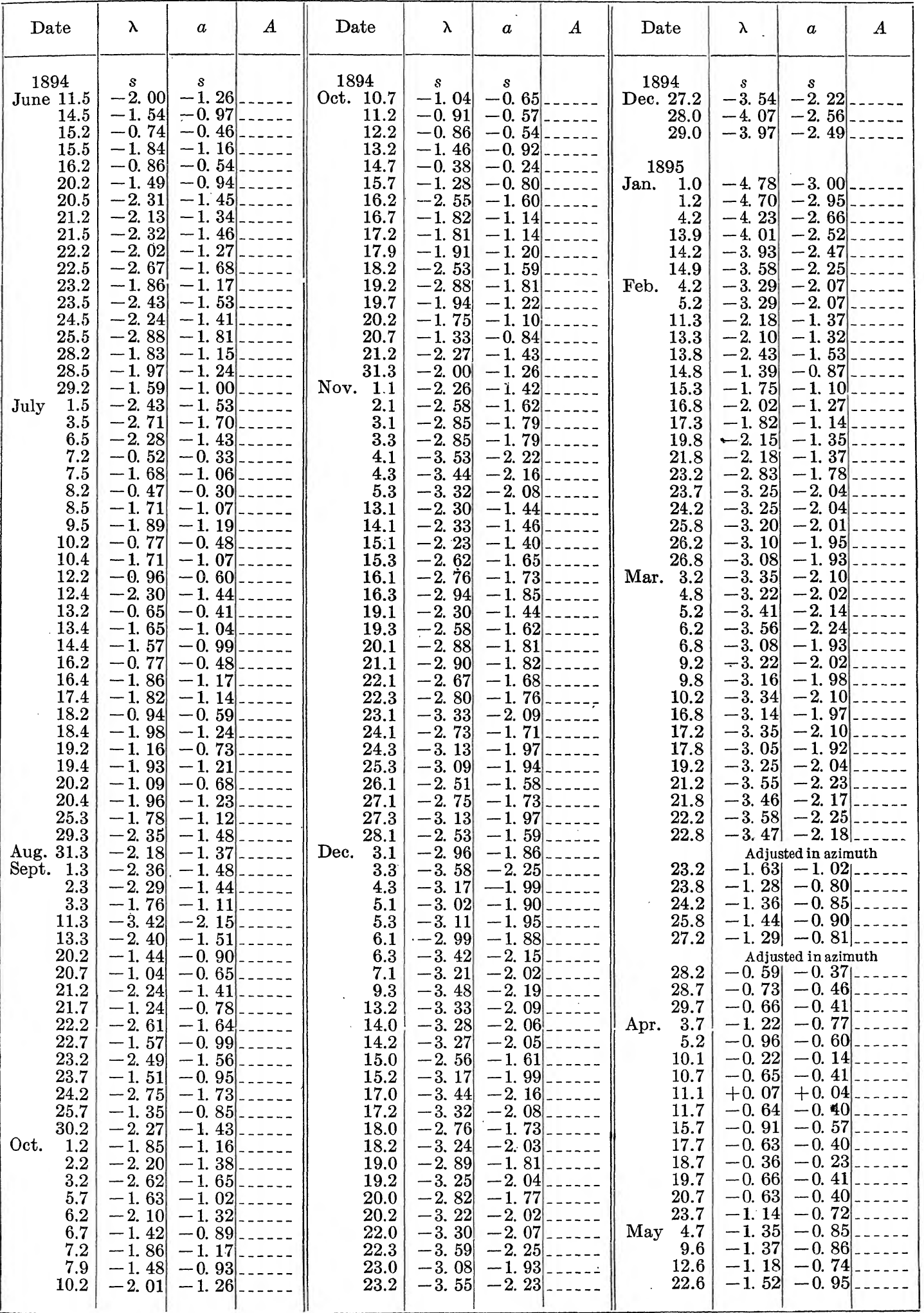


TABLE VII.-The Azimuth of the Instrument and the Mark-Continued

\begin{tabular}{|c|c|c|c|c|c|c|c|c|c|c|c|c|}
\hline & Date & $\lambda$ & $a$ & $A$ & Date & $\lambda$ & $a$ & $A$ & Date & $\lambda$ & $a$ & $A$ \\
\hline & 1895 & & & & 1895 & & & & 1896 & & & \\
\hline May & ay 23.6 & -1.72 & -1.08 & & Oct. 20.2 & +0.06 & +0.04 & & Feb. 11.3 & +3.08 & +1.93 & \\
\hline & 27.6 & -1.42 & -0.89 & & 20.7 & +0.02 & +0.01 & & 11.9 & +2.76 & +1.73 & \\
\hline & 28.6 & -1.22 & -0.77 & & 21.2 & -0.49 & -0.31 & & 13.8 & +2.66 & +1.67 & \\
\hline & 29.6 & -0.59 & -0.37 & & 21.7 & +0.01 & +0.01 & & 14.3 & +2.60 & +1.63 & \\
\hline & 30.6 & -0.76 & -0.48 & & 22.2 & +0.25 & +0.16 & & 14.8 & +3.21 & +2.02 & \\
\hline & 31.6 & -1.25 & -0.78 & & 23.2 & +0.05 & +0.03 & & 15.3 & +2.81 & +1.76 & \\
\hline June & ne 1.6 & -1.13 & -0.71 & & 23.7 & +0.12 & +0.08 & & 16.3 & +4.19 & +2.63 & \\
\hline & & -0.40 & -0.25 & & 24.2 & +0.21 & +0.13 & & 17.3 & +3.17 & +1.99 & \\
\hline & 3.6 & -0.67 & -0.42 & & 25.2 & -0.23 & -0.14 & & 17.8 & +2.32 & +1.46 & \\
\hline & 7.5 & -0.34 & -0.21 & & 25.7 & -0.03 & $\begin{array}{l}-0.02 \\
+0.06\end{array}$ & & & +2.32 & +1.46 & \\
\hline & $\begin{array}{r}8.5 \\
16.5\end{array}$ & -0.69 & -0.43 & & $\begin{array}{l}26.2 \\
267\end{array}$ & $\begin{array}{r}+0.09 \\
+0.16\end{array}$ & $\begin{array}{l}+0.06 \\
+0.10\end{array}$ & & $\begin{array}{l}19.3 \\
19.8\end{array}$ & $\begin{array}{r}+3.25 \\
+3.55\end{array}$ & $\begin{array}{l}+2.04 \\
+2.23\end{array}$ & \\
\hline & $\begin{array}{l}16.5 \\
22.5\end{array}$ & $\begin{array}{l}+0.11 \\
-0.13\end{array}$ & $\begin{array}{l}+0.07 \\
-0.08\end{array}$ & & $\begin{array}{l}20 \\
27.2\end{array}$ & $\begin{array}{l}+0.10 \\
-0.03\end{array}$ & $\begin{array}{l}+0.10 \\
-0.02\end{array}$ & & 25.3 & $\begin{array}{l}+0.03 \\
+3.42\end{array}$ & $\begin{array}{l}+2.20 \\
+2.15\end{array}$ & \\
\hline & 23.5 & -0.31 & -0.19 & & 28.2 & +0.69 & +0.43 & & 27.3 & +2.85 & $\begin{array}{r}1.79 \\
\end{array}$ & \\
\hline Aug & g. 18.3 & -0.43 & -0.27 & & 28.7 & +0.87 & +0.55 & & Mar. 2.3 & +3.23 & +2.03 & \\
\hline & 19.3 & -0.37 & -0.23 & & 30.2 & +0.25 & +0.16 . & & 2.8 & +3.29 & +2.07 & \\
\hline & 21.3 & -0.08 & -0.05 & & Nov. 1.2 & -0.19 & -0.12 & & 3.3 & $\begin{array}{r}+2.99 \\
\end{array}$ & +1.88 & \\
\hline & 22.3 & -0.43 & -0.27 & & 3.1 & +1.33 & +0.84 & & 3.8 & +3.25 & +2.04 & \\
\hline & 23.3 & -0.51 & -0.32 & & 4.1 & +1.34 & +0.84 & & 4.3 & +3.12 & +1.96 & \\
\hline & 25.3 & -0.33 & -0.21 & & 5.1 & +0.98 & +0.62 & & 4.8 & +3.36 & +2.11 & \\
\hline & 26.3 & +0.45 & +0.28 & & 5.3 & +0.82 & +0.51 & & 5.3 & +2.45 & +1.54 & \\
\hline & 27.3 & -0.20 & -0.13 & & 12.1 & +0.99 & +0.62 & & 7.3 & +2.76 & +1.73 & \\
\hline & 28.3 & +0.27 & +0.17 & & 12.3 & +1.03 & +0.65. & & 7.8 & +2.53 & +1.59 & \\
\hline Sept & t. 1.3 & -1.24 & -0.78 & & 13.1 & +1.24 & $\begin{array}{l}0.78 \\
\end{array}$ & & 8.8 & $\begin{array}{l}+3.10 \\
\end{array}$ & $\begin{array}{r}1.95 \\
\end{array}$ & \\
\hline & 2.3 & -0.16 & -0.10 & & 13.3 & +1.22 & +0.77 & & 9.3 & +2.82 & +1.77 & \\
\hline & 3.3 & +0.13 & +0.08 & & 18.3 & +2.34 & +1.47 & & 12.3 & +3.13 & +1.97 & \\
\hline & 4.3 & -0.16 & -0.10 & & 19.1 & +2.01 & +1.26 & & 12.8 & +2.92 & +1.83 & \\
\hline & 5.3 & -0.79 & -0.50 & & 19.3 & +1.61 & +1.01 & & 13.2 & +2.67 & +1.68 & \\
\hline & 7.3 & -1.10 & -0.69 & & 27.1 & +3.69 & +2.32 & & 13.8 & +1.71 & +1.07 & \\
\hline & 9.3 & -0.96 & -0.60 & & 27.3 & +3.25 & +2.04 & & 14.2 & +2.39 & +1.50 & \\
\hline & 10.3 & -0.97 & -0.61 & & 29.1 & +3.37 & +2.12 & & 17.2 & +2.89 & +1.81 & \\
\hline & 11.3 & -1.09 & -0.68 & & Dec. 3.3 & +2.27 & +1.43. & & 17.8 & +2.82 & +1.77 & \\
\hline & 11.7 & -0.26 & -0.16 & & 4.1 & +2.19 & +1.38 . & & 20.2 & +3.43 & +2.15 & \\
\hline & 12.3 & -1.60 & -1.00 & & 6.1 & +2.57 & +1.61 . & & 20.8 & +3.44 & +2.16 & \\
\hline & 13.7 & -0.61 & -0.38 & & 6.3 & +1.98 & +1.24 & & 21.2 & +3.24 & +2.03 & \\
\hline & 14.3 & -1.61 & -1.01 & & 10.2 & +2.95 & +1.85. & & 24.2 & +3.43 & +2.15 & \\
\hline & 15.3 & -1.45 & -0.91 & & 13.0 & +1.80 & +1.13. & & 24.8 & +3.92 & +2.46 & \\
\hline & 15.7 & -0.51 & -0.32 & & 13.3 & +1.63 & $\begin{array}{l}1.02 \\
\text {. }\end{array}$ & & 25 & $\begin{array}{r}8.22 \\
\end{array}$ & $\begin{array}{l}+2.02 \\
\end{array}$ & \\
\hline & 19.7 & -0.57 & -0.36 & & 14.0 & +2.06 & +1.29 & & 26.8 & +3.62 & +2.27 & \\
\hline & 20.3 & -1.44 & -0.90 & & 14.2 & +1.51 & +0.95 & & Apr. 4.2 & +4.22 & +2.65 & \\
\hline & 21.3 & -1.60 & -1.00 & & 15.3 & +2.12 & +1.33. & & 4.7 & +4.18 & +2.63 & \\
\hline & 21.7 & -0.95 & -0.60. & & 16.0 & +2.41 & +1.51 & & 5.2 & +3.74 & +2.35 & \\
\hline & 22.2 & -1.61 & $-1.01]$ & & 16.3 & +2.43 & +1.53 & & 7.7 & +3.88 & +2.44 & \\
\hline & 22.7 & -0.89 & -0.56 & & 22.0 & +3.79 & +2.38 & & 8.2 & +3.93 & +2.47 & \\
\hline & 23.2 & -1.26 & -0.79 & & 22.2 & +2.95 & +1.85 & & 8. & +3.69 & +2.32 & \\
\hline & 23.7 & -0.89 & -0.56 & & 27.0 & +2.28 & +1.43. & & 11.7 & +3.51 & +2.20 & \\
\hline & 27.2 & -1.12 & -0.70 & & 31.0 & +2.64 & +1.66 & & 12. & +3.52 & +2.21 & \\
\hline & 27.7 & -0.11 & -0.07 & & 31.2 & +2.21 & +1.39 & & 17.7 & +3.46 & +2.17 & \\
\hline & 28.2 & +0.02 & +0.01 & & & & & & 18.7 & +3.48 & +2.19 & \\
\hline Oct. & . $\quad 1.2$ & -0.89 & $-0: 56$ & & 1896 & & & & 21.7 & +3.52 & +2.21 & \\
\hline & 1.7 & -0.27 & -0.17 & & Jan. $\quad 1.0$ & +2.16 & +1.36 & & 22.7 & $+3.3 \overline{7}$ & +2.12 & \\
\hline & 2.2 & -0.90 & -0.57 & & & +1.18 & +0.74 & & 26.7 & +3.06 & +1.92 & \\
\hline & 2.7 & -0.06 & -0.04 & & 2.0 & +1.18 & +0.74 & & 28.7 & +1.91 & +1.20 & \\
\hline & 3.2 & -0.88 & -0.55 & & 2.2 & +1.35 & +0.85 & & May 4.7 & +2.81 & +1.76 & \\
\hline & 3.7 & -0.17 & -0.11 & & 4.0 & +2.06 & +1.29 & & 10.6 & +2.53 & +1.59 & \\
\hline & 4.2 & -1.10 & -0.69 & & 8.0 & +1.45 & +0.91 & & 11.6 & +2.40 & +1.51 & \\
\hline & 4.7 & -0.18 & -0.11 & & 11.2 & +1.43 & +0.90 & & 15.6 & +1.17 & +0.73 & \\
\hline & 6.2 & -0.38 & -0.24 & & 13.9 & +2.53 & +1.59 & & 17.6 & +2.63 & +1.65 & \\
\hline & 8.2 & -0.49 & -0.31 & & 14.9 & +1.96 & +1.23 & & 29.6 & +3.28 & +2.06 & \\
\hline & 8.7 & -0.40 & -0.25 & & 15.9 & +2.24 & +1.41 & & 30.6 & +3.25 & +2.04 & \\
\hline & 9.7 & -0.02 & -0.01 & & 17.9 & +2.33 & +1.46 & & 31.6 & $\begin{array}{r}+3.48 \\
\end{array}$ & $\begin{array}{r}2.19 \\
\end{array}$ & \\
\hline & 13.7 & +0.19 & +0.12 & & 24.9 & +2.21 & +1.39 & & June 1.6 & +3.47 & +2.18 & \\
\hline & 14.2 & -0.31 & -0.19 & & 26.9 & +3.11 & +1.95 & & 5.6 & +3.74 & +2.35 & \\
\hline & 15.2 & -0.10 & -0.06 & & 27.9 & +3.07 & +1.93. & & 10.5 & +4.45 & $\begin{array}{r}2.79 \\
\end{array}$ & \\
\hline & 16.2 & -0.53 & -0.33 & & 28.9 & +3.24 & +2.03 & & 11.5 & $\begin{array}{l}4.32 \\
\end{array}$ & +2.71 & \\
\hline & 16.7 & -0.08 & -0.05 & & 29.9 & +3.30 & +2.07 & & 12.5 & +4.49 & +2.82 & \\
\hline & 17.2 & -0.04 & $-\left.0.03\right|_{-}$ & & Feb. $\quad 6.9$ & +3.32 & +2.08 & & 17.5 & +4.27 & +2.68 & \\
\hline & 17.7 & +0.18 & $+0.11{ }_{-}$ & & 7.3 & +3.24 & +2.03. & & 19.5 & +3.41 & +2.14 & \\
\hline & 18.2 & -0.13 & -0.08 & & 10.3 & +2.99 & +1.88 & & 20.5 & +3.38 & +2.12 & \\
\hline & 19.2 & +0.33 & +0.21 & & 10.9 & +2.89 & +1.81 & & 21.5 & +3.30 & +2.07 & \\
\hline
\end{tabular}


INTRODUCTION.

A Lxxxv

TABLE VII.-The Azimuth of the Instrument and the Mark-Continued

\begin{tabular}{|c|c|c|c|c|c|c|c|c|c|c|c|}
\hline Date & $\lambda$ & $a$ & $A$ & Date & $\lambda$ & $a$ & A & Date & $\lambda$ & $a$ & $A$ \\
\hline 1896 & & $s$ & & 1896 & $s$ & $s$ & & 1897 & & & \\
\hline July 1.5 & +3.57 & +2.24 & & Dec. $\quad 9.2$ & +3.49 & +2.19 & & Apr. 18.7 & -1.43 & -0.90 & \\
\hline 9.5 & +3.14 & +1.97 & & & +3.94 & +2.47 & & 19.5 & -2.14 & -1.34 & \\
\hline $\begin{array}{l}11.5 \\
12.5\end{array}$ & $\begin{array}{l}+3.00 \\
+3.26\end{array}$ & $\begin{array}{r}+1.88 \\
+2.05\end{array}$ & & $\begin{array}{l}10.2 \\
11.2\end{array}$ & $\begin{array}{r}+3.49 \\
+3.50\end{array}$ & $\begin{array}{r}+2.19 \\
+2.20\end{array}$ & & 19.7 & $\begin{array}{l}-1.49 \\
-0.98\end{array}$ & & \\
\hline 17.4 & $\begin{array}{r}\text { +3. } \\
+30\end{array}$ & $\begin{array}{r}+2.14 \\
\end{array}$ & & 16.2 & $\begin{array}{r}.3 .66 \\
\end{array}$ & $\begin{array}{r}+2.30 \\
\end{array}$ & & $\begin{array}{l}20.5 \\
20.7\end{array}$ & $\begin{array}{l}-0.90 \\
-1.11\end{array}$ & $\begin{array}{l}-0.62 \\
-0.70\end{array}$ & \\
\hline 18.4 & $\begin{array}{r}2.89 \\
\end{array}$ & +1.81 . & & 17.0 & +3.65 & $\begin{array}{r}+2.29 \\
\end{array}$ & & 22.5 & -1.39 & -0.87 & \\
\hline 31.4 & +3.61 & +2.27 & & 23.2 & +3.32 & +2.08 & & 22.7 & -1.78 & -1.12 & \\
\hline Aug. $\quad 2.4$ & +2.99 & +2.51 & & 24.0 & +2.73 & +1.71 & & 26.7 & -1.89 & -1.19 & \\
\hline & +4.23 & +2.66 & & 28.0 & +3.02 & +1.90 & & 27.5 & -0.44 & -0.28 & \\
\hline 4.4 & +3.72 & +2.34 & & 28.2 & +2.87 & +1.80 & & 27.7 & -1.04 & -0.65 & \\
\hline 5.4 & +3.39 & +2.13 & & 31.2 & +2.88 & +1.81 & & May 2.5 & +0.07 & +0.04 & \\
\hline 6.4 & +3.84 & +2.41 & & & & & & 5.5 & -0.59 & -0.37 & \\
\hline 7.4 & +3.71 & +2.33 & & 1897 & & & & 6.5 & -0.87 & -0.55 & \\
\hline 8.4 & +4.36 & +2.74 & & Jan. 2.0 & +3.31 & +2.08 & & 6.6 & -1.27 & -0.80 & \\
\hline 9.4 & +4.35 & +2.73 & & 6.0 & +1.50 & +0.94 & & 7.5 & -0.13 & -0.08 & \\
\hline 11.4 & +4.02 & +2.52 & & 7.0 & +2.55 & +1.60 & & 7.6 & -0.15 & -0.09 & \\
\hline 14.4 & +4.51 & +2.83 & & 7.2 & +2.55 & +1.60 & & 10.5 & -0.93 & -0.58 & \\
\hline 15.4 & +4.53 & +2.84 & & 8.0 & +2.26 & +1.42 & & 15.6 & -1.29 & -0.81 & \\
\hline 17.4 & +4.43 & +2.78 & & 9.0 & +2.51 & +1.58 & & 16.4 & -0.35 & -0.22 & \\
\hline 19.4 & +3.85 & +2.42 & & 8.2 & +2.27 & +1.43 & & 16.6 & -0.36 & -0.23 & \\
\hline 20.4 & +3.74 & +2.35 & & 9.2 & +2.40 & $\begin{array}{l}1.51 \\
\end{array}$ & & 17.4 & -0.79 & -0.50 & \\
\hline 23.3 & +3.74 & +2.35 & & 21.9 & +2.19 & +1.38 & & 21.4 & -0.20 & -0.13 & \\
\hline 25.3 & +3.72 & +2.34 & & 22.9 & +2.02 & +1.27 & & 21.6 & -0.85 & -0.53 & \\
\hline 26.3 & $\begin{array}{r}+4.44 \\
\end{array}$ & $\begin{array}{r}+2.79 \\
\end{array}$ & & 24.9 & +1.82 & +1.14 & & 22.4 & -0.05 & -0.03 & \\
\hline 27.3 & +4.38 & +2.75 & & 29.9 & +1.42 & +0.89 & & 25.4 & -0.50 & -0.31 & \\
\hline 28.3 & +4.05 & +2.54 & & 30.4 & +1.24 & +0.78 & & 25.6 & -0.23 & -0.14 & \\
\hline 29.3 & +3.94 & +2.47 & & 30.9 & +1.34 & +0.84 & & 26.4 & +0.08 & +0.05 & \\
\hline Sept. 1.3 & $\begin{array}{r}+4.15 \\
\end{array}$ & +2.61 & & 31.4 & +1.62 & +1.02 & & 26.6 & -0.82 & -0.51 & \\
\hline 4.3 & $\begin{array}{r}+3.79 \\
\end{array}$ & +2.38 & & Feb. $\quad 3.4$ & $\begin{array}{r}1.47 \\
\end{array}$ & $\begin{array}{r}+0.92 \\
\end{array}$ & & 27.4 & -0.14 & -0.09 & \\
\hline 7.3 & +4.01 & +2.52 & & 3.9 & +1.50 & +0.94 & & 27.6 & -0.07 & -0.04 & \\
\hline 8.3 & +4.21 & +2.64 & & 4.4 & $\begin{array}{r}1.39 \\
\end{array}$ & +0.87 & & 29.4 & -0.19 & -0.12 & \\
\hline 9.3 & $\begin{array}{r}3.86 \\
\end{array}$ & $\begin{array}{r}+2.42 \\
\end{array}$ & & 4.9 & $\begin{array}{r}1.71 \\
+1.7\end{array}$ & $\begin{array}{r}.07 \\
+1.07\end{array}$ & & June 1.4 & -0.19 & -0.12 & \\
\hline 9.8 & $\begin{array}{r}5.17 \\
\end{array}$ & +3.25 & & 9.3 & +0.84 & +0.53 & & 1.5 & -0.35 & -0.22 & \\
\hline 10.3 & +3.34 & +2.10 & & 12.9 & +0.67 & $\begin{array}{l}+0.42 \\
\end{array}$ & & 2.4 & +0.06 & +0.04 & \\
\hline 23.3 & +5.04 & +3.17 & & 13.3 & +0.50 & +0.31 & & 2.6 & -0.43 & -0.27 & \\
\hline 23.8 & +5.67 & +3.56 & & 13.9 & +1.00 & +0.63 & & 9.5 & -0.70 & -0.44 & \\
\hline 24.2 & +4.96 & +3.11 . & & 14.3 & +0.46 & +0.29 & & 10.5 & -0.55 & -0.35 & \\
\hline 25.2 & +5.33 & +3.35 & & 16.3 & +0.92 & +0.58 & & 12.4 & -0.62 & -0.39 & \\
\hline Oct. $\quad 5.8$ & $\begin{array}{r}+5.57 \\
\end{array}$ & $\begin{array}{r}3.50 \\
\end{array}$ & & 17.3 & +0.92 & +0.58 & & 12.5 & -0.72 & -0.45 & \\
\hline 6.2 & +5.28 & +3.32 & & 19.3 & +1.02 & +0.64 & & 14.4 & -0.39 & -0.24 & \\
\hline 2 & +5.77 & +3.62 & & 23.3 & +0.69 & +0.43 & & 14.5 & -1.36 & -0.85 & \\
\hline 8.2 & +5.37 & $\begin{array}{r}+3.37 \\
\end{array}$ & & 24.3 & $\begin{array}{l}+0.61 \\
\end{array}$ & $\begin{array}{l}+0.38 \\
\end{array}$ & & 18.3 & -0.89 & -0.56 & \\
\hline 8.8 & +5.60 & +3.52 & & 26.8 & +0.94 & +0.59 & & 18.5 & -0.27 & -0.17 & \\
\hline 9.2 & +4.57 & +2.87 & & 27.8 & +1.30 & +0.82 & & 21.3 & +0.19 & +0.12 & \\
\hline 15.2 & $\begin{array}{r}+5.71 \\
+5\end{array}$ & $\begin{array}{r}+3.59 \\
\end{array}$ & & 28.3 & +0.75 & +0.47 & & 21.5 & +0.60 & +0.38 & \\
\hline 15.7 & +5.90 & +3.71 & & Mar. 3.3 & +0.10 & +0.06 & & July 23.4 & -0.89 & -0.56 & \\
\hline 16.2 & $\begin{array}{r}5.77 \\
\end{array}$ & $\begin{array}{r}+3.62 \\
\end{array}$ & & 7.3 & -0.14 & -0.09 & & 24.4 & -0.37 & -0.23 & \\
\hline 18.7 & +5.80 & +3.64 & & 10.3 & -1.61 & -1.01 & & 29.4 & +0.12 & +0.08 & \\
\hline 19.2 & +5.54 & +3.48 & & 10.8 & -1.12 & -0.70 & & 30.4 & -0.09 & -0.06 & \\
\hline 20.2 & $\begin{array}{l}+6.14 \\
\end{array}$ & $\begin{array}{r}3.86 \\
\end{array}$ & & 12.3 & -2.33 & -1.46 & & 31.4 & -0.31 & -0.19 & \\
\hline 21.2 & +5.78 & $\begin{array}{r}+3.63 \\
\end{array}$ & & 12.8 & -1.92 & -1.21 & & Aug. $\quad 2.4$ & +0.09 & +0.06 & \\
\hline 21.7 & +6.20 & $\begin{array}{r}+3.89 \\
\end{array}$ & & 14.3 & -2.20 & -1.38 & & 6.4 & -0.37 & -0.23 & \\
\hline 24.2 & +5.36 & $\begin{array}{l}3.37 \\
\end{array}$ & & 20.2 & -2.94 & -1.85 & & 7.4 & +0.11 & +0.07 & \\
\hline 24.7 & +5.67 & +3.56 & & 21.8 & -2.70 & -1.70 & & - 11.4 & -0.33 & -0.21 & \\
\hline 25.7 & +5.31 & $\begin{array}{l}+3.33 \\
\end{array}$ & & 25.2 & -1.71 & -1.07 & & 12.4 & -0.48 & -0.30 & \\
\hline 26.2 & +5.29 & +3.32 & & 26.2 & -0.71 & -0.45 & & 13.4 & -0.62 & -0.39 & \\
\hline 26.7 & +6.15 & +3.86 & & 26.7 & -0.51 & -0.32 & & 16.4 & -0.54 & -0.34 & \\
\hline 27.2 & $\begin{array}{r}5.45 \\
+5.4\end{array}$ & $\begin{array}{r}.32 \\
+3.42 \\
\end{array}$ & & 28.2 & -0.85 & -0.53 & & 16.9 & $\begin{array}{l}+0.24 \\
\end{array}$ & $\begin{array}{l}0.15 \\
+0.1\end{array}$ & \\
\hline 29.7 & $\begin{array}{r}5.44 \\
+5.4\end{array}$ & $\begin{array}{r}+3.42 \\
\end{array}$ & & 28.7 & -1.02 & -0.64 & & 18.4 & -0.42 & -0.26 & \\
\hline Nov. 13.3 & +6.32 & +3.97 & & 31.2 & -0.67 & -0.42 & & 22.4 & -0.66 & -0.41 & \\
\hline 14.1 & +5.90 & +3.71 & & 31.7 & -1.04 & -0.65 & & 24.3 & -0.92 & -0.58 & \\
\hline 14.3 & $\begin{array}{r}6.14 \\
+6 .\end{array}$ & $\begin{array}{r}3.86 \\
\end{array}$ & & Apr. $\quad 1.2$ & -0.66 & -0.41 & & 26.3 & -0.22 & -0.14 & \\
\hline 16.1 & $\begin{array}{r}+5.00 \\
\end{array}$ & $\begin{array}{r}.3 .14 \\
\end{array}$ & & $\begin{array}{ll}1.7 \\
\end{array}$ & -1.10 & -0.69 & & 27.3 & -0.19 & -0.12 & \\
\hline 16.3 & $\begin{array}{r}+4.73 \\
\end{array}$ & $\begin{array}{r}+2.97 \\
\end{array}$ & & 3.2 & -0.65 & -0.41 & & 27.8 & +0.21 & +0.13 & \\
\hline 22.3 & $\begin{array}{r}7.15 \\
+5.15\end{array}$ & $\begin{array}{r}+3.23 \\
\end{array}$ & & 6.7 & -0.67 & -0.42 & & 28.3 & -0.67 & -0.42 & \\
\hline 23.1 & +4.87 & $\begin{array}{l}+3.06 \\
\end{array}$ & & 9.7 & -0.96 & -0.60 & & 31.3 & -0.53 & -0.33 & \\
\hline 24.1 & +4.80 & +3.01 & & 13.5 & -1.44 & -0.90 & & Sept. 1.3 & +0.02 & +0.01 & \\
\hline 25.1 & $\begin{array}{r}5.05 \\
+5.0\end{array}$ & $\begin{array}{r} \\
+3.17 \\
\end{array}$ & & 15.5 & -1.20 & -0.75 & & 2.3 & -0.49 & -0.31 & \\
\hline 25.3 & $\begin{array}{r}+4.65 \\
\end{array}$ & +2.92 & & 17.5 & -1.84 & -1.16 & & 3.3 & -0.05 & -0.03 & \\
\hline Dec. 7.1 & +4.30 & +2.70 & & 17.7 & -1.45 & -0.91 & & 4.3 & -0.42 & -0.26 & \\
\hline 9.1 & +3.81 & +2.39 & & 18.5 & -1.05 & -0.66 & & 4.8 & +0.17 & +0.11 & \\
\hline
\end{tabular}


TABLE VII.-The Azimuth of the Instrument and the Mark-Continued

\begin{tabular}{|c|c|c|c|c|c|c|c|c|c|c|c|}
\hline Date & $\lambda$ & $a$ & $A$ & Date & $\lambda$ & $a$ & $A$ & Date & $\lambda$ & $a$ & $A$ \\
\hline 1897 & & & & 1898 & & & & 1900 & & & \\
\hline $\begin{array}{ll}\text { Sept. } & 6.8 \\
8.3\end{array}$ & $\begin{array}{l}+0.01 \\
-0.44\end{array}$ & $\begin{array}{r}+0.01 \\
-0.28\end{array}$ & & Feb. $\begin{array}{r}24.8 \\
25.8\end{array}$ & $\begin{array}{l}-0.42 \\
-0.64\end{array}$ & $\begin{array}{l}-0.26 \\
-0.40\end{array}$ & & Aug. $\begin{array}{r}8.4 \\
17.4\end{array}$ & $\begin{array}{l}-0.58 \\
-0.69\end{array}$ & $\begin{array}{l}-0.36 \\
-0.43\end{array}$ & \\
\hline $\begin{array}{l}0.0 \\
9.8\end{array}$ & $\begin{array}{l}-0.44 \\
-0.23\end{array}$ & $\begin{array}{l}-0.28 \\
-0.14\end{array}$ & & $\begin{array}{l}20.0 \\
26.3\end{array}$ & $\begin{array}{l}-0.04 \\
-0.76\end{array}$ & $\begin{array}{l}-0.40 \\
-0.48\end{array}$ & & Sept. 2.3 & $\begin{array}{l}-0.09 \\
-1.24\end{array}$ & $\begin{array}{l}-0.43 \\
-0.78\end{array}$ & \\
\hline 10.3 & -1.55 & -0.97 & & 26.8 & -0.48 & -0.30 & & 3.4 & -0.56 & -0.35 & \\
\hline 10.8 & $\begin{array}{l}-0.67 \\
-0.6\end{array}$ & -0.42 & & 27.8 & $\begin{array}{l}-0.48 \\
-0.39\end{array}$ & -0.24 & & $\begin{array}{l}.0 .4 \\
4.3\end{array}$ & -1.18 & -0.74 & \\
\hline 13.3 & -0.80 & -0.50 & & 28.8 & $\begin{array}{l}-0.74 \\
-0.78\end{array}$ & $\begin{array}{l}-0.46 \\
-0 .\end{array}$ & & 12.3 & -0.90 & -0.57 & \\
\hline 14.8 & -0.06 & -0.04 & & Mar. 1.2 & -0.57 & -0.36 & & 16.4 & -0.45 & -0.28 & \\
\hline 15.8 & -0.22 & -0.14 & & 13.8 & -0.38 & -0.24 & & 17.3 & -0.73 & -0.46 & \\
\hline 16.3 & -0.37 & $\begin{array}{ll}-0.23 \\
-1\end{array}$ & & 14.2 & -0.73 & -0.46 & & 18.4 & -0.75 & -0.47 & \\
\hline $\begin{array}{r}17.8 \\
3\end{array}$ & +0.35 & +0.22 & & 14.8 & -0.43 & -0.27 & & 24.2 & +0.55 & +0.35 & \\
\hline Oct. $\quad 3.2$ & $\begin{array}{l}+0.17 \\
+0.38\end{array}$ & 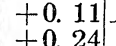 & & $\begin{array}{c}17.8 \\
10 ?\end{array}$ & -0.44 & $\begin{array}{l}-0.28 \\
-0 .\end{array}$ & & $\begin{array}{r}27.2 \\
9.2\end{array}$ & $\begin{array}{l}+0.81 \\
+0.70\end{array}$ & $\begin{array}{l}+0.51 \\
+0.044\end{array}$ & \\
\hline $\begin{array}{l}3.1 \\
4.2\end{array}$ & $\begin{array}{r}+0.58 \\
+0.11\end{array}$ & $\begin{array}{l}+0.24 \\
+0.07\end{array}$ & & $\begin{array}{l}19.2 \\
25.8\end{array}$ & $\begin{array}{r}-1.12 \\
+0.04\end{array}$ & $\begin{array}{l}-0.70 \\
+0.03\end{array}$ & & Oct. $\quad \begin{array}{l}9.2 \\
9.2\end{array}$ & $\begin{array}{l}+0.70 \\
+0.81\end{array}$ & $\begin{array}{r}+0.44 \\
+0.51\end{array}$ & \\
\hline $\begin{array}{l}4.2 \\
5.2\end{array}$ & $\begin{array}{l}+0.11 \\
-0.27\end{array}$ & -0.17 & & $\begin{array}{l}25.8 \\
31.7\end{array}$ & $\begin{array}{r}+0.04 \\
+0.29\end{array}$ & $\begin{array}{l}+0.05 \\
+0.18\end{array}$ & & 11.2 & $\begin{array}{l}+0.81 \\
-0.22\end{array}$ & $\begin{array}{r}+0.01 \\
-0.14\end{array}$ & \\
\hline 6.2 & -0.09 & -0.06 & & Apr. $\quad 2.7$ & +0.21 & +0.13 & & 19.2 & -0.19 & -0.12 & \\
\hline 8.2 & -0.01 & -0.01 & & 3.1 & $\begin{array}{r}1.2 \\
+0.82 \\
\end{array}$ & +0.51 & & 21.2 & +0.63 & +0.42 & \\
\hline 8.8 & +0.27 & +0.17 & & $\begin{array}{l}0.1 \\
3.7 \\
\end{array}$ & $\begin{array}{r}+.02 \\
+1.06\end{array}$ & $\begin{array}{l}0.67 \\
+0 .\end{array}$ & & 27.2 & $\begin{array}{r}0.14 \\
+0.0\end{array}$ & $\begin{array}{r}7.09 \\
+0.0\end{array}$ & \\
\hline 15.7 & $\begin{array}{l}+0.01 \\
\end{array}$ & $\begin{array}{l}0.01 \\
+0\end{array}$ & & 7.7 & -1.18 & -0.74 & & 30.2 & $\begin{array}{r}0.59 \\
+0.5\end{array}$ & $\begin{array}{l}+0.37 \\
\end{array}$ & \\
\hline 16.2 & -0.49 & -0.31 & & May 9.6 & -0.75 & -0.47 & & Nov. 21.1 & $\begin{array}{r}-0.52 \\
\end{array}$ & -0.33 & \\
\hline 17.2 & $\begin{array}{l}+0.02 \\
\end{array}$ & $+\begin{array}{lll}0 & 0 & 0\end{array}$ & & $\begin{array}{r}11.6 \\
\end{array}$ & -0.75 & -0.47 & & 23.1 & -0.71 & -0.45 & \\
\hline $\begin{array}{ll}18.2 \\
302\end{array}$ & $\begin{array}{ll}-0.02 \\
0.04\end{array}$ & $\begin{array}{l}-0.01 \\
-0.01\end{array}$ & & 12.6 & -0.61 & -0.38 & & $\begin{array}{r}30.3 \\
.\end{array}$ & +0.79 & +0.50 & \\
\hline $\begin{array}{r}30.2 \\
\text { Nov. } \\
2.2\end{array}$ & $\begin{array}{l}-0.44 \\
-0.77\end{array}$ & $\begin{array}{l}-0.28 \\
-0.48\end{array}$ & & & See Table & e Clock Corr & and & Dec. $\begin{array}{r}2.1 \\
27.0\end{array}$ & $\begin{array}{r}+0.81 \\
+0.43\end{array}$ & $\begin{array}{l}+0.51 \\
+0.27\end{array}$ & \\
\hline & -0.85 & -0.53 & & & see table & $\begin{array}{l}\text { Rates. } \\
\text { Rat }\end{array}$ & & & & & \\
\hline $\begin{array}{l}3.3 \\
4.1\end{array}$ & $\begin{array}{r}-1.08 \\
-0.95\end{array}$ & $\begin{array}{l}-0.68 \\
-0.60\end{array}$ & & $\begin{array}{l}1899 \\
\text { Aug. } 2.4\end{array}$ & -4.82 & -3.03 . & & 1901 & & & \\
\hline 6.1 & $\begin{array}{l}-0.90 \\
-0.45\end{array}$ & $\begin{array}{l}-0.28 \\
-0 .\end{array}$ & & & $\begin{array}{l}-3.73 \\
-3.73\end{array}$ & -2.34 & & Jan. 4.0 & +0.61 & +0.38 . & \\
\hline 6.3 & -0.92 & -0.58 & & & $\begin{array}{l}-3.59 \\
-3.36\end{array}$ & $\begin{array}{ll}-2.25 & 25 \\
-2 & 1\end{array}$ & & $\begin{array}{r}5.3 \\
6.0\end{array}$ & 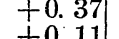 & $\begin{array}{l}0.23 \\
+0.07\end{array}$ & \\
\hline 9.3 & -0.18 & -0.11 & & $\begin{array}{l}7.4 \\
8.4\end{array}$ & $\begin{array}{l}-3.36 \\
-3.49\end{array}$ & 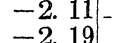 & & $\begin{array}{r}6.0 \\
12.9\end{array}$ & $\begin{array}{l}+0.111 \\
-0\end{array}$ & $\begin{array}{l}+0.07 \\
-0.03\end{array}$ & \\
\hline 10.3 & +0.10 & +0.06 & & $\begin{array}{r}8.4 \\
16.4\end{array}$ & $\begin{array}{l}-2.84 \\
-2.84\end{array}$ & -1.78 & & 15.9 & $\begin{array}{l}-0.04 \\
+0.25\end{array}$ & $\begin{array}{l}-0.03 \\
+0.16\end{array}$ & \\
\hline 11.3 & -0.52 & -0.33 & & 17.4 & -3.29 & -2.07 & & 18.9 & $\begin{array}{l}+0.25 \\
+0.37 \\
\end{array}$ & $\begin{array}{l}+0.16 \\
+0.23\end{array}$ & \\
\hline $\begin{array}{l}13.1 \\
181\end{array}$ & +0.21 & +0.13 & & 20.4 & -3.57 & -2.24 & & 25.9 & $\begin{array}{l}+0.27 \\
-0.27\end{array}$ & \pm 0.28 & \\
\hline $\begin{array}{l}18.1 \\
18.3\end{array}$ & -0.37 & \begin{tabular}{|c|c|c|}
-0.23 & 23
\end{tabular} & & 22.3 & -3.20 & -2.01 & & Feb. $\quad 5.9$ & $\begin{array}{l}-0.35 \\
-0.35\end{array}$ & $\begin{array}{l}-0.16 \\
-0.22\end{array}$ & \\
\hline $\begin{array}{l}18.3 \\
20.1\end{array}$ & $\begin{array}{l}-0.63 \\
-0.42\end{array}$ & $\mid \begin{array}{l}-0.40 \\
-0.26\end{array}$ & & 22.8 & -2.78 & -1.75 & & 6.9 & +0.31 & $\begin{array}{l}-0.22 \\
+0.19\end{array}$ & \\
\hline 20.3 & -0.32 & -0.20 & & 24.3 & -2.94 & -1.85 & & 11.9 & -0.11 & -0.07 & \\
\hline 21.1 & -0.29 & -0.18 & & 24.8 & -2.75 & -1.73 & & 27.8 & +0.03 & +0. & \\
\hline 24.1 & +0.13 & $\begin{array}{l}0.08 \\
\end{array}$ & & Sept. 27.2 & -2.81 & -1.76 & & Mar. 16.8 & +1.19 & $\begin{array}{r}.0 .75 \\
+0 .\end{array}$ & \\
\hline 24.3 & -0.17 & -0.11 & & 28.2 & -2.56 & -1.61 & & 18.8 & +0.6 & +0. & \\
\hline 27.1 & -0.90 & -0.57 & - & Oct. $\quad 3.2$ & -2.89 & -1.81 & & 28.7 & +1 & & \\
\hline 27.3 & -0.80 & -0.50 & & $\begin{array}{r}9.2 \\
102\end{array}$ & $\begin{array}{l}-3.26 \\
-0.82\end{array}$ & $\begin{array}{l}-2.05 \\
-1.77\end{array}$ & & Apr. $\quad 4.7$ & +1.18 & +0.74 & \\
\hline $\begin{array}{l}30.1 \\
30.2\end{array}$ & -0.22 & -0.14 & & 10.2 & $\begin{array}{l}-2.82 \\
-3.26\end{array}$ & $=-1.705$ & & $\begin{array}{r}9.7 \\
16.5\end{array}$ & $\begin{array}{r}+1.85 \\
+2 \\
+2\end{array}$ & +1.16 & \\
\hline $\begin{array}{r}30.3 \\
\text { Dec. } \quad 1.1\end{array}$ & -0.52 & $\mid \begin{array}{ll}-0.33 \\
-0.33\end{array}$ & & $\begin{array}{l}12.2 \\
13.2\end{array}$ & $\begin{array}{l}-3.20 \\
-2.16\end{array}$ & $\begin{array}{l}-2.00 \\
-1.36\end{array}$ & & $\begin{array}{l}16.5 \\
17.5\end{array}$ & $\begin{array}{r}+2.48 \\
+2.21\end{array}$ & $\begin{array}{r}+1.56 \\
+1.39\end{array}$ & \\
\hline $\begin{array}{ll}\text { Dec. } & 1.1 \\
1.3\end{array}$ & $\begin{array}{l}-0.45 \\
-0.45\end{array}$ & $\begin{array}{l}-0.28 \\
-0.28\end{array}$ & & 19.2 & -3.15 & -1.98 & & 26.3 & $\begin{array}{r}+2.21 \\
+2.19\end{array}$ & $\begin{array}{r}+1.39 \\
+1.38\end{array}$ & \\
\hline 6.1 & -1.16 & -0.73 & & & -2.94 & -1.85 & & 27.3 & +2.09 & +1.31 & \\
\hline 7.1 & -0.54 & -0.34 & & & $x_{0}$ & & & 29.5 & +1.92 & +1 & \\
\hline 7.3 & -0.71 & -0.45 & & & See $\mathrm{Tal}$ & $\begin{array}{l}\text { Clock } \mathrm{C} \\
\text { Rates. }\end{array}$ & & May 3.7 & $\begin{array}{r}+1.10 \\
\end{array}$ & & \\
\hline & . 57 & -0.36 & & 1900 & & -0 & & & & +1 & \\
\hline $\begin{array}{r}9.3 \\
11.1\end{array}$ & $\begin{array}{l}-0.75 \\
-0.70\end{array}$ & $\begin{array}{ll}-0.47 \\
-0.44\end{array}$ & & Mar. 21.8 & -3.82 & -2.40 & & $\begin{array}{l}14.6 \\
22.6\end{array}$ & $\begin{array}{r}+2.29 \\
+2.08\end{array}$ & $\begin{array}{r}+1.44 \\
+1.31\end{array}$ & \\
\hline $\begin{array}{l}1.1 \\
12.3\end{array}$ & $\begin{array}{l}-0.90 \\
-0.95\end{array}$ & $\begin{array}{l}-0.44 \\
-0.60\end{array}$ & & & -2.96 & ed in azi & & 23.6 & $\begin{array}{r}2.01 \\
\end{array}$ & $\begin{array}{r}1.26 \\
+1.26 \\
\end{array}$ & \\
\hline 15.3 & -0.89 & -0.56 & & 31.7 & -5.71 & & & $\begin{array}{l}28.6 \\
30.4\end{array}$ & +1.73 & $\begin{array}{l}+1.09 \\
\end{array}$ & \\
\hline 1898 & & & & Apr. 1.7 & $\begin{array}{l}-5.98 \\
\text { Adjuster }\end{array}$ & $\begin{array}{l}-3.7 \\
\text { ed in } 7 \text { i }\end{array}$ & & $\begin{array}{r}30.4 \\
\text { June }\end{array}$ & $\begin{array}{r}+2.20 \\
+1.53\end{array}$ & $\begin{array}{l}+1.38 \\
+0.96\end{array}$ & \\
\hline Jan. 16.9 & -0.76 & -0.48 & & 4.7 & -0.99 & -0.62 & & 8.5 & $\begin{array}{r}1.94 \\
\end{array}$ & +1.22 & \\
\hline 17.9 & -0.42 & -0.26 & & 7.7 & -1.20 & -0 . & & 9.5 & +2 & +1.61 & \\
\hline 22.9 & -1.50 & -0.94 & & 9.7 & -0.58 & -0 . & & 10.3 & $\begin{array}{r}+2.54 \\
\end{array}$ & +1.6 & \\
\hline 23.9 & -1.60 & -1.00 & & & -0.64 & -0 & & 23.5 & +2.84 & +1. & \\
\hline 26.9 & -1.27 & -0.80 & & June 11.4 & -0.77 & -0 . & & 24.5 & & +2. & \\
\hline Feb. $\quad 2.9$ & -1.66 & -1.04 & & & -1.55 & -0 & & 28.5 & +3 . & +2 & \\
\hline 3.3 & -1.37 & -0.86 & & 30.5 & -1.05 & -0 & & 30.5 & +3 & +2 & \\
\hline 3.9 & -1.50 & -0.94 & & July $\quad 2.5$ & -0.58 & -0.36 & & July 3.5 & +3.28 & +2 & \\
\hline 4.4 & & -0.86 & & 9.5 & -0.86 & -0.5 & & 9.4 & +4.22 & +2 & \\
\hline $\begin{array}{l}7.9 \\
8.9\end{array}$ & -0.26 & -0.16 & & 17.4 & -0.94 & -0.5 & & 10.5 & +3.55 & +2 & \\
\hline $\begin{array}{l}8.3 \\
9.3\end{array}$ & $\begin{array}{l}-2.61 \\
+2.84\end{array}$ & -1.64 & & 24.4 & -0.75 & -0 . & & 21.4 & +3.66 & & \\
\hline $\begin{array}{r}9.3 \\
10.3\end{array}$ & $\begin{array}{r}+2.84 \\
+1.96 \\
\end{array}$ & $\begin{array}{r}+1.78 \\
+1.23\end{array}$ & & $\begin{array}{r}27.4 \\
27.5\end{array}$ & $\begin{array}{l}-0.37 \\
-0.54\end{array}$ & -0. & & $\begin{array}{l}24.4 \\
28.4\end{array}$ & $\begin{array}{r}+3.53 \\
+4.18\end{array}$ & +2 & \\
\hline 000 & -1.01 & & & Aug. $\quad 1.4$ & -0.85 & -0.5 & & 29.4 & $\begin{array}{r}+4.02 \\
\end{array}$ & $\begin{array}{r}2.00 \\
+2.52\end{array}$ & \\
\hline
\end{tabular}


INTRODUCTION.

A LXXXviI

TABLE VII.-The Azimuth of the Instrument and the Mark-Continued

\begin{tabular}{|c|c|c|c|c|c|c|c|c|c|c|c|}
\hline Date & $\lambda$ & $a$ & $A$ & Date & $\lambda$ & $a$ & $A$ & Date & $\lambda$ & $a$ & $A$ \\
\hline 1901 & & $s$ & & 1902 & $\therefore-1$ & & & 1903 & & & \\
\hline Aug. 8.4 & $\begin{array}{c}+5.26 \mid \\
\text { Instrument }\end{array}$ & $\begin{array}{l}+3.30{ }_{-} \\
t \text { moved in a }\end{array}$ & & $\begin{array}{ll}\text { June } & \mathbf{1 . 6} \\
\mathbf{6 . 6}\end{array}$ & $\begin{array}{r}+0.55 \\
+1.07\end{array}$ & $\begin{array}{l}+0.35 \\
+0.67\end{array}$ & & $\begin{array}{ll}\text { May } & 7.6 \\
9.6\end{array}$ & $\begin{array}{l}+4.59 \\
+4.81\end{array}$ & $\begin{array}{r}+2.88 \\
+3.02\end{array}$ & \\
\hline 22.4 & $\begin{array}{l}+7.52 \mid \\
\end{array}$ & +4.72 & & $\begin{array}{r}0.0 \\
11.5\end{array}$ & $\begin{array}{l}+1.00 \\
+1.74\end{array}$ & $+\left.1.09\right|^{-}$ & & 11.6 & $\begin{array}{l}\text { T. } \\
+3.66\end{array}$ & $\begin{array}{l}+0.02 \\
+2.30\end{array}$ & \\
\hline 26.3 & Instrument & t moved in & & 17.5 & +1.17 & +0.73 & & 15.6 & +4.12 & +2.59 & \\
\hline 20.3 & $\begin{array}{l}10.00 \\
\text { Adjuste }\end{array}$ & ed in azim & & 21.5 & +1.20 & +0.75 & & 21.6 & +4.37 & +2.74 & \\
\hline Sept. 19.4 & +1.19 & +0.75 & & July $\quad 1.5$ & +1.02 & +0.64 & & 28.6 & +3.86 & +2.42 & \\
\hline $\begin{array}{l}20.4 \\
24.3\end{array}$ & +1.32 & +0.83 & & 2.5 & $\begin{array}{l}+1.15 \\
+1.35\end{array}$ & +0.72 & & $\begin{array}{ll}\text { June } & 2.6 \\
3.6\end{array}$ & $\begin{array}{r}+4.17 \\
+469\end{array}$ & $\begin{array}{r}+2.62 \\
+295\end{array}$ & \\
\hline $\begin{array}{r}24.3 \\
\text { Oct. } 3.3\end{array}$ & $\begin{array}{l}+0.34 \\
-0.42\end{array}$ & $\begin{array}{l}+0.21 \\
-0\end{array}$ & & $\begin{array}{l}12.5 \\
14.5\end{array}$ & $\begin{array}{l}+1.35 \\
+1.25\end{array}$ & $\begin{array}{r}+0.80 \\
+0.78\end{array}$ & & $\begin{array}{l}3.0 \\
8.6\end{array}$ & $\begin{array}{l}+4.09 \\
+4.48\end{array}$ & +2.81 & \\
\hline $\begin{array}{ll}\text { Uet. } & 3.0 \\
& 7.3 \\
& 82\end{array}$ & -0.21 & $\begin{array}{l}-0.13 \\
-0.13\end{array}$ & & 27.4 & +3.38 & +2.12 & & 10.6 & $\begin{array}{l}+4.78 \\
\end{array}$ & +3.00 & \\
\hline & -0.41 & -0.26 & & Aug. 4.4 & +2.75 & +1.73 & & 14.5 & +5.70 & +3.58 & \\
\hline $\begin{array}{l}21.2 \\
22.2\end{array}$ & +0.45 & +0.28 & & 21.3 & $\begin{array}{r}+2.70 \\
+2.74\end{array}$ & $\begin{array}{r}+1.70 \\
+1.72\end{array}$ & & $\begin{array}{l}18.5 \\
21.5\end{array}$ & $\begin{array}{l}+5.51 \\
+5.00\end{array}$ & $\begin{array}{r}+3.46 \\
+3.14\end{array}$ & \\
\hline $\begin{array}{l}22.2 \\
26.2\end{array}$ & $\begin{array}{r}+0.30 \\
-1.18\end{array}$ & $\begin{array}{l}+0.19 \\
-0.74\end{array}$ & & $\begin{array}{l}20.0 \\
30.3\end{array}$ & $\begin{array}{r}+2.94 \\
+2.98\end{array}$ & $\begin{array}{l}1.8 \\
+1.87\end{array}$ & & 30.5 & $\begin{array}{r}1.00 \\
+5.55\end{array}$ & $\begin{array}{r}0.14 \\
+3.49\end{array}$ & \\
\hline $\begin{array}{l}20.2 \\
27.2\end{array}$ & $\begin{array}{l}-1.18 \\
-0.89\end{array}$ & $\begin{array}{l}-0.84 \\
-0.56\end{array}$ & & Sept. 6.3 & +2.50 & +1.57 & & July $\quad 1.5$ & +5.41 & +3.40 & \\
\hline 28.2 & -0.66 & -0.41 & & 15.3 & +2.29 & +1.44 & & 6.5 & +4.91 & +3.08 & \\
\hline 29.2 & -1.20 & -0.75 & & 16.3 & +2.16 & +1.36 & & 7.5 & +5.36 & +3.37 & \\
\hline Nov. 3.2 & -1.12 & -0.70 & & 17.3 & $\begin{array}{r}+2.19 \\
+2.32\end{array}$ & $\begin{array}{l}+1.38 \\
+1.46\end{array}$ & & 8.5 & $\begin{array}{r}+5.64 \\
+5.58\end{array}$ & $\begin{array}{r}+3.54 \\
+3.32\end{array}$ & \\
\hline $\begin{array}{l}6.2 \\
7.2\end{array}$ & -0.91 & -0 & & $\begin{array}{l}22.3 \\
29.2\end{array}$ & $\begin{array}{r}+2.33 \\
+2.83\end{array}$ & $\begin{array}{r}+1.46 \\
+1.78\end{array}$ & & 9.5 & $\begin{array}{l}\text { +5. } \\
\text { Adjusted ir }\end{array}$ & $\begin{array}{l}+3.32 \\
\text { in azimuth }\end{array}$ & \\
\hline 10.1 & $\begin{array}{l}-0.83 \\
-1.19\end{array}$ & $\begin{array}{l}-0.52 \\
-0.75\end{array}$ & & Oct. $\quad 1.2$ & +3.43 & & & 15.5 & $\begin{array}{r}+0.21 \\
\end{array}$ & $|+0.13|$ & \\
\hline 11.1 & -1.16 & -0.73 & & 2.2 & +3.55 & +2.23 & & 18.5 & +0.71 & +0.45 & \\
\hline 14.3 & -1.10 & -0.69 & & 3.2 & +3.51 & +2.20 & & 23.4 & +1.21 & +0.76 & \\
\hline 26.3 & -1.49 & -0.94 & & 6.2 & $\begin{array}{r}+3.78 \\
+380\end{array}$ & $\begin{array}{r}+2.37 \\
+2.39\end{array}$ & & 25.4 & $\begin{array}{l}+2.02 \\
+106\end{array}$ & $\begin{array}{r}+1.27 \\
+1.23\end{array}$ & \\
\hline $\begin{array}{r}28.1 \\
\text { Dec. } \quad 2.1\end{array}$ & -1.34 & $\begin{array}{l}-0.84 \\
-0.72\end{array}$ & & $\begin{array}{r}9.2 \\
12.2\end{array}$ & $\begin{array}{l}+3.80 \\
+3.06\end{array}$ & $\begin{array}{l}+2.39 \\
+1.92\end{array}$ & & $\begin{array}{r}27.4 \\
\text { Aug. } 7.4\end{array}$ & $\begin{array}{r}+1.96 \\
+1.60\end{array}$ & $\begin{array}{l}+1.23 \\
+1.00\end{array}$ & \\
\hline Dec. $\quad \begin{array}{l}2.1 \\
4.1\end{array}$ & $\begin{array}{l}-1.15 \\
-1.47\end{array}$ & $\begin{array}{l}-0.72 \\
-0.92\end{array}$ & & 14.2 & $\begin{array}{r}2.60 \\
+2.6\end{array}$ & $\begin{array}{r}1.63 \\
\end{array}$ & & 9.4 & +2.66 & $|+1.67|$ & \\
\hline 5.1 & -2.11 & -1.33 & & 15.2 & +2.47 & +1.55 & & & Instrumer & at being re & paired. \\
\hline 6.1 & -1.77 & -1.11 & & 16.2 & +1.84 & +1.16 & & Dec. $\quad 6.1$ & & & \\
\hline 7.1 & -1.66 & -1.04 & & 21.2 & $\begin{array}{r}+1.95 \\
+146\end{array}$ & $\begin{array}{l}+1.22 \\
+0.92\end{array}$ & & $\begin{array}{r}7.1 \\
14.0\end{array}$ & $\begin{array}{l}-0.30 \\
-0.48\end{array}$ & $\begin{array}{l}-0.19 \\
-0.30\end{array}$ & \\
\hline 31.0 & -2.33 & --1.46 - & & $\begin{array}{l}29.2 \\
31.2\end{array}$ & $\begin{array}{l}+1.46 \\
+1.63\end{array}$ & $\begin{array}{l}+0.92 \\
+1.02\end{array}$ & & 17.0 & $\begin{array}{l}-0.48 \\
+0.31\end{array}$ & $\begin{array}{l}-0.00 \\
+0.19\end{array}$ & \\
\hline 1902 & & & & Nov. 28.1 & +1.78 & +1.12 & & 23.0 & -0.49 & -0.31 & \\
\hline Jan. 4.0 & -1.77 & -1.11 & & 29.1 & +1.63 & +1.02 & & 28.0 & -1.10 & -0.69 & \\
\hline 16.9 & -1.77 & -1.11 & & Dec. 1.1 & +1.55 & +0.97 & & 29.0 & -0.97 & -0.61 & \\
\hline 18.9 & -1.58 & -0.99 & & 27.0 & +0.51 & +0 & & 30.0 & -0.77 & -0.48 & \\
\hline $\begin{array}{l}19.9 \\
27.9\end{array}$ & $\begin{array}{l}-1.63 \\
-2.89\end{array}$ & $\begin{array}{l}-1.02 \\
-1.81\end{array}$ & & 28.0 & +0.35 & +0.22 & & 1904 & & & \\
\hline Feb. $\quad 2.9$ & -2.95 & -1.85 & & 1903 & & & & Jan. 26.9 & -0.74 & -0.46 & -0.62 \\
\hline 4.9 & -2.27 & -1.43 . & & Jan. $\quad 9.0$ & +0.52 & +0.33 & & Feb. 2.8 & -0.99 & -0.62 & -.92 \\
\hline 5.9 & -1.69 & -1.06 & & 12.0 & $\begin{array}{r}0.95 \\
\end{array}$ & +0.60 & & 3.8 & -0.45 & -0.28 & -.58 \\
\hline 7.9 & $\begin{array}{c}\text { Instrument } \\
-4.91\end{array}$ & $\begin{array}{l}t \\
\text { moved in } \\
-3.08 \mid\end{array}$ & & 13.0 & +0.33 & +0.21 & & 8.8 & -0.71 & -0.45 & -.53 \\
\hline 9.8 & $\begin{array}{l}-3.99 \\
-3.9\end{array}$ & $-\left.2.51\right|_{-} ^{-}$ & & 18.0 & +0.87 & +0.55 & & 10.8 & -0.08 & -0.05 & -.33 \\
\hline & Adjust & ted in azim & & Feb. $\quad 5.9$ & -0.84 & -0.53 & & 12.8 & $\begin{array}{l}-0.59 \\
-0.35\end{array}$ & $\begin{array}{l}-0.37 \\
-0.22\end{array}$ & $\begin{array}{l}53 \\
47\end{array}$ \\
\hline 12.8 & -2.91 & -1.83 & & $\begin{array}{r}9.9 \\
119\end{array}$ & +0.05 & $\begin{array}{l}+0.03 \\
-0.05\end{array}$ & & $\begin{array}{l}14.8 \\
15.8\end{array}$ & $\begin{array}{l}-0.30 \\
-0.74\end{array}$ & $\mid \begin{array}{l}-0.22 \\
-0.46\end{array}$ & $=.48$ \\
\hline $\begin{array}{l}13.8 \\
18.8\end{array}$ & $\begin{array}{l}-2.04 \\
-1 \\
\end{array}$ & -1.28 & & $\begin{array}{l}11.9 \\
12.9\end{array}$ & $\begin{array}{l}-0.08 \\
+0.03\end{array}$ & $\begin{array}{l}-0.05 \\
+0.02\end{array}$ & & 24.8 & -0.03 & -0.02 & -.61 \\
\hline $\begin{array}{l}18.8 \\
19.8\end{array}$ & 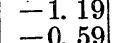 & $\begin{array}{l}-0.75 \\
-0.37\end{array}$ & & $\begin{array}{l}12.9 \\
17.9\end{array}$ & $\begin{array}{l}+0.00 \\
-0.21\end{array}$ & -0.13 & & Mar. 3.8 & -0.56 & -0.35 & -.61 \\
\hline $\begin{array}{l}19.8 \\
22.8\end{array}$ & $\begin{array}{r}-0.59 \\
+0.07\end{array}$ & $\begin{array}{l}-0.37 \\
+0.04\end{array}$ & & 22.9 & -0.46 & -0.29 & & 4.8 & -0.37 & -0.23 & -.38 \\
\hline Mar. 6.8 & $\begin{array}{l}+0.07 \\
+0.90\end{array}$ & $\begin{array}{l}+0.04 \\
+0.57\end{array}$ & & 23.9 & +0.21 & +0.13 & & 8.8 & -0.18 & -0.11 & -.64 \\
\hline 9.8 & $\begin{array}{r}0.77 \\
+0 .\end{array}$ & $\begin{array}{r}+.48 \\
+0 .\end{array}$ & & 24.9 & +0.62 & +0.39 & & 16.8 & +4.66 & +2.93 & $1-.64$ \\
\hline 10.8 & +0.47 & +0.30 & & 25.8 & +0.38 & +0.24 & & & & & uth. \\
\hline 20.7 & -0.06 & -0.04 & & Mar. 1.8 & +1.03 & +0.65 & & $\begin{aligned} 23.8 \\
8.8\end{aligned}$ & & $\begin{array}{l}-0.57 \\
-0.03\end{array}$ & $\begin{array}{r}+.90 \\
+1.21\end{array}$ \\
\hline 22.7 & -0.19 & -0.12 & & $\begin{array}{r}2.8 \\
13.8\end{array}$ & $\begin{array}{r}+2.57 \\
+2.40\end{array}$ & $\begin{array}{l}+1.61 \\
+1.51\end{array}$ & & Apr. $\begin{array}{l}0.0 \\
1.8\end{array}$ & $\begin{array}{l}-0.00 \\
-0.12\end{array}$ & -0.08 & +.64 \\
\hline $\begin{array}{l}23.7 \\
25.7\end{array}$ & $\begin{array}{r}-0.10 \\
+0.38\end{array}$ & $\begin{array}{r}-0.06 \\
+0.24\end{array}$ & & $\begin{array}{l}13.8 \\
17.8\end{array}$ & $\begin{array}{l}+2.40 \\
+3.04\end{array}$ & $\begin{array}{l}+1.51 \\
+1.91\end{array}$ & & 3.7 & +0.19 & +0.12 & +.87 \\
\hline 29.7 & $\begin{array}{r}+0.00 \\
-0.63\end{array}$ & -0.40 & & 24.8 & +1.76 & +1.11 & & 5.7 & -0.01 & -0.01 & +.82 \\
\hline Apr. 17.7 & +0.61 & +0.38 & & 25.8 & +2.36 & +1.48 & & $\begin{array}{l}14.7 \\
17.7\end{array}$ & $\begin{array}{r}+0.36 \\
-0.50\end{array}$ & $\begin{array}{l}+0.23 \\
-0.31\end{array}$ & $\begin{array}{l}+.96 \\
+\quad .50\end{array}$ \\
\hline 23.7 & -0.10 & -0.06 & & $\begin{array}{l}26 . \xi \\
27 . \xi\end{array}$ & $\begin{array}{r}+1.90 \\
+2.10\end{array}$ & $\begin{array}{l}+1.19 \\
+1.32 \\
\end{array}$ & & 19.7 & -0.50 & -0.31 & +.5 \\
\hline 27.7 & $\begin{array}{r}-0.37 \\
+0.68\end{array}$ & $\begin{array}{l}-0.23 \\
+0.43\end{array}$ & & $\begin{array}{l}20.8 \\
31.8\end{array}$ & $\begin{array}{l}+2.10 \\
+1.69\end{array}$ & $\begin{array}{l}1.06 \\
+1.0\end{array}$ & & 21.7 & -0.20 & -0.13 & +.6 \\
\hline 30.7 & $\begin{array}{r}0.00 \\
+0.10\end{array}$ & $\begin{array}{r}0.06 \\
\end{array}$ & & Apr. 4.8 & +2.32 & +1.46 & & May 1.6 & +0.08 & +0.05 & +1.0 \\
\hline May 1.7 & +0.34 & +0.21 & & $\begin{array}{l}10.7 \\
177\end{array}$ & +1.95 & +1.22 & & $\begin{array}{l}2.6 \\
4.6\end{array}$ & $\begin{array}{r}-0.18 \\
+0.09\end{array}$ & $\begin{array}{l}-0.11 \\
+0.06\end{array}$ & $\begin{array}{l}+.58 \\
+\quad .7\end{array}$ \\
\hline 4.6 & $\begin{array}{r}+0.55 \\
+075\end{array}$ & $\begin{array}{r}+0.35 \\
+0.47\end{array}$ & & $\begin{array}{l}17.7 \\
21.7\end{array}$ & $\begin{array}{r}+2.54 \\
+2.51\end{array}$ & $\begin{array}{r}+1.00 \\
+1.58\end{array}$ & & $\begin{array}{l}\mathbf{4 . 0} \\
5.6\end{array}$ & $\begin{array}{l}+0.15 \\
\end{array}$ & $\begin{array}{l}+0.09 \\
\end{array}$ & +.7 \\
\hline $\begin{array}{l}8.0 \\
8.6\end{array}$ & $\begin{array}{r}+0.10 \\
+0.13\end{array}$ & $\begin{array}{l}+0.41 \\
+0.08\end{array}$ & & 28.7 & +2.80 & +1.76 & & 11.6 & +0.16 & +0.1 & +.79 \\
\hline 9.6 & $\begin{array}{r}0.62 \\
\end{array}$ & $\begin{array}{r}+39 \\
\end{array}$ & & 29.7 & +2.41 & +1.51 & & 12.6 & +0.73 & +0.46 & +1.1 \\
\hline 15.6 & +1.13 & +0.71 & & May 1.7 & +3.62 & +2.27 & & 15.6 & -0.06 & -0.04 & $=+.6$ \\
\hline $\begin{array}{l}21.6 \\
29.6\end{array}$ & $\begin{array}{l}+0.75 \\
+0.55\end{array}$ & +0.47 & & $\begin{array}{r}4.7 \\
5.7\end{array}$ & $\begin{array}{l}+3.14 \\
+3.68\end{array}$ & $\begin{array}{l}+1.97 \\
+2.31\end{array}$ & & $\begin{array}{l}23.6 \\
24.6\end{array}$ & $\begin{array}{l}+0.17 \\
+0.01\end{array}$ & $\begin{array}{l}+0.11 \\
+0.01\end{array}$ & $\begin{array}{l}+.76 \\
+.74\end{array}$ \\
\hline & & & & & & & & & & & \\
\hline
\end{tabular}


TABLE VII.- The Azimuth of the Instrument and the Mark-Continued

\begin{tabular}{|c|c|c|c|c|c|c|c|c|c|c|c|}
\hline Date & $\lambda$ & $a$ & $A$ & Date & $\lambda$ & $a$ & $A$ & Date & $\lambda$ & $a$ & $A$ \\
\hline 1904 & & & & 1905 & & & & 1906 & & & \\
\hline May 25.6 & $\begin{array}{l}-0.01 \\
-0.039\end{array}$ & -0.01 & +0.68 & Apr. 2.7 & -1.34 & $\mid-0.84$ & $4-0.15$ & Sept. 11.3 & -3.08 & -1.93 & -1.34 \\
\hline June $\quad 3.6$ & $\begin{array}{l}-0.39 \\
+0.80\end{array}$ & -0.24 & & 9.7 & -0.87 & mation adju & justed 26 & 12.3 & $\begin{array}{l}-1.70 \\
-2.09\end{array}$ & $\begin{array}{r}-1.07 \\
-1\end{array}$ & $\begin{array}{r}55 \\
82\end{array}$ \\
\hline 8.6 & $\begin{array}{r}0.44 \\
+0.0\end{array}$ & +0.28 & +.88 & 13.7 & -0.68 & $|-0.43|$ & $3-.13$ & $\begin{array}{l}14.2 \\
18.3\end{array}$ & $\begin{array}{l}-2.09 \\
-1.77\end{array}$ & $\mid \begin{array}{l}-1.51 \\
-1.11\end{array}$ & $1=.82$ \\
\hline 13.5 & +0.86 & +0.54 & +.95 & 18.7 & -0.69 & -0.43 & $3-.06$ & 19.3 & -1.60 & -1.00 & -.62 \\
\hline 14.5 & +0.77 & +0.48 & +.88 & 27.7 & -1.10 & -0.69 & $9-.38$ & 21.3 & -1.78 & -1.12 & .67 \\
\hline 15.5 & +0.70 & +0.44 & +.88 & May 2.7 & -0.12 & -0.08 & $8+.27$ & 23 & -1.65 & -1.04 & \\
\hline 17.5 & +0.40 & +0.25 & +.71 & 8.7 & -1.15 & -0.72 & $2-.31$ & 24.3 & -2.13 & -1.34 & 99 \\
\hline 18.5 & $\begin{array}{r}0.63 \\
\end{array}$ & +0.40 & +.93 & 12.6 & +0.59 & +0.37 & $7+.77$ & Oct. 11.2 & -1.83 & -1.15 & .77 \\
\hline 22.5 & +0.57 & +0.36 & +.95 & 21.4 & -0.39 & -0.24 & $4+.11$ & 13.2 & -1.86 & -1.17 & 58 \\
\hline 23.0 & +0.56 & +0.35 & +.89 & 23.6 & -0.82 & -0.51 & $1-.24$ & 25.2 & -2.57 & -1.61 & .73 \\
\hline 24.5 & $\begin{array}{l}+0.58 \\
\end{array}$ & +0.36 & +1.05 & 27.6 & -0.97 & -0.61 & $1-.18$ & 26.2 & -2.88 & -1.81 & .82 \\
\hline 25.5 & +0.52 & $+0.33-$ & $\begin{array}{r}1.60 \\
+\quad .69\end{array}$ & June 3.6 & -0.61 & -0.38 & $8-.11$ & Nov. 1.2 & $\begin{array}{l}-3.19 \\
-3.19\end{array}$ & -2.00 & .. \\
\hline July $\quad 2.5$ & +0.73 & +0.46 & +.77 & Oct. 23.3 & -1.01 & -0.63 & & 2.2 & -3.10 & -1.95 & 5. \\
\hline 6.5 & +0.92 & +0.58 & +.83 & 30.2 & -1.44 & -0.90 & $0-.60$ & 4.2 & -3.42 & -2.15 & \\
\hline 11.5 & +0.80 & +0.50 & +.68 & Nov. 2.2 & -1.42 & -0.89 & $9-.60$ & 5.2 & -2.91 & -1.83 & - \\
\hline 13.5 & +0.83 & +0.52 & +.65 & $\begin{array}{r}4.2 \\
111\end{array}$ & $\begin{array}{l}-1.42 \\
-1.49\end{array}$ & $\begin{array}{r}-0.89 \\
-0.94\end{array}$ & $9-.59$ & 7.2 & -3.32 & -2.08 & 3 \\
\hline $\begin{array}{l}14.5 \\
17.5\end{array}$ & $\begin{array}{l}+1.05 \\
+0.88\end{array}$ & $\mid \begin{array}{l}+0.66 \\
+0.55\end{array}$ & +.71 & $\begin{array}{l}11.1 \\
14.1\end{array}$ & $\begin{array}{l}-1.49 \\
-1.51\end{array}$ & $\mid \begin{array}{l}-0.94 \\
-0.95\end{array}$ & $5-.52$ & 22.1 & $\begin{array}{r}\text { Adjuste } \\
-2.16\end{array}$ & ted in azimu & \\
\hline 20.4 & $\begin{array}{r}+0.00 \\
+0.72\end{array}$ & $\begin{array}{r}+0.05 \\
+0.45\end{array}$ & $\begin{array}{l}+.81 \\
+.51\end{array}$ & 17.1 & -1.33 & -0.84 & $4-.30$ & 22.1 & Object gla & lass adjusted & ed in cell. \\
\hline 26.4 & +1.16 & +0.73 & +.86 & 21.1 & -1.76 & -1.11 & -.60 & 24.1 & -0.87 & -0.55 & \\
\hline 27.4 & +1.02 & +0.64 & +.74 & 22.1 & -1.70 & -1.07 & $7-.49$ & 27.1 & -1.16 & -0.73 & -.06 \\
\hline Aug. $\quad 3.4$ & +0.48 & +0.30 & +.50 & 23.1 & -1.38 & -0.87 & -.31 & & & & \\
\hline $\begin{array}{r}6.4 \\
154\end{array}$ & $\begin{array}{r}+0.62 \\
+0.91\end{array}$ & $\begin{array}{l}+0.39 \\
+0.57\end{array}$ & $\begin{array}{l}+.60 \\
+\quad 67\end{array}$ & 1006 & & & & Jan. 5.0 & -1.96 & -1.23 & $-\quad 24$ \\
\hline $\begin{array}{l}15.4 \\
23.4\end{array}$ & $\begin{array}{l}+0.91 \\
+0.66\end{array}$ & $\begin{array}{r}+0.57 \\
+0.41\end{array}$ & $\begin{array}{l}+.67 \\
+.56\end{array}$ & $\begin{array}{c}1906 \\
\text { Jan. } \quad 5.9\end{array}$ & -2.90 & -1.82 & $2-.70$ & 7.0 & -1.09 & -0.68 & -.24 \\
\hline 25.4 & -0.05 & $-0.03+$ & $\begin{array}{r}+.50 \\
+.54\end{array}$ & & -2.58 & -1.62 & -.52 & 21.0 & -2.10 & -1.32 & +.21 \\
\hline 28.4 & +0.32 & +0.20 & $\begin{array}{r}+.59 \\
\end{array}$ & 9.9 & $\begin{array}{l}-2.45 \\
\end{array}$ & $\begin{array}{l}-1.02 \\
-1.54\end{array}$ & $4-.50$ & 22.0 & -2.02 & -1.27 & \\
\hline Sept. 7.3 & +0.07 & $+0.04+$ & +.50 & 18.9 & -2.74 & -1.72 & -.48 & 28.0 & -2.49 & -1.56 & -.09 \\
\hline 8.3 & +0.31 & +0.19 & +.54 & 28.9 & -3.20 & -2.01 & -.43 & Feb. 8.9 & -1.55 & $-0.97 \mid$ & +.20 \\
\hline 15.3 & +0.86 & +0.54 & +.72 & 29.9 & -3.11 & -1.95 & -.38 & 11.9 & -2.08 & $|-1.31|-$ & +.03 \\
\hline 16.3 & +1.19 & +0.75 & +.89 & Feb. 2.8 & -3.04 & -1.91 & -.41 & $\begin{array}{r}15.9 \\
\end{array}$ & -1.83 & -1.15 & +.04 \\
\hline 17.3 & +0.85 & +0.53 & +.57 & 9.8 & -2.68 & -1.68 & -.39 & Mar. 15.8 & -2.14 & -1.34 & +.14 \\
\hline 21.3 & +0.48 & $+0.30+$ & +.46 & 10.8 & -3.10 & $\begin{array}{l}1.00 \\
-1.95\end{array}$ & -.50 & 23.8 & -2.69 & -1.69 & -.30 \\
\hline 22.3 & +1.13 & $+0.71-$ & +.92 & 16.8 & -2.93 & -1.84 & -.36 & 29.8 & -1.54 & -0.97 & \\
\hline 23.3 & +0.18 & $+0.11+$ & +.32 & & & & & Apr. & -1.53 & -0.96 & .10 \\
\hline 23.3 & +0.79 & $+0.50+$ & +.71 & 19.8 & $-2.781-$ & -1.75 & $3-1.41$ & 2.7 & -1.83 & -1.15 & -.09 \\
\hline 29.2 & +0.57 & +0.36 & $\begin{array}{l}+.79 \\
+\quad 59\end{array}$ & Mar. 5.8 & $\begin{array}{r}\text { Collimi } \\
-3.89\end{array}$ & nation adjus & usted. 54 & $\begin{array}{l}21.7 \\
29.7\end{array}$ & -1.25 & -0.78 & +.22 \\
\hline Oct. $\begin{array}{r}29.2 \\
1.2\end{array}$ & +0.27 & +0.17 & $\begin{array}{l}+.59 \\
+\quad 51\end{array}$ & 17.8 & -3.66 & $\begin{array}{l}2.44 \\
-2.30\end{array}$ & -.25 & $\begin{array}{r}29.7 \\
\operatorname{May} 4.6\end{array}$ & $\begin{array}{l}-1.49 \\
-1.53\end{array}$ & $\begin{array}{l}-0.94 \\
-0.96\end{array}$ & $\begin{array}{r}+.23 \\
+\quad 12\end{array}$ \\
\hline $\begin{array}{ll}1.2 \\
\end{array}$ & $\begin{array}{l}+0.17 \\
+0.21\end{array}$ & $\begin{array}{l}+0.11 \\
+0.13\end{array}$ & $\begin{array}{r}+.51 \\
+\quad .59\end{array}$ & 20.8 & -4.10 & -2.57 & -.72 & $\begin{array}{l}9.6 \\
\end{array}$ & $\begin{array}{l}-1.82 \\
-1.8\end{array}$ & -1.14 & +.08 \\
\hline 42 & +0.12 & $+0.08+$ & & 22.8 & -3.51 & -2.20 & -.47 & 11.6 & -1.65 & -1.04 & +.07 \\
\hline 7.2 & $\begin{array}{r}+0.38 \\
\end{array}$ & +0.24 & $\begin{array}{r}0.06 \\
+.66\end{array}$ & Apr. 1.8 & -4.18 & -2.63 & -.57 & 13.6 & -1.55 & -0.97 & .11 \\
\hline 142 & Object gla & ass adjusted & in cell. & $\begin{array}{l}12.7 \\
15.7\end{array}$ & $\begin{array}{l}-3.72 \\
-3.76\end{array}$ & -2.34 & -.49 & 20.6 & -1.43 & -0.90 & 11 \\
\hline & $\begin{array}{l}-0.26 \\
-2.94\end{array}$ & $\begin{array}{ll}-0 . & 16 \\
-1 & 85\end{array}$ & +.63 & 17.7 & $\begin{array}{l}-3.76 \\
-3.11\end{array}$ & $\begin{array}{l}-2.36 \\
-1.95\end{array}$ & {$\left[\begin{array}{l}-.56 \\
-.30\end{array}\right.$} & $\begin{array}{l}21.6 \\
27.6\end{array}$ & $\begin{array}{l}-1.23 \\
-1.77\end{array}$ & -0.77 & . 12 \\
\hline 27.2 & -1.52 & -0 & -.20 & 18.7 & -3.30 & -2.07 & -.45 & 28.6 & -1.38 & $\begin{array}{l}-1.11 \\
-0.87\end{array}$ & $\begin{array}{r}+.08 \\
+.22\end{array}$ \\
\hline & & & & 24.7 & -2.98 & -1.87 & -.56 & June 6.6 & -1.82 & -1.14 & \\
\hline & $\begin{array}{l}-0.58 \\
-0.54\end{array}$ & $|-0.36|+$ & +.27 & May 3.6 & -2.48 & -1.56 & -.38 & 8.6 & -1.67 & -1.05 & \\
\hline 7.1 & $\begin{array}{l}-0.46 \\
-0.52\end{array}$ & -0.29 & .26 & $\begin{array}{l}7.6 \\
96\end{array}$ & -2.53 & -1.59 & -.41 & 15.5 & -1.62 & $-1.02+$ & +.02 \\
\hline 15.1 & $\begin{array}{l}-0.52 \\
-0.39\end{array}$ & $\begin{array}{l}-0.33 \\
-0.24\end{array}$ & $\begin{array}{r}.21 \\
+.26\end{array}$ & $\begin{array}{r}9.6 \\
16.6\end{array}$ & $\begin{array}{l}-2.01 \\
-2 \\
-258\end{array}$ & -1.26 & -.56 & 16.5 & -1.72 & -1.08 & \\
\hline 16.1 & -0.61 & -0.38 & +.28 & 21.6 & $\begin{array}{l}-2.58 \\
-2.33\end{array}$ & $\begin{array}{l}-1.62 \\
-1.46\end{array}$ & $\begin{array}{r}-36 \\
-\quad .24\end{array}$ & $\begin{array}{l}17.5 \\
21.5\end{array}$ & -1.79 & -1.12 & 07 \\
\hline 17.1 & -0.31 & $-0.19+$ & +.47 & 22.6 & -2.54 & $\left.\begin{array}{l}-1.40 \\
-1.60\end{array}\right]$ & $\begin{array}{r}.24 \\
-.39\end{array}$ & $\begin{array}{l}21.5 \\
26.5\end{array}$ & $\begin{array}{l}-1.74 \\
-1 \\
-1\end{array} 4$ & $\begin{array}{l}-1.09 \\
-0\end{array}$ & .09 \\
\hline 19.1 & 0.58 & $-0.36+$ & +.26 & 23.6 & -2.62 & -1.65 & -.50 & July 3.5 & $\begin{array}{l}-1.44 \\
-0.81\end{array}$ & $\begin{array}{l}-0.90 \\
-0.51\end{array}$ & $\begin{array}{l}+.04 \\
+\quad 05\end{array}$ \\
\hline & & & +.24 & June 3.6 & -2.71 & -1.70 & -.51 & 4.5 & -0.89 & -0.56 & .00 \\
\hline $\begin{array}{r}28.1 \\
\text { Dec. } 23.0\end{array}$ & $\begin{array}{l}-0.49 \\
-0.89\end{array}$ & $-0.31+$ & +.49 & 4.6 & -2.56 & -1.61 & -.30 & 8.5 & -1.22 & -0.77 & \\
\hline Dec. & -0.89 & $-0.56+$ & +.48 & 11.5 & -2.42 & -1.52 & -.32 & 12.5 & -0.58 & -0.36 & \\
\hline 1905 & & & & 25.5 & $\begin{array}{l}-2.06 \\
-2.02\end{array}$ & $\begin{array}{l}-1.29 \\
-1.27\end{array}$ & $=32$ & $\begin{array}{l}14.5 \\
16.5\end{array}$ & $\begin{array}{l}-0.65 \\
-0.70\end{array}$ & $\begin{array}{l}-0.41 \\
-0.44\end{array}$ & \begin{tabular}{|r}
+.02 \\
$+\quad .06$
\end{tabular} \\
\hline 9.0 & -1.60 & -1.01 & & 28.5 & -2.01 & -1.26 & 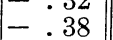 & & -1.08 & -0.68 & +.04 \\
\hline Feb. & -1.50 & $-0.94+$ & +.62 & 29.5 & -3.27 & -2.05 & -.94 & 21.4 & -0.90 & -0.57 & + \\
\hline 6.9 & -1.02 & $-0.64+$ & 47 & July $\quad 5.5$ & -2.06 & -1.29 & -.4 & 23.4 & -1.04 & -0.65 & -.03 \\
\hline $\begin{array}{r}9.9 \\
\end{array}$ & -1.61 & $-1.01+$ & .05 & 7.5 & -1.72 & -1.08 & -.2 & & -1.03 & -0.65 & -.05 \\
\hline [ar. 10.8 & -2.65 & -1.66 & -.21 & 12.5 & -1.76 & & -.4 & 27.4 & -0.49 & $-0.31+$ & +.21 \\
\hline 12.8 & -2.56 & -1.61 & & 13.5 & -1.69 & -1.06 & -.47 & 30.4 & -0.6 & -0.40 & 10 \\
\hline $\begin{array}{r}\text { ar. } 13.8 \\
15.8\end{array}$ & $\begin{array}{l}-2.24 \\
-2 \\
-2\end{array}$ & $-1.41+$ & 13 & 19.5 & -2.44 & -1.53 & -.77 & 31.4 & -0.53 & -0.33 & 17 \\
\hline $\begin{array}{l}10.8 \\
25.8\end{array}$ & $\begin{array}{l}-2.13 \\
-1\end{array}$ & $-1.34+$ & F. 04 & $\begin{array}{r}24.4 \\
\end{array}$ & -1.00 & -0.63 & +.02 & Aug. 4.4 & -0.78 & $-0.49+$ & 07 \\
\hline & -1.82 & -1.14 & -.02 & $\begin{array}{l}8.3 \\
9.3\end{array}$ & $\begin{array}{l}-1.86 \\
-1.84\end{array}$ & $\begin{array}{l}-1.17 \\
-1.16\end{array}$ & {$\left[\begin{array}{r}-.68 \\
-.66\end{array}\right.$} & $\begin{array}{r}6.4 \\
15.4\end{array}$ & $\begin{array}{l}-0.91 \\
-0.84\end{array}$ & $\begin{array}{l}-0.57 \\
-0.53\end{array}$ & $\begin{array}{l} \pm .05 \\
-.01\end{array}$ \\
\hline
\end{tabular}


TABLE VII.-The Azimuth of the Instrument and the Mark-Continued

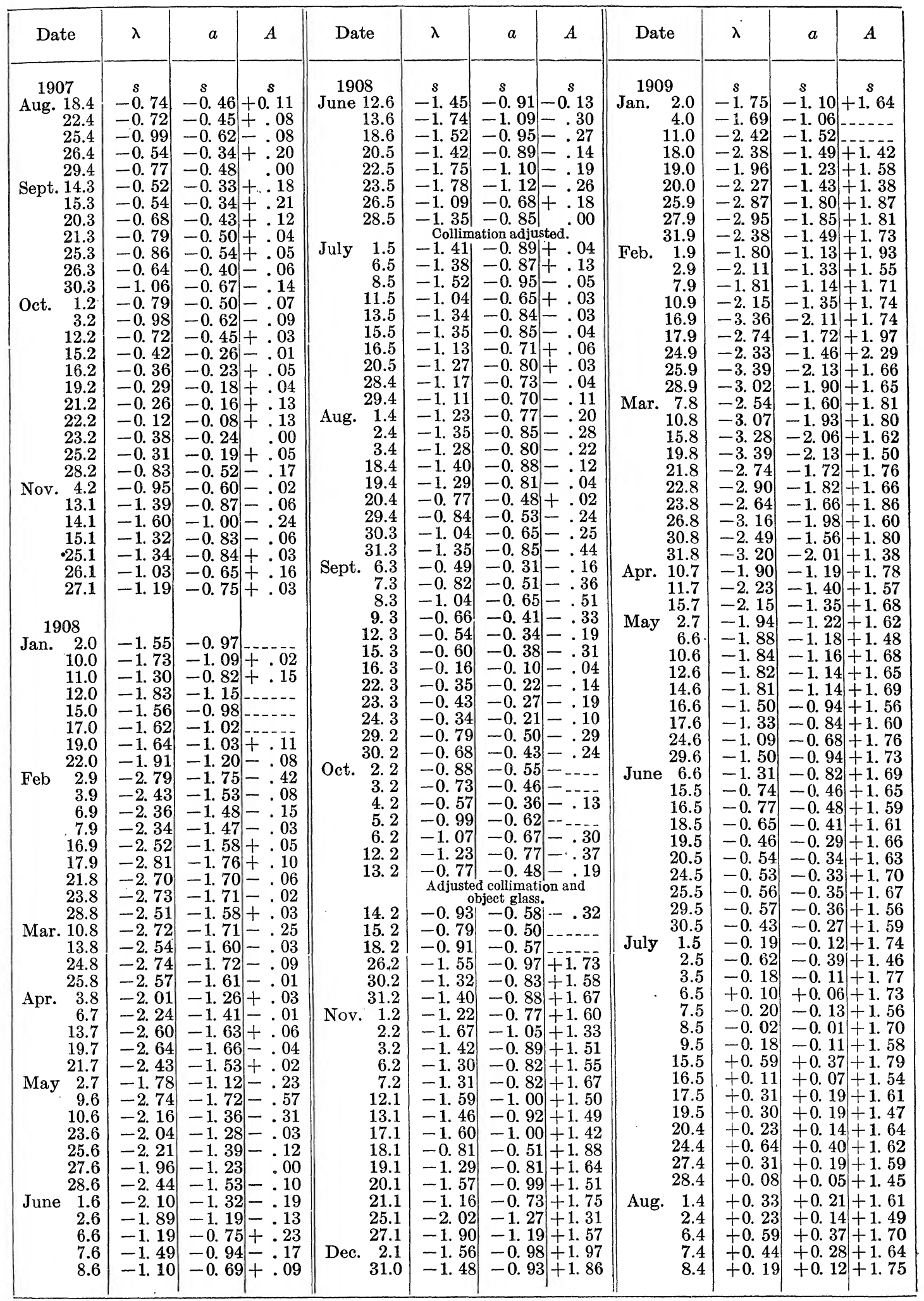


TABLE VII.-The Azimuth of the Irstrument and the Mark-Continued

\begin{tabular}{|c|c|c|c|c|c|c|c|c|c|c|c|}
\hline Date & $\lambda$ & $a$ & $A$ & Date & $\lambda$ & $a$ & $A$ & Date & $\lambda$ & $a$ & $A$ \\
\hline 1909 & & & & 1910 & & & & 1911 & & $s$ & \\
\hline Aug. $\begin{array}{l}10.4 \\
11.4\end{array}$ & $\begin{array}{r}+0.08 \\
+0.17\end{array}$ & $\begin{array}{r}+0.05 \\
+0.11\end{array}$ & $\begin{array}{r}+1.72 \\
+1.68\end{array}$ & Apr. $\begin{array}{l}28.7 \\
30.7\end{array}$ & $\begin{array}{l}-4.02 \\
-4.35\end{array}$ & $\begin{array}{l}-2.52 \\
-2.73\end{array}$ & $\begin{array}{l}+1.34 \\
+1.42\end{array}$ & Feb. $\quad 2.9$ & $\begin{array}{r}-3.45 \\
\text { Move }\end{array}$ & $\begin{array}{r}-2.17 \\
\text { ed telesco }\end{array}$ & $1+2.34$ \\
\hline 19.4 & $\begin{array}{l}\text { T. } \\
+0.28\end{array}$ & $\begin{array}{l}1.11 \\
+0.18\end{array}$ & $\begin{array}{r}1.00 \\
+1.79\end{array}$ & May 4.6 & -4.00 & -2.51 & $\begin{array}{r}1.36 \\
+1.36\end{array}$ & 9.9 & -1.63 & $\begin{array}{c}\text { ed telesco } \\
-1.02\end{array}$ & $1+2$ \\
\hline 21.4 & -0.05 & -0.03 & +1.61 & 6.6 & -3.84 & -2.41 & +1.38 & 20.8 & -2.12 & -1.33 & \\
\hline 22.4 & +0.11 & +0.07 & +1.62 & 15.6 & -3.36 & -2.11 & +1.44 & Mar. 4.8 & -1.18 & -0.74 & +2 \\
\hline 23.4 & +0.19 & +0.12 & +1.67 & June 7.6 & -4.15 & -2.61 & +1.80 & 6.8 & -1.40 & -0.88 & +2. \\
\hline 24.4 & +0.19 & +0.12 & $\begin{array}{r}1.69 \\
\end{array}$ & & -3.91 & -2.46 & +1.93 & 8.8 & -1.85 & -1.16 & \\
\hline 26.4 & +0.36 & +0.23 & +1.67 & 19.5 & -4.42 & -2.78 & +1.72 & 10.8 & -1.95 & -1.22 & +2.09 \\
\hline 27.4 & +0.42 & +0.26 & & 21.5 & -4.11 & -2.58 & +1.78 & 16.8 & -1.94 & -1.22 & $\begin{array}{r}2.31 \\
\end{array}$ \\
\hline 29.3 & +0.33 & +0.21 & +1.68 & 22.5 & -4.33 & -2.72 & +1.70 & 20.8 & -2.57 & -1.61 & +2.06 \\
\hline 30.3 & +0.69 & +0.43 & +1.72 & 24.5 & -3.64 & -2.29 & +1.93 & 21.8 & -2.67 & -1.68 & +2.01 \\
\hline Sept. 1.3 & +0.34 & +0.21 & +1.53 & 26.5 & -3.30 & -2.07 & +1.78 & 23.8 & -2.48 & -1.56 & +1.76 \\
\hline 7.3 & +0.57 & +0.36 & +1.66 & 29.5 & -3.28 & -2.06 & +1.79 & 28.8 & -2.83 & -1.78 & +1.47 \\
\hline 8.3 & $\begin{array}{l}1.75 \\
+0.75\end{array}$ & $\begin{array}{r}0.40 \\
+0.47\end{array}$ & $\begin{array}{r}1.00 \\
+1.77\end{array}$ & July $\quad 9.5$ & -3.27 & -2.05 & $\begin{array}{r}1.73 \\
\end{array}$ & 31.8 & -3.00 & -1.88 & $\begin{array}{r}1.97 \\
+1.97\end{array}$ \\
\hline 11.3 & +0.32 & +0.20 & +1.63 & 14.5 & -2.86 & -1.80 & +1.77 & Apr. $\quad 9.7$ & -3.93 & -2.47 & +1.90 \\
\hline 13.3 & +0.52 & +0.33 & +1.69 & 19.5 & -2.37 & -1.49 & +1.92 & 10.7 & -3.45 & -2.17 & +2.23 \\
\hline 14.3 & +0.61 & +0.38 & $\begin{array}{r}1.79 \\
\end{array}$ & 20.5 & -2.56 & -1.61 & $\begin{array}{r}1.82 \\
+1.8\end{array}$ & 25.7 & -3.85 & -2.42 & +2.02 \\
\hline 28.3 & +0.78 & +0.49 & +1.56 & 21.5 & -2.53 & -1.59 & +1.83 & 26.7 & -3.81 & -2.39 & +2.01 \\
\hline 29.3 & +0.44 & +0 & +1.32 & 22.5 & -2.39 & -1.50 & +2.00 & May 2.7 & -3.72 & -2.34 & +2.03 \\
\hline Oct. 1.3 & +0.71 & +0 & +1.55 & 24.5 & -2.92 & -1.83 & +1.87 & 5.7 & -3.03 & -1.90 & +2.33 \\
\hline 2.2 & +0.59 & +0 & +1.38 & 31.4 & -2.67 & -1.68 & +1.93 & 10.6 & -3.20 & -2.01 & +2 \\
\hline 5.2 & +0.28 & +0.18 & +1.44 & Aug. 4.4 & -3.20 & -2.01 & $\begin{array}{r}+1.69 \\
\end{array}$ & 20.6 & -3.26 & -2.05 & +2.31 \\
\hline 7.2 & +0.81 & +0.51 & +1.49 & 5.4 & -2.47 & -1.55 & +2. & 22.6 & -3.26 & -2.05 & +2.13 \\
\hline 12.2 & +0.55 & +0.35 & +1.53 & 9.4 & -2.82 & -1.77 & +1.78 & 24.6 & -3.04 & -1.91 & +1.98 \\
\hline 13.2 & $\begin{array}{r}0.62 \\
+0.62\end{array}$ & $\begin{array}{r}0.39 \\
+0 .\end{array}$ & $\begin{array}{r}1.00 \\
+1.47\end{array}$ & 16.4 & -2.67 & -1.68 & $\begin{array}{r}1.80 \\
+1.80\end{array}$ & 25.6 & -2.53 & -1.59 & $\begin{array}{r}2.23 \\
+2.23\end{array}$ \\
\hline 22.2 & +0.47 & +0.30 & +1.51 & 18.4 & -2.67 & -1.68 & +1.77 & 29.6 & -2.51 & -1.5 & +2.1 \\
\hline 25.2 & +0.43 & +0 & +1.44 & 19.4 & -2.40 & -1.51 & +1.96 & June 8.6 & -2.01 & -1.26 & +2.28 \\
\hline 28.2 & +0.34 & +0.21 & +1.41 & 20.4 & -2.45 & -1.54 & +1.90 & 9.6 & -2.39 & -1.50 & +2.17 \\
\hline 31.2 & +0.26 & +0.16 & +1.32 & 22.4 & -2.61 & -1.64 & +1.85 & 11.6 & -2.63 & -1.65 & +2.31 \\
\hline Nov. 1.2 & +0.29 & +0.18 & +1.50 & 24.4 & -2.61 & -1.64 & +1.93 & 18.5 & -2.39 & -1.50 & +2.25 \\
\hline 4.2 & +0.04 & +0.03 & +1.50 & 30.4 & -2.48 & -1.56 & +1.85 & 21.5 & -2.80 & -1.76 & +2.26 \\
\hline 5.2 & +0.29 & +0.18 & +1.50 & Sept. 4.3 & -2.60 & -1.63 & +1.85 & 28.5 & -3.08 & -1.9 & +2.23 \\
\hline 8.2 & +0.26 & +0.16 & +1.44 & 7.3 & -2.40 & -1.51 & +2.05 & 29.5 & -3.02 & -1.9 & +2.21 \\
\hline 12.1 & +0.06 & +0.04 & +1.43 & 10.3 & -2.50 & -1.57 & +1.84 & 30.5 & -2.63 & -1.65 & +2.42 \\
\hline 17.1 & +0.08 & +0.05 & & 12.3 & -2.53 & -1.59 & +1.81 & July $\quad 5.5$ & -3.48 & -2.1 & +2 \\
\hline 18.1 & -0.32 & -0.20 & & 16.3 & -2.30 & -1.44 & +1.95 & 6.5 & -3.52 & -2 & +2.23 \\
\hline 22.1 & -1.21 & -0.76 & & 17.3 & -2.07 & -1.30 & +2.1 & 9.5 & -3.29 & -2.07 & +2.2 \\
\hline 26.1 & -1.23 & & +1.22 & 22.3 & -2.55 & -1.60 & +1.92 & 10.5 & -3.46 & -2.17 & 2 \\
\hline Dec. 2.1 & -0.32 & -0.20 & & 26.3 & -3.20 & -2.01 & +1.74 & 12.5 & -3.39 & -2.13 & +2.16 \\
\hline 3.1 & +0.24 & -0.15 & +1.58 & 27.3 & -2.87 & -1.80 & +2. & 16.5 & -2.41 & -1.51 & +2.59 \\
\hline 4.1 & -0.66 & -0.41 & +1.31 & Oct. $\quad 9.2$ & -2.74 & -1.72 & +1.90 & 22.4 & -2.33 & -1.46 & +2.24 \\
\hline 9.1 & -0.92 & -0.58 & +1.58 & 10.2 & -2.31 & -1.45 & +1. & 25.4 & -2.72 & -1.7 & +1 \\
\hline 10.1 & -0.67 & -0.42 & +1.88 & 12.2 & -2.18 & -1. & +1 & 30. & -2.07 & -1 & +2 \\
\hline 17.0 & -1.67 & -1.05 & +1.36 & 13.2 & -2.22 & -1.39 & +2.01 & 31.4 & -3.59 & -2.25 & +1.58 \\
\hline 18.0 & -1.94 & -1.22 & +1.24 & 15.2 & -2.79 & -1.75 & +1. & Aug. $\quad 6.4$ & -2.82 & -1. & +2 \\
\hline 21.0 & -1.82 & -1.14 & +1.57 & 17.2 & -2.80 & -1.76 & +1.8 & 7.4 & -2.65 & -1.6 & +2 \\
\hline 30.0 & -1.06 & -0.67 & +1.52 & 18.2 & -2.51 & -1.58 & +1.90 & 10.4 & -2.87 & -1.8 & +2 \\
\hline 31.0 & -1.04 & -0.65 & & 24.2 & -2.26 & -1.42 & +1.95 & 16.4 & -3.04 & -1.91 & +1.91 \\
\hline 1910 & & & & $\begin{array}{l}26.2 \\
29.2\end{array}$ & $\begin{array}{l}-2.25 \\
-2.93\end{array}$ & -1.41 & & & Move & $d$ in & \\
\hline Jan. 8.0 & -2.25 & -1.41 & +1.58 & 31.2 & -2.93 & $\begin{array}{l}-1.84 \\
-1.84\end{array}$ & $\begin{array}{l}1.84 \\
+1.73\end{array}$ & $\begin{array}{l}18.4 \\
20.4\end{array}$ & $\begin{array}{l}-0.16 \\
-4.63\end{array}$ & $-\begin{array}{r}3.21 \\
-2.91\end{array}$ & $\begin{array}{l}+2.04 \\
+2.13\end{array}$ \\
\hline 10.0 & -2.57 & -1.61 & +1.45 & Nov. 7.2 & -2.84 & -1.78 & $\begin{array}{r}1.80 \\
+1.80\end{array}$ & & Adjust & ed in azin & \\
\hline 15.0 & -2.11 & -1.33 & +1.59 & 9.1 & -3.16 & -1.98 & +1.73 & 21.4 & & & \\
\hline 25.0 & -2.16 & -1.36 & +1.74 & 18.1 & -2.14 & -1.34 & +2.23 & Sept. 1.3 & -0.97 & -0.61 & +2.03 \\
\hline 31.9 & -2.22 & -1.39 & +1.62 & 26.1 & -2.94 & -1.85 & +2 & 4.3 & -1.03 & -0 & \\
\hline Feb. $\quad 3.9$ & -1.95 & -1.22 & +1.73 & Dec. 3.1 & -2.33 & -1.46 & +2.05 & 7.3 & -1.39 & -0.87 & +2.15 \\
\hline 4.9 & -2.07 & -1.30 & +1.64 & 12.1 & -2.24 & -1.41 & +2 & 11.3 & -1.27 & -0 & \\
\hline 9.9 & -2.10 & -1.32 & +1.57 & 13.1 & -1.81 & -1.14 & +2.30 & 16.3 & -1.35 & -0 & \\
\hline 13.9 & -2.21 & -1.39 & +1.64 & 16.0 & -2.06 & -1.29 & +2.16 & 23.3 & -1.23 & -0.77 & +2.1 \\
\hline 18.9 & -2.06 & -1.29 & +1.80 & 17.0 & -1.95 & -1.22 & +2 & 24.3 & -1.50 & -0 & \\
\hline 220 & & -1.65 & +1.61 & 21.0 & -1.98 & -1.24 & +2.21 & Oct. & -0.74 & -0.46 & +2.04 \\
\hline & -2.48 & -1.56 & +1.62 & & & & & 11.2 & -1.04 & -0.65 & +1.88 \\
\hline & New micr & ometer $\mathrm{Mg}$ & & 1911 & & & & 12.2 & -1.03 & -0.65 & +1.86 \\
\hline Mar. 6.8 & -3.43 & -2. & +1.47 & Jan. $\quad 4.0$ & -2.98 & -1.87 & +2.20 & 13.2 & -0.71 & -0.45 & +2.04 \\
\hline Apr. $\quad 5.7$ & -3.15 & -1.98 & +1.51 & 5.0 & -3.40 & -2.14 & & 16.2 & -0.61 & -0.38 & +1.97 \\
\hline $\begin{array}{ll}\text { Apr. } & 5.7 \\
9\end{array}$ & -3.65 & -2.29 & +1.44 & 7.0 & -3.51 & -2.20 & +1.90 & 18.2 & -1.04 & -0.65 & +1.99 \\
\hline 10.7 & $\begin{array}{l}-3.06 \\
-3\end{array}$ & -1.92 & & 22.9 & -3.10 & -1.95 & +2. & 23.2 & -1.20 & -0.75 & +1.77 \\
\hline 12.7 & $\begin{array}{l}-3.53 \\
-2.53\end{array}$ & $\begin{array}{l}-2.09 \\
-1.59\end{array}$ & $\begin{array}{r}+1.40 \\
+181\end{array}$ & $\begin{array}{l}23.9 \\
24.9\end{array}$ & $\begin{array}{l}-5.05 \\
-4.62\end{array}$ & $\begin{array}{l}-3.17 \\
-2\end{array}$ & +2 & 24.2 & $\begin{array}{l}-0.87 \\
-0.93\end{array}$ & -0.55 & . 59 \\
\hline 13.7 & -3.44 & -2.16 & $\begin{array}{r}+1.47 \\
\end{array}$ & 27.9 & $\begin{array}{l}-4.02 \\
-4.90\end{array}$ & $\begin{array}{l}-2.90 \\
-3.08\end{array}$ & $\begin{array}{r}1.90 \\
+2.17\end{array}$ & 29.2 & -0.62 & $\begin{array}{l}-0.58 \\
-0.39\end{array}$ & $\begin{array}{r}+1.56 \\
+1.71\end{array}$ \\
\hline 20.6 & -4.37 & -2.74 & $\ldots$ & 29.9 & -4.86 & -3.05 & +2.20 & Nov. 3.2 & -0.11 & -0.07 & +1.71 \\
\hline
\end{tabular}


INTRODUCTION.

TABLE VII.-The Azimuth of the Instrument and the Mark-Continued

\begin{tabular}{|c|c|c|c|c|c|c|c|c|c|c|c|}
\hline Date & $\lambda$ & $a$ & $A$ & Date & $\lambda$ & $a$ & $A$ & Date & $\dot{\lambda}$ & $a$ & $A$ \\
\hline 1911 & & $s$ & & 1912 & & $s$ & & 1912 & & & \\
\hline Nov. 7.2 & -0.61 & -0.38 & +2.08 & Apr. $\quad 6.7$ & -1.30 & -0.82 & +1.78 & Aug. 23.4 & -0.33 & -0.21 & +2.03 \\
\hline 10.1 & -0.40 & -0.25 & +1.92 & 27.7 & -1.12 & -0.70 & +2.12 & 24.4 & -0.39 & -0.24 & \\
\hline 11.1 & -0.55 & -0.35 & +1.88 & May 1.7 & -0.66 & -0.41 & +2.20 & 27.4 & -0.07 & -0.04 & +2.20 \\
\hline 15.1 & -0.49 & -0.31 & +1.92 & 3.6 & -0.55 & -0.35 & +2.21 & 28.4 & +0.85 & +0.53 & \\
\hline 16.1 & -0.11 & -0.07 & +2.14 & 10.6 & -0.91 & -0.57 & +2.28 & Sept. 5.3 & +0.04 & +0.03 & +2.12 \\
\hline 18.1 & -0.72 & -0.45 & +2.04 & 13.6 & -1.09 & -0.68 & +2.07 & & +0.40 & +0.25 & +2.37 \\
\hline 25.1 & -0.60 & -0.38 & +1.83 & 17.6 & -0.78 & -0.49 & +2.36 & 10.3 & +0.08 & +0.05 & +2.17 \\
\hline Dec. 1.1 & -0.15 & -0.09 & +2.06 & 18.6 & -0.93 & -0.58 & +2.30 & 12.3 & +0.45 & +0.28 & +2.37 \\
\hline & -0.39 & -0.24 & +1.97 & 20.6 & -1.44 & -0.90 & +2.02 & Oct. & +0.40 & +0.25 & $\cdots$ \\
\hline $\begin{array}{l}5.1 \\
6.1\end{array}$ & $\begin{array}{l}-0.56 \\
-0.33\end{array}$ & $\begin{array}{l}-0.35 \\
-0.21\end{array}$ & $\begin{array}{r}+1.75 \\
+2.04\end{array}$ & June $\begin{array}{r}24.6 \\
1.6\end{array}$ & $\begin{array}{l}-1.36 \\
-0.86\end{array}$ & $\begin{array}{l}-0.85 \\
-0.54\end{array}$ & $\begin{array}{l}+2.13 \\
+212\end{array}$ & $\begin{array}{r}9.2 \\
10.2\end{array}$ & $\begin{array}{l}+0.27 \\
+0.09\end{array}$ & $\begin{array}{l}+0.17 \\
+0.06\end{array}$ & $\begin{array}{l}+2.06 \\
+1.61\end{array}$ \\
\hline 7.1 & -0.55 & $\begin{array}{l}0.35 \\
-0.35\end{array}$ & $\begin{array}{r}1.04 \\
+1.95\end{array}$ & 8.6 & -0.02 & -0.01 & $\begin{array}{r}+2.20 \\
+2\end{array}$ & 12.2 & -0.09 & -0.06 & \\
\hline 8.1 & -0.56 & -0.35 & +1.92 & 9.6 & -0.02 & -0.01 & +2.29 & 15.2 & -0.08 & --0.05 & +1.83 \\
\hline 19.0 & -0.12 & -0.08 & +1.99 & 10.6 & +0.31 & +0.19 & $\begin{array}{r}+2.36 \\
\end{array}$ & 16.2 & -0.19 & -0.12 & +2.10 \\
\hline & & & & 12.6 & -0.58 & -0.36 & +2.06 & 20.2 & -0.77 & -0.48 & +1.80 \\
\hline 1912 & & & & 20.5 & -0.70 & -0.44 & +2.19 & 21.2 & -0.38 & -0.24 & +1.98 \\
\hline Jan. $\quad 7.0$ & -0.51 & -0.32 & +1.70 & July & -0.23 & -0.14 & +2.41 & 26.2 & -0.18 & -0.11 & +1.96 \\
\hline 10.0 & -0.26 & -0.16 & +1.88 & & -0.53 & -0.33 & +2.25 & & -0.54 & -0.34 & $=1.70$ \\
\hline 21.0 & -0.43 & -0.27 & +2.17 & 6.5 & -0.29 & -0.18 & +2.40 & Nov. 3.2 & +0.10 & +0.06 & +2.11 \\
\hline 23.0 & -0.72 & -0.45 & +2.0 & 7.5 & -0.55 & -0.35 & +2.23 & 8.2 & -0.77 & -0 . & +2.13 \\
\hline 24.9 & -0.32 & -0.20 & +2.0 & 8.5 & -0.68 & -0.43 & +2.17 & 11. & -0.53 & -0.33 & +2.10 \\
\hline 30.9 & -0.53 & -0.33 & +2.06 & 13.5 & -0.77 & -0.48 & +2.19 & 16.1 & -0.10 & -0.06 & +2.07 \\
\hline Feb. 4.9 & -0.16 & -0.10 & +2.06 & 22.5 & -0.25 & -0.16 & +2.18 & 21.1 & +0.32 & +0.20 & +2.24 \\
\hline 6.9 & -0.11 & -0.07 & +2.10 & 26.4 & 0.00 & 0.00 & +2.08 & 22.1 & -0.05 & -0.03 & +2.12 \\
\hline 16.9 & +0.32 & +0.20 & +2.32 & Aug. 1.4 & +0.40 & +0.25 & +2. & 27.1 & +0.33 & +0.21 & +2.06 \\
\hline 22.9 & -0.24 & -0.15 & +2.45 & 3.4 & +0.83 & +0.52 & +2.36 & 29.1 & +0.82 & +0.51 & +2.10 \\
\hline 27.8 & +0.10 & +0.06 & +2.32 & 5.4 & +0.85 & +0.53 & +2.28 & 30.1 & +0.07 & +0.04 & +2.02 \\
\hline Mar. 9.8 & -0.58 & -0.36 & +2.07 & 10.4 & +0.31 & +0.19 & +2.32 & Dec. 10.0 & -0.34 & -0.21 & +2.02 \\
\hline 10.8 & -0.42 & -0.26 & +2.10 & 11.4 & -0.53 & -0.33 & +2.11 & 12.0 & -0.59 & -0.37 & +1.89 \\
\hline $\begin{array}{l}16.8 \\
25.8\end{array}$ & $\begin{array}{l}-1.23 \\
-0.52\end{array}$ & -0.77 & +2.19 & $\begin{array}{l}12.4 \\
22.4\end{array}$ & -0.59 & -0.37 & +2.12 & 14.0 & 0.00 & 0.00 & +1.78 \\
\hline 25.8 & & & & 22.4 & & -0.41 & & & & & \\
\hline
\end{tabular}

Observations secured through readings of the mark were commenced on January 26, 1904, and the azimuths of the mark on and after that date are included in the above table, being designated by $A$.

To compute it we will assume the following:

$A=$ the azimuth of the mark, positive when south of east.

$a=$ azimuth of the rotation axis of the instrument, positive when east of north.

$c=$ collimation constant of the middle thread, positive when the thread is north of the collimation axis.

$R_{1}=$ micrometer distance of mark, clamp north.

$R_{2}=$ micrometer distance of mark, clamp south.

$R_{0}=$ micrometer reading on middle thread.

$M=$ value of one revolution of micrometer screw.

Then,

$$
\begin{aligned}
& A=a+\frac{\left(R_{1}-R_{0}\right) M+b \cos \zeta+c}{\sin \zeta} \text { clamp north. } \\
& A=a+\frac{\left(R_{0}-R_{2}\right) M+b \cos \zeta-c}{\sin \zeta} \text { clamp south. }
\end{aligned}
$$

Whence

$$
\begin{aligned}
& A=a+\frac{1 / 2\left(R_{1}-R_{2}\right) M+b \cos \zeta}{\sin \zeta} \\
& c=R_{0} M-1 / 2\left(R_{1}+R_{2}\right) M
\end{aligned}
$$


The zenith distance of the azimuth mark is $94^{\circ} 24^{\prime}$, therefore, $A=a+.501\left(R_{1}-R_{2}\right) M-0.077 b$.

The following table indicates the corrections which are necessary to take account of the level term in the above equation. As these quantities are small and do not in any way affect the declinations they have not been included in values of $A$.

As the instrument has been kept, as a rule, in such adjustment that the correction for level did not exceed $\pm 1.5^{\prime \prime}$ there are but few instances in which this additional term would be as large as $0^{\mathrm{s}} .01$. Moreover, this refinement is beyond what might be expected in obtaining azimuths from stars whose zenith distances are as small as those observed with the instrument.

\begin{tabular}{|c|c|}
\hline$b^{\prime \prime}$ & $b . \cot \zeta$ \\
\hline$\prime \prime$ & \\
0.50 & 0.003 \\
1.00 & 5 \\
1.50 & 8 \\
2.00 & 10 \\
2.50 & 13 \\
3.00 & 15 \\
3.50 & 18 \\
4.00 & 20 \\
\hline
\end{tabular}

The following table will assist in the conversion of values of $\lambda$ into those of $a$. The table extends from 0.1 to 5.0 seconds of time. The values of $a$ have been computed by the formula

$$
a=\lambda \sin \varphi
$$

in which $\varphi$ is the latitude of the instrument, $\lambda$ is expressed in time, and also $a$. The algebraic sign of $\lambda$ is established by the fact that when the observed sidereal time of a star passing the meridian of the instrument is less than its ephemeris right. ascension, the signs of both $\lambda$ and $a$ are minus.

TABLE FOR AZIMUTH DETERMINATIONS

\begin{tabular}{|c|c|c|c|c|c|c|c|}
\hline$\lambda$ & $a$ & $\lambda$ & $a$ & $\lambda$ & $a$ & $\lambda$ & $a$ \\
\hline$s$ & $s$ & & & & & \\
0.1 & 0.06 & 1.4 & 0.88 & 2.7 & 1.70 & 4.0 & 2.51 \\
.2 & .12 & 1.5 & .94 & 2.8 & 1.76 & 4.1 & 2.57 \\
.3 & .19 & 1.6 & 1.00 & 2.9 & 1.82 & 4.2 & 2.64 \\
.4 & .25 & 1.7 & 1.07 & 3.0 & 1.88 & 4.3 & 2.70 \\
.5 & .31 & 1.8 & 1.13 & 3.1 & 1.95 & 4.4 & 2.76 \\
.6 & .38 & 1.9 & 1.19 & 3.2 & 2.01 & 4.5 & 2.83 \\
.7 & .44 & 2.0 & 1.26 & 3.3 & 2.07 & 4.6 & 2.89 \\
.9 & .50 & 2.1 & 1.32 & 3.4 & 2.14 & 4.7 & 2.95 \\
1.0 & .57 & 2.2 & 1.38 & 3.5 & 2.20 & 4.8 & 3.01 \\
1.1 & .63 & 2.3 & 1.44 & 3.6 & 2.26 & 4.9 & 3.08 \\
1.2 & .69 & 2.4 & 1.51 & 3.7 & 2.32 & 5.0 & 3.14 \\
1.3 & .75 & 2.5 & 1.57 & 3.8 & 2.39 & & \\
\hline
\end{tabular}


THE ASSUMED AND THE ADOPTED LATITUDE

In assuming a value of the latitude to be introduced into the trigonometric formulæ by which the declination of a star is derived from transits observed in the prime vertical, the observer is confronted with the condition that the latitude he has assumed can not be fundamentally derived through the medium of his own observations. He is therefore obliged to adopt a latitude that has been fundamentally determined by the proper instruments located in close proximity to his instrument, or to accept a latitude based upon some system of catalogue declinations of stars that he has observed. This means, in the final analysis that the declinations derived from the observations will be based upon the mean latitude which these catalogue declinations indicate.

The flexibility of the several methods which may be used in the reduction of an observation made of a star in the prime vertical permits the observer to express his results by the quantity $\varphi^{\prime}-\delta^{\prime}$, in which $\varphi^{\prime}$ is the assumed latitude and $\delta^{\prime}$ the declination obtained with that latitude. If $\varphi$ is known fundmentally, the value of $\delta$ based thereon can be obtained.

Moreover, on page A LxIx there was shown the manner in which a lack of horizontality of the axis of the instrument, at the time transits were obtained, was taken account of in the value of $\varphi^{\prime}$ used in equation G. Any level error which exists at the time transits are observed produces an erroneous value of $\delta^{\prime}$, which is corrected in accordance with the method previously explained.

The assumed value $\varphi^{\prime}$, differing from $\varphi$ by the amount of the level correction, causes a varying correction in the deduced value of $\delta^{\prime}$ which is equal to $b . \sin 2 \delta^{\prime}$ $\operatorname{cosec} 2 \varphi^{\prime}$.

This error decreases with decreasing declinations, which is just the reverse of the effect of the error caused by $d t$, as shown on page A Lxx.

At the time observations were begun with the prime vertical transit at the new Naval Observatory, a fundamental latitude had not been obtained with either of the two transit circles or with the vertical circle. The first approximate latitude at the new site was obtained from observations secured by Profs. J. R. Eastman and A. N. Skinner, United States Navy.

In the annual report of the Superintendent of the Naval Observatory for the year ending June 30, 1893, the following facts in connection therewith are mentioned:

In February, 1893, a portable transit instrument, equipped as a zenith telescope, was mounted on the pier of the transit circle at the old Observatory. Another transit of similar type was placed on the pier upon which the 6-inch transit circle is now mounted.

The observers determined the difference of latitude between the two instruments, using TALCOTT's method. The same pairs of stars were used at both places. From three nights' work at the new and four nights' work at the old Observatory they found that the pier of the 6-inch transit circle was north $1^{\prime} 35.88^{\prime \prime} \pm 0.023^{\prime \prime}$ of the pier at the old Observatory.

It being assumed that the latitude of the pier at.the old Observatory was $+38^{\circ} 53^{\prime} 38.80^{\prime \prime}$, the application of the above difference to it gives as the latitude of the pier of the 6-inch transit circle

$$
+38^{\circ} 55^{\prime} 14.68^{\prime \prime} \text {. }
$$


In Volume I, Second Series, Publications United States Naval Observatory, page VI, there is a table giving differences in latitude and longitude for all astronomical instruments that were in use at the Naval Observatory at that time with respect to the center of the clock house, which has been adopted as the reference point from which such differences are to be taken.

The pier of the 6-inch transit circle is north $0.07^{\prime \prime}$ of that reference point. The pier of the prime vertical transit is $0.52^{\prime \prime}$ north of the same reference point. Therefore the latitude of the pier of the prime vertical transit would be

$$
+38^{\circ} 55^{\prime} 15.13^{\prime \prime} \text {. }
$$

based on the value derived by Professors Eastman and Skinner.

All observations of a Lyræ for the entire series, as well as all observations secured of other stars prior to February 13, 1900, have been reduced with an assumed latitude

$$
+38^{\circ} 55^{\prime} 14.7^{\prime \prime}
$$

and they so appear in the pages of the journal of observations. After February 13, 1900, all stars observed, with the exception of a Lyræ, were reduced with an assumed latitude

$$
\text { . }+38^{\circ} 55^{\prime} 14.48^{\prime \prime} \text {. }
$$

In the period during which prime vertical observations were being accumulated a practically fundamental latitude was secured by the observers in charge of the 6-inch transit circle and the alt-azimuth, respectively. From the results secured on these two instruments there has been adopted for this work the following latitude for the center of the clock house:

$$
+38^{\circ} 55^{\prime} 14.09^{\prime \prime} \text {. }
$$

The prime vertical transit is situated $0.52^{\prime \prime}$ north of that reference point, and applying that quantity to the last-mentioned latitude gives as the provisional latitude of the instrument with which all declinations which appear in the individual results and the catalogue have been finally reduced, namely,

$$
+38^{\circ} 55^{\prime} 14.61^{\prime \prime} \text {. }
$$

THE LATITUDE OF THE INSTRUMENT BASED UPON NEWCOMB'S AND BOSS'S DECLINATIONS, RESPECTIVELY

In the list of stars which were observed for their declinations and collected in the catalogue printed on pages A 39-44, 25 of them will be found in Professor NEwCOMB's Fundamental Catalogue and 78 of them in the Preliminary General Catalogue prepared by Professor Boss. All of the 25 stars in the Newcomb Catalogue also appear in the Boss Catalogue.

By a method mentioned below, latitudes were derived by a comparison of the observed declinations of each of these stars with the catalogue positions. The purpose was to obtain a series of latitudes based upon the declinations systems of the two catalogues. However, it was discovered that those data would add further confirmation to the daylight effect, which will be discussed later. 
Let $\delta_{\mathrm{N}}$ and $\delta_{\mathrm{B}}$ represent the declination of any of these stars taken from the Newcomb or Boss Catalogues, respectively, and each reduced to the epoch of the observed declination with which it is to be compared.

Let $\delta^{\prime}$ equal the observed position of any of these stars, then approximately

$$
\begin{aligned}
& \delta_{\mathrm{N}}-\delta^{\prime}=d \varphi_{\mathrm{N}} \\
& \delta_{\mathrm{B}}-\delta^{\prime}=d \varphi_{\mathrm{B}}
\end{aligned}
$$

from which we may obtain a latitude of the instrument based upon either of the catalogue declinations.

However, the two expressions, namely, $d \varphi_{\mathrm{N}}$ and $d \varphi_{\mathrm{B}}$ are not quite rigorous, and they must be multiplied by a factor.

- By differentiating the equation

$$
\tan \varphi=\tan \delta \sec t
$$

we have

$$
d \varphi=d \delta \frac{\sin 2 \varphi}{\sin 2 \delta}
$$

If $\varphi^{\prime}$ represents the value of the latitude which has been used in solving for $\delta^{\prime}$, then

$$
\begin{aligned}
& \varphi_{\mathrm{N}}=\varphi^{\prime}+d \delta_{\mathrm{N}} \frac{\frac{\sin 2 \varphi}{\sin 2 \delta}}{\varphi_{\mathrm{B}}=\varphi^{\prime}+\mathrm{d} \delta_{\mathrm{B}} \frac{\sin 2 \varphi}{\sin 2 \delta}}
\end{aligned}
$$

In Table VIII are tabulated by successive dates the latitude of the instrument based upon declinations of the observed stars whose positions are given in each of those two catalogues. The column headed $N$ contains latitudes based upon the Newcomb declinations and that headed $B$ gives the latitudes derived from the Boss declinations. When a star was observed by reflection it is indicated by an asterisk*). Values of $\Delta \varphi$ (variation of latitude) which appear in the last column have not been applied to these observed latitudes.

\section{DAYLIGHT EFFECT UPON A DECLINATION OR LATITUDE}

The declinations of those stars which were observed in that part of the day when the sun was above the horizon all show a very interesting and somewhat involved phenomenon. It takes the form of a varying value of the observed declination of a star, depending upon what hour in the daylight the star was observed in the prime vertical. 
A XCVi PRIME Vertical transit instrument.

TABLE VIII.-The Latitude of the Instrument, Obtained by the Use of Newcomb and Boss Declinations

$+38^{\circ} 55^{\prime} 10^{\prime \prime}+$

* Indicates reflected observation.

\begin{tabular}{|c|c|c|c|c|c|c|c|c|c|c|c|c|}
\hline \multicolumn{2}{|c|}{ Date } & \multicolumn{2}{|r|}{ Star } & N. & B. & $\Delta \varphi$ & Date & & Star & N. & B. & $\Delta \varphi$ \\
\hline \multicolumn{2}{|c|}{1893} & & & "' & "' & '1 & 1893 & & & "I & $" \prime$ & $\prime \prime$ \\
\hline July & & $\alpha$ & Lyræ & 4. 20 & 3. 94 & -0.04 & Nov. 19 & $\mu$ & Andromedæ & 4. 99 & 4. 73 & -0.09 \\
\hline & & & Lyræ & 4.64 & 4. 38 & -.04 & 20 & a & Lyræ & 5. 55 & 5. 29 & -.08 \\
\hline & & & Lyræ & 4. 81 & 4. 55 & -.04 & 22 & c & Lyræ & 4. 95 & 4. 69 & -.08 \\
\hline & & $\alpha$ & Lyræ & 4.50 & 4. 24 & -.04 & 22 & $\mu$ & Andromedæ & 5. 24 & 4. 98 & -.08 \\
\hline Aug. & & $\alpha$ & Lyræ & 4. 98 & 4. 72 & -.08 & 24 & a & Lyræ & 5. 27 & 5. 01 & -.08 \\
\hline Sept. & & & Lyræ & 4. 82 & 4. 56 & -.08 & 24 & $\mu$ & Andromedæ & 4. 84 & 4. 58 & \\
\hline & & $\alpha$ & Lyræ & 4.91 & 4. 65 & -.09 & 25 & $a$ & Lyræ & 5. 42 & 5. 16 & -.08 \\
\hline & 6 & & Lyræ & 4. 37 & 4. 11 & -.09 & 25 & $\mu$ & Andromedæ & 4. 71 & 4. 45 & -.08 \\
\hline & 7 & & Lryæ & 4. 49 & 4. 23 & -.09 & 26 & a & Lyræ & 5. 35 & 5. 09 & \\
\hline & 8 & $\alpha$ & Lyræ & 4. 69 & 4. 43 & -.09 & 26 & $\mu$ & Andromedæ & 4. 04 & 3. 78 & -.08 \\
\hline & 6 & $\alpha$ & Lyræ & 4. 82 & 4. 56 & -.10 & 28 & $\mu$ & Andromedæ & 4. 88 & 4. 62 & -.08 \\
\hline & 7 & $\alpha$ & Lyræ & 5.05 & 4. 79 & -.10 & 29 & $a$ & Lyræ & 5. 06 & 4. 80 & -.08 \\
\hline & 9 & $\alpha$ & Lyræ & 4. 91 & 4. 65 & -.10 & 29 & $\mu$ & Andromedæ & 5. 23 & 4. 97 & -.08 \\
\hline & & $\alpha$ & Lyræ & 5. 06 & 4. 80 & -.10 & 30 & $a$ & Lyræ & 5. 04 & 4. 78 & -.08 \\
\hline & 2 & $\alpha$ & Lyræ & 4. 80 & 4. 54 & -.10 & 30 & $\mu$ & Andromedæ & 5. 24 & 4. 98 & -.08 \\
\hline & 7 & $\alpha$ & Lyræ & 5. 00 & 4. 74 & -.10 & Dec. 1 & $\mu$ & Andromedæ & 5. 16 & 4. 90 & -.08 \\
\hline & & & Cygni & 5. 21 & 4. 78 & -.10 & 2 & $a$ & Lyræ & 5. 26 & 5. 00 & -.08 \\
\hline & 8 & $\alpha$ & Lyræ & 4. 83 & 4.57 & -.10 & 4 & $a$ & Lyræ & 5. 13 & 4. 87 & -.08 \\
\hline & 8 & $\theta$ & Aurigæ & 5. 66 & 5. 44 & -.10 & 4 & $\mu$ & Andromedæ & 4. 86 & 4. 60 & -.08 \\
\hline & 9 & $\alpha$ & Lyræ & 4. 58 & 4. 32 & -.11 & 7 & $\mu$ & Andromedæ & 4. 94 & 4. 68 & -.07 \\
\hline & 9 & $\tau$ & Cygni & 5. 69 & 5. 27 & -.11 & 8 & $\alpha$ & Lyræ & 5. 24 & 4. 98 & -.07 \\
\hline & 9 & $\theta$ & Aurigæ & 5. 52 & 5. 30 & -.11 & 8 & $\mu$ & Andromedæ & 4. 67 & 4. 41 & -.07 \\
\hline & 0 & $\alpha$ & Lyræ & 4. 69 & 4. 43 & -.11 & 10 & $a$ & Lyræ & 4. 76 & 4.50 & -.07 \\
\hline Oct. & 1 & $\theta$ & Aurigæ & 5. 70 & 5. 48 & -.11 & 10 & $\mu$ & Andromedæ & 4. 97 & 4. 71 & -.07 \\
\hline & 2 & $\alpha$ & Lyræ & 5. 30 & 5. 04 & -.11 & 11 & $\mu$ & Andromedæ & 4. 99 & 4. 73 & -.07 \\
\hline & 2 & $\tau$ & Cygni & 5. 19 & 4. 76 & -.11 & 11 & $\rho$ & Persei & 4. 80 & 4.77 & -.07 \\
\hline & 2 & $\theta$ & Aurigæ & 5. 05 & 4. 82 & -.11 & 12 & $\rho$ & Persei & 5. 04 & 5. 01 & -.07 \\
\hline & 3 & $\alpha$ & Lyræ & 4. 87 & 4. 61 & -.11 & 12 & $\gamma$ & Bootis & 5. 42 & 5. 10 & -.07 \\
\hline & 7 & $\alpha$ & Lyræ & 4. 84 & 4.58 & -.11 & 13 & $\mu$ & Andromedæ & 4. 98 & 4. 72 & -.07 \\
\hline & 7 & $\theta$ & Aurigæ & 5. 78 & 5. 56 & -.11 & 13 & $\rho$ & Persei & 5. 11 & 5. 08 & -.07 \\
\hline & 8 & $\theta$ & Aurigæ & 5. 41 & 5. 19 & -.11 & 18 & $a$ & Lyræ & 5. 28 & 5. 02 &.- .07 \\
\hline & 9 & $\alpha$ & Lyræ & 5. 01 & 4. 75 & -.11 & 19 & $\rho$ & Persei & 5. 30 & 5. 27 & -.07 \\
\hline & 9 & $\tau$ & Cygni & 4. 28 & 3.85 & -.11 & 20 & $a$ & Lyræ & 5. 26 & 5. 00 & -.07 \\
\hline & 9 & $\theta$ & Aurigæ & 4. 95 & 4. 73 & -.11 & 20 & $\rho$ & Persei & 5.57 & 5. 54 & -.07 \\
\hline & 0 & $\alpha$ & Lyræ & 4. 65 & 4. 39 & -.11 & 20 & $\gamma$ & Bootis & 5. 74 & 5. 42 & -.07 \\
\hline & 0 & $\theta$ & Aurigæ & 5. 94 & 5. 71 & -.11 & 21 & $a$ & Lyræ & 5. 62 & 5. 36 & -.07 \\
\hline & 1 & $\alpha$ & Lyræ & 5. 00 & 4. 74 & -.11 & 21 & $\rho$ & Persei & 5.65 & 5. 62 & -.07 \\
\hline & 1 & $\theta$ & Aurigæ & 5. 37 & 5. 15 & -.11 & 23 & $\rho$ & Persei & 5. 24 & 5. 21 & -.06 \\
\hline & 4 & $\alpha$ & Lyræ & 5. 31 & 5.05 & -.11 & 24 & $a$ & Lyræ & 5. 69 & 5. 43 & -.06 \\
\hline & & $\alpha$ & Lyræ & 5. 03 & 4. 77 & -.11 & 25 & $\rho$ & Persei & 4. 92 & 4. 89 & -.06 \\
\hline & 6 & $\alpha$ & Lyræ & 4. 97 & 4. 71 & -.11 & 26 & $a$ & Lyræ & 5. 48 & 5. 22 & -.06 \\
\hline & 6 & $\theta$ & Aurigæ & 5. 13 & 4. 90 & -.11 & 26 & $\rho$ & Persei & 5.4 & 5. 39 & -.06 \\
\hline & 7 & $\alpha$ & Lyræ & 5. 26 & 5. 00 & -.11 & 27 & $a$ & Lyræ & 5. 23 & 4.97 & -.06 \\
\hline & 7 & $\theta$ & Aurigæ & 4. 58 & 4.35 & -.11 & 27 & $\rho$ & Persei & 4. 76 & 4. 73 & -.06 \\
\hline & 0 & $\alpha$ & Lyræ & 5. 03 & 4. 77 & -.11 & & & & & & \\
\hline & 1 & $\alpha$ & Lyræ* & 4. 83 & 4.57 & -.11 & 1894 & & & & & \\
\hline & 3 & $\alpha$ & Lyræ & 5. 22 & 4. 96 & -.11 & Jan. 1 & $\rho$ & Persei & 4. 84 & 4. 82 & -.06 \\
\hline & 24 & $\alpha$ & Lyræ & 5. 01 & 4. 75 & -.11 & 1 & $\alpha$ & Lyræ & 5. 72 & 5.45 & -.06 \\
\hline & 29 & $\alpha$ & Lyræ & 5. 57 & 5. 31 & -.10 & 2 & $\rho$ & Persei & 5. 09 & 5. 07 & -.05 \\
\hline & 30 & $\alpha$ & Lyræ & 5. 67 & 5. 41 & -.10 & 8 & $\rho$ & Persei & 4. 82 & 4. 80 & -.05 \\
\hline & 31 & $\mu$ & Andromedæ & 4.87 & 4. 61 & -.10 & 11 & $\alpha$ & Lyræ & 4.76 & 4. 49 & -.04 \\
\hline Nov. & 1 & $\alpha$ & Lyræ & 5. 46 & 5. 20 & -.10 & 12 & $\rho$ & Persei & 4. 12 & 4. 10 & -.04 \\
\hline & 1 & $\mu$ & Andromedæ & 5. 50 & 5. 23 & -.10 & 12 & $\alpha$ & Lyræ & 4.80 & 4.53 & -.04 \\
\hline & 2 & $\mu$ & Andromedæ & 5. 03 & 4. 77 & -.10 & 13 & $\rho$ & Persei & 4. 76 & 4. 74 & -.04 \\
\hline & 6 . & $\alpha$ & Lyræ & 5. 38 & 5. 12 & -.10 & 13 & $\alpha$ & Lyræ & 4.78 & 4. 51 & -.04 \\
\hline & 6 & $\mu$ & Andromedæ & 5. 11 & 4. 85 & -.10 & 14 & $\rho$ & Persei & 4.07 & 4.05 & -.04 \\
\hline & 8 & $\gamma$ & Bootis & 5. 66 & 5. 34 & -.10 & 18 & $\alpha$ & Lyræ & 4.17 & 3. 90 & -.04 \\
\hline & 9 & $\mu$ & Andromedæ & 4. 94 & 4. 68 & -.10 & 22 & $\rho$ & Persei & 3. 94 & 3.92 & -.03 \\
\hline & 9 & $\rho$ & Persei & 5. 11 & 5. 08 & -.10 & 22 & $\alpha$ & Lyræ & 5. 21 & 4. 94 & -.03 \\
\hline & 10 & $\alpha$ & Lyræ & 5. 36 & 5. 10 & -.10 & 27 & $\rho$ & Persei & 4. 79 & 4. 77 & -.02 \\
\hline & 10 & $\mu$ & Andromedæ & 5. 19 & 4. 93 & -.10 & 29 & $\alpha$ & Lyræ & 5. 45 & 5. 18 & -.02 \\
\hline & 11 & $\alpha$ & Lyræ & 5. 45 & 5. 19 & -.09 & 30 & $a$ & Lyræ & 4. 77 & 4. 50 & -.02 \\
\hline & 11 & $\mu$ & Andromedæ & 5. 28 & 5. 02 & -.09 & Feb. & $\rho$ & Persei & 4.50 & 4. 48 & -.02 \\
\hline & 15 & $\alpha$ & Lyræ & 4. 87 & 4.61 & -.09 & 1 & a & Lyræ & 5. 06 & 4. 79 & -.02 \\
\hline & 15 & $\mu$ & Andromedæ & 5. 34 & 5. 07 & -.09 & 4 & $\alpha$ & Ly & 5. 64 & 5.37 & -.02 \\
\hline & 16 & $\alpha$ & Lyræ & 5. 18 & 4. 92 & -.09 & 6 & $\theta$ & Aurigæ & 5. 18 & 4.95 & -.02 \\
\hline & 16 & $\mu$ & Andromedæ & 4. 58 & 4. 32 & -.09 & 10 & $a$ & Lyræ & 4. 92 & 4. 65 & -.02 \\
\hline & 18 & $\mu$ & Andromedæ & 5. 11 & 4. 85 & -.09 & Mar. 12 & $a$ & Lyræ & 4. 34 & 4. 07 & .00 \\
\hline
\end{tabular}


INTRODUCTION.

A XCVII

TABLE VIII.-The Latitude of the Instrument, Obtained by the Use of Newcomb and Boss Declinations-Continued

$+38^{\circ} 55^{\prime} 10^{\prime \prime}+$

*Indicates reflected observation.

\begin{tabular}{|c|c|c|c|c|c|c|c|c|c|c|c|}
\hline Date & & Star & N. & B. & $\Delta \varphi$ & \multicolumn{2}{|l|}{ Date } & Star & N. & B. & \multirow{2}{*}{$\begin{array}{c}\Delta \varphi \\
\end{array}$} \\
\hline $\begin{array}{c}1894 \\
\text { Mar. } 13\end{array}$ & & & 441 & 4.14 & 0 & \multicolumn{2}{|c|}{1894} & & 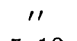 & 11 & \\
\hline Mar. 1 & & $\begin{array}{ll}\alpha & \text { Lyræ } \\
\alpha & \text { Lyræ }\end{array}$ & $\begin{array}{l}\text { 4. } 41 \\
\text { 4. } 33\end{array}$ & $\begin{array}{l}\text { 4. } 14 \\
\text { 4. } 06\end{array}$ & 0.00 & & 6 & Lyræ & 5. 10 & 4. 83 & +0.09 \\
\hline 2 & & $\theta \quad$ Aurigæ & $\begin{array}{l}\text { 4. } 33 \\
\text { 3. } 87\end{array}$ & $\begin{array}{l}\text { 4. } 06 \\
\text { 3. } 65\end{array}$ & $\begin{array}{l}.00 \\
.00\end{array}$ & & $\begin{array}{l}7 \\
7\end{array}$ & $\begin{array}{l}\text { Can. Venat. } \\
\text { Bootis }\end{array}$ & 4. 72 & 4. 33 & $\begin{array}{r}+.09 \\
\end{array}$ \\
\hline & & Lyræ & 4. 52 & 4. 25 & .00 & & 7 & Lyræ & $\begin{array}{l}\text { 4. } 55 \\
4.60\end{array}$ & $\begin{array}{l}\text { 4. } 23 \\
\text { 4. } 33\end{array}$ & $\begin{array}{l}+.09 \\
+.09\end{array}$ \\
\hline & & Lyræ & 3. 69 & 3. 42 & 00 & & 8 & Can. Venat. & 4. 60 & 4. 21 & $\begin{array}{r}.09 \\
+.09\end{array}$ \\
\hline \multirow{9}{*}{$\begin{array}{r}\text { Apr. } \\
1 \\
1 \\
1 \\
2 \\
2 \\
2 \\
2 \\
3\end{array}$} & & Lyræ & 5. 57 & 5. 30 & 00 & & 8 & Bootis & 3. 84 & 3. 52 & +.09 \\
\hline & & Lyræ & 5. 49 & 5. 22 & 00 & & 8 & Lyræ & 3. 49 & 3. 22 & +.09 \\
\hline & & $\alpha \quad$ Lyræ & $\begin{array}{l}\text { 5. } 22 \\
4.74\end{array}$ & $\begin{array}{l}4.95 \\
4.47\end{array}$ & .00 & & 9 & Can. Venat. & 4. 80 & 4. 41 & +.09 \\
\hline & & $\begin{array}{ll}\alpha & \text { Lyræ } \\
\alpha & \text { Lyræ }\end{array}$ & $\begin{array}{l}\text { 4. } 74 \\
\text { 4. } 90\end{array}$ & $\begin{array}{l}\text { 4. } 47 \\
\text { 4. } 63\end{array}$ & $\begin{array}{r}.00 \\
+.01\end{array}$ & 10 & $\begin{array}{l}9 \\
0\end{array}$ & $\begin{array}{l}\text { Lyræ } \\
\text { Bootis }\end{array}$ & $\begin{array}{l}\text { 4. } 81 \\
4.09\end{array}$ & $\begin{array}{l}\text { 4. } 54 \\
\text { 3. } 77\end{array}$ & $\begin{array}{l}+.09 \\
+\quad 09\end{array}$ \\
\hline & & $\alpha \quad$ Lyræ & 4. 49 & 4. 22 & $\begin{array}{l}T .01 \\
+.02\end{array}$ & 10 & 0 & Lyræ & 4. 61 & 4. 34 & $\begin{array}{l}+.09 \\
+.09\end{array}$ \\
\hline & & Lyræ & 4. 97 & 4. 70 & +.02 & 12 & 2 & Can. Venat. & 4.53 & 4. 14 & $\begin{array}{r}+.09 \\
\end{array}$ \\
\hline & & Lyræ & 4. 64 & 4. 37 & +.02 & 12 & 2 & Bootis & 4. 14 & 3. 82 & +.09 \\
\hline & & $\boldsymbol{\alpha} \quad$ Lyræ & 4. 47 & 4. 20 & +.03 & 12 & 2 & Lyræ & 4. 46 & 4. 19 & +.09 \\
\hline & & Lyræ & 4. 39 & 4. 12 & +.03 & 18 & & Bootis & 4. 16 & 3. 84 & +.09 \\
\hline \multirow[t]{13}{*}{ May } & & Lyræ & 4. 54 & 4. 27 & +.03 & 13 & 3 & Lyræ* & 4. 52 & 4. 25 & +.09 \\
\hline & & Lyræ & 4. 64 & 4. 37 & +.04 & 14 & & Lyræ & 5. 10 & 4. 83 & +.09 \\
\hline & & Lyræ* * & 4. 53 & 4. 26 & +.04 & 16 & 6 & Bootis & 4. 70 & 4. 38 & +.09 \\
\hline & & Lyræ* & 4. 31 & 4. 04 & +.04 & 16 & 6 & Lyræ & 4. 84 & 4. 57 & +.09 \\
\hline & & Lyræ & 4. 37 & 4. 10 & +.04 & 17 & 7 & Lyræ* & 3.56 & 3. 29 & +.09 \\
\hline & & Lyræ* & 4. 54 & 4. 27 & +.05 & 18 & 8 & Bootis & 4. .50 & 4. 18 & +.09 \\
\hline & & Lyræ & 4. 43 & 4. 16 & +.05 & 18 & 8 & Lyræ & 4. 55 & 4. 28 & +.09 \\
\hline & & Lyræ* & 4. 30 & 4. 03 & +.05 & 1 & 9 & Bootis & 4. 37 & 4. 05 & +.09 \\
\hline & & Lyræ & 4. 54 & 4. 27 & +.06 & 1 & 9 & Lyræ. & 4. 62 & 4. 35 & +.09 \\
\hline & & Lyræ & 4. 79 & 4. 52 & +.07 & 2 & 0 & Bootis & 4. 19 & 3. 87 & +.09 \\
\hline & & Lyræ* & 4. 05 & 3.78 & +.07 & 2 & 0 & Lyræ* & 5. 12 & 4.85 & +.09 \\
\hline & & Lyræ & 4. 60 & 4. 33 & +.07 & 2 & 5 & Lyræ* & 4. 85 & 4. 58 & +.09 \\
\hline & & Lyræ & 4. 45 & 4. 18 & +.08 & 2 & 9 & Lyræ & 4. 20 & 3.93 & +.09 \\
\hline \multirow{31}{*}{ June } & & Bootis & 3. 85 & 3. 53 & +.08 & Aug. 3 & 1 & Lyræ & 4. 29 & 4. 02 & +.07 \\
\hline & & Lyræ & 3. 84 & 3. 57 & +.08 & Sept. & 1 & Lyræ & 4. 85 & 4. 58 & +.07 \\
\hline & & Bootis & 4. 11 & 3. 79 & +.08 & & 2 & Lyræ & 4. 70 & 4. 43 & +.07 \\
\hline & & Lyræ* & 4. 64 & 4. 37 & +.08 & & 3 & Lyræ & 4. 67 & 4. 40 & +.06 , \\
\hline & & Lyræ & 4. 14 & 3. 87 & +.08 & & 11 & Lyræ & 4. 38 & 4. 11 & +.05 \\
\hline & & Bootis & 3. 86 & 3. 54 & +.08 & & 13 & Lyræ & 4. 64 & 4. 37 & +.05 \\
\hline & & Lyræ & 4. 11 & 3. 84 & +.08 & & 20 & Lyræ* * & 4. 36 & 4. 09 & +.04 \\
\hline & & Lyræ* & 5. 05 & 4. 38 & +.08 & & 20 & Aurigæ & 4. 55 & 4. 33 & +.04 \\
\hline & & Lyræ & 4. 13 & 3. 86 & +.09 & & 21 & Lyræ & 4. 27 & 4. 00 & +.04 \\
\hline & & Can. Venat. & 3. 65 & 3. 26 & +.09 & & 21 & Aurigæ & 4. 40 & 4. 18 & +.04 \\
\hline & & Lyræ* & 4. 41 & 4. 14 & +.09 & & 22 & Lyræ & 4. 37 & 4. 10 & +.04 \\
\hline & & Can. Venat. & 3. 60 & 3. 21 & +.09 & & 22 & Aurigæ & 4. 57 & 4. 35 & +.04 \\
\hline & & Bootis & 3. 69 & 3. 37 & +.09 & & 23 & Lyræ* & 4. 70 & 4. 43 & +.04 \\
\hline & & Lyræ & 4. 16 & 3. 89 & +.09 & & 23 & Aurigæ & 3. 91 & 3. 69 & +.04 \\
\hline & & Can. Venat. & 3. 78 & 3. 39 & +.09 & & 24 & Lyræ & 3. 88 & 3. 61 & +.04 \\
\hline & & Bootis & 3. 97 & 3.65 & +.09 & & 25 & Aurigæ & 4. 59 & 4. 37 & +.04 \\
\hline & & Bootis & 3. 56 & 3. 24 & +.09 & & 30 & Lyræ* & 4. 41 & 4. 14 & +.03 \\
\hline & & Lyræ* & 4. 55 & 4. 28 & +.09 & Oct. & 1 & Lyræ & 4. 62 & 4. 35 & +.03 \\
\hline & & Can. Venat. & 4.95 & 4. 56 & +.09 & & 2 & Lyræ* & 3. 90 & 3. 63 & +.02 \\
\hline & & Bootis & 4. 93 & 4. 61 & +.09 & & 3 & Lyræ & 4. 68 & 4. 41 & +.02 \\
\hline & & Lyræ & 5. 23 & 4. 96 & +.09 & & 5 & Aurigæ & 4. 88 & 4. 66 & +.01 \\
\hline & & Can. Venat. & 3. 93 & 3. 54 & +.09 & & 6 & Lyræ & 3. 77 & 3. 50 & +.01 \\
\hline & & Bootis & 4. 61 & 4. 29 & +.09 & & 6 & Aurigæ & 3. 95 & 3.73 & +.01 \\
\hline & & Lyræ & 4. 81 & 4. 54 & +.09 & & 7 & Lyræ* & 4. 98 & 4. 71 & +.01 \\
\hline & & Can. Venat. & 3. 75 & 3. 36 & +.09 & & 7 & Aurigæ & 4. 27 & 4. 05 & +.01 \\
\hline & & Bootis & 4. 30 & 3. 98 & +.09 & & 10 & Lyræ & 3. 90 & 3. 63 & .00 \\
\hline & & Lyræ* & 3. 94 & 3. 67 & +.09 & & 10 & Aurigæ & 4. 76 & 4. 54 & .00 \\
\hline & & Lyræ & 5. 21 & 4. 94 & +.09 & & 11 & Lyræ & 4. 09 & 3. 82 & .00 \\
\hline & & Can. Venat. & 4. 81 & 4. 42 & +.09 & & 12 & Lyræ* & 4. 90 & 4. 63 & .00 \\
\hline & & Lyræ & 4. 97 & 4. $70=$ & +.09 & & 13 & Lyræ & 4. 35 & 4. 08 & .00 \\
\hline & & Can. Venat. & 4. 64 & 4. 25 & +.09 & & 14 & Aurigæ & 4. 18 & 3. 96 & .00 \\
\hline & & Can. Venat. & 4. 53 & 4. 14 & +.09 & & 15 & Aurigæ & 4. 05 & 3.83 & .00 \\
\hline & & Bootis & 4. 44 & 4. 12 & +.09 & & 16 & Lyræ & 4. 55 & 4. 28 & .00 \\
\hline & & Lyræ & 5. 00 & 4. 73 & +.09 & & 16 & Aurigæ & 4. 02 & 3. 80 & \\
\hline & & Can. Venat. & 4. 91 & 4. 52 & +.09 & & 17 & Lyræ & 4.03 & 3. 76 & -.01 \\
\hline & & Bootis & 4. 50 & 4. 18 & +.09 & & 17 & Aurigæ & 4. 56 & 4. 34 & -.01 \\
\hline \multirow[t]{3}{*}{ July } & I & Lyræ & 4. 94 & 4. 67 & +.09 & & 18 & Lyræ* & 5. 07 & 4. 80 & -.01 \\
\hline & 3 & Lyræ* & 4. 15 & 3. 88 & +.09 & & 19 & Lyræ & 4. 40 & 4. 13 & -.01 \\
\hline & & Can. Venat. & 5.75 & 5. 36 & +.09 & & 19 & Aurigæ & 4. 78 & 4.56 & -.01 \\
\hline
\end{tabular}

$101141^{\circ}-26 \dagger-P T I-7$ 
TABLE VIII.- The Latitude of the Instrument, Obtained by the Use of Newcomb and Boss Declinations - Continued

$+38^{\circ} 55^{\prime} 10^{\prime \prime}+$

* Indicates reflected observation.

\begin{tabular}{|c|c|c|c|c|c|c|c|c|c|c|c|}
\hline Date & & Star & $N^{\top}$ & B. & $\Delta \varphi$ & Date & \multicolumn{2}{|r|}{ Star } & N. & B. & $\Delta \varphi$ \\
\hline 1894 & & & 11 & 11 & 11 & 1894 & & & & 11 & 11 \\
\hline Oct. 20 & $\alpha$ & Lyræ* & 4. 68 & 4. 41 & -0.01 & Dec. 19 & $\alpha$ & Lyræ & 4. 82 & 4. 55 & -0.09 \\
\hline 20 & $\theta$ & Aurigæ & 4. 41 & 4. 18 & -.01 & 19 & $\mu$ & Andromedæ & 4. 42 & 4. 15 & -.09 \\
\hline 21 & $\alpha$ & Lyræ & 4. 52 & 4. 25 & -.02 & 19 & $\alpha$ & Can. Venat. & 4. 74 & 4. 35 & -.09 \\
\hline 31 & $\mu$ & Andromedæ & 4. 44 & 4. 17 & -.02 & 20 & $\alpha$ & Lyræ & 5. 08 & 4. 81 & -.09 \\
\hline 31 & $\alpha$ & Can. Venat. & 4. 46 & 4. 07 & -.02 & 20 & $\mu$ & Andromedæ & 4. 52 & 4. 25 & -.09 \\
\hline Nov. 1 & $\alpha$ & Lyræ & 4. 81 & 4. 54 & -.03 & 20 & $\alpha$ & Can. Venat. & 4. 90 & 4. 51 & -.09 \\
\hline & $\alpha$ & Lyræ & 4. 56 & 4. 29 & -.03 & 22 & $\alpha$ & Lyræ & 4. 92 & 4. 65 & -.09 \\
\hline 2 & $\alpha$ & Can. Venat. & 4. 89 & 4. 50 & -.03 & 22 & $\mu$ & Andromedæ & 4. 65 & 4. 38 & -.09 \\
\hline 3 & $\alpha$ & Lyræ & 4. 40 & 4. 13 & -.03 & 22 & $\alpha$ & Can. Venat. & 4. 26 & 3. 87 & -.09 \\
\hline 3 & $\mu$ & Andromedæ & 3. 90 & 3. 63 & -.03 & 23 & $\alpha$ & Lyræ & 4. 70 & 4. 43 & -.09 \\
\hline 4 & $\alpha$ & Lyræ & 4. 58 & 4. 31 & -.04 & 23 & $\mu$ & Andromedæ & 4. 47 & 4. 20 & -.09 \\
\hline 4 & $\mu$ & Andromedæ & 4. 32 & 4. 05 & -.04 & 23 & $\alpha$ & Can. Venat. & 4. 47 & 4. 08 & -.09 \\
\hline 5 & $\mu$ & Andromedæ & 4. 21 & 3. 94 & -.04 & 27 & $\mu$ & Andromedæ & 4. 47 & 4. 20 & -.10 \\
\hline 13 & $\alpha$ & Lyræ & 4. 81 & 4. 54 & -.05 & 28 & $\alpha$ & Lyræ & 4. 81 & 4. 54 & -.10 \\
\hline 14 & $\alpha$ & Lyræ & 4. 75 & 4. 48 & -.05 & 29 & $\alpha$ & Lyræ & 5. 00 & 4. 73 & -.10 \\
\hline 14 & $\alpha$ & Can. Venat. & 4. 52 & 4. 13 & -.05 & 31 & $\alpha$ & Can. Venat. & 4. 38 & 3. 99 & -.10 \\
\hline $\begin{array}{l}15 \\
15\end{array}$ & $\begin{array}{l}\alpha \\
\mu\end{array}$ & Andromedæ & $\begin{array}{l}\text { 4. } 57 \\
\text { 4. } 33\end{array}$ & $\begin{array}{l}\text { 4. } 30 \\
\text { 4. } 06\end{array}$ & $\begin{array}{l}-.06 \\
-.06\end{array}$ & 1895 & & & & & \\
\hline 16 & $\alpha$ & Lyræ* & 4. 70 & 4. 43 & -.06 & Jan. 1 & $\alpha$ & Lyræ & 4. 97 & 4. 70 & -.10 \\
\hline 16 & $\mu$ & Andromedæ & 4. 50 & 4. 23 & -.06 & 1 & $\mu$ & Andromedæ & 4. 44 & 4. 18 & -.10 \\
\hline 19 & $\alpha$ & Lyræ & 4. 63 & 4. 36 & -.06 & 1 & $\alpha$ & Can. Venat. & 3. 74 & 3. 34 & -.10 \\
\hline 19 & $\mu$ & Andromedæ & 4. 46 & 4. 19 & -.06 & 4 & $\mu$ & Andromedæ & 4. 27 & 4. 00 & -.10 \\
\hline 19 & $\alpha$ & Can. Venat. & 4. 61 & 4. 22 & -.06 & 4 & $\alpha$ & Can. Venat. & 4. 06 & 3. 66 & -.10 \\
\hline 20 & $\alpha$ & Lyræ* & 5. 00 & 4. 73 & -.06 & 11 & $\alpha$ & Can. Venat. & 4. 41 & 4. 01 & -.10 \\
\hline 21 & $\alpha$ & Lyræ & 5. 21 & 4. 94 & -.06 & 13 & $\alpha$ & Can. Venat. & 4. 27 & 3. 87 & -.11 \\
\hline 21 & $\alpha$ & Can. Venat. & 4. 38 & 3. 99 & -.06 & 13 & $\alpha$ & Lyræ & 4. 85 & 4. 58 & -.11 \\
\hline 22 & $\alpha$ & Lyræ & 4. 63 & 4. 36 & -.06 & 14 & $\mu$ & Andromedæ & 4. 12 & 3. 85 & -.11 \\
\hline 22 & $\mu$ & Andromedæ & 4. 44 & 4. 17 & -.06 & 14 & $\alpha$ & Lyræ & 4. 84 & 4. 57 & -.11 \\
\hline 23 & $\alpha$ & Lyræ & 5. 06 & 4. 79 & -.06 & Feb. $\quad 4$ & $\theta$ & Aurigæ & 4. 16 & 3. 94 & -.11 \\
\hline 23 & $\alpha$ & Can. Venat. & 4. 64 & 4. 25 & -.06 & 5 & $\theta$ & Aurigæ & 4. 34 & 4. 12 & -.11 \\
\hline 24 & $\alpha$ & Lyræ & 4. 62 & 4. 35 & -.06 & 11 & $\theta$ & Aurigæ & 4. 25 & 4. 03 & -.11 \\
\hline 24 & $\mu$ & Andromedæ & 4. 50 & 4. 23 & --.06 & 13 & $\theta$ & Aurigæ & 4. 58 & 4. 35 & -.11 \\
\hline 24 & $\alpha$ & Can. Venat. & 4. 43 & 3. 94 & -.06 & 13 & $\alpha$ & Lyræ & 4. 19 & 3. 92 & -.11 \\
\hline 25 & $\mu$ & Andromedæ & 4. 06 & 3. 79 & -.06 & 14 & $\alpha$ & Lyræ & 4. 52 & 4. 25 & -.11 \\
\hline 25 & $\alpha$ & Can. Venat. & 4. 59 & 4. 20 & -.06 & 15 & $\theta$ & Aurigæ & 4. 34 & 4. 12 & -.11 \\
\hline 26 & $\alpha$ & Lyræ & 4. 50 & 4. 23 & -.07 & 16 & $\alpha$ & Lyræ & 4. 42 & 4. 15 & -.11 \\
\hline 26 & $\alpha$ & Can. Venat. & 4. 42 & 4. 03 & -.07 & 17 & $\theta$ & Aurigæ & 4. 49 & 4. 27 & -.11 \\
\hline 27 & $\alpha$ & Lyræ & 4. 61 & 4. 34 & -.07 & 19 & $\alpha$ & Lyræ & 4. 95 & 4. 68 & -.11 \\
\hline 27 & $\mu$ & Andromedæ & 4. 58 & 4. 31 & -.07 & 21 & $\alpha$ & Lyræ & 4. 65 & 4. 38 & -.11 \\
\hline $\begin{array}{l}27 \\
28\end{array}$ & $\alpha$ & . & 4. 31 & 3.92 & -.07 & 23 & $\theta$ & Aurigæ & 4. 37 & 4. 15 & -.10 \\
\hline Dec. & $\alpha$ & Can Venat. & $\begin{array}{l}4.04 \\
4.48\end{array}$ & 409 & -07 & $\begin{array}{l}23 \\
24\end{array}$ & $\alpha$ & $\begin{array}{l}\text { Lyræ } \\
\text { Aurigr }\end{array}$ & 4. 36 & 4. 09 & -.10 \\
\hline Det. & $\alpha$ & Lyræ & 4. 57 & 4. 30 & -.07 & $\begin{array}{l}24 \\
25\end{array}$ & $\alpha$ & $\begin{array}{l}\text { Aurigæ } \\
\text { Lyræ }\end{array}$ & 4. 23 & 4. 01 & -.10 \\
\hline 3 & $\mu$ & Andromedæ & 4. 25 & 3. 97 & -.07 & 26 & $\theta$ & Lyræ & & 4. 34 & -.10 \\
\hline 4 & $\mu$ & Andromedæ & 4. 16 & 3.88 & -.08 & 26 & $\alpha$ & Lvræ & 4. 16 & 3. 94 & -.10 \\
\hline 4 & $\alpha$ & Can. Venat. & 4. 13 & 3.74 & -.08 & Mar. 3 & $\theta$ & Aurigæ & $\begin{array}{l}\text { 4. } 37 \\
4.48\end{array}$ & 4. 10 & -.10 \\
\hline 5 & $\alpha$ & Lyræ* & 5. 36 & 5.09 & -.08 & 4 & $\alpha$ & Lyræ & & $\begin{array}{l}\text { 4. } 25 \\
4.27\end{array}$ & -.10 \\
\hline 5 & $\mu$ & Andromedæ & 4. 16 & 3. 88 & -.08 & 5 & $\theta$ & Aurigæ & $\begin{array}{l}\text { 4. } 04 \\
\text { 4. } 27\end{array}$ & $\begin{array}{l}\text { 4. } 27 \\
4.05\end{array}$ & -.10 \\
\hline 5 & $\alpha$ & Can. Venat. & 4. 39 & 4.00 & -.08 & 6 & $\theta$ & Auri & 4. 21 & $\begin{array}{l}\text { 4. } 00 \\
3.99\end{array}$ & $\begin{array}{l}-.09 \\
-09\end{array}$ \\
\hline 6 & $\alpha$ & Lyræ & 4. 85 & 4. 58 & -.08 & 6 & $\alpha$ & Lyr & 4. 93 & 4. 66 & $\begin{array}{l}-.09 \\
-\quad 09\end{array}$ \\
\hline 6 & $\mu$ & Andromedæ & 4. 68 & 4. 41 & -.08 & 9 & $\theta$ & Aurigæ & 4. 34 & 4. 12 & -.09 \\
\hline 6 & $\alpha$ & Can. Venat. & 4. 39 & 4. 00 & -.08 & 9 & $\alpha$ & Lyr & 4. 38 & 4. 11 & -.09 \\
\hline 7 & $\alpha$ & Lyræ & 4. 69 & 4. 42 & -.08 & 10 & $\theta$ & Aurigæ & 4. 27 & 4. 05 & -.08 \\
\hline 9 & $\mu$ & Andromedæ & 4. 10 & 3. 82 & -.08 & 16 & $\alpha$ & Lyr & 4. 55 & 4. 28 & -.08 \\
\hline 9 & $\alpha$ & Can. Venat. & 4. 22 & 3.83 & -.08 & 17 & $\theta$ & Aurigæ & 4. 52 & 4. 30 & -.08 \\
\hline 13 & $\mu$ & Andromedæ & 3. 82 & 3.55 & -.08 & 17 & $\alpha$ & Lyræ & 4. 30 & 4. 03 & -.08 \\
\hline 13 & $\alpha$ & Can. Venat. & 3. 85 & 3.46 & -.08 & 19 & $\theta$ & Aurigæ & 4. 18 & 3. 96 & -.07 \\
\hline 14 & $\alpha$ & Lyræ & 4. 76 & 4. 49 & -.08 & 21 & $\theta$ & Aurigæ & 4. 53 & 4. 30 & -.07 \\
\hline 14 & $\mu$ & Andromedæ & 4. 53 & 4. 26 & -.08 & 21 & $\alpha$ & Lyræ & 4. 61 & 4. 34 & -.07 \\
\hline 14 & $\alpha$ & Can. Venat. & 4. 48 & 4. 09 & -.08 & 22 & $\theta$ & Aurigæ & 4. 17 & 3. 95 & -.07 \\
\hline 15 & $\alpha$ & Lyræ & 4. 67 & 4. 40 & -.08 & 22 & $\alpha$ & Lyræ & 4. 57 & 4. 30 & -.07 \\
\hline 15 & $\mu$ & Andromedæ & 4. 23 & 3.95 & -.08 & 23 & $\theta$ & Aurigæ & 4. 13 & 3. 91 & -.07 \\
\hline 17 & $\alpha$ & Lyræ & 5. 20 & 4. 93 & -.08 & 23 & $\alpha$ & Lyra & 4. 35 & 4. 08 & -.07 \\
\hline 17 & $\mu$ & Andromedæ & 4. 47 & 4. 20 & -.08 & 24 & $\theta$ & Aurigæ & 4. 20 & 3. 98 & -.07 \\
\hline 17 & $\alpha$ & Can. Venat. & 4. 76 & 4. 37 & -.08 & 25 & $\alpha$ & Lyræ & 4. 40 & 4. 13 & -.07 \\
\hline 18 & $\alpha$ & Lyræ & 5. 21 & 4. 94 & -.09 & 27 & $\theta$ & Aurigæ & 4. 31 & 4. 09 & -.06 \\
\hline 18 & $\mu$ & Andromedæ & 4. 35 & 4. 07 & -.09 & 28 & $\theta$ & Aurigæ & 4. 60 & 4. 38 & -.06 \\
\hline
\end{tabular}


INTRODUCTION.

A XCIX

TABLE VIII.-The Latitude of the Instrument, Obtained by the Use of Newcomb and Boss Declinations-Continued

$+38^{\circ} 55^{\prime} 10^{\prime \prime}+$

* Indicates reflected observation.

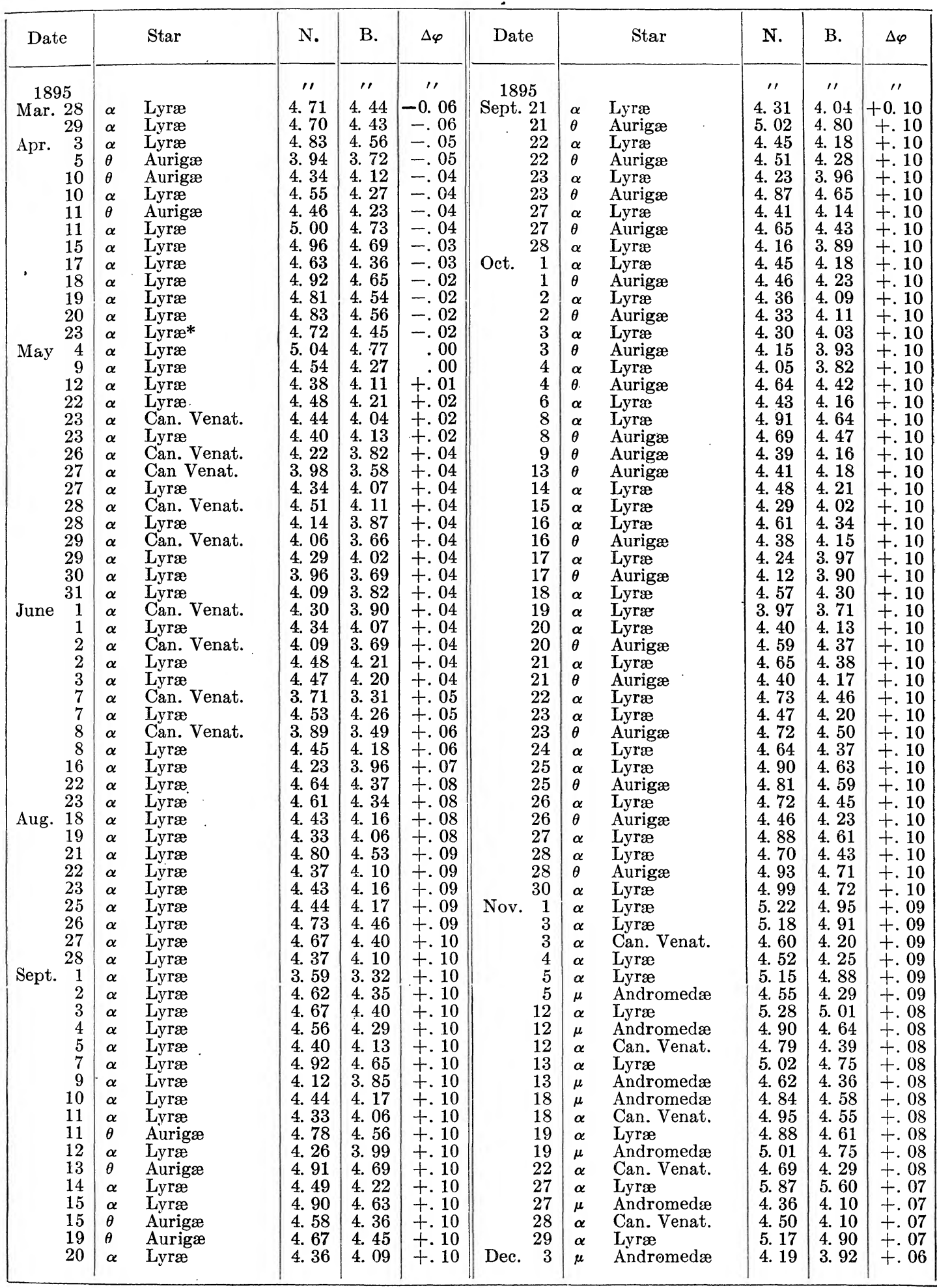


TABLE VIII.-The Latitude of the Instrument, Obtained by the Use of Newcomb and Boss Declinations-Continued

$+38^{\circ} 55^{\prime} 10^{\prime \prime}+\quad *$ Indicates reflected observation.

\begin{tabular}{|c|c|c|c|c|c|c|c|c|c|c|c|c|}
\hline Date & & Star & N. & B. & $\Delta \varphi$ & \multicolumn{2}{|c|}{ Date } & \multicolumn{2}{|r|}{ Star } & N. & B. & $\Delta \varphi$ \\
\hline \multirow{2}{*}{$\begin{array}{c}1895 \\
\text { Dec. } \quad 3\end{array}$} & & & $\prime \prime$ & "' & "I & 189 & & & & $" 1$ & $" \prime$ & '1 \\
\hline & $\alpha$ & Can. Venat. & 4.95 & 4. 55 & +0.06 & Mar. & 3 & $\theta$ & Aurigæ & 4. 70 & 4. 48 & -0.10 \\
\hline & $\alpha$ & Lyræ & 5.25 & 4. 98 & +.06 & & & $\alpha$ & Lyræ & 4.85 & 4. 58 & -.10 \\
\hline 5 & $\alpha$ & Can. Venat. & 4. 56 & 4. 16 & +.06 & & 4 & $\theta$ & Aurigæ & 4. 47 & 4. 24 & -.11 \\
\hline & $\alpha$ & Lyræ & 5. 05 & 4. 78 & +.06 & & 4 & $\alpha$ & Lyræ & 4. 18 & 3. 91 & -.11 \\
\hline 6 & $\mu$ & Andromedæ & 5. 00 & 4. 74 & +.06 & & 5 & $\theta$ & Aurigæ & 4. 64 & 4. 42 & -.11 \\
\hline 10 & $\mu$ & Andromedæ & 4. 79 & 4. 53 & +.04 & & 7 & $\theta$ & Aurigæ & 4. 57 & 4. 34 & -.11 \\
\hline 10 & $\alpha$ & Can. Venat. & 4. 61 & 4. 21 & +.04 & & 7 & $\alpha$ & Lyræ & 4. 79 & 4. 52 & -.11 \\
\hline 12 & $\alpha$ & Can. Venat. & 4. 36 & 3. 96 & +.04 & & 8 & $\alpha$ & Lyræ & 4. 82 & 4. 55 & -.11 \\
\hline 13 & $\alpha$ & Lyræ & 5. 11 & 4. 84 & $\begin{array}{l}+.04 \\
\end{array}$ & & 9 & $\theta$ & Aurigæ & 4. 79 & 4. . .7 & -.11 \\
\hline 13 & $\mu$ & Andromedæ & 4. 63 & 4. 37 & +.04 & & 12 & $\theta$ & Aurigæ & 4. 43 & 4. 20 & -.12 \\
\hline 13 & $\alpha$ & Can. Venat. & 4. 50 & 4. 10 & +.04 & & 12 & $\alpha$ & Lyræ & 5. 04 & 4. 77 & -.12 \\
\hline 14 & $\alpha$ & Lyræ & 5. 11 & 4. 84 & +.04 & & 13 & $\theta$ & Aurigæ & 4. 37 & 4. 14 & -.12 \\
\hline 14 & $\mu$ & Andromedæ & 4. 86 & 4. 60 & +.04 & & 13 & $\alpha$ & Lyræ* & 5. 07 & 4. 80 & -.12 \\
\hline 14 & $\alpha$ & Can. Venat. & 4. 78 & 4. 38 & +.04 & & 14 & $\theta$ & Aurigæ & 4. 68 & 4. 46 & -.12 \\
\hline 15 & $\mu$ & Andromedæ & 4. 87 & 4. 61 & +.03 & & 14 & $\theta$ & Aurigæ & 4. 68 & 4. 46 & -.12 \\
\hline 15 & $\alpha$ & Can. Venat. & 4. 27 & 3. 87 & +.03 & & 17 & $\theta$ & Aurigæ & 4. 47 & 4. 24 & -.12 \\
\hline 16 & $\alpha$ & Lyræ & 5. 27 & 5. 00 & +.03 & & 17 & $\alpha$ & Lyræ & 4. 79 & 4. 52 & -.12 \\
\hline 16 & $\mu$ & Andromedæ & 4. 55 & 4. 29 & +.03 & & 20 & $\theta$ & Aurigæ & 4. 24 & 4. 02 & -.12 \\
\hline 17 & $\alpha$ & Can. Venat. & 4. 96 & 4. 56 & +.03 & & 20 & $\alpha$ & Lyræ & 4. 31 & 4. 04 & -.12 \\
\hline 21 & $\alpha$ & Can. Venat. & 4. 40 & 4. 00 & +.02 & & 21 & $\theta$ & Aurigæ & 4. 15 & 3. 93 & -.12 \\
\hline 22 & $\alpha$ & Lyræ & 5. 10 & 4. 83 & +.02 & & 24 & $\theta$ & Aurigæ & 4. 57 & 4. 34 & -.12 \\
\hline 22 & $\mu$ & Andromedæ & 4. 96 & 4. 70 & .00 & & 24 & $\alpha$ & Lyræ & 4. 97 & 4. 70 & -.12 \\
\hline 22 & $\alpha$ & Can. Venat. & 4. 85 & 4. 45 & .00 & & 25 & $\alpha$ & Lyræ* & 5. 25 & 4. 98 & -.12 \\
\hline 27 & $\alpha$ & Lyræ & 5. 23 & 4. 96 & .00 & & 26 & $\alpha$ & Lyræ & 4. 89 & 4. 62 & -.13 \\
\hline 31 . & $\alpha$ & Lyræ & 4. 86 & 4. 59 & .00 & Apr. & & $\theta$ & Aurigæ & 4. 77 & 4. 55 & -.14 \\
\hline 31 & $\mu$ & Andromedæ & 4. 65 & 4. 39 & .00 & & 4 & $\alpha$ & Lyræ & 5. 24 & 4. 97 & -.14 \\
\hline 31 & & Can. Venat. & 5.01 & 4. 61 & .00 & & 5 & $\theta$ & Aurigæ & 4. 52 & 4. 30 & -.14 \\
\hline 1896 & & & & & & & $\begin{array}{l}7 \\
8\end{array}$ & $\underset{\theta}{\alpha}$ & $\begin{array}{l}\text { Lyræ } \\
\text { Aurigæ }\end{array}$ & $\begin{array}{l}5.02 \\
4.55\end{array}$ & $\begin{array}{l}\text { 4. } 75 \\
4.32\end{array}$ & $\begin{array}{l}-.14 \\
-.14\end{array}$ \\
\hline Jan. 1 & $\alpha$ & Lyræ & 5. 05 & 4. 78 & .00 & & 8 & $\alpha$ & Lyræ* * & $\begin{array}{l}\text { 5. } 41 \\
\text { 5. } 41\end{array}$ & 5. 14 & $=.14$ \\
\hline & $\mu$ & Andromedæ & 3. 80 & 3. 53 & .00 & & 11 & $\alpha$ & Lyræ & 4. 90 & $\begin{array}{l}4.63 \\
4.63\end{array}$ & -.14 \\
\hline & $\alpha$ & Lyræ & 4. 90 & 4.63 & .00 & & 12 & $\alpha$ & Lyræ & 4. 91 & 4. 64 & -.14 \\
\hline 2 & $\mu$ & Andromedæ & 4. 98 & 4. 71 & .00 & & 17 & $\alpha$ & Lyræ & 4. 49 & 4. 22 & -.14 \\
\hline 4 & $\alpha$ & Lyræ & 4. 86 & 4. 59 & -.01 & & 18 & $\alpha$ & Lyræ* & 4. 41 & 4. 14 & -.14 \\
\hline 7 & $\alpha$ & Lyræ & 5. 37 & 5. 10 & -.02 & & 21 & $\alpha$ & Lyræ & 4.69 & 4. 42 & -.14 \\
\hline 10 & $\alpha$ & Can. Venat. & 4. 45 & 4. 04 & -.02 & & 22 & $\alpha$ & Lyræ & 4. 58 & 4. 31 & -.14 \\
\hline 11 & $\mu$ & Andromedæ & 4.63 & 4. 36 & -.02 & & 26 & $\alpha$ & Can. Venat. & 4. 21 & 3. 80 & -.15 \\
\hline 11 & $\alpha$ & Can. Venat. & 4.75 & 4. 34 & -.02 & & 26 & $\alpha$ & Lyræ & 4. 44 & 4. 17 & -.15 \\
\hline 13 & $\alpha$ & Lyræ & 5. 50 & 5. 23 & -.04 & & 28 & $\alpha$ & Lyræ & 4. 51 & 4. 24 & -.15 \\
\hline 14 & $\alpha$ & Lyræ & 5. 31 & 5. 04 & -.04 & & 29 & $\alpha$ & Can. Venat. & 4. 4 & 4.1 & -.15 \\
\hline 15 & $\alpha$ & Lyræ & 4. 51 & 4.24 & -.04 & May & 4 & $\alpha$ & Can. Venat. & 4. 64 & 4. 23 & -.15 \\
\hline 17 & $\alpha$ & Lyræ & 4. 67 & 4. 40 & -.04 & & 4 & $\alpha$ & Lyræ & 4. 4 & 4. 20 & -.15 \\
\hline 24 & $\alpha$ & Lyræ & 4. 99 & 4. 72 & -.05 & & 6 & $\alpha$ & Can. Venat. & 4. 4 & 4. 02 & -.15 \\
\hline 26 & $\alpha$ & Lyræ & 5. 12 & 4. 85 & -.05 & & 10 & $\alpha$ & Can. Venat. & 4. 6 & 4. 22 & -.15 \\
\hline 27 & $\alpha$ & Lyræ & 5. 07 & 4. 80 & -.05 & & 10 & $\alpha$ & Lyræ & & & -.15 \\
\hline 28 & $\alpha$ & Lyræ & 4. 90 & 4. 63 & -.06 & & 11 & $\alpha$ & Can. Venat. & 4. 96 & 4. 55 & -.15 \\
\hline 29 & $\alpha$ & Lyræ & 4. 97 & 4. 70 & -.06 & & 11 & $\alpha$ & Lyræ & 4. 8 & 4. 54 & -.15 \\
\hline Feb. 6 & $\alpha$ & Lyræ & 4. 78 & 4. 51 & -.08 & & 15 & $\alpha$ & Can. Venat. & 4.04 & 3.63 & -.15 \\
\hline 7 & $\theta$ & Aurigæ & 4.31 & 4.09 & -.08 & & 15 & $\alpha$ & Lyræ & 3. 6 & 3. 39 & -.15 \\
\hline 10 & $\theta$ & Aurigæ & 4. 84 & 4. 62 & -.08 & & 16 & $\alpha$ & Can. Venat. & & 4. 10 & -.15 \\
\hline 10 & $\alpha$ & Lyræ & 4. 63 & 4. 36 & -.08 & & 17 & $\alpha$ & Lyræ* & 4. 44 & 4. 17 & -.15 \\
\hline 11 & $\theta$ & Aurigæ & 4. 41 & 4. 18 & -.08 & & 21 & $\alpha$ & Can. Venat. & 4.8 & 4.3 & -.15 \\
\hline 11 & $\alpha$ & Lyræ & 4.91 & 4. 64 & -.08 & & 27 & $\alpha$ & Can. Venat. & 4. & 3. & -.15 \\
\hline 13 & $\alpha$ & Lyræ & 5. 22 & 4.95 & -.08 & & 29 . & $\alpha$ & Can. Venat. & 4. 5 & 4. & -.15 \\
\hline 14 & $\theta$ & Aurigæ & 4. 61 & 4. 39 & -.08 & & 29 & $\alpha$ & Lyræ & 4. & 4. 68 & -.15 \\
\hline 14 & $\alpha$ & Lyræ & 4.37 & 4.10 & -.08 & & 30 & $\alpha$ & Can. Venat. & 4. 60 & 4. 19 & -15 \\
\hline 15 & $\theta$ & Aurigæ & 4. 6 & 4. 47 & -.09 & & 30 & $\alpha$ & Lyræ & 4.82 & 4. 55 & -.15 \\
\hline 16 & $\theta$ & Aurigæ & 4. 51 & 4. 29 & -.09 & & 31 & $\alpha$ & Lyræ & 4. 69 & 4. 42 & -.1 \\
\hline 17 & $\theta$ & Aurigæ & 4. 45 & 4. 22 & -.09 & June & 1 & $\alpha$ & Can. Venat. & 4. 78 & 4. 37 & -.15 \\
\hline 17 & $\alpha$ & Lyræ & 5. 01 & 4.74 & -.09 & & & $\alpha$ & Lyræ & & 4. 58 & -.15 \\
\hline 18 & $\alpha$ & Lyræ & 4.51 & 4.24 & -.10 & & 5 & $\alpha$ & Can. Venat. & 4. 50 & 4. 09 & -.15 \\
\hline 19 & $\theta$ & Aurigæ & 4. 29 & 4. 07 & -.10 & & 5 & $\alpha$ & Lyræ & 4. 74 & 4. 47 & -.15 \\
\hline 19 & $\alpha$ & Lyræ & 4. 64 & 4.37 & -.10 & & 10 & $\alpha$ & Lyræ & & 4. 49 & -.1 \\
\hline 25 & $\theta$ & Aurigæ & 4. 45 & 4. 22 & -.10 & & 11 & $\alpha$ & Can. Venat. & 4. 90 & $\begin{array}{l}\text { 4. } 49 \\
\text {. }\end{array}$ & -.14 \\
\hline 27 & $\theta$ & Auriga & 4. 60 & 4.38 & -.10 & & 11 & $\alpha$ & Lyræ & 5. 05 & 4. 78 & -.14 \\
\hline Mar. 2 & $\theta$ & Aurigæ & 4. 62 & 4. 40 & -.10 & & 12 & $\alpha$ & Can. Venat. & 4. 77 & 4. 36 & -.14 \\
\hline 2 & $\alpha$ & Lyræ & 4. 81 & 4. 54 & -.10 & & 12 & $\alpha$ & Lyræ* . & 4. 48 & 4. 21 & -.14 \\
\hline
\end{tabular}


INTRODUCTION。

A CI

TABLE VIII.-The Latitude of the Instrument, Obtained by the Use of Newcomb and Boss Declinations-Continued

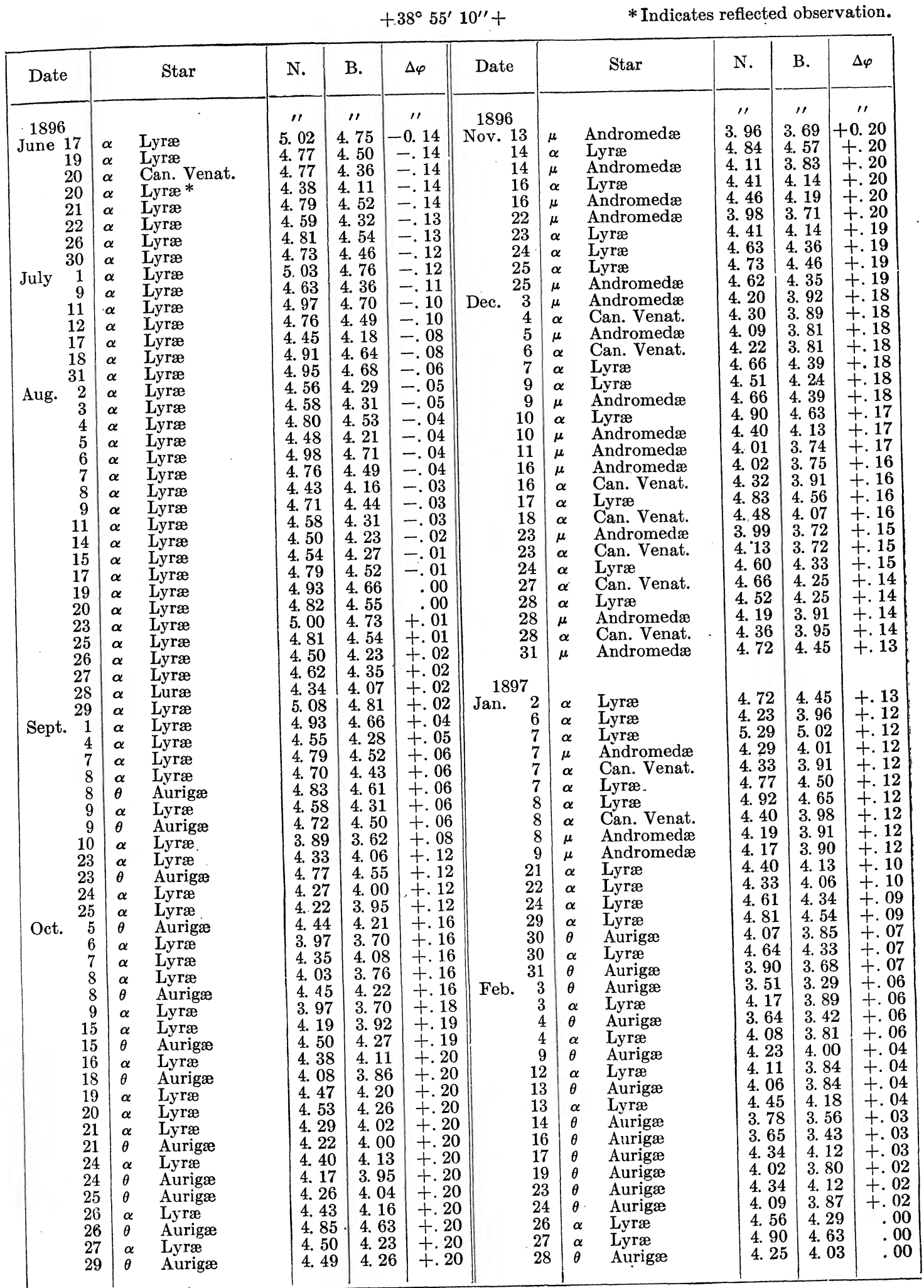


TABLE VIII.-The Latitude of the Instrument, Obtained by the Use of Newcomb and Boss Declinations-Continued

* Indicates reflected observation.

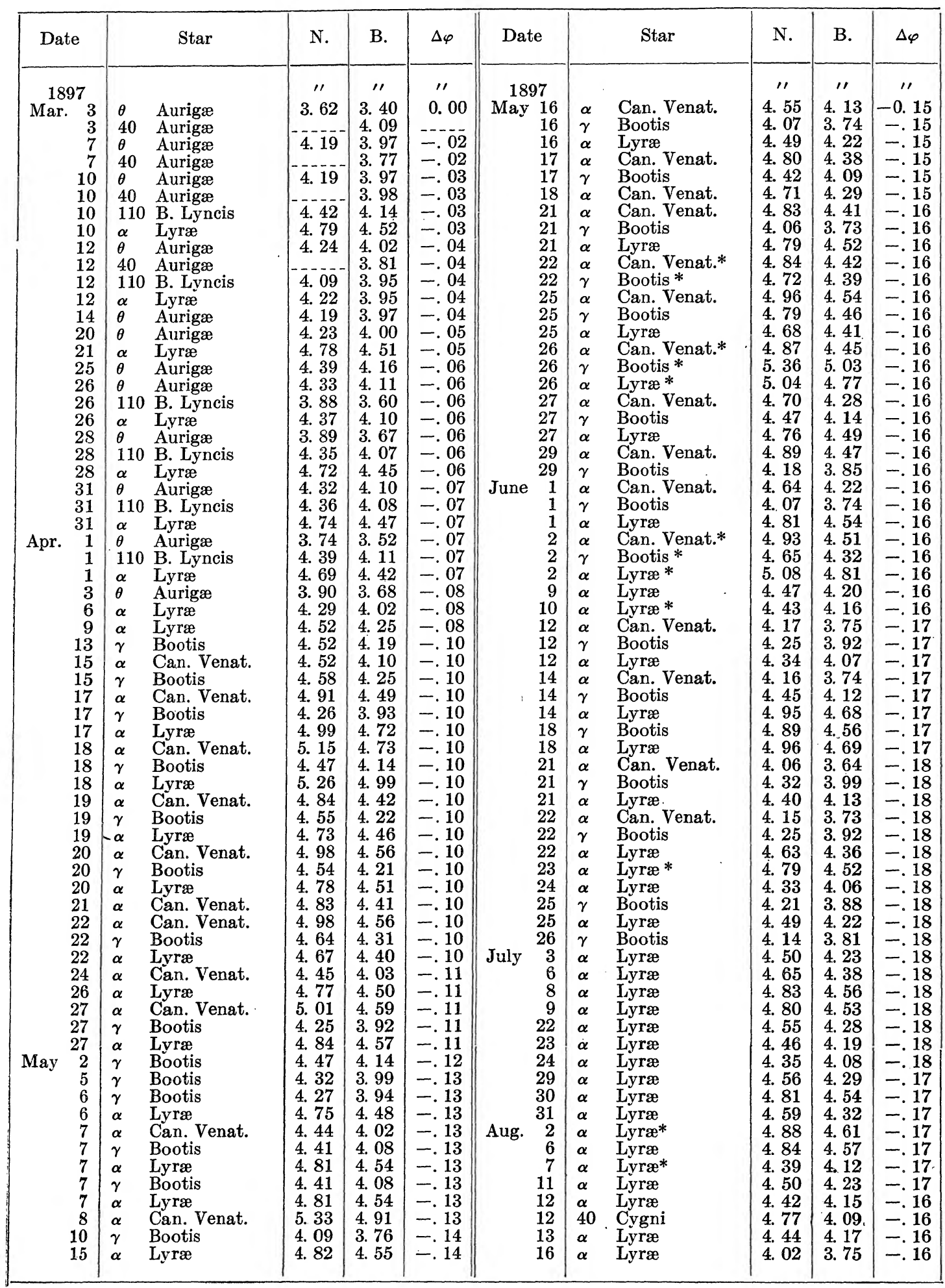


TABLE VIII.-The Latitude of the Instrument, Obtained by the Use of Newcomb and Boss Declinations-Continued

$+38^{\circ} 55^{\prime} 10^{\prime \prime}+\quad \cdot *$ Indicates reflected observation.

\begin{tabular}{|c|c|c|c|c|c|c|c|c|c|c|c|c|}
\hline \multicolumn{2}{|c|}{ Date } & \multicolumn{2}{|r|}{ Star } & N. & B. & $\Delta \varphi$ & \multicolumn{2}{|l|}{ Date } & Star & N. & B. & $\Delta \varphi$ \\
\hline \multicolumn{2}{|c|}{1897} & & & "' & "' & "' & \multirow{2}{*}{\multicolumn{2}{|c|}{ Dec. }} & & 'I & $" \prime$ & 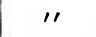 \\
\hline Aug. & & $\theta$ & Aurigæ & 4. 22 & 4. 00 & -0.16 & & 6 & Can. Venat. & 4. 57 & 4. 15 & +0.12 \\
\hline & & $\alpha$ & Lyræ & $\begin{array}{l}\text { 4. } 50 \\
4.19\end{array}$ & $\begin{array}{l}\text { 4. } 23 \\
\text { 3. }\end{array}$ & $\begin{array}{l}-.16 \\
-15\end{array}$ & & 7 & Lyræ & 4. 67 & 4. 40 & +.12 \\
\hline & 22 & 40 & $\begin{array}{l}\text { Lyrax } \\
\text { Cygni }\end{array}$ & $\begin{array}{l}\text { 4. } 19 \\
4.82\end{array}$ & $\begin{array}{l}\text { J. } 92 \\
\text { 4. } 14\end{array}$ & $\begin{array}{l}-.15 \\
-.15\end{array}$ & & $\begin{array}{l}7 \\
8\end{array}$ & $\begin{array}{l}\text { Anaromeaæ } \\
\text { Andromedæ }\end{array}$ & $\begin{array}{l}\text { 4. } 34 \\
\text { 4. } 31\end{array}$ & $\begin{array}{l}\text { 4. } 07 \\
\text { 4. } 04\end{array}$ & $\begin{array}{l}+.12 \\
+.12\end{array}$ \\
\hline & 24 & $\alpha$ & Lyræ & 4.73 & 4. 46 & -.14 & & 8 & Can. Venat. & 4.59 & 4. 17 & $\begin{array}{r}+12 \\
+.12\end{array}$ \\
\hline & 26 & $\alpha$ & Lyræ & 4. 48 & 4. 21 & -.14 & & 9 & Andromedæe & 4. 08 & 3. 80 & +.12 \\
\hline & 26 & 40 & Cygni & 4. 69 & 4. 01 & -.14 & & 11 & Lyræ & 4. 29 & 4. 02 & +.12 \\
\hline & 27 & $\alpha$ & Lyræ & 4. 09 & 3. 82 & -.14 & & 12 & Andromedæ & 3. 99 & 3. 72 & +.12 \\
\hline & 27 & $\theta$ & Aurigæ & 4. 39 & 4. 16 & -.14 & & 15 & Andromedæx & 3. 90 & 3.63 & +.13 \\
\hline & 28 & $\alpha$ & Lyræ. & 3. 89 & 3. 62 & -.14 & & 15 & Can. Venat. & 4.22 & 3.80 & +.13 \\
\hline & 28 & 40 & Cygni & 4. 46 & 3. 78 & -.14 & & & & & & \\
\hline & 31 & $\alpha$ & Lyræ & 4. 48 & 4. 21 & -.14 & 189 & & & & & \\
\hline Sept. & & $\alpha$ & Lyræ & 4. 48 & 4. 21 & -.14 & Jan. & 16 & Lyræ & 4. 94 & 4. 67 & +.13 \\
\hline & 2 & $\alpha$ & Lyræ & 4. 08 & 3. 81 & -.14 & & 17 & Lyræ & 4.87 & 4. 60 & +.13 \\
\hline & 3 & $\alpha$ & Lyræ & 4. 10 & 3. 83 & -.13 & & 22 & Lyræ & 4.67 & 4. 40 & +.13 \\
\hline & 4 & $\alpha$ & Lyræ & 4. 10 & 3. 83 & -.13 & & 23 & Lyræ & 4.76 & 4. 49 & +13 \\
\hline & 4 & $\theta$ & Aurigæ & 4. 39 & 4. 16 & -.13 & & 26 & Lyræ & 4.66 & 4. 39 & +.13 \\
\hline & 6 & $\theta$ & Aurigæ & 4. 31 & 4. 09 & -.13 & Feb. & 2 & Lyræ & 4. 83 & 4. 56 & $\begin{array}{l}+12 \\
\text { t. }\end{array}$ \\
\hline & 8 & $\alpha$ & Lyræ & 4. 39 & 4. 12 & -.12 & & 3 & Aurigæ & 4. 03 & 3. 81 & +.12 \\
\hline & 9 & $\theta$ & Aurigæ & 4. 34 & 4. 12 & -.12 & & 3 & Lyræ & 4. 28 & 4. 01 & +.12 \\
\hline & 0 & $\alpha$ & Lyræ & 4. 89 & 4. 62 & -.12 & & 4 & Aurigæ & 4. 06 & 3. 74 & +.12 \\
\hline & 10 & $\theta$ & Aurigæ & 4. 47 & 4. 24 & -.12 & & 7 & Lyræ & 4. 06 & 3. 79 & +.12 \\
\hline & 3 & $\alpha$ & Lyræ & 4. 33 & 4. 06 & -.12 & & 8 & Aurigæ & 4. 27 & 4. 05 & +.12 \\
\hline & 4 & $\theta$ & Aurigæ & 4. 57 & 4. 34 & -.11 & & 9 & Aurigæ & 4. 07 & 3. 85 & +12 \\
\hline & 5 & $\theta$ & Aurigæ & 4. 46 & 4. 23 & -.11 & & 10 & Aurigæ & 4. 09 & 3. 87 & +.12 \\
\hline & 6 & $\alpha$ & Lyræ & 4. 36 & 4. 09 & -.11 & & 10 & Lyræ & 4. 36 & 4. 09 & +.12 \\
\hline & 7 & $\theta$ & Aurigæ & 4. 89 & 4. 67 & -.11 & & 12 & Aurigæ & 3. 73 & 3. 50 & +.12 \\
\hline Oct. & 3 & $\alpha$ & Lyræ & 4. 15 & 3. 88 & -.09 & & 14 & Aurigæ & 4. 08 & 3. 86 & +.11 \\
\hline & 3 & $\theta$ & Äurigæ & 4. 71 & 4. 49 & -.09 & & 16 & Aurigæ & 3. 65 & 3. 43 & +.11 \\
\hline & 4 & $\alpha$ & Lyræ & 4. 11 & 3. 84 & -.09 & & 16 & Lyræ & 4. 51 & 4. 24 & +.11 \\
\hline & 5 & $\alpha$ & Lyræ & 3. 98 & 3. 71 & -.09 & & 22 & Lyræ & 4. 26 & 3. 99 & +.11 \\
\hline & 6 & $\alpha$ & Lyræ & 4. 45 & 4. 18 & -.08 & & 23 & Lyræ & 4. 34 & 4. 07 & +.11 \\
\hline & 8 & $\alpha$ & Lyræ & 4. 75 & 4. 48 & -.08 & & 24 & Lyræ & 4. 21 & 3. 94 & +.11 \\
\hline & 8 & $\theta$ & Aurigæ & 4. 21 & 3. 99 & -.08 & & 25 & Lyræ & 4. 26 & 3. 99 & +.11 \\
\hline & 5 & $\theta$ & Aurigæ & 4. 47 & 4. 24 & -.07 & & 26 & Aurigæ & 4. 10 & 3. 88 & +.11 \\
\hline & 6 & $\alpha$ & Lyræ & 4. 32 & 4. 05 & -.07 & & 26 & Lyræ & 4.53 & 4. 26 & +.11 \\
\hline & 7 & $\alpha$ & Lyræ & 4.15 & 3. 88 & -.06 & & 27 & Lyræ & 4.15 & 3. 88 & +.11 \\
\hline & 8 & $\alpha$ & Lyræ & 4. 66 & 4. 29 & -.06 & & 28 & Lyræ & 4.34 & 4. 07 & +11 \\
\hline & 30 & $\alpha$ & Lyræ & 4. 98 & 4. 71 & -02 & Mar. & 1 & Aurigæ & 4. 12 & 3. 90 & +10 \\
\hline Nov. & 2 & $\alpha$ & Lyræ & 4. 35 & 4. 08 & .00 & & 3 & Aurigæ & 3. 85 & 3. 62 & +.10 \\
\hline & 3 & $\alpha$ & Lyræ & 4. 71 & 4. 44 & .00 & & 5 & Aurigæ & 4. 15 & 3. 93 & +.10 \\
\hline & 3 & $\mu$ & Andromedæ & 4. 39 & 4. 12 & .00 & & 5 & Lyræ & 4. 34 & 4. 07 & +.10 \\
\hline & 3 & $\alpha$ & Can. Venat. & 5. 49 & 5. 07 & .00 & & 7 & Aurigæ & 3.89 & 3. 66 & +.10 \\
\hline & 4 & $\alpha$ & Lyræ & 4. 43 & 4. 16 & +.02 & & 8 & Aurigæ & 4.28 & 3. 86 & +10 \\
\hline & 6 & $\alpha$ & Lyræ & 4. 68 & 4. 41 & +.02 & & 9 & Aurigæ & 3. 92 & 3. 70 & +.10 \\
\hline & 6 & $\mu$ & Andromedæ & 4.94 & 4. 67 & +.02 & & 13 & Lyræ & 4. 61 & 4. 34 & +.09 \\
\hline & 9 & $\mu$ & Andromedæ & 4.20 & 3. 92 & +.04 & & 14 & Aurigæ & 4. 43 & 4. 21 & +.09 \\
\hline & 0 & $\mu$ & Andromedæ & 4. 17 & 3. 89 & +.04 & & 14 & Lyræ & 4. 27 & 4. 00 & +.09 \\
\hline & 1 & $\mu$ & Andromedæ & 4. 30 & 4. 02 & +.04 & & 17 & Lyræ & 4. 30 & 4. 03 & +09 \\
\hline & 2 & $\alpha$ & Can. Venat. & 4. 47 & 4. 05 & +.04 & & 19 & Aurigæ & 4. 05 & 3. 83 & +.08 \\
\hline & 3 & $\alpha$ & Lyræ & 4. 46 & 4. 19 & +.04 & & 25 & Lyræ & 4. 2 & 4. 01 & +.08 \\
\hline & 7 & $\alpha$ & Can. Venat. & 4. 83 & 4. 41 & +06 & & 31 & Lyræ & 4. 38 & 4.11 & +.07 \\
\hline & 8 & $\alpha$ & Lyræ & 4.89 & 4. 62 & +.06 & Apr. & 2 & Lyræ & 4. 57 & 4. 30 & +.07 \\
\hline & 8 & $\mu$ & Andromedæ & 4. 43 & 4.16 & +.06 & & 3 & Aurigæ & 4. 1 & 3. 90 & +.06 \\
\hline & 0 & $\alpha$ & Lyræ & 4. 09 & 3. 82 & +.08 & & 3 & Lyræ & 4. 41 & 4. 14 & +.06 \\
\hline & 0 & $\mu$ & Andromedæ & 4. 08 & 3. 80 & +.08 & & 7 & Lyræ & 4. 40 & 4. 13 & +.06 \\
\hline & 1 & $a$ & Lyræ & 4. 69 & 4. 42 & +.08 & & 8 & Aurigæ & 4. 38 & 4. 15 & +.06 \\
\hline & 33 & $\alpha$ & Can. Venat. & 4.30 & 3.88 & +10 & & 29 & Lyræ & 4. 50 & 4. 23 & +.01 \\
\hline & 4 & $\alpha$ & Lyræ & 4.93 & 4. 66 & +10 & May & 9 & Lyræ & 4.2 & 4. 01 & -.01 \\
\hline & 4 & $\mu$ & Andromedæ & 4. 50 & 4. 23 & +.10 & & 11 & Lyræ & 4.20 & 3. 93 & -.01 \\
\hline & 7 & $a$ & Lyræ & 4. 73 & 4.46 & +10 & & 12 & Lyræ & 4. 32 & 4. 05 & -.02 \\
\hline & 7 & $\mu$ & Andromedæ & 4. 11 & 3. 83 & +.10 & & 13 & Ursæ Maj. & & 3. 33 & -.02 \\
\hline & 30 & $\alpha$ & Lyræ & 5. 01 & 4. 74 & +.11 & & 13 & Lyræ & 4.38 & 4. 11 & -.02 \\
\hline & 30 & $\mu$ & Andromedæ & 4. 41 & 4. 13 & +.11 & & 14 & Ursæ Maj. & $\ldots$ & 3. 65 & -.02 \\
\hline Dec. & 1 & $\alpha$ & Lyræ & 4. 19 & 3. 92 & +.11 & & 17 & Ursæ Maj. & $\ldots$ & 3. 61 & -.03 \\
\hline & 1. & $\mu$ & Andromedæ & 4. 34 & 4. 07 & +.11 & & 17 & Lyræ & 4.62 & 4. 35 & -.03 \\
\hline & 6 & $\alpha$ & Lyræ & 4. 49 & 4. 22 & +.12 & & 18 & $\alpha \quad$ Iyræ & 4.43 & 4. 16 & -.03 \\
\hline
\end{tabular}


TABLE VIII.-The Latitude of the Instrument, Obitained by the Use of Newcomb and Boss Declinations-Continued

$+38^{\circ} 55^{\prime} 10^{\prime \prime}+$

*Indicates reflected observation.

\begin{tabular}{|c|c|c|c|c|c|c|c|c|c|c|c|c|}
\hline \multicolumn{2}{|c|}{ Date } & \multicolumn{2}{|r|}{ Star } & \multirow{2}{*}{$\prime \prime$} & \multirow{2}{*}{$\frac{\text { B. }}{\prime \prime}$} & $\Delta \varphi$ & Date & \multicolumn{2}{|r|}{ Star } & N. & B. & $\Delta \varphi$ \\
\hline 189 & & & & & & 11 & 1898 & & & "I & $\prime \prime$ & 11 \\
\hline May & & $\alpha$ & Lyræ & 4. 65 & 4. 38 & -0.04 & Oct. 27 & 0 & Lyræ & 4. 81 & 4. 54 & -0.09 \\
\hline & & $\alpha$ & Lyræ & 4.57 & 4. 30 & -.04 & 28 & & Lyræ & 5. 27 & 5. 00 & -.08 \\
\hline & & $\alpha$ & Lyræ & 4. 34 & 4. 07 & -.06 & Nov. 1 & & Lyræ & 4. 80 & 4. 53 & -.07 \\
\hline June & 2 & $\alpha$ & Lyræ & 4. 40 & 4. 13 & -.06 & 7 & & Lyræ & 4. 86 & 4. 59 & -.06 \\
\hline & & $\alpha$ & Lyræ & 4. 85 & 4. 58 & -.07 & 11 & & Lyræ & 4. 90 & 4. 63 & -.04 \\
\hline & 6 & $\alpha$ & Lyræ & 5. 03 & 4. 76 & -.07 & 15 & c & Lyræ & 5. 21 & 4. 94 & -.02 \\
\hline & 9 & $\alpha$ & Lyræ & 4. 58 & 4. 31 & -.08 & 21 & & Lyræ & 4. 86 & 4. 59 & -.02 \\
\hline & 19 & $\alpha$ & Lyræ & 4. 64 & 4. 37 & -.10 & 25 & & Lyræ & 4. 70 & 4. 43 & .00 \\
\hline & 22 & $\alpha$ & Lyræ & 4. 54 & 4. 27 & -.11 & 30 & $a$ & Lyræ & 5. 03 & 4. 76 & +.02 \\
\hline & 23 & $\alpha$ & Lyræ & 4. 41 & 4. 14 & -.11 & Dec. 1 & & Lyræ & 5. 13 & 4. 86 & +.02 \\
\hline & 24 & $\alpha$ & Lyræ & 4. 04 & 3. 77 & -.11 & $\begin{array}{l}1 \\
7\end{array}$ & & Lyræ & 4. 46 & 4. 19 & $\begin{array}{l}T .02 \\
+.03\end{array}$ \\
\hline & 29 & $\alpha$ & Lyræ & 4. 72 & 4. 45 & -.12 & 8 & $a$ & Lyræ & 4. 91 & 4. 64 & +.03 \\
\hline & 30 & $\alpha$ & Lyræ & 4.78 & 4. 51 & -.12 & 9 & a & Lyræ & 4. 72 & 4. 45 & $\begin{array}{r}.00 \\
+.03\end{array}$ \\
\hline July & 1 & $\alpha$ & Lyræ & 4. 81 & 4. 54 & -.12 & 10 & 0 & Lyræ & 4. 75 & 4.48 & $\begin{array}{r}.003 \\
+.03\end{array}$ \\
\hline & 7 & $\alpha$ & Lyræ & 4. 52 & 4. 25 & -.13 & 11 & & Lyræ & 4. 60 & 4. 33 & +.04 \\
\hline & 10 & $\alpha$ & Lyræ & 4. 34 & 4. 07 & -.14 & 13 & & Lyræ & 4. 33 & 4. 06 & +.04 \\
\hline & 11 & $\alpha$ & Lyræ & 4. 43 & 4. 16 & -.14 & 14 & $a$ & Lyræ & 5. 12 & 4. 85 & +.04 \\
\hline & 15 & $\alpha$ & Lyræ & 4. 34 & 4. 07 & -.15 & 15 & $\alpha$ & Lyræ & 4. 76 & 4. 49 & +.04 \\
\hline & 18 & $\alpha$ & Lyræ & 4. 66 & 4. 39 & -.16 & 16 & 0 & Lyræ & 4. 94 & 4. 67 & $\begin{array}{r}+.04 \\
\end{array}$ \\
\hline & 23 & $\alpha$ & Lyræ & 4. 27 & 4. 00 & -.16 & 23 & $\alpha$ & Lyræ & 4. 65 & 4. 38 & +.06 \\
\hline & 24 & & Lyræ & 4. 40 & 4. 13 & -.16 & 29 & a & Lyræ & 4. 51 & 4. 24 & +.08 \\
\hline & 28 & $\alpha$ & Lyræ & 4. 68 & 4. 41 & -.16 & 1899 & & & & & \\
\hline & 29 & $\alpha$ & Lyræ & 4. 41 & 4. 14 & -.17 & Jan. 18 & $\alpha$ & Lyræ & 5. 99 & 5. 72 & +.11 \\
\hline & 30 & $\alpha$ & Lyræ & 4. 52 & 4. 25 & -.17 & 19 & $a$ & Lyræ & 5. 02 & 4. 75 & $\begin{array}{r}T .11 \\
+.11\end{array}$ \\
\hline Aug. & 3 & $\alpha$ & Lyræ & 4. 75 & 4. 48 & -.18 & 24 & $a$ & Lyræ & 4. 47 & 4. 20 & $\begin{array}{r}12 \\
+.12\end{array}$ \\
\hline & 5 & & Lyræ & 4. 71 & 4.44 & -.18 & 26 & $\alpha$ & Lyræ & 4. 98 & 4. 71 & $\begin{array}{r}+12 \\
+.12\end{array}$ \\
\hline & 6 & $\alpha$ & Lyræ & 4. 75 & 4. 48 & -.18 & 30 & $\theta$ & Aurigæ & 4. 00 & 3. 78 & +.14 \\
\hline & & $\alpha$ & Lyræ & 4. 45 & 4. 18 & -.18 & Feb. $\quad 1$ & $\theta$ & Aurigæ & 4. 03 & 3. 81 & +.15 \\
\hline & 30 & $\alpha$ & Lyræ & 4. 74 & 4. 47 & -.18 & & $\alpha$ & Lyræ & 4. 67 & 4. 36 & +.15 \\
\hline & $\begin{array}{l}31 \\
31\end{array}$ & $\underset{\theta}{\alpha}$ & $\begin{array}{l}\text { Lyræ } \\
\text { Aurigæ }\end{array}$ & 5. 04 & 4. 77 & -.18 & 20 & $\theta$ & Aurigæ & 3. 78 & 3. 55 & +.15 \\
\hline & & & Aurigæ & 5. 60 & 5. 38 & -.18 & 22 & $\alpha$ & Lyræ & 4. 23 & 3. 96 & +.15 \\
\hline Sept. & $\frac{1}{3}$ & $\alpha$ & Lyræ & 4. 94 & 4. 67 & -.18 & 24 & $\alpha$ & Lyræ & 5. 34 & 5. 07 & +.15 \\
\hline & $\begin{array}{l}5 \\
5\end{array}$ & $\begin{array}{l}\alpha \\
\alpha\end{array}$ & Lyræ & 4. 69 & 4. 42 & -.18 & Mar. 3 & $\alpha$ & Lyræ & 4. 47 & 4. 20 & +.15 \\
\hline & $\begin{array}{l}5 \\
5\end{array}$ & ${ }_{\theta}^{\alpha}$ & $\begin{array}{l}\text { Lyræ } \\
\text { Aurigm }\end{array}$ & 4. 67 & 4. 40 & -.18 & & $\alpha$ & Lyræ & 4.07 & 3. 80 & +.15 \\
\hline & $\begin{array}{l}5 \\
6\end{array}$ & $\theta$ & Aurigæ & 4. 79 & 4. 57 & -.18 & 10 & $\theta$ & Aurigæ & 4.01 & 3. 79 & +.15 \\
\hline & $\begin{array}{l}6 \\
8\end{array}$ & $\alpha$ & Lyræ & 4. 64 & 4. 37 & -.18 & 11 & $\theta$ & Aurigæ & 4.07 & 3. 85 & +.15 \\
\hline & $\begin{array}{l}8 \\
9\end{array}$ & $\alpha$ & Lyræ & 4. 81 & 4. 54 & -.18 & 16 & $\alpha$ & Lyræ & 3. 93 & 3. 66 & +14 \\
\hline & 9 & $\alpha$ & Lyræ & 4. 68 & 4. 41 & -.18 & 17 & $\theta$ & Aurigæ & 4. 38 & 4. 15 & +14 \\
\hline & 10 & $\alpha$ & Lyræ & 4. 36 & 4. 09 & -.17 & 19 & $\alpha$ & Lyræ & 4. 14 & 3. 87 & +.14 \\
\hline & 12 & $\alpha$ & Lyræ & 4. 35 & 4. 08 & -.17 & 20 & $\theta$ & Aurigæ & 3. 77 & 3. 54 & +.14 \\
\hline & 12 & $\theta$ & Aurigæ & 4. 69 & 4. 47 & -.17 & 23 & $\theta$ & Aurigæ & 4. 12 & 3. 90 & +14 \\
\hline & 13 & $\alpha$ & Lyræ & 4. 54 & 4. 27 & -.17 & 24 & $\theta$ & Aurigæ & 4.22 & 4. 00 & $\begin{array}{r}+.14 \\
+.14\end{array}$ \\
\hline & 16 & $\alpha$ & Lyræ & 4. 80 & 4. 53 & -.17 & 29 & $\theta$ & Aurigæ & 3.96 & 3. 74 & +.13 \\
\hline & 16 & $\theta$ & Aurigæ & 4. 75 & 4. 53 & -.17 & Apr. 3 & $\theta$ & Aurigæ & 4. 16 & 3. 94 & +.13 \\
\hline & 17 & $\alpha$ & Lyræ & 4.99 & 4. 72 & -.17 & 5 & $\theta$ & Aurigæ & 4. 27 & 4. 05 & +.13 \\
\hline & 17 & $\theta$ & Aurigæ & 4. 78 & 4. 56 & -.17 & 5 & $\alpha$ & Lyræ & 4. 72 & 4. 45 & +.13 \\
\hline & 19 & $\alpha$ & Lyræ & 4. 72 & 4.45 & -.16 & 9 & $\alpha$ & Lyræ & 4.55 & 4.28 & $\begin{array}{l}+13 \\
+.13\end{array}$ \\
\hline & 20 & $\alpha$ & Lyræ & 4. 29 & 4. 02 & -.16 & 10 & $\alpha$ & Lyræ & 4. 43 & 4. 16 & +12 \\
\hline & 23 & $\alpha$ & Lyræ & 4. 47 & 4. 20 & -.16 & 11 & $\theta$ & Aurigæ & 4.23 & 4. 01 & $\begin{array}{r}+12 \\
+.12\end{array}$ \\
\hline & 24 & $\alpha$ & Lyræ & 4. 10 & 3. 83 & -.16 & 12 & $\alpha$ & Lyræ & 4.25 & 3. 98 & +.12 \\
\hline & 26 & $\theta$ & Aurigæ & 4. 32 & 4. 10 & -.15 & 16 & $\alpha$ & Lyræ & 4. 24 & 3. 97 & +12 \\
\hline & 27 & $\alpha$ & Lyræ & 4. 16 & 3. 89 & -.15 & 17 & $\alpha$ & Lyræ & 4.27 & 4.00 & +12 \\
\hline & 28 & $\alpha$ & Lyræ & 4. 11 & 3. 84 & -.15 & 19 & $\alpha$ & Lyræ & 4. 38 & 4.11 & +11 \\
\hline & 28 & $\theta$ & Aurigæ & 4. 39 & 4. 16 & -.15 & 21 & $\alpha$ & Lyræ & 4. 56 & 4. 29 & +10 \\
\hline & 29 & $\alpha$ & Lyræ & 4. 28 & 4. 01 & -.14 & 22 & $\alpha$ & Lyræ & 4. 44 & 4. 17 & +10 \\
\hline & 29 & $\theta$ & Aurigæ & 4. 28 & 4. 06 & -.14 & 23 & $\alpha$ & Lyræ & 4. 11 & 3. 84 & +.10 \\
\hline & 30 & $\alpha$ & Lyræ & 4. 42 & 4. 15 & -.14 & 24 & $\alpha$ & Lyræ & 4. 14 & 3. 87 & $\begin{array}{l}+10 \\
+.10\end{array}$ \\
\hline Oct. & 9 & $\alpha$ & Lyræ & 4. 20 & 3. 93 & -.13 & 26 & $\alpha$ & Lyræ & 4. 00 & 3. 73 & +10 \\
\hline & 10 & $\alpha$ & Lyræ & 4. 17 & 3. 90 & -.12 & 28 & $\alpha$ & Lyræ & 4.28 & 4. 01 & $\begin{array}{r}10 \\
+.10\end{array}$ \\
\hline & 12 & $\alpha$ & Lyræ & 4. 58 & 4. 31 & -.12 & 29 & $\alpha$ & Lyræ & 4. 40 & 4. 13 & +.10 \\
\hline & 13 & $\alpha$ & Lyræ & 4. 62 & 4. 35 & -.12 & 30 & $\alpha$ & Lyræ & 4. 12 & 3. 85 & $\begin{array}{l}+10 \\
+.10\end{array}$ \\
\hline & 16 & $\alpha$ & Lyræ & 3. 87 & 3. 60 & -.12 & May 11 & $\alpha$ & Lyræ & 4. 29 & 4. 02 & $\begin{array}{l}+07 \\
+.07\end{array}$ \\
\hline & 17 & $\alpha$ & Lyræ & 4. 66 & 4. 39 & -.11 & 13 & $\alpha$ & Lyræ & 4.02 & 3. 85 & +06 \\
\hline & 19 & $\alpha$ & Lyræ & 4. 66 & 4. 39 & -.11 & 19 & $\alpha$ & Lyræ & 4. 41 & 4. 14 & $\begin{array}{l}+.06 \\
+.06\end{array}$ \\
\hline & 20 & $\alpha$ & Lyræ & 4. 89 & 4. 62 & -.11 & 20 & $\alpha$ & Lyræ & 4. 53 & 4. 26 & +.05 \\
\hline & 22 & $\alpha$ & Lyræ & 4. 41 & 4. 14 & -.11 & 25 & $\alpha$ & Lyræ & 4. 26 & 3. 99 & $\begin{array}{r}.04 \\
+.04\end{array}$ \\
\hline & 24 & $\alpha$ & Lyræ & 4. 51 & 4. 24 & -.09 & 26 & $\alpha$ & Lyræ & 4. 21 & 3. 94 & +.04 \\
\hline
\end{tabular}


INTRODUCTION.

A CV

TABLE VIII.-The Latitude of the Instrument, Obtained by the Use of Newcomb and Boss Declinations-Continued

$+38^{\circ} 55^{\prime} 10^{\prime \prime}+$

*Indicates reflected observation.

\begin{tabular}{|c|c|c|c|c|c|c|c|c|c|c|c|}
\hline \multicolumn{2}{|c|}{ Date } & \multicolumn{2}{|r|}{ Star } & N. & B. & $\Delta \varphi$ & Date & Star & N. & B. & $\Delta \varphi$ \\
\hline \multirow{2}{*}{\multicolumn{2}{|c|}{$\begin{array}{c}1899 \\
\text { June } 2\end{array}$}} & & & "' & $1 \prime$ & 11 & \multirow{2}{*}{$\begin{array}{c}1899 \\
\text { Oct. } \quad 23\end{array}$} & & 11 & 11 & 11 \\
\hline & & $\alpha$ & Lyræ & 4. 20 & 3. 93 & +0.03 & & Lyræ & 4. 73 & 4. 46 & -0.12 \\
\hline & & & Lyræ & 4. 04 & 3. 77 & +.03 & & Lyræ & 4. 42 & 4. 15 & -.12 \\
\hline & 5 & $\alpha$ & Lyræ & 4.13 & 3. 86 & +.02 & 25 & Lyræ & 4.85 & 4. 58 & -.12 \\
\hline & 7 & $\alpha$ & Lyræ & 4. 21 & 3. 94 & +.02 & 26 & Lyræ & 4. 75 & 4. 48 & -.12 \\
\hline & 13 & $\alpha$ & Lyræ & 4. 29 & 4. 02 & +.01 & 27 & Lyræ & 4. 61 & 4. 34 & -.12 \\
\hline & 14 & & Lyræ & 4. 33 & 4. 06 & +.01 & Nov. 2 & Lyræ & 4. 82 & 4. 55 & -.12 \\
\hline & 16 & $\alpha$ & Lyræ & 4. 25 & 3. 98 & .00 & 27 & Lyræ & 5. 09 & 4. 82 & -.10 \\
\hline & 18 & $\alpha$ & Lyræ & 4. 54 & 4. 27 & .00 & Dec. 1 & Lyræ & 4. 88 & 4. 61 & -.09 \\
\hline & 21 & $\alpha$ & Lyræ & 4. 25 & 3. 98 & .00 & 2 & Lyræ & 4. 63 & 4. 36 & -.09 \\
\hline & 22 & $\alpha$ & Lyræ & 4. 09 & 3. 82 & -.01 & 4 & Lyræ & 4. 95 & 4. 68 & -.08 \\
\hline & 23 & $\alpha$ & Lyrræ & 4. 62 & 4. 35 & -.01 & 5 & Lyræ & 4. 99 & 4. 72 & -.08 \\
\hline & 24 & $\alpha$ & Lyræ & 4. 37 & 4. 10 & -.01 & 7 & Lyræ & 4. 74 & 4. 47 & -.07 \\
\hline & 25 & $\alpha$ & Lyræ & 4. 56 & 4. 29 & -.01 & 8 & Lyræ & 4. 90 & 4. 63 & -.07 \\
\hline July & 1 & $\alpha$ & Lyræ & 4. 23 & 3. 96 & -.02 & 9 & Lyræ & 4. 84 & 4. 57 & -.07 \\
\hline & 2 & $\alpha$ & Lyræ & 4.05 & 3. 78 & -.02 & 12 & Lyræ & 4.55 & 4. 28 & -.06 \\
\hline & $\overline{9}$ & $\alpha$ & Lyræ & 4. 31 & 4. 04 & -.03 & 13 & Lyræ & 4. 72 & 4. 45 & -.06 \\
\hline & 11 & $\alpha$ & Lyræ & 4. 35 & 4. 08 & -.04 & 20 & Lyræ & 5. 24 & 4. 97 & -.06 \\
\hline & 14 & $\alpha$ & Lyræ & 4. 30 & 4. 03 & -.05 & 21 & Lyræ & 5. 43 & 5. 16 & -.03 \\
\hline & 17 & $\alpha$ & Lyræ & 4. 35 & 4. 08 & -.05 & 22 & Lyræ & 5. 12 & 4.85 & -.02 \\
\hline & 18 & $\alpha$ & Lyræ & 4. 42 & 4. 15 & -.06 & & & & & \\
\hline & 20 & $\alpha$ & Lyræ & 4. 38 & 4. 11 & -.06 & 1900 & & & & \\
\hline & 22 & $\alpha$ & Lyræ & 4. 23 & 3. 96 & -.07 & Jan. 21 & Lyræ & 4. 49 & 4. 22 & +.03 \\
\hline & 27 & $\alpha$ & Lyræ & 4. 47 & 4. 20 & -.08 & 22 & Lyræ & 4. 61 & 4. 34 & +.03 \\
\hline & 30 & $\alpha$ & Lyræ & 4. 41 & 4. 16 & -.08 & 23 & Lyræ & 4.69 & 4. 42 & +.03 \\
\hline & 31 & & Lyræ & 4. 28 & 4. 01 & -08 & 27 & Lyræ & 4.57 & 4. 30 & +.04 \\
\hline Aug. & 1 & $\alpha$ & Lyræ & 4. 57 & 4. 30 & -.08 & Feb. 2 & Lyræ & 4. 93 & 4. 66 & +.04 \\
\hline & 2 & $\alpha$ & Lyræ & 4. 57 & 4. 30 & -.09 & 4 & $\alpha \quad$ Lyræ & 4. 62 & 4. 35 & +.05 \\
\hline & 3 & $\alpha$ & Lyræ & 4. 24 & 3. 97 & -.09 & 13 & 62 Aurigæ & & 4. 31 & +.06 \\
\hline & 6 & $\alpha$ & Lyræ & 4. 75 & 4. 48 & -.10 & 14 & $\mu \quad$ Aurigæ & 4. 60 & 4. 49 & +.06 \\
\hline & 7 & $\alpha$ & Lyræ & 4. 36 & 4. 09 & -.10 & 19 & $\alpha \quad$ Lyræ & 4. 44 & 4. 27 & +.06 \\
\hline & 8 & $\alpha$ & Lyræ & 4. 40 & 4. 13 & -.10 & 23 & 110 B. Lyncis & 4. 20 & 3. 83 & +.07 \\
\hline & 16 & $\alpha$ & Lyræ & 4.28 & 4. 01 & -.10 & 25 & $\alpha \quad$ Lyræ & 4. 51 & 4. 24 & +.07 \\
\hline & 17 & $\alpha$ & Lyræ & 4. 16 & 3. 89 & -.11 & 26 & $40 \quad$ Aurigæ & & 3. 90 & +.07 \\
\hline & 20 & $\alpha$ & Lyræ & 4. 43 & 4. 16 & -.12 & 26 & $\alpha \quad$ Lyræ & 4. 70 & 4. 43 & +.07 \\
\hline & 22 & $\alpha$ & Lyræ & 3. 61 & 3. 34 & -.12 & Mar. 2 & 110 B. Lyncis & 4. 21 & 3. 84 & +.08 \\
\hline & 22 & $\theta$ & Aurigæ & 4. 66 & 4. 44 & -.12 & 3 & 60 Aurigæ & & 3. 99 & +.08 \\
\hline & 24 & $\alpha$ & Lyræ & 4. 37 & 4. 10 & -.12 & 3 & $\alpha \quad$ Lyræ & 4. 35 & 4. 08 & +.08 \\
\hline & 24 & $\theta$ & Aurigæ & 4. 31 & 4. 09 & -.12 & 16 & B. D. $+38^{\circ} 1539$ & $\ldots$ & 4. 16 & +.09 \\
\hline & 31 & $\alpha$ & Lyræ & 4.32 & 4. 05 & -.12 & 16 & B. D. 371769 & & 3. 71 & +.09 \\
\hline Sept. & 1 & $\alpha$ & Lyræ & 4. 40 & 4. 13 & -.12 & 16 & Lyræ & 4. 32 & 4. 05 & +.09 \\
\hline & 5 & $\alpha$ & Lyræ & 4.57 & 4. 30 & -.13 & 21 & Lyræ & 4. 35 & 4. 08 & +.10 \\
\hline & 6 & $\alpha$ & Lyræ & 4. 40 & 4. 13 & --.13 & 22 & $\alpha \quad$ Lyræ & 4. 80 & 4. 53 & +.10 \\
\hline & 6 & $\theta$ & Aurigæ & 4. 46 & 4. 23 & -.13 & 24 & B. D. $+37^{\circ} 1769$ & & 4. 01 & +.10 \\
\hline & 9 & $\alpha$ & Lyræ & 4. 41 & 4. 14 & -.13 & 31 & $\alpha \quad$ Lyræ & 4. 42 & 4. 15 & +.10 \\
\hline & 9 & $\theta$ & Aurigæ & 4. 23 & 4. 01 & -.13 & Apr. 1 & Lyræ & 4. 45 & 4. 18 & +.10 \\
\hline & 11 & $\alpha$ & Lyræ & 4.66 & 4. 39 & -.13 & 4 & Lyræ & 4. 19 & 3. 92 & +.11 \\
\hline & 11 & $\theta$ & Aurigæ & 4.51 & 4. 28 & -.13 & 5 & Lyncis & 3. 99 & 3. 86 & +.11 \\
\hline & 12 & $\alpha$ & Lyræ & 4.77 & 4. 50 & -.13 & 7 & 17 Leo. Min. & & 3. 73 & +.11 \\
\hline & 12 & $\theta$ & Aurigæ & 4. 53 & 4. 30 & -.13 & 7 & Lyræ & 4. 43 & 4. 16 & +.11 \\
\hline & 13 & $\alpha$ & Lyræ & 4.64 & 4. 37 & -.13 & 9 & Leo. Min. & & 3. 68 & +.11 \\
\hline & 14 & $\alpha$ & Lyræ & 4. 43 & 4. 16 & -.13 & 9 & Lyræ & 4. 34 & 4. 07 & +.11 \\
\hline & 14 & $\theta$ & Aurigæ & 5. 05 & 4. 82 & -.13 & 14 & $\alpha \quad$ Lyræ & 4. 49 & 4. 22 & +.11 \\
\hline & 15 & $\alpha$ & Lyræ & 4. 43 & 4. 16 & -.13 & 19 & 31 Leo. Min. & 3. 91 & 3. 85 & +.12 \\
\hline & 24 & $\alpha$ & Lyræ & 4. 45 & 4. 18 & -.13 & June 11 & 295 B. Boötis & 4. 93 & 4. 41 & +.13 \\
\hline & 27 & $\alpha$ & Lyræ & 4. 49 & 4. 22 & -.13 & 11 & $\mu^{1}$ Boötis & 4. 61 & 4. 26 & +.13 \\
\hline & 28 & $\alpha$ & Lyræ & 4. 31 & 4.04 & -.13 & 11 & Boötis & $\ldots$ & 4. 48 & +.13 \\
\hline & 30 & $\alpha$ & Lyræ & 4.23 & 3. 96 & -.13 & 11 & 25 Herculis & & 4. 12 & +.13 \\
\hline Oct. & 1 & $\alpha$ & Lyræ & 4. 38 & 4. 11 & -.13 & 11 & $\alpha \quad$ Lyræ & 4. 93 & 4. 66 & +.13 \\
\hline & 3 & $\alpha$ & Lyræ & 4. 20 & 3. 93 & -.13 & 20 & B. D. $+37^{\circ} 2580$ & & 3. 84 & +.13 \\
\hline & 9 & $\alpha$ & Lyræ & 4. 37 & 4. 10 & -.13 & 20 & $\alpha \quad$ Lyræ & 4. 89 & 4. 62 & +.13 \\
\hline & 10 & $\alpha$ & Lyræ & 4.47 & 4.20 & -.13 & 30 & B. D. $+38^{\circ} 2629$ & & 4. 19 & +.13 \\
\hline & 12 & $\alpha$ & Lyræ & 4. 35 & 4. 08 & -.13 & 30 & $\alpha \quad$ Lyræ & 4. 49 & 4. 22 & +.13 \\
\hline & 13 & $\alpha$ & Lyræ & 4. 38 & 4. 11 & -.13 & July & B. D. $+37^{\circ} 2580$ & & 3. 84 & +.13 \\
\hline & 14 & $\alpha$ & Lyræ & 4. 66 & 4. 39 & -.12 & 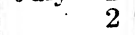 & $\alpha$ Lyræ & 4.81 & 4. 54 & +.13 \\
\hline & 19 & $\alpha$ & Lyræ & 4. 37 & 4. 10 & -.12 & 9 & Lyræ & 4. 80 & 4. 53 & +.13 \\
\hline & 20 & $\alpha$ & Lyræ & 4. 94 & 4.67 & -.12 & 10 & $\lambda$ Cornæ Bor. & $\ldots$ & 4. 37 & +.12 \\
\hline & 21 & $\alpha$ & Lyræ & 4. 24 & 3. 97 & -.12 & 10 & 25 Herculis & $\ldots$ & 3.81 & +.12 \\
\hline
\end{tabular}


A CVI

PRIME VERTICAL TRANSIT INSTRUMENT.

TABLE VIII.-The Latitude of the Instrument, Obtained by the Use of Newcomb and Boss Declinations-Continued

$+38^{\circ} 55^{\prime} 10^{\prime \prime}+\quad *$ Indicates reflected observation.

\begin{tabular}{|c|c|c|c|c|c|c|c|c|c|c|}
\hline Dat & & Star & N. & B. & $\Delta \varphi$ & Date & Star & N. & B. & $\Delta \varphi$ \\
\hline \multirow{2}{*}{\multicolumn{2}{|c|}{$\begin{array}{c}1900 \\
\text { July } 10\end{array}$}} & & $\prime \prime$ & $\prime \prime$ & $\prime \prime$ & 1900 & & & "' & "I \\
\hline & & B. D. 373882 & & 3. 99 & +0.12 & Oct. 27 & 72 Cygni & 4. 63 & 4. 17 & +0.02 \\
\hline & 11 & $\mu^{1}$ Boötis & 4. 42 & 4. 07 & +.12 & 27 & B. D. $+37^{\circ} 4537$ & & 5. 17 & +.02 \\
\hline & 11 & $\alpha \quad$ Lyræ & 4. 53 & 4. 26 & +.12 & 30 & $\alpha \quad$ Lyræ & 4. 77 & 4. 50 & +.02 \\
\hline & 13 & Lyræ & 4. 09 & 3. 82 & +.12 & Nov. 21 & Lyræ & 4. 68 & 4. 41 & -.00 \\
\hline & 15 & $\lambda$ Cornæ Bor. & $---\overline{-}$ & 3. 52 & +.12 & 23 & $\alpha \quad$ Lyræ & 5. 08 & 4. 81 & -.00 \\
\hline & 15 & $e \quad$ Herculis & 3. 81 & 3. 26 & +.12 & 27 & 12 Andromedæ & & 4. 18 & -.00 \\
\hline & 15 & $\alpha \quad$ Lyre & 4. 24 & 3. 97 & +.12 & 27 & $\rho \quad$ Andromedæ & 5.05 & 4. 79 & -.00 \\
\hline & 17 & B. D. $+37^{\circ} 2882$ & & 3. 72 & +.12 & 27 & $\theta \quad$ Andromedæ & & 4. 80 & -.00 \\
\hline & 17 & $\theta \quad$ Herculis & 4. 68 & 4. 48 & +.12 & 30 & 10 Lacertæ & 5. 04 & 4. 82 & -.01 \\
\hline & 24 & $\zeta \quad$ Lyræ & $\ldots$ & 4. 33 & +.10 & 30 & 14 Andromedæ & 107 & 4. 60 & -.01 \\
\hline & 24 & $7 \quad$ Lyræ & & 4. 35 & +.10 & Dec. 1 & $\alpha \quad$ Lyræ $^{*}$ & 4. 07 & 3. 80 & -.01 \\
\hline & 24 & Lyræ & 4. 48 & 4. 21 & +.10 & 2 & $\begin{array}{ll}\alpha & \text { Lyræ }\end{array}$ & 5. 79 & 5. 52 & -.01 \\
\hline & 27 & Herculis & 3. 79 & 3. 64 & +.11 & 2 & 14 Andromedæ & 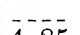 & 4. 68 & -.01 \\
\hline & 27 & Herculis & 4. 53 & 4. 33 & +.11 & 6 & $\rho \quad$ Andromedæ & 4. 85 & 4. 60 & -.01 \\
\hline & 27 & Lyræ & 4. 52 & 3. 97 & +.11 & 27 & Lyræ & 5.30 & 5. 03 & -.02 \\
\hline Aug. & & Lyræ & $\ldots$ & 3. 92 & +.10 & 27 & Andromedæ & & 4. 82 & -.02 \\
\hline & 1 & Lyræ & & 4. 13 & +.10 & 29 & $\alpha \quad$ Lyræ * & 4. 49 & 4. 22 & -.02 \\
\hline & 1 & Lyræ & 3. 96 & 3. 69 & +.10 & 29 & 47 Andromedæ & $\ldots$ & 5. 12 & -.02 \\
\hline & 3 & $e \quad$ Herculis & 4. 20 & 3. 64 & +.10 & & & & & \\
\hline & $\begin{array}{l}8 \\
8\end{array}$ & $\rho \quad$ Herculis & 3. 79 & 3. 64 & $\begin{array}{l}+.10 \\
+\quad 10\end{array}$ & 1901 & Lvræ & 5.74 & 5.46 & -02 \\
\hline & 14 & $\begin{array}{l}\alpha \\
\text { B. D. }+383113\end{array}$ & $\begin{array}{l}4.20 \\
\ldots .-1\end{array}$ & $\begin{array}{l}\text { 3. } 98 \\
\text { 3. } 29\end{array}$ & $\begin{array}{l}+.10 \\
+.09\end{array}$ & $\begin{array}{ll}\text { Jan. } & 5 \\
3\end{array}$ & Andromedæ & 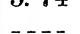 & $\begin{array}{l}\text { J. } 40 \\
\text { 4. } 65\end{array}$ & $\begin{array}{l}-.02 \\
-02\end{array}$ \\
\hline & 17 & B. D. +383113 & -1 & $\begin{array}{l}3.53 \\
\text { 3. } 53\end{array}$ & +.09 & 3 & 47 Andromedæ & $\ldots$ & 5. 17 & -.02 \\
\hline & 17 & $\alpha \quad$ Lyræ & 4. 28 & 4. 01 & +.09 & 3 & 58 Andromedæ & --- & 4. 85 & -.02 \\
\hline & 17 & 40 Cygni & 4. 37 & 3. 65 & +.09 & 4 & Lyræ* & 4. 96 & 4. 68 & -.02 \\
\hline & 28 & 15 Cygni & 4. 77 & 4. 20 & +.08 & 4 & 58 Andromedæ & & 4. 69 & -.02 \\
\hline & 28 & B. D. $+38^{\circ} 4325$ & & 4. 17 & +.08 & 5 & $\mu \quad$ Andromedæ & 4. 78 & 4. 50 & -.02 \\
\hline Sept. & 2 & $\alpha \quad$ Lyræ & 4. 44 & 4. 17 & +.07 & 6 & Lyræ & 5. 33 & 5. 05 & -.02 \\
\hline & $\begin{array}{l}2 \\
2\end{array}$ & & $\begin{array}{l}\text { 4. } 91 \\
\text { 4. } 45\end{array}$ & $\begin{array}{l}\text { 4. } 33 \\
4.22\end{array}$ & $\begin{array}{l}+.07 \\
+.07\end{array}$ & $\begin{array}{r}7 \\
12\end{array}$ & $\begin{array}{ll}\alpha & \text { Lyræ * } \\
\alpha & \text { Lyræ }\end{array}$ & $\begin{array}{l}5.12 \\
5.40\end{array}$ & 4. 84 & $\begin{array}{l}-.02 \\
-.02\end{array}$ \\
\hline & $\begin{array}{l}2 \\
2\end{array}$ & $\begin{array}{l}61^{1} \text { Cygni } \\
61^{2} \text { Cygni }\end{array}$ & 4. 40 & $\begin{array}{l}\text { 4. } 13 \\
\text { 4. }\end{array}$ & +.07 & 13 & $\begin{array}{l}\alpha \\
\text { B. D. }+37^{\circ} 372\end{array}$ & & 4. 66 & -.02 \\
\hline & 3 & $\theta \quad$ Lyræ & 4. 66 & 4. 11 & +.07 & 14 & $\alpha \quad$ Lyræ* & 4. 83 & 4.55 & -.02 \\
\hline & 4 & $\alpha \quad$ Lyræ & 4. 17 & 3. 90 & +.07 & 15 & $\alpha \quad$ Lyræ & 4. 96 & 4. 6 & -.02 \\
\hline & 6 & $\alpha \quad$ Lyræ* & 4. 49 & 4. 22 & +.07 & 16 & $59^{1}$ Andromedæ & $\ldots$ & 4. 43 & -.02 \\
\hline & 6 & 40 Cygni & 5. 04 & 4. 33 & +.07 & 16 & $59^{2}$ Andromedæ & & 4. 66 & -.02 \\
\hline & 11 & B. D. $+38^{\circ} 3373$ & $-\cdots$ & 4. 49 & +.06 & 18 & $\rho \quad$ Persei & 4. 39 & 4. 41 & -.02 \\
\hline & 11 & B. D. $+38^{\circ} 4325$ & & 3. 67 & +.06 & 18 & $\alpha \quad$ Lyræ & 4.90 & 4. 6 & -.02 \\
\hline & 12 & $\alpha \quad$ Lyræ & 3. 88 & 3. 61 & +.06 & 19 & B. D. $+37^{\circ} 811$ & $\therefore--$ & 4. 8 & -.02 \\
\hline & 12 & 79 Cygni & & 4. 24 & +.06 & 19 & 49 Persei & 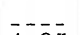 & 4. 68 & -.02 \\
\hline & 16 & Cygni & 4. 90 & 4. 43 & +.06 & 19 & Lyræ* * & 4.95 & 4. 6 & -.02 \\
\hline & 17 & $\alpha \quad$ Lyræ & 4. 65 & 4. 38 & +.06 & 20 & 16 Persei & $\ldots$ & 4. 85 & -.02 \\
\hline & 18 & Lyræ* & 4. 39 & 4. 12 & +.06 & 20 & B. D. $+37^{\circ} 878$ & - & 5. 1 & -.02 \\
\hline & 18 & $\tau \quad$ Cygni & 4. 69 & 4. 22 & +.06 & 25 & $\alpha \quad$ Lyræ & 5. 41 & 5. 1 & -.02 \\
\hline & 19 & B. D. $+37^{\circ} 3916$ & & 4. 54 & +.06 & 29 & B. D. $+37^{\circ} 811$ & $\ldots$ & 4. 60 & -.02 \\
\hline & 24 & $\alpha \quad$ Lyræ & 3. 85 & 3.58 & +.05 & 31 & 20 Persei & $\ldots$ & 4. 5 & -.02 \\
\hline & 26 & $\alpha \quad$ Lyræ* & 4. 83 & 4. 56 & +.05 & 31 & Persei & & 4. 6 & -.02 \\
\hline & 27 & Lyræ & 3. 91 & 3. 64 & +.05 & Feb. & Lyræ* & 5. 14 & 4. 8 & -.02 \\
\hline Oct. & 9 & Lyræ & 3. 99 & 3. 72 & +.04 & 5 & Aurigæ & & & -.02 \\
\hline & 9 & Cygni & 4. 46 & 4. 00 & +.04 & 5 & Lyræ & 4. 92 & 4. 6 & -.02 \\
\hline & 9 & 10 Lacertæ & 4. 33 & 4. 11 & +.04 & 6 & Lyræ & 5.49 & 5. & -.02 \\
\hline & 10 & B. D. +383758 & $\ldots$ & 4. 21 & +.03 & 7 & $\rho \quad$ Persei & 4. 20 & 4. 22 & -.02 \\
\hline & 10 & B. D. $+37^{\circ} 4537$ & & 5. 51 & +.03 & 7 & $50 \quad$ Persei & $\ldots$ & 4. 3 & -.02 \\
\hline & 11 & $\alpha \quad$ Lyræ & 4. 49 & 4. 22 & +.03 & 7 & Aurigæ & $-x_{1}$ & & -.02 \\
\hline & 15 & $\alpha \quad$ Lyræ* & 4. 40 & 4.13 & +.03 & $\dot{9}$ & $\alpha \quad$ Lyræ & 4.93 & 4.6 & -.02 \\
\hline & 17 & $61^{1}$ Cygni & 4. 88 & 4. 65 & +.03 & 10 & B. D. $+37^{\circ} 878$ & & 4. 33 & -.03 \\
\hline & 17 & $61^{2}$ Cygni & & 4. 56 & $+: 03$ & 11 & $\alpha \quad$ Lyræ & 4.82 & 4. 5 & -.03 \\
\hline & 18 & $\alpha \quad$ Lyræ & 4. 67 & 4. 40 & +.0 & 12 & Aurigæ & & 3. 2 & -.03 \\
\hline & 19 & Lyræ & 4. 65 & 4. 38 & +.03 & 12 & Lyræ & 4. 42 & 4. & -.03 \\
\hline & 19 & Cygni & $\ldots$. & 4. 13 & +.03 & 27 & Lyræ & 4. 48 & 4. 20 & -.03 \\
\hline & 19 & Lacertæ & $\ldots$ & 3. 88 & +.03 & Mar. 7 & Aurigæ & & 4. 52 & -.03 \\
\hline & 19 & Andromedæ & $\ldots$ & 3. 84 & +.03 & 14 & 38 Lyncis & 4. 14 & 4. 00 . & -.03 \\
\hline & 20 & Lyræ* & 4. 83 & 4. 56 & +.03 & 16 & B. D. $+38^{\circ} 1539$ & & 3. 66 & -.03 \\
\hline & 21 & Lyræ & 4. 40 & 4. 13 & +.02 & 16 & 38 Lyncis & 4. 23 & 4. 09 & -.03 \\
\hline & 25 & Lyræ* & 4. 99 & 4. 72 & +.02 & 16 & $\alpha \quad$ Lyræ & 4. 49 & 4. 21 & -.03 \\
\hline & 26 & Cygni & -..- & 4. 20 & +.02 & 17 & 110 B. Lyncis & 4. 41 & 4. 05 & -.03 \\
\hline & 26 & Lacertæ & 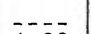 & 4. 08 & +.02 & 17 & $\alpha \quad$ Lyræ* & 4. 69 & 4. 41 & -.03 \\
\hline & 27 & Lyræ & 4. 39 & 4. 12 & +.02 & 18 & 62 Aurigæ & $\ldots$ & 3. 76 & -.03 \\
\hline
\end{tabular}


INTRODUCTION.

A CVII

TABLE VIII.-The Latitude of the Instrument, Obtained by the Use of Newcomb and Boss Declinations-Continued

$+38^{\circ} 55^{\prime} 10^{\prime \prime}+\quad *$ Indicates reflected observation.

\begin{tabular}{|c|c|c|c|c|c|c|c|c|c|c|}
\hline Date & Star & N. & B. & $\Delta \varphi$ & \multicolumn{2}{|l|}{ Date } & Star & N. & B. & $\Delta \varphi$ \\
\hline & & 11 & 11 & 11 & \multicolumn{2}{|c|}{1901} & & 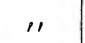 & 11 & $\prime \prime$ \\
\hline Mar. 1 & $\alpha \quad$ Lyræ & 4. 37 & 4. 09 & -0.03 & June & 4 & Lyræ & 4. 66 & 4. 38 & +0.05 \\
\hline & B. D. $+38^{\circ} 1539$ & $\ldots$ & 3. 69 & -.03 & & 8 & Lyræ & & 4.73 & $\begin{array}{r}T 0.00 \\
+.07\end{array}$ \\
\hline & 60 Aurigæ & $\ldots$ & 3. 68 & -.03 & & 9 & Can. Venat. & 5. 40 & 4. 78 & +07 \\
\hline 2 & B. D. $+38^{\circ} 1539$ & & 4. 48 & -.03 & & 9 & Bootis & 4. 97 & 4. 62 & +.07 \\
\hline 2 & B. D. $+37^{\circ} 1769$ & & 4. 45 & -.02 & & 9 & Bootis & $\ldots$ & 4. 90 & +.07 \\
\hline 2 & 110 B. Lyncis & 4. 52 & 4. 16 & -.02 & & 9 & Coronæ Bor. & & 4. 30 & +.07 \\
\hline 2 & $\alpha \quad$ Lyræ & 4. 43 & 4. 15 & -.02 & & 9 & Lyræ & 4.84 & 4. 56 & +.07 \\
\hline 2 & B. D. $+37^{\circ} 1769$ & & 3. 47 & -.02 & & 10 & Can. Ven & 5. 32 & 4. 70 & +.07 \\
\hline 2 & 38 Lyncis & 3. 92 & 3. 79 & -.02 & & 10 & Bootis & 5. 22 & 4. 86 & +.07 \\
\hline 3 & $\alpha \quad$ Lyræ & 4. 87 & 4. 59 & -.02 & & 10 & Bootis & & $\begin{array}{l}\text { 5. } 25 \\
\text { 5. }\end{array}$ & $\begin{array}{l}+.07 \\
+.07\end{array}$ \\
\hline Apr. & $\alpha \quad$ Lyræ & 4. 53 & 4. 25 & -.02 & & 23 & $\alpha \quad$ Lyræ & 4.55 & 4. 27 & +10 \\
\hline spen & $\alpha \quad$ Lyræ & 4. 38 & 4. 10 & -.02 & & 24 & B. D. $+38^{\circ} 2629$ & & 4. 21 & +.10 \\
\hline 1 & 17 Leo. Min. & $\ldots$ & 4. 11 & -.01 & & 24 & $\rho$ Herculis & 4.41 & 4. 26 & $\begin{array}{l}+10 \\
+.10\end{array}$ \\
\hline 1 & B. D. $+38^{\circ} 2324$ & $\ldots$ & 5. 04 & -.01 & & 24 & Herculis & 5. 09 & & +.10 \\
\hline 1 & B. D. $+38^{\circ} 2373$ & & 4.47 & -.01 & & 27 & $\alpha \quad \mathrm{Lyr}$ & 4.99 & 4. 7 & +.10 \\
\hline 1 & 17 Can. Venat. & 4.70 & 4. 09 & -.01 & & 28 & $\mathrm{Hel}$ & & 4.6 & +.10 \\
\hline 1 & $\alpha \quad$ Lyræ* $*$ & 5.02 & 4. 74 & -.01 & & 28 & Lyr & & & +.10 \\
\hline 1 & 295 B. Bootis & 5. 08 & 4.55 & -.01 & & 30 & Her & & & +.11 \\
\hline 1 & $\mu^{1}$ Bootis & 4.78 & 4. 43 & -.01 & July & 3 & Lyræ & & 57 & +.11 \\
\hline 1 & $\mu^{2} \quad$ Bootis & & 4. 76 & -.01 & & 5 & Her & & & +12 \\
\hline 2 & 31 Leo. Min. & 4. 60 & 4.5 & .00 & & 9 & $\mathrm{He}$ & & & +.12 \\
\hline 2 & 38 Leo. Min. & & 4. 7 & .00 & & 9 & Her & & 57 & +.12 \\
\hline 2 & 17 Can. Venat. & $5.3 \overline{3}$ & 4. 71 & .00 & & 10 & $\mathrm{He}$ & & & +.12 \\
\hline$\overline{2}$ & 295 B. Bootis & 5. 35 & 4.8 & .00 & & 10 & Lyr & & & +.12 \\
\hline 2 & $\alpha \quad$ Lyræ & 1.99 & 4. 7 & .00 & & 21 & Ly & 4. 64 & 4. & +14 \\
\hline 2 & 31 Leo. Min. & 3.95 & 3.8 & .00 & & 23 & Ly & $\ldots$ & & +14 \\
\hline 2 & 38 Leo. Min. & $\ldots$ & 4. 4 & .00 & & 23 & $7 \quad$ Ly & & 4. 2 & +.14 \\
\hline 2 & B. D. $+38^{\circ} 2629$ & & 4.2 & .00 & & 24 & $\mathrm{Ly}$ & & & +14 \\
\hline 2 & $\alpha \quad$ Lyræ & 4. 72 & 4. 4 & .00 & & 24 & Ly & & 4. & +.14 \\
\hline 2 & $\alpha \quad$ Lyr & 4. 96 & 4. 6 & .00 & & 24 & $\mathrm{Ly}$ & 4. 84 & 66 & +.14 \\
\hline 2 & 1830 Groombridge & 5. 05 & 4.2 & 00 & & 28 & Aur & 5. 63 & & +.14 \\
\hline 2 & B. D. $+37^{\circ} 258$ & & 3. & .00 & & 29 & $\zeta \quad$ Lyr & $\ldots$ & 66 & +.15 \\
\hline 2 & 295 B. Bootis & 4.96 & 4. & 00 & & 29 & $\mathrm{Ly}$ & 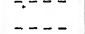 & & +.15 \\
\hline 2 & $\mu^{1}$ Bootis & 4. 55 & 4. 2 & .00 & & 29 & $\theta \quad \mathrm{Ly}$ & 5.52 & & +.15 \\
\hline 2 & $\mu^{2}$ Boot & & 4. & .00 & & 29 & B. D. +3 & & & +.15 \\
\hline 2 & 25 Herc & & 3. & 00 & & 29 & 19 Cygni & & & +.15 \\
\hline 2 & $\alpha \quad$ Lyra & 4.47 & 4. 19 & .00 & Aug. & 8 & $\theta \quad$ Lyræ & 5. 48 & 4. 91 & +.16 \\
\hline May & 25 Herculis & & 4.14 & .00 & & 8 & B. D. $+38^{\circ} 3772$ & $\ldots$ & & +.16 \\
\hline & $\alpha \quad$ Lyræ & 4. 51 & 4. 23 & +.01 & & 8 & 19 Cygni & & & +16 \\
\hline & B. D. +3 & $\ldots$ & 5. 09 & +.01 & & 9 & 15 Cygni & 5.65 & & +16 \\
\hline & B. D. +37 & $\ldots$ & 4.6 & +.01 & & 19 & B. D. $+38^{\circ} 3373$ & & & 16 \\
\hline & 25 Herc & & 4. 2 & +.01 & & 20 & 15 Cygni & 5. 56 & & +.16 \\
\hline & $\alpha$ Lyra & 4.44 & 4. & +.01 & & 20 & $P \quad \mathrm{Cy}$ & & & +.16 \\
\hline & $295 \mathrm{~B}$. B & 5. 14 & 4.6 & +.01 & & 22 & $\alpha \quad \mathrm{Ly}$ & 5.06 & & +.16 \\
\hline & B. D. +3 & $\ldots$ & 5. 2 & +.01 & & 22 & $15 \mathrm{Cy}$ & & & +.16 \\
\hline & B. D. +3 & -... & 4. & +.01 & & 26 & $\alpha \quad \mathrm{Ly}$ & 5. 20 & & +1 \\
\hline 1 & B. D. +3 & & 4. & +.02 & & 28 & $P \quad \mathrm{Cy}$ & & & +.1 \\
\hline 1 & 1830 Gro & 5.15 & 4. & $\dashv .02$ & & 29 & $40 \mathrm{Cy}$ & 5. 35 & & 1 \\
\hline 1 & B. D. +3 & $\ldots$ & 5. & +.02 & Sept. 1 & 19 & $40 \mathrm{Cy}$ & & & +1 \\
\hline 1 & B. D. +3 & $\ldots$ & 4. & +.02 & & 19 & $\tau \quad \mathrm{Cy}$ & & & \\
\hline 1 & B. D. $+38^{\circ} 2629$ & & 4. & +.02 & & 20 & $\tau \quad$ Cygni & 5. 23 & & \\
\hline 1 & $\alpha \quad$ Lyra & 4. 92 & 4. & +.02 & & 22 & B. D. $+37^{\circ} 3916$ & $\ldots$ & & +.1 \\
\hline 1 & $1830 \mathrm{Grc}$ & 5. 05 & & +.0 & & 23 & 22 Cygni & & & +.1 \\
\hline 1 & B. D. +3 & $\ldots$ & 5. & +.02 & & 24 & $P \quad \mathrm{Cy}$ & & & +1 \\
\hline 1 & B. D. +3 & $\ldots$ & 4. & +.02 & & 24 & Cyg & 5. 49 & & +.1 \\
\hline 1 & B. D. $+38^{\circ} 2629$ & & 4 & +.02 & & 25 & $P \quad$ Cygni & & & +1 \\
\hline 1 & $\alpha \quad$ Lyr & 5. 02 & 4. & +.02 & & 25 & B. D. $+38^{\circ} 4325$ & & & +.1 \\
\hline 1 & 1830 Groombridge & 4. 96 & 4.1 & +.02 & Oct. & 3 & $61^{1}$ Cygni & 4.83 & & +1 \\
\hline 1 & $\alpha$ Lyra & 4. 34 & 4. & $\begin{array}{l}.02 \\
+.02\end{array}$ & & 3 & $61^{2}$ Cygni & $\ldots$ & & +1 \\
\hline 2 & B. D. $+37^{\circ} 2580$ & & & +.03 & & 5 & B. D. $+37^{\circ} 3$ s & $\ldots$ & & +.1 \\
\hline 2 & $\alpha \quad$ Lyræ & 4.85 & 4. & $\begin{array}{l}+.03 \\
+\end{array}$ & & 6 & B. D. $+38^{\circ} 43$ & - & & +.1 \\
\hline 2 & $\alpha \quad$ Lyræ & 4. 13 & 3. & +.0 & & 7 & B. D. $+37^{\circ} 3916$ & & & +.1 \\
\hline 2 & $\lambda$ Coronæ Bor. & & 4. & +.04 & & 7 & $61^{1}$ Cygni & 5. 06 & & +.1 \\
\hline 2 & $\alpha \quad$ Lyra & 4.93 . & 4. & $\begin{array}{l}+.04 \\
\end{array}$ & & 7 & $61^{2}$ Cygni & $\ldots$ & 4.62 & +.16 \\
\hline 3 & 17 Can. Venat. & $4.89^{\circ}$ & 4. & +.04 & & 8 & B. D. $+38^{\circ} 3758$ & $\ldots$ & 4.24 & +.16 \\
\hline June & $\lambda$ Coronæ Bor. & & 3. 9 & +.05 & & 8 & B. D. $+37^{\circ} 3916$ & $\ldots$ & 4.48 & +.16 \\
\hline & $e \quad$ Herculis & 4. 62 & 4. 06 & +.05 & & 8 & $61^{1}$ Cygni & 4. 41 & 4. 18 & +.16 \\
\hline
\end{tabular}


A CVIII

PRIME VERTICAL TRANSIT INSTRUMENT.

TABLE VIII.-The Latitude of the Instrument, Obtained by the Use of Newcomb and Boss Declinations-Continued

$+38^{\circ} 55^{\prime} 10^{\prime \prime}+$

* Indicates reflected observation.

\begin{tabular}{|c|c|c|c|c|c|c|c|c|c|}
\hline Date & Star & N. & B. & $\Delta \varphi$ & Date & Star & N. & B. & $\Delta \varphi$ \\
\hline 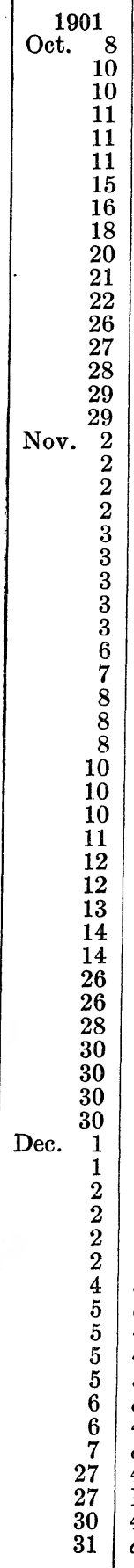 & 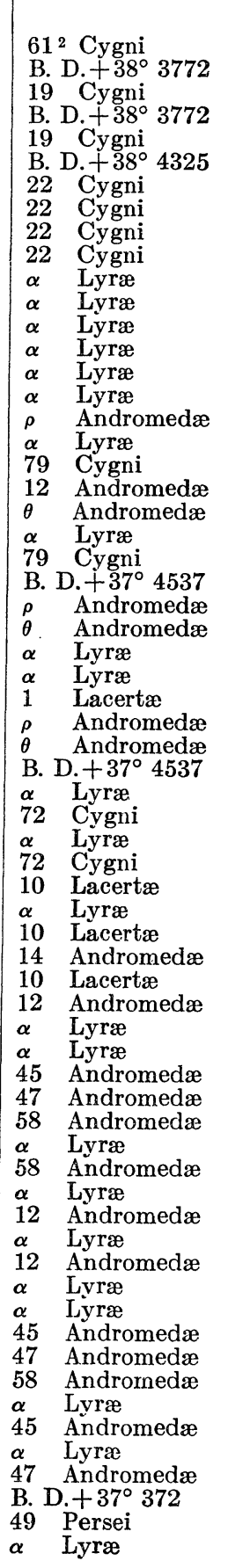 & 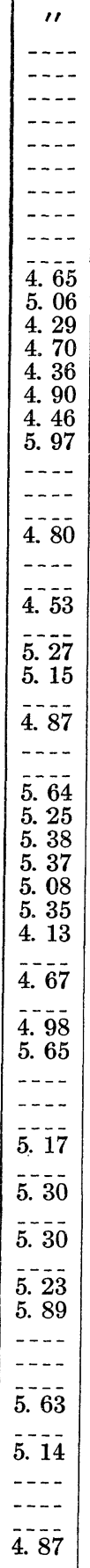 & 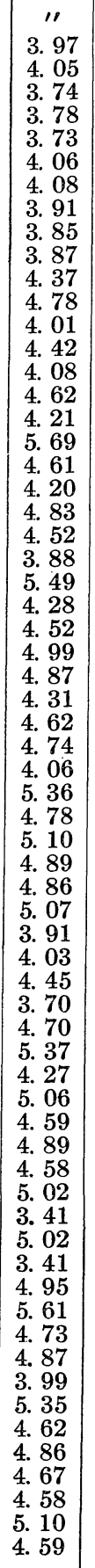 & $\begin{array}{c}11 \\
+0.16 \\
+.16 \\
+.16 \\
+.16 \\
+.16 \\
+.16 \\
+.15 \\
+.15 \\
+.15 \\
+.15 \\
+.15 \\
+.15 \\
+.15 \\
+.15 \\
+.15 \\
+.15 \\
+.15 \\
+.14 \\
+.14 \\
+.14 \\
+.14 \\
+.14 \\
+.14 \\
+.14 \\
+.14 \\
+.14 \\
+.14 \\
+.14 \\
+.14 \\
+.14 \\
+.14 \\
+.14 \\
+.14 \\
+.14 \\
+.14 \\
+.14 \\
+.14 \\
+.14 \\
+.14 \\
+.14 \\
+.13 \\
+.13 \\
+.12 \\
+.12 \\
+.12 \\
+.12 \\
+.12 \\
+.12 \\
+.12 \\
+.12 \\
+.12 \\
+.12 \\
+.12 \\
+.12 \\
+.12 \\
+.12 \\
+.12 \\
+.12 \\
+.12 \\
+.12 \\
+.12 \\
+.08 \\
+.08 \\
+.08 \\
+.08\end{array}$ & \begin{tabular}{rr}
\multicolumn{1}{r}{1902} \\
Jan. & 1 \\
1 \\
3 \\
4 \\
5 \\
5 \\
5 \\
11 \\
16 \\
17 \\
17 \\
17 \\
18 \\
19 \\
19 \\
19 \\
19 \\
20 \\
20 \\
27 \\
Feb. \\
2 \\
2 \\
2 \\
4 \\
4 \\
4 \\
5 \\
6 \\
7 \\
7 \\
7 \\
7 \\
7 \\
8 \\
8 \\
8 \\
8 \\
8 \\
9 \\
9 \\
9 \\
9 \\
12 \\
13 \\
14 \\
14 \\
18 \\
18 \\
19 \\
19 \\
19 \\
22 \\
23 \\
26 \\
Mar. \\
3 \\
6 \\
9 \\
10 \\
11 \\
17 \\
20 \\
20 \\
22 \\
22 \\
23 \\
23 \\
25 \\
\end{tabular} & 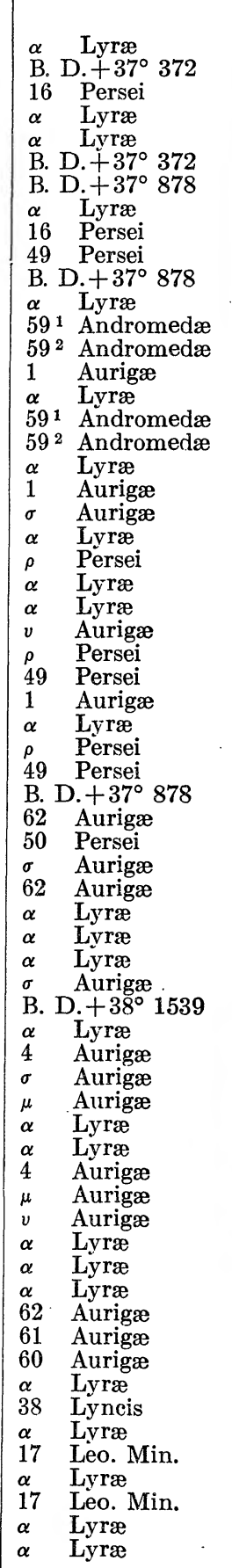 & 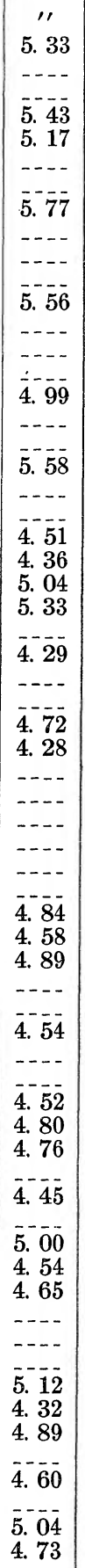 & 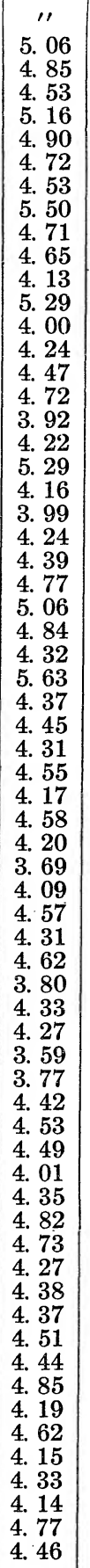 & $\begin{array}{l}11 \\
+0.08 \\
+.08 \\
+.07 \\
+.07 \\
+.07 \\
+.07 \\
+.05 \\
+.04 \\
+.04 \\
+.04 \\
+.04 \\
+.04 \\
+.04 \\
+.04 \\
+.04 \\
+.04 \\
+.04 \\
+.04 \\
+.02 \\
.00 \\
.00 \\
.00 \\
-.01 \\
-.01 \\
-.01 \\
-.01 \\
-.01 \\
-.01 \\
-.01 \\
-.01 \\
-.01 \\
-.01 \\
-.01 \\
-.01 \\
-.02 \\
-.02 \\
-.02 \\
-.02 \\
-.03 \\
-.03 \\
-.03 \\
-.03 \\
-.04 \\
-.04 \\
-.04 \\
-.04 \\
-.04 \\
-.04 \\
-.06 \\
-.06 \\
-.07 \\
-.08 \\
-.09 \\
-.09 \\
-.09 \\
-.10 \\
-.11 \\
-.11 \\
-.11 \\
-.11 \\
-.11 \\
-.11 \\
-.12 \\
\end{array}$ \\
\hline
\end{tabular}


TABLE VIII.-The Latitude of the Instrument, Obtained by the Use of Newcomb and Boss Declinations-Continued

$+38^{\circ} 55^{\prime} 10^{\prime \prime}+$

* Indicates reflected observation.

\begin{tabular}{|c|c|c|c|c|c|c|c|c|c|}
\hline Date & Star & N. & B. & $\Delta \varphi$ & Date & Star & N. & B. & $\Delta \varphi$ \\
\hline 1902 & & " & " & $" \prime$ & 1902 & & $" \prime$ & "' & 11 \\
\hline Apr. 15 & 31 Leo. Min. & 4. 10 & 4. 04 & -0.13 & Nov. 28 & $\alpha \quad$ Lyræ & 4. 48 & 4. 21 & +0.16 \\
\hline 17 & 31 Leo. Min. & 4. 02 & 3. 96 & -.13 & 28 & B. D. $+37^{\circ} 372$ & & 4. 25 & +.16 \\
\hline 17 & $\begin{array}{ll}\alpha & \text { Lyræ }\end{array}$ & 4. 66 & 4. 39 & -.15 & $\begin{array}{r}29 \\
-1\end{array}$ & $\alpha \quad$ Lyræ & 4. 24 & 3. 97 & +.16 \\
\hline & 38 Leo. Min. & $\ldots$ & 4. 28 & -.16 & Dec. 1 & $\alpha \quad$ Lyræ & 4. 56 & 4. 29 & +.16 \\
\hline 22 & 38 Leo. Min. & $\ldots$ & 4. 24 & -.16 & 1 & 45 Andromedæ & & 4. 04 & +.16 \\
\hline 23 & 38 Leo. Min. & & 4. 16 & -.16 & 27 & $\alpha \quad$ Lyræ & 4.39 & 4. 12 & +.13 \\
\hline 23 & $\alpha \quad$ Lyræ & 5. 02 & 4. 75 & -.16 & 27 & 50 Persei & & 3. 50 & +.13 \\
\hline 2 & $\alpha \quad$ Lyræ & 4. 25 & 3.98 & -.16 & 28 & $\alpha \quad$ Lyræ & 4.54 & 4. 27 & +.13 \\
\hline $\begin{array}{l}27 \\
27\end{array}$ & 1830 Groombridge & $\begin{array}{l}\text { 5. } 06 \\
4.98\end{array}$ & $\begin{array}{l}\text { 4. } 26 \\
4.71\end{array}$ & $\begin{array}{l}-.17 \\
-.17\end{array}$ & 1903 & & & & \\
\hline 30 & $\begin{array}{ll}\alpha & \text { Lyræ } \\
\alpha & \text { Lyræ }\end{array}$ & $\begin{array}{l}4.98 \\
4.60\end{array}$ & $\begin{array}{l}\text { 4. } 71 \\
\text { 4. } 33\end{array}$ & $\begin{array}{l}-.17 \\
-.17\end{array}$ & Jan. 8 & Lyræ & 4. 49 & 4. 21 & +.12 \\
\hline May & $\alpha \quad \mathrm{I} y \mathbf{x}$ & 4. 53 & 4. 26 & -.17 & & $\alpha \quad$ Lyræ & 5. 14 & 4. 86 & $\begin{array}{l}+12 \\
+.12\end{array}$ \\
\hline & Lyræ & 4. 72 & 4. 45 & -.17 & 10 & 591 Andromedæ & & 3. 67 & +.11 \\
\hline & Lyræ & 4. 65 & 4. 38 & -.17 & 10 & $59^{2}$ Andromedæ & $\ldots$ & 3. 64 & +.11 \\
\hline$\varepsilon$ & Lyræ & 5. 02 & 4. 75 & -.17 & 10 & 16 Persei & & 4. 17 & +.11 \\
\hline 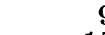 & Lyræ & 4.83 & 4. 56 & -.17 & 11 & $\alpha$ Lyræ & 4. 29 & 4. 01 & +.11 \\
\hline 15 & Lyræ & 4. 58 & 4. 31 & -.17 & 12 & $\alpha \quad$ Lyræ & 4. 83 & 4. 55 & +.11 \\
\hline 2. & Lyræ & 4. 50 & 4. 23 & -.17 & 14 & $59^{1}$ Andromedæ & & 3. 71 & +.10 \\
\hline $2 !$ & Lyræ & 4. 73 & 4. 46 & -.17 & 14 & $59^{2}$ Andromedæ & & 3. 94 & +.10 \\
\hline June & Lyræ & 4. 80 & 4. 53 & -.16 & 17 & $\alpha \quad$ Lyræ & 4. 87 & 4. 59 & +.10 \\
\hline & Lyræ & 4. 82 & 4. 55 & -.15 & 18 & Persei & & 3. 98 & +.10 \\
\hline 1. & Lyræ & 4.55 & 4. 28 & -.15 & 18 & Lyræ & 5. 27 & 4. 99 & $\begin{array}{l}+10 \\
+.10\end{array}$ \\
\hline 17 & Lyræ & 4. 15 & 3.88 & -.13 & 20 & $\alpha \quad$ Lyræ & 4. 82 & 4. 54 & +.10 \\
\hline 2 & Lyræ & 4. 58 & 4. 31 & -.10 & 22 & B. D. $+37^{\circ} 811$ & $\ldots$ & 4. 32 & +.08 \\
\hline July & Lyræ & 4. 47 & 4. 20 & -.10 & 23 & $4 \quad$ Aurigæ & ...- & 3. 49 & +.08 \\
\hline & Lyræ & 4. 26 & 3. 99 & -.08 & 30 & Aurigæ & & 3. 57 & +.08 \\
\hline 12 & Lyræ & 4. 28 & 4. 01 & -.08 & 30 & Lyræ & 4. 55 & 4. 27 & +.08 \\
\hline 1 & $\alpha \quad$ Lyræ & 4. 88 & 4. 61 & -.05 & Feb. 5 & Aurigæ & & 4. 35 & +.06 \\
\hline 1 & B. D. $+38^{\circ} 3373$ & $\ldots$ & 4. 26 & -.05 & 5 & Lyræ & 4. 51 & 4. 23 & +.06 \\
\hline 1 & B. D. $+38 \quad 3373$ & -... & 4. 33 & -.05 & 6 & Aurigæ & & 4. 18 & +.06 \\
\hline 2 & B. $D_{.}+38^{\circ} 3373$ & --- & 4. 53 & -.05 & 9 & Lyræ & 4. 47 & 4. 19 & +.05 \\
\hline 27 & $\alpha \quad$ Lyræ & 4. 30 & 4. 03 & -.05 & 11 & Lyræ & 5. 02 & 4. 74 & +.05 \\
\hline Aug. & Lyræ & 4. 03 & 3. 76 & -.03 & 12 & Lyræ & 4. 69 & 4. 41 & +.04 \\
\hline 2 & $\alpha \quad$ Lyræ & 4. 13 & 3. 86 & +.04 & 17 & Lyræ & 3. 76 & 3. 48 & +.03 \\
\hline 2 & B. D. $+38^{\circ} 3758$ & & 3. 62 & +.04 & 18 & Aurigæ & & 2. 99 & +.03 \\
\hline 28 & $\alpha \quad$ Lyræ & 4. 10 & 3. 83 & +.04 & 22 & Lyræ & 4. 19 & 3. 91 & +.02 \\
\hline 30 & $\alpha \quad$ Lyræ & 4. 06 & 3. 79 & +.04 & 23 & Lyræ & 4. 5 & 4. 30 & +.01 \\
\hline Sept. & B. D. $+38^{\circ} 3758$ & $\ldots$ & 4. 53 & +.06 & 24 & Lyræ & 4. 39 & 4. 11 & +.01 \\
\hline & B. $D_{\dot{r}}+383758$ & $--\overline{-}=$ & 4. 32 & +.06 & 25 & Aurigæ & & 3. 59 & +.01 \\
\hline & $\alpha \quad$ Lyræ & 4. 25 & 3. 98 & +.06 & 25 & Lyræ & 4. 24 & 3. 96 & +.01 \\
\hline 1. & Lyræ. & 4. 25 & 3. 98 & +.08 & 26 & Aurigæ & & 4. 02 & 00 \\
\hline 1 & Cygni & 4.33 & 3. 85 & +.08 & Mar. 1 & Lyræ & 4. 26 & 3. 9 & 00 \\
\hline 1 & Lyræ & 4. 06 & 3. 79 & +.08 & 2 & Lyræ & 4. 34 & 4. 06 & -.02 \\
\hline 1 & Lyræ & 4. 29 & 4. 02 & +.08 & 13 & Aurigæ & & 4. 19 & -.04 \\
\hline 2 & Lyræ & 4. 24 & 3.97 & +.10 & 13 & Lyræ & 4. 48 & 4. 20 & -.04 \\
\hline 2 & Lyræ & 4. 23 & 3. 96 & +.11 & 17 & Lyræ & 4. 41 & 4. 13 & -.06 \\
\hline 2 & Lyræ & 3. 88 & 3. 61 & +.11 & 18 & Aurigæ & & 4. 28 & -.06 \\
\hline Oct. & Lyræ & 4. 02 & 3. 75 & +.12 & 19 & Aurigæ & & 4. 14 & -.06 \\
\hline & Lacertæ & & 3.84 & +.12 & 24 & Lyræ & 4. 50 & & -.08 \\
\hline & Lyræ & 4. 07 & 3. 80 & +.12 & 25 & Lyræ & 4. 12 & 3. 84 & -.08 \\
\hline & Lacertæ & & 3.86 & +.12 & 26 & Lyr & 4. 47 & 4. 19 & -.08 \\
\hline & Lyræ & 4. 66 & 4. 39 & +.12 & 27 & Lyræ & 4. 29 & & -.08 \\
\hline & Lyræ & 4. 40 & 4. 13 & +.12 & 31 & Lyræ & 4. 12 & 3. 84 & -.10 \\
\hline & Lyræ. & 3. 87 & 3. 60 & +.13 & Apr. 4 & Lyræ & 4. 57 & 4. 2 & -.11 \\
\hline & $P \quad$ Cygni & $\ldots$ & 4. 42 & +.13 & 9 & Lyræ & & & -.12 \\
\hline & B. D. $+37^{\circ} 4537$ & & 4.71 & +.13 & 10 & Lyræ & 4. 38 & 4. 10 & -.12 \\
\hline & $\alpha \quad$ Lyræ & 4. 40 & 4. 13 & +.13 & 17 & Lyræ & 4. 33 & 4.05 & -.13 \\
\hline 1 & Lyræ & 3. 84 & 3.5 & +.14 & 18 & Lyræ* & 5. 25 & 4.97 & -.13 \\
\hline 1 & Lyræ & 4. 32 & 4. 05 & +.14 & 21 & Lyræ & 4. 71 & 4. 43 & -.14 \\
\hline 1. & Lyræ & 4. 36 & 4. 09 & +.14 & 28 & Lyræ & 4. 90 & & -.16 \\
\hline 1 & Lyræ & 4. 40 & 4. 13 & +.14 & 29 & Lyræ & 4. 68 & 4. 40 & -.16 \\
\hline 2 & Lyræ & 4. 51 & 4. 24 & +.15 & May 1 & Lyræ & 4.48 & 4. 20 & -.17 \\
\hline 2 & Andromedæ & & 3. 95 & +.15 & 4 & Lyræ & 4. 68 & 4. 40 & -.18 \\
\hline 2 & Lyræ & 4. 32 & 4. 05 & $t_{*} .16$ & 5 & Lyræ & 4.77 & 4. 49 & -.18 \\
\hline 2 & Lyræ & 4. 84 & 4. 57 & +.16 & 7 & Iuyræ & 4. 57 & 4. 29 & -.18 \\
\hline 2 & 14 Andromedæ & & 4. 01 & +.16 & 9 & Lyræ & 4. 43 & 4. 15 & -.18 \\
\hline 3 & $\alpha \quad$ Lyræ & 4. 29 & 4.02 & +.16 & 11 & Lyræ & 4.60 & 4. 32 & -.19 \\
\hline
\end{tabular}


TABLE VIII. - The Latitude of the Instrument, Obtained by the Use of Newcomb and Boss Declinations-Continued

* Indicates reflected observation.

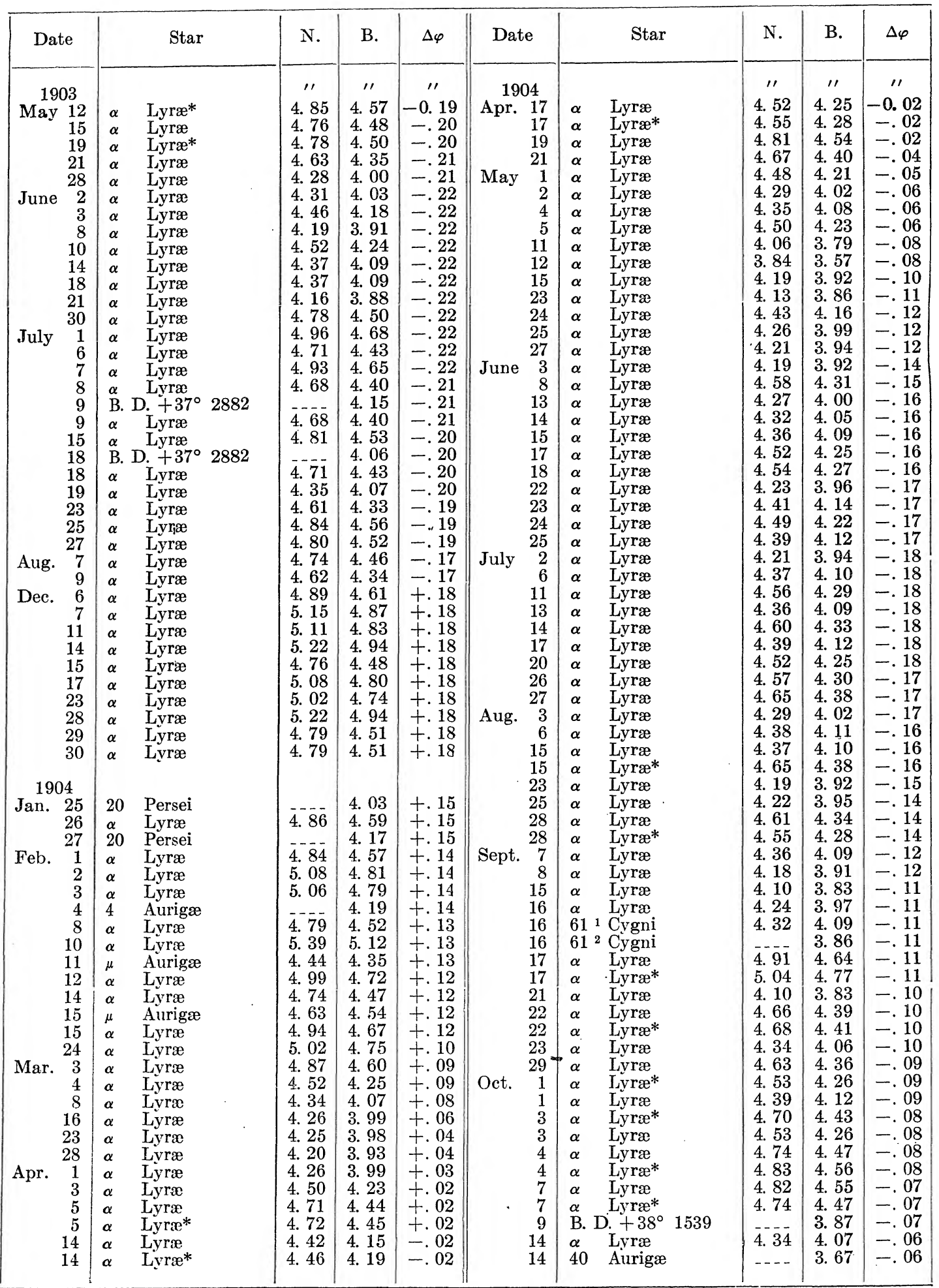


TABLE VIII.-The Latitude of the Instrument, Obtained by the Use of Newcomb and Boss Declinations-Continued

$+38^{\circ} 55^{\prime} 10^{\prime \prime}+\quad *$ Indicates reflected observation.

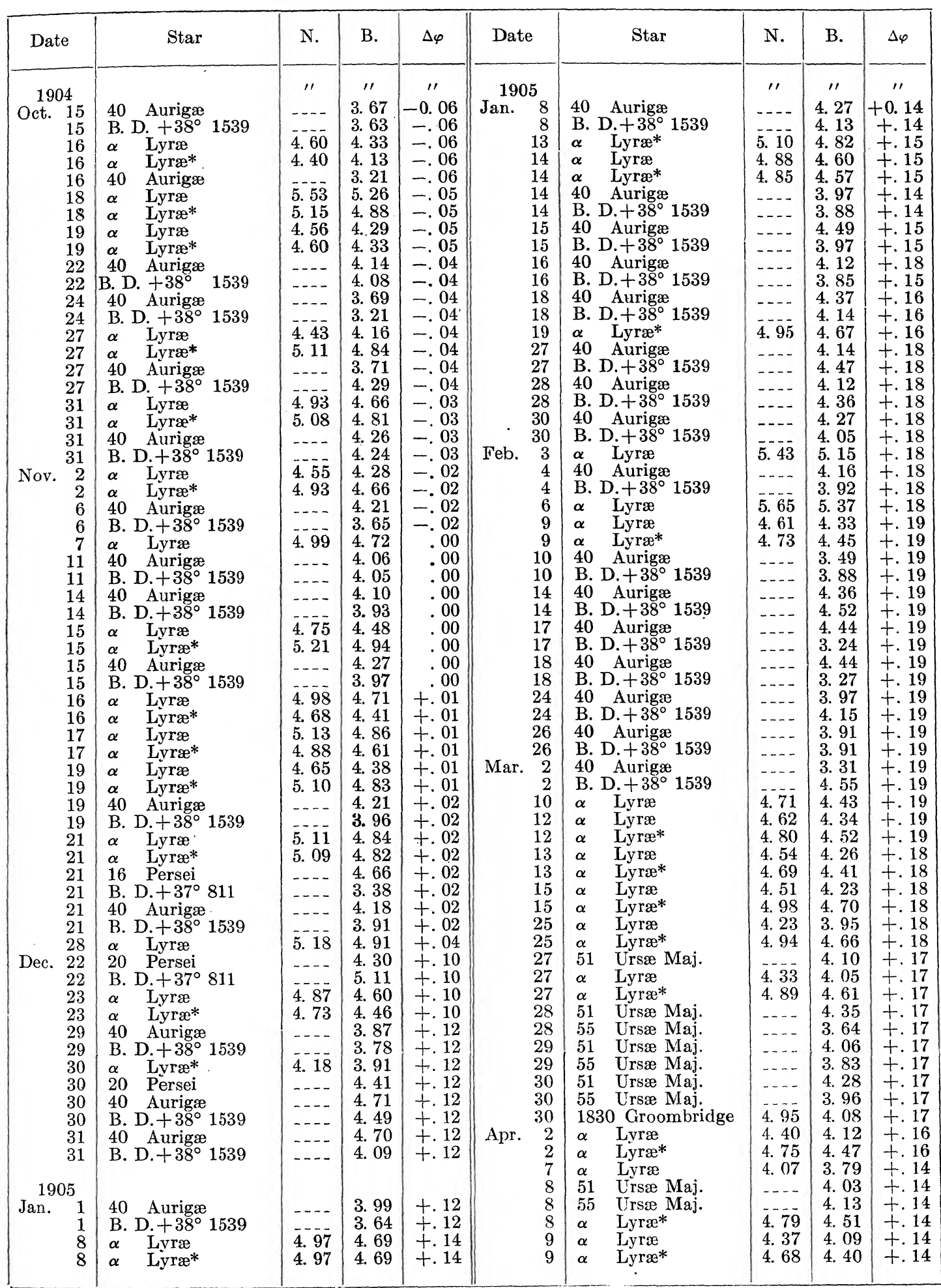


A CXII

PRIME VERTICAL TRANSIT INSTRUMENT.

TABLE VIII.-The Latitude of the Instrument, Obtained by the Use of Newcomb and Boss Declinations-Continued

$+38^{\circ} 55^{\prime} 10^{\prime \prime}+$

*Indicates reflected observation.

\begin{tabular}{|c|c|c|c|c|c|c|c|c|c|}
\hline Date & Star & N. & B. & $\Delta \varphi$ & Date & Star & N. & B. & $\Delta \varphi$ \\
\hline 1905 & & "' & "' & " & 1906 & & 11 & 11 & $\prime \prime$ \\
\hline Apr. 13 & Lyræ & 4. 33 & 4. 05 & +0.14 & Jan. $\quad$ S & B. D. $+38^{\circ} 1539$ & -..- & 4. 33 & +0.06 \\
\hline 13 & $\alpha \quad$ Lyræ* & 4. 74 & 4. 46 & +.14 & 10 & 40 Aurigæ & -1 & 4. 15 & $\begin{array}{r}\text { T. } 00 \\
+.06\end{array}$ \\
\hline 17 & B. D. $+39^{\circ} 2418$ & $\ldots$ & 3. 62 & +.13 & 10 & B. $D_{\dot{r}}+38^{\circ} 1539$ & & 4. 03 & +.06 \\
\hline 17 & $55 \quad$ Ursæ Maj. & . & 3. 59 & +.13 & 18 & $\alpha \quad$ Lyræ & 4. 79 & 4. 51 & +.07 \\
\hline 18 & $\alpha \quad$ Lyræ & 4.56 & 4. 28 & +.12 & 18 & $\alpha \quad$ Lyræ* $*$ & 5. 26 & 4. 98 & +.07 \\
\hline 18 & $\boldsymbol{\alpha} \quad$ Lyræ* & 4. 49 & 4. 21 & +.12 & 18 & 40 Aurigæ & $-\cdots$ & 4. 70 & +.07 \\
\hline 19 & B. $D_{i}+39^{\circ} 2418$ & & 4. 21 & +.12 & 18 & B. D. $+38^{\circ} 1539$ & $\ldots$ & 3.95 & +.07 \\
\hline 27 & $\alpha \quad$ Lyræ & 4.87 & 4. 59 & +.11 & 24 & 40 Aurigæ & $-\cdots$ & 4. 15 & +.08 \\
\hline $\begin{array}{l}30 \\
30\end{array}$ & B. D. $+39^{\circ} 2418$ & $5 . \overline{34}$ & $\begin{array}{l}\text { 4. } 50 \\
\text { 5. } 06\end{array}$ & $\begin{array}{l}+.10 \\
+10\end{array}$ & 24 & B. $D_{1}+38^{\circ} 1539$ & $\overline{4} \overline{94}$ & $\begin{array}{l}\text { 3. } 81 \\
4.66\end{array}$ & $\begin{array}{l}+.08 \\
+09\end{array}$ \\
\hline May 1 & $\stackrel{\alpha}{\text { B. D. D. }+39^{\circ} 2418}$ & $\begin{array}{l}0.04 \\
-\ldots\end{array}$ & $\begin{array}{l}5.06 \\
4.25\end{array}$ & $\begin{array}{l}+.10 \\
+.10\end{array}$ & $\begin{array}{l}2 \varepsilon \\
2 \varepsilon\end{array}$ & $\begin{array}{ll}\alpha & \text { Lyræ } \\
\alpha & \text { Lyræ * }\end{array}$ & $\begin{array}{l}4.94 \\
5.60\end{array}$ & $\begin{array}{l}\text { 4. } 66 \\
\text { 5. } 32\end{array}$ & $\begin{array}{l}+.09 \\
+.09\end{array}$ \\
\hline & B. D. $+39^{\circ} 2418$ & & 4. 55 & +.10 & $2 \varepsilon$ & 40 Aurigæ & $\ldots$ & 3.99 & +09 \\
\hline 2 & $\alpha \quad$ Lyræ & 5. 31 & 5. 03 & +.10 & 28 & B. $D_{\dot{r}}+38^{\circ} 1539$ & $a^{2}=0$ & 3. 68 & +.09 \\
\hline 7 & $\alpha \quad$ Lyræ* & 4. 95 & 4. 67 & +10 & 29 & $\alpha \quad$ Lyræ & 4. 59 & 4. 31 & +.08 \\
\hline 8 & $\alpha \quad$ Lyræ & 4. 85 & 4. 57 & +.08 & 29 & Lyræ* & 4. 82 & 4. 54 & +.08 \\
\hline 12 & Lyræ & 5.55 & 5. 27 & +.07 & 3 & 40 Aurigæ & $\ldots$ & 3. 80 & +.09 \\
\hline 19 & $\alpha \quad$ Lyræ* & 4. 67 & 4. 39 & +.05 & 3 & B. $D_{\dot{r}}+38^{\circ} 1539$ & & 3. 71 & +.09 \\
\hline 20 & $\alpha \quad$ Lyræ* & 4. 83 & 4.55 & +.05 & Feb. & $\alpha \quad$ Lyræ & 5. 16 & 4. 88 & +.09 \\
\hline 21 & 17 Can. Venat. & 4. 70 & 4. 03 & +.04 & & Lyræ* & 5. 71 & 5. 43 & +.09 \\
\hline 23 & $\alpha \quad$ Lyræ & 4. 27 & 3. 99 & +.04 & 3 & 40 Aurigæ & $\ldots$ & 4. 02 & +.09 \\
\hline 24 & Lyræ* & 4. 63 & 4. 35 & +.04 & 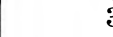 & B. D. $+38^{\circ} 1539$ &.-- & 4. 03 & +.09 \\
\hline 27 & Lyræ & 4. 32 & 4. 04 & +.02 & 4 & 40 Aurigæ & -..- & 4. 05 & +.09 \\
\hline June 1 & Lyræ* & 4. 79 & 4. 51 & .00 & 4 & B. D. $+38^{\circ} 1539$ & $\ldots$ & 4. 03 & +.09 \\
\hline & $\begin{array}{ll}\alpha & \text { Lyræ } \\
& \end{array}$ & 4. 57 & 4. 29 & .00 & 5 & 40 Aurigæ & $\cdots$ & 4. 22 & +.09 \\
\hline $\begin{array}{l}8 \\
\text { Oct. } 23\end{array}$ & & $4.5 \overline{2}$ & $\begin{array}{l}3.36 \\
4.32\end{array}$ & $\begin{array}{l}-.01 \\
-.12\end{array}$ & 5 & B. D. $+38^{\circ} 1539$ & $\overline{4} \overline{4}$ & 3. 95 & $\begin{array}{l}+.09 \\
+\quad 10\end{array}$ \\
\hline & $\begin{array}{l}10 \text { Lacertæ } \\
40 \text { Aurigæ }\end{array}$ & $\begin{array}{l}4.52 \\
-\ldots\end{array}$ & $\begin{array}{l}\text { 4. } 32 \\
4.20\end{array}$ & -.12 & 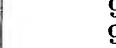 & $\begin{array}{ll}\alpha & \text { Lyræ } \\
\alpha & \text { Lyræ }\end{array}$ & $\begin{array}{l}\text { 4. } 46 \\
\text { 5. } 01\end{array}$ & $\begin{array}{l}\text { 4. } 18 \\
\text { 4. } 73\end{array}$ & $\begin{array}{l}+.10 \\
+.10\end{array}$ \\
\hline 28 & B. D. $+38^{\circ} 1539$ & $\ldots$ & 4. 11 & -.10 & ? & 40 Aurigæ & $\ldots$ & 4. 10 & +10 \\
\hline 29 & 40 Aurigæ & $\cdots$ & 4. 07 & -.10 & ؛ & B. D. $+38^{\circ} 1539$ & & 4. 00 & +10 \\
\hline 29 & B. D. $+38^{\circ} 1539$ & & 3. 97 & -.10 & 10 & $\alpha \quad$ Lyræ & 5. 10 & 4. 82 & +.10 \\
\hline 30 & $\alpha \quad$ Lyræ & 4.98 & 4. 70 & -.10 & 10 & $\alpha \quad$ Lyræ* & 5. 30 & 5. 02 & +.10 \\
\hline 30 & Lyræ* & 4. 72 & 4. 44 & -.10 & 10 & 40 Aurigæ & $\ldots$ & 4. 23 & +.10 \\
\hline Nov. 1 & 40 Aurigæ & $\ldots$ & 4. 22 & -.10 & 10 & B. D. $+38^{\circ} 1539$ & $\ldots$ & 3. 89 & +.10 \\
\hline 1 & B. $D_{i}+38^{\circ} 1539$ & 400 & 4. 15 & -.10 & 13 & 40 Aurigæ & $\cdots$ & 3. 76 & +.10 \\
\hline 2 & $\alpha \quad$ Lyræ & 4. 99 & 4. 71 & -.10 & 13 & B. D. $+38^{\circ} 1539$ & & 3. 68 & +.10 \\
\hline 2 & Lyræ* & 5. 24 & 4. 96 & -.10 & 16 & $\alpha \quad$ Lyræ & 4. 79 & 4. 51 & +.10 \\
\hline 4 & Lyræ & 4. 71 & 4. 43 & -.10 & 16 & $\alpha \quad$ Lyræ * & 5. 50 & 5. 22 & +.10 \\
\hline 4 & 40 Aurigæ & $\ldots$ & 4. 10 & -.10 & 16 & 40 Aurigæ & $\ldots$ & 3. 84 & +.10 \\
\hline 4 & B. $D_{+}+38^{\circ} 1539$ & & 3. 95 & -.10 & 16 & B. $D_{\dot{r}}+38^{\circ} 1539$ & & 3. 69 & +.10 \\
\hline 11 & $\boldsymbol{\alpha} \quad$ Lyræ & 4. 69 & 4. 41 & -.08 & 19 & $\alpha \quad$ Lyræ & 4. 65 & 4. 37 & +.10 \\
\hline 11 & $\alpha \quad$ Lyræ* & 5.21 & 4. 93 & -.08 & 19 & Lyræ* * & 4. 94 & 4. 66 & +.10 \\
\hline 12 & 40 Aurigæ & $\ldots$ & 4. 07 & -.07 & 19 & 40 Aurigæ & $\ldots$ & 3. 89 & +.10 \\
\hline 12 & B. $D_{+}+38^{\circ} 1539$ & $=--$ & 4. 05 & -.07 & 15 & B. D. $+38^{\circ} 1539$ & $\ldots$ & 3. 8 & +.10 \\
\hline 14 & $\alpha \quad$ Lyræ & 5.67 & 5. 39 & -.07 & 2 & 40 Aurigæ & -..- & 3. 90 & +10 \\
\hline 14 & $\alpha \quad$ Lyræ * & 5. 58 & 5. 30 & -.07 & 2 & B. D. $+38^{\circ} 1539$ & $\ldots$ & 3.9 & +.10 \\
\hline 14 & 40 Aurigæ & & 4. 31 & -.07 & 24 & 40 Aurigæ & $\ldots$ & 3. 81 & +.10 \\
\hline 14 & B. D. $+38^{\circ} 1539$ & & 4. 03 & -.07 & 24 & B. D. $+38^{\circ} 1539$ & -... & 3. 75 & +.10 \\
\hline 17 & $\alpha \quad$ Lyræ & 5. 13 & 4. 85 & -.06 & 26 & 40 Aurigæ & $\ldots$ & 4. 1 & +.11 \\
\hline 17 & Lyræ* & 5. 11 & 4. 83 & -.06 & 26 & B. D. $+38^{\circ} 1539$ & $\ldots$ & 4. 00 & +.11 \\
\hline 21 & Lyræ & 5. 09 & 4. 81 & -.05 & 28 & 40 Aurigæ & $\ldots$ & 4. 0 & +.11 \\
\hline 21 & Lyræ* & 5. 61 & 5. 33 & -.05 & 28 & B. D. $+38^{\circ} 1539$ & $\ldots$ & 3. 6 & +.11 \\
\hline 21 & 40 Aurigæ & & 4. 38 & -.05 & Mar. 2 & 40 Aurigæ & $\ldots$ & 3. 60 & +.11 \\
\hline 22 & $\alpha \quad$ Lyræ & 5. 10 & 4. 82 & -.05 & 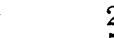 & B. $D_{i}+38^{\circ} 1539$ & & & +.11 \\
\hline 22 & Lyræ* & 4. 77 & 4. 49 & -.05 & 5 & $\alpha \quad$ Lyræ & 4. 70 & 4. 42 & +.11 \\
\hline 23 & Lyræ & 5. 16 & 4. 88 & -.04 & 5 & Lyræ* & 5. 08 & 4. 80 & +.11 \\
\hline 23 & $\alpha \quad$ Lyræ * & 5. 00 & 4. 72 & -.04 & 17 & Lyræ & 4. 36 & 4. 08 & +.11 \\
\hline & & & & & & Lyræ * & 5. 01 & 4. 73 & +.11 \\
\hline \begin{tabular}{l}
\multicolumn{2}{c}{1906} \\
Jan. 5
\end{tabular} & $\alpha \quad$ Lyræ & 4. 53 & 4.25 & +.04 & $\begin{array}{l}20 \\
22\end{array}$ & $\alpha \quad$ Lyræ & 4. 48 & 4. 20 & $\begin{array}{l}+.11 \\
+11\end{array}$ \\
\hline $\begin{array}{l}5 \\
5\end{array}$ & 40 Aurigæ & & 4. 10 & $\begin{array}{r}.0 x \\
+.04\end{array}$ & 22 & $\begin{array}{ll}\alpha & \text { Lyræ } \\
\alpha & \text { Lyræ * }\end{array}$ & $\begin{array}{l}4.32 \\
\text { 4. } 58\end{array}$ & $\begin{array}{l}\text { 4. } 04 \\
\text { 4. } 30\end{array}$ & $\begin{array}{l}+.11 \\
+.11\end{array}$ \\
\hline 6 & Lyræ & 4. 96 & 4. 68 & +.06 & Apr. & Lyræ & 4. 32 & 4. 04 & +.10 \\
\hline 6 & Lyræ* & 4. 73 & 4. 45 & +.06 & $x_{1}$ & Lyræ* & 4. 83 & 4. 55 & +.10 \\
\hline 6 & 40 Aurigæ & $\cdots$ & 4. 04 & +.06 & 2 & Lyræ* & 4. 76 & 4. 48 & +.10 \\
\hline 6 & B. $D_{\dot{+}}+38^{\circ} 1539$ & $-1-$ & 4. 14 & +.06 & 7 & Lyræ* & 4. 82 & 4. 54 & +.10 \\
\hline 9 & $\alpha \quad$ Lyræ & 4. 56 & 4. 28 & +.06 & 12 & Lyræ & 4. 20 & 3. 92 & +.10 \\
\hline 9 & $\alpha \quad$ Lyræ * & 5. 11 & 4. 83 & +.06 & 12 & $\alpha \quad$ Lyræ* & 4. 78 & 4. 50 & +.10 \\
\hline 9 & 40 Aurigæ & --- & 4. 28 & +.06 & 13 & B. D. $+39^{\circ} 2418$ & $-\ldots$ & 4. 08 & +.10 \\
\hline
\end{tabular}


INTRODUCTION.

A CXIII

TABLE VIII.-The Latitude of the Instrument, Obtained by the Use of Newcomb and Boss Declinations-Continued

$+38^{\circ} 55^{\prime} 10^{\prime \prime}+$

*Indicates reflected observation.

\begin{tabular}{|c|c|c|c|c|c|c|c|c|c|c|}
\hline \multicolumn{2}{|c|}{ Date } & Star & N. & B. & $\Delta \varphi$ & Date & Star & N. & B. & $\Delta \varphi$ \\
\hline \multicolumn{2}{|c|}{1906} & & 11 & $\prime \prime$ & "' & 1906 & & $n$ & $" 1$ & 11 \\
\hline & & B. $D_{i}+38^{\circ} 3113$ & & 3. 36 & +0.09 & Nov. 1 & Lyræ & 5. 22 & 4. 94 & -0.10 \\
\hline & & $\begin{array}{ll}\alpha & \text { Lyræ } \\
\alpha & \text { Lyræ } *\end{array}$ & 4. 42 & 4. 14 & +.09 & & 40 Aurigg & $\ldots$ & 4. 24 & -.10 \\
\hline & 17 & B. D. $+38^{\circ} 3113$ & & $\begin{array}{l}4.83 \\
3.38\end{array}$ & $\begin{array}{l}+.09 \\
+.09\end{array}$ & $\begin{array}{l}1 \\
2\end{array}$ & $\begin{array}{l}\text { B. D. }{ }_{\alpha}+38^{\circ} 1539 \\
\text { Lvræ }\end{array}$ & $=-20$ & $\begin{array}{l}\text { 4. } 23 \\
4.92\end{array}$ & $\begin{array}{l}-.10 \\
-10\end{array}$ \\
\hline & 17 & $\alpha \quad$ Lyræ & 3. 93 & 3. 65 & +.09 & 2 & 40 Aurigæ & & $\begin{array}{l}\text { 4. } 92 \\
\text { 4. } 22\end{array}$ & $\begin{array}{l}=.10 \\
-.10\end{array}$ \\
\hline & 18 & B. D. $+38^{\circ} 3113$ & & 3. 46 & +.09 & 2 & B. D. $+38^{\circ} 1539$ & & 3. 92 & -.10 \\
\hline & 18 & $\boldsymbol{\alpha} \quad$ Lyræ & 4. 05 & 3. 77 & +.09 & 4 & $\alpha \quad$ Lyræ & 5. 03 & 4. 75 & -.10 \\
\hline & 18 & $\alpha \quad$ Lyræ * & 4. 59 & 4. 31 & +.09 & 4 & $\alpha \quad$ Lyræ* & 5. 33 & 5. 05 & -.10 \\
\hline & 24 & B. $D_{-}+38^{\circ} 3113$ & & 3. 58 & +09 & 5 & $\alpha \quad{ }_{r}^{\text {Lyræ }}$ & 4. 67 & 4. 39 & -.10 \\
\hline & 24 & $\alpha \quad$ Lyræ & 4. 15 & 3.87 & +.08 & 5 & $\alpha \quad$ Lyræ* & 4. 62 & 4. 34 & -.10 \\
\hline & 24 & $\alpha \quad$ Lyræ * & 4. 71 & 4. 43 & +.08 & 6 & 40 Aurigæ & $\ldots$ & 4. 33 & -.10 \\
\hline May & & $\alpha \quad$ Lyræ & 4. 18 & 3. 90 & +.08 & 6 & B. D. $+38^{\circ} 1539$ & & 4. 33 & -.10 \\
\hline & 7 & Lyræ & 4. 59 & 4. 31 & +.07 & 7 & $\alpha \quad$ Lyræ & 5. 13 & 4. 85 & -.10 \\
\hline & 9 & Lyræ & 4. 44 & 4. 16 & +.07 & 7 & 40 Aurigæ & --- & 4. 24 & -.10 \\
\hline & 16 & Lyræ & 4. 35 & 4. 07 & +.06 & 7 & B. D. $+38^{\circ} 1539$ & $\ldots$ & 4. 00 & -.10 \\
\hline & 21 & Lyræ & 4. 34 & 4. 06 & +.05 & 13 & 40 Aurigæ & & 4. 21 & -.10 \\
\hline & 22 & Lyræ & 4. 27 & 3. 99 & +.05 & 13 & B. D. $+38^{\circ} 1539$ & -... & 4. 31 & -.10 \\
\hline & 23 & $\alpha \quad$ Lyræ & 4. 21 & 3. 93 & +.05 & 16 & 40 Aurigæ & & 4. 40 & -.10 \\
\hline June & 3 & $\alpha \quad$ Lyræ & 4. 20 & 3.92 & +.04 & 16 & B. D. $+38^{\circ} 1539$ & -... & 4. 25 & -.10 \\
\hline & 4 & $\alpha \quad$ Lyræ & 4. 22 & 3. 94 & +.04 & 21 & 40 Aurigæ & & 4. 78 & -.10 \\
\hline & 11 & Lyræ & 4. 31 & 4. 03 & +.03 & 22 & $\alpha \quad$ Lyræ & 5.48 & 5. 20 & -.10 \\
\hline & 22 & Lyræ & 4. 18 & 3.90 & .00 & 22 & 40 Aurigæ & $\ldots$ & 4. 61 & -.10 \\
\hline & 25 & Lyræ & 4. 66 & 4. 38 & .00 & 22 & B. D. $+38^{\circ} 1539$ & $\ldots$ & 4.15 & -.10 \\
\hline & 28 & Lyræ & 4. 31 & 4. 03 & -.01 & 23 & 40 Aurigæ & $\ldots$ & 4. 37 & -.10 \\
\hline & 29 & Lyræ & 4. 57 & 4. 29 & -.01 & 23 & B. D. $+38^{\circ} 1539$ & & 4. 21 & -.10 \\
\hline July & 5 & Lyræ & 4. 21 & 3. 93 & -.02 & 24 & $\alpha \quad$ Lyræ & 5.27 & 4. 99 & -.10 \\
\hline & 7 & Lyræ & 4.15 & 3. 87 & -.02 & 25 & 40 Aurigæ & - . - & 4. 31 & -.10 \\
\hline & 12 & Lyræ & 4. 38 & 4. 10 & -.03 & 25 & B. D. $+38^{\circ} 1539$ & & 4. 19 & -.10 \\
\hline & 13 & $\alpha \quad$ Lyræ & 4. 24 & 3.96 & -.03 & 27 & $\alpha \quad$ Lyræ & 5. 28 & 5.00 & -.10 \\
\hline & 19 & $\alpha \quad$ Lyræ & 4. 28 & 4. 00 & -.04 & 1907 & & & & \\
\hline & 24 & $\alpha \quad$ Lyræ & 5. 07 & 4. 79 & -.04 & Jan. 4 & Lyræ & 4. 79 & 4.51 & -.08 \\
\hline Aug. & 15 & B. D. $+38^{\circ} 3772$ & -..- & 3.85 & -.06 & 4 & Lyræ* & 5. 27 & 4.99 & -.08 \\
\hline Sept. & - 7 & 19 Cygni & $\overline{4} \overline{9}$ & 3. 77 & -.08 & 5 & 40 Aurigæ & -..- & 4. 15 & -.08 \\
\hline & 8 & $\alpha \quad$ Lyræ & 4. 79 & 4. 51 & -.08 & 5 & B. D. $+38^{\circ} 1539$ & & 4. 12 & -.08 \\
\hline & 9 & $\alpha \quad$ lyræ & $\begin{array}{l}4.42 \\
4.40\end{array}$ & 4. 14 & -.08 & 6 & $\alpha \quad$ Lyræ & 4. 99 & 4. 71 & -.07 \\
\hline & 11 & $\alpha \quad$ Lyræ & $\begin{array}{l}4.40 \\
4.33\end{array}$ & $\begin{array}{l}4.12 \\
4.05\end{array}$ & -.08 & 6 & Lyræ* & 4. 95 & 4. 67 & -.07 \\
\hline & 12 & Lyræ & 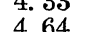 & 4. 05 & -.08 & 9 & Lyr: & 4. 86 & 4. 58 & -.07 \\
\hline & 14 & $\alpha \quad$ Lyræ & 4. 64 & 4. 36 & -.08 & 10 & 40 Aurigæ & -..- & 4. 17 & -.07 \\
\hline & 14 & $\alpha \quad$ Lyræ* & 4.92 & 4. 64 & -.08 & 10 & B. D. $+38^{\circ} 1539$ & & 4. 1 & -.07 \\
\hline & 18 & Lyræ & 4. 71 & 4. 43 & -.08 & 20 & $\alpha \quad$ Lyræ & 5. 31 & 5. 03 & -.06 \\
\hline & 18 & Lyræ* & 5.33 & 5. 05 & -.08 & 21 & 40 Aurigæ & $\cdots$ & 4. 68 & -.05 \\
\hline & 19 & Lyræ & 4. 16 & 3. 88 & -.08 & 21 & B. D. $+38^{\circ} 1539$ & & 4. & -.05 \\
\hline & 21 & Lyræ & 5. 16 & 4. 88 & -.08 & 23 & $\alpha \quad$ Lyræ & 5.15 & 4. 87 & -.05 \\
\hline & 23 & Lyræ & 4. 50 & 4. 22 & -.08 & 26 & 40 Aurigæ & & 4. 3 & -.04 \\
\hline & 23 & Lyræ* * & 5. 30 & 5. 02 & -.08 & 26 & B. D. $+38^{\circ} 1539$ & & 4. 05 & -.04 \\
\hline & 24 & & 4. 64 & 4. 36 & -.08 & 27 & $\alpha \quad$ Lyræ & 4. 95 & 4. 67 & -.04 \\
\hline & 24 & Lyræ* & 5. 33 & 5.05 & -.08 & 28 & 40 Aurigæ & & & -.04 \\
\hline Oct. & 11 & $\alpha \quad$ Lyræ & 4. 58 & 4. 30 & -.09 & 28 & B. D. $+38^{\circ} 1539$ & $\ldots$ & 4. 29 & -.04 \\
\hline & 11 & 40 Aurigæ & $\ldots$ & 4. 41 & -.09 & 30 & 40 Aurigæ & & & -.04 \\
\hline & 11 & B. D. $+38^{\circ} 1539$ & -.-- & 3. 83 & -.09 & 30 & B. D. $+38^{\circ} 1539$ & -... & 4. 04 & -.04 \\
\hline & 12 & 40 Aurigæ & $-\cdots$ & 4.23 & -.09 & Feb. & 40 Aurigæ & $\ldots$ & 4. 45 & -.03 \\
\hline & 12 & B. D. $+38^{\circ} 1539$ & & 4. 19 & -.09 & 6 & B. D. $+38^{\circ} 1539$ & & & -.03 \\
\hline & 13 & $\alpha \quad$ Lyræ & 4. 50 & 4.22 & -.09 & 8 & $\alpha \quad$ Lyræ & 4.88 & 4. 60 & -.02 \\
\hline & 13 & Lyræ* & 5. 20 & 4. 92 & -.09 & 8 & 40 Aurigæ & . & 4. 41 & -.02 \\
\hline & 14 & 40 Aurigæ & ---- & 4. 20 & -.09 & 8 & B. D. $+38^{\circ} 1539$ & & 4. 12 & -.02 \\
\hline & 14 & B. $D_{\dot{+}}+38^{\circ} 1539$ & & 4. 35 & -.09 & 11 & $\alpha \quad$ Lyræ & 5. 22 & 4. 94 & -.02 \\
\hline & 25 & $\alpha \quad$ Lyræ & 4. 66 & 4. 38 & -.10 & 11 & 40 Aurigæ & & 4. 14 & -.02 \\
\hline & 25 & Lyræ* & 5. 24 & 4.96 & -.10 & 11 & B. D. $+38^{\circ} 1539$ & $\ldots$ & 3. 97 & -.02 \\
\hline & 25 & 40 Aurigæ & & 4.54 & -.10 & 13 & 40 Aurigæ & & 4. 22 & -.02 \\
\hline & 25 & B. D. $+38^{\circ} 1539$ & & 3.95 & -.10 & 13 & B. D. $+38^{\circ} 1539$ & & 4.06 & -.02 \\
\hline & 26 & $\alpha \quad$ Lyræ & 4. 66 & 4. 38 & -.10 & 15 & $\alpha \quad$ Lyræ & 4. 50 & 4. 22 & -.02 \\
\hline & 26 & Lyræ* & 5.18 & 4.90 & -.10 & 15 & 40 Aurigæ & & 4.07 & -.02 \\
\hline & 26 & 40 Aurigæ & $\ldots$ & 4. 19 & -.10 & 15 & B. D. $+38^{\circ} 1539$ & & 3. 99 & -.02 \\
\hline & 26 & B. D. $+38^{\circ} 1539$ & $\ldots$ & 4.05 & -.10 & Mar. 15 & $\alpha \quad$ Lyræ & 4. 39 & 4. 11 & +.02 \\
\hline & 29 & 40 Aurigæ & & 4. 56 & -.10 & 23 & $\alpha \quad$ Lyræ & 4. 63 & 4.35 & +.02 \\
\hline & 29 & B. D. $+38^{\circ} 1539$ & -... & 4.17 & -.10 & 29 & $\alpha \quad$ Lyræ & 3.99 & 3. 71 & +.03 \\
\hline
\end{tabular}

$101141^{\circ}-26 \dagger$ PT I -8 
TABLE VIII.-The Latitude of the Instrument, Obtained by the Use of Newcomb and Boss Declinations-Continued

\begin{tabular}{|c|c|c|c|c|c|c|c|c|c|}
\hline Date & Star & N. & B. & $\Delta \varphi$ & Date & Star & $\mathrm{N}$. & B. & $\Delta \varphi$ \\
\hline 1907 & & & & & & & & & \\
\hline $\begin{array}{ll}\text { Apr. } & 1 \\
2\end{array}$ & $\begin{array}{ll}\alpha & \text { Lyræ } \\
\alpha & \text { Lyræ }\end{array}$ & $\begin{array}{l}\text { 4. } 36 \\
\text { 4. } 15\end{array}$ & $\begin{array}{l}\text { 4. } 08 \\
\text { 3. } 87\end{array}$ & $\begin{array}{r}+0.04 \\
+.04\end{array}$ & $\begin{array}{ll}\text { Oct. } & 21 \\
22\end{array}$ & $\underset{\alpha}{\text { B. D. }}+{ }_{\text {Lvræ }}+38^{\circ} 1539$ & 4. 71 & 4. 04 & $\begin{array}{r}+0.02 \\
+\quad 02\end{array}$ \\
\hline & $\alpha \quad$ Lyræ & $\begin{array}{l}\text { 4. } 17 \\
\text { 4. } 17\end{array}$ & $\begin{array}{l}\text { 3. } 87 \\
\text { 3. } 88\end{array}$ & $\begin{array}{l}+.04 \\
+.06\end{array}$ & 23 & $\begin{array}{ll}\alpha & \text { Lyræ } \\
\alpha & \text { Lyræ }\end{array}$ & $\begin{array}{l}\text { 4. } 71 \\
\text { 4. } 38\end{array}$ & $\begin{array}{l}\text { 4. } 43 \\
\text { 4. } 10\end{array}$ & $\begin{array}{l}+.02 \\
+.02\end{array}$ \\
\hline 24 & $\begin{array}{ll}\alpha & \text { Lyræ } \\
\alpha & \text { Lvræ }\end{array}$ & 4. 14 & 3. 86 & $\begin{array}{r}+.06 \\
\end{array}$ & 23 & 40 Aurige &.-- & 3. 91 & \\
\hline $\begin{array}{ll}\text { May } & 4 \\
9\end{array}$ & $\begin{array}{l}\text { Lyræ } \\
\text { Lyræ }\end{array}$ & $\begin{array}{l}\text { 4. } 32 \\
\text { 4. } 21\end{array}$ & $\begin{array}{l}\text { 4. } 04 \\
\text { 3. } 93\end{array}$ & $\begin{array}{l}+.07 \\
+.08\end{array}$ & $\begin{array}{l}23 \\
25\end{array}$ & $\underset{\alpha}{\mathrm{B} .} \mathrm{D}_{\dot{\mathrm{Ly}}}^{+}$ & 4.71 & $\begin{array}{l}\text { 4. } 20 \\
\text { 4. } 43\end{array}$ & +.0 \\
\hline & $\alpha \quad$ Lyræ & 4. 30 & $\begin{array}{l}\text { 4. } 02 \\
\text { 4. } 02\end{array}$ & $\begin{array}{l}+.08 \\
+.08\end{array}$ & 25 & $\begin{array}{l}\alpha \\
40\end{array}$ & & $\begin{array}{l}\text { 4. } 40 \\
\text { 4. } 13\end{array}$ & $\begin{array}{l}+.0 \\
+.0\end{array}$ \\
\hline 13 & $\begin{array}{ll}\alpha & \text { Lyræ } \\
\alpha & \text { Lyræ }\end{array}$ & $\begin{array}{l}\text { 4. } 02 \\
\text { 4. } 06\end{array}$ & $\begin{array}{l}3.74 \\
3 \\
78\end{array}$ & 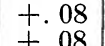 & $\begin{array}{l}25 \\
28\end{array}$ & B. ${ }_{i}^{+}$ & 470 & 3. 89 & +.01 \\
\hline 21 & Lyr & $\begin{array}{l}\text { 4. } 06 \\
\text { 4. } 25\end{array}$ & $\begin{array}{l}\text { 3. } 98 \\
\text { 3. } 97\end{array}$ & $\begin{array}{l}+.0 \\
+.0\end{array}$ & 28 & $\begin{array}{l}\alpha \\
40 \\
4 \text { Aurigr } \\
\text { Aurige }\end{array}$ & 4.70 & $\begin{array}{l}\text { 4. } 42 \\
\text { 3. } 88\end{array}$ & $\begin{array}{l}+.01 \\
+.01\end{array}$ \\
\hline 27 & Lyræ & 4. 14 & 3. 86 & $\begin{array}{r}+10 \\
\end{array}$ & 28 & B. D. $+38^{\circ} 1539$ & & 3. 75 & $\begin{array}{l}+.01 \\
+.01\end{array}$ \\
\hline & Lyræ & 3. 80 & 3. 52 & +.10 & Nov. 4 & $\alpha \quad$ Lyræ & 4. 66 & 4. 38 & 1.0 \\
\hline $\begin{array}{ll}\text { June } & 6 \\
8\end{array}$ & $\begin{array}{l}\text { Lyræ } \\
\text { Lyræ }\end{array}$ & $\begin{array}{l}\text { 4. } 16 \\
\text { 4. } 47\end{array}$ & $\begin{array}{l}\text { 3. } 88 \\
\text { 4. } 19\end{array}$ & $\begin{array}{l}+.10 \\
+.10\end{array}$ & & 40 Auri & & 4. 23 & .00 \\
\hline 15 & Lyræ & 3. 91 & 3. 63 & +.11 & $\frac{4}{7}$ & 40 Aurigx & $-\cdots$ & $\begin{array}{l}\text { 4. } 26 \\
4.11\end{array}$ & $\begin{aligned} .00 \\
-.01\end{aligned}$ \\
\hline 16 & $\alpha \quad \operatorname{Lyr}$ & 4. 18 & 3. 90 & +.11 & 7 & B. D. $+38^{\circ} 1$ & & $\begin{array}{l}\text { 4. } 13 \\
\text { 4. } 13\end{array}$ & $\begin{array}{l}-.01 \\
-.01\end{array}$ \\
\hline 17 & $\begin{array}{ll}\alpha & \text { Lyr } \\
\alpha & \end{array}$ & $\begin{array}{l}\text { 4. } 12 \\
\text { 4. }\end{array}$ & $\begin{array}{l}3.84 \\
3\end{array}$ & $\begin{array}{l}+.11 \\
+11\end{array}$ & 13 & $\alpha \quad$ Lyræ & 4. 54 & 4. 26 & -.02 \\
\hline $\begin{array}{l}21 \\
26\end{array}$ & $\begin{array}{l}\text { Lyræ } \\
\text { Lyræ }\end{array}$ & $\begin{array}{l}\text { 4. } 09 \\
\text { 4. } 09\end{array}$ & $\begin{array}{l}\text { 3. } 99 \\
\text { 3. } 81\end{array}$ & $\begin{array}{l}+.11 \\
+.12\end{array}$ & $\begin{array}{l}14 \\
14\end{array}$ & $\begin{array}{ll}\alpha & \text { Lyræ } \\
40 & \text { Aurigæ }\end{array}$ & 5. 02 & $\begin{array}{l}4.74 \\
4.09\end{array}$ & $\begin{array}{l}-.02 \\
-.02\end{array}$ \\
\hline July 3 & $\alpha \quad$ Lyræ & 3. 96 & 3. & $\begin{array}{l}+.12 \\
+\end{array}$ & $\begin{array}{l}14 \\
14\end{array}$ & B. D. $+38^{\circ} 1539$ & & $\begin{array}{l}\begin{array}{l}\text { 4. } 09 \\
\text { 4. } 04\end{array}\end{array}$ & $\begin{array}{l}-.02 \\
-.02\end{array}$ \\
\hline & $\begin{array}{ll}\alpha & \text { Lyræ } \\
\alpha & \text { Lvræ }\end{array}$ & 4. 07 & & $\begin{array}{l}+.1 \\
+.1\end{array}$ & 15 & $\alpha \quad$ Lyr & 4. 62 & 4. 34 & -.02 \\
\hline 12 & Lyræ & $\begin{array}{l}\text { 4. } 03 \\
\text { 4. } 40\end{array}$ & $\begin{array}{l}\text { 3. } 75 \\
\text { 4. } 12\end{array}$ & $\begin{array}{l}+.12 \\
+.12\end{array}$ & $\begin{array}{l}15 \\
15 \\
\end{array}$ & 40 Aur & & $\begin{array}{l}\text { 3. } 98 \\
3.92\end{array}$ & $=.02$ \\
\hline 14 & Lyræ & 3. 94 & & +.12 & $\begin{array}{l}10 \\
25\end{array}$ & ${ }_{\alpha}^{\mathrm{B}} \dot{\mathrm{L}}_{\mathrm{Ly}}^{+}$ & 4.73 & & $\begin{array}{l}-.02 \\
-.02\end{array}$ \\
\hline 16 & Lyræ & 4. 31 & 4. 03 & +.1 & 25 & $40 \mathrm{Au}$ & 4.10 & 35 & $\begin{array}{l}-.04 \\
-.04\end{array}$ \\
\hline 20 & $\begin{array}{l}\text { Lyræ } \\
\text { Lyræ }\end{array}$ & 4. 01 & 3. 73 & $\begin{array}{l}+.12 \\
+12\end{array}$ & 25 & B. $\mathrm{D}+3$ & - & & -.04 \\
\hline 21 & $\begin{array}{l}\text { Lyr } \\
\text { Lyr }\end{array}$ & $\begin{array}{l}\text { 4. } 00 \\
\text { 3. } 95\end{array}$ & $\begin{array}{l}\text { 3. } 72 \\
\text { 3. } 67\end{array}$ & $\begin{array}{l}+.12 \\
+.12\end{array}$ & $\begin{array}{l}26 \\
27\end{array}$ & $\alpha \quad$ Lyræ & 4. 98 & 4. 70 & -.04 \\
\hline 26 & $\alpha$ Lyræ & $\begin{array}{l}\text { 3. } 85 \\
\text { 3. }\end{array}$ & $\begin{array}{l}\text { 3. } 57 \\
\text { 3. }\end{array}$ & $\begin{array}{l}7.12 \\
+.12\end{array}$ & & $\alpha \quad$ Lyræ & 5. 06 & 4. 78 & -.04 \\
\hline $\begin{array}{l}27 \\
30\end{array}$ & $\begin{array}{ll}\alpha & \text { Lyr: } \\
\alpha & \text { Lyr: }\end{array}$ & $\begin{array}{l}\text { 4. } 22 \\
\text { 4. } 05\end{array}$ & 3. 94 & $\begin{array}{l}+.12 \\
+.12\end{array}$ & 1908 & & & & \\
\hline & $\alpha \quad$ Lyræ & $\begin{array}{l}\text { 4. } 11 \\
\text { 4. }\end{array}$ & 3. 83 & +.12 & Jan. 1 & Lyræ & 5. 13 & 4. 85 & -.12 \\
\hline Aug. 4 & Lyræ & 4. 13 & 3. 85 & +.12 & $\frac{1}{2}$ & $\alpha \quad \overline{\mathrm{Ly}}$ & 5. 26 & 4.98 & -.12 \\
\hline $\begin{array}{r}0 \\
15\end{array}$ & $\begin{array}{l}\text { Lyrä } \\
\text { Lyræ }\end{array}$ & $\begin{array}{l}\text { 4. } 09 \\
\text { 4. } 04\end{array}$ & $\begin{array}{l}\text { 3. } 81 \\
\text { 3. } 76\end{array}$ & $\begin{array}{l}+.11 \\
+.11\end{array}$ & $\begin{array}{l}2 \\
3\end{array}$ & $\begin{array}{l}\alpha \\
40 \text { Aur } \\
\text { Aur }\end{array}$ & 5. 16 & $\begin{array}{l}88 \\
35\end{array}$ & $\begin{array}{l}-.12 \\
-.13\end{array}$ \\
\hline & Lyræ & 4. 08 & 3. 80 & +.1 & 3 & B. D. +3 & & & -13 \\
\hline 2 & Lyra & 4. 20 & 3. & + & 5 & $40 \mathrm{Aur}$ & - & & -.12 \\
\hline & Lyrs & 4. 26 & 3. & & 5 & B. D. +3 & -... & & -.13 \\
\hline 26 & $\begin{array}{l}\text { Lyx } \\
\text { Lyr }\end{array}$ & 3. 87 & 3. 59 &.+ & $\begin{array}{l}6 \\
6\end{array}$ & 40 Aur & $\cdots$ & & -.13 \\
\hline Sept. 14 & $\begin{array}{ll}\alpha & \text { Lyre } \\
\alpha & \text { Lyra }\end{array}$ & $\begin{array}{l}\text { 4. } 13 \\
\text { 4. } 09\end{array}$ & $\begin{array}{l}\text { 3. } 85 \\
\text { 3. } 81\end{array}$ & $\begin{array}{l}+.09 \\
+.08\end{array}$ & 9 & ${ }_{\alpha}^{\text {B. D }}$ D $_{\text {Ly }}^{+}$ & 5. 32 & $\begin{array}{l}\text { 4. } 24 \\
\text { 5. } 04\end{array}$ & $\begin{array}{l}=.13 \\
-.14\end{array}$ \\
\hline 15 & Lyr & 3. 91 & 3. 63 & +.07 & 9 & $40 \mathrm{Au}$ & $\ldots$ & & -.14 \\
\hline 20 & $\begin{array}{l}\text { Lyræ } \\
\text { Lyræ }\end{array}$ & $\begin{array}{l}\text { 4. } 08 \\
\text { 4. } 12\end{array}$ & $\begin{array}{l}3.80 \\
\text { 3. } 84\end{array}$ & 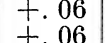 & $\begin{array}{r}9 \\
10\end{array}$ & B. $\mathrm{D}_{\dot{\mathrm{L}}}^{+}$ & 492 & 4. 11 & -.14 \\
\hline 25 & Lyræ & 4. 11 & $\begin{array}{l}\text { 3. } \\
\text { 3. } 83\end{array}$ &.+ & 10 & $\begin{array}{l}\alpha \\
40 \mathrm{Au}\end{array}$ & & & $=.1$ \\
\hline & Lyræ & 4. 30 & 4. & & 10 & B. D. + & $\cdots$ & & -.14 \\
\hline & Ly & 0 & 3.8 & & & $\dot{L}_{\mathrm{V}}$ & $4.8 \overline{7}$ & & -.14 \\
\hline & $\alpha$ & 4. 14 & 3. & + . & 44 & & 4. 91 & & -.14 \\
\hline $\begin{array}{r}3 \\
12\end{array}$ & $\begin{array}{l}\text { Lyræ } \\
\text { Lyræ }\end{array}$ & $\begin{array}{l}\text { 4. } 17 \\
\text { 4. } 41\end{array}$ & $\begin{array}{l}3.89 \\
4.13\end{array}$ & $\begin{array}{l}+.8 \\
+.8\end{array}$ & $\begin{array}{l}14 \\
14\end{array}$ & $\begin{array}{l}40 \text { Aur } \\
\text { B. D. }+3\end{array}$ & $\cdots$ & 4. 27 & $\begin{array}{l}-.14 \\
-.14\end{array}$ \\
\hline 12 & 40 Auri & & &.+ & 16 & $\alpha \quad$ Lyr & 5. 23 & 4. 95 & -1 \\
\hline 12 & B. D. $t$ & $-\cdots$ & &.+ & 16 & & & 4. & -.14 \\
\hline 13 & $40 \mathrm{~A}$ & & & & & B. D & $-5 i$ & 4. 25 & -.14 \\
\hline $\begin{array}{l}13 \\
14\end{array}$ & $\begin{array}{l}\text { B. D. }+ \\
40 \mathrm{Au}\end{array}$ & $\begin{array}{ll}\cdots-\cdot \\
\cdots--\end{array}$ & $\begin{array}{l}\text { 4. } 18 \\
\text { 4. } 08\end{array}$ & $\begin{array}{l}+.8 \\
+.2\end{array}$ & $\begin{array}{l}18 \\
18\end{array}$ & $\begin{array}{ll}\alpha & \mathrm{L} \\
40 & \mathrm{~A}\end{array}$ & 4. 54 & $\begin{array}{l}\text { 4. } 26 \\
\text { 4. } 24\end{array}$ & $\begin{array}{l}-.15 \\
-.15\end{array}$ \\
\hline 14 & B. $\mathrm{D}+2$ & & $\begin{array}{l}4.00 \\
4.00\end{array}$ &.+ & 18 & B. D. & $\ldots$ & & -.1 \\
\hline 15 & $\underset{40}{\alpha} \quad \stackrel{\mathrm{Ly}}{\mathrm{Au}}$ & 4. 35 & 4. 07 & + & 19 & & $\ldots$ & 4. 41 & -.1 \\
\hline $\begin{array}{l}15 \\
15\end{array}$ & $\begin{array}{l}\text { 40 Aurlga } \\
\text { B. D. }+38^{\circ} 15399\end{array}$ & & 4. & 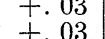 & $\begin{array}{l}19 \\
21\end{array}$ & $\begin{array}{l}\text { B. D. } \\
\alpha . \mathrm{I}\end{array}$ & 5.18 & & -1. \\
\hline 16 & $\alpha \quad$ Lyr & 4.28 & 4. 00 & +.0 & 24 & $40 \quad \mathrm{~A}$ & -... & $\begin{array}{l}\text { 4. } 90 \\
\text { 4. } 46\end{array}$ & $\begin{array}{l}-.15 \\
-.15\end{array}$ \\
\hline 17 & & $\ldots$ & &.+ & & & 烈 & 4. 23 & -.1 \\
\hline $\begin{array}{l}17 \\
19\end{array}$ & B. D. + & $\overline{4} . \overline{6}$ & 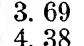 & $\begin{array}{l}+.0 \\
+0\end{array}$ & $\begin{array}{l}25 \\
25\end{array}$ & $\begin{array}{l}40 \mathrm{~A} \\
\text { B. D. }\end{array}$ & $\cdots$ & $\begin{array}{l}\text { 4. } 10 \\
\text { 3. }\end{array}$ & $\begin{array}{l}=.16 \\
-.16\end{array}$ \\
\hline $\begin{array}{l}19 \\
10\end{array}$ & $\begin{array}{ll}\alpha & L y \\
40 & \mathrm{Au}\end{array}$ & x. 00 & $\begin{array}{l}\text { 4. } 4.09 \\
\text { 4. } 09\end{array}$ &.+ & & & $\cdots$ & $\begin{array}{l}\text { 3. } 94 \\
\text { 4. } 52\end{array}$ & -.1 \\
\hline 19 & B. $\mathrm{D}_{\dot{+}+}^{+}$ & & 4. 0 & & & & $\cdots$ & 4. 33 & -.16 \\
\hline $\begin{array}{l}21 \\
21\end{array}$ & $\begin{array}{ll}\alpha & \text { Lyræ } \\
40 & \text { Aurigæ }\end{array}$ & 4. 50 & $\begin{array}{l}\text { 4. } 22 \\
\text { 4. } 27\end{array}$ & $\begin{array}{l}+.02 \\
+.02\end{array}$ & $\begin{array}{l}30 \\
30\end{array}$ & $\begin{array}{l}\text { 40 Aurigæ } \\
\text { B. D. }+38^{\circ} 1539\end{array}$ & $\cdots$ & $\begin{array}{l}\text { 4. } 09 \\
\text { 4. } 28\end{array}$ & $\begin{array}{l}-.16 \\
-.16\end{array}$ \\
\hline
\end{tabular}


INTRODUCTION.

A CXv

Table VIII.-The Latitude of the Instrument, Obtained by the Use of Newcomb and Boss Declinations-Continued

$+38^{\circ} 55^{\prime} 10^{\prime \prime}+$

* Indicates reflected observation.

\begin{tabular}{|c|c|c|c|c|c|c|c|c|c|c|}
\hline \multicolumn{2}{|l|}{ Date } & Star & N. & B. & $\Delta \varphi$ & Date & Star & N. & B. & $\Delta \varphi$ \\
\hline 1908 & & & $\prime \prime$ & "' & "' & 1908 & & 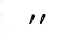 & 11 & 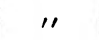 \\
\hline Feb. & & $\alpha \quad$ Lyræ & 4. 47 & 4. 19 & -0.16 & Aug. 3 & $\alpha \quad$ Lyræ & 4. 54 & 4. 26 & +0.14 \\
\hline & & $\begin{array}{ll}\alpha & \text { Lyræ } \\
40 & \text { Aurigæ }\end{array}$ & 4. 96 & 4. 68 & -16 & $\begin{array}{l}18 \\
10\end{array}$ & $\alpha \quad$ Lyræ & 4. 22 & 3. 94 & +.16 \\
\hline & 4 & $\begin{array}{l}40 \\
40 \\
\text { Aurigæ }\end{array}$ & $-\cdots$ & $\begin{array}{l}\text { 4. } 29 \\
4.13\end{array}$ & $\begin{array}{l}-.10 \\
-.16\end{array}$ & $\begin{array}{l}19 \\
19\end{array}$ & $\begin{array}{ll}\alpha & \text { Lyræ } \\
\alpha & \text { Lyræ* }\end{array}$ & $\begin{array}{l}\text { 4. } 4 b \\
4.61\end{array}$ & $\begin{array}{l}\text { 4. } 17 \\
4.33\end{array}$ & $\begin{array}{l}+.16 \\
+.16\end{array}$ \\
\hline & 4 & B. D. $+38^{\circ} 1539$ & & 3. 95 & -.16 & 20 & $\alpha \quad$ Lyræ & $\begin{array}{l}\text { 4. } 91 \\
\text { 3. } 96\end{array}$ & $\begin{array}{l}\text { 4. } 00 \\
\text { 3. } 68\end{array}$ & $\begin{array}{l}+.10 \\
+.16\end{array}$ \\
\hline & 6 & $\alpha \quad$ Lyræ & 4. 35 & 4. 07 & -.17 & 29 & $\alpha \quad$ Lyræ & 4. 18 & 3. 90 & +.18 \\
\hline & 7 & Lyræ & 4. 59 & 4. 31 & -.17 & 30 & Lyræ & 4. 08 & 3. 80 & +.18 \\
\hline & 7 & 40 Aurigæ & $\ldots$ & 3. 79 & -.17 & 30 & Lyræ* & 4. 60 & 4. 32 & +.18 \\
\hline & 7 & B. D. $+38^{\circ} 1539$ & -... & 3. 89 & -.17 & 31 & Lyræ & 3. 85 & 3. 57 & +.18 \\
\hline & 8 & 40 Aurigæ & -..- & 4. 05 & -.17 & Sept. 6 & Lyræ & 4. 25 & 3. 97 & +.18 \\
\hline & 8 & B. D. $+38^{\circ} 1539$ & & 3. 67 & -.17 & 7 & Lyræ & 3. 90 & 3. 62 & +.19 \\
\hline 1 & & $\alpha \quad$ Lyræ & 4. 72 & 4. 44 & -.18 & 8 & Lyræ & 4. 46 & 4. 18 & +.19 \\
\hline 1 & & Lyræ & 4. 73 & 4.45 & -.18 & 8 & Lyræ* & 4. 36 & 4. 08 & +.19 \\
\hline 1 & & 40 Aurigæ & -..- & 4. 20 & -.18 & 9 & Lyræ & 4. 03 & 3. 75 & +.19 \\
\hline 1 & & B. D. $+38^{\circ} 1539$ & -... & 4. 53 & -.18 & 9 & Lyræ*. & 4. 94 & 4. 66 & +.19 \\
\hline 2 & & 40 Aurigæ & $\ldots$ & 3. 86 & -.18 & 12 & Lyræ & 4. 02 & 3. 74 & +.19 \\
\hline$\overline{2}$ & & B. D. $+38^{\circ} 1539$ & & 4. 19 & -.18 & 15 & Lyræ & 4.07 & 3. 79 & +.20 \\
\hline 2 & & $\alpha \quad$ Lyræ & 4.50 & 4. 22 & -.18 & 15 & Lyræ* & 4.84 & 4. 56 & +.20 \\
\hline 2 & & Aurigæ & & 4. 04 & -.18 & 16 & Lyræ & 4. 13 & 3. 85 & +.20 \\
\hline 2 & & Lyræ & 4. 57 & 4. 29 & -.18 & 16 & $\alpha \quad$ Lyræ* & 4. 24 & 3. 96 & +.20 \\
\hline 2 & & 40 Aurigæ & $\ldots$ & 3. 89 & -.18 & 22 & Lyræ & 4. 00 & 3. 72 & +.20 \\
\hline 2 & & B. D. $+38^{\circ} 1539$ & $\ldots$ & 3. 90 & -.18 & 23 & Lyræ & 4. 22 & 3. 94 & +.20 \\
\hline 2 & & 40 Aurigæ & - & 4. 19 & -.18 & 24 & Lyræ & 4. 10 & 3. 82 & +.20 \\
\hline 2 & & Lyræ & 4. 60 & 4. 32 & -.18 & 29 & Lyræ & 4. 06 & 3. 78 & +.21 \\
\hline 2 & & 40 Aurigæ & $\ldots$ & 4. 27 & -.18 & 30 & Lyræ & 4. 36 & 4. 08 & +.21 \\
\hline 2 & & B. D. $+38^{\circ} 1539$ & $-\ldots$ & 4. 20 & -.18 & Oct. & Lyræ & 3. 95 & 3. 67 & +.21 \\
\hline Mar. 1 & & $\alpha \quad$ Lyræ & 4. 62 & 4. 34 & -.18 & 3 & Lyræ & 3. 92 & 3. 64 & +.21 \\
\hline & & $\alpha \quad$ Lyræ & 4. 60 & 4. 32 & -.18 & 4 & Lyræ & 3. 80 & 3. 52 & +.21 \\
\hline 2 & & $\alpha \quad$ Lyræ & 4. 52 & 4. 24 & -.17 & 5 & Lyræ & 3. 97 & 3. 69 & +.21 \\
\hline 2 & 5 & Lyræ & 4. 50 & 4. 22 & -.17 & 6 & Lyræ & 4. 38 & 4. 10 & +.21 \\
\hline Apr. & 3 & Lyræ & 4. 60 & 4. 32 & -.16 & 11 & 40 Aurigæ & $\ldots$ & 4. 10 & +.21 \\
\hline & 6 & Lyræ & 4. 94 & 4. 66 & -.16 & 11 & B. D. $+38^{\circ} 1539$ & & 3. 72 & +.21 \\
\hline 1 & & Lyræ & 4. 52 & 4. 24 & -.14 & 12 & $\alpha \quad$ Lyræ & 4. 35 & 4. 07 & +.21 \\
\hline 1 & 9 & $\alpha \quad$ Lyræ & 4. 70 & 4. 42 & -.12 & 12 & 40 Aurigæ & $-\ldots$ & 3. 77 & +.21 \\
\hline 2 & 1 & Lyræ & 4. 39 & 4.11 & -.11 & 12 & B. D. $+38^{\circ} 1539$ & $\ldots$ & 3. 62 & +.21 \\
\hline May & 2 & Lyræ & 4. 57 & 4. 29 & -.10 & 13 & $\alpha \quad$ Lyræ & 4. 21 & 3. 93 & +21 \\
\hline & 9 & Lyræ & 4. 21 & 3. 93 & -.09 & 14 & $\alpha \quad$ Lyræ & 4. 25 & 3. 97 & +21 \\
\hline 1 & 0 & Lyræ & 4. 30 & 4. 02 & -.08 & 14 & 40 Aurigæ & .... & 3. 80 & +21 \\
\hline 2 & 3 & Lyræ & 4. 32 & 4. 04 & -.04 & 14 & B. D. $+38^{\circ} 1539$ & & 3. 48 & +21 \\
\hline 2 & 5 & Lyræ & 4.23 & 3. 95 & -.03 & 15 & $\alpha \quad$ Lyræ & 4. 41 & 4. 13 & \\
\hline 2 & 7 & Lyræ & 4. 20 & 3. 92 & -.03 & 16 & 40 Aurigæ & -... & 3.54 & \\
\hline 2 & 8 & Lyræ & 4. 31 & 4. 03 & -.02 & 16 & B. D. $+38^{\circ} 1539$ & $\cdots$ & 3. 26 & \\
\hline June & 1 & Lyræ & 4. 17 & 3.85 & -.01 & 18 & $\alpha \quad$ Lyræ & 4. 48 & 4. 20 & +21 \\
\hline & 2 & Lyræ & 4. 33 & 4. 05 & -.01 & 26 & Lyræ & 4. 23 & 3.95 & +20 \\
\hline & 6 & Lyræ & 4. 00 & 3. 72 & .00 & 30 & Lyræ & 4. 30 & 4. 02 & +20 \\
\hline & 7 & Lyræ & 4. 49 & 4. 21 & .00 & 30 & 40 Aurigæ & $\ldots$ & 3. 89 & +.20 \\
\hline & 8 & Lyræ & 4. 37 & 4. 09 & +.01 & 30 & B. D. $+38^{\circ} 1539$ & & 3.83 & +.20 \\
\hline 1 & 2 & Lyræ & 4. 01 & 3. 73 & +.02 & 31 & $\alpha \quad$ Lyræ & 4. 27 & 3. 99 & +.20 \\
\hline 1 & 3 & Lyræ & 4. 27 & 3. 99 & +.02 & 31 & 40 Aurigæ & $\ldots$ & 3. 88 & +.20 \\
\hline 1 & 8 & Lyræ & 4. 03 & 3. 75 & +.03 & 31 & B. D. $+38^{\circ} 1539$ & $\ldots$ & 3. 57 & +.20 \\
\hline 2 & 0 & Lyræ & 3. 94 & 3. 66 & +.04 & Nov. 1 & $\alpha \quad$ Lyræ & 4. 54 & 4. 26 & +.20 \\
\hline 2 & 2 & Lyræ & 4. 25 & 3. 97 & +.04 & 1 & 40 Aurigæ & ...- & 3. 96 & +.20 \\
\hline 2 & 3 & Lyræ & 4. 38 & 4. 10 & +.04 & 1 & B. D. $+38^{\circ} 1539$ & & 3. 68 & +.20 \\
\hline 2 & 6 & Lyræ & 3. 78 & 3. 50 & +.05 & 2 & $\alpha \quad$ Lyræ & 4. 61 & 4. 33 & +.20 \\
\hline 2 & 8 & Lyræ & 4. 22 & 3. 94 & +.05 & 3 & $\alpha \quad$ Lyræ & 4.29 & 4. 01 & +.20 \\
\hline July & 1 & Lyræ & 4. 18 & 3. 90 & +.06 & 5 & 40 Aurigæ & $\ldots$ & 3.65 & +.19 \\
\hline & 6 . & Lyræ & 4. 09 & 3. 81 & +.07 & 5 & B. D. $+38^{\circ} 1539$ & $\ldots$ & 3. 74 & +.19 \\
\hline & 8 & Lyræ & 3. 91 & 3.63 & +.08 & 6 & $\alpha \quad$ Lyræ & 4. 40 & 4. 12 & +.19 \\
\hline 1 & 1 & Lyræ & 4. 00 & 3. 72 & +.09 & 7 & $\alpha \quad$ Lyræ & 4.24 & 3. 96 & +.19 \\
\hline 1 & 3 & Lyræ & 4. 11 & 3. 83 & +.09 & 8 & 40 Aurigæ & $\ldots$ & 3. 72 & +.18 \\
\hline 1 & 5 & Lyræ & 4. 31 & 4. 03 & +.10 & 8 & B. D. $+38^{\circ} 1539$ & $\ldots$ & 3. 62 & +.18 \\
\hline 1 & 6 & Lyræ & 4. 25 & 3. 97 & +.10 & 12 & $\alpha \quad$ Lyræ & 4.61 & 4. 33 & +18 \\
\hline 2 & 20 & Lyræ & 4. 26 & 3. 98 & +.11 & 12 & 40 Aurigæ & $\ldots$ & 3. 66 & +.18 \\
\hline 2 & 88 & Lyræ & 4. 09 & 3. 81 & +.12 & 12 & B. D. $+38^{\circ} 1539$ & & 3. 58 & +.18 \\
\hline 2 & 9 & Lyræ & 4. 37 & 4. 09 & +.13 & 13 & $\alpha \quad$ Lyræ & 4. 34 & 4. 06 & +.18 \\
\hline Áug. & 1 & Iyræ & 4. 20 & 3. 92 & +.13 & 13 & 40 Aurigæ & $\ldots$ & 3. 81 & +.18 \\
\hline & 2 & Lyræ & 4. 14 & 3. 86 & +.14 & 13 & B. D. $+38^{\circ} 1539$ & $\ldots$ & 3. 84 & +.18 \\
\hline
\end{tabular}


TABLE VIII.-The Latitude of the Instrument, Obtained by the Use of Newcomb and Boss Declinations-Continued

$$
+38^{\circ} 55^{\prime} 10^{\prime \prime}+\quad \text { *Indicates reflected observation. }
$$

\begin{tabular}{|c|c|c|c|c|c|c|c|c|c|}
\hline Date & Star & N. & B. & $\Delta \varphi$ & Date & Star & N. & B. & $\Delta \varphi$ \\
\hline 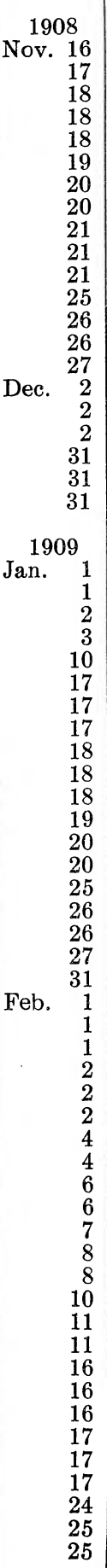 & 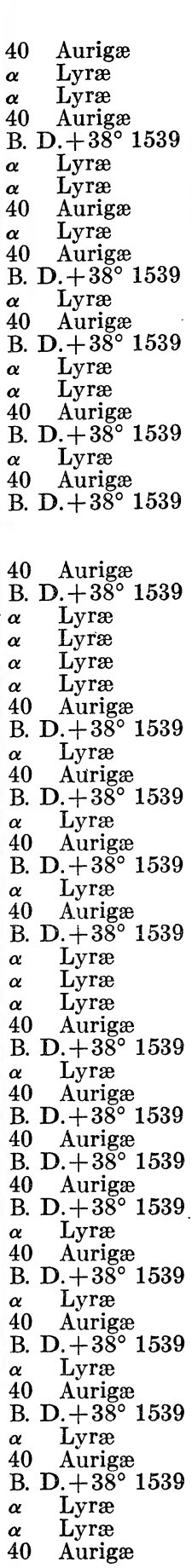 & 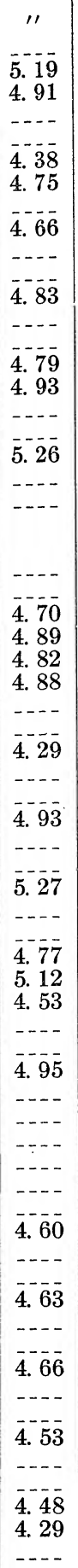 & $\begin{array}{l}\text { 3. } 78 \\
\text { 3. } 60 \\
4.42 \\
4.61 \\
4.54 \\
4.60 \\
4.06 \\
\text { 3. } 67 \\
4.01 \\
\text { 3. } 94 \\
3.71 \\
4.65 \\
4.11 \\
\text { 3. } 91 \\
4.99 \\
4.05 \\
4.09 \\
4.49 \\
4.84 \\
4.25 \\
4.05 \\
4.15 \\
4.67 \\
4.15 \\
\text { 3. } 96 \\
3.91 \\
3.81 \\
4.31 \\
4.12 \\
4.32 \\
3.92 \\
3.75 \\
4.35 \\
4.36 \\
3.85 \\
4.38 \\
4.21 \\
4.25 \\
4.25 \\
4.29 \\
4.33 \\
4.20 \\
4.01 \\
3.83\end{array}$ & $\begin{array}{l}+.08 \\
+.08 \\
+.06 \\
+.06 \\
+.04 \\
+.02 \\
+.02 \\
+.02 \\
+.02 \\
+.02 \\
+.02 \\
+.02 \\
.00 \\
.00 \\
-.02 \\
-.02 \\
-.02 \\
-.02 \\
-.04 \\
-.04 \\
-.04 \\
-.04 \\
-.04 \\
-.04 \\
-.04 \\
-.06 \\
-.06 \\
-.06 \\
-.06 \\
-.06 \\
-.08 \\
-.08 \\
-.08 \\
-.09 \\
-.09 \\
-.10 \\
-.10 \\
-.10 \\
-.10 \\
-.10 \\
-.10 \\
-.14 \\
-.14 \\
-.14\end{array}$ & 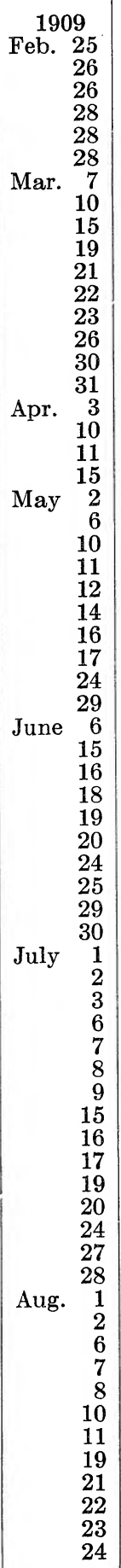 & 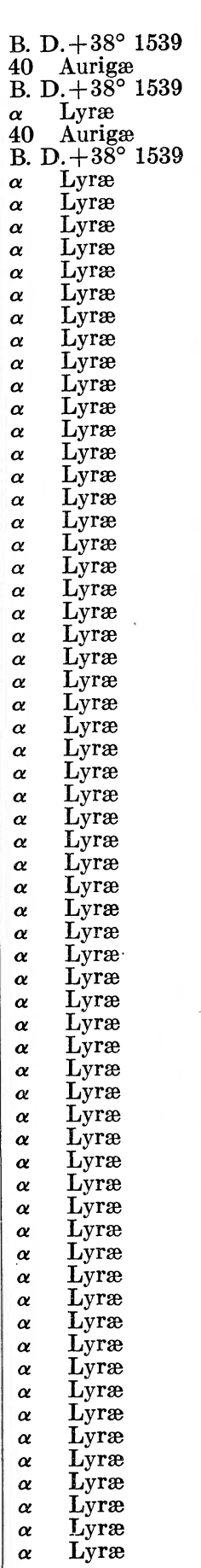 & 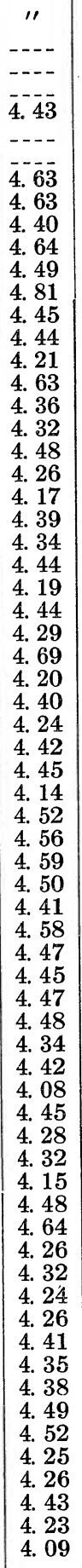 & 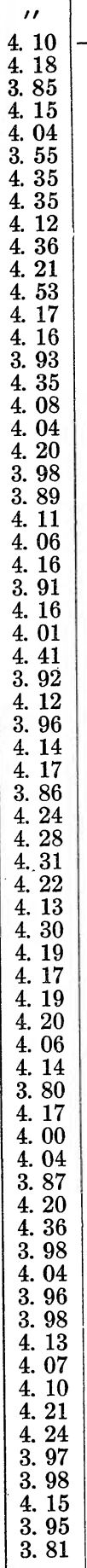 & $\begin{array}{r}11 \\
-0.14 \\
-.14 \\
-.14 \\
-.15 \\
-.15 \\
-.15 \\
-.16 \\
-.18 \\
-.20 \\
-.21 \\
-.22 \\
-.22 \\
-.23 \\
-.23 \\
-.24 \\
-.24 \\
-.25 \\
-.26 \\
-.27 \\
-.28 \\
-.29 \\
-.29 \\
-.29 \\
-.29 \\
-.29 \\
-.29 \\
-.29 \\
-.29 \\
-.29 \\
-.28 \\
-.24 \\
-.24 \\
-.24 \\
-.23 \\
-.23 \\
-.22 \\
-.22 \\
-.21 \\
-.20 \\
-.20 \\
-.20 \\
-.20 \\
-.19 \\
-.18 \\
-.18 \\
-.18 \\
-.15 \\
-.15 \\
-.15 \\
-.14 \\
-.14 \\
-.12 \\
-.11 \\
-.11 \\
-.10 \\
-.09 \\
-.08 \\
-.08 \\
-.08 \\
-.06 \\
-.06 \\
-.03 \\
-.02 \\
-.02 \\
.00\end{array}$ \\
\hline
\end{tabular}


INTRODUCTION.

A CXVII

TABLE VIII.-The Latitude of the Instrument, Obtained by the Use of Newcomb and Boss Declinations-Continued

$+38^{\circ} 55^{\prime} 10^{\prime \prime}+$

* Indicates reflected observation.

\begin{tabular}{|c|c|c|c|c|c|c|c|c|c|c|}
\hline \multicolumn{2}{|c|}{ Date } & Star & N. & B. & $\Delta \varphi$ & Date & Star & N. & B. & $\Delta \varphi$ \\
\hline 1909 & & & 'l & $" \prime$ & " & 1909 & & $\prime \prime$ & $\prime \prime$ & 'I \\
\hline Aug. ? & & $\alpha \quad$ Lyræ & 4. 35 & 4. 07 & 0.00 & Dec. 10 & B. D. $+38^{\circ} 1539$ & $\ldots$ & 3. 51 & +0.32 \\
\hline & & $\alpha \quad$ Lyræ & 4. 09 & 3. 81 & +.02 & 16 & 40 Aurigæ & & 3. 67 & +.32 \\
\hline & & Lyræ & 4. 41 & 4.13 & +.02 & 16 & B. $D_{+}+38^{\circ} 1539$ & & 3. 66 & +.32 \\
\hline & 0 & $\alpha \quad$ Lyræ & 4. 55 & 4. 27 & +.02 & 17 & $\alpha \quad$ Lyræ & 4. 38 & 4. 10 & +.32 \\
\hline Sept. & & $\alpha \quad$ Lyræ & 4. 32 & 4. 04 & +.04 & 18 & $\alpha \quad$ Lyræ & 4. 61 & 4. 33 & +.32 \\
\hline & & Lyræ & 4. 12 & 3. 84 & +.06 & 18 & 40 Aurigæ & $\ldots$ & 3. 82 & +.32 \\
\hline & 8 & Lyræ & 4. 20 & 3. 92 & +.06 & 18 & B. D. $+38^{\circ} 1539$ & $\ldots$ & 3. 62 & +.32 \\
\hline & 1 & Lyræ & 4. 08 & 3. 80 & +.08 & 20 & 40 Aurigæ & -... & 3. 47 & +.32 \\
\hline & 3 & Lyræ & 4. 20 & 3.92 & +.08 & 20 & B. $D_{\dot{i}}+38^{\circ} 1539$ & & 3. 61 & +.32 \\
\hline & & Lyræ & 4. 38 & 4. 10 & +.08 & 21 & $\alpha \quad$ Lyræ & 4. 51 & 4. 23 & +.32 \\
\hline & 8 & Lyræ & 4. 08 & 3. 80 & +.14 & 29 & 40 Aurigæ & $\ldots$ & 3. 90 & +.32 \\
\hline & 9 & Lyræ & 4. 29 & 4. 01 & +.15 & 29 & B. D. $+38^{\circ} 1539$ & $-\overline{-n}$ & 3.50 & +.32 \\
\hline Oct. & 1 & Lyræ & 4. 46 & 4. 18 & +.15 & 30 & $\alpha \quad$ Lyræ & 3. 91 & 3. 63 & +.30 \\
\hline & 2 & $\alpha \quad$ Lyræ & 3. 96 & 3. 68 & +.15 & 31 & $\alpha \quad$ Lyræ & 3. 92 & 3.64 & +.30 \\
\hline & $\begin{array}{l}5 \\
7\end{array}$ & $\begin{array}{ll}\alpha . & \text { Lyræ } \\
\alpha & \text { Lyræ }\end{array}$ & $\begin{array}{l}\text { 4. } 10 \\
\text { 4. } 11\end{array}$ & $\begin{array}{l}\text { 3. } 82 \\
\text { 3. } 83\end{array}$ & $\begin{array}{l}+.16 \\
+.18\end{array}$ & 1910 & & & & \\
\hline & 7 & $\alpha \quad$ Lyræ * & 4. 79 & 4. 51 & +.18 & Jan. 3 & 40 Aurigæ & $\ldots$ & 3.90 & +.30 \\
\hline & 2 & Lyræ & 3.94 & 3. 66 & +.20 & 3 & B. $D_{+}+38^{\circ} 1539$ & & 3. 47 & +.30 \\
\hline & 2 & 40 Aurigæ & $\ldots$ & 3.70 & +.20 & 7 & $\alpha \quad$ Lyræ & 4.61 & 4. 33 & +.28 \\
\hline & 2 & B. D. $+38^{\circ} 1539$ & & 3. 68 & +.20 & 7 & 40 Aurigæ & $\ldots$ & 4. 00 & +.28 \\
\hline & 3 & $\alpha \quad$ Lyræ & 3. 90 & 3. 62 & +.20 & 7 & B. D. $+38^{\circ} 1539$ & & 3. 66 & +.28 \\
\hline & 9 & 40 Aurigæ & -..- & 3. 94 & +.22 & 8 & 40 Aurigæ & $\ldots$ & 3. 83 & +.28 \\
\hline & 9 & B. D. $+38^{\circ} 1539$ & & 3. 62 & +.22 & 8 & B. $D_{i}+38^{\circ} 1539$ & & 3. 84 & +.28 \\
\hline & 2 & $\alpha$ Lyræ & 4. 36 & 4. 08 & +.24 & 9 & $\alpha \quad$ Lyræ & 4. 46 & 4. 18 & +.28 \\
\hline & 5 & Lyræ & 4. 18 & 3. 90 & +.24 & 10 & 40 Aurigæ & $\ldots$ & 3. 45 & +.28 \\
\hline & 6 & 40 Aurigæ & $\ldots$ & 3. 61 & +.24 & 10 & B. $D_{\cdot}+38^{\circ} 1539$ & 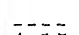 & 3. 50 & +.28 \\
\hline & 6 & B. $D_{\dot{r}}+38^{\circ} 1539$ & & 3. 53 & +.24 & 14 & $\alpha \quad$ Lyræ & 4.15 & 3. 87 & +.27 \\
\hline & 8 & $\alpha \quad$ Lyræ & 4. 26 & 3. 98 & +.24 & 15 & 40 Aurigæ & $\ldots$ & 3. 75 & +.27 \\
\hline & 8 & 40 Aurigæ & & 3. 58 & +.24 & 15 & B. D. $+38^{\circ} 1539$ & $\ldots$ & 3. 51 & +.27 \\
\hline & 8 & B. D. $+38^{\circ} 1539$ & -... & 3. 39 & +24 & 16 & 40 Aurigæ & $\ldots$ & 3. 27 & +.26 \\
\hline & 9 & 40 Aurigæ & -..- & 3. 69 & +.26 & 16 & B. D. $+38^{\circ} 1539$ & -... & 3. 24 & +.26 \\
\hline & 9 & B. D. $+38^{\circ} 1539$ & $\ldots$ & 3. 52 & +.26 & 19 & 40 Aurigæ & $\ldots$ & 3. 80 & +.26 \\
\hline & 0 & 40 Aurigæ & & 3. 89 & +.26 & 19 & B. D. $+38^{\circ} 1539$ & & 3. 64 & +.26 \\
\hline & 0 & B. D. $+38^{\circ} 1539$ & & 3. 62 & +.26 & 24 & $\alpha \quad$ Lyræ & 4. 26 & 3.98 & +.22 \\
\hline & 1 & $\alpha \quad$ Lyræ & 4. 69 & 4. 41 & +.26 & 25 & 40 Aurigæ & $\ldots$ & 3. 83 & +.22 \\
\hline Nov. & 1 & $\alpha \quad$ Lyræ & 4. 29 & 4. 01 & +.26 & 25 & B. D. $+38^{\circ} 1539$ & & 3. 74 & +.22 \\
\hline & 4 & $\boldsymbol{\alpha} \quad$ Lyræ & 4. 25 & 3. 97 & +.27 & 31 & $\alpha \quad$ Lyræ & 4. 77 & 4. 49 & +.21 \\
\hline & 5 & $\alpha \quad$ Lyræ & 4. 17 & 3. 89 & +.27 & Feb. & 40 Aurigæ &.-- & 3.87 & +.20 \\
\hline & 8 & Lyræ & 4. 10 & 3. 82 & +.28 & 1 & B. D. $+38^{\circ} 1539$ & $\ldots$ & 3. 67 & +.20 \\
\hline & 0 & 40 Aurigæ & $\ldots$ & 3. 48 & +.28 & 2 & 40 Aurigæ & & 4. 01 & +.20 \\
\hline & 0 & B. D. $+38^{\circ} 1539$ & $\ldots$ & 3. 67 & +.28 & 3 & Lyræ & 4.45 & 4. 17 & +.20 \\
\hline & 1 & 40 Aurigæ & & 3. 50 & +.29 & 4 & $\alpha \quad$ Lyræ & 4.57 & 4. 29 & +.18 \\
\hline & 1 & B. D. $+38^{\circ} 1539$ & & 3. 58 & +.29 & 4 & 40 Aurigæ & $\ldots$ & 3. 78 & +.18 \\
\hline & 2 & $\alpha \quad$ Lyræ & 4. 22 & 3. 94 & +.30 & 4 & B. D. $+38^{\circ} 1539$ & $\ldots$ & 3. 56 & +.18 \\
\hline & 2 & 40 Aurigæ & $\ldots$ & 3. 59 & +.30 & 7 & 40 Aurigæ & $\ldots$ & 3. $\varepsilon$ & +18 \\
\hline & 2 & B. D. $+38^{\circ} 1539$ & & 3. 39 & +.30 & 7 & B. D. $+38^{\circ} 1539$ & & 3. 55 & +.18 \\
\hline & 7 & $\alpha \quad$ Lyræ & 4. 64 & 4. 36 & +.30 & 9 & $\alpha \quad$ Lyræ & 4. 23 & 3. 95 & +.18 \\
\hline & 8 & Lyræ & 4. 47 & 4. 19 & +.30 & 10 & 40 Aurigæ & $\ldots$ & 3. 48 & +.17 \\
\hline & 9 & 40 Aurigæ & & 3. 94 & +.30 & 10 & B. D. $+39^{\circ} 1539$ & $\ldots$ & 3. 2 & +.17 \\
\hline & 9 & B. D. $+38^{\circ} 1539$ & & 3. 77 & +.30 & 12 & 40 Aurigæ & $\ldots$ & 3. 66 & +.16 \\
\hline & 2 & $\alpha \quad$ Lyræ & 4. 60 & 4. 32 & +.32 & 12 & B. $\mathrm{D}_{+}+38^{\circ} 1539$ & & 3. 54 & +.16 \\
\hline & 5 & 40 Aurigæ & & 3.85 & +.32 & 13 & $\alpha \quad$ Lyræ & 4. 39 & 4. 11 & +.16 \\
\hline & 5 & B. D. $+38^{\circ} 1539$ & & 3. 71 & +.32 & 18 & Lyræ. & 4. 43 & 4. 15 & +.14 \\
\hline & 6 & $\alpha \quad$ Lyræ & 4.86 & 4. 58 & +.32 & 18 & 40 Aurigæ & $\ldots$ & 3. 74 & +.14 \\
\hline & 9 & 40 Aurigæ & & 3. 74 & +.32 & 18 & B. D. $+38^{\circ} 1539$ & & 3.85 & +.14 \\
\hline & 9 & B. D. $+38^{\circ} 1539$ & & 3. 71 & +.32 & 22 & $\alpha \quad$ Lyræ & 4. 39 & 4. 11 & +.10 \\
\hline Dec. & 2 & $\alpha \quad$ Lyræ & 4. 47 & 4. 19 & +.32 & 22 & 40 Aurigæ & $\ldots$ & 3. 83 & +.10 \\
\hline & 3 & Lyræ & 4.93 & 4.65 & +.32 & 22 & B. $\mathrm{D}_{+}+38^{\circ} 1539$ & $-\cdots$ & 3. 70 & +.10 \\
\hline & 4 & Lyræ & 4. 44 & 4. 16 & +.32 & 24 & $\alpha \quad$ Lyræ & 4. 21 & 3. 93 & +.10 \\
\hline & 4 & 40 Aurigæ & & 3. 56 & +.32 & 25 & 40 Aurigæ & $\ldots-$ & 3. 92 & +.10 \\
\hline & 4 & B. D. $+38^{\circ} 1539$ & $\ldots$ & 3. 45 & +.32 & 25 & B. D. $+38^{\circ} 1539$ & 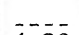 & 4. 04 & +.10 \\
\hline & 6 & 40 Aurigæ & & 3. 74 & +.32 & Mar. 6 & $\boldsymbol{\alpha} \quad$ Lyræ & 4. 30 & 4. 02 & +.06 \\
\hline & 6 & B. D. $+38^{\circ} 1539$ & & 3. 59 & +.32 & 18 & Lyræ & 3.99 & 3. 71 & .00 \\
\hline & 9 & $\alpha \quad$ Lyræ & 4. 25 & 3. 97 & +.32 & Apr. 5 & Lyræ & 4. 57 & 4. 29 & -.09 \\
\hline & 9 & Aurigæ & & 3. 58 & +.32 & 9 & Lyræ & 4. 51 & 4. 23 & -.10 \\
\hline & 0 & $\alpha \quad$ Lyræ & 4. 12 & 3. 84 & +.32 & 10 & $\alpha \quad$ Lyræ & 4. 76 & 4. 48 & -.10 \\
\hline & 0 & 40 Aurigæ & & 3. 46 & +.32 & 12 & $\alpha \quad$ Lyræ & 4.53 & 4. 25 & -.12 \\
\hline
\end{tabular}


TABLE VIII.-The Latitude of the Instrument, Obtained by the Use of Newcomb and Boss Declinations-Continued

\begin{tabular}{|c|c|c|c|c|c|c|c|c|c|}
\hline Date & Star & N. & B. & $\Delta \varphi$ & Date & Star & N. & B. & $\Delta_{\varphi}$ \\
\hline \begin{tabular}{r|}
1910 \\
Apr. 13 \\
25 \\
28 \\
30 \\
May \\
4 \\
15 \\
June \\
7 \\
8 \\
19 \\
21 \\
22 \\
24 \\
26 \\
29 \\
July \\
14 \\
19 \\
20 \\
21 \\
22 \\
24 \\
31 \\
Aug. \\
4 \\
5 \\
9 \\
16 \\
18 \\
19 \\
20 \\
22 \\
24 \\
30 \\
4 \\
75 \\
10 \\
12 \\
16 \\
17 \\
22 \\
26 \\
27 \\
9 \\
9 \\
9 \\
10 \\
10 \\
10 \\
12 \\
13 \\
15 \\
16 \\
16 \\
17 \\
17 \\
17 \\
18 \\
20 \\
20 \\
23 \\
23 \\
24 \\
26 \\
29 \\
29 \\
29 \\
31
\end{tabular} & 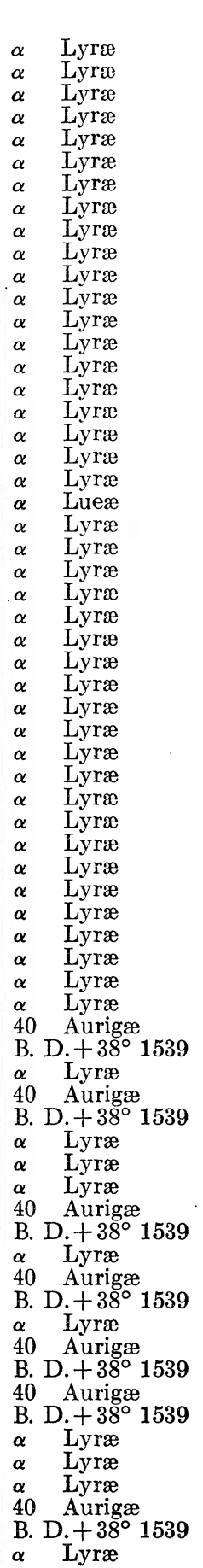 & 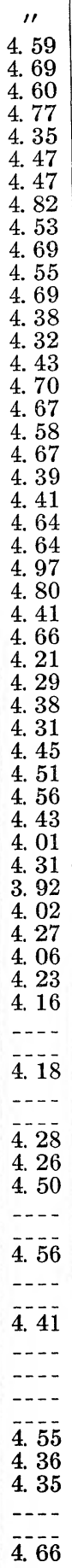 & 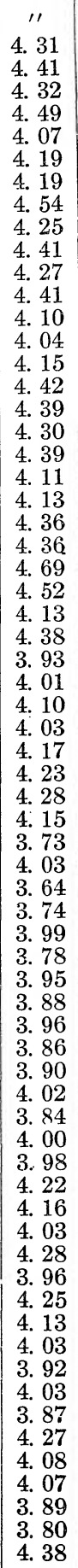 & 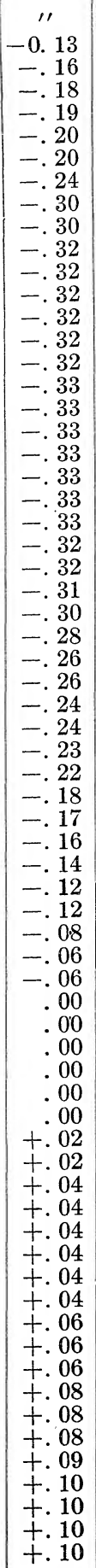 & $\begin{array}{rr}1910 \\
\text { Oct. } & 31 \\
& 31 \\
\text { Nov. } & 6 \\
6 \\
7 \\
9 \\
9 \\
18 \\
19 \\
19 \\
22 \\
22 \\
26 \\
26 \\
26 \\
26 \\
\text { Dec. } \\
1 \\
1 \\
3 \\
12 \\
13 \\
13 \\
13 \\
14 \\
14 \\
16 \\
17 \\
17 \\
17 \\
20 \\
20 \\
21 \\
21 \\
30 \\
30 \\
1911 \\
\text { Jan. } \\
3 \\
4 \\
4 \\
4 \\
6 \\
9 \\
9 \\
16 \\
16 \\
19 \\
19 \\
22 \\
23 \\
23 \\
23 \\
24 \\
24 \\
24 \\
27 \\
28 \\
28 \\
29 \\
30 \\
30 \\
\text { Feb. } \\
2 \\
2 \\
2 \\
4 \\
4 \\
7 \\
7 \\
9\end{array}$ & 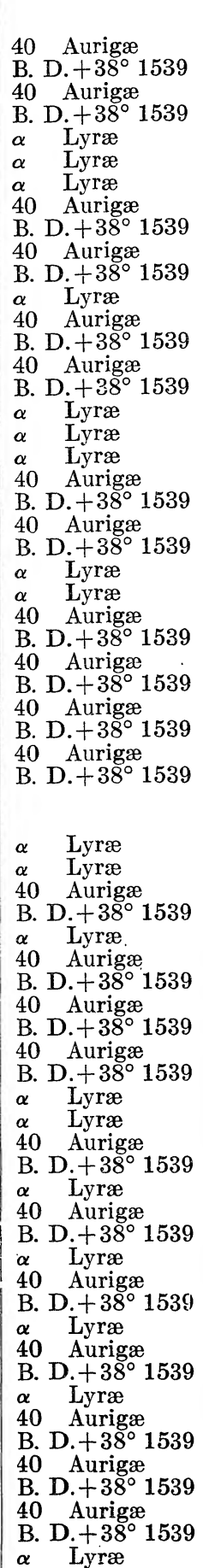 & $\begin{array}{c}1 " \\
-\cdots \\
-.- \\
4.37 \\
4.02 \\
4.30 \\
-.- \\
-.- \\
4.97 \\
-.- \\
-.\end{array}$ & $\begin{array}{l}\prime \prime \\
4.07 \\
3.80 \\
3.67 \\
4.76 \\
4.09 \\
3.74 \\
4.02 \\
4.04 \\
4.05 \\
4.02 \\
3.71 \\
4.69 \\
3.90 \\
3.97 \\
3.98 \\
3.92 \\
4.84 \\
3.96 \\
4.10 \\
4.03 \\
3.61 \\
3.75 \\
3.70 \\
4.61 \\
4.08 \\
4.25 \\
3.96 \\
3.94 \\
3.99 \\
4.04 \\
4.13 \\
3.85 \\
3.84\end{array}$ & $\begin{array}{r}11 \\
+0.10 \\
+.10 \\
+.14 \\
+.14 \\
+.14 \\
+.15 \\
+.17 \\
+.17 \\
+.17 \\
+.18 \\
+.18 \\
+.20 \\
+.20 \\
+.22 \\
+.22 \\
+.22 \\
+.26 \\
+.26 \\
+.26 \\
+.26 \\
+.26 \\
+.26 \\
+.27 \\
+.27 \\
+.27 \\
+.28 \\
+.28 \\
+.28 \\
+.28 \\
+.30 \\
+.30\end{array}$ \\
\hline
\end{tabular}


INTRODUCTION.

A CXIX

TABLE VIII.-The Latitude of the Instrument, Obtained by the Use of Newcomb and Boss Declinations-Continued

$+38^{\circ} 55^{\prime} 10^{\prime \prime}+\quad$ *Indicates reflected observation.

\begin{tabular}{|c|c|c|c|c|c|c|c|c|c|}
\hline Date & Star & N. & B. & $\Delta \varphi$ & Date & Star & N. & B. & $\Delta \varphi$ \\
\hline 1911 & & $\prime \prime$ & '" & "I & & & "' & 11 & . \\
\hline Feb. 10 & 40 Aurigæ & $\ldots$ & 3. 36 & +0.28 & Sept. 16 & Lyræ & 4. 44 & 4. 15 & -0.29 \\
\hline 10 & B. D. $+38^{\circ} 1539$ & $\ldots$ & 3.46 & +.28 & & $\alpha \quad$ Lyræ & 4. 68 & 4. 39 & -.28 \\
\hline 12 & 40 Aurigæ & $\ldots$ & 4. 14 & +.26 & 24 & $\alpha \quad$ Lyræ & 4. 63 & 4. 34 & -.28 \\
\hline 12 & B. D. $+38^{\circ} 1539$ & & 3. 63 & +.26 & Oct. 8 & $\alpha \quad$ Lyræ & 4. 49 & 4. 20 & -.23 \\
\hline 20 & $\alpha \quad$ Lyræ & 4. 01 & 3. 72 & +.24 & 11 & $\alpha \quad$ Lyræ & 4. 06 & 3. 77 & -.22 \\
\hline 20 & 40 Aurigæ & $\ldots$ & 3.88 & +.24 & 12 & $\alpha \quad$ Lyræ & 4. 26 & 3. 97 & -.22 \\
\hline 20 & B. D. $+38^{\circ} 1539$ & $\ldots$ & 3. 92 & +.24 & 13 & $\alpha \quad$ Lyræ & 4. 40 & 4. 11 & -.22 \\
\hline 21 & 40 Aurigæ & $\ldots$ & 3. 68 & +.24 & 16 & Lyræ & 4. 54 & 4. 25 & -.21 \\
\hline 21 & B. D. $+38^{\circ} 1539$ & -... & 3. 37 & +.24 & 18 & $\alpha \quad$ Lyræ & 4. 44 & 4.15 & -.20 \\
\hline 22 & 40 Aurigæ & $\ldots$ & 3. 48 & +.24 & 23 & $\alpha \quad$ Lyræ & 4. 35 & 4. 06 & -.18 \\
\hline 22 & B. D. $+38^{\circ} 1539$ & - & 3. 64 & +.24 & 23 & 40 Aurigæe & $\ldots$ & 4. 07 & -.18 \\
\hline 23 & 40 Aurigæ & $\ldots$ & 3. 89 & +.24 & 23 & B. D. $+38^{\circ} 1539$ & & 4. 18 & -.18 \\
\hline 23 & B. D. $+38^{\circ} 1539$ & $\ldots$ & 3. 76 & +.24 & 24 & $\alpha \quad$ Lyræ & 4. 62 & 4. 33 & -.18 \\
\hline 25 & 40 Aurigæ & & 3. 79 & +.24 & 24 & 40 Aurigæ & $\ldots$ & 4. 16 & -.18 \\
\hline 25 & B. D. $+38^{\circ} 1539$ & -... & 3. 80 & +.24 & 24 & B. $D_{i}+38^{\circ} 1539$ & & 4. 01 & -.18 \\
\hline 27 & 40 Aurigæ & & 3. 81 & +.22 & 25 & $\alpha \quad$ Lyræ & 4. 65 & 4. 36 & -.16 \\
\hline 27 & B. D. $+38^{\circ} 1539$ & & 3. 63 & +.22 & 25 & 40 Aurigæ & $\ldots$ & 3. 98 & -.16 \\
\hline Mar. 4 & $\alpha \quad$ Lyræ & 4. 29 & 4. 00 & +.22 & 25 & B. D. $+38^{\circ} 1539$ & & 4. 01 & -.16 \\
\hline & $\alpha \quad$ Lyræ & 3. 87 & 3.58 & +.20 & 29 & $\alpha \quad$ Lyræ & 4. 54 & 4. 25 & -16 \\
\hline 8 & Lyræ & 4. 08 & 3. 79 & +.19 & 29 & 40 Aurigæ & $\ldots$ & 3. 94 & -.16 \\
\hline 10 & Lyræ & 4. 35 & 4. 06 & +.19 & 29 & B. D. $+38^{\circ} 1539$ & $\ldots$ & 3. 77 & -.16 \\
\hline 16 & $\alpha \quad$ Lyræ & 4. 12 & 3.83 & +.18 & Nov. 2 & 40 Aurigæ & .... & 4. 14 & -.14 \\
\hline 20 & Lyræ & 4. 14 & 3.85 & +.14 & 2 & B. D. $+38^{\circ} 1539$ & & 3. 80 & -.14 \\
\hline 21 & Lyræ & 4. 40 & 4. 11 & +.14 & 3 & $\alpha \quad$ Lyræ & 4. 55 & 4. 26 & -.14 \\
\hline 23 & Lyræ & 4.54 & 4.25 & +.14 & 7 & $\alpha \quad$ Lyræ & 4. 86 & 4. 57 & -.13 \\
\hline 28 & Lyræ & 4. 56 & 4. 27 & +.12 & 10 & $\alpha \quad$ Lyræ & 4. 75 & 4. 46 & -.12 \\
\hline 31 & Lyræ & 4.20 & 3. 91 & +.10 & 10 & 40 Aurigæ & .... & 4. 19 & -.12 \\
\hline Apr. 9 & Lyræ & 4.57 & 4. 28 & +.08 & 10 & B. D. $+38^{\circ} 1539$ & & 4. 19 & -.12 \\
\hline 10 & Lyræ & 4. 34 & 4. 05 & +.08 & 11 & $\alpha \quad$ Lyræ & 4.55 & 4. 26 & -.12 \\
\hline 25 & Lyræ & 4. 29 & 4.00 & +.02 & 15 & $\alpha \quad$ Lyræ & 4. 76 & 4. 47 & -.10 \\
\hline 26 & Lyræ & 4. 27 & 3. 98 & .00 & 16 & $\alpha \quad$ Lyræ & 4.63 & 4. 34 & -.08 \\
\hline May 2 & Lyræ & 4. 40 & 4. 11 & -.01 & 16 & 40 Aurigæ & $\ldots$ & 3. 61 & -.08 \\
\hline 5 & Lyræ & 4. 27 & 3. 98 & -.02 & 16 & B. D. $+38^{\circ} 1539$ & $\ldots-$ & 3. 59 & -.08 \\
\hline 10 & Lyræ & 4. 40 & 4. 11 & -.06 & 18 & $\alpha \quad$ Lyræ & 5. 17 & 4. 88 & -.08 \\
\hline 20 & Lyræ & 4. 76 & 4. 47 & -.10 & 21 & 40 Aurigæ & $\ldots$ & 3. 59 & -.08 \\
\hline 22 & Lyræ & 4. 40 & 4. 11 & -.11 & 21 & B. D. $+38^{\circ} 1539$ & -.. & 3. 27 & -.08 \\
\hline 24 & Lyræ & 4. 35 & 4. 06 & -.11 & 22 & 40 Aurigæ & $\ldots$ & 4. 00 & -.08 \\
\hline 25 & Lyræ & 4. 28 & 3. 99 & -.12 & 22 & B. D. $+38^{\circ} 1539$ & & 3. 77 & -.08 \\
\hline$\quad 29$ & Lyræ & 4. 20 & 3. 91 & -.14 & 25 & $\alpha \quad$ Lyræ & 4. 89 & 4. 60 & -.06 \\
\hline June 8 & Lyræ & 4. 29 & 4. 00 & -.16 & 26 & 40 Aurigæ & .... & 3. 92 & -.06 \\
\hline 9 & Lyræ & 4. 30 & 4. 01 & -.18 & 26 & B. D. $+38^{\circ} 1539$ & - & 3. 64 & -.06 \\
\hline 11 & Lyræ & 4. 71 & 4.42 & -.18 & Dec. 1 & $\alpha \quad$ Lyræ & 4. 33 & 4. 04 & -.04 \\
\hline 18 & Lyræ & 4. 30 & 4. 01 & -.21 & 4 & $\alpha \quad$ Lyræ & 4. 89 & 4. 60 & -.04 \\
\hline 21 & Lyræ & 4. 05 & 3. 76 & -.22 & 5 & $\alpha \quad$ Lyræ & 4. 85 & 4. 56 & -.02 \\
\hline 28 & Lyræ & 4. 30 & 4. 01 & -.26 & 5 & 40 Aurigæ & $\ldots$ & 3. 53 & -.02 \\
\hline 29 & Lyræ & 4.38 & 4.09 & -.26 & 5 & B. D. $+38^{\circ} 1539$ & & 3. 55 & -.02 \\
\hline 30 & Lyræ & 4. 84 & 4. 55 & -.30 & 6 . & $\alpha \quad$ Lyræ & 5. 37 & 5. 08 & -.02 \\
\hline July 5 & Lyræ & 4. 70 & 4. 41 & -.28 & $6^{\circ}$ & 40 Aurigæ & $\ldots$ & 3. 95 & -.02 \\
\hline 6 & Lyræ & 4. 56 & 4. 27 & -.28 & 6 & B. D. $+38^{\circ} 1539$ & $\ldots$ & 3. 82 & -.02 \\
\hline 9 & Lyræ & 4.58 & 4. 29 & -.28 & 7 & $\alpha \quad$ Lyræ & 4. 97 & 4. 68 & -.02 \\
\hline 10 & Lyræ & 4.80 & 4. 51 & -.28 & 8 & Lyræ & 5.09 & 4. 80 & -.01 \\
\hline 12 & Lyræ & 4. 39 & 4. 10 & -.28 & 10 & 40 Aurigæ & -...- & 4. 01 & -.02 \\
\hline 16 & Lyræ & 4. 32 & 4. 03 & -.29 & 10 & B. D. $+38^{\circ} 1539$ & -... & 3. 84 & -.02 \\
\hline 22 & Lyræ & 4. 76 & 4. 47 & -.30 & 18 & B. D. $+38^{\circ} 1539$ & & 3. 67 & +.02 \\
\hline 25 & Lyræ & 4. 20 & 3. 91 & -.30 & 19 & $\alpha \quad$ Lyræ & 5. 14 & 4.85 & +.02 \\
\hline 30 & Lyræ & 5. 05 & 4. 76 & -.31 & & & & & \\
\hline 31 & Lyræ & 4. 16 & 3.87 & -.31 & 1912 & & & & \\
\hline Aug. 6 & Lyræ & 4. 59 & 4. 30 & -.31 & Jan. 1 & 40 Aurigæ & $\ldots$ & 3. 78 & +.04 \\
\hline 7 & Lyræ & 4. 43 & 4. 14 & -.31 & & B. D. $+38^{\circ} 1539$ & & 3. 40 & +.04 \\
\hline 10 & Lyræ & 4. 37 & 4. 08 & -.31 & 6 & $\alpha \quad$ Lyræ & 4. 48 & 4. 20 & +.06 \\
\hline 16 & Lyræ & 4. 34 & 4. 05 & -.31 & 7 & 40 Aurigæ & .... & 3. 42 & +.06 \\
\hline 18 & Lyræ & 4. 42 & 4. 13 & -.31 & 7 & B. $D_{.}+38^{\circ} 1539$ & & 3. 82 & +.06 \\
\hline 20 & Lyræ & 4. 53 & 4. 24 & -.31 & 9 & $\alpha \quad$ Lyræ & 4.48 & 4. 20 & +.06 \\
\hline 21 & Lyræ & 4. 12 & 3. 83 & -.31 & 9 & 40 Aurigæ & -... & 3. 60 & +.06 \\
\hline Sept. 1 & Lyræ & 4. 73 & 4.44 & -.31 & 9 & B. D. $+38^{\circ} 1539$ & -... & 3. 20 & +.06 \\
\hline 4 & Lyræ & 4. 53 & 4. 24 & -.30 & 15 & 40 Áurigæ & $\ldots$ & 3. 61 & +.10 \\
\hline 7 & Lyræ & 4. 67 & 4. 38 & -.30 & 15 & B. D. $+38^{\circ} 1539$ & $-\ldots$ & 3. 39 & +.10 \\
\hline 11 & Lyræ & 4. 84 & 4.55 & -.30 & 19 & 40 Aurigæ & $\ldots$ & 3. 38 & +.10 \\
\hline
\end{tabular}


A cxx

PRIME VERTICAL TRANSIT INSTRUMENT.

TABLE VIII.-The Latitude of the Instrument, Obtained by the Use of Newcomb and Boss Declinations-Continued $+38^{\circ} 55^{\prime} 10^{\prime \prime}+$

* Indicates reflected observation.

\begin{tabular}{|c|c|c|c|c|c|c|c|c|c|}
\hline Date & Star & N. & B. & $\Delta \varphi$ & Date & Star & N. & B. & $\Delta \varphi$ \\
\hline 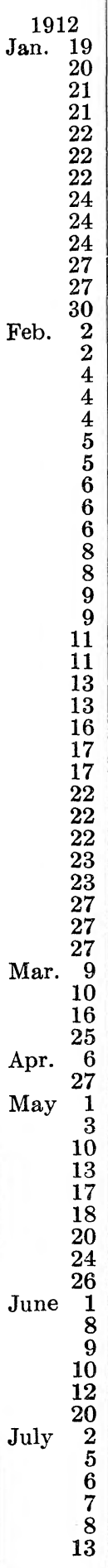 & 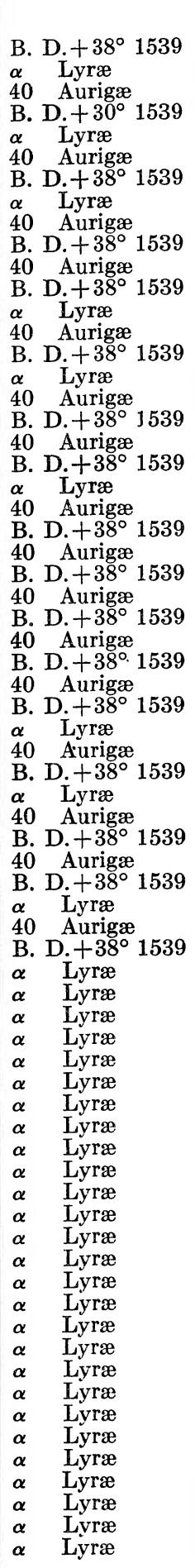 & 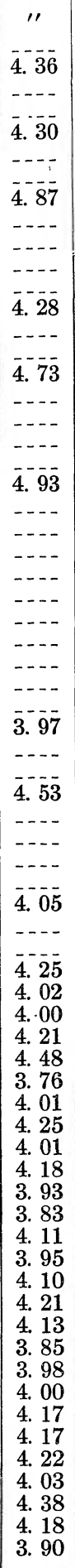 & 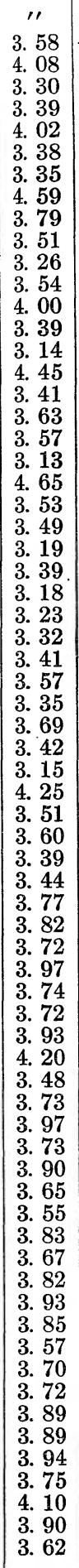 & 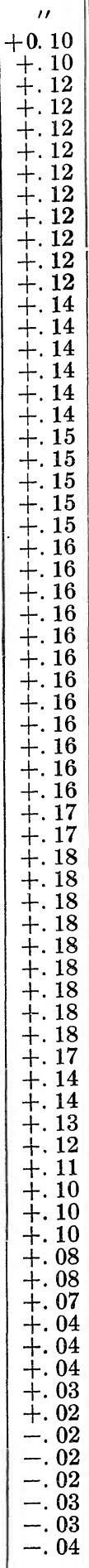 & $\begin{array}{rr}1912 \\
\text { July } 22 \\
26 \\
\text { Aug. } \\
1 \\
3 \\
5 \\
10 \\
11 \\
12 \\
22 \\
23 \\
24 \\
27 \\
28 \\
\text { Sept. } 5 \\
9 \\
10 \\
12 \\
\text { Oct. } \\
9 \\
10 \\
12 \\
15 \\
15 \\
15 \\
16 \\
16 \\
16 \\
20 \\
21 \\
26 \\
26 \\
26 \\
28 \\
28 \\
28 \\
30 \\
30 \\
3 \\
3 \\
3 \\
8 \\
9 \\
9 \\
9 \\
11 \\
11 \\
11 \\
16 \\
16 \\
16 \\
21 \\
22 \\
26 \\
26 \\
27 \\
29 \\
29 \\
29 \\
30 \\
3 \\
3 \\
9 \\
9 \\
9 \\
10 \\
12 \\
12 \\
12 \\
14\end{array}$ & 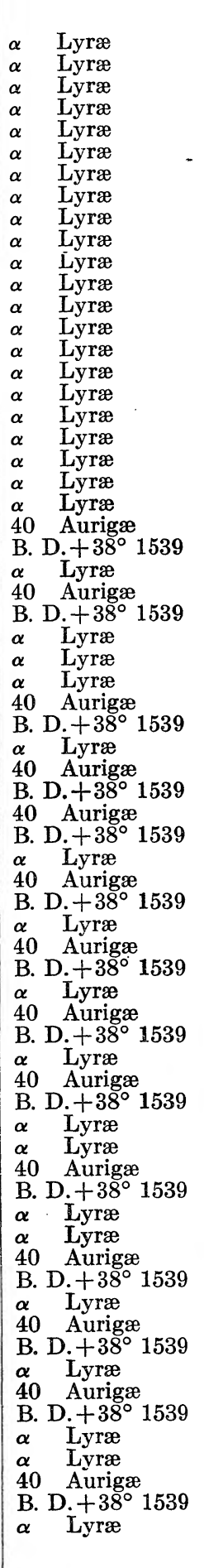 & 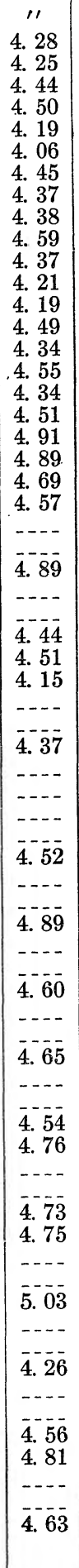 & 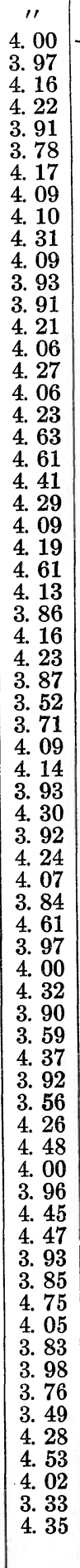 & 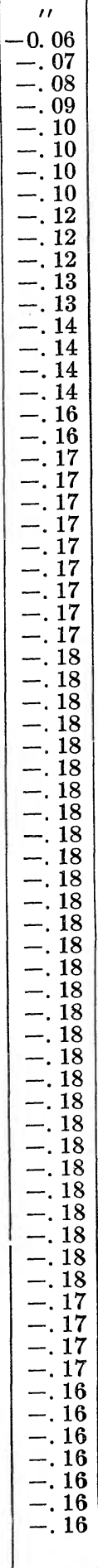 \\
\hline
\end{tabular}


In Table IX are given the times of sunrise and sunset, at intervals of five days, expressed in Washington sidereal time. With the data in the above table, and the right ascension of the star to be found in the catalogue (pages A 39-44) one may ascertain what latitudes appearing in Table VIII were observed in daylight.

If the right ascension of a star is greater than the sidereal time given opposite each date in the sunrise column of Table IX it was observed in daylight. Similarly, if the star's right ascension is less than the value given in the sunset column, it also was observed in daylight.

In the following discussion of this subject we will first consider the declinations of $\alpha$ Lyræ, because of their greater continuity. It is extremely unfortunate for the present and future study of this anomaly that other bright stars are not favorably placed with respect to our zenith, to permit obtaining their declinations at or near noon at other times of the year than $\alpha$ Lyræ, and especially in the summer months, when conditions are opposite to those prevailing at the time $\alpha$ Lyræ is observed at or near noon.

Early in the accumulation of observed declinations of that star, a comparison of those secured near noon and near midnight clearly indicated a difference between day and night observed declinations which was not accidental, but was systematic and repeated itself each year. To show with more clearness how pronounced is the daylight effect upon declinations which had been observed when the sun was above the horizon, the first step was to assemble all the declinations which had been obtained in the 19 years, and arrange them according to the hour in a day. These data are given in Table $\mathbf{X}$.

Previous to that, however, all night declinations in each year were formed into yearly means. The only correction which had been applied to them was that for the variation of latitude. 
TABLE IX.-Time of Sunrise and Sunset, at Intervals of Five Days, Expressed in Washington Sidereal Time

\begin{tabular}{|c|c|c|c|c|c|c|c|c|c|c|c|}
\hline Date & \multicolumn{2}{|c|}{$\begin{array}{c}\text { Time, } \\
\text { sunrise }\end{array}$} & $\begin{array}{l}\text { Date } \\
\text { July } 47\end{array}$ & \multicolumn{2}{|c|}{$\begin{array}{c}\text { Time, } \\
\text { sunrise }\end{array}$} & $\begin{array}{c}\text { Date } \\
\text { Jan. i. } 2\end{array}$ & \multicolumn{2}{|c|}{$\begin{array}{l}\text { Time, } \\
\text { sunset }\end{array}$} & $\begin{array}{c}\text { Date } \\
\text { July } 5.3\end{array}$ & \multicolumn{2}{|c|}{$\begin{array}{l}\text { Time, } \\
\text { sunset }\end{array}$} \\
\hline $\begin{array}{r}\text { Jan. } 0.8 \\
5.8 \\
10.8 \\
15.8 \\
20.8 \\
25.8 \\
30.8 \\
\text { Feb. } 4.8 \\
9.8 \\
14.8 \\
19.8 \\
24.8 \\
\text { Mar. } 1.8 \\
6.8 \\
11.8 \\
16.7 \\
21.7 \\
26.7 \\
\text { Apr. } 0.7 \\
5.7 \\
10.7 \\
15.7 \\
20.7 \\
25.7 \\
\text { May } 0.7 \\
5.7 \\
10.7 \\
15.7 \\
20.7 \\
25.7 \\
30.7 \\
\text { June } 4.7 \\
9.7 \\
14.7 \\
19.7 \\
24.7 \\
29.7\end{array}$ & $\begin{array}{cc}h & n \\
14 & \\
14 & 2 \\
14 & 3 \\
14 & 5 \\
15 & 1 \\
15 & 3 \\
15 & 4 \\
16 & \\
16 & 1 \\
16 & 3 \\
16 & 4 \\
17 & \\
17 & 15 \\
17 & 2 \\
17 & 3 \\
17 & 47 \\
17 & 58 \\
18 & 10 \\
18 & 22 \\
18 & 34 \\
18 & 45 \\
18 & 57 \\
19 & 9 \\
19 & 21 \\
19 & 33 \\
19 & 47 \\
20 & 1 \\
20 & 15 \\
20 & 30 \\
20 & 46 \\
21 & 3 \\
21 & 20 \\
21 & 38 \\
21 & 57 \\
22 & 17 \\
22 & 39 \\
23 & 02\end{array}$ & $\begin{array}{r}m \\
0 \\
20 \\
39 \\
57 \\
14 \\
31 \\
47 \\
3 \\
18 \\
32 \\
46 \\
0 \\
12 \\
23 \\
35 \\
47 \\
58 \\
10 \\
22 \\
34 \\
45 \\
57 \\
9 \\
21 \\
33 \\
47 \\
1 \\
15 \\
30 \\
46 \\
3 \\
20 \\
38 \\
57 \\
17 \\
39 \\
02\end{array}$ & $\begin{array}{r}\text { July } 4.7 \\
9.7 \\
14.7 \\
19.7 \\
24.7 \\
29.7 \\
\text { Aug. } 3.7 \\
8.7 \\
13.7 \\
18.7 \\
23.7 \\
28.7 \\
\text { Sept. } 2.7 \\
7.7 \\
12.7 \\
17.7 \\
22.7 \\
27.7 \\
\text { Oct. } 2.7 \\
7.7 \\
12.7 \\
17.8 \\
22.8 \\
27.8 \\
\text { Nov. } 1.8 \\
6.8 \\
11.8 \\
16.8 \\
21.8 \\
26.8 \\
\text { Dec. } 1.8 \\
6.8 \\
11.8 \\
16.8 \\
21.8 \\
26.8 \\
\text { Jan. } 0.8\end{array}$ & $\begin{array}{r}h \\
23 \\
23 \\
0 \\
0 \\
0 \\
1 \\
1 \\
2 \\
2 \\
3 \\
3 \\
3 \\
4 \\
4 \\
5 \\
5 \\
5 \\
6 \\
6 \\
7 \\
7 \\
7 \\
8 \\
8 \\
9 \\
9 \\
10 \\
10 \\
10 \\
11 \\
11 \\
12 \\
12 \\
12 \\
13 \\
13 \\
13\end{array}$ & $\begin{array}{r}m \\
24 \\
47 \\
10 \\
34 \\
58 \\
22 \\
46 \\
11 \\
37 \\
1 \\
27 \\
52 \\
16 \\
41 \\
5 \\
30 \\
55 \\
20 \\
44 \\
9 \\
34 \\
58 \\
23 \\
47 \\
12 \\
36 \\
2 \\
28 \\
52 \\
17 \\
42 \\
7 \\
31 \\
54 \\
17 \\
38 \\
59\end{array}$ & 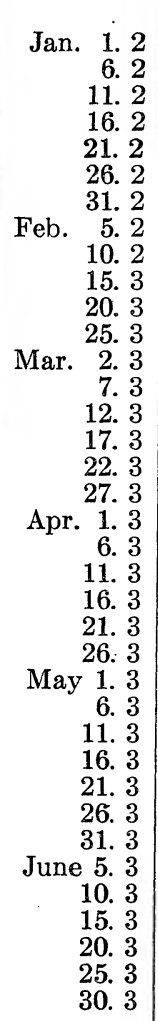 & $\begin{array}{r}h \\
23 \\
23 \\
0 \\
0 \\
1 \\
1 \\
1 \\
2 \\
2 \\
3 \\
3 \\
4 \\
4 \\
4 \\
5 \\
5 \\
6 \\
6 \\
6 \\
7 \\
7 \\
8 \\
8 \\
9 \\
9 \\
9 \\
10 \\
10 \\
11 \\
11 \\
11 \\
12 \\
12 \\
13 \\
13 \\
13 \\
14\end{array}$ & $\begin{array}{r}m \\
29 \\
54 \\
18 \\
43 \\
9 \\
33 \\
57 \\
23 \\
48 \\
13 \\
39 \\
4 \\
30 \\
54 \\
20 \\
45 \\
9 \\
34 \\
59 \\
24 \\
49 \\
14 \\
38 \\
2 \\
28 \\
53 \\
19 \\
43 \\
20 \\
33 \\
57 \\
20 \\
44 \\
6 \\
27 \\
47 \\
7\end{array}$ & $\begin{array}{r}\text { July } 5.3 \\
10.3 \\
15.3 \\
20.3 \\
25.3 \\
30.3 \\
\text { Aug. } 4.3 \\
9.3 \\
14.3 \\
19.3 \\
24.3 \\
29.3 \\
\text { Sept. 3. } 3 \\
8.3 \\
13.3 \\
18.3 \\
23.3 \\
28.3 \\
\text { Oct. } 3.2 \\
8.2 \\
13.2 \\
18.2 \\
23.2 \\
28.2 \\
\text { Nov. } 2.2 \\
7.2 \\
12.2 \\
17.2 \\
22.2 \\
27.2 \\
\text { Dec. } 2.2 \\
7.2 \\
12.2 \\
17.2 \\
22.2 \\
27.2 \\
\text { Jan. } 1.2\end{array}$ & $\begin{array}{l}h \\
14 \\
14 \\
15 \\
15 \\
15 \\
15 \\
16 \\
16 \\
16 \\
16 \\
16 \\
17 \\
17 \\
17 \\
17 \\
17 \\
18 \\
18 \\
18 \\
18 \\
18 \\
19 \\
19 \\
19 \\
19 \\
19 \\
20 \\
20 \\
20 \\
21 \\
21 \\
21 \\
21 \\
22 \\
22 \\
23 \\
23\end{array}$ & $\begin{array}{r}m \\
26 \\
43 \\
1 \\
18 \\
33 \\
48 \\
02 \\
15 \\
27 \\
41 \\
53 \\
04 \\
17 \\
28 \\
39 \\
50 \\
01 \\
13 \\
24 \\
36 \\
48 \\
01 \\
14 \\
28 \\
42 \\
56 \\
11 \\
28 \\
45 \\
02 \\
20 \\
40 \\
59 \\
21 \\
43 \\
05 \\
28\end{array}$ \\
\hline
\end{tabular}


TABLE X.-Decinations of $\alpha$ Lyræ, 1900, for the 19 Years, Grouped According to the Times of the Year of the Observations; Reduced with a Proper Motion of +0.301" per Year; Reduced with a Parallax of $+0.123^{\prime \prime}$ and with the Aberration, $20.580^{\prime \prime}$

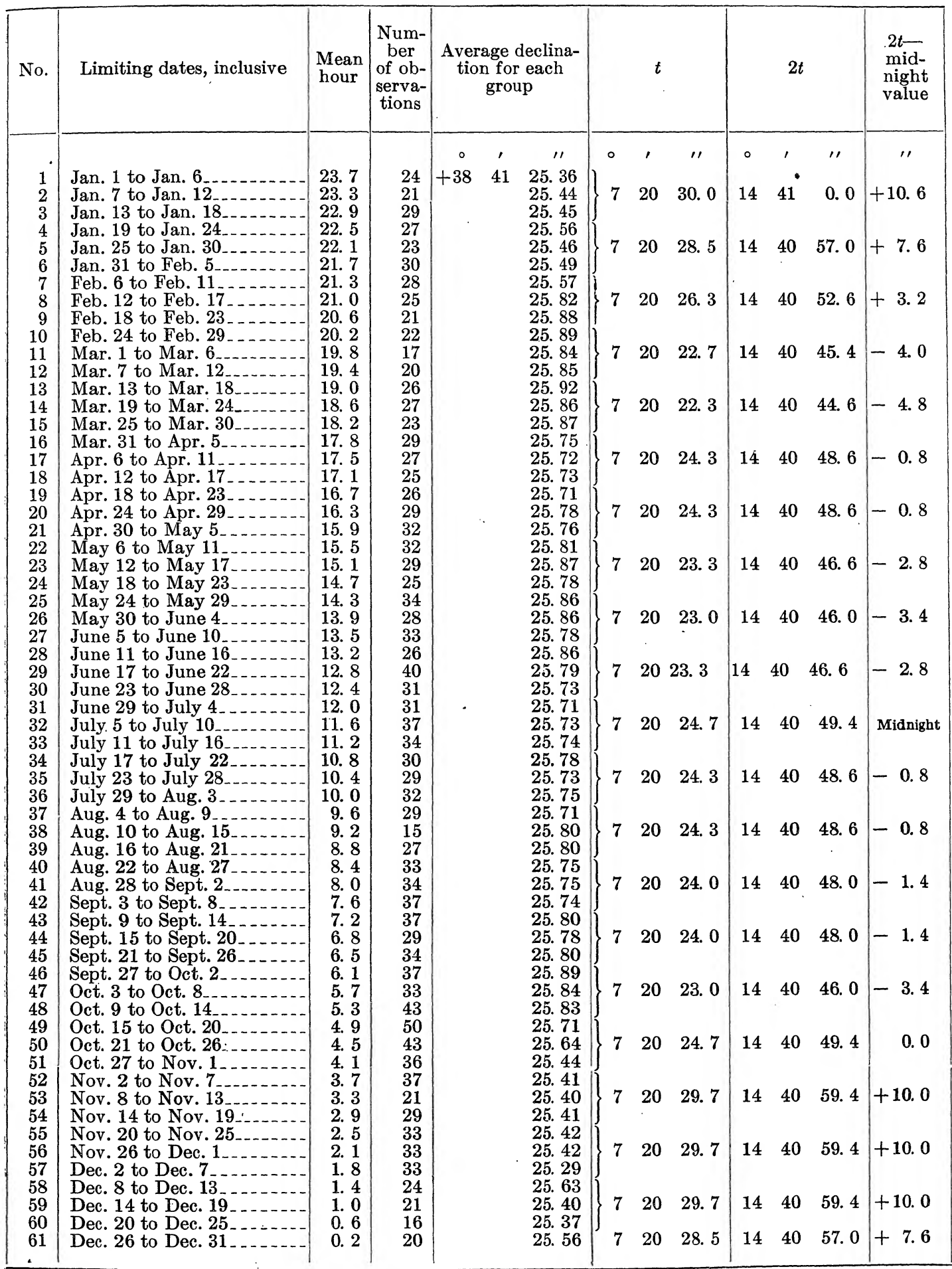

Star on meridian at sunrise April 6. Star on meridian at sunset October 4. 
With the material thus collected a solution was made to obtain the correction to the assumed proper motion. From that solution a corrected proper motion of $+0.301^{\prime \prime}$ per year was obtained. Each observed declination was then corrected with that proper motion.

Then, the night observations only were grouped according to the day in a year, and with these group means a least square solution was made to obtain the parallax of the star, the details of which will be mentioned later.

After the parallax of the star had been derived the correction for it was applied to all declinations, both day and night. This correction was computed as follows:

The observed position of the star had been reduced to mean place through the aid of the Besselian star numbers, in which we have

$$
-\Delta \delta=A a^{\prime}+B b^{\prime}+C c^{\prime}+D d^{\prime}+\mu_{\delta} \tau
$$

Let $\Delta \delta^{\prime}=$ the correction for parallax,

$\pi^{\prime \prime}=$ the parallax,

$R=$ radius vector of earth,

$\odot=$ sun's longitude,

$\epsilon=$ obliquity of the ecliptic,

$c_{1}^{\prime}=c^{\prime} \pi^{\prime \prime}$

$d_{1}^{\prime}=d^{\prime} \pi^{\prime \prime}$

$C_{1}=R \cos \epsilon \sin \odot$

$D_{1}=-R \cos \odot$

where $c^{\prime}, d^{\prime}, C, D$ have the same meaning as in the Bessilian star numbers; then.

$$
-\Delta \delta^{\prime}=C_{1} c_{1}{ }^{\prime}+D_{1} d_{1}{ }^{\prime}
$$

Values of $-\Delta \delta^{\prime}$ were computed for every six days during the entire year and applied to each observed declination. The means of the six-day groups in Table $\mathrm{X}$ are based upon declinations thus corrected.

In the second column of the table will be found the limiting dates in a year, in which period, for all years, there were included the declinations forming the means in column 5 . In column 4 are given the number of observed declinations. contained in the adjacent mean.

In column 3 will be found the hour and tenth of Washington mean time when the star was on the meridian for the mean date between six-day intervals. At the bottom of the table is shown the date in a year when it is sunrise and the star is on the meridian, and also a similar date when it is sunset and the star is on the meridian.

However, it should be remembered that in the first instance $\alpha$ Lyræ will be observed about 30 minutes before sunrise on the east side and 30 minutes after sunrise on the west side. At sunset these conditions will be reversed.

The two means having as dates September 21 to 26, and October 3 to 8, are: within $0.04^{\prime \prime}$ of each other. Those of March 31 to April 5, and April 12 to 17, differ by only $0.03^{\prime \prime}$, which would appear to indicate that the daylight effect had not at those times become appreciable, although in both cases the sun was above and below the horizon during the time transits of the star were being taken. 
An examination of the data contained in column 5 of Table $\mathrm{X}$ establishes the following: During what have been termed the night hours-that is, when the sun is below the horizon-these several means differ between themselves by an amount, without regard to signs, which averages about $0.04^{\prime \prime}$. There does not appear to exist any indication, in that portion of the day, that these declinations are influenced by a lateral refraction, unless it affects them all alike.

On account of such a phenomenon being brought to light in this discussion it was decided not to use day declinations in solving for the parallax of the star, for the reason that the position of $\alpha$ Lyræ in the heavens is such that the maximum positive effect of parallax occurs about the last of June and the maximum negative effect about the last of December.

This daylight effect is still shown in the day declinations, after they have been corrected for the effect of parallax, and hence it is due to some other cause or causes.

There is presented at this point a description of the house in which the prime vertical transit was mounted at the old Naval Observatory. ${ }^{1}$

The room in which this instrument (prime vertical transit) is mounted is 18 by 17 feet, its length being $\mathrm{E}$. and $\mathrm{W}$. The walls are of brick, with a coppered roof. It has a south exposure, with a glazed window. It has two slits, each 18 inches broad, going across the roof and coming down the east and west walls to within $3 \frac{1}{2}$ feet of the floor. These slits are 38 inches apart. ... The walls and ceilings of the room are plastered and painted sky-blue. . . .

In the publication referred to there is included a small drawing of the plan of the house. (Plate I.) There is not included in the text an explanation of how the shutters were operated, nor of what material they were constructed. However, from a statement made by Professor Newcomb in the quotation from the Astronomical Journal, which will be referred to below, the inference may be drawn that the shutters when opened assumed an upright position and that they were made of wood. It will also be noted that each slit in the old house was 18 inches wide, as compared to 30 inches for the width of the slit in the roof of the present house.

Before passing to the next step attention is invited to the fact that these declinations indicate a condition diametrically opposite to that disclosed by the late Prof. $\mathrm{S}$. NEwCOMB in his discussion of the prime vertical transit observations made at the old Naval Observatory in the period 1862-1867. A comparison of the two series becomes exceedingly interesting, because the instrument with which the 1862-1867 observations were made was the original form of that used in the present one. However, the two types of houses in which the instrument was mounted are entirely different in a number of respects.

Professor Newcomb discusses the material above mentioned in the Astronomical Journal (Vol. XI, pp. 81 and 82). The reader who is familiar with that series will recall that the observations showed two kinds of anomaly, one in which a negative parallax for the star $\alpha$ Lyræ was found, and the other showing systematic deviations from the general mean, which he says may be explained by periodic variations of latitude. It is extremely doubtful if with our present knowledge of the terms involved, the variation of latitude could be safely computed for that epoch, much as that is desired.

${ }^{1}$ Astronomical Observations Made at the Naval Observatory, Vol. I, page LXXIV. 
On page 82 of the Astronomical Journal, Volume XI, will be found these remarks made by Professor Newcomb upon this subject: We quote as follows:

The changes thus shown can be immediately interpreted, when we recall that the transit of the star ( $\alpha$ Lyræ) occurs at midnight June 28 and at noon December 28. Observations made from April to September, inclusive, are therefore made with the sun below the horizon; those from October to March with the sun above the horizon. The effect of parallax is clearly shown by the fact that the midnight observations give a larger declination than those made in April and October. But instead of this law of change continuing throughout the day, we find that the apparent declination increases rapidly throughout the day reaching a maximum about noon.

There is an obvious explanation of this. The day observations are necessarily made during clear weather, when the sun is shining. The slits above the instrument were closed by shutters, against the vertical side of which the sun always shone. On the south slit the sun shone on the outside of the shutter, and therefore no effect would be likely. But when observations were made through the north slit, the line of sight passed within a foot of the heated surface of the shutter. The result would be a refraction of the ray oflight, such as to throw the apparent direction of the star toward the north, and thus to increase its declination. [The italics are by the writer.]

At this point attention is especially invited to the last portion of the above paragraph.

An inspection of the contents of Table $\mathrm{X}$ will plainly indicate that declinations obtained with the present prime vertical transit at or near noon are less in numerical value than when the same star is observed near midnight or near sunrise or sunset, the exact opposite of what was found by Professor NEwcomb in his discussion of the 1862-1867 work. Moreover, the data in Table $\mathrm{X}$ have been corrected for the variation of latitude and the parallax of the star.

If a mean is taken of all the night declinations, and differences taken between it and each night group, there will be found 12 minus and 15 plus quantities and 4 of the same value as the mean.

An examination of Table $X$ will also show that in the morning, at about 9 a. $m$., a rapid diminution in the value of the declination commences and continues until about noon. In the afternoon this change commences about $4.5 \mathrm{p} . \mathrm{m}$. It is of the same character, and also continues until about noon. In the first instance the difference is over $0.4^{\prime \prime}$ and in the second about $0.3^{\prime \prime}$.

Quite strangely there appears to be an increase in the value of the declination very near noon, although the mean value on each side of it is much smaller. However, we are convinced that the real cause is a scantiness of material just at that point. The last week in December and the first week in January are rather cloudy in the vicinity of Washington. It will also be seen by consulting Table $\mathrm{X}$ that the means at that part of the year are in general based upon fewer observations than the others.

After this first discussion of the statistical matter involved in the declinations we will turn to an examination of the daylight effect as shown by the observations of stars other than $\alpha$ Lyræ.

In order that the declinations of $\alpha$ Lyræ may be considered on the same basis as the other stars it is necessary to reduce the declinations of all these stars to observed latitudes. By so doing the number of observations available has been increased from 1,780 to 2,484 .

Just at this point attention is invited to two charts which will be found at the end of the volume. Upon them is shown a graphical representation of both the varying values of the declination of $\alpha$ Lyræ and also the varying values in the latitude. 
On the chart headed Declinations of $\alpha$ Lyræ have been plotted the 61 values of the declination of that star taken from Table X. Each plotted point represents the value of the mean declination which was obtained at the hour and tenth indicated by the point on the chart.

In a similar manner the latitudes are shown on the chart headed Latitude of Instrument, and their values and the hour in a day when obtained have been taken from Table XI. In this latter case, however, the plotted points have been placed half way between the hour of time which immediately precedes or follows.

It will be noted that on both charts there appears to be a slight minimum in the values of the declination of $\alpha$ Lyræ and an increase in the values of the latitude at about 5 a. $\mathrm{m}$.

The first step in the preparation of this material was to divide these latitudes into groups which were observed during the same hours of the day. In Table XI will be found these hourly mean latitudes. The several headings will show the nature of the data contained in the table.

The latitudes which were derived from the observed declinations of $\alpha$ Lyræ and which were included in this table have not been corrected for the parallax of the star. All declinations upon which these latitudes are based have been corrected for the variation of latitude and reduced to the finally adopted latitude of the instrument.

The question now suggests itself, What is the cause of this change of the declination or of the latitude when stars are observed in sunlight with a prime vertical transit instrument?

TABLE XI.-The Latitude of the Instrument, Grouped for Each Hour in the Day, and Based upon Declinations of Newcomb and Boss

$+38^{\circ} 55^{\prime} 10^{\prime \prime}+$

\begin{tabular}{|c|c|c|c|c|}
\hline Hours & $\begin{array}{l}\text { Latitude, } \\
\text { Newcomb }\end{array}$ & $\begin{array}{c}\text { Latitude, } \\
\text { Boss }\end{array}$ & $\begin{array}{l}\text { Number } \\
\text { of obser- } \\
\text { vations }\end{array}$ & $\begin{array}{l}\text { Mean of } \\
\text { N. and B. }\end{array}$ \\
\hline 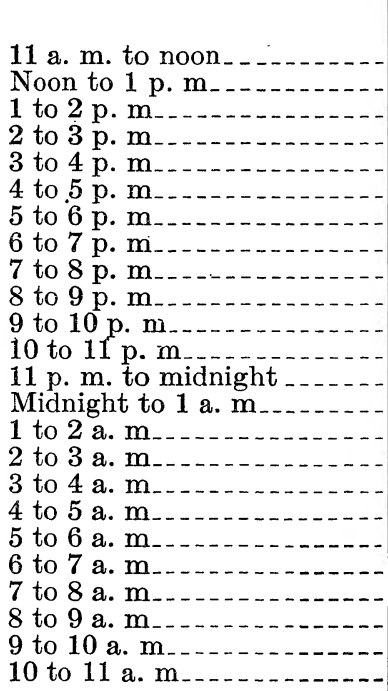 & $\begin{array}{l}\text { '" } \\
\text { 4. } 96 \\
\text { 4. } 96 \\
\text { 4. } 89 \\
\text { 4. } 88 \\
\text { 4. } 84 \\
\text { 4. } 63 \\
\text { 4. } 38 \\
4.42 \\
\text { 4. } 38 \\
\text { 4. } 46 \\
\text { 4. } 46 \\
4.47 \\
\text { 4. } 43 \\
4.44 \\
4.39 \\
4.39 \\
4.45 \\
4.56 \\
4.63 \\
4.48 \\
4.54 \\
4.53 \\
\text { 4. } 80 \\
\text { 4. } 88\end{array}$ & $\begin{array}{c}\text { "' } \\
4.66 \\
4.68 \\
4.61 \\
4.61 \\
4.54 \\
4.35 \\
4.11 \\
\text { 4. } 14 \\
4.12 \\
4.17 \\
4.17 \\
4.17 \\
4.12 \\
4.15 \\
4.11 \\
4.10 \\
4.18 \\
4.37 \\
4.33 \\
4.21 \\
4.23 \\
4.25 \\
4.52 \\
4.62\end{array}$ & $\begin{array}{r}67 \\
49 \\
72 \\
91 \\
87 \\
120 \\
135 \\
153 \\
178 \\
210 \\
151 \\
114 \\
102 \\
106 \\
81 \\
66 \\
87 \\
104 \\
107 \\
98 \\
79 \\
71 \\
87 \\
69\end{array}$ & $\begin{array}{l}\text { '" } \\
\text { 4. } 81 \\
\text { 4. } 82 \\
4.75 \\
4.75 \\
4.69 \\
4.49 \\
4.24 \\
4.28 \\
4.25 \\
4.32 \\
4.32 \\
4.32 \\
4.28 \\
4.29 \\
4.25 \\
4.25 \\
4.31 \\
4.46 \\
4.48 \\
4.34 \\
4.38 \\
4.39 \\
4.66 \\
4.75\end{array}$ \\
\hline Total observations_. & & & 2,484 & \\
\hline
\end{tabular}


Is this effect the result of a condition which exists within the house in which the instrument is mounted, and thereby influences the position of the instrument? Is it meteorological? And by that is meant an anomoly due to differences of temperature between the inside and outside air. Is it prismatic? And by that is meant that the ray of light from the star is refracted abnormally as it passes through the layer of air just above the opening in the roof of the transit house? Is it the effect of house temperature in which the air in different portions of the room is not uniform in temperature?

The controlling factor in a prime vertical observation is the observed time between the two passages of a star across a supposed fixed plane. The elevation of the star in that plane on account of vertical refraction would not affect the resulting declination. What does bias the time interval and hence the declination is, apparently, that the image of the star is thrown laterally away from the true prime vertical.

The smaller declinations which have been obtained in the daytime as compared with those secured at night indicate that the observed times between transits over the apparently displaced prime vertical have been increased by some causes and not decreased.

From this it follows that the cosine of the hour angle $t$ would be smaller, and hence the resulting declination would also be smaller.

This is easily confirmed by an examination of the trignometric formula used in solving for either the declination, latitude, or elapsed time, namely,

$\tan \delta=\tan \varphi \cos t$.

We will return again to this particular point.

The next question is whether this effect is due to a house temperature. We do not refer in this connection to the heated rays of air in the slit, but to the effect of the sun shining on the south side of the transit house, and by radiation of accumulated heated air affecting the bubble in the level.

It has already been stated that the walls of the house are galvanized iron fastened to a framework of iron, with an air space of 8 inches between the two walls. During that portion of the day when the daylight effect appears to be at its maximum the sun shines directly upon the south side of the house. The distance from the inner south wall to the level tube is about 10 feet.

If this assumed radiated heat is so pronounced as to have an effect upon the position of the air bubble in the level vial, it would heat the south end of the vial more than it did the north end and that would continue during the time the rays of the sun were falling on the south wall of the house. In eonsequence the bubble would be shifted toward the south end. Suppose we assume that this is the condition that actually prevails.

In the discussion relative to the method of determining the sign of the level correction in relation to its application to an observed declination, it was shown on page A LXIX that when the south end of the axis appeared to be too high, the level correction was plus. Hence a level correction biased by conditions named above would increase the observed declination, the exact opposite of the conditions found. 
I think it may be safely assumed that the level bubble is not influenced by radiation of heated air from the south wall of the transit house.

It is the opinion of the writer that the nature of this anomaly which has produced varying values of the declination of a star, according to whether the star is observed in the daytime or the night, is a prismatic effect. It has often been called lateral refraction.

We define our meaning of prismatic effect by saying that in prime vertical observations it is a condition which changes the true or normal position of the star when transits are being secured of it. Its effect is to apparently increase the normal interval of time between observed transits across opposite sides of the circle of the prime vertical.

In observations made with a prime vertical transit we are concerned in a very important degree with the correctness of an elapsed time between the transits of a star across two points on a vertical circle. The differences shown in the values of the day and night declinations are due to the varying value of that interval, and are entirely separate from the instrument itself.

There can be no question but what a star in daylight, when observed with our instrument, makes a transit of a thread across a false prime vertical plane which is north of the true one. From this it follows that the elapsed time $2 t$ is larger in the daytime than at night.

It is the writer's opinion that the sun shining on the south shutter, which is projected upward when open, heats it, and that heat is conducted through the shutter and radiated across the slit. This radiated heat in turn raises the temperature of the concentric layers of the air immediately over the opening.

Instead of these several layers of air. remaining symmetrical with respect to the opening through the shutter they are tilted, being higher on the south side than on the north, and not so dense. The effect, as compared between daylight and night, is to cause the apparent image of the star to be displaced toward the north, and that increment is what is added to the elapsed time to make it larger.

To bring out more clearly the magnitude of this increment, attention is called to the data contained in columns 6,7 , and 8 of Table $\mathrm{X}$. The values of $t$ there given were computed by the aid of the following formula:

$\cos t=\tan \delta \operatorname{cotan} \varphi$.

The mean of the three declination groups which were observed the nearest to midnight were taken as representing a normal value of $t$. The value of $\varphi$ which was used in the above equation for solving for the several values of $\delta$ was $+38^{\circ}$ $55^{\prime} 14.61^{\prime \prime}$ 。

General means were formed based upon each three consecutive groups, each mean weighted according to the number of observations it contains. That is to say, each mean represents an interval of 18 days throughout the year, except for the first and last, which is based upon two groups each, and the interval for them is 12 days. In other words, the differences of mean time in a day at which each of these group declinations was observed were approximately 1.2 hours, except for the first and last, which were approximately 0.8 of an hour.

$101141^{\circ}-26 \dot{\dagger}$-PT I- 9 
Substituting in the above equation the tangent of the declination which corresponds to each group mean, the resulting values of $t$ are shown in the sixth column. If each of those values is doubled, we then have the value of the arc over which the star apparently moved based upon these varying values in the declination of the star.

Each of these 21 values of $2 t$ was subtracted from the midnight value of that quantity, and those differences are shown in the last column of Table X. During the night hours the values of these differences are less, in each instance, than the midnight value, the mean amounting to $-1^{\prime \prime} .7$.

However, from about 4 p. m. toward noon, and from about 9 a. m. in the same direction, the angular value of $2 t$ has been increased by at least $9^{\prime \prime}$.

These data indicate that when this anomaly has its maximum effect the star passes a false circle of the prime vertical and by so doing it has increased the angular value of $t$ by at least $5^{\prime \prime}$.

This false circle moves toward the true one, until about the middle of February. From that time until about April 6 it apparently swings to the opposite side of the true prime vertical.

About April 6, when observations are made at sunrise it becomes normal.

At the other end of daylight, about the middle of October, the two planes are again in coincidence. The false plane then appears to move toward the north again, reaching its maximum distance from the true in the middle of November, and remaining stationary during December.

DISCUSSION OF THE ANNUAL PARALLAX OF $\alpha$ LYR

It was obvious that in the solution for the parallax of $\alpha$ Lyræ, day declinations would have to be omitted, for the reasons which have already been mentioned, unless some method could be adopted by which to reduce the day observations to the night. An examination of the material contained in Table $\mathrm{X}$ leads to the belief that a term depending on either the cosine of the sun's azimuth or the cosine of the hour angle of the star from the sun would not properly reduce the day to the night declinations.

In Table XII are given the values of the 30 groups of declinations used, their mean date in a year, mean date of observing, and number of observations included in each mean. These declinations have been corrected for the variation of latitude. The corrections for parallax and aberration appears in the sixth column of the table, and in the last column are shown these declinations after the corrections in the sixth. column have been applied. 


$$
\text { INTRODUCTION. }
$$

TaBle XII.-Observed Night Declinations of a Lyræ, for All Years, Corrected to a Proper Motion of $+0.301^{\prime \prime}$ per Year and Reduced with an Aberration of 20.5". These. Declinations were used in Solving for the Parallax of the Star and the Correction to the Aberration

\begin{tabular}{|c|c|c|c|c|c|c|c|c|c|c|}
\hline No. & $\begin{array}{l}\text { Mean } \\
\text { date }\end{array}$ & $\begin{array}{l}\text { Number } \\
\text { of obser- } \\
\text { vations }\end{array}$ & $\begin{array}{c}\text { Mean } \\
\text { observing } \\
\text { date }\end{array}$ & \multicolumn{3}{|c|}{$\begin{array}{c}\text { Declination, } \\
1900.0\end{array}$} & $\begin{array}{l}\text { Correc- } \\
\text { tion }\end{array}$ & \multicolumn{3}{|c|}{$\begin{array}{c}\text { Corrected } \\
\text { declination, } \\
1900.0\end{array}$} \\
\hline $\begin{array}{r}1 \\
2 \\
3 \\
4 \\
5 \\
6 \\
7 \\
8 \\
9 \\
10 \\
11 \\
12 \\
13 \\
14 \\
15 \\
16 \\
17 \\
18 \\
19 \\
20 \\
21 \\
22 \\
23 \\
24 \\
25 \\
26 \\
27 \\
28 \\
29 \\
30\end{array}$ & $\begin{array}{lr}\text { Apr. } & 9 \\
15 \\
21 \\
27 \\
\text { May } 3 \\
9 \\
15 \\
21 \\
21 \\
27 \\
\text { June } 2 \\
8 \\
14 \\
14 \\
20 \\
26 \\
\text { July } 2 \\
8 \\
14 \\
14 \\
20 \\
26 \\
\text { Aug. } \\
17 \\
7 \\
13 \\
19 \\
25 \\
31 \\
\text { Sept. } 6 \\
12 \\
18 \\
24 \\
30\end{array}$ & $\begin{array}{l}27 \\
25 \\
26 \\
29 \\
32 \\
33 \\
29 \\
25 \\
34 \\
28 \\
33 \\
26 \\
40 \\
31 \\
31 \\
37 \\
34 \\
30 \\
29 \\
32 \\
29 \\
15 \\
27 \\
33 \\
34 \\
37 \\
37 \\
34 \\
37 \\
33\end{array}$ & $\begin{array}{l}1903.09 \\
1901.57 \\
1900.15 \\
1901.87 \\
1903.68 \\
1902.89 \\
1902.75 \\
1904.31 \\
1903.02 \\
1900.49 \\
1903.13 \\
1902.53 \\
1902.92 \\
1902.35 \\
1903.76 \\
1904.35 \\
1903.71 \\
1903.62 \\
1903.15 \\
1902.96 \\
1903.36 \\
1904.15 \\
1904.30 \\
1903.34 \\
1901.25 \\
1901.41 \\
1902.78 \\
1902.16 \\
1902.17 \\
1901.15\end{array}$ & $\begin{array}{r}\circ \\
+38\end{array}$ & ${ }^{\prime}$ & $\begin{array}{r}\prime \prime \\
25.67 \\
.70 \\
.69 \\
.77 \\
.77 \\
.83 \\
.91 \\
.83 \\
.92 \\
.93 \\
.86 \\
.94 \\
.89 \\
.84 \\
.82 \\
.85 \\
.86 \\
.90 \\
.86 \\
.88 \\
.84 \\
.93 \\
.92 \\
.87 \\
.87 \\
.85 \\
.90 \\
.87 \\
.88 \\
.96\end{array}$ & $\begin{array}{l}\prime \prime \\
+.05 \\
+.03 \\
+.02 \\
+.01 \\
-.01 \\
-.02 \\
=.03 \\
-.05 \\
-.06 \\
-.07 \\
-.08 \\
-.09 \\
-.10 \\
=.11 \\
-.11 \\
=.12 \\
-.12 \\
-.13 \\
-.13 \\
-.13 \\
=.13 \\
=.13 \\
=.12 \\
=.12 \\
=.12 \\
=.11 \\
=.09 \\
=.08 \\
-.07\end{array}$ & $\begin{array}{l}\circ \\
+38\end{array}$ & '́ & $\begin{array}{r}25.72 \\
.73 \\
.71 \\
.78 \\
.76 \\
.81 \\
.88 \\
.78 \\
.86 \\
.86 \\
.78 \\
.85 \\
.79 \\
.73 \\
.71 \\
.73 \\
.74 \\
.77 \\
.73 \\
.75 \\
.71 \\
.80 \\
.80 \\
.75 \\
.75 \\
.74 \\
.80 \\
.78 \\
.80 \\
.89\end{array}$ \\
\hline
\end{tabular}

Let $\delta_{\mathrm{o}}$ equal the general mean of all these groups, namely, $+38^{\circ} 41^{\prime} 25.857^{\prime \prime}$, and $\delta^{\prime}$ any one of them. Let $n=\left(\delta_{0}-\delta^{\prime}\right)$

$\Delta \kappa=$ the correction to the aberration used,

$\pi=$ the parallax of the star,

$\alpha=$ the right ascension of the star for the epoch, 1903,

$\delta=$ the declination of the star for the same epoch,

$\epsilon=$ the obliquity of the ecliptic for the same epoch,

$\odot=$ the longitude of the sun at dates in 1903 corresponding to mean dates of groups,

$R=$ the radius vector of the earth for the same dates,

$\Delta e=$ the correction to the proper motion used,

$t^{\prime}=$ the epoch 1900, and $t$ the observed epoch for each group.

Let $b \cdot \sin B=\sin \alpha \sin \delta \cos \epsilon-\cos \delta \sin \epsilon$

b. $\cos \mathrm{B} \doteq-\cos \alpha \sin \delta$

From the several data just given we form the following equations of condition for each of the 30 groups:

$$
\Delta \delta+\Delta \kappa . b \cdot \sin (B+\odot)+\pi \cdot b \cdot \cos (B+\odot)+\left(t-t^{\prime}\right) \Delta e+n=0
$$


If $x, y, w$, and $z$ are made to represent, $\Delta \delta, \Delta \kappa, \pi$ and $\Delta e$, respectively, we have the following material upon which to base a least square solution:

$$
\begin{array}{cc}
\text { Equations of Condition } & \\
x-0.862 y+0.191 z+3.09 w+0.187=0 & +.058 \\
x-.838 y+.278 z+1.57 w+.157=0 & +.052 \\
x-.805 y+.363 z+.15 w+.167=0 & +.087 \\
x-.764 y+.444 z+1.87 w+.087=0 & +.007 \\
x-.716 y+.521 z+3.68 w+.087=0 & +.006 \\
x-.660 y+.592 z+2.89 w+.027=0 & -.035 \\
x-.598 y+.657 z+2.75 w-.053=0 & -.101 \\
x-.530 y+.715 z+4.31 w+.027=0 & -.020 \\
x-.456 y+.766 z+3.02 w-.063=0 & -.088 \\
x-.378 y+.809 z+.49 w-.073=0 & -.067 \\
x-.297 y+.844 z+3.13 w-.003=0 & -.007 \\
x-.213 y+.870 z+2.53 w-.083=0 & -.072 \\
x-.127 y+.888 z+2.92 w-.033=0 & -.017 \\
x-.039 y+.897 z+2.35 w+.017=0 & +.046 \\
x+.049 y+.896 z+3.76 w+.037=0 & +.063 \\
x+.136 y+.887 z+4.35 w+.007=0 & +.034 \\
x+.222 y+.868 z+3.71 w-.003=0 & +.034 \\
x+.306 y+.841 z+3.62 w-.043=0 & -.003 \\
x+.387 y+.806 z+3.15 w-.003=0 & +.043 \\
x+.464 y+.762 z+2.96 w-.023=0 & +.026 \\
x+.537 y+.711 z+3.36 w+.017=0 & +.062 \\
x+.604 y+.652 z+4.15 w-.073=0 & -.036 \\
x+.665 y+.587 z+4.30 w-.063=0 & -.031 \\
x+.720 y+.515 z+3.34 w-.013=0 & +.023 \\
x+.768 y+.439 z+1.25 w-.013=0 & +.033 \\
x+.808 y+.358 z+1.41 w+.007=0 & +.045 \\
x+.840 y+.273 z+2.78 w-.043=0 & -.023 \\
x+.863 y+.185 z+2.16 w-.013=0 & +.003 \\
x+.877 y+.096 z+2.17 w-.023=0 & -.017 \\
x+.883 y+.005 z+1.15 w-.103=0 & -.100
\end{array}
$$

From the above equations we derive the normal equations and the elimination equations shown below. The figures in bracket are logarithms.

$$
\begin{aligned}
+30.000 x+1.846 y+17.716 z+82.370 w+0.100 & =0 \\
+1.846 x+11.151 y+.117 z+6.598 w-.747 & =0 \\
+17.716 x+.117 y+12.571 z+52.732 w-.091 & =0 \\
+82.370 x+6.598 y+52.732 z+261.915 w-.078 & =0 \\
x+(8.789111) y+(9.771245) z+(0.438648) w+(7.522879) & =0 \\
y+\left(8.945262_{\mathrm{n}}\right) z+(9.141556) w+\left(8.833944_{\mathrm{n}}\right) & =0 \\
z+(0.319831) w+\left(9.028458_{\mathrm{n}}\right) & =0 \\
w+(7.878531) & =0
\end{aligned}
$$

The values of $\Delta \delta, \Delta \kappa, \pi$, and $\Delta e$ thus found were substituted in the equations of condition and the residuals computed. These residuals are shown in the last column to the right in the list of equations of condition. The sum of their squares is 0.07480 , and the sum of the squares of the absolute terms is 0.15143 . Therefore the sub- 
stitution of the values of the unknowns in the equations of condition has reduced the sum of the squares of the absolute terms about 49 per cent.

The probable error of each group mean was computed from the formula:

$$
r=0.6745 \sqrt{\frac{[v v]}{(m-\mu)}}
$$

in which $(v v)$ is the sum of the squares of the residuals, $m$ the number of groups, and $\mu$ the number of unknowns. The value thus obtained is $\pm 0.0362 "$. By the aid of that quantity and the square root of the relative weights of the four unknowns the probable error of each was derived.

Collecting the several quantities we have,

$$
\begin{aligned}
& x=\Delta \delta=-0.0600^{\prime \prime} \pm 0.0196^{\prime \prime} \text { Wt. } 3.42 \\
& y=\Delta \kappa=+.0800 \pm .0113 \quad \text { " } 10.17 \\
& z=\pi=+.1226 \pm .0293 \text { " } \quad 1.52 \\
& w=\Delta e=-.00756 \pm .0070 \quad \text { " } 26.72
\end{aligned}
$$

The number of separate determinations of the absolute parallax of $\alpha$ Lyræ which have been secured in the past is extremely small. In No. 24 of the Publications of the Astronomical Laboratory at Groningen, published as late as 1910, Dr. J. C. KAPTEYN includes only two determinations, one by Doctor ELKIN with the Yale heliometer, and the other by Professor FLINT of the Washburn Observatory at Madison, Wis.

The value obtained by Doctor EuKIN was $+0.082^{\prime \prime}$ and that by Professor FLINT $+0.10^{\prime \prime}$. To the first of these Doctor KAPTEYN applies a correction of $+0.007^{\prime \prime}$ and to the second $+0.008^{\prime \prime}$, giving $+0.089^{\prime \prime}$ and $+0.108^{\prime \prime}$, respectively, for the absolute parallax of the star. He gives a weight of 3 to Eukin's value and a weight of 1 to FurNT's value, and adopts as the absolute parallax of the star the quantity $+0.094^{\prime \prime}$.

Another value of the parallax of the star which was recently determined photographically at the McCormick Observatory, University of Virginia, is +0.131" $\pm 0.006^{\prime \prime}$. (See Publications of the Astronomical Society of the Pacific, Vol. 34, page 257.)

The low weight obtained of the parallax value in this discussion is due to the fact that but one maximum of the parallax coefficients could be used in the equations of condition for reasons already mentioned.

However, it will be noted that the probable error of the group means is but $\pm 0.036^{\prime \prime}$.

In addition this solution also gave a correction of $+0.080^{\prime \prime}$ to the adopted aberration, making that constant as derived only from observations of $\alpha$ Lyræ, $20.580^{\prime \prime}$. The aberration value found by the polygon method, the details of which will be mentioned later, was $20.542^{\prime \prime}$.

In this connection it may be stated that if the apparent places of ephemeris stars are to be published to the second decimal in declination, and the third decimal in right ascension, then a correction for a parallax as large as that indicated for $\alpha$ Lyræ should be included in the apparent places. 
This does not apply with so much weight to the aberration adopted because the deduced corrections to it, as obtained by various forms of astronomical instruments, have rather large systematic differences. There still remains much to investigate as to the causes for those differences.

\section{ZENITH STARS}

In connection with the work with the instrument an observing list of close zenith stars, situated between $+37^{\circ} 00^{\prime}$ and $+38^{\circ} 48^{\prime}$ declination was prepared in the spring of 1900. Observations for the declinations of these stars were commenced shortly afterwards, and they were finished in the early part of 1904 .

In preparing this list the Harvard and Potsdam Photometric Catalogues were consulted, and from them were selected stars between the above limits which were as bright or brighter than magnitude 7.9.

It was decided to secure five or more declinations of each star, and except in a few instances that was done. These stars, including those which had been observed prior to 1900, make up a total of 366 stars for which positions in declination have been obtained with the instrument.

They have been reduced to the epoch 1900, corrected for the variation of latitude corresponding to dates on which observed, and to the finally adopted latitude of the instrument,

$$
+38^{\circ} 55^{\prime} 14.61^{\prime \prime} \text {. }
$$

Except for the Ephemeris stars, the annual precession and secular variation in declination have been computed by the aid of the tables published in the second volume of the Annals of the Strassburg Observatory. The right ascensions with which to enter those tables are those of the Catalog der Astronomischen Gesellschaft, Lund Zones $+35^{\circ}$ bis $+40^{\circ}$, reduced to 1900.0 .

All observed declinations of the following stars have been corrected for proper motion in declination. The values of the proper motions so used will be found in column 10 of the catalogue, and the stars to which that correction has been applied are marked by an asterisk.

They are,

$\begin{array}{llll}\mu & \text { Andromedæ. } & \gamma & \text { Bootis. } \\ \theta & \text { Aurigæ. } & \alpha & \text { Lyræ. } \\ 110 & \text { B. Lyncis. } & 40 & \text { Cygni. } \\ & \text { Groombridge 1830. } & 61^{1} & \text { Cygni. } \\ \alpha & \text { Can. Venaticorum. } & \mathbf{6 1}^{2} & \text { Cygni. } \\ & & \tau & \text { Cygni. }\end{array}$

The declinations of all stars contained in the catalogue, and in the individual results, with the exception of the 11 named above, have not been corrected for proper motion, and their observed positions, as published, correspond to the mean date adjacent to the printed declination.

\section{INDIVIDUAL RESULTS}

The Individual Results will be found on pages A 3-38. Each star therein is either headed by its Greek-letter designation in a constellation; by a number given to it by Flamsteed, Hevelius, Bode, and others, or by its degree and number 
as given in the Bonner Sternverzeichniss, Band 4, 1855.0. Then follow its approx imate right ascension for 1900.0. In the first column is printed the year, month, and day upon which the observed declination was obtained. In the second column is given the declination of the star reduced to the epoch 1900.0. Directly under the several individual results will be found the mean epoch of the observed declination, and to its right the mean of the individual results.

Observations of the 11 stars mentioned above have been reduced to mean place with an adopted aberration constant of $20.50^{\prime \prime}$, and not with the value published in the American Ephemeris.

The Struve-Peters constants of precession and nutation were used in the reduction to mean place of the above-named stars; special tables having been prepared by the Nautical Almanac Division of the Naval Observatory for use after 1911, at which time the American Ephemeris adopted other constants.

All of the 16 stars which were used in the polygon method of observing as well as all other stars which appear in the Individual Results have also been reduced with the above mentioned constants.

\section{CATALOGUE OF STARS}

On pages A 39-44 will be found a catalogue of the stars whose declinations have been observed. The magnitude given for each of these stars was taken from the Harvard Photometric Catalogue. The approximate right ascensions which appear in the fourth column were taken from the Lund Catalogue brought up by precession to 1900.

The values of the annual precession and secular variation which are to be found in columns 8 and 9 were taken from Doctor BEckER's Tables, Strassburg, Band 2, using Newcomb's values.

In the column headed "proper motion" the values contained therein are based upon the authorities mentioned in the last column, and are given for all stars for which proper motions in declination could be found.

The headings to the other columns will indicate what are contained therein.

\section{THE JOURNAL OF OBSERVATIONS}

The journal containing values of the elapsed intervals of time of a star transit over the several threads, east to west vertical, will be found on pages A 54 to A 382 . The correction for level for each observation is also given, as well as the resulting observed declination and its reduction from date of observation to the beginning of the year in which observed.

The first column of the journal contains the date of observation and the name of star. In the second column is indicated the position of the clamp when the star wás observed, $\mathrm{N}$ for north and $\mathrm{S}$ for south.

In columns 3 to 9 , inclusive, are printed the elapsed intervals of time, mention of which was made above, for each thread. These are printed in two horizontal columns adjacent to the name of the star. The first set of time intervals corresponds, for each thread, to the expression $t$ in formula $\mathrm{G}$ (page A LXIX) and the second set to $t^{\prime}$ in the same formula. 
A CXXXVi Prime vertical transit instrument.

In the journal the observed transits of a Canum Venaticorum will be found on pages A 47 to A 53. The intervals of time printed in columns 3 to 9 , inclusive, are the hour angles obtained from transits over the movable thread in two positions of the clamp. They are the values of $t$ to be substituted in formula $\mathrm{H}$ (page A LXXI) and $t^{\prime}$ to be substituted in formula I next page. The values of $t$ will be found in the first line adjacent to the date, and $t^{\prime}$ directly below it. The other data in the columns are similar to those which have just been explained for the other stars.

The journal contains 7,947 observed declinations. Included in that number are 1,867 observed declinations of a Lyræ.

\section{VARIATION OF LATITUDE}

The corrections for the variation of latitude which have been applied to the observed declinations are those published by the International Geodetic Association and have been taken from its publications, and also in some instances from the Astronomische Nachrichten.

In general, these variations of latitude have been printed in the form of the two coordinates, $x$ and $y$, for the Greenwich meridian. They have been reduced to the meridian of the prime vertical transit by aid of the formula $\phi-\phi_{0}=x \cdot \cos \lambda+y \cdot \sin \lambda$ in which $\lambda$ is the longitude of the instrument from Greenwich, $\phi$ being the instantaneous and $\phi_{0}$ the mean latitude. The $z$-term in the variation of the latitude has not been included in those corrections. The numerical values of the variation of the latitude for the running dates of the series will be found in Table XIII.

THE PROPER MOTION IN DECLINATION OF $\alpha$ LYRE

The star a Lyræ having been observed continuously over a period of nearly 20 years, the material is sufficient to determine the value of the proper motion of the star in the coordinate in which it was observed.

A very casual inspection of the observed declinations secured in the middle of 1893 and at the end of 1912, each having been reduced to a middle epoch, clearly indicates that the proper motion which was first adopted and used in the reduction, is too small.

When these observations were commenced in 1893 there were but two relatively well-determined proper motions of the star available. One of these was a value published by Prof. L. Boss in his paper to be found in the Report of the Northern Boundary Commission, 1879. The other was a value derived by Dr. A. Auwers and published in his Fundamental Catalogue.

- The proper motion published by Professor Boss had a value of $+27.24^{\prime \prime}$ per century, and that derived by Doctor Auwers was $+29.50^{\prime \prime}$. In both cases the epoch of the proper motion was 1875. A comparison of those values indicates that the Boss value is $2.26^{\prime \prime}$ per century smaller than the Auwers value.

In the Preliminary General Catalogue prepared by Professor Boss and published by the Carnegie Institution of Washington, 1910, he increases the value of . the proper motion from his former value to $+27.90^{\prime \prime}$ per century, for the epoch 1900 . 
INTRODUCTION.

A cxxxviı

TABLE XIII.- The Corrections to the Declinations for the Variation of Latitude

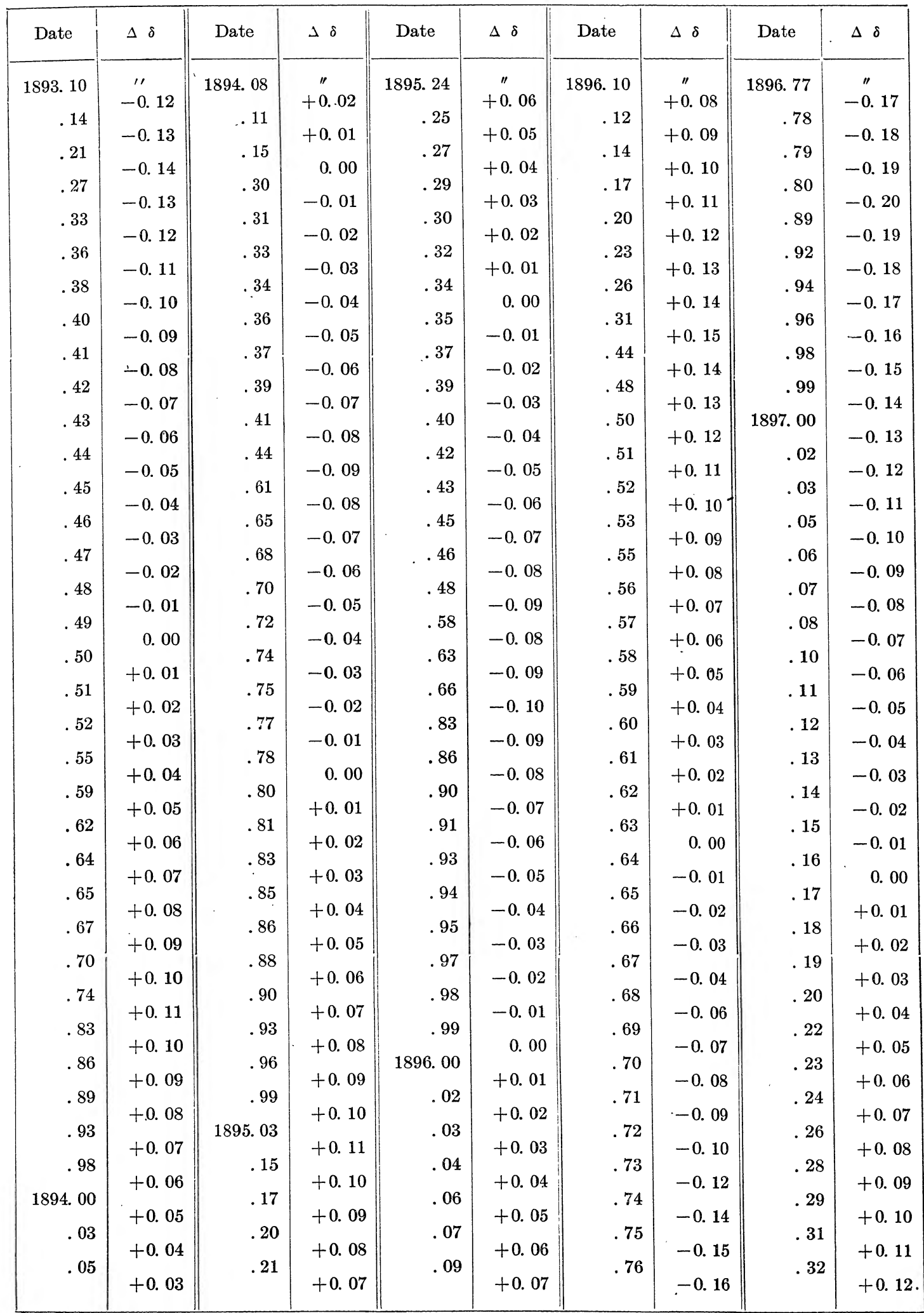


PRIME VERTICAL TRANSIT INSTRUMENT.

TABLE XIII.-The Corrections to the Declinations for the Variation of Latitude-Continued

\begin{tabular}{|c|c|c|c|c|c|c|c|c|c|}
\hline Date & $\Delta \delta$ & Date & $\Delta \delta$ & Date & $\Delta \delta$ & Date & $\Delta \delta$ & Date & $\Delta \delta$ \\
\hline 1897. 34 & $\prime \prime$ & 1898. 22 & & 1898.82 & & 1899. 43 & & 1900. 20 & \\
\hline .36 & +0.13 & .24 & -0.08 & .83 & +0.08 & .44 & -0.02 & .22 & -0.09 \\
\hline .37 & +0.14 & .26 & -0.07 & .84 & +0.07 & .46 & -0.01 & .25 & -0.10 \\
\hline 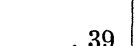 & +0.15 & .27 & -0.06 & 85 & +0.06 & & 0.00 & & -0.11 \\
\hline $\begin{array}{r}.05 \\
42\end{array}$ & +0.16 & 28 & -0.05 & .00 & +0.05 & & +0.01 & .00 & -0.12 \\
\hline$\cdot 42$ & +0.17 & .20 & -0.04 & .86 & +0.04 & .49 & +0.02 & .36 & -0.13 \\
\hline .46 & +0.18 & .30 & -0.03 & .87 & +0.03 & .50 & +0.03 & .51 & -0.12 \\
\hline .58 & +0.17 & .31 & -0.02 & .88 & +0.02 & .52 & +0.04 & .55 & -0.11 \\
\hline .62 & +0.16 & .32 & -0.01 & .89 & +0.01 & .53 & +0.05 & .58 & -0.10 \\
\hline .64 & +0.15 & .34 & 0.00 & .90 & 0.00 & .54 & +0.06 & .61 & -0.09 \\
\hline .65 & +0.14 & .35 & +0.01 & 91 & -0.01 & .55 & +0.07 & .64 & -0.08 \\
\hline .67 & +0.13 & .36 & +0.02 & .92 & -0.02 & .57 & +0.08 & . . .66 & -0.07 \\
\hline .68 & +0.12 & .37 & +0.03 & .94 & -0.03 & .58 & +0.09 & & -0.06 \\
\hline .70 & +0.11 & .38 & $+0: 04$ & .95 & -0.04 & .60 & +0.10 & .72 & -0.05 \\
\hline .72 & +0.10 & .40 & +0.05 & .96 & -0.05 & .61 & +0.11 & .74 & -0.04 \\
\hline .74 & $\begin{array}{r}0 \\
+009\end{array}$ & .41 & $\begin{array}{r}0.06 \\
+0.06\end{array}$ & .97 & -006 & .64 & 0.10 & .77 & 0.05 \\
\hline .76 & +0.09 & .42 & +0.06 & .98 & -0.06 & .68 & +0.12 & .80 & -0.03 \\
\hline .78 & +0.08 & .44 & +0.07 & 1899. 00 & -0.07 & .79 & +0.13 & .84 & -0.02 \\
\hline .79 & +0.07 & .45 & +0.08 & .01 & -0.08 & .87 & +0.12 & .87 & -0.01 \\
\hline .80 & +0.06 & 46 & +0.09 & 02 & -0.09 & .90 & +0.11 & 91 & 0.00 \\
\hline .81 & +0.05 & 48 & +0.10 & .04 & -0.10 & & +0.10 & & +0.01 \\
\hline 82 & +0.04 & - Io & +0.11 & $.0 \pm$ & -0.11 & . 91 & +0.09 & .96 & +0.02 \\
\hline . 0 & +0.02 & .50 & +0.12 & .00 & -0.12 & .92 & +0.08 & 1901.10 & +0.03 \\
\hline .83 & 0.00 & .51 & +0.13 & .07 & -0.13 & .93 & +0.07 & & +0.02 \\
\hline .84 & -0.01 & .52 & +0.14 & .09 & -0.14 & .94 & +0.06 & .28 & +0.01 \\
\hline .85 & -0.02 & .54 & +0.15 & .12 & -0.15 & .95 & +0.05 & .31 & 0.00 \\
\hline .86 & -0.04 & .55 & +016 & .21 & -014 & .96 & 100 & .34 & \\
\hline .87 & & .57 & +0.10 & .25 & -0.14 & .97 & +0.04 & .36 & -0.01 \\
\hline .88 & -0.06 & .59 & +0.17 & .28 & -0.13 & .98 & +0.02 & - & -0.02 \\
\hline .00 & -0.08 & & +0.18 & & -0.12 & $\cdot .70$ & +0.01 & .00 & -0.03 \\
\hline .89 & -0.09 & .69 & +0.17 & .30 & -0.11 & .99 & 0.00 & .39 & -0.04 \\
\hline .90 & -0.10 & .72 & +0 & .31 & -0.10 & 1900.00 & -0.01 & .41 & \\
\hline .91 & -0.11 & .74 & 10.00 & .33 & -0.10 & .02 & -0.01 & .42 & . 00 \\
\hline .93 & -0.11 & .7 .5 & +0.15 & .34 & -0.09 & .04 & -0.02 & .43 & -0.06 \\
\hline .95 & -0.12 & .76 & +0.14 & .36 & -0.08 & 06 & -0.03 & . & -0.07 \\
\hline 1898,08 & -0.13 & .78 & +0.13 & 37 & -0.07 & .00 & -0.04 & $\cdot . \pm \pm$ & -0.08 \\
\hline & -0.12 & & +0.12 & .37 & -0.06 & .09 & -0.05 & .45 & -0.09 \\
\hline . 12 & -0.11 & .79 & +0.11 & .38 & -0.05 & .11 & -0.06 & .48 & -0.10 \\
\hline .16 & -0.10 & .80 & +0.10 & .40 & -0.04 & .14 & -0.07 & . 49 & -0.11 \\
\hline .19 & -0.09 & .81 & +0.09 & .41 & -0.03 & .17 & -0.08 & .50 & -0.12 \\
\hline
\end{tabular}


TABLE XIII.-The Corrections to the Declinations for the Variation of Latitude-Continued

\begin{tabular}{|c|c|c|c|c|c|c|c|c|c|}
\hline Date & $\Delta \delta$ & Date & $\Delta \delta$ & Date & $\Delta \delta$ & Date & $\Delta \delta$ & Date & $\Delta \delta$ \\
\hline 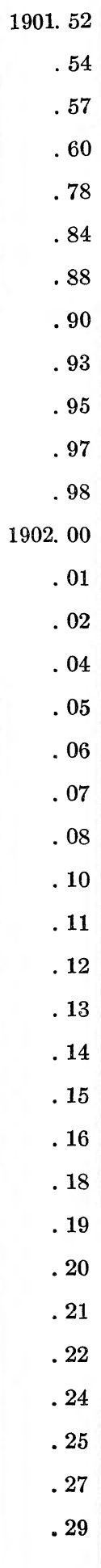 & 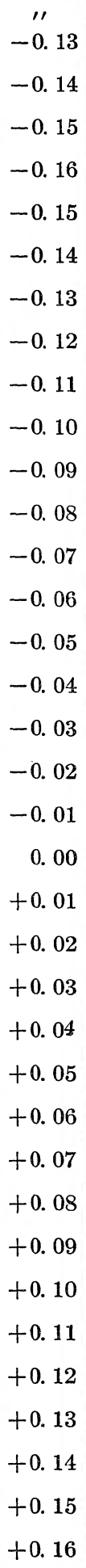 & 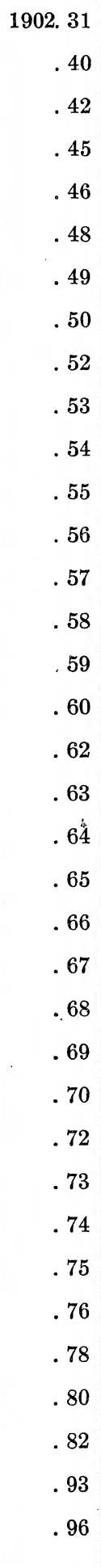 & 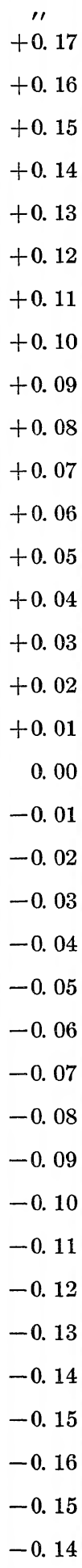 & 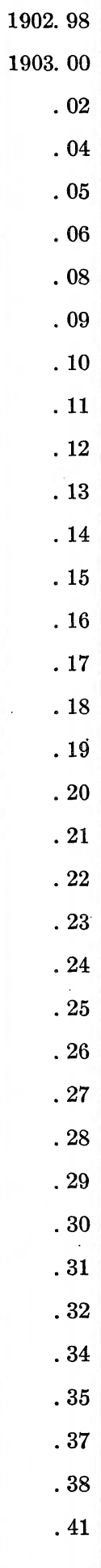 & 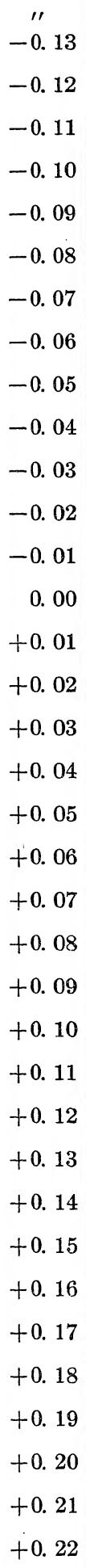 & 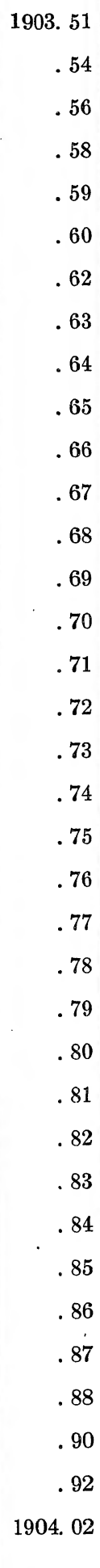 & 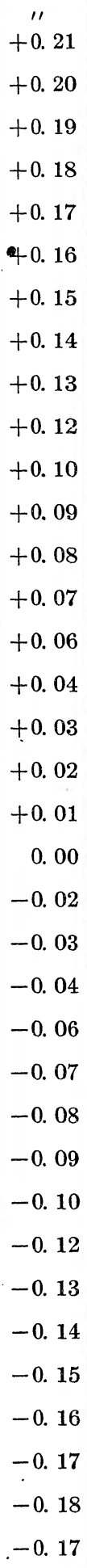 & $\begin{array}{r}.20 \\
.21 \\
.23 \\
.24 \\
.25 \\
.26 \\
.27 \\
.28 \\
.29 \\
.30 \\
.31\end{array}$ & 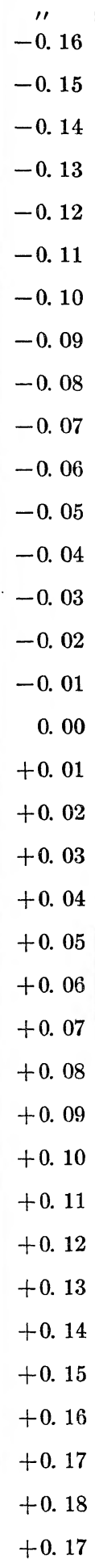 \\
\hline
\end{tabular}


A CXL

PRIME VERTICAL TRANSIT INSTRUMENT.

TABLE XIII.-The Corrections to the Declinations for the Variation of Latitude-Continued

\begin{tabular}{|c|c|c|c|c|c|c|c|c|c|}
\hline Date & $\Delta \delta$ & Date & $\Delta \delta$ & Date & $\Delta \delta$ & Date & $\Delta \delta$ & Date & $\Delta \delta$ \\
\hline 1904. 60 & $\begin{array}{l}\prime \prime \prime \\
+0.16\end{array}$ & 1905. 20 & $\begin{array}{c}\prime \prime \\
-0.18\end{array}$ & 1905. 78 & $\begin{array}{l}\prime \prime \prime \\
+0.13\end{array}$ & 1906. 49 & $\begin{array}{c}\prime \prime \\
+0.01\end{array}$ & 1907.70 & $\begin{array}{c}\prime \prime \\
-0.07\end{array}$ \\
\hline .63 & +0.15 & .23 & -0.17 & .80 & +0.12 & .50 & +0.02 & .72 & -0.06 \\
\hline .65 & +0.14 & .25 & -0.16 & .81 & +0.11 & .52 & +0.03 & .74 & -0.05 \\
\hline .67 & +0.13 & .26 & -0.15 & .82 & +0.10 & .54 & +0.04 & .76 & -0.04 \\
\hline .69 & +0.12 & .27 & -0.14 & .84 & +0.09 & .57 & +0.05 & .78 & -0.03 \\
\hline .70 & +0.11 & 28 & -0.13 & .85 & +0.08 & .60 & +0.06 & .80 & -0.02 \\
\hline .72 & +0.10 & .30 & -0.12 & .86 & +0.07 & .63 & +0.07 & .81 & -0.01 \\
\hline .74 & +0.09 & . 31 & -0.11 & .88 & +0.06 & .68 & +0.08 & .83 & 0.00 \\
\hline .75 & +0.08 & .32 & -0.10 & .89 & +0.05 & .73 & +0.09 & .84 & +0.01 \\
\hline .76 & +0.07 & .33 & -0.09 . & .90 & +0.04 & .80 & +0.10 & .86 & +0.02 \\
\hline .78 & +0.06 & .34 & -0.08 & .91 & +0.03 & .95 & +0.09 & .87 & +0.03 \\
\hline .80 & +0.05 & .35 & -0.07 & .92 & +0.02 & .99 & +0.08 & .88 & +0.04 \\
\hline .81 & +0.04 & .36 & -0.06 & .94 & +0.01 & 1907. 01 & +0.07 & .90 & +0.05 \\
\hline .82 & +0.03 & .31 & -0.05 & .95 & 0.00 & .04 & +0.06 & .91 & +0.06 \\
\hline .84 & +0.02 & .38 & -0.04 & .96 & -0.01 & .05 & +0.05 & .92 & +0.07 \\
\hline .80 & +0.01 & & -0.03 & .98 & -0.02 & . 07 & +0.04 & .94 & +0.08 \\
\hline$\cdot 80$ & 0.00 & .40 & -0.02 & .98 & -0.03 & .09 & +0.03 & .95 & +0.09 \\
\hline .81 & -0.01 & .41 & -0.01 & 1906.00 & -0.04 & .11 & +0.02 & .96 & +0.10 \\
\hline .89 & -0.02 & . 42 & 0.00 & .01 & -0.05 & .13 & +0.01 & .97 & +0.11 \\
\hline .90 & -0.03 & .44 & +0.02 & .02 & -0.06 & .15 & 0.00 & .99 & +0.12 \\
\hline .91 & -0.04 & .45 & +0.03 & .04 & -0.07 & .17 & -0.01 & 1908.00 & +0.13 \\
\hline .92 & -0.05 & .46 & +0.04 & .06 & -0.08 & .20 & -0.02 & .02 & +0.14 \\
\hline .93 & -0.06 & .47 & +0.05 & .08 & -0.09 & .22 & -0.03 & .04 & \\
\hline .94 & -0.07 & .48 & +0.06 & .11 & -0.10 & .25 & -0.04 & .07 & 10 \\
\hline .95 & -0.08 & .49 & +0.07 & .15 & -0.11 & .28 & 0. & .09 & \\
\hline .96 & 0.00 & .50 & T. 00 & .24 & -0.11 & .30 & -0.05 & .13 & +0.17 \\
\hline .97 & -0.09 & .51 & +0.08 & .28 & -0.10 & 33 & -0.06 & 91 & +0.18 \\
\hline .98 & -0.10 & 52 & +0.09 & 31 & -0.09 & 35 & -0.07 & .21 & +0.17 \\
\hline 100500 & -0.11 & 54 & +0.10 & 24 & -0.08 & .30 & -0.08 & .24 & +0.16 \\
\hline & -0.12 & .04 & +0.11 & & -0.07 & .38 & -0.09 & .26 & +0.15 \\
\hline .01 & -0.13 & .55 & +0.12 & .36 & -0.06 & .40 & -0.10 & .28 & +0.14 \\
\hline .02 & -0.14 & .56 & +0.13 & .39 & -0.05 & .44 & -0.11 & .29 & +013 \\
\hline .03 & -0.15 & .58 & +0.14 & .40 & -0.04 & .48 & -0.12 & .30 & $\begin{array}{r}10 \\
+0.12\end{array}$ \\
\hline .05 & -0.16 & .60 & +0.15 & .42 & -0.03 & .59 & -0.11 & .31 & +0.11 \\
\hline .06 & -0.17 & .62 & +0.16 & .44 & -0.02 & .62 & -0.10 & .32 & \\
\hline .07 & -0.18 & $\therefore 73$ & $\begin{array}{r}0.15 \\
+0.15\end{array}$ & .45 & -0.01 & .65 & $\begin{array}{r}-000 \\
-000\end{array}$ & .34 & 00 \\
\hline .10 & -0.19 & .75 & +0.14 & .47 & 0.00 & .68 & -0.08 & .35 & $\begin{array}{r}+0.09 \\
+0.08\end{array}$ \\
\hline
\end{tabular}


TABLE XIII.-The Corrections to the Declinations for the Variation of Latitude-Continued

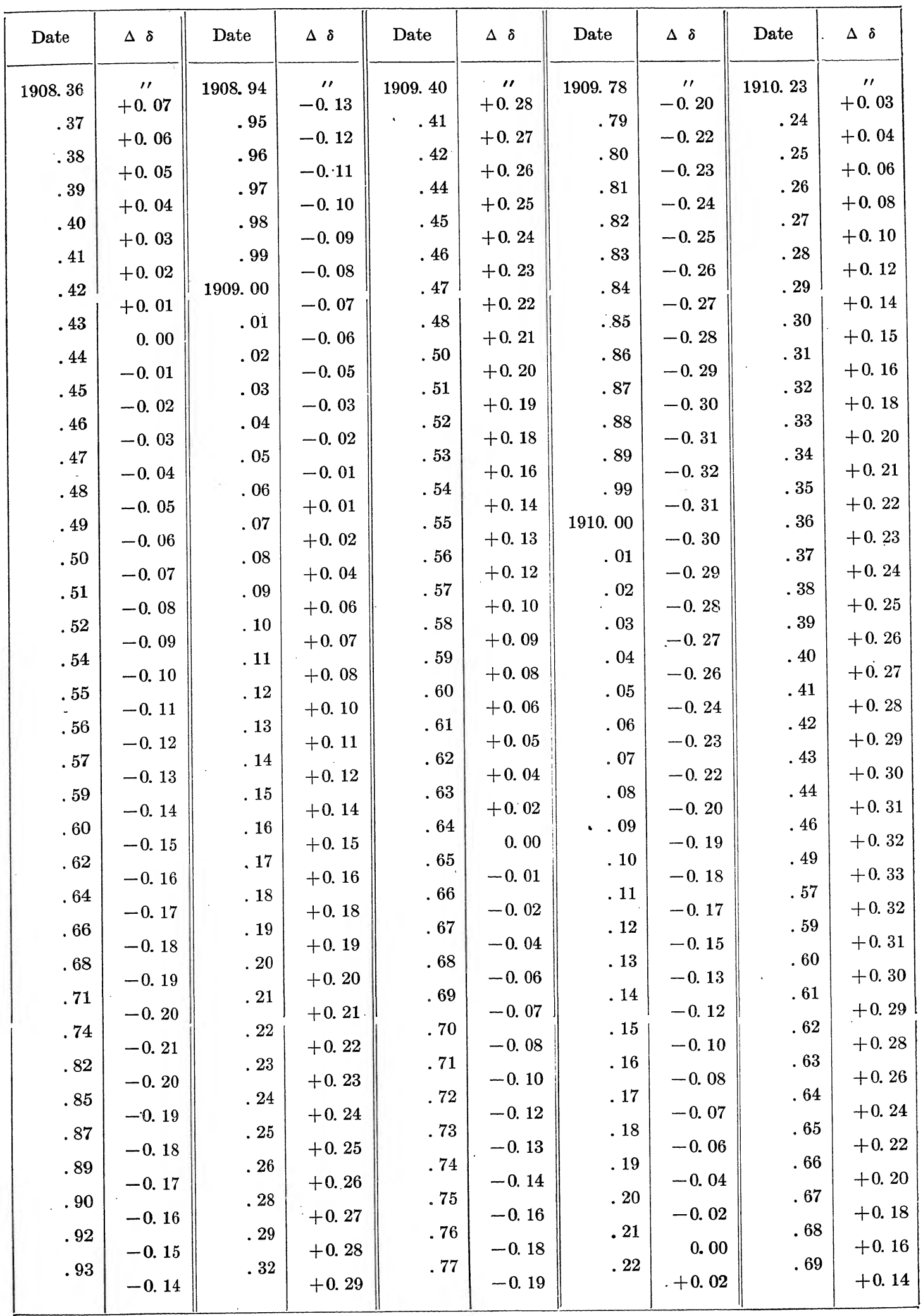


TABLE XIII.-The Corrections to the Declinations for the Variation of Latitude-Continued

\begin{tabular}{|c|c|c|c|c|c|c|c|c|c|}
\hline Date & $\Delta \delta$ & Date & $\Delta \delta$ & Date & $\Delta \delta$ & Date & $\Delta \delta$ & Date & $\Delta \delta$ \\
\hline 1910. 70 & ' & 1911. 11 & $\begin{array}{c}\prime \prime \\
-0.27\end{array}$ & 1911. 44 & $\begin{array}{l}\prime \prime \\
+0.18\end{array}$ & 1911. 92 & $\begin{array}{r}\prime \prime \\
+0.03\end{array}$ & 1912.43 & "I \\
\hline .71 & $\begin{array}{r}0.10 \\
+0.12\end{array}$ & .12 & -0.26 & .45 & +0.20 & .93 & $\begin{array}{l}+0.00 \\
+0.02\end{array}$ & .44 & -0. \\
\hline .72 & $\begin{array}{r}0.10 \\
+0 .\end{array}$ & .13 & -0.25 & .46 & +0.22 & .94 & +0.01 & .45 & -0.04 \\
\hline .73 & $\begin{array}{r}0.0 \\
+0.0\end{array}$ & .14 & -0.24 & .47 & $\begin{array}{r}0.23 \\
+0.23\end{array}$ & .95 & T0. 01 & .46 & -0.03 \\
\hline .73 & +0 & .15 & -0.23 & .48 & +0 . & .96 & $\begin{array}{l}+0.00 \\
-0.01\end{array}$ & .47 & -0.02 \\
\hline .74 & +0.04 & .16 & -0.22 & .49 & +0.26 & .97 & -0.02 & .48 & -0. \\
\hline .75 & $\begin{array}{r}1.0 x \\
+0.02\end{array}$ & .17 & -0.21 & .50 & $\begin{array}{r}10.20 \\
+027\end{array}$ & .98 & -0. & .49 & 0.00 \\
\hline .76 & & .18 & -0. & .51 & +028 & .99 & -0.03 & .50 & +0.01 \\
\hline .77 & $\begin{array}{r}0.00 \\
-0.01\end{array}$ & .19 & -0.20 & .53 & +0.28 & 1912. 00 & -0.04 & .51 & +0.02 \\
\hline .78 & $\begin{array}{l}-0.01 \\
-0.02\end{array}$ & .20 & -0.18 & .55 & +0.29 & .01 & -0.05 & .52 & +0.03 \\
\hline .79 & -0.02 & .21 & -0.17 & .57 & +0.30 & .02 & -0.06 & .53 & +0.04 \\
\hline .80 & -0.04 & .22 & -0.16 & .68 & +0.31 & .03 & -0.07 & .55 & +0.05 \\
\hline .81 & -0.06 & .23 & -0.14 & .70 & +0.30 & .04 & -0.08 & .56 & +0.06 \\
\hline .82 & -0.08 & 24 & -0.13 & .71 & +0.29 & 05 & -0.10 & & +0.07 \\
\hline 83 & -0.10 & 25 & -0.12 & 73 & +0.28 & .00 & -0.11 & . 57 & +0.08 \\
\hline 84 & -0.11 & 26 & -0.10 & & +0.27 & .00 & -0.12 & - 59 & +0.09 \\
\hline $\begin{array}{r}.84 \\
85\end{array}$ & -0.12 & $\begin{array}{r}.20 \\
27\end{array}$ & -0.08 & .74 & +0.26 & .07 & -0.13 & .60 & +0.10 \\
\hline $\begin{array}{r}\cdot 80 \\
86\end{array}$ & -0.14 & $\cdot 28$ & -0.07 & .75 & +0.25 & .08 & -0.14 & .62 & +0.11 \\
\hline & -0.16 & & -0.06 & .60 & +0.24 & . U9 & -0.15 & .64 & +0.12 \\
\hline .87 & -0.17 & .29 & -0.04 & .77 & +0.22 & .11 & -0.16 & .66 & +0.13 \\
\hline .88 & -0.18 & .30 & -0.02 & .78 & +0.21 & .13 & -0.17 & .68 & +0.14 \\
\hline .89 & -0.19 & .31 & -0.01 & .79 & +0.20 & .15 & -0.18 & .71 & \\
\hline .90 & -0.20 & .32 & 0.00 & .80 & +0.19 & .25 & -0.17 & .74 & \\
\hline .91 & -0.22 & .33 & +0.02 & .81 & +0.18 & .28 & & .77 & \\
\hline .92 & -0.23 & .34 & 100 & .82 & 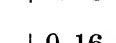 & .30 & & .81 & \\
\hline .93 & & .35 & & .83 & & .32 & -0.15 & .91 & +0.18 \\
\hline .94 & -0.24 & .36 & +0.05 & 8 & +0.15 & 34 & -0.14 & & +0.17 \\
\hline & -0.25 & 37 & +0.06 & & +0.14 & .04 & -0.13 & $\cdot$ & +0.16 \\
\hline & -0.26 & & +0.08 & .85 & +0.13 & .35 & -0.12 & .96 & +0.1 \\
\hline 86 & -0.27 & .38 & +0.10 & .86 & +0.12 & .36 & -0.11 & .98 & \\
\hline .97 & -0.28 & .39 & +0.11 & .87 & & .38 & . & 1913. 01 & \\
\hline .98 & 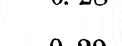 & .40 & & .88 & & .39 & 0.20 & .03 & +0.13 \\
\hline .99 & & .41 & +0.12 & .89 & +0.08 & .40 & -0.09 & .05 & +0.12 \\
\hline 11. 07 & -0.30 & .42 & +0.14 & .90 & +0.07 & 41 & -0.08 & .07 & +0.11 \\
\hline & -0.29 & 43 & +0.16 & & +0.06 & & -0.07 & .11 & +0.10 \\
\hline & -0.28 & & +0.17 & & +0.04 & . & -0.06 & .13 & \\
\hline
\end{tabular}


Professor Newcoms in his Fundamental Catalogue, published as Volume VIII, Part II, Astronomical Papers, prepared for the use of the American Ephemeris and Nautical Almanac, gives as the proper motion of the star the value $+27.98^{\prime \prime}$ per century, for the epoch 1900 .

In Veröffentlichungen des Königlichen Astronomischen Rechen-Instituts zu Berlin, No. 33, there is published a Neuer Fundamentalkatalog des Berliner Astronomischen Jahrbuchs, based upon the previous work of Doctor Auwers. In that catalogue the Newcomb precessions have been substituted for those of Struve. The value of $+29.50^{\prime \prime}$ per century for the proper motion of the star which had previously been published in the Berliner Jahrbuch, was, in 1907, changed to $+28.10^{\prime \prime}$ per century.

When observations of the star $\alpha$ Lyræ were begun in 1893 a proper motion of $+0.275^{\prime \prime}$ per year was adopted. It has been called in this work the Boss proper motion although if the Boss value is brought up to 1900 by its secular variation it differs from the value thus called by $+0.002^{\prime \prime}$. Later developments indicated that both of the above values of the proper motion were slightly erroneous.

However, all observed declinations of $\alpha$ Lyræ which appear in the individual results have been reduced to the epoch 1900, using NEwcomb's value of the precession and the proper motion of $+0.275^{\prime \prime}$ per year.

To ascertain what value of the proper motion would best satisfy these declinations observed continuously for so many years, the following plan was followed:

Only those declinations which had been observed after sunset and before sunrise were considered. In each year declinations thus designated were formed into general means. The individual declinations forming these means had previously been corrected for the variation of latitude; for the parallax of the star provisionally adopted, $+0.102^{\prime \prime}$; and reduced with a corrected aberration, $20.566^{\prime \prime}$.

Values of these 20 yearly means thus formed are shown in Table XIV, together with the mean date of observing of each, the number of observations included in the mean, and their assigned relative weights.

From a least square solution of the data contained in the above table a final corrected declination of

$$
+38^{\circ} 41^{\prime} 25.830^{\prime \prime} \pm 0.010^{\prime \prime}(1900.0)
$$

was obtained for the star $\alpha$ Lyræ.

From the same solution was found a corrected proper motion in declination of

$$
+0.3001^{\prime \prime} \pm 0.0017^{\prime \prime} \text { per year. }
$$

In the above solution there were included 870 observed declinations. Before it was made they had been reduced to a latitude of

for the instrument.

$$
+38^{\circ} 55^{\prime} 14.61^{\prime \prime}
$$

It may be interesting for purposes of comparison to insert here the values of the proper motion in declination of $\alpha$ Lyræ, per century, according to the following authorities and all of them representing that motion for 1900.0:

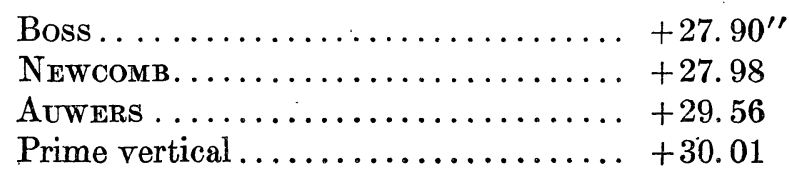


Table XIV.-Mean Declinations of a Lyræ, Night Observations Only

\begin{tabular}{|c|c|c|c|c|c|c|c|}
\hline \multirow[t]{2}{*}{$\begin{array}{l}\text { Mean } \\
\text { date }\end{array}$} & \multicolumn{3}{|c|}{$\begin{array}{c}\text { Yearly declination. } \\
1900.0\end{array}$} & \multirow[t]{2}{*}{$\begin{array}{l}\text { Number } \\
\text { of obser- } \\
\text { vations }\end{array}$} & \multirow[t]{2}{*}{ Wt. } & \multirow{2}{*}{$n^{n}$} & \multirow{2}{*}{$\begin{array}{c}v \\
\prime \prime\end{array}$} \\
\hline & $\circ$ & 1 & "' & & & & \\
\hline 1893. 69 & +38 & 41 & 25. 693 & 20 & 2 & -0.129 & -0.142 \\
\hline 1894. 50 & & & .811 & 57 & 3 & -.011 & -.024 \\
\hline 1895. 55 & & & .823 & 52 & 4 & +.001 & -.011 \\
\hline 1896. 52 & & & . 724 & 62 & 3 & -.098 & -.109 \\
\hline 1897. 50 & & & .847 & 53 & 4 & +.025 & +.015 \\
\hline 1898. 56 & & & .860 & 55 & 4 & +.038 & +.029 \\
\hline 1899. 51 & & & . 942 & 71 & 7 & +.120 & +.112 \\
\hline 1900. 57 & & & .834 & 20 & 1 & +.012 & +.004 \\
\hline 1901. 40 & & & . 681 & 12 & 1 & 141 & -.148 \\
\hline 1902. 52 & & & .855 & 34 & 2 & +.033 & +.027 \\
\hline 1903. 43 & & & .781 & 38 & 2 & -.041 & -.046 \\
\hline 1904. 53 & & & .866 & 57 & 5 & 044 & +.040 \\
\hline 1905. 35 & & & .654 & 11 & 1 & 168 & -.171 \\
\hline 1906. 49 & & & .728 & 34 & 3 & 094 & .096 \\
\hline 1907. 54 & & & .880 & 47 & 8 & +.058 & +.057 \\
\hline 1908. 56 & & & . 778 & 57 & 6 & -.044 & .045 \\
\hline 1909. 54 & & & .824 & 65 & 7 & +.002 & +.002 \\
\hline 1910. 54 & & & .792 & 44 & 7 & -.030 & -.029 \\
\hline 1911. 52 & & & .785 & 42 & 3 & -.037 & -.035 \\
\hline 1912.52 & & & . 824 & 39 & 4 & +.002 & +.005 \\
\hline
\end{tabular}

A COMPARISON BETWEEN DECLINATIONS OBTAINED WITH THE PRIME VERTICAL TRANSIT AND THOSE OF THE SAME STARS IN THE CATALOGUES OF LUND, 1875; YARNALL, 1860; AND LALANDE, 1800

In Table XV are presented certain stars for which proper motions in declination could not be found in existing catalogues. To provide a means whereby the possible existence of proper motions in the declinations of these stars would become apparent, their declinations as given in these respective catalogues have been brought up to 1900 by the precession in declination corresponding to each star.

No attempt has been made to determine their proper motions, and the table is merely an indication of the possibility of any being so affected. There are, however, some instances in which a small proper motion is indicated, although probably in all of them it is less than $10^{\prime \prime}$ per century.

The number given each star is that by which it may be identified in the catalogue contained in this volume. The other data are the names of the stars; their observed positions for 1900; and the Lund, Yarnall, and LaLande declinations, respectively, brought forward to that epoch.

A DISCUSSION OF THE CORRECTION TO THE ADOPTED ABERRATION CONSTANT

OBSERVATIONS MADE BY THE POLYGON METHOD

In the spring of 1904 the observing of a list of stars selected for the purpose of obtaining their declinations had practically been finished. The developments which had arisen in connection with the discovery by Dr. S. C. CHanduen of Cambridge, Mass., of a variation in the latitude had indicated that a correction to the adopted aberration constant used in the reduction of the star places would be involved, and thus affect the material which had been accumulated for the purpose of obtaining a correction to the constant above mentioned. It was self evident that the correction could not be obtained from observed declinations of one star, or from several stars, unless the plan of observing was made to conform to practically one method. 
INTRODUCTION.

A CXLV

TABLE XV.-A Comparison Between Declinations Obtained with the Prime Vertical Transit and Those of the Same Stars in the Catalogues of Lund, Yarnall, and Lalande; Epoch 1900.0

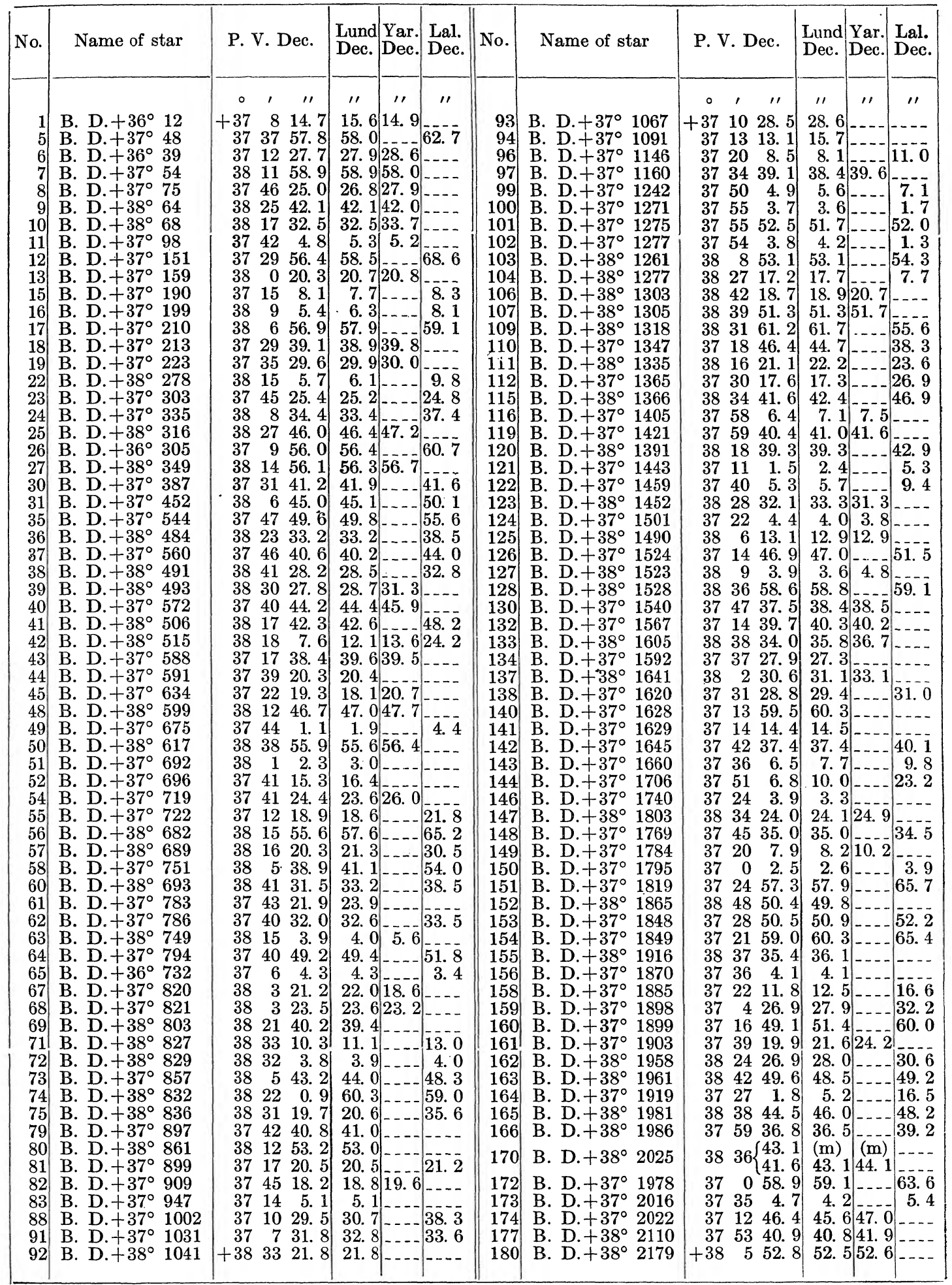

$101141^{\circ}-26 \dagger-P T I-10$ 
TaBle XV.-A Comparison Between Declinations Obtained with the Prime Vertical Transit and Those of the Same Stars in the Catalogues of Lund, Yarnall, and Lalande; Epoch 1900.0Continued

\begin{tabular}{|c|c|c|c|c|c|c|c|c|c|c|c|}
\hline No. & Name of star & P. V. Dec. & $\begin{array}{l}\text { Lund } \\
\text { Dec. }\end{array}$ & $\begin{array}{l}\text { Yar. } \\
\text { Dec. }\end{array}$ & $\begin{array}{l}\text { Lal. } \\
\text { Dec. }\end{array}$ & No. & Name of star & P. V. Dec. & $\begin{array}{l}\text { Lund } \\
\text { Dec. }\end{array}$ & $\begin{array}{l}\text { Yar. } \\
\text { Dec. }\end{array}$ & $\begin{array}{l}\text { Lal. } \\
\text { Dec. }\end{array}$ \\
\hline & & $\circ, 11$ & $\prime \prime$ & & "I & & & $\circ \quad 1$ & 11 & 11 & 11 \\
\hline 181 & B. D. $+37^{\circ} 2123$ & +371732.6 & 32.9 & & & 283 & B. D. $+36^{\circ} 3550$ & $+37 \quad 251.4$ & 52.5 & & \\
\hline & B. D. $+37^{\circ} 2145$ & $\begin{array}{lll}37 & 12 & 50.7\end{array}$ & 49. 2 & & & 284 & B. D. $+37^{\circ} 3465$ & $\begin{array}{lll}37 & 44 & 15 .\end{array}$ & 15. 9 & & \\
\hline 185 & B. D. $+37^{\circ} 2167$ & $\begin{array}{llll}37 & 26 & 10 . & 1\end{array}$ & 9. 3 & & & 285 & B. D. $+36^{\circ} 3632$ & $\begin{array}{llll}38 & 11 & 21 . & 0\end{array}$ & 21. 0 & & \\
\hline 187 & B. D. $+38^{\circ} 2228$ & $\begin{array}{llll}38 & 38 & 59.2\end{array}$ & 60. 6 & & 63.8 & 286 & B. D. $+38^{\circ} 3650$ & $\begin{array}{llll}38 & 32 & 38.5\end{array}$ & 38.0 & & \\
\hline 188 & B. D. $+38^{\circ} 2234$ & $\begin{array}{lll}37 & 47 & 2.0\end{array}$ & 3. 0 & & & 287 & B. D. $+38^{\circ} 3677$ & $\begin{array}{lll}38 & 9 & 32.6\end{array}$ & 32.9 & & \\
\hline 190 & B. D. $+38^{\circ} 2250$ & $\begin{array}{llll}38 & 30 & 19.6\end{array}$ & 19.6 & & & 288 & B. D. $+38^{\circ} 3680$ & $\begin{array}{lll}38 & 22 & 6.9\end{array}$ & 7.3 & & 8. 0 \\
\hline 193 & B. D. $+37^{\circ} 2230$ & $\begin{array}{llll}37 & 18 & 51 . & 0\end{array}$ & 51.0 & & & 289 & B. D. $+38^{\circ} 3725$ & $\begin{array}{lll}38 & 25 & 59.6\end{array}$ & 59.3 & & \\
\hline 195 & B. D. $+38^{\circ} 2326$ & $\begin{array}{llll}38 & 34 & 43.9\end{array}$ & 43.3 & & 47. 0 & 290 & B. D. $+37^{\circ} 3582$ & $\begin{array}{lll}38 & 4 & 56.8\end{array}$ & 57. 1 & & \\
\hline 196 & B. D. $+38^{\circ} 2347$ & $\begin{array}{llll}38 & 37 & 15.5\end{array}$ & 15.7 & & 25.6 & 293 & B. D. $+37^{\circ} 3616$ & $\begin{array}{llll}37 & 28 & 34.4\end{array}$ & 34. 1 & & \\
\hline 200 & B. D. $+37^{\circ} 2383$ & $\begin{array}{lll}37 & 25 & 3.4\end{array}$ & 4.3 & & & 296 & B. D. $+37^{\circ} 3636$ & $\begin{array}{lll}37 & 34 & 16.2\end{array}$ & 16. 6 & & \\
\hline 201 & B. D. $+38^{\circ} 2435$ & $\begin{array}{lll}38 & 22 & 51.9\end{array}$ & 52.2 & & & 298 & B. D. $+38^{\circ} 3832$ & $\begin{array}{lll}38 & 11 & 19.8\end{array}$ & 20.1 & & \\
\hline 202 & B. D. $+37^{\circ} 2404$ & $\begin{array}{lll}37 & 33 & 21.8\end{array}$ & 21.3 & & & 299 & B. D. $+37^{\circ} 3703$ & $\begin{array}{lll}37 & 50 & 2.4\end{array}$ & 3. 2 & & \\
\hline $\begin{array}{l}203 \\
204\end{array}$ & B. D. $+37^{\circ} 2421$ & $37 \quad 19\left\{\begin{array}{l}58.4 \\
56.6\end{array} \mid\right.$ & & & 56. 6 & $\begin{array}{l}300 \\
301\end{array}$ & $\begin{array}{l}\text { B. D. }+37^{\circ} 3735 \\
\text { B. D. }+37^{\circ} 3744\end{array}$ & $\begin{array}{rrr}37 & 31 & 55.6 \\
38 & 2 & 43.1\end{array}$ & & & \\
\hline $\begin{array}{l}204 \\
209\end{array}$ & B. D. $+37^{\circ} 2467$ & $\begin{array}{lll}37 & 33 & 36.0 \\
36\end{array}$ & 39.1 & & 57.8 & $\begin{array}{l}501 \\
302\end{array}$ & B. D. $+38^{\circ} 3896$ & 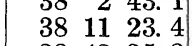 & 21. 8 & & \\
\hline 210 & B. D. $+38^{\circ} 2518$ & $\begin{array}{lll}37 & 48 & 8.3\end{array}$ & 8. 1 & & & 303 & B. D. $+38^{\circ} 3906$ & $\begin{array}{lll}38 & 48 & 35.3\end{array}$ & 34.4 & & \\
\hline 213 & B. D. $+37^{\circ} 2545$ & $\begin{array}{lll}37 & 24 & 2.8\end{array}$ & 5. 5 & & & 304 & B. D. $+38^{\circ} 3821$ & $\begin{array}{lll}38 & 3 & 19.6\end{array}$ & 19. 1 & & 1. 3 \\
\hline 214 & B. D. $+37^{\circ} 2551$ & $\begin{array}{lllll}37 & 3 & 54.6\end{array}$ & 54.5 & & & 305 & B. D. $+38^{\circ} 3946$ & $\begin{array}{lll}38 & 8 & 33.3\end{array}$ & 33.5 & & \\
\hline 215 & B. D. $+38^{\circ} 2578$ & $\begin{array}{llll}38 & 32 & 24.0\end{array}$ & 23. 7 & & & 306 & B. D. $+38^{\circ} 3956$ & $\begin{array}{lll}38 & 27 & 47 . \\
\end{array}$ & 48.6 & & \\
\hline 217 & B. D. $+37^{\circ} 2568$ & $\begin{array}{lllll}37 & 10 & 56.8\end{array}$ & 56.3 & & & 307 & B. D. $+38^{\circ} 3957$ & $\begin{array}{llll}38 & 25 & 35 . & 3\end{array}$ & 36. 2 & & \\
\hline 220 & B. D. $+37^{\circ} 2616$ & $\begin{array}{llll}37 & 7 & 48 . & 4\end{array}$ & 48. 0 & & 37.9 & 308 & B. D. $+36^{\circ} 3958$ & $\begin{array}{lll}37 & 2 & 57.2\end{array}$ & 57. 1 & & 5 \\
\hline 222 & B. D. $+38^{\circ} 2631$ & $\begin{array}{llll}38 & 40 & 13.8\end{array}$ & 13.0 & & & 309 & B. D. $+37^{\circ} 38$ & $\begin{array}{lll}37 & 23 & 22 .\end{array}$ & 21. 4 & & 22.6 \\
\hline & B. D. $+37^{\circ} 2625$ & & 12. 4 & & & 310 & B. D. $+38^{\circ} 3977$ & 383 & 28.5 & 29.9 & \\
\hline 224 & B. D. $+38^{\circ} 2652$ & $\begin{array}{lllll}38 & 32 & 38 . & 3\end{array}$ & 40. 1 & & & 311 & B. D. $+37^{\circ} 3867$ & $\begin{array}{lll}37 & 55 & 3\end{array}$ & 31.7 & & \\
\hline 228 & B. D. $+38^{\circ} 2678$ & $\begin{array}{lll}38 & 42 & 19 .\end{array}$ & 19. 0 & & 22.8 & 313 & B. D. $+38^{\circ} 4003$ & $\begin{array}{llll}38 & 41 & 2\end{array}$ & 26. 6 & & \\
\hline 229 & B. D. $+38^{\circ} 2687$ & $\begin{array}{lll}37 & 50 & 22.6\end{array}$ & 22. 2 & & & 316 & B. D. $+37^{\circ} 39$ & $37:$ & & & \\
\hline 230 & B. D. $+37^{\circ} 2666$ & $\begin{array}{llll}37 & 20 & 20.7\end{array}$ & 20.8 & & & 317 & B. D. $+37^{\circ} 4002$ & $\begin{array}{lll}37 & 58 & 48.9\end{array}$ & 49. 7 & 52. & \\
\hline 232 & B. D. $+38^{\circ} 2715$ & $\begin{array}{llll}38 & 6 & 48 . & 0\end{array}$ & 48. 2 & & 48.7 & 318 & $38^{\circ} 4187$ & $\begin{array}{llll}38 & 43 & 3\end{array}$ & & & \\
\hline 233 & B. D. $+38^{\circ} 2736$ & $\begin{array}{llll}38 & 19 & 32 . & 4\end{array}$ & 32.23 & 3 & & 320 & B. D. $+37^{\circ} 4076$ & 37365 & 50.5 & & \\
\hline 234 & B. D. $+38^{\circ} 2755$ & $\begin{array}{llll}38 & 0 & 29.9\end{array}$ & 30.3 & 31. & & 321 & B. D. $+38^{\circ} 4306$ & 38255 & 58. & & \\
\hline & B. D. $+37^{\circ} 2741$ & $\begin{array}{lll}7 & 12 & 53.2\end{array}$ & 53. 7 & & & 325 & $-37^{\circ} 41$ & $\begin{array}{llll}37 & 38 & 2\end{array}$ & & & \\
\hline 237 & B. D. $+38^{\circ} 2795$ & $\begin{array}{llll}8 & 17 & 50.8\end{array}$ & 48. 8 & & & 326 & $-37^{\circ} 4222$ & $\begin{array}{llll}38 & 9 & 19.1\end{array}$ & 19. 2 & & \\
\hline 2 & B. D. $+38^{\circ} 2811$ & & 29. 2 & & & 328 & $38^{\circ} 4445$ & $\begin{array}{lll}38 & 23 & 3.6\end{array}$ & & & \\
\hline 239 & B. D. $+37^{\circ} 2802$ & $\begin{array}{llll}7 & 44 & 13.7\end{array}$ & 14. 2 & & & 329 & $-37^{\circ} 42$ & $\begin{array}{llll}37 & 48 & 54 .\end{array}$ & 54. & & \\
\hline 242 & B. D. $+38^{\circ} 2928$ & $\begin{array}{lll}8 & 40 & 21.8\end{array}$ & 20.6 & & & 330 & $8^{\circ} 4471$ & $3812 \quad 2$ & 25. 2 & & \\
\hline & B. D. $+37^{\circ} 2881$ & & & & & 331 & B. D. & 381 & & & \\
\hline 245 & B. D. $+37^{\circ} 2908$ & $\begin{array}{llll}7 & 21 & 52.2\end{array}$ & 52. 5 & & & 332 & $-37^{\circ} 4330$ & $\begin{array}{llll}37 & 31 & 3\end{array}$ & 34.3 & & \\
\hline & B. D. $+38^{\circ} 2994$ & 2151.2 & 50. & & 50.8 & 335 & B. I & 375 & & & \\
\hline & B. D. $+37^{\circ} 2949$ & & 43. & & 54.6 & 337 & B. D. & 38215 & & & \\
\hline 2 & B. D. $+37^{\circ} 2988$ & $\begin{array}{llll}37 & 48 & 48 . & 0\end{array}$ & 47. 3 & & & 338 & B. D.t & $\begin{array}{llll}38 & 45 & 54.4\end{array}$ & 53. 7 & & \\
\hline & B. D. $+38^{\circ} 3159$ & $17 \quad 28.0$ & 27. 9 & & 26. 7 & 344 & B. $\mathrm{I}$ & 371 & & & \\
\hline & B. D. $+38^{\circ} 3160$ & $\begin{array}{ll}41 & 5.1\end{array}$ & 5. 5 & & & 346 & B. D. & $\begin{array}{lll}38 & 13 & 4\end{array}$ & & & \\
\hline 255 & B. D. $+38^{\circ} 3166$ & $\begin{array}{lll}3 & 23 & 0.8\end{array}$ & 0.9 & & 4. 7 & 347 & B. I & 37 & & & \\
\hline & B. D. $+38^{\circ} 3211$ & 4727.6 & 25. 8 & & & 348 & B. 1 & $\begin{array}{lll}37 & 16 & 4\end{array}$ & & & \\
\hline 259 & B. D. $+37^{\circ} 3176$ & $\begin{array}{ll}57 & 5.9\end{array}$ & 6.3 & 7 & & 349 & B. I & 384 & 35. & & \\
\hline & $+37^{\circ} 3180$ & 741366 & 36.6 & & & 350 & B. I & 385 & & & \\
\hline & $+37^{\circ} 3196$ & 359.5 . & & & & 351 & B. & $\begin{array}{llll}38 & 10 & 1\end{array}$ & 16 & & \\
\hline 263 & B. D. $+38^{\circ} 3254$ & 3 & 27. & & & & B. I & 3745 & 39.2 & & \\
\hline 264 & 3276 & 3 & 48 & & & 353 & B. I & & & & 45.8 \\
\hline 2 & $+38^{\circ} 3280$ & & & & & 354 & B. 1 & $\begin{array}{llll}38 & 22 & 25 . & 0\end{array}$ & 25. & 6.9 & \\
\hline 268 & B. D. $+38^{\circ} 3312$ & 18 & 42. & & 42.6 & 356 & B. D & $\begin{array}{lll}38 & 2 & 5.2\end{array}$ & 5. 9 & 4.5 & \\
\hline 269 & B. D. $+38^{\circ} 3327$ & $\begin{array}{llll}38 & 30 & 20\end{array}$ & & & 20.1 & 357 & B. 1 & $\begin{array}{llll}38 & 6 & 37 . & 0\end{array}$ & 37.2 & 37.0 & \\
\hline 27 & B. D. $+37^{\circ} 3262$ & 372 & 44. 1 & & 47.1 & & B. $\bar{D}$ & $\begin{array}{lll}37 & 45 & 18.6\end{array}$ & 19. 2 & 19.3 & \\
\hline & B. D. $+37^{\circ} 3341$ & & 57.6 & 58.7 & & 360 & B. I & & & & \\
\hline 283 & B. D. $+37^{\circ} 3357$ & 373756 . & 57.2 & 6.8 & & 361 & B. D. $+37^{\circ} 4866$ & $\begin{array}{llll}37 & 28 & 15 & 1\end{array}$ & 15. & & 17. \\
\hline 274 & B. D. $+38^{\circ} 3466$ & 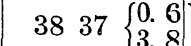 & 3.1 & & 14. 8 & 362 & B. D. $+36^{\circ} 5098$ & $\begin{array}{lll}37 & 6 & 2.3\end{array}$ & & & 15.9 \\
\hline 276 & B. D. $+38^{\circ} 3504$ & $\begin{array}{llll}38 & 32 & 1.2\end{array}$ & 59.1 & 56.3 & 51.1 & 363 & B. D. $+37^{\circ} 4898$ & $3720\left\{\begin{array}{l}14.0 \\
13.8\end{array}\right.$ & $\{15$. & & \\
\hline & B. D. $+38^{\circ} 3506$ & $\begin{array}{ll}31 & 10.2\end{array}$ & 9.4 & & & 365 & B. D. $+38^{\circ} 5091$ & & & $\begin{array}{llll}34 & 0\end{array}$ & \\
\hline & B. D. $+37^{\circ} 3394$ & $\begin{array}{lll}7 & 21 . & 1\end{array}$ & 20.9 & & & 366 & B. D & 6 & 20.2 & & \\
\hline & B. D. $+37^{\circ} 3417$ & $\begin{array}{lll}37 & 8 & 59.3\end{array}$ & 63.4 & 63.8 & & 367 & $+38^{\circ} 5108$ & & 8. 8 & 8.8 & \\
\hline & B. D. $+37^{\circ} 3432$ & $+37 \quad 2317.7$ & 18. 2 & & 19.0 & 368 & B. D. $+37^{\circ} 4912$ & +374451.5 & 52.3 & 52.5 & \\
\hline
\end{tabular}


The outlines of that method had been suggested by Dr. F. Küstner, then an observer in the Berlin Observatory, and which he has given in a paper to be found in the Astronomische Nachrichten, Band 126, No. 3015. It has been called the polygon method.

A number of astronomers, observing with zenith telescopes, were using this method by which to determine the correction to the aberration constant adopted in the reduction of their star positions, and it was decided to carry on a similar series of observations with the prime vertical transit.

After some preliminary study had been given to the subject, the conclusion was reached that the maximum number of stars which could be included in each group was four. Those who have used the polygon method in connection with zenith telescopes have usually included from 8 to 10 pairs in each group, thus giving them from 16 to 20 latitudes upon which to base an instantaneous latitude for a night's work.

But it is not practicable when observing with a prime vertical transit to obtain that many latitudes both in the evening and early morning, especially in the summer, when the nights are short. Therefore it became necessary not to include in each group more than four stars. In the following table is shown the time of beginning, ending, and elapsed interval of time between the first and last star of each group. These are expressed in sidereal time.

\begin{tabular}{|c|c|c|c|}
\hline Group & $\begin{array}{c}\text { Time of } \\
\text { beginning }\end{array}$ & $\begin{array}{l}\text { Time of } \\
\text { ending }\end{array}$ & Interval \\
\hline 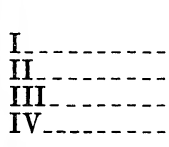 & $\begin{array}{rl}h & m \\
5 & 04 \\
12 & 22 \\
16 & 42 \\
20 & 51\end{array}$ & $\begin{array}{rl}h & m \\
7 & 11 \\
15 & 30 \\
19 & 17 \\
23 & 18\end{array}$ & $\begin{array}{cc}h & m \\
2 & 07 \\
3 & 8 \\
2 & 35 \\
2 & 27\end{array}$ \\
\hline
\end{tabular}

In selecting stars to be included in groups the first consideration was that the mean of their right ascensions should be as near as possible to $6,14,18$, and 22 hours sidereal time, respectively. The next consideration was to select the stars so that the average magnitude of each group would be nearly the same.

The average magnitude of the four groups is 6.4, 7.1, 7.0, and 6.7, respectively. With the exception of $\alpha$ Lyræ, the selected stars range in magnitude between 5.3 and 7.6. With respect to $\alpha$ Lyræ its magnitude was diminished, by means of a wire screen placed in front of the object glass, to about 6.5. 
In the following table are given the names, magnitudes, and approximate right ascensions and declinations of the 16 stars used:

TABLE XVI

\begin{tabular}{|c|c|c|c|c|c|c|}
\hline & Name & Mag. & R. A., & , 1900 & Dec., & 1900 \\
\hline $\begin{aligned} \text { Group I. Star } \ldots . . . . & \text { I...- } \\
& \text { II...- } \\
& \text { III..- } \\
& \text { IV.. }\end{aligned}$ & $\begin{array}{l}\text { B. D. }+38^{\circ} \cdot 1357 \\
40 \text { Aurigæ } \\
\text { B. D. }+38^{\circ} \cdot 1382 \\
\text { B. D. }+38^{\circ}: 1539\end{array}$ & $\begin{array}{l}\text { 7. } 2 \\
\text { 5. } 3 \\
\text { 7. } 0 \\
\text { 5. } 9\end{array}$ & $\begin{array}{lr}h & m \\
5 & 55 \\
5 & 59 \\
6 & 0 \\
6 & 29\end{array}$ & $\begin{array}{l}s \\
11 \\
41 \\
39 \\
40\end{array}$ & $\begin{array}{r}\circ \\
+38 \\
+38 \\
+38 \\
+38\end{array}$ & $\begin{aligned} & \\
& 43 . 0 \\
& 29 . 5 \\
& 5.6 \\
& 31 . 6\end{aligned}$ \\
\hline $\begin{aligned} \text { Group II........... } & \text { I... } \\
& \text { II... } \\
& \text { III. } \\
& \text { IV.. }\end{aligned}$ & $\begin{array}{l}\text { B. D. }+37^{\circ}: 2457 \\
\text { B. D. }+38^{\circ} 2477 \\
\text { B. D. }+38^{\circ}: 2479 \\
\text { B. D. }+37^{\circ}: 2528\end{array}$ & $\begin{array}{l}\text { 6. } 4 \\
\text { 7. } 6 \\
\text { 7. } 1 \\
\text { 7. } 4\end{array}$ & $\begin{array}{ll}13 & 45 \\
13 & 41 \\
13 & 43 \\
14 & 19\end{array}$ & $\begin{array}{l}24 \\
40 \\
11 \\
20\end{array}$ & $\begin{array}{l}+37 \\
+38 \\
+38 \\
+37\end{array}$ & $\begin{array}{r}\text { 7. } 7 \\
\text { 1. } 6 \\
23.5 \\
\text { 39. } 6\end{array}$ \\
\hline $\begin{aligned} \text { Group III.......... } & \text { I...- } \\
& \text { II...- } \\
& \text { III.-- } \\
& \text { IV.- }\end{aligned}$ & $\begin{array}{l}\text { B. D. }+38^{\circ}: 2984 \\
\text { B. D. }+38^{\circ}: 3095 \\
\text { B. D. }+38^{\circ}: 3219 \\
\alpha \text { Lyræ* }\end{array}$ & $\begin{array}{l}\text { 7. } 3 \\
6.4 \\
\text { 7. } 6 \\
0.1\end{array}$ & $\begin{array}{rr}17 & 38 \\
18 & 6 \\
18 & 30 \\
18 & 33\end{array}$ & $\begin{array}{l}51 \\
19 \\
46 \\
33\end{array}$ & $\begin{array}{l}+38 \\
+38 \\
+38 \\
+38\end{array}$ & $\begin{array}{r}6.9 \\
27.1 \\
21.5 \\
41.4\end{array}$ \\
\hline $\begin{aligned} \text { Group IV.......... } & \text { I...- } \\
& \text { II...- } \\
& \text { IV..- }\end{aligned}$ & $\begin{array}{l}\text { B. D. }+37^{\circ}: 4427 \\
\text { B. D. }+37^{\circ}: 4506 \\
\text { B. D. }+38^{\circ}: 4727 \\
\text { B. D. }+37^{\circ} 4560\end{array}$ & $\begin{array}{l}5.8 \\
7.4 \\
7.5 \\
6.2\end{array}$ & $\begin{array}{lr}21 & 44 \\
22 & 7 \\
22 & 13 \\
22 & 19\end{array}$ & $\begin{array}{l}20 \\
26 \\
29 \\
28\end{array}$ & $\begin{array}{l}+38 \\
+37 \\
+38 \\
+38\end{array}$ & $\begin{array}{r}\text { 11. } 0 \\
55.4 \\
31.5 \\
3.8\end{array}$ \\
\hline
\end{tabular}

In the reduction of the declinations of the above stars from observed to mean place the values of log. $A$ and log. $B$ of the Besselian star numbers, which were used, were taken from the American Ephemeris, and are based upon the constants of Struve-Peters. The values of $\log$. $C$ and $\log$. $D$, also used in the reductions, were not those which appear in the American Ephemeris, but to each of them was applied the logarithm of the ratio between $20.5^{\prime \prime}$ and the aberration constant published in each yearly issue of the American Ephemeris. In that publication for 1912 a new value of the aberration constant was introduced, and also a new value for the nutation constant. All observations of these stars made in that year were reduced with the STRUVE-PETER's constants, and also with an aberration constant of $20.5^{\prime \prime}$.

After these stars had been selected a search was made through all the star catalogues in the library for published positions of them, for the purpose of obtaining fairly definitive declinations and proper motions in that coordinate. No attempt was made toward securing definitive right ascensions.

An examination of the catalogues indicated, in a few instances, that the material was rather meager upon which to base definitive declinations and the proper motions.

\section{LIST OF STAR CATALOGUE USED}

Below is given a list of the star catalogues in which were found positions in declination of the 15 stars observed by the polygon method. The right ascension and the declination of a Lyræ were taken from the Boss Preliminary General Catalogue, but the proper motion used was not the value given in that catalogue but that which had been adopted at the beginning of the work in 1893, namely, $+.275^{\prime \prime}$ per year.

Instead of publishing the complete title of each of these catalogues, it was decided to print the name of the author of the catalogue, or when necessary, name of the observatory at which the stars included in the catalogue were observed. 
Therefore in the following list the name of the author and the epoch of the catalogue will serve for identification purposes:

\begin{tabular}{|c|c|c|c|c|c|}
\hline Name of catalogue & Epoch & Name of catalogue & Epoch & Name of catalogue & Epoch \\
\hline 1. Piazzi & 1800 & 13. Pulkova. & 1855 & 25. Respighi_- & 1875 \\
\hline 2. Lalande... & 1800 & 14. Paris & 1855 & 26. Greenwich- & 1880 \\
\hline 3. Groombridge & 1810 & 15. Yarnall & 1860 & 27. Washington- & 1883 \\
\hline 4. Weisse-Bessel_ & 1825 & 16. Greenwich & 1864 & 28. Pulkova_... & 1885 \\
\hline 5. Madras ..... & 1835 & 17. Brussels _- & 1865 & 29. Strassburg & 1885 \\
\hline 6. Rumker & 1836 & 18. Glasgow & 1870 & 30. Glasgow -- & 1890 \\
\hline 7. Armagh & 1840 & 19. Greenwich & 1872 & 31. Dunsink... & 1890 \\
\hline 8. Radcliffe & 1845 & 20. Lund & 1875 & 32. Cincinnati & 1890 \\
\hline 9. Paris & 1845 & 21. Armagh & 1875 & 33. Greenwich & 1890 \\
\hline 10. Madras & 1850 & 22. Eastman & 1875 & 34. Cape & 1890 \\
\hline 11. Rumker & 1850 & 23. Paris & 1875 & 35. Cincinnati & 1900 \\
\hline 12. Bonn VI & 1855 & 24. Pulkova & 1875 & 36. Washington & 1900 \\
\hline
\end{tabular}

Nоте.-No. 27. Prime vertical observations made at Naval Observatory 1882-1884, Naval Observatory Publications, Vol. III, second series.

No. 36. Prime vertical observations published in this volume.

The weights which were given to each of the foregoing catalogues, according to the number of observations of each star, and based very largely upon the relative magnitudes of their respective probable errors, are given in Table XVII. That table is based upon a similar one which was prepared by Mr. H. B. Hedrick. This latter table will be found on page 424 of his publication entitled "Catalogue of Zodiacal Stars for the Epochs 1900 and 1920," Volume VIII, Part III, of Astronomical Papers prepared for the use of the American Ephemeris.

There are other catalogues included in Table XVII which are not included in the HEDRICK table. In those cases the weights as assigned are based in so far as practicable on the same system.

The catalogue positions of the selected latitude stars, with the exception of $\alpha$ Lyræ, were reduced to the system of the New Fundamental Catalogue of Doctor Auwers, inasmuch as he has published systematic corrections to practically all the catalogues from which positions of the latitude stars were obtained.

These corrections were taken from his tables in Astronomische Abhandlungen als Ergänzungs hefte zu den Astronomischen Nachrichten, No. 7. In a few instances corrections do not appear in that publication for some of the catalogues used, and in those cases the declinations taken from the catalogues were not corrected. These corrections will be found in column 7, Table XVIII.

A least square solution was made to obtain the most probable declination and proper motion of each star. It was noticed while discussing these star places that the second star in Group III had a proper motion in declination of nearly $50^{\prime \prime}$ per century which had not been previously announced. A discussion of the then existing material concerning the star was published by the writer in the Astronomical Journal, Nos. 584, 585. 
PRIME VERTICAL TRANSIT INSTRUMENT.

TaBLE XVII.-Table of Weights in Declination

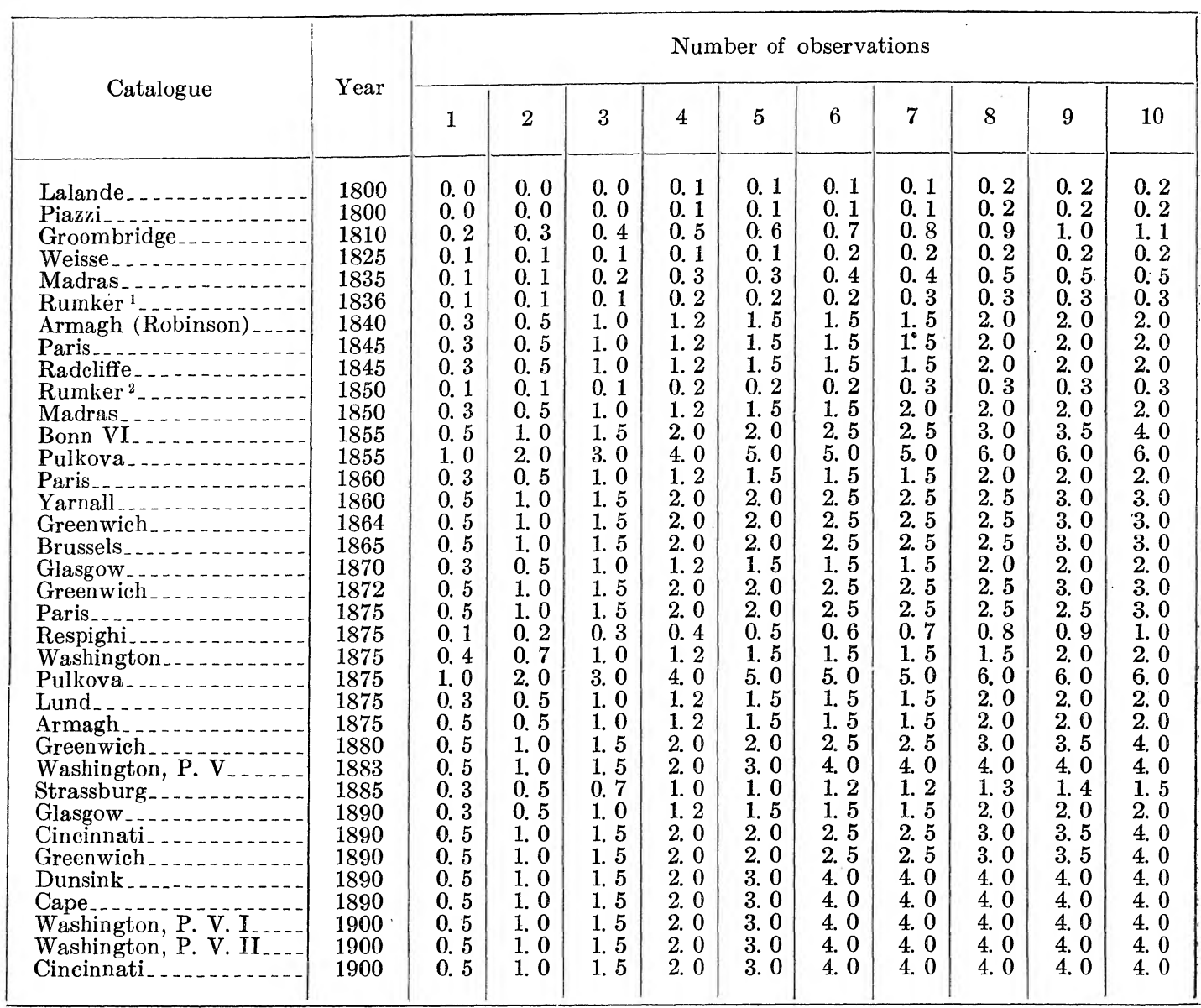

The selected epoch for the reduction is 1900. The right ascensions and the declinations which were assumed for 1900 were taken from the following source:

Lund A. G. Catalogue, 1875 . $+34^{\circ} 30^{\prime}$ to $+40^{\circ} 10^{\prime}$.

By the aid of those values of the coordinates of the 15 stars brought up to 1900 the precessions in declination, the secular variations, and the third terms were computed, using Newcomb's value of the precession. The second and third terms in the precession were taken from Doctor Becker's Tables, Strassburg (Vol. 2).

The next step was to reduce the provisional declinations for 1900, with an assumed proper motion, to the epoch of every catalogue containing an observation of the given star.

In the formulæ below

$\delta=$ the declination of the star at epoch of catalogue,

$\delta_{1900}=$ the assumed declination of the star for 1900,

$\frac{d \delta}{d t}=P \cos a+\mu_{0}^{\prime}$ in which $a$ is the right ascension of the star for 1900 and $P$ the value of NEwcomb's precession for the same epoch.

$$
\delta=\delta_{1900}+\left[\frac{d \delta}{d t}\right](\tau-1900)+\frac{1}{2}\left[\frac{d^{2} \delta}{d t^{2}}\right](\tau-1900)^{2}+\frac{1}{6}\left[\frac{d^{3} \delta}{d t^{3}}\right](\tau-1900) .^{3}
$$


In addition we have the following:

$\tau=$ the epoch of a catalogue declination,

$t=$ the date of observation,

$\mu_{0}^{\prime}=$ the assumed proper motion,

$n=$ the difference between the corrected catalogue declination of any of these stars and its provisional value for the epoch of the catalogue,

$p=$ the weight given to the catalogue declination,

$\Delta \delta_{0}=$ the correction for 1900 to the provisional declination,

$\Delta \mu^{\prime}{ }_{0}=$ the correction to the assumed proper motion.

Let $t_{0}$ equal the weighted mean of the epochs of the several catalogues, and $t_{1}, t_{2} \ldots \ldots t_{\mathrm{n}}$ equal the date of observations in the catalogues,

$$
T_{1}, T_{2} \ldots \ldots T_{\mathrm{n}}=\left(t_{1}-t_{0}\right),\left(t_{2}-t_{0}\right) \ldots \ldots\left(t_{\mathrm{n}}-t_{0}\right) .
$$

$\Sigma p . T$ should be equal to zero.

Then we have,

and,

$$
\Delta \delta_{0}=\frac{\Sigma p n}{\Sigma p}
$$

The check formula is

$$
\Delta \mu_{0}^{\prime}=\frac{\Sigma p T n}{\Sigma p T^{2}}
$$

$$
\Sigma p v v=\Sigma p n n-(\Sigma p n) \Delta \delta_{0}-(\Sigma p T n) \Delta \mu_{0}^{\prime},
$$

in which $v$ is the residual between a corrected catalogue declination and a corrected provisional declination,

$$
\text { and, }
$$

$$
\Delta \delta_{1900}=\Delta \delta_{0}+\left(1900-t_{0}\right) \Delta \mu^{\prime}{ }_{0}
$$

\begin{tabular}{|c|c|c|c|c|c|c|c|c|}
\hline Catalogue and No. & $\begin{array}{c}n= \\
\text { C. }- \text { A. }\end{array}$ & $t$ & $n$ & $p$ & $p t$ & $p n$ & $T$ & $p T$ \\
\hline \multirow[t]{2}{*}{$\begin{array}{l}\text { 1. Lalaude } 11319 \\
\text { 2. Radcliffe } 16111 \\
\text { 3. Lund } 3055 \\
\text { 4. Pulkova } 1830 \\
\text { 5. Washington P. V. I } \\
\text { 6. Washington P. V. II }\end{array}$} & $\begin{aligned} & \prime \prime \\
&- 8.28 \\
&+ .82 \\
&-.02 \\
&+.11 \\
&+.08 \\
&+.05\end{aligned}$ & $\begin{array}{r}-3.9 \\
+\quad 51.1 \\
+79.9 \\
+\quad 75.1 \\
+104.8 \\
+112.9\end{array}$ & $\begin{array}{l}-8.28 \\
+.82 \\
.02 \\
+.11 \\
+.08 \\
+.05\end{array}$ & $\begin{array}{l}0 \\
0.3 \\
0.5 \\
4.0 \\
4.0 \\
4.0\end{array}$ & $\begin{array}{r}0 \\
15.33 \\
39.95 \\
300.40 \\
419.20 \\
451.60\end{array}$ & $\begin{array}{r}0 \\
+0.246 \\
+.010 \\
+.440 \\
+.320 \\
+\quad .200\end{array}$ & $\begin{array}{r}-44.72 \\
-15.92 \\
-2.07 \\
+\quad 8.98 \\
+17.08\end{array}$ & $\begin{array}{r}-13.42 \\
-\quad 7.96 \\
-82.88 \\
+35.92 \\
+68.32\end{array}$ \\
\hline & & & & $\begin{array}{l}\Sigma p \\
12.8\end{array}$ & $\begin{array}{c}\Sigma p t \\
1226.48\end{array}$ & $\begin{array}{c}\Sigma p n \\
+1.196\end{array}$ & & $\begin{array}{c}\Sigma p T \\
-\quad 0.02\end{array}$ \\
\hline
\end{tabular}

In the following example are shown the several steps used in obtaining the best definite declinations for the 15 stars, and also their proper motions in that coordinate:

Star I, Group I $=$ B. D. $+38^{\circ} 1357$.

Assumed place 1900. $\alpha 5^{\mathrm{h}} 55^{\mathrm{m}} 10^{\mathrm{s}} .99 . \delta+38^{\circ} 43^{\prime} 1.31^{\prime \prime}, \mu_{\mathrm{o}}^{\prime}=0.000^{\prime \prime}$.

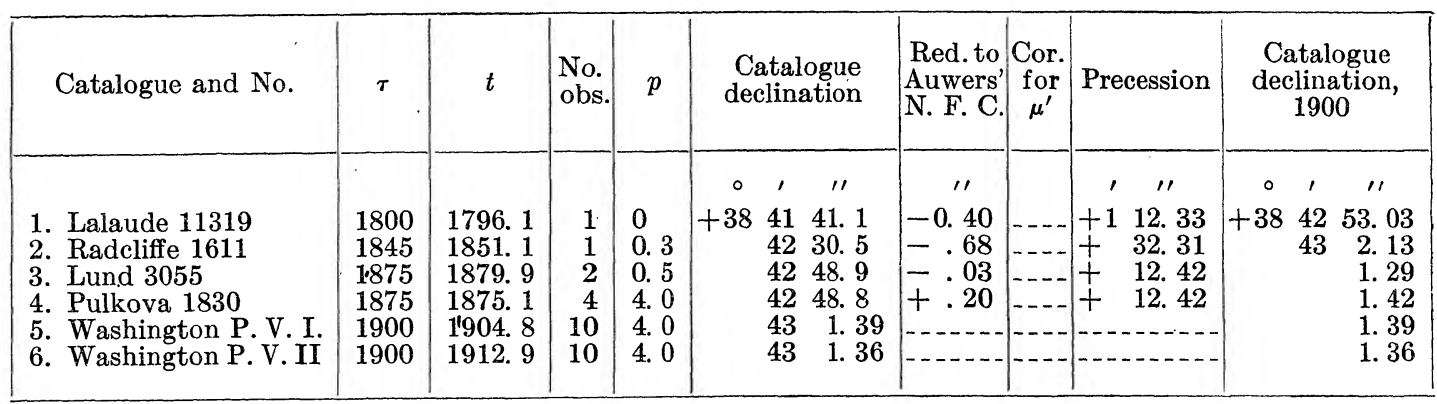




\begin{tabular}{|c|c|c|c|c|c|c|c|c|}
\hline Catalogue and No. & $p T n$ & $T^{2}$ & $p T^{2}$ & $n^{2}$ & $p n^{2}$ & $v$ & $v v$ & $p v v$ \\
\hline $\begin{array}{l}\text { 1. Lalaude } 11319 \\
\text { 2. Radcliffe } 1611 \\
\text { 3. Lund } 3055 \\
\text { 4. Pulkova } 1830 \\
\text { 5. Washington P. V. I } \\
\text { 6. Washington P. V. II }\end{array}$ & $\begin{array}{l}-11.004 \\
+\quad .159 \\
+9.117 \\
+\quad 2.874 \\
+\quad 3.416\end{array}$ & $\begin{array}{r}1999.88 \\
253.45 \\
429.32 \\
80.64 \\
291.73\end{array}$ & $\begin{array}{r}599.96 \\
126.72 \\
1717.28 \\
322.56 \\
1166.92\end{array}$ & $\begin{array}{l}0.6742 \\
.0004 \\
.0121 \\
.0064 \\
.0025\end{array}$ & $\begin{array}{r}0.2017 \\
.0002 \\
.0484 \\
.0256 \\
.0100\end{array}$ & $\begin{array}{l}+0.57 \\
-.17 \\
-.06 \\
+.02 \\
+.02\end{array}$ & $\begin{array}{r}0.3249 \\
.0289 \\
.0036 \\
.0004 \\
.0000\end{array}$ & $\begin{array}{r}0.0975 \\
.0144 \\
.0144 \\
.0016 \\
.0016\end{array}$ \\
\hline & $\begin{array}{c}\Sigma p T n \\
-13.672\end{array}$ & $\begin{array}{c}\Sigma p T^{2} \\
3933.44\end{array}$ & & & $\begin{array}{c}\Sigma p n^{2} \\
0.2859\end{array}$ & & * & $\begin{array}{c}\Sigma p v v \\
0.1294\end{array}$ \\
\hline
\end{tabular}

$$
\begin{aligned}
& t_{\mathrm{o}}=\frac{1226.48}{12.8}=1895.82 \\
& \text { Assumed } \delta=+38^{\circ} 43^{\prime} 1.31^{\prime \prime} \text { Assumed } \mu^{\prime} \quad 0.0000^{\prime \prime} \\
& \Delta \delta_{\mathrm{o}}=\frac{+1.196}{12.8}=+0.093^{\prime \prime} \\
& \text { Final } \\
& \Delta \delta=\quad+0.08 \\
& \Delta \mu^{\prime}{ }_{0}=\frac{-13.672}{3933.44}=-0.0035^{\prime \prime}
\end{aligned}
$$

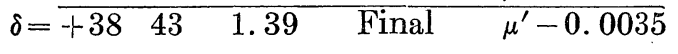

$$
\begin{aligned}
& \Sigma p n^{2}=+0.2859 \\
& \Delta \delta_{1900}=+0.093^{\prime \prime}-0.0035^{\prime \prime}(1900-1895.82)=+0.078^{\prime \prime} \\
& -(\Sigma p n) \Delta \delta_{\mathrm{o}}=-.1112 \\
& -(\dot{\Sigma} p T n) \Delta \mu_{0}^{\prime}=-.0479 \\
& \text { Check }=.1268
\end{aligned}
$$

In Table XVIII there are presented the catalogue declinations for 1900 of each of the 15 stars from which material these definitive declinations and proper motions were obtained, in accordance with the example just given.

In Table XIX are given the declinations and the proper motions for 1900 of the 16 stars which are used in obtaining latitudes of the instrument during the period 1904-1912, inclusive.

At the bottom of the table is shown the mean declination of each of the stars for each of the years in the above period.

In Table XX will be found the logarithms of the BesseL's star constants which were used in reducing an observed declination from the date of observation to the beginning of the year.

In Table XXI is presented a comparison between the calculated declinations and the mean of all observed positions obtained with the instrument in the interval between 1904 and 1912. The observed positions have been corrected for the variation of the latitude, and each has been reduced to 1900, using the proper motions found above. The number of observations of each star, with the respective mean date of observation, is also given in the same table.

In the last column of Table XXI will be found the adjusted declinations deduced from the observations in this series, as explained under Group Corrections (page A CCII).

It should also be stated that in each case from 5 to 10 observations made with the prime vertical transit have been used in obtaining the preliminary declinations. That became necessary in view of the lack of other modern observations of these 15 stars. 
TABLe XVIII.-Mean Declinations of 15 Stars, Their Proper Motions, and Catalogues from Which Obtained.-Definitive Positions, 1900.0

\begin{tabular}{|c|c|c|c|c|c|c|c|c|c|c|}
\hline Catalogue and No. & $\begin{array}{l}\text { Cat. } \\
\text { epoch. }\end{array}$ & $\begin{array}{c}\text { Epoch } \\
\text { of } \\
\text { obs. }\end{array}$ & $\begin{array}{l}\text { No. } \\
\text { obs. }\end{array}$ & Wt. & $\begin{array}{l}\text { Catalogue } \\
\text { declination }\end{array}$ & $\begin{array}{c}\text { Reduction } \\
\text { to } 1900 .\end{array}$ & $\begin{array}{l}\text { Cor. } \\
\text { A. G. } \\
\text { S. }\end{array}$ & $\begin{array}{l}\text { Cor. } \\
\text { p. m. }\end{array}$ & $\begin{array}{c}1900 \\
\text { declination }\end{array}$ & $\mathrm{O}-\mathrm{C}$ \\
\hline
\end{tabular}

1. B. D. $+38^{\circ} 1357 . \alpha=5^{\mathrm{h}} 55^{\mathrm{m}} 11^{\mathrm{s}}, \delta=+38^{\circ} 43^{\prime} 1.39^{\prime \prime}, \mu^{\prime}=-0.0035^{\prime \prime}$

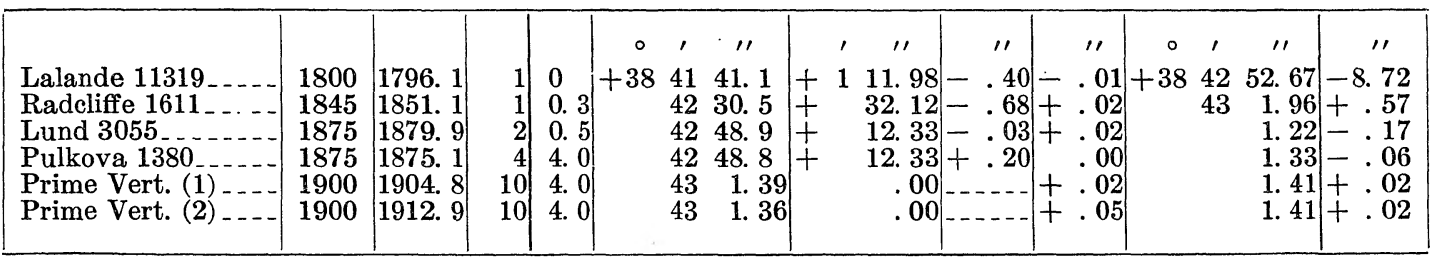

2. 40 Aurigæ. $\alpha=5^{\text {h }} 59^{\mathrm{m}} 41^{\mathrm{s}}, \delta=+38^{\circ} 29^{\prime} 30.50^{\prime \prime}, \mu^{\prime}=-0.0471^{\prime \prime}$

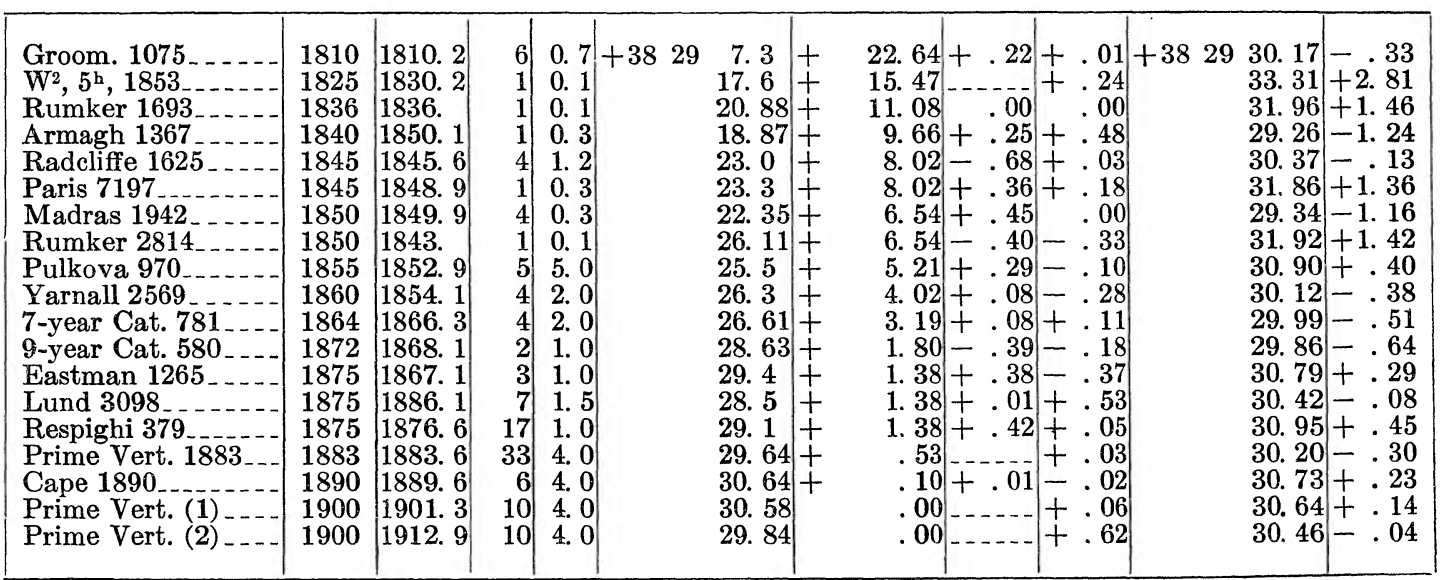

3. B. D. $+38^{\circ} 1382 . \quad \alpha=6^{\mathrm{h}} 0^{\mathrm{m}} 39^{\mathrm{s}}, \delta=+38^{\circ} 5^{\prime} 33.95^{\prime \prime}, \mu^{\prime}=-0.0060^{\prime \prime}$

\begin{tabular}{|c|c|c|c|c|c|c|c|c|c|c|c|c|c|}
\hline Lalande 11508 & 1800 & 1796.1 & & 0 & +38 & $\begin{array}{lll}5 & 14.8\end{array}$ & + & 23.68 & 40 & - & +38 & 538.10 & +4.15 \\
\hline Pi. Vh, 318 . & 1800 & 1804.0 & 5 & .1 & & 10.8 & + & 23. 68 & .40 & 02 & & 34. 10 & +.15 \\
\hline Madras 2276 & 1835 & 1836. 5 & 4 & .3 & & 23. 65 & t+ & 8. 56 & 66 & 01 & & 32.88 & -1.07 \\
\hline Armagh 1371 & 1840 & 1852.5 & 2 & .5 & & 26. 99 & $\begin{array}{lll}+ \\
+\end{array}$ & 7. 00 & 36 & 08 & & 33.71 & -.24 \\
\hline Radcliffe $1634_{2}$ & 1845 & 1849. 1 & 4. & 1. 2 & & 29. 4 & + & 5. 59 & -.71 & 02 & & 34. 30 & + \\
\hline Yarnall 2574_. & 1860 & 1865. 1 & 3 & 1. $\overline{5}$ & & 31.7 & t+ & 2. 26 & +.08 & 03 & & 34. 07 & $1+$ \\
\hline Brussels 2461 & 1865 & 1868. 1 & 3 & 1. 5 & & 31. 92 & t & 1. 45 & +.10 & 01 & & 33.48 & 47 \\
\hline Lund 3107 & 1875 & 1888. 3 & 5 & 1.5 & & 33.3 & t+ & .29 & -.01 & +.05 & & 33. 63 & -.32 \\
\hline Cincinnati 1156 & 1900 & 1900.1 & 3 & 1. 5 & & 34. 7 & & .00 & & .00 & & 34. 70 & + \\
\hline Prime Vert. (1) & 1900 & 1904. 6 & 10 & 4. 0 & & 34.01 & & .00 & & +.02 & & 34. 01 & $1+$ \\
\hline Prime Vert. (2) & 1900 & 1912. 6 & 10 & 4. 0 & & 33. 68 & & .00 & & & & 33. 76 & - \\
\hline
\end{tabular}

4. B. D. $+38^{\circ} 1539 . \alpha=6^{\text {h }} 29^{\mathrm{m}} 40^{\mathrm{s}}, \delta=+38^{\circ} 31^{\prime} 34.64^{\prime \prime}, \mu^{\prime}=-0.0262^{\prime \prime}$

\begin{tabular}{|c|c|c|c|c|c|c|c|c|c|c|c|c|c|}
\hline Lalande 1256 & 1800 & 1794. 0 & 1 & 0 & +38 & 3523.6 & -3 & 51.68 & -.40 & -.16 & +3831 & 31.36 & -3.28 \\
\hline Groom. $1190^{-}$ & 1810 & 1813. 1 & 6 & .7 & & $\begin{array}{ll}35 & 5.9\end{array}$ & & 31.19 & +.22 & .08 & & 35.01 & +.37 \\
\hline Radcliffe 1768 & 1845 & 1851. 1 & 4 & 1. 2 & & 3350.5 & -2 & 14. 79 & -.71 & + & & 35.16 & \\
\hline Paris 7898 & 1860 & 1859.0 & 2 & .5 & & 33 14. 6 & -1 & 39. 82 & +.30 & $1-$ & & 35. 05 & $5+.41$ \\
\hline Yarnall $2730_{2}$ & 1860 & 1847. 7 & 5 & 2.0 & & 3314.7 & -1 & 39.82 & .10 & -.32 & & 34. 66 & \\
\hline 7-year Cat. 841 & 1864 & 1867.9 & 1 & .5 & & $\begin{array}{ll}33 & 3.34\end{array}$ & -1 & 30.26 & .07 & +.10 & & 33.25 & -1.39 \\
\hline 9-year Cat. 636 & 1872 & 1868. 1 & 4 & 2.0 & & 3245.54 & -1 & 10.87 & .39 & - & & 34. 18 & $3-.46$ \\
\hline Respighi 405 & 1875 & 1876. 0 & 16 & 1. 0 & & 37.24 & -1 & 3. 50 & + & + & & 34. 27 & -.37 \\
\hline Paris 7898... & 1875 & 1881. 0 & 2 & 1. 0 & & 38.6 & -1 & 3. 50 & 05 & + & & 35. 31 & $1+$ \\
\hline Lund $3390_{\ldots} \ldots$ & 1875 & 1885. 1 & 3 & 1. 0 & & 38. 3 & -1 & 3.50 & + & + & & 35.09 & \\
\hline 10-year Cat. 2019 & 1890 & 1890.1 & 5 & 2. 0 & & $32 \quad 0.12$ & - & 25.85 & -.20 & .00 & & 34. 07 & $7+$ \\
\hline Prime Vert. (1) - & 1900 & 1901. 2 & 5 & 3. 0 & & 3134.60 & & .00 & & 03 & & 34.63 & \\
\hline Prime Vert. (2) & 1900 & $|1912.9|$ & 10 & 4. 0 & & 34.53 & & & & +.34 & & 34. 87 & $7+.23$ \\
\hline
\end{tabular}


TABLE XVIII.-Mean Declinations of 15 Stars, Their Proper Motions, and Catalogues from Which Obtained.-Definitive Positions, 1900.0-Continued

\begin{tabular}{|c|c|c|c|c|c|c|c|c|c|c|}
\hline Catalogue and No. & $\begin{array}{l}\text { Cat. } \\
\text { epoch. }\end{array}$ & $\begin{array}{c}\text { Epoch } \\
\text { of } \\
\text { obs. }\end{array}$ & $\begin{array}{l}\text { No. } \\
\text { obs. }\end{array}$ & Wt. & $\begin{array}{r}\text { Catalogue } \\
\text { declination }\end{array}$ & $\begin{array}{c}\text { Reduction } \\
\text { to } 1900 .\end{array}$ & $\begin{array}{l}\text { Cor. } \\
\text { A. G. } \\
\text { S. }\end{array}$ & $\begin{array}{l}\text { Cor. } \\
\text { p. m. }\end{array}$ & $\begin{array}{c}1900 \\
\text { declination }\end{array}$ & $\mathrm{O}-\mathrm{C}$ \\
\hline
\end{tabular}

5. B. D. $+38^{\circ} 2477 . \quad \alpha=13^{\text {b }} 41^{\mathrm{m}} 40^{\mathrm{s}}, \delta=+38^{\circ} 1^{\prime} 27.59^{\prime \prime}, \mu^{\prime}=-0.0606^{\prime \prime}$

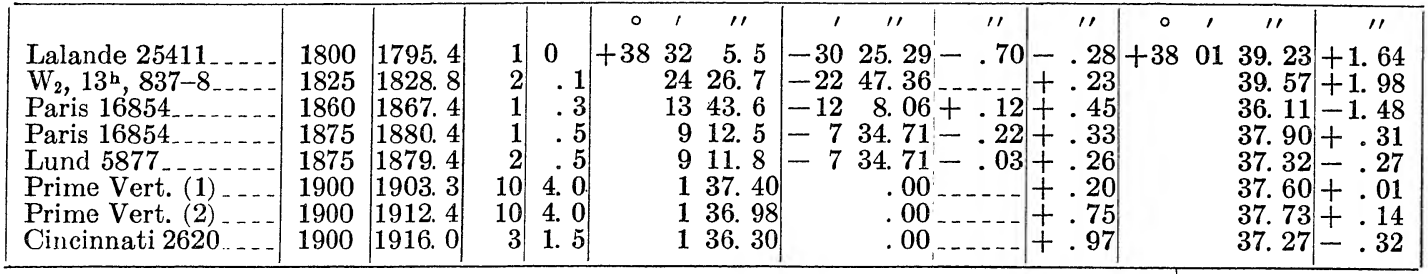

6. B. D. $+38^{\circ} 2479 . \quad \alpha=13^{\text {b }} 43^{\mathrm{m}} 11^{\mathrm{s}}, \delta=+38^{\circ} 23^{\prime} 32.91^{\prime \prime}, \mu^{\prime}=-0.0104^{\prime \prime}$

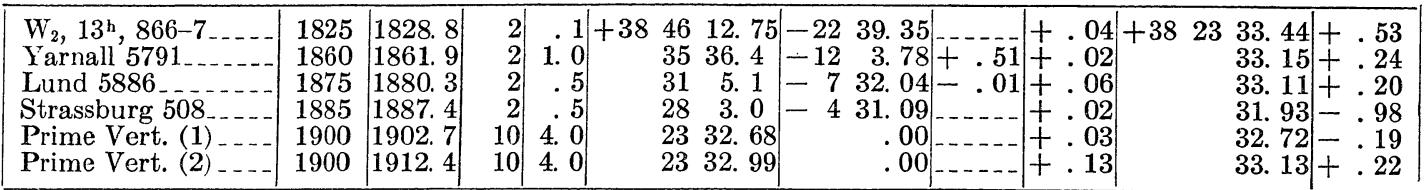

7. B. D. $+37^{\circ} 2457$. $\alpha=13^{\text {b }} 45^{\mathrm{m}} 24^{\mathrm{s}}, \delta=+37^{\circ} 7^{\prime} 43.69^{\prime \prime}, \mu^{\prime}=+0.0163^{\prime \prime}$

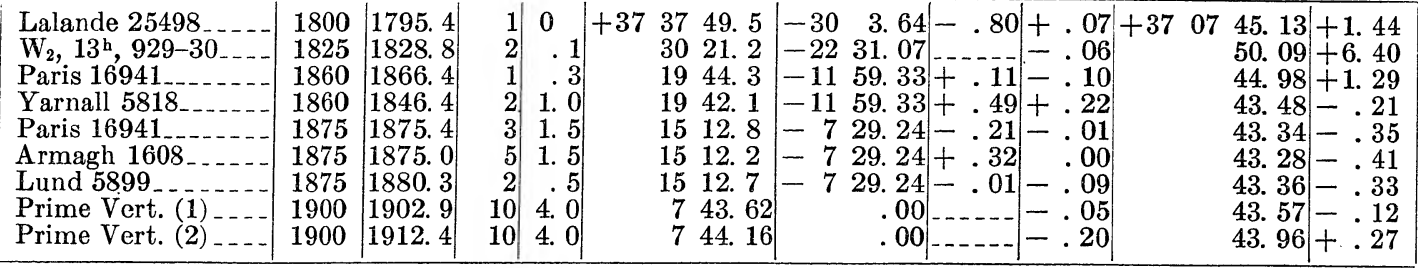

8. B. D. $+37^{\circ} 2528$. $\alpha=14^{\text {h }} 19^{\text {m }} 20^{\text {s }}, \delta=+37^{\circ} 39^{\prime} 33.09^{\prime \prime}, \mu^{\prime}=+0.0398^{\prime \prime}$

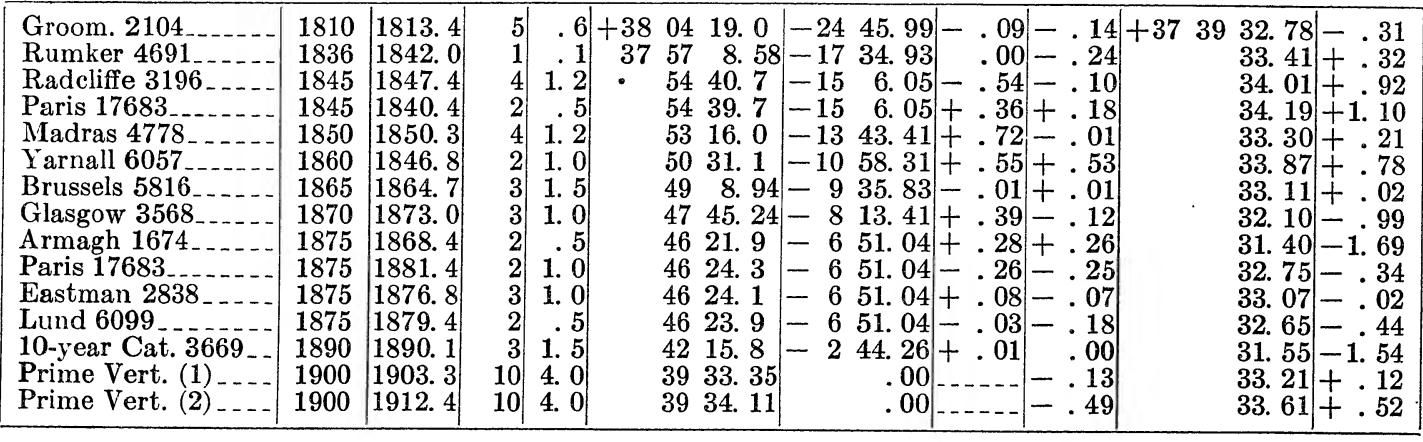

9. B. D. $+38^{\circ} 2984 . \quad \alpha=17^{\mathrm{b}} 38^{\mathrm{m}} 51^{\mathrm{s}}, \delta=+38^{\circ} 6^{\prime} 53.11^{\prime \prime}, \mu^{\prime}=+0.1089^{\prime \prime}$

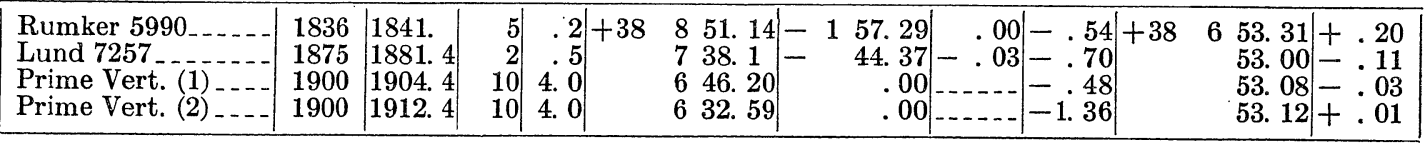

10. B. D. $+38^{\circ} 3095$. $\alpha=18^{\mathrm{b}} 6^{\mathrm{m}} 19^{\mathrm{s}}, \delta=+38^{\prime} 27^{\circ} 4.87^{\prime \prime}, \mu^{\prime}=-0.4591^{\prime \prime}$

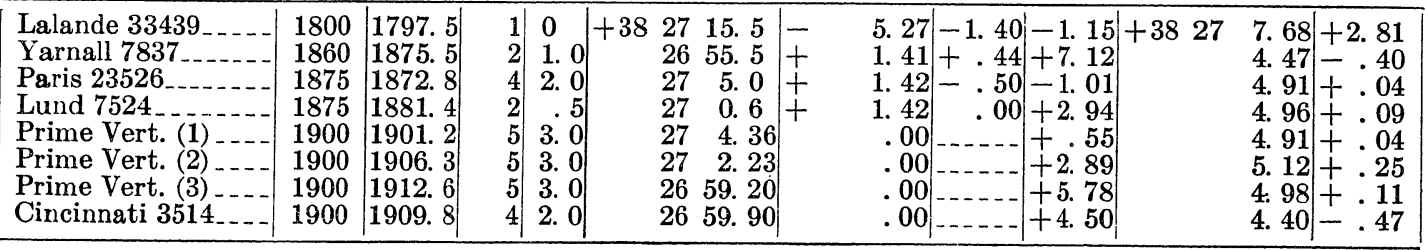


TABLE XVIII.-Mean Declinations of 15 Stars, Their Proper Motions, and Catalogues from Which Obtained.-Definitive Positions, 1900.0-Continued

\begin{tabular}{|c|c|c|c|c|c|c|c|c|c|c|}
\hline Catalogue and No. & $\begin{array}{l}\text { Cat. } \\
\text { epoch. }\end{array}$ & $\begin{array}{c}\text { Epoch } \\
\text { of } \\
\text { obs. }\end{array}$ & $\begin{array}{l}\text { No. } \\
\text { obs. }\end{array}$ & Wt. & $\begin{array}{l}\text { Catalogue } \\
\text { declination }\end{array}$ & $\begin{array}{l}\text { Reduction } \\
\text { to } 1900 .\end{array}$ & $\begin{array}{l}\text { Cor. } \\
\text { A. G. } \\
\text { S. }\end{array}$ & $\begin{array}{l}\text { Cor. } \\
\text { p. m. }\end{array}$ & $\begin{array}{c}1900 \\
\text { declination }\end{array}$ & $\mathrm{O}-\mathrm{C}$ \\
\hline
\end{tabular}

11. B. D. $38^{\circ} 3219$. $\alpha=18^{\mathrm{b}} 30^{\mathrm{m}} 46^{\mathrm{s}}, \delta=+38^{\circ} 21^{\prime} 26.87^{\prime \prime}, \mu^{\prime}=+0.0471^{\prime \prime}$

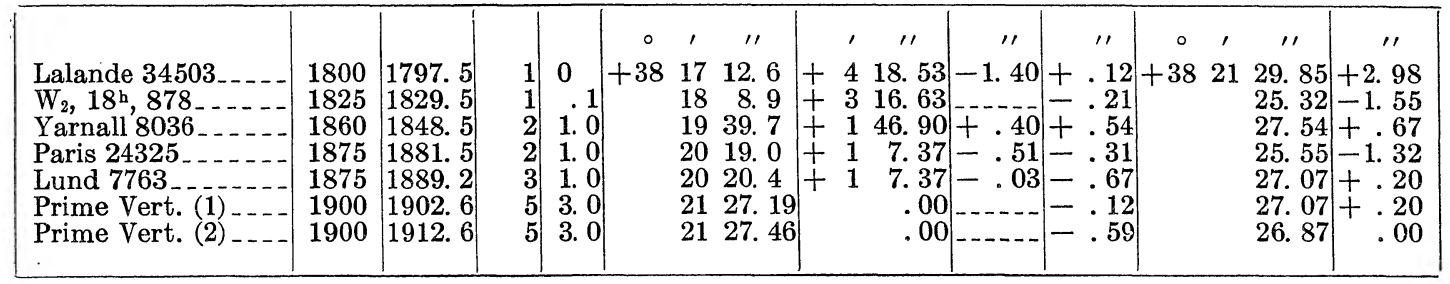

13. B. D. $+37^{\circ} 4427 . \quad \alpha=21^{\mathrm{h}} 44^{\mathrm{m}} 20^{\mathrm{s}}, \delta=+38^{\circ} 11^{\prime} 1.57^{\prime \prime}, \mu^{\prime}=+0.0053^{\prime \prime}$

\begin{tabular}{|c|c|c|c|c|c|c|c|c|c|c|c|c|c|}
\hline Lalande 42563 & 1800 & 1793. 6 & & 0 & +37 & 43 & 28.7 & +2734.37 & -1.20 & +.03 & +3811 & 1. 90 & +.33 \\
\hline Yarnall 9815 & 1860 & 1847.5 & 3 & 1. 5 & +37 & 59 & 57.2 & +114.09 & & +.07 & & 1. 74 & +.17 \\
\hline Paris 30993 & 1875 & 1880.6 & 2 & 1. 0 & +38 & 4 & 7.5 & +655.42 & -.45 & 03 & & 2.44 & 87 \\
\hline Lund 10343 & 1875 & 1880. 7 & 2 & .5 & & 4 & 6.0 & $\begin{array}{lll}6 & 55.42\end{array}$ & 00 & 03 & & 1. 39 & -.18 \\
\hline 10 -year Cat. 3646 & 1880 & 1884.0 & 3 & 1. 5 & & $\mathbf{5}$ & 28.23 & 532.44 & 14 & -.02 & & 0.84 & - \\
\hline Prime Vert. (1) & 1900 & 1901. 4 & 5 & 3. 0 & & 11 & 1. 29 & .00 & & -.01 & & 1. 28 & -.29 \\
\hline Prime Vert. (2) & 1900 & $1912.8 \mid$ & 5 & 3. 0 & & 11 & 1.95 & 00 & & -.07 & & 1.88 & +.31 \\
\hline
\end{tabular}

14. B. D. $+37^{\circ} 4506$. $\alpha=22^{\text {h }} 7^{\mathrm{m}} 26^{\mathrm{s}}, \delta=37^{\circ} 55^{\prime} 22.68^{\prime \prime}, \mu^{\prime}=+0.0052^{\prime \prime}$

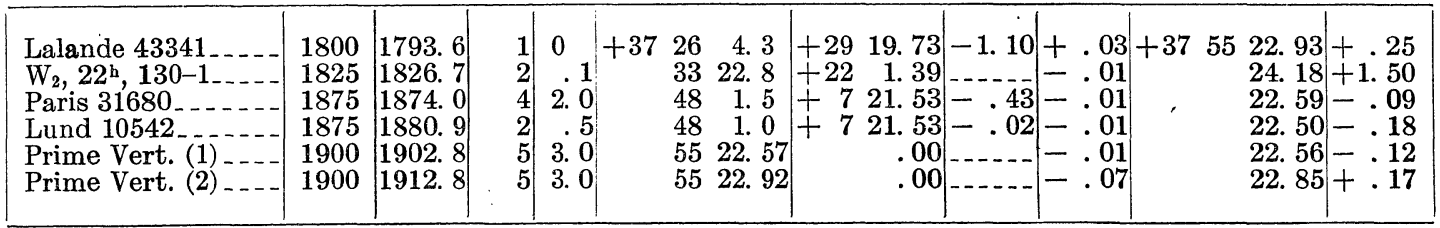

15. B. D. $+38^{\circ} 4727 . \quad \alpha=22^{\text {h }} 13^{\mathrm{m}} 29^{\mathrm{s}}, \delta=38^{\circ} 31^{\prime} 32.25^{\prime \prime}, \mu^{\prime}=+0.0206^{\prime \prime}$

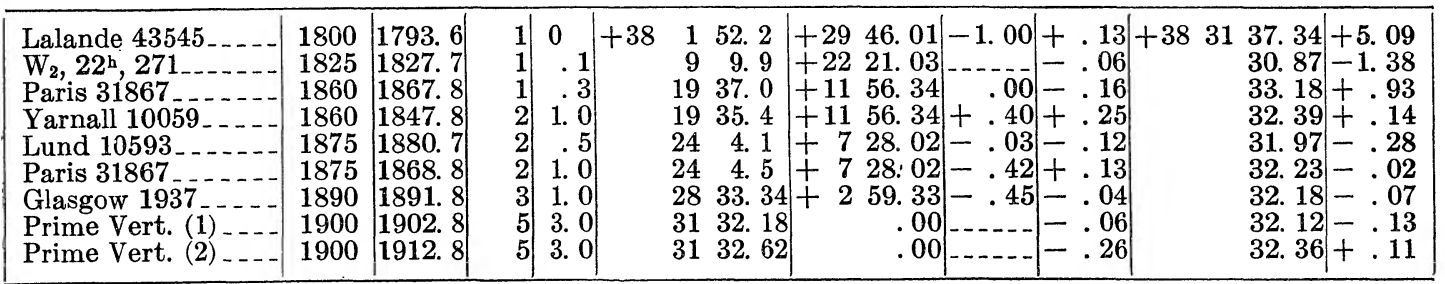

16. B. D. $+37^{\circ} 4560 . \quad \alpha=22^{\text {b }} 19^{\mathrm{m}} 28^{\mathrm{s}}, \delta=38^{\circ} 3^{\prime} 49.92^{\prime \prime}, \mu^{\prime}=+0.1252^{\prime \prime}$

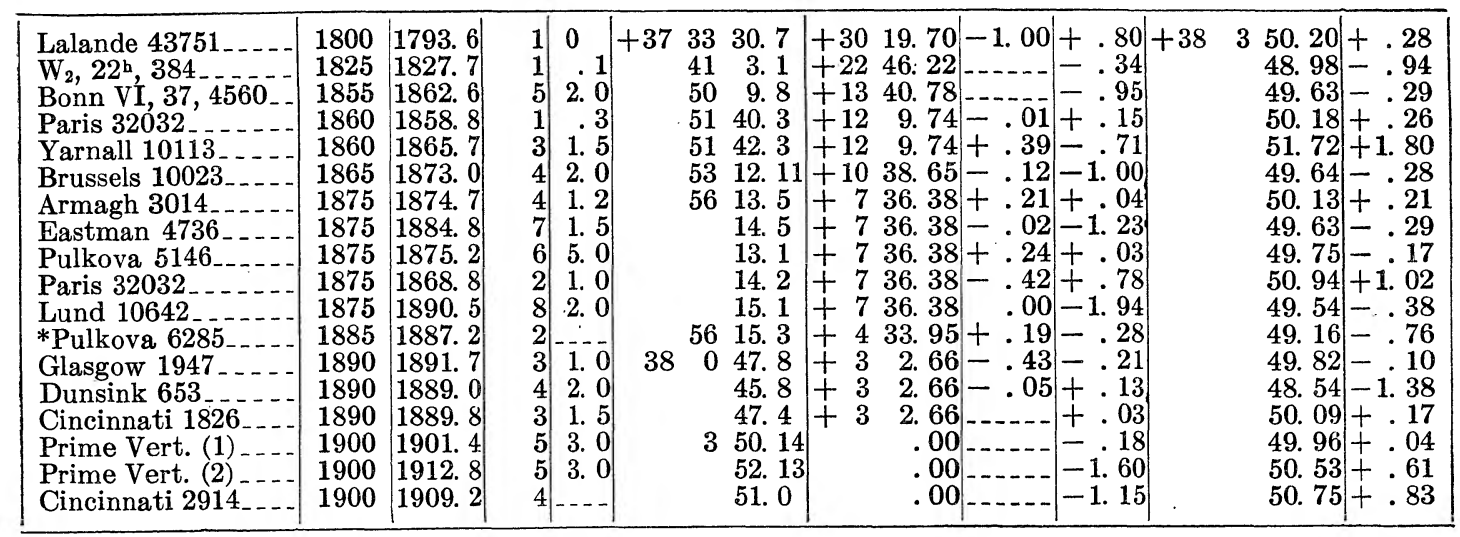

* Not used in the reduction for the place of star in declination. 
TABLE XIX.-Declinations and Proper Motions of the 16 Stars Used in Obtaining Latitudes from the Period 1904 to 1912, Inclusive, and also Their Means Places for Each Year

\begin{tabular}{|c|c|c|c|c|c|c|c|c|c|}
\hline Group & No. & Name & Mag. & $\begin{array}{l}\text { Right } \\
\text { ascension, } \\
1900\end{array}$ & $\begin{array}{c}\text { Declination, } \\
1900\end{array}$ & $\begin{array}{l}\text { Preces- } \\
\text { sion }\end{array}$ & $\begin{array}{l}\text { Secular } \\
\text { varia- } \\
\text { tion }\end{array}$ & $\begin{array}{l}\text { Third } \\
\text { term }\end{array}$ & $\begin{array}{l}\text { Proper } \\
\text { motion }\end{array}$ \\
\hline I & $\left\{\begin{array}{l}1 \\
2 \\
3 \\
4\end{array}\right.$ & $\begin{array}{l}\text { B. D. }+38^{\circ} 1357 \\
40 \text { Aurigæ } \\
\text { B. D. }+38^{\circ} 1382 \\
\text { B. D. }+38^{\circ} 1539\end{array}$ & $\begin{array}{l}\text { 7. } 2 \\
\text { 5. } 3 \\
7.0 \\
\text { 5. } 9\end{array}$ & $\begin{array}{rrr}h & m & s . \\
5 & 55 & 11 \\
& 59 & 41 \\
6 & 0 & 39 \\
& 29 & 40\end{array}$ & $\begin{array}{rrc}\circ & \prime & \prime \prime \\
+38 & 43 & 1.39 \\
+38 & 29 & 30.50 \\
+38 & 5 & 33.95 \\
+38 & 31 & 34.64\end{array}$ & $\begin{aligned} & \prime \prime \\
+\quad & 0.4213 \\
+ & .0269 \\
- & .0576 \\
- & 2.5884\end{aligned}$ & \begin{aligned} & \multicolumn{1}{l}{} \\
&-0.604 \\
&-.603 \\
&-.601 \\
&-.596\end{aligned} & $\begin{array}{l}-0.024 \\
+\quad .005 \\
+\quad .006 \\
+\quad .061\end{array}$ & $\begin{array}{c}\prime \prime \\
-0.0035 \\
-.0471 \\
-.0060 \\
-.0262\end{array}$ \\
\hline II & $\left\{\begin{array}{l}5 \\
6 \\
7 \\
8\end{array}\right.$ & $\begin{array}{l}\text { B. D. }+38^{\circ} 2477 \\
\text { B. D. }+38^{\circ} 2479 \\
\text { B. D. }+37^{\circ} 2457 \\
\text { B. D. }+37^{\circ} 2528\end{array}$ & $\begin{array}{l}\text { 7. } 6 \\
\text { 7. } 1 \\
\text { 6. } 4 \\
\text { 7. } 4\end{array}$ & $\begin{array}{rrr}13 & 41 & 40 \\
& 43 & 11 \\
& 45 & 24 \\
14 & 19 & 20\end{array}$ & $\begin{array}{rrr}+38 & 1 & 37.59 \\
+38 & 23 & 32.91 \\
+37 & 7 & 43.69 \\
+37 & 39 & 33.09\end{array}$ & $\begin{array}{l}-18.1063 \\
-18.0494 \\
-17.9641 \\
-16.4547\end{array}$ & $\begin{array}{l}+0.172 \\
+.173 \\
+.177 \\
+.214\end{array}$ & $\begin{array}{l}-0.060 \\
+0.098 \\
+0.099 \\
+0.099\end{array}$ & $\begin{array}{r}-0.0606 \\
-\quad .0104 \\
+\quad .0163 \\
+\quad .0398\end{array}$ \\
\hline III & $\left\{\begin{array}{r}9 \\
10 \\
11 \\
12\end{array}\right.$ & $\begin{array}{l}\text { B. D. }+38^{\circ} 2984 \\
\text { B. D. }+38^{\circ} 3095 \\
\text { B. D. }+38^{\circ} 3219 \\
\alpha \text { Lyræ }\end{array}$ & $\begin{array}{l}\text { 7. } 3 \\
\text { 6. } 4 \\
\text { 7. } 6 \\
0.1\end{array}$ & $\begin{array}{rrr}17 & 38 & 51 \\
18 & 6 & 19 \\
18 & 30 & 46 \\
18 & 33 & 33\end{array}$ & $\begin{array}{rrr}+38 & 6 & 53.11 \\
+38 & 27 & 4.87 \\
+38 & 21 & 26.87 \\
+38 & 41 & 25 . \\
+\end{array}$ & $\begin{array}{l}-1.8470 \\
+\quad .5529 \\
+\quad 2.6838 \\
+\quad 2.9245\end{array}$ & $\begin{array}{l}+0.295 \\
+\quad .293 \\
+\quad .291 \\
+.289\end{array}$ & $\begin{array}{l}+0.082 \\
-.005 \\
-.005 \\
-.01\end{array}$ & $\begin{array}{l}+0.1089 \\
-\quad .4591 \\
+\quad .0471 \\
+\quad .275\end{array}$ \\
\hline IV & $\left\{\begin{array}{l}13 \\
14 \\
15 \\
16\end{array}\right.$ & $\begin{array}{l}\text { B. D. }+37^{\circ} 4427 \\
\text { B. D. }+37^{\circ} 4506 \\
\text { B. D. }+38^{\circ} 4727 \\
\text { B. D. }+37^{\circ} 4560\end{array}$ & $\begin{array}{l}5.8 \\
7.4 \\
7.5 \\
6.2\end{array}$ & $\begin{array}{rrr}21 & 44 & 20 \\
22 & 7 & 26 \\
22 & 13 & 29 \\
22 & 19 & 28\end{array}$ & $\begin{array}{rrr}+38 & 11 & 1.57 \\
+37 & 55 & 22.68 \\
+38 & 31 & 32.25 \\
+38 & 3 & 49.92\end{array}$ & $\begin{array}{l}+16.6360 \\
+17.6771 \\
+17.9205 \\
+18.1492\end{array}$ & $\begin{array}{r}+0.195 \\
+\quad .170 \\
+.162 \\
+.155\end{array}$ & $\begin{array}{r}-0.011 \\
-.082 \\
-.094 \\
-.096\end{array}$ & $\begin{array}{r}+0.0053 \\
+\quad .0052 \\
+\quad .0206 \\
+\quad .1252\end{array}$ \\
\hline
\end{tabular}

NotE.- The declination of $\alpha$ Lyræ in the above table was taken from Boss's General Catalogue; its proper motion in declination from his paper in the Report of the Northern Boundary Survey.

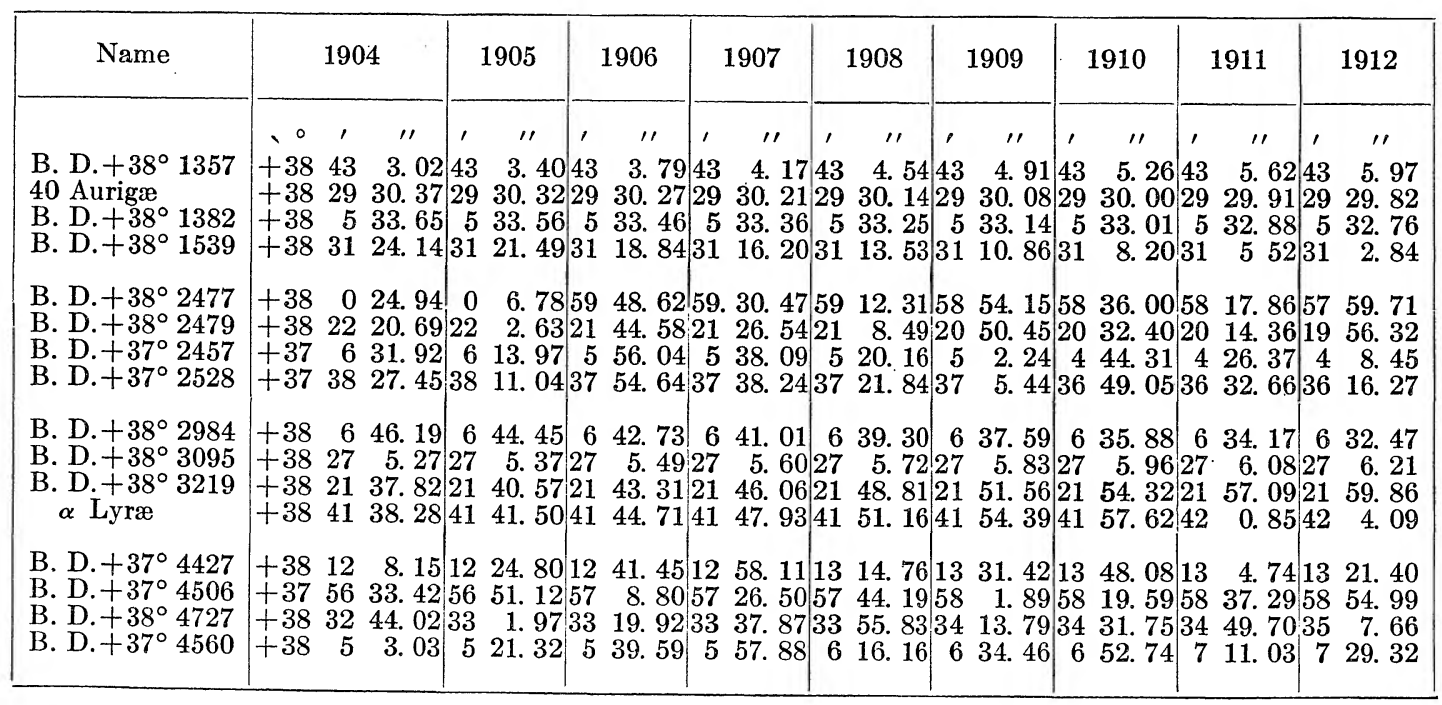


Table XX.-Bessel's Star Constants

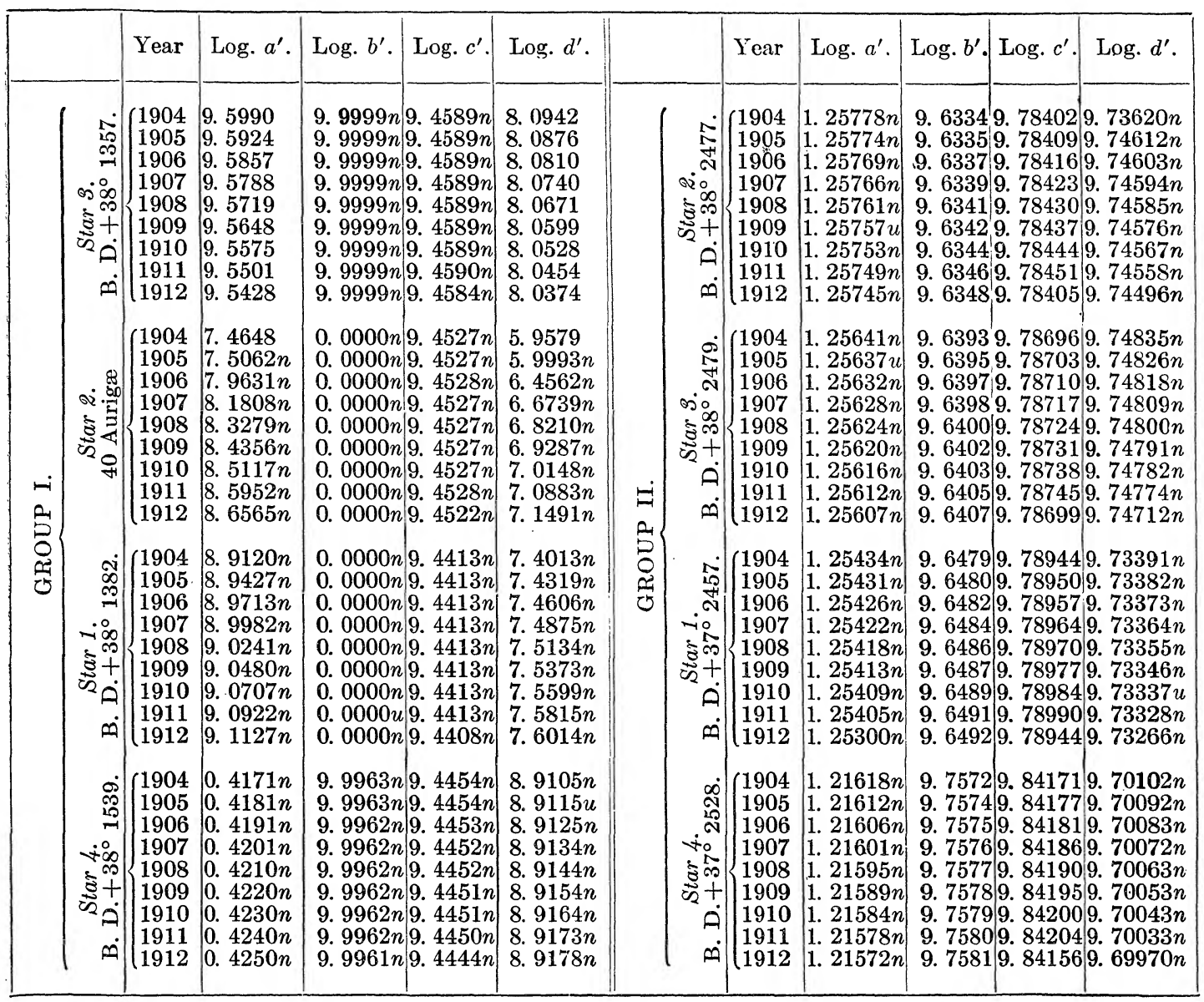


TABLE XX.-Bessel's Star Constants-Continued

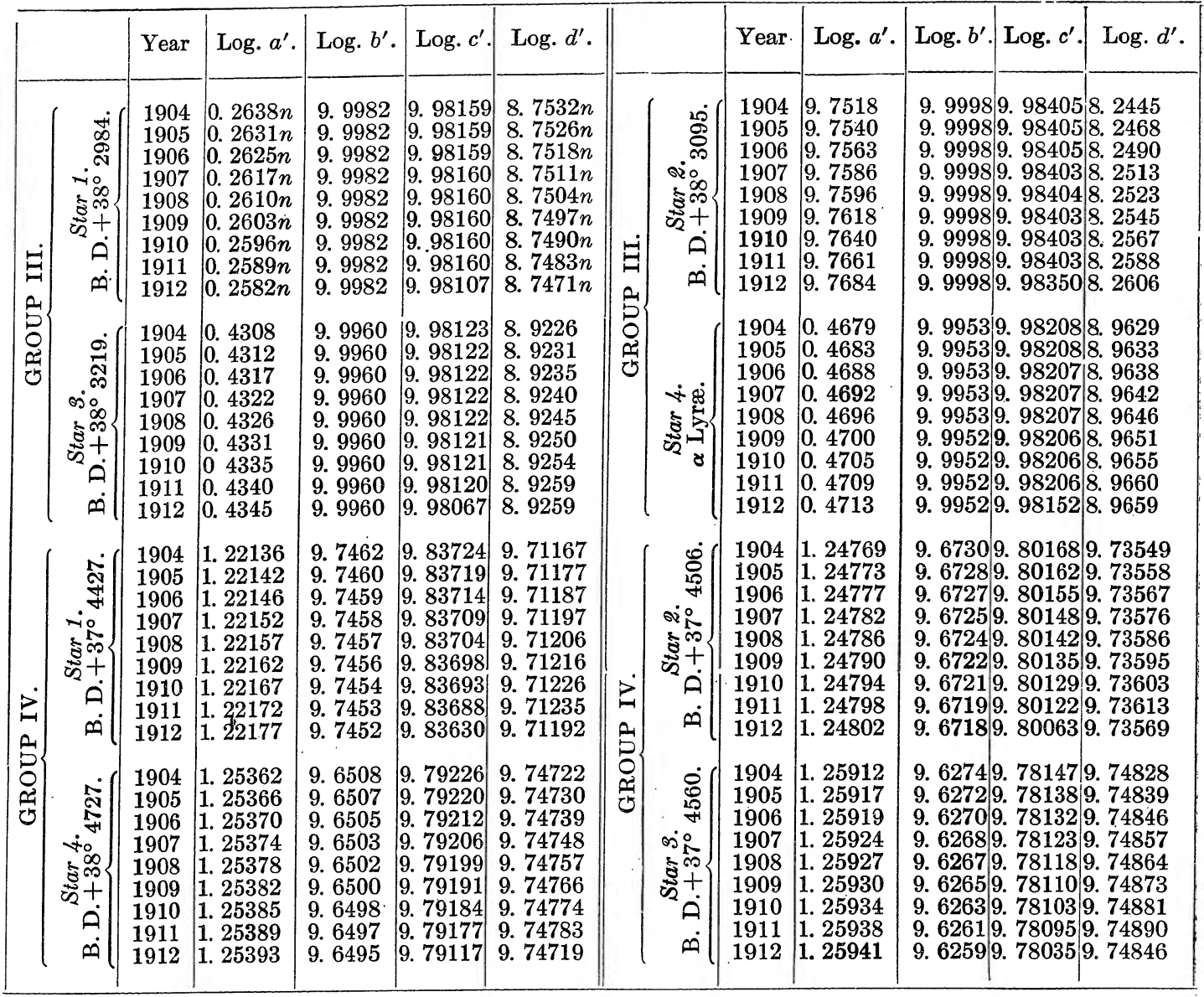

TABLE XXI.-A Comparison of Declinations Resulting from Catalogue Positions and the Positions Observed in the Period 1904-1912

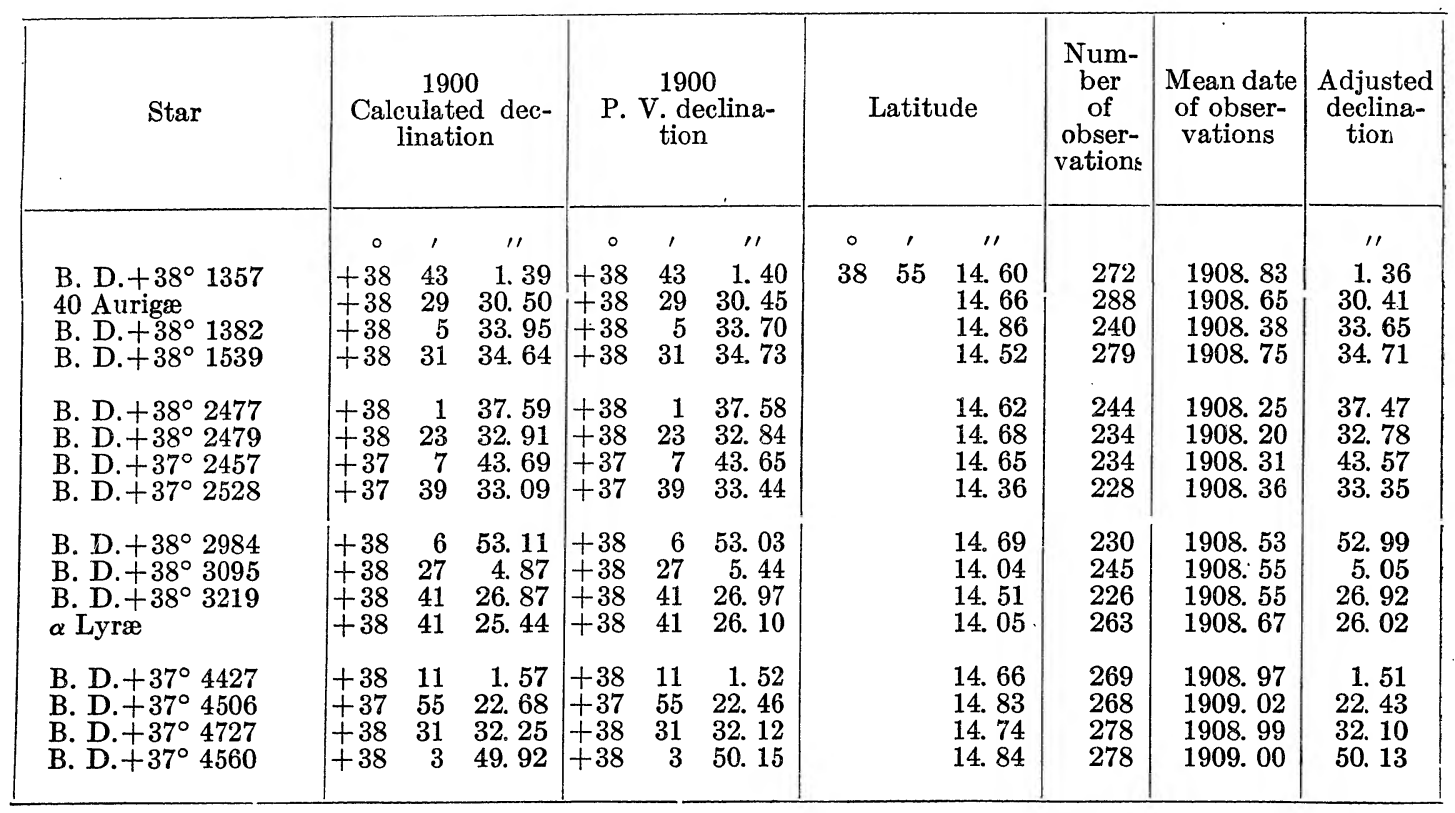


If there is any appreciable error in the adopted proper motion of the star it will be revealed by an intercomparison of the latitudes as determined from the various stars.

In the case of the star B. D. $+38^{\circ} 3095$, No. II of Group III, there is an indication that either its declination is not well determined from existing material, or that a correction is necessary to its adopted proper motion. It will be seen by comparing the calculated and the adjusted declination of that star there is a difference between them of $0.39^{\prime \prime}$. That amount greatly exceeds similar differences between the declinations of any of the other stars which are tabulated in Table XXI.

The star B. D. $+38^{\circ} 3095$ is in the sixth-magnitude class. In the interval of time between 1875 and 1900 the only observed positions which have been secured of it, aside from those which were made with the prime vertical transit of this Observatory, are four observations made at the Cincinnati Observatory. Nevertheless this star possesses a relatively large proper motion, and on this account it has been made the subject of parallax determinations.

In this connection it should be stated that four determinations of its parallax have been made in recent years. The star is LALANDE 33439. The following are the observed values of its parallax:

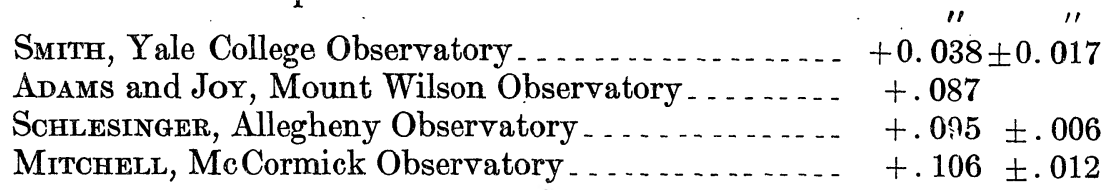

In Table XXII there are given the individual latitudes of the instrument which were derived from the observed declinations of the 16 stars which make up the four groups, based upon their respective calculated declinations. The method by which those latitudes were obtained is indicated by the following formulæ:

TABLE XXII.-Individual Latitudes

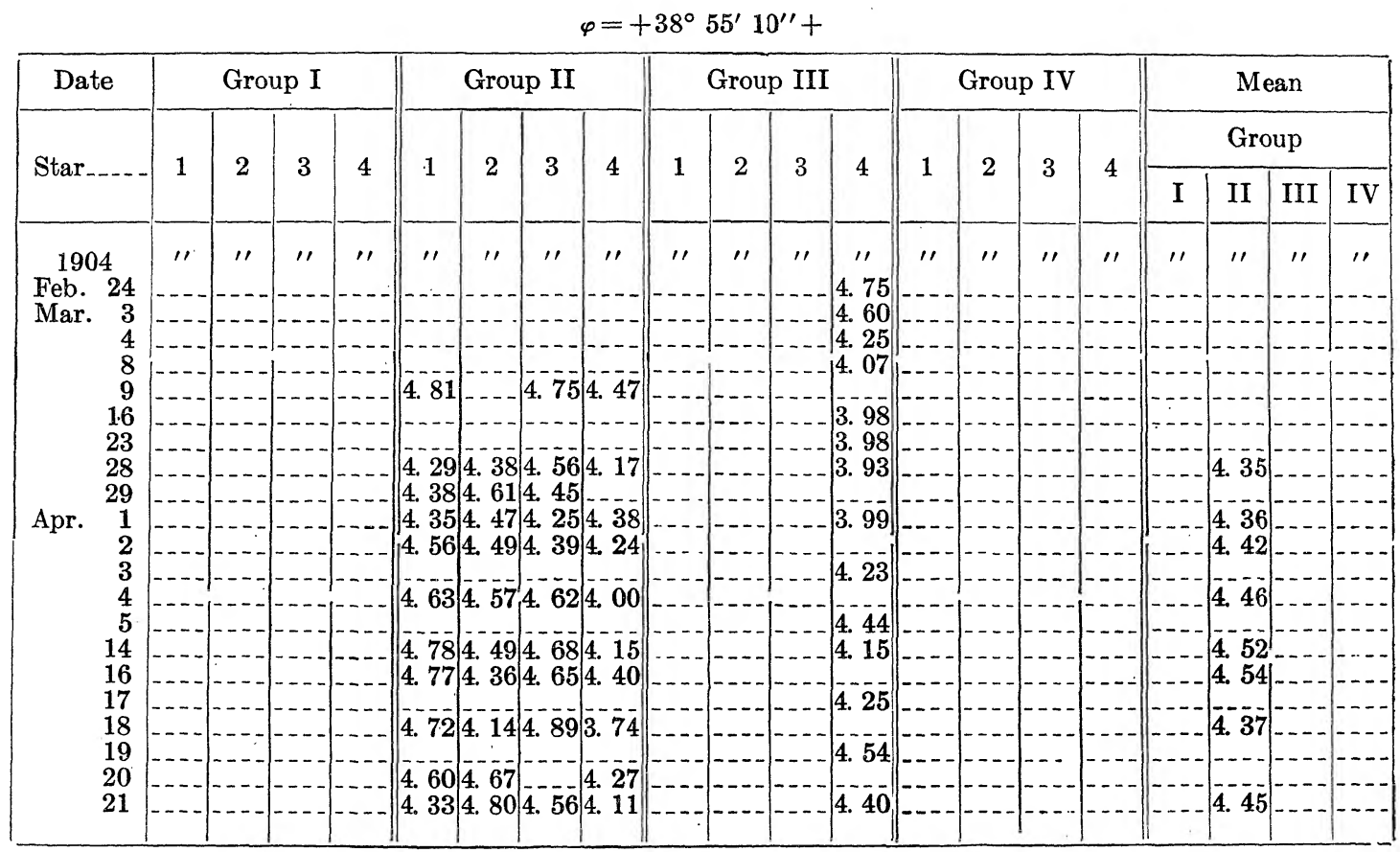


A CLX

PRIME VERTICAL TRANSIT INSTRUMENT.

TABLE XXII._Individual Latitudes-Continued

$\varphi=+38^{\circ} 55^{\prime} 10^{\prime \prime}+$

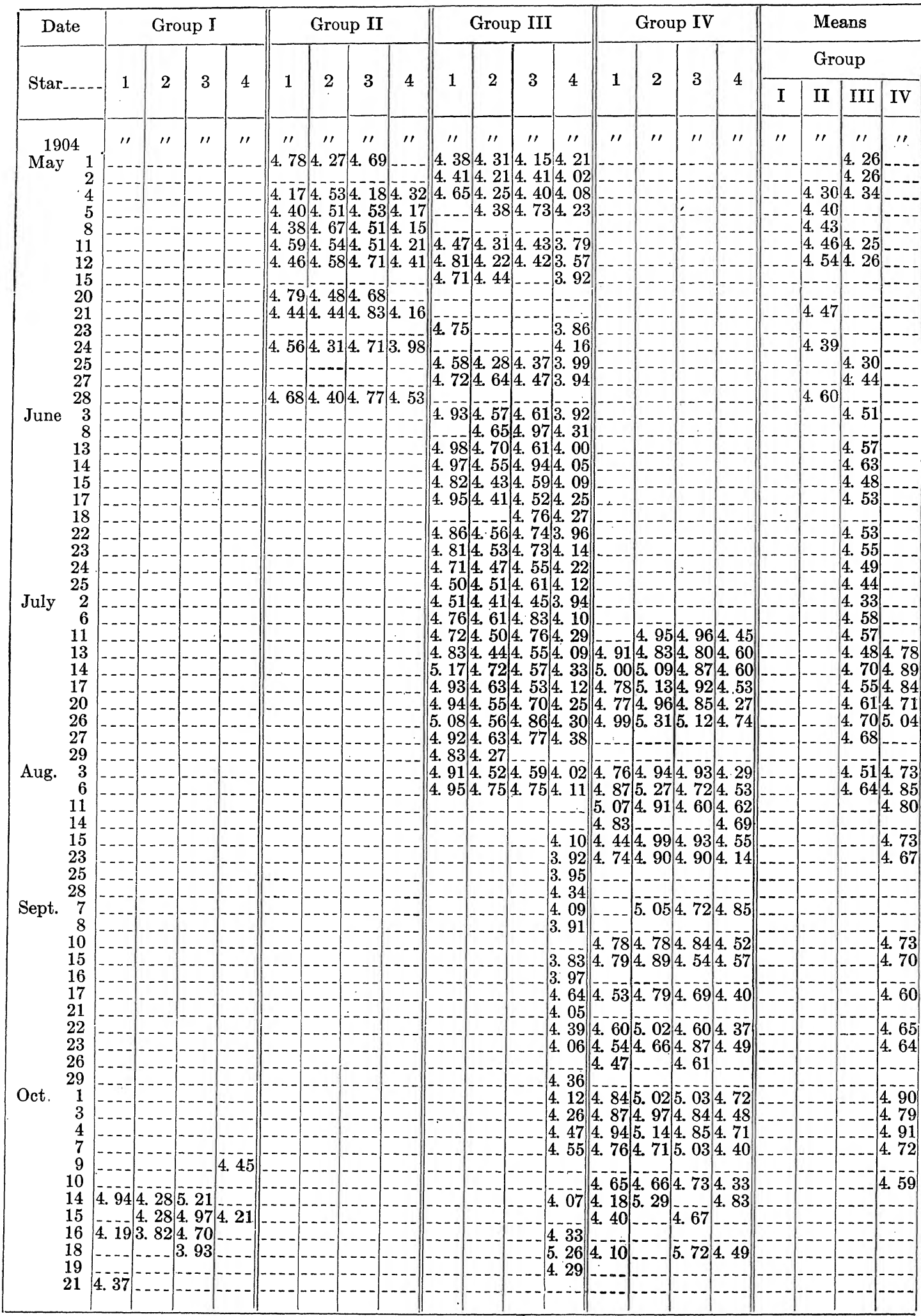


TABLE XXII.-Individual Latitudes-Continued

$\varphi=+38^{\circ} 55^{\prime} 10^{\prime \prime}+$

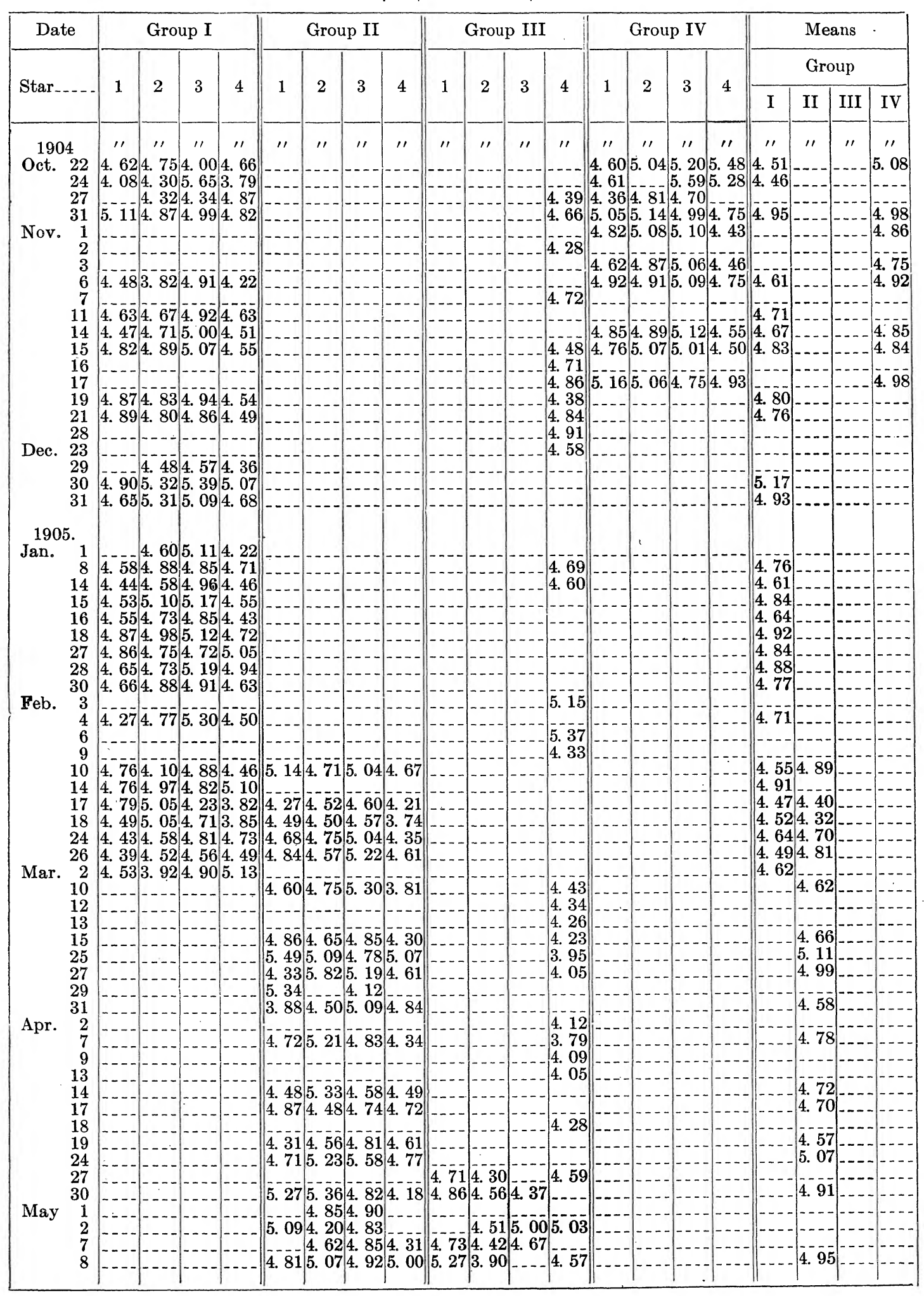

$101141^{\circ}-26$ †—PT I- 11 
PRIME VERTICAL TRANSIT INSTRUMENT.

TABLE XXII.-Individual Latitudes-Continued

$\varphi=+38^{\circ} 55^{\prime} 10^{\prime \prime}+$

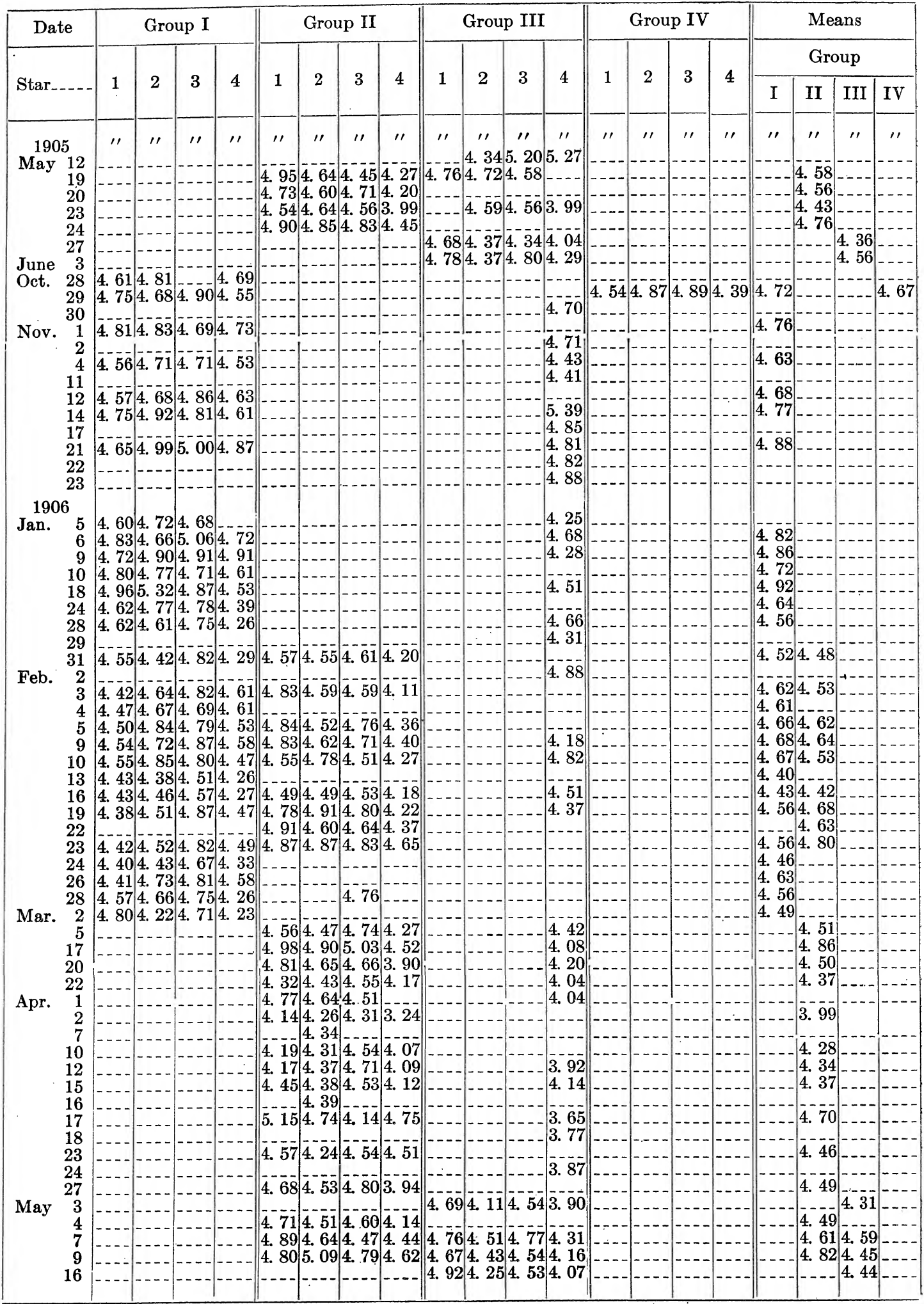


TABLE XXII.-Individual Latitudes-Continued

$\varphi=+38^{\circ} 55^{\prime} 10^{\prime \prime}+$

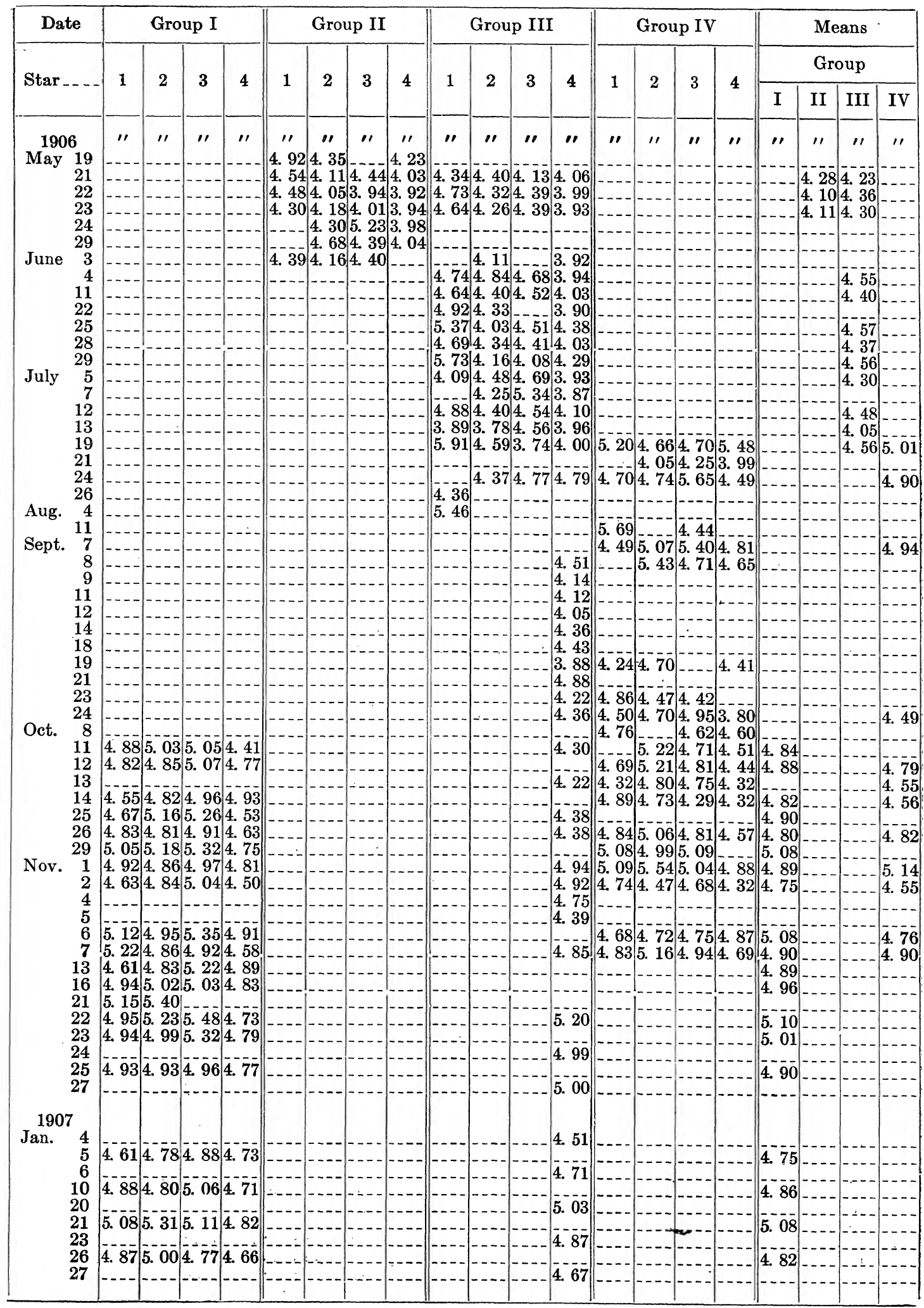


PRIME VERTICAL TRANSIT INSTRUMENT.

TABLE XXII.-Individual Latitudes-Continued

$\varphi=+38^{\circ} 55^{\prime} 10^{\prime \prime}+$

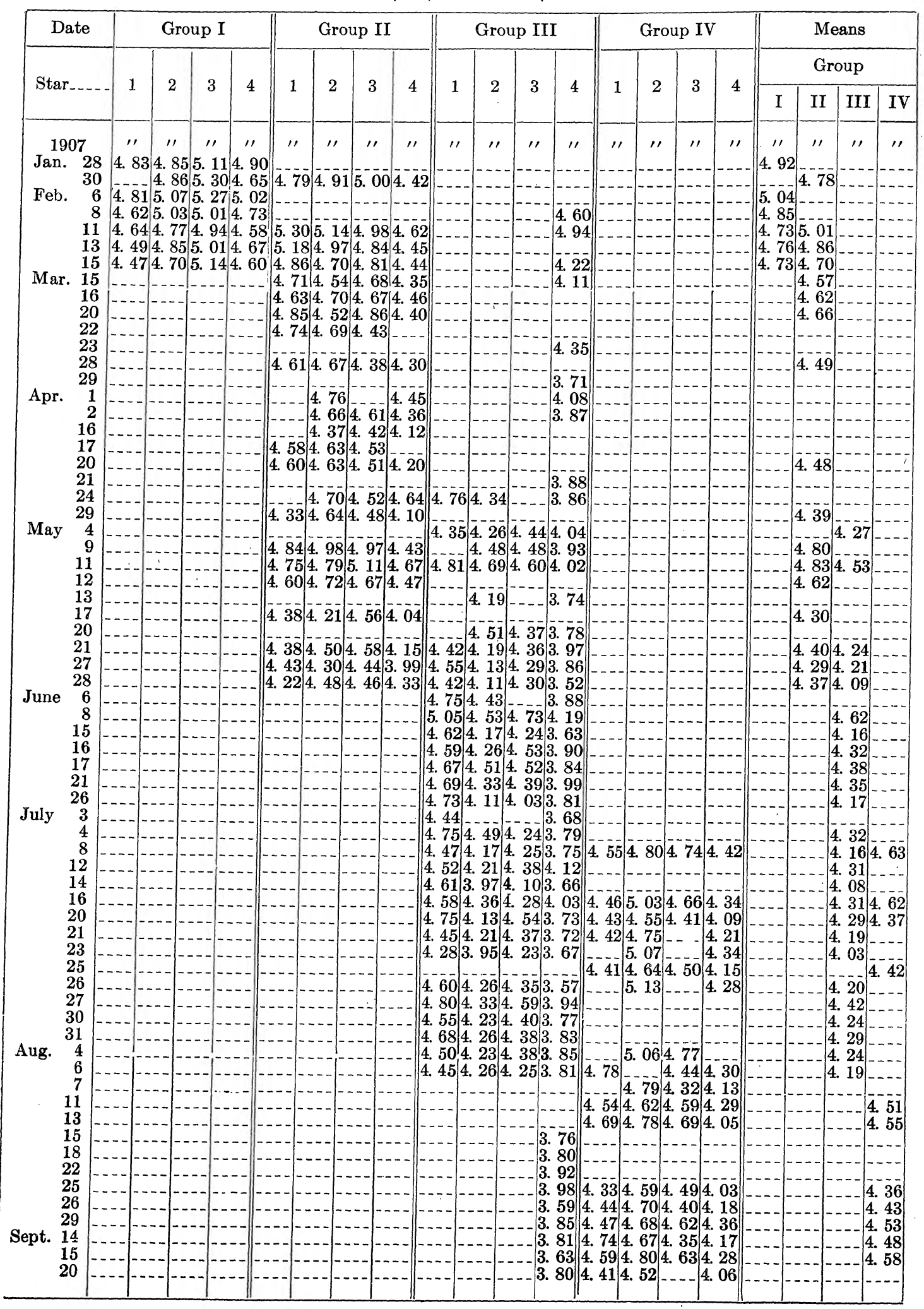


IN TRODUCTION.

TABLE XXII.-Individual Latitudes-Continued

$\varphi=+38^{\circ} 55^{\prime} 10^{\prime \prime}+$

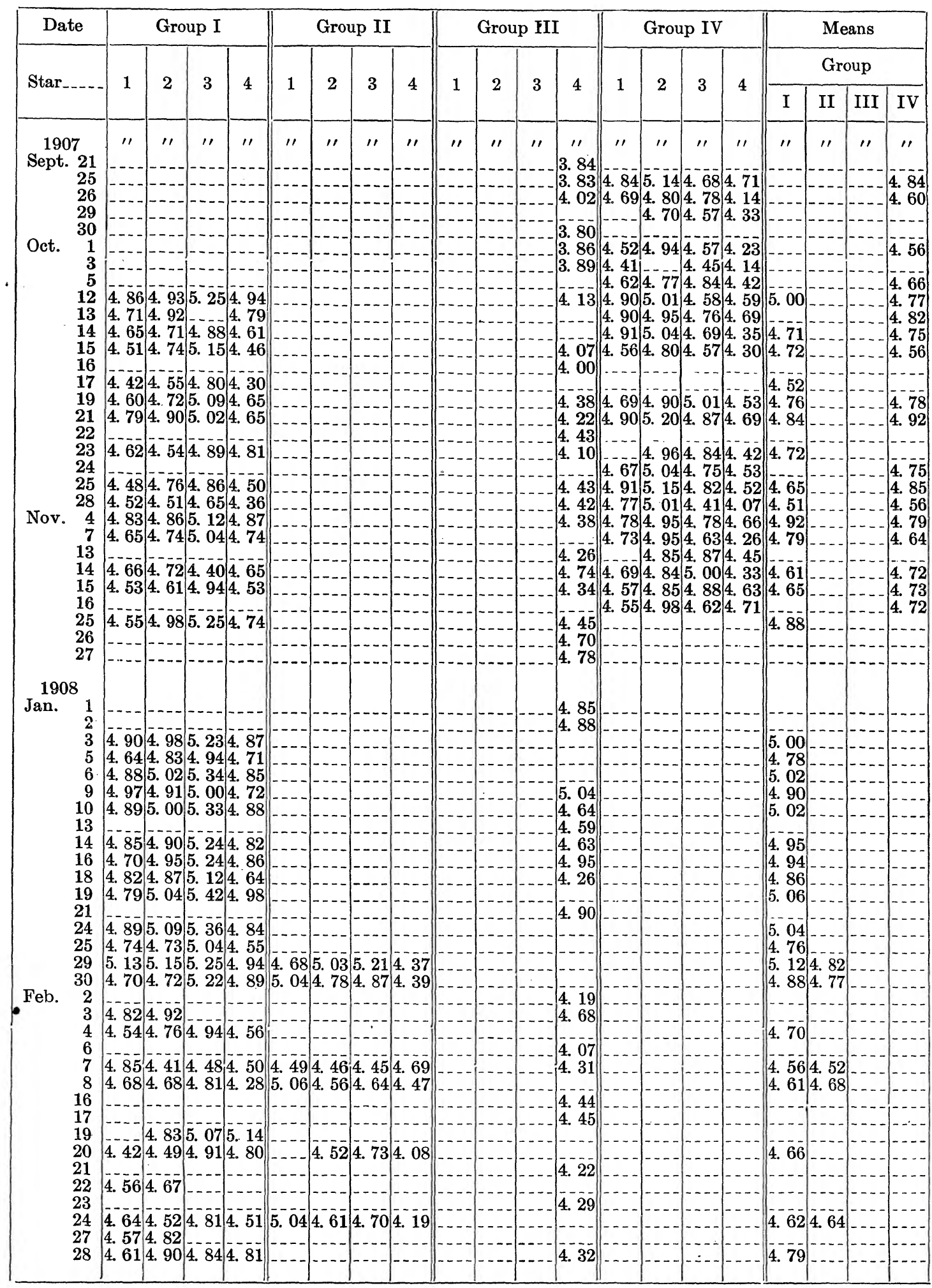


$\varphi=+38^{\circ} 55^{\prime} 10^{\prime \prime}+$

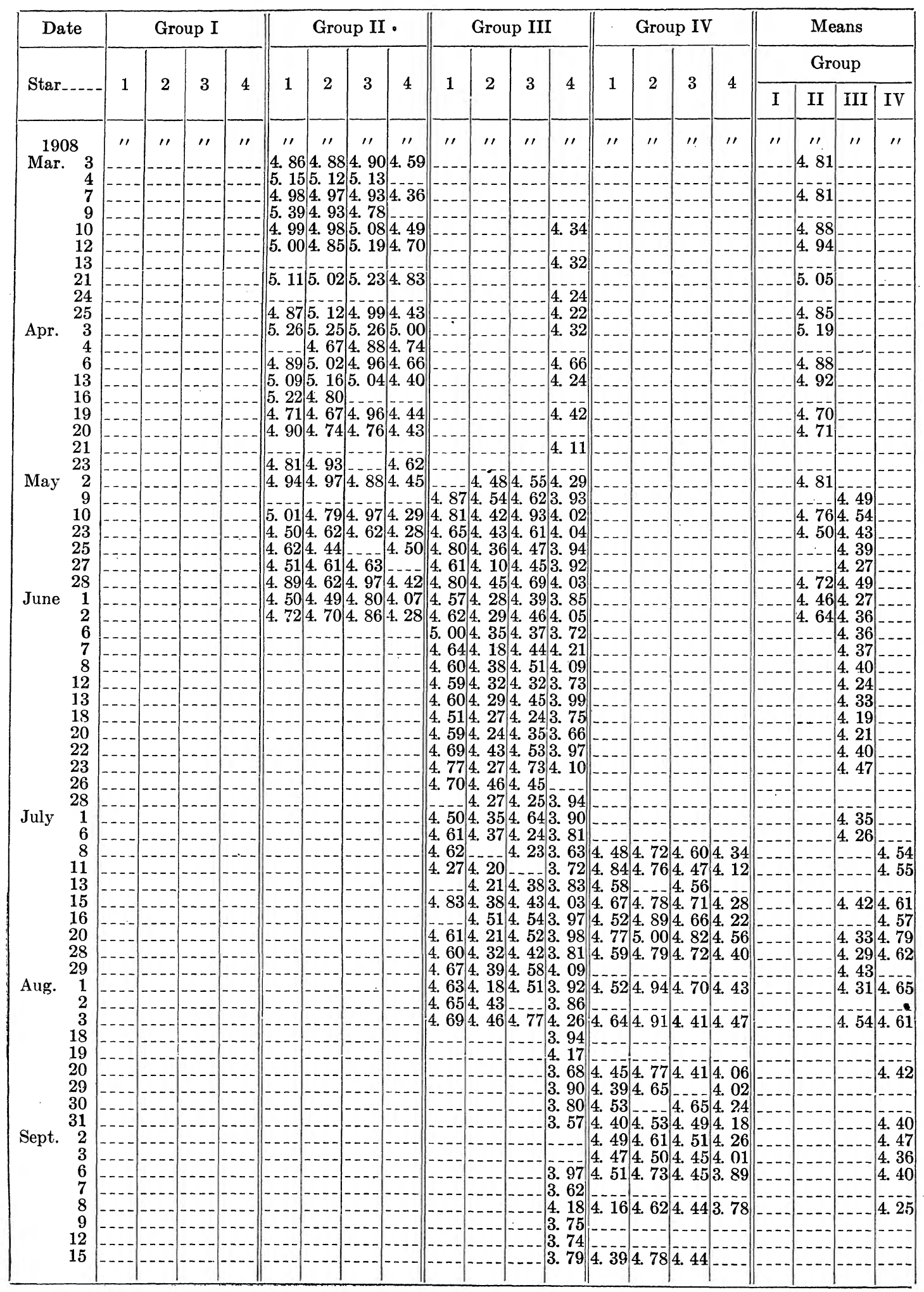


TABLE XXII.-Individual Latitudes-Continued

$\varphi=+38^{\circ} 55^{\prime} 10^{\prime \prime}+$

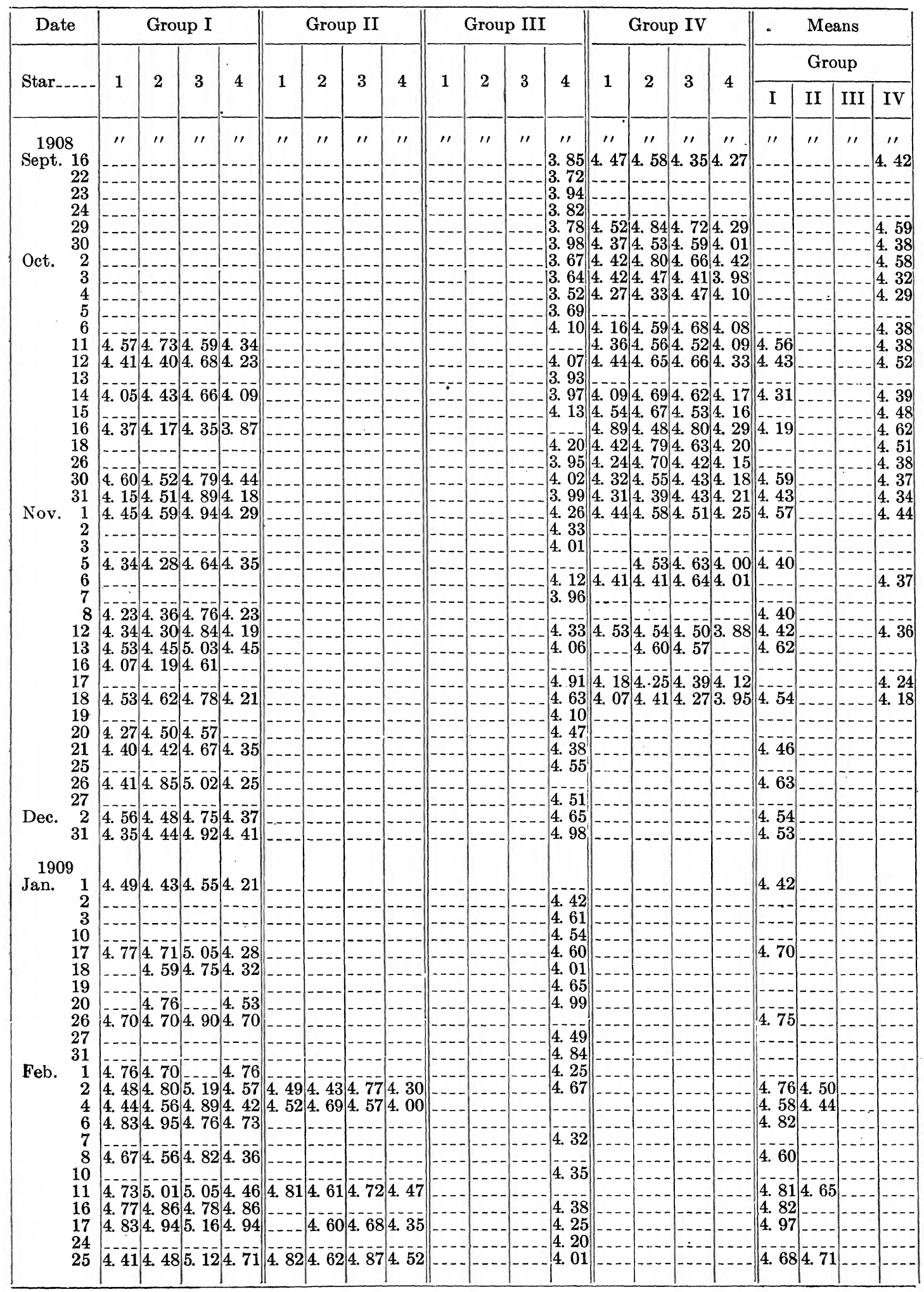


A CLXviII

PRIME VERTICAI TRANSIT INSTRUMENT.

TABLE XXII.-Individual Latitudes-Continued

$\varphi=+38^{\circ} 55^{\prime} 10^{\prime \prime}+$

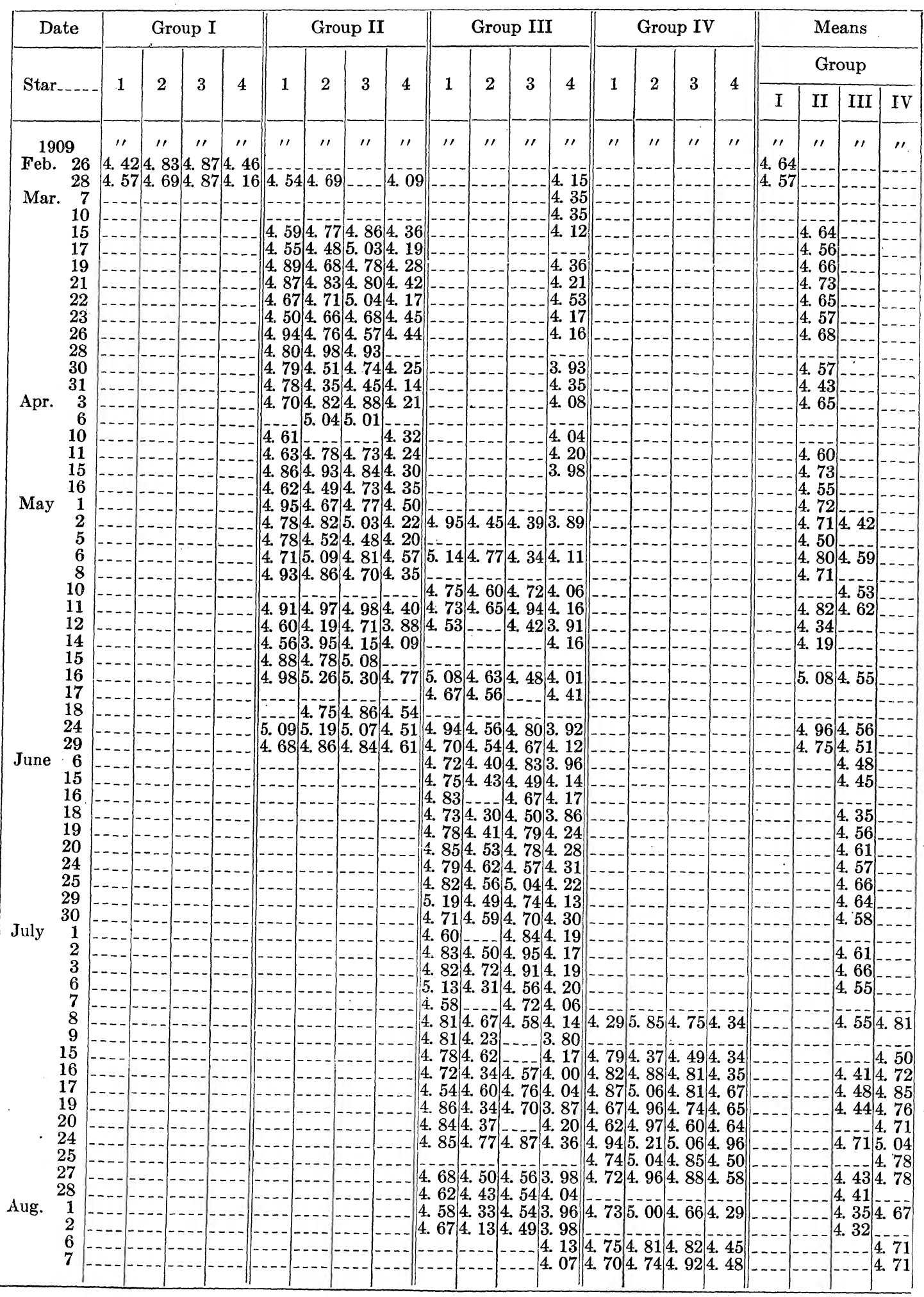


TABLE XXII.-Individual Latitudes-Continued

$\varphi=+38^{\circ} 55^{\prime} 10^{\prime \prime}+$

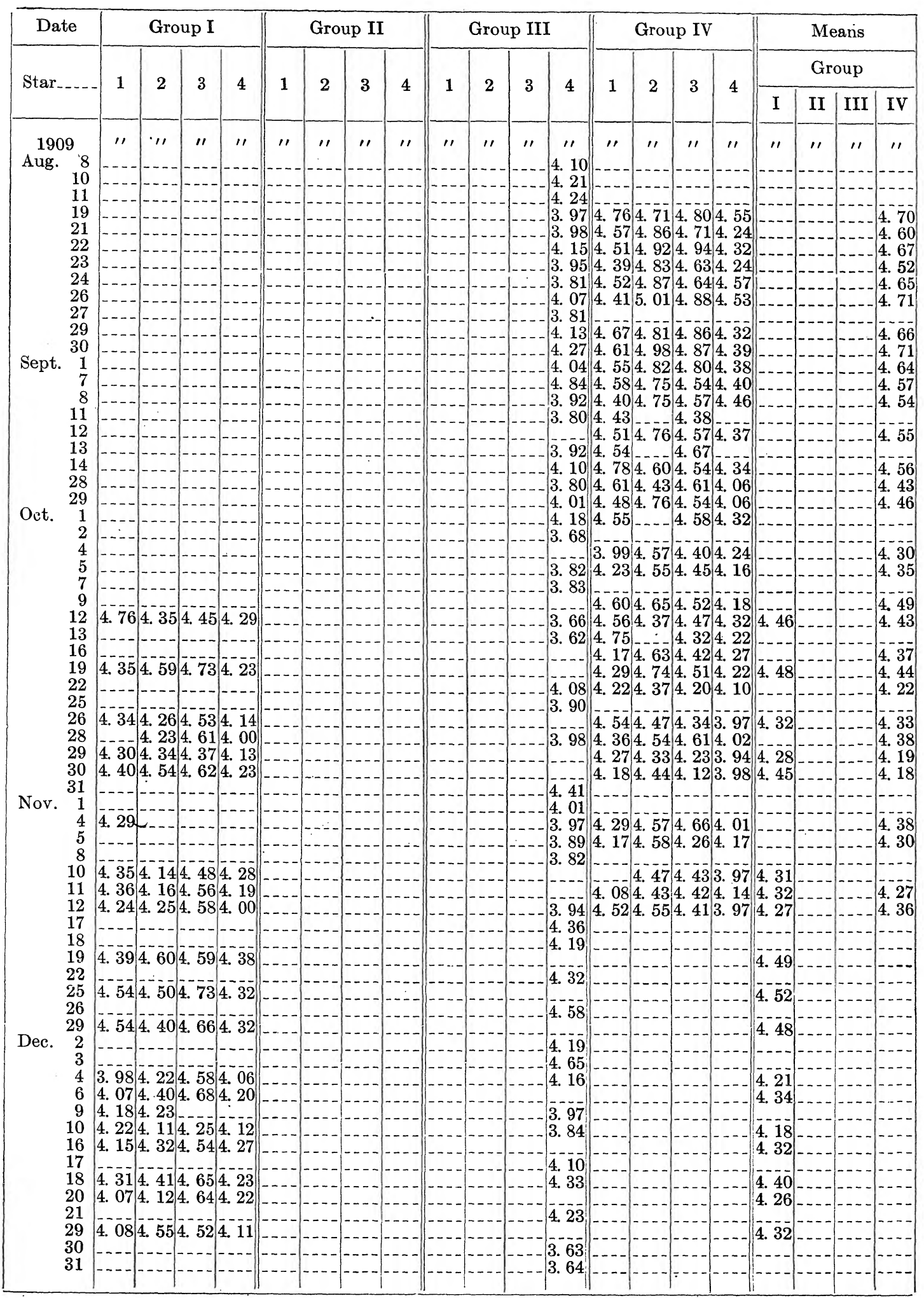


A CLXX

PRIME VERTICAL TRANSIT INSTRUMENT.

TABLE XXII.-Individual Latitudes-Continued

$\varphi=+38^{\circ} 55^{\prime} 10^{\prime \prime}+$

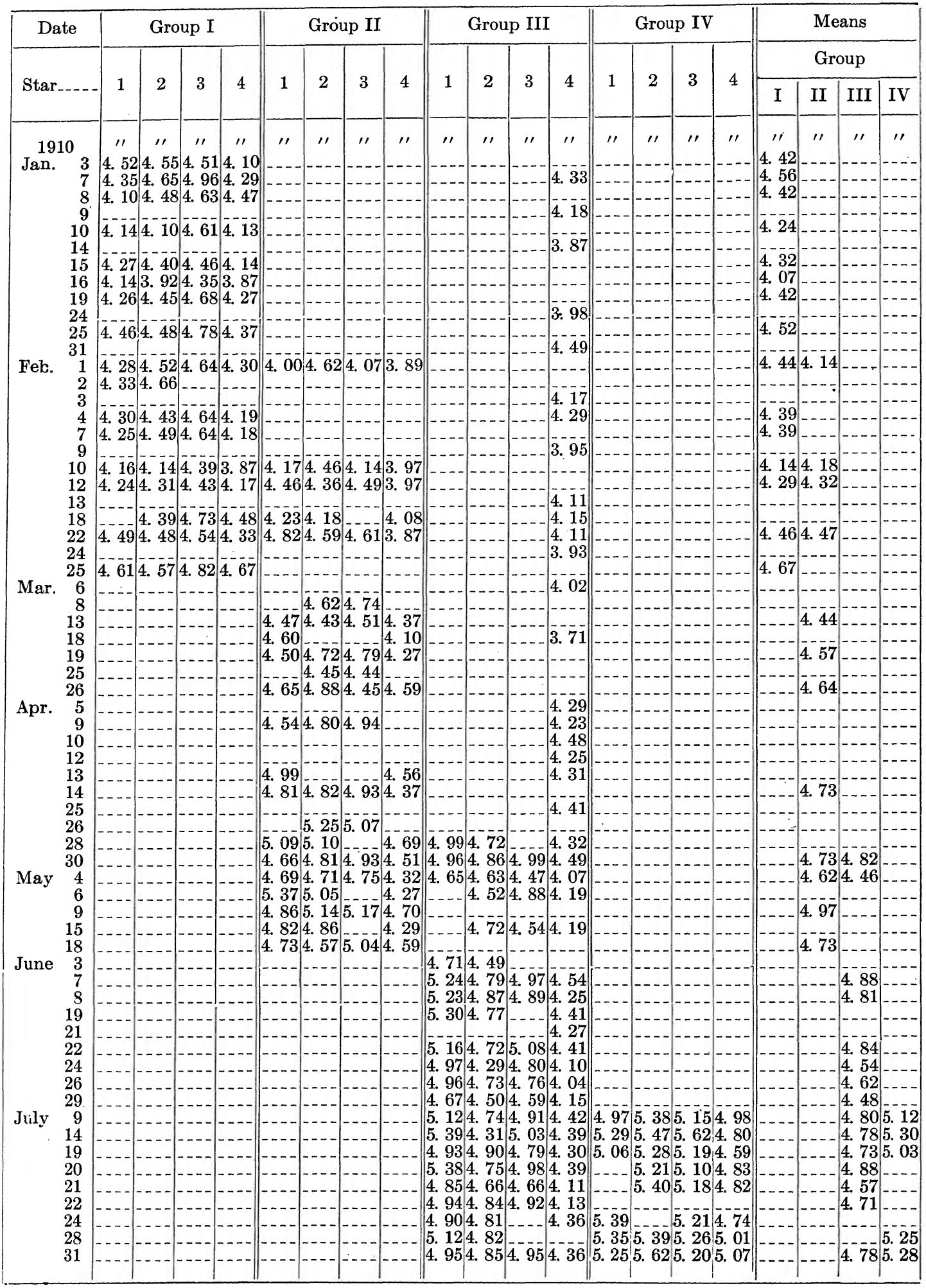


TABLE XXII.-Individual Latitudes-Continued

$\varphi=+38^{\circ} 55^{\prime} 10^{\prime \prime}+$

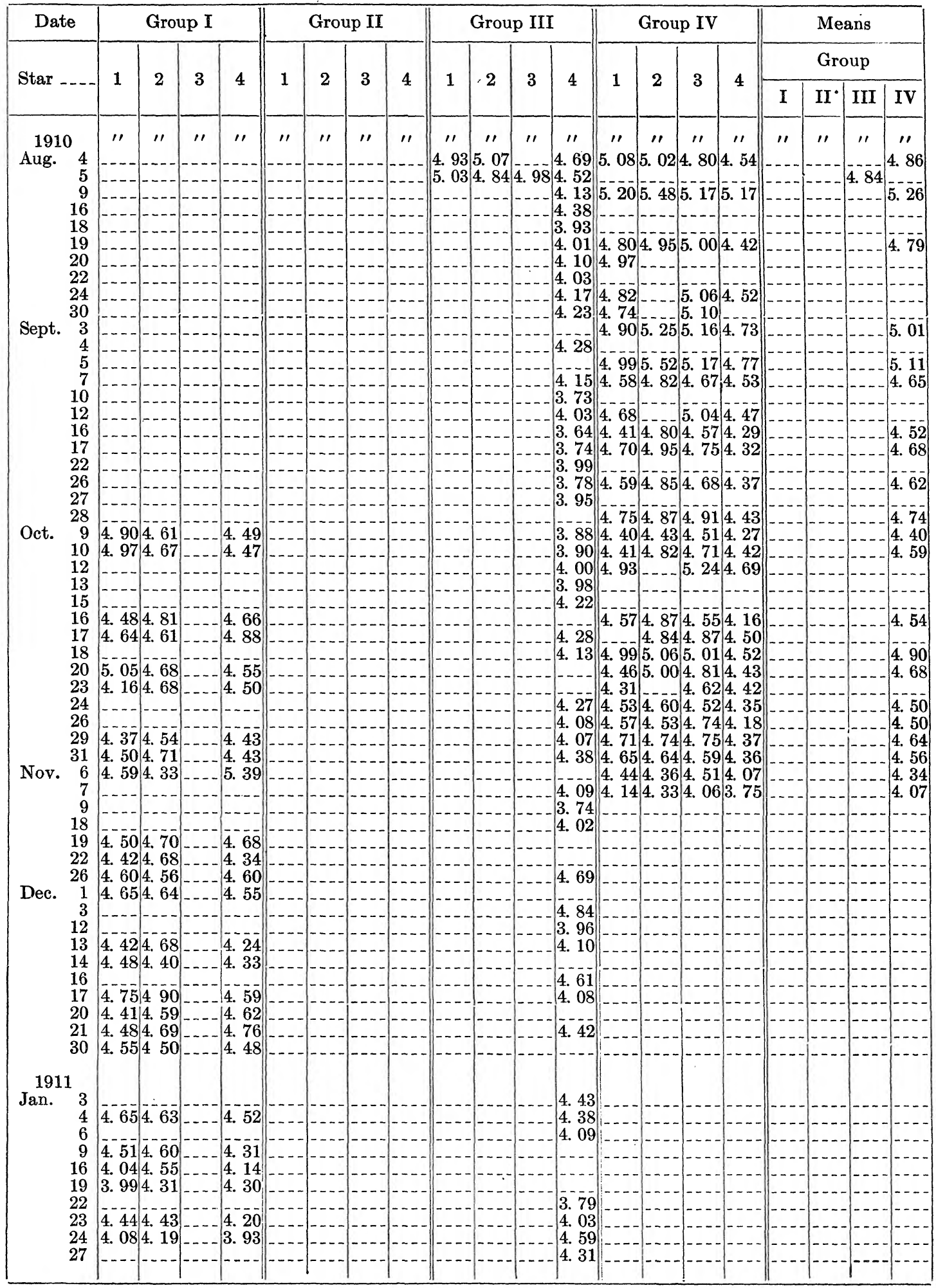


PRIME VERTICAL TRANSIT INSTRUMENT.

TABLE XXII.-Individual Latitudes.-Continued

$\varphi=+38^{\circ} 55^{\prime} 10^{\prime \prime}+$

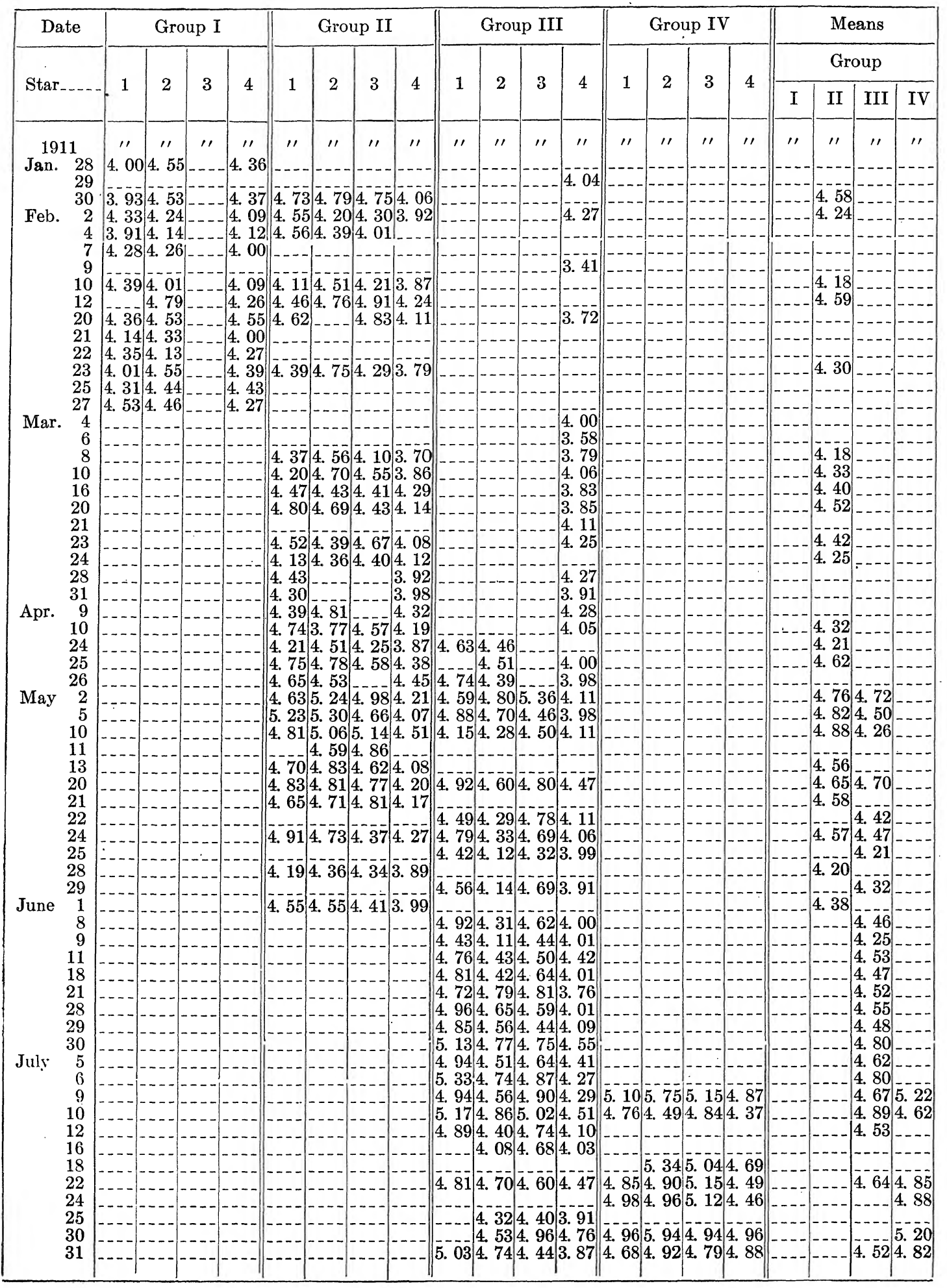


TABLE XXII. - Individual Latitudes.-Continued

$\varphi=+38^{\circ} 55^{\prime} 10^{\prime \prime}+$

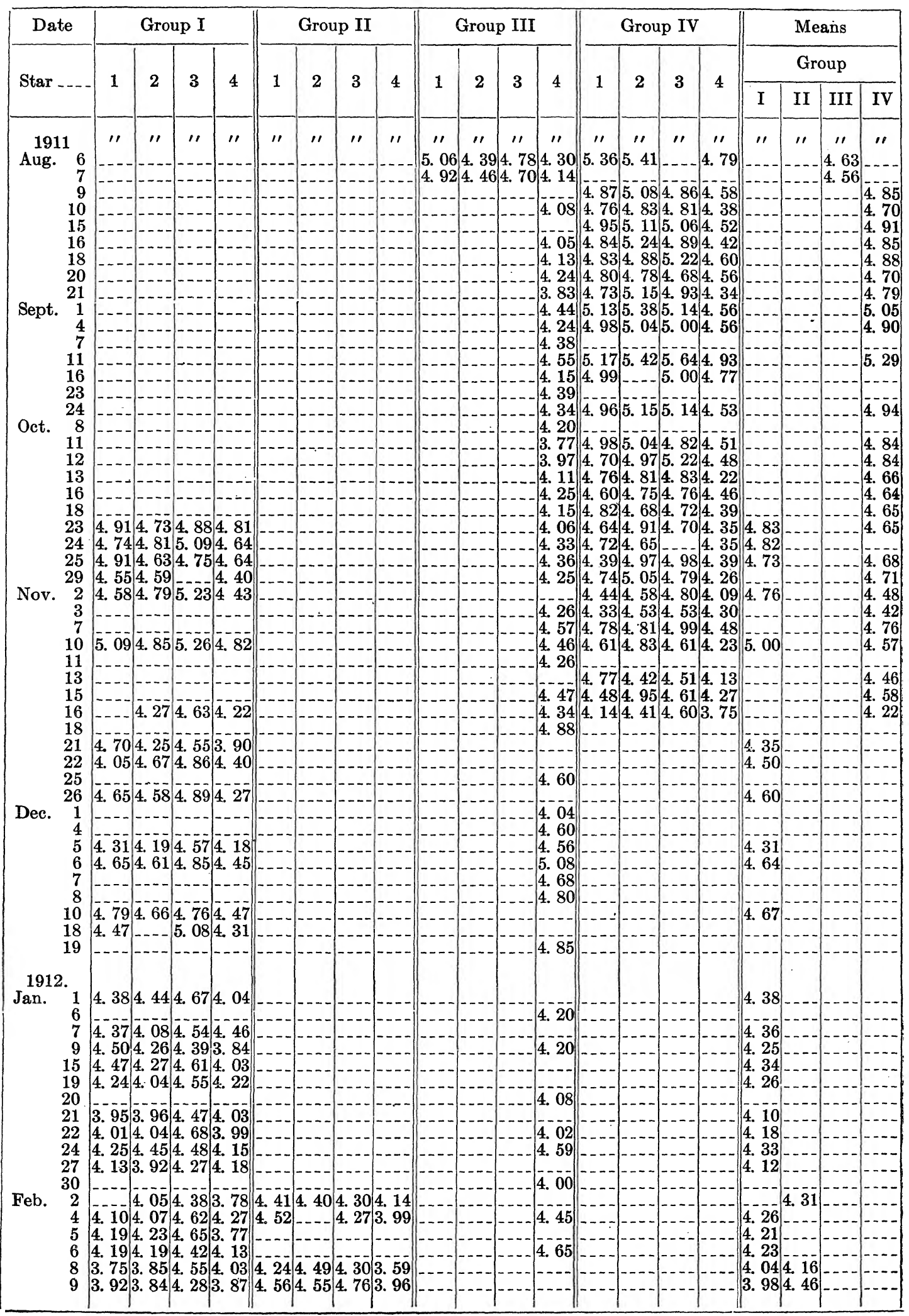


A CLXXIV

PRIME VERTICAL TRANSIT INSTRUMENT.

TABLE XXII.-Individual Latitudes-Continued $\varphi=+38^{\circ} 55^{\prime} 10^{\prime \prime}+$

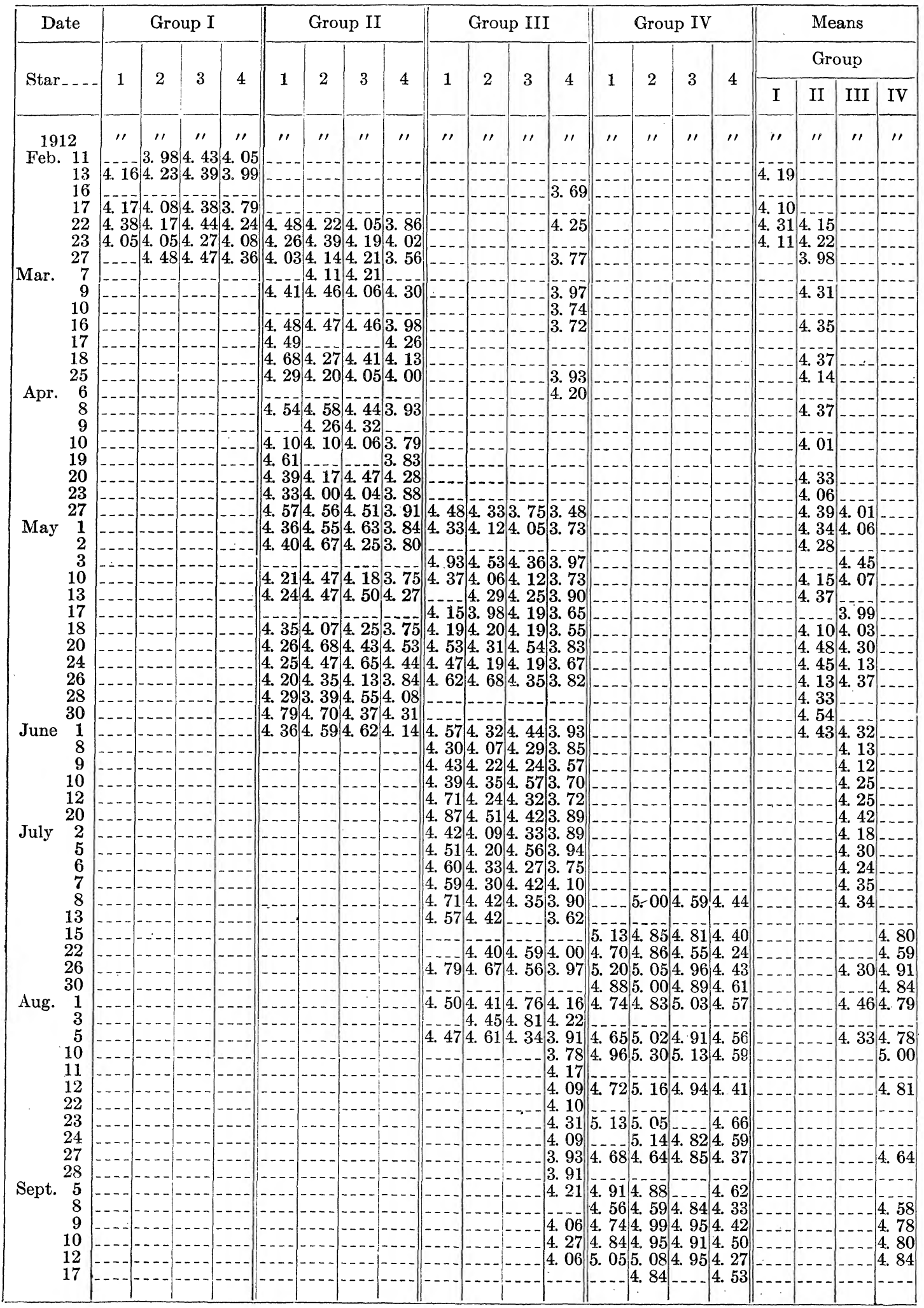


TABLE XXII.-Individual Latitudes-Continued

$\varphi=+38^{\circ} 55^{\prime} 10^{\prime \prime}+$

\begin{tabular}{|c|c|c|c|c|c|c|c|c|c|c|c|c|c|c|c|c|c|c|c|c|}
\hline \multirow{3}{*}{$\begin{array}{c}\text { Date } \\
\text { Star }\end{array}$} & \multicolumn{4}{|c|}{ Group I } & \multicolumn{4}{|c|}{ Group II } & \multicolumn{4}{|c|}{ Group III } & \multicolumn{4}{|c|}{ Group IV } & \multirow{2}{*}{\multicolumn{4}{|c|}{$\frac{\text { Means }}{\text { Group }}$}} \\
\hline & \multirow{2}{*}{1} & \multirow{2}{*}{2} & \multirow{2}{*}{3} & \multirow{2}{*}{4} & \multirow{2}{*}{1} & \multirow{2}{*}{2} & \multirow{2}{*}{3} & \multirow{2}{*}{4} & \multirow{2}{*}{1} & \multirow{2}{*}{2} & \multirow{2}{*}{3} & \multirow{2}{*}{4} & \multirow{2}{*}{1} & \multirow{2}{*}{2} & \multirow{2}{*}{3} & \multirow{2}{*}{4} & & & & \\
\hline & & & & & & & & & & & & & & & & & I & II & III & IV \\
\hline & " & " & 11 & 11 & '1 & 11 & $" \prime$ & $\prime \prime$ & 11 & $\prime \prime$ & "1 & "' & 11 & $" \prime$ & , & $\prime \prime$ & 11 & ' & "' & \\
\hline $\begin{array}{ll}\text { Oct. } & 6 \\
& 9\end{array}$ & & & & $\ldots$ & & & & & & & & $\begin{array}{l}\text { 4. } 2 \\
\text { 4. } 6\end{array}$ & $\begin{array}{l}\text { 4. } 83 \\
\text { 5. } 09\end{array}$ & 4. 68 & & 4. 02 & & & & 4.60 \\
\hline 10 & - & & & & & & & & & & & $\begin{array}{l}\text { 4. } 0 \\
\text { 4. } 6\end{array}$ & & & & & & & & \\
\hline .12 & 486 & & 51 & 4,83 & & & & & & & & $\begin{array}{l}4.4 \\
4.2\end{array}$ & & 476 & 49 & & 490 & & & $-\overline{6} 5$ \\
\hline 16 & 4.88 & 4. 79 & 5. 0 & 4. 50 & & & & & & & & 4. 6 & & 4. 74 & & 4.18 & $\begin{array}{l}\text { 4. } 80 \\
\text { 4. } 81\end{array}$ & & & 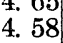 \\
\hline $\begin{array}{l}20 \\
21\end{array}$ & & & & $\ldots$ & & & & & & & & $\begin{array}{l}\text { 4. } 1 \\
4.2\end{array}$ & 4. 58 & 4. 68 & & 4. 11 & $\ldots$ & & & 4. 48 \\
\hline 26 & 4. 48 & 4. 18 & 4.6 & 4. 35 & - & & & & & & & 3. 8 & 4.41 & 4. 26 & 4. 4 & $3.7 \overline{6}$ & 4.42 & & & 4.21 \\
\hline $\begin{array}{l}28 \\
30\end{array}$ & $\begin{array}{l}4.77 \\
4.84\end{array}$ & $\begin{array}{l}\text { 4. } 80 \\
4.96\end{array}$ & 5. 1 & $\begin{array}{l}4.57 \\
4.56\end{array}$ & & & & & & & & 4. 0 & 4. 08 & 4. 26 & & $\begin{array}{l}\text { 4. } 04 \\
\text { 3. } 96\end{array}$ & $\begin{array}{l}4.82 \\
4.86 \\
\end{array}$ & & & $\begin{array}{l}\text { 4. } 2 \\
4.1\end{array}$ \\
\hline Nov. 3 & 4. 56 & 4. 73 & 4. 8 & 4. 48 & & & & & & & & $4 . \overline{2}$ & 4.50 & 4. 38 & 4. & 4. 26 & 4. 65 & & & 4.42 \\
\hline & 3.87 & 4.63 & 5. 0 & 4.65 & & & & & & & & 4.6 & & & & & 4.54 & & & \\
\hline 11 & 4.78 & 4. 56 & 4. 4 & 4. 23 & & & & & & & & 4. 3 & $--\overline{0}$ & 4.73 & & 3. 87 & 4.50 & & & \\
\hline $\begin{array}{l}16 \\
21\end{array}$ & 4.68 & 4.59 & 5. 0 & 4.20 & & & & & & & & 4. 3 & 4.40 & 4. 54 & & 3. 93 & 4. 63 & & & 4. 36 \\
\hline 22 & & & & & & & & & & & & 4. 4 & $\cdots$ & $\cdots$ & & $\cdots$ & $\cdots$ & & & \\
\hline 26 & 4.56 & 4.67 & 4. 9 & 4.60 & & & & & & & & & $\cdots$ & & & & $4 . \overline{70}$ & & & \\
\hline 29 & 4.70 & 4.60 & 4. 3 & 4.49 & & & & & & & & $\begin{array}{l}4.4 \\
4.4\end{array}$ & & & & & 4.54 & & & \\
\hline & & & & & & & & & & & & 4.7 & & & & & & & & \\
\hline Dec. 3 & 4. 75 & 4. 71 & $-\overline{-}$ & 4. 49 & & & & & & & & & & & & & & & & \\
\hline $\begin{array}{r}9 \\
10\end{array}$ & 4. 48 & & 4. 7 & 4. 16 & & & & & & & & 3.9 & & & & & 4. 46 & & & \\
\hline 12 & 4.7 & 4.68 & 4.5 & 3. $9 \overline{7}$ & & & & & & & & 4. 5 & & & & & 4.49 & & & \\
\hline & & & & & & & & & & & & & & & & & & & & \\
\hline
\end{tabular}

Let $\delta_{\mathrm{c}}$ equal any of these calculated declinations and $\delta_{\mathrm{o}}$ the observed declination of the star whose declinations is represented by $\delta_{c}$.

Let $\varphi$ equal the latitude of the instrument used in obtaining $\delta_{0}$.

$$
\varphi=\left(\delta_{0}-\delta_{0}\right) \frac{\sin 2 \varphi^{\prime}}{\sin 2 \delta_{0}}+\varphi^{\prime} .
$$

Values of $\varphi$ thus computed for each of the 16 stars are tabulated in the table.

In addition there have been included in the table latitudes obtained from the observed declinations of $\alpha$ Lyræ at those portions of a year when that star was not observed in a group. These latitudes appear under star IV, Group III. If all four stars were observed on the same night, the mean latitude of the group is shown in one of the four columns on the right-hand side of the page.

In Table XXIII are exhibited the mean differences found by subtracting each latitude in a.group from the mean of the group on those nights when all stars were observed. In column 1 are shown the periods of time in each year when all four stars in a group were observed on the same night, and the data in column 2 indicate the number of nights. In columns $3,4,5$, and 6 will be found the average departure of each individual latitude from the mean in each year. These when added together should be equal to zero.

In instances in which the observer was unable on account of clouds or other causes to observe the total number of stars in a group during a night's work, and only one, two, or three of them were observed, a method must be found by which 
the latitudes which were observed may be reduced to that mean daily latitude which would have resulted had all the stars in a group been observed.

To accomplish this there is shown in Table XXIII for each of the 16 stars a quantity designated by the expression "mean $r$." The method of deriving each of the values of "mean $r$ " has just been explained.

TABLE XXIII.-Reduction of Latitudes to Mean of Group

GROUP I

\begin{tabular}{|c|c|c|c|c|c|}
\hline Date & $\underset{\text { nights }}{\text { Number }}$ & Star 1 & Star 2 & Star 3 & Star 4 \\
\hline $\begin{array}{l}\text { Oct. 22, 1904, to Feb. 26, 1905 } \\
\text { Oct. 29, 1905, to Mar. 2, 1906 } \\
\text { Oct. 11, 1906, to Feb. 15, 1907 } \\
\text { Oct. 12, 1907, to Feb. 28, 1908 } \\
\text { Oct. 11, 1908, to Feb. 28, } 1909 \\
\text { Oct. 12, 1909, to Feb. 25, } 1910 \\
\text { Oct. 23, 1911, to Feb. 23, 1912 } \\
\text { Oct. 15, 1912, to Dec. 12, } 1912\end{array}$ & $\begin{array}{l}18 \\
26 \\
25 \\
33 \\
29 \\
33 \\
29 \\
12\end{array}$ & $\begin{array}{l}\quad \prime \prime \\
+0.095 \\
+0.047 \\
+0.079 \\
+0.079 \\
+0.081 \\
+0.065 \\
+0.013 \\
+0.047\end{array}$ & $\begin{array}{l}\quad \prime \prime \\
-0.025 \\
-0.042 \\
-0.047 \\
+0.009 \\
-0.011 \\
-0.002 \\
+0.070 \\
+0.004\end{array}$ & $\begin{aligned} & \prime \prime \\
&-0.194 \\
&-0.144 \\
&-0.193 \\
&-0.202 \\
&-0.261 \\
&-0.215 \\
&-0.255 \\
&-0.191\end{aligned}$ & $\begin{aligned} & \prime \prime \\
+ & 0.126 \\
+ & 0.134 \\
+ & 0.164 \\
+ & 0.112 \\
+ & 0.194 \\
+ & 0.154 \\
+ & 0.167 \\
+ & 0.237\end{aligned}$ \\
\hline Mean $r=$ & & +0.058 & -0.004 & -0.210 & +0.155 \\
\hline
\end{tabular}

GROUP II

\begin{tabular}{|c|c|c|c|c|c|}
\hline $\begin{array}{l}\text { Mar. 28, } 1904 \text {, to May 28, } 1904 \\
\text { Feb. 10, } 1905 \text {, to May 24, } 1905 \\
\text { Jan. 31, 1906, to May 23, } 1906 \\
\text { Jan. 30, 1907, to May 28, } 1907 \\
\text { Jan. 29, 1908, to June 2, } 1908 \\
\text { Feb. 2, 1909, to May 24, } 1909 \\
\text { Feb. 1, 1910, to May 18, } 1910 \\
\text { Jan. 30, 1911, to June 1, 1911 } \\
\text { Feb. 2, 1912, to June 1, 1912 }\end{array}$ & $\begin{array}{l}15 \\
17 \\
24 \\
17 \\
22 \\
26 \\
12 \\
22 \\
26\end{array}$ & $\begin{array}{l}-0.047 \\
-0.088 \\
-0.133 \\
-0.076 \\
-0.112 \\
-0.118 \\
-0.023 \\
-0.090 \\
-0.087\end{array}$ & $\begin{array}{l}-0.057 \\
-0.099 \\
-0.036 \\
-0.072 \\
-0.056 \\
-0.046 \\
-0.131 \\
-0.218 \\
-0.123\end{array}$ & $\begin{array}{l}-0.118 \\
-0.088 \\
=0.100 \\
=0.109 \\
-0.146 \\
=0.141 \\
=0.112 \\
=0.079 \\
-0.063\end{array}$ & $\begin{array}{l}+0.221 \\
+0.274 \\
+0.270 \\
+0.256 \\
+0.310 \\
+0.306 \\
+0.260 \\
+0.387 \\
+0.274\end{array}$ \\
\hline Mean $r=$ & & -0.092 & -0.092 & -0.106 & +0.289 \\
\hline
\end{tabular}

\section{GROUP III}

\begin{tabular}{|c|c|c|c|c|c|}
\hline $\begin{array}{l}\text { May } 1,1904 \text {, to Aug. } 6,1904 \\
\text { May } 27,1905 \text {, to June } 3,1905 \\
\text { May 3, } 1906 \text {, to June } 13,1906 \\
\text { May 4, 1907, to Aug. 6, } 1907 \\
\text { May 9, 1908, to Aug. 3, } 1908 \\
\text { May 2, 1909, to Aug. 3, } 1909 \\
\text { Apr. 30, 1910, to Aug. 5, 1910 } \\
\text { May 5, 1911, to Aug. } 7,1911 \\
\text { Apr. } 27,1912 \text {, to Aug. 5, 1912, }\end{array}$ & $\begin{array}{r}27 \\
2 \\
13 \\
25 \\
25 \\
28 \\
16 \\
24 \\
23\end{array}$ & $\begin{array}{l}-0.299 \\
-0.270 \\
=0.219 \\
=0.331 \\
=0.309 \\
=0.291 \\
=0.306 \\
=0.295 \\
-0.274\end{array}$ & $\begin{array}{l}-0.003 \\
+0.090 \\
+0.024 \\
+0.010 \\
+0.035 \\
+0.015 \\
+0.016 \\
+0.039 \\
+0.067\end{array}$ & $\begin{array}{l}-0.101 \\
-0.110 \\
-0.143 \\
-0.102 \\
-0.141 \\
-0.150 \\
-0.139 \\
-0.122 \\
-0.087\end{array}$ & $\begin{array}{l}+0.404 \\
+0.295 \\
+0.340 \\
+0.424 \\
+0.414 \\
+0.427 \\
+0.429 \\
+0.373 \\
+0.430\end{array}$ \\
\hline Mean $r=$ & $\ldots$ & -0.294 & +0.009 & -0.121 & +0.407 \\
\hline
\end{tabular}

GROUP IV

\begin{tabular}{|c|c|c|c|c|c|}
\hline $\begin{array}{l}\text { July } 13,1904 \text {, to Nov. } 17,1904 \\
\text { [Oct. } 29,1905] \\
\text { Sept. } 7,1906 \text {, to Nov. } 7,1906 \\
\text { July } 8,1907 \text {, to Nov. } 16,1907 \\
\text { July } 8,1908 \text {, to Nov. } 18,1908 \\
\text { July } 15,1909 \text {, to Nov. } 12,1909 \\
\text { July } 9,1910 \text {, to Nov. } 7,1910 \\
\text { July } 9,1911 \text {, to Nov. } 16,1911\end{array}$ & $\begin{array}{l}27 \\
{[1]} \\
9 \\
29 \\
35 \\
41 \\
25 \\
30 \\
22\end{array}$ & $\begin{array}{l}-0.013 \\
{[+0.130]} \\
+0.049 \\
+0.012 \\
+0.011 \\
+0.030 \\
+0.006 \\
+0.009 \\
-0.057\end{array}$ & $\begin{array}{l}-0.168 \\
{[-0.200]} \\
-0.194 \\
-0.230 \\
-0.188 \\
-0.184 \\
=0.197 \\
=0.175 \\
-0.126\end{array}$ & $\begin{array}{l}-0.086 \\
-0.220] \\
-0.051 \\
-0.028 \\
-0.094 \\
=0.074 \\
=0.072 \\
=0.138 \\
-0.169\end{array}$ & $\begin{array}{l}+0.267 \\
+0.280] \\
+0.199 \\
+0.268 \\
+0.275 \\
+0.227 \\
+0.262 \\
+0.322 \\
+0.351\end{array}$ \\
\hline Mean $r=$ & & 0.000 & -0.184 & -0.090 & +0.274 \\
\hline
\end{tabular}


Therefore when all the stars in a group are not observed on a night, to those which were observed has been applied the value of the "mean $r$ " which corresponds to each of these stars. The means of the latitudes thus corrected are then on the same system as they would have been had all the stars been observed.

In 1910-1911 star I, Group I, was wrongly identified in observing, and observations of the star for that period are lacking.

It will be noted that these several mean residuals are fairly uniform in amount in each year. A progressive change in any of them would indicate an erroneous proper motion.

In 1905, due to the absence of the observer on an eclipse expedition, Group IV is lacking in material upon which to base the residuals for that year.

It is not of material importance, in the reduction of individual latitudes to the mean of a group, that the numerical values of these corrections should be small, although it has its advantages.

It will be noted that the adopted declination of $\alpha$ Lyræ yields latitudes which need, when they are to be reduced to the mean of the four latitudes in Group III, a rather large plus correction. In other words, there is shown, in a general way, the magnitude of the correction necessary to bring its position as published by Boss to the system of AuwERs.

In order to abridge the publishing of tables of the deviations of these several mean residuals from the individual ones from which the probable error of an individual latitude could be ascertained the following method was used:

TABLE XXIV.-Probable Errors of an Individual Latitude

\begin{tabular}{|c|c|c|c|c|c|c|c|c|}
\hline \multirow{2}{*}{ Year } & \multicolumn{2}{|c|}{ Group I } & \multicolumn{2}{|c|}{ Group II ${ }^{\circ}$} & \multicolumn{2}{|c|}{ Group III } & \multicolumn{2}{|c|}{ Group IV } \\
\hline & $\begin{array}{l}\text { Number } \\
\text { of nights }\end{array}$ & & $\begin{array}{l}\text { Number } \\
\text { of nights }\end{array}$ & & $\begin{array}{l}\text { Number } \\
\text { of nights }\end{array}$ & & $\begin{array}{l}\text { Number } \\
\text { of nights }\end{array}$ & \\
\hline 1904 & & $" \prime$ & 15 & $\begin{array}{c}\prime \prime \\
\pm 0.109\end{array}$ & 27 & $\begin{array}{c}\prime \prime \\
\pm 0.086\end{array}$ & 27 & $\begin{array}{c}\prime \prime \prime \\
\pm 0.094\end{array}$ \\
\hline $\begin{array}{l}1904-5 \\
1905\end{array}$ & 18 & \pm 0.121 & 17 & +0.164 & 2 & & & \\
\hline $1905-6$ & 26 & \pm 0.089 & & & & \pm 0.090 & & \\
\hline 1906 & & 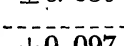 & 24 & \pm 0.101 & 13 & \pm 0.128 & 9 & \pm 0.145 \\
\hline $\begin{array}{l}1906-7 \\
1907\end{array}$ & 25 & \pm 0.097 & 17 & \pm 0.084 & 25 & \pm 0.078 & 29 & \pm 0.084 \\
\hline $\begin{array}{l}1907-8 \\
1908\end{array}$ & 33 & \pm 0.094 & 22 & \pm 0.098 & 25 & \pm 0.073 & 35 & \pm 0.083 \\
\hline $1908-9$ & 29 & \pm 0.095 & 0 & +0101 & 28 & +0095 & 41 & +0085 \\
\hline $1909-1$ & 33 & \pm 0.080 & & \pm 0.101 & & \pm 0.090 & 41 & \pm 0.080 \\
\hline 1910 & $\cdots$ & 10.00 & 12 & \pm 0.110 & 16 & \pm 0.095 & 25 & \pm 0.076 \\
\hline $\begin{array}{l}1910-1 \\
1911 \ldots\end{array}$ & & & 22 & \pm 0.115 & 24 & \pm 0.109 & 30 & \pm 0.098 \\
\hline $\begin{array}{l}1911-1 \\
1912\end{array}$ & $\begin{array}{l}29 \\
12\end{array}$ & $\begin{array}{l} \pm 0.105 \\
\pm 0.110\end{array}$ & 26 & \pm 0.113 & 23 & \pm 0.092 & 22 & \pm 0.091 \\
\hline Mea & $\ldots \ldots$ & \pm 0.097 & (a) & \pm 0.110 & 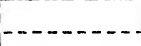 & \pm 0.092 & 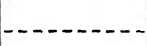 & \pm 0.089 \\
\hline
\end{tabular}

In forming the weighted means for the series the number of nights were taken into consideration.

The mean residuals exhibited in Table XXIII have involved in them two quantities - one, the accidental error of an observation and the other the difference between each declination used and that system which would make all the latitudes equal in amount. The second is, of course, systematic.

$$
101141^{\circ}-26 \dagger-P T \text { I }-12
$$


We need not concern ourselves with the value of the variation of latitude at the time observed declinations of stars in a group were secured, because it would have equal effect on all and would not appear in these residuals as a systematic error.

By the aid of the several values of $r$ of Table XXIII there has been computed the probable error of a single latitude in each of the years. These probable errors which are given in Table XXIV were derived as follows:

Let $n$ represent the number of stars in a single group, in which all stars included in it have been observed on $m$ nights. The difference between the mean latitude of a group and the individual latitudes obtained from the declination of each star was taken, and this we call $d$. The value of $r$ in each instance is the average value of $d$ and was computed separately for each star, as is shown in Table XXIII.

In a collection of a large number of observations secured in accordance with the plan outlined above the chances are that accidental errors of observing would be in a large measure eliminated, and hence $d$ in each case would represent the correction that each declination needs to reduce it to that system which would give the same value to each latitude.

The quantities designated by $v$ were formed by the use of the expression,

$$
v=r-d,
$$

from which the probable error $\epsilon$ of a single latitude was computed by the aid of the following formula,

$$
\epsilon= \pm 0.674 \sqrt{\frac{\Sigma v^{2}}{(m-1)(n-1)}} .
$$

A scrutiny of these probable errors of a single latitude will indicate that declinations obtained with the instrument in the winter months as an average, show a larger probable error than is indicated for those which were observed in the summer time. Group II was observed in that period of the year when the effect of winter conditions was at a maximum. The probable error of a latitude derived from the observations of the stars in that group is numerically larger than are similar probable errors obtained from positions of each of the other stars in the other three groups.

Group I was also observed when winter conditions were nearly the same as for Group II, and the probable error of a latitude determined in that portion of the year is next in magnitude to similar probable errors for latitudes derived from stars in Group II. Both Groups III and IV, which were observed from the commencement of summer until late fall, show smaller probable errors than either of the other two groups.

In Table XXV there are represented the daily mean latitudes, as derived from the declinations of all stars in a group. The heading, "No" indicates the number of latitudes included in each daily mean.

Attention is again called to the fact that in those cases in which less than a complete group was observed on a night, each latitude which was obtained has been corrected by applying to it the proper correction taken from Table XXIII under the heading "mean $r$," so that the mean of the latitudes which were secured on a night would be on the same system as if all of them had been observed. 
TABLE XXV.-Daily Mean Latitude, by Groups

$\varphi=+38^{\circ} 55^{\prime} 10^{\prime \prime}+$

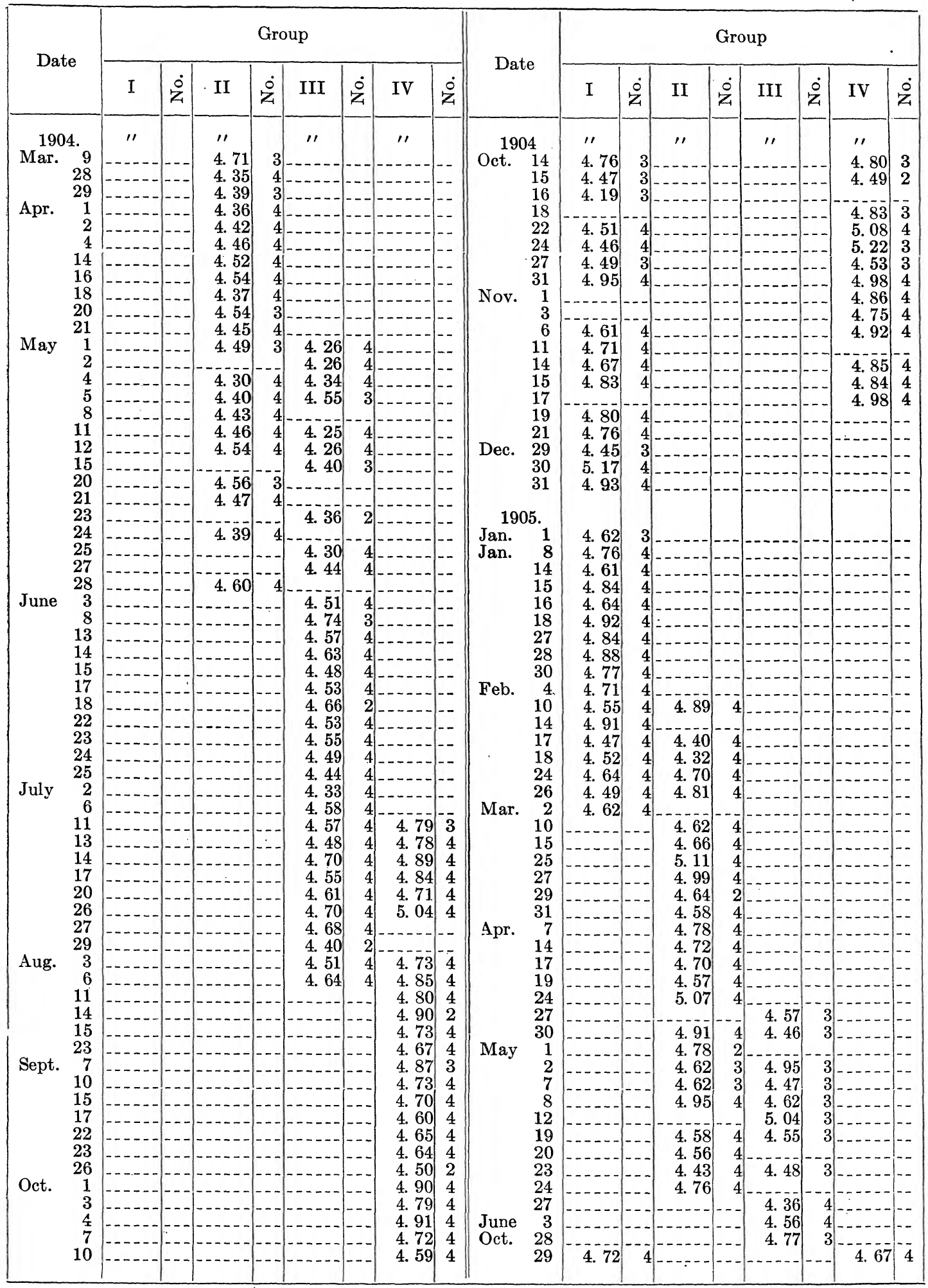


A CLXXX

PRIME VERTICAL TRANSIT INSTRUMENT.

TABLe XXV.-Daily Mean Latitude, by Groups-Continued

$\varphi=+38^{\circ} 55^{\prime} 10^{\prime \prime}+$

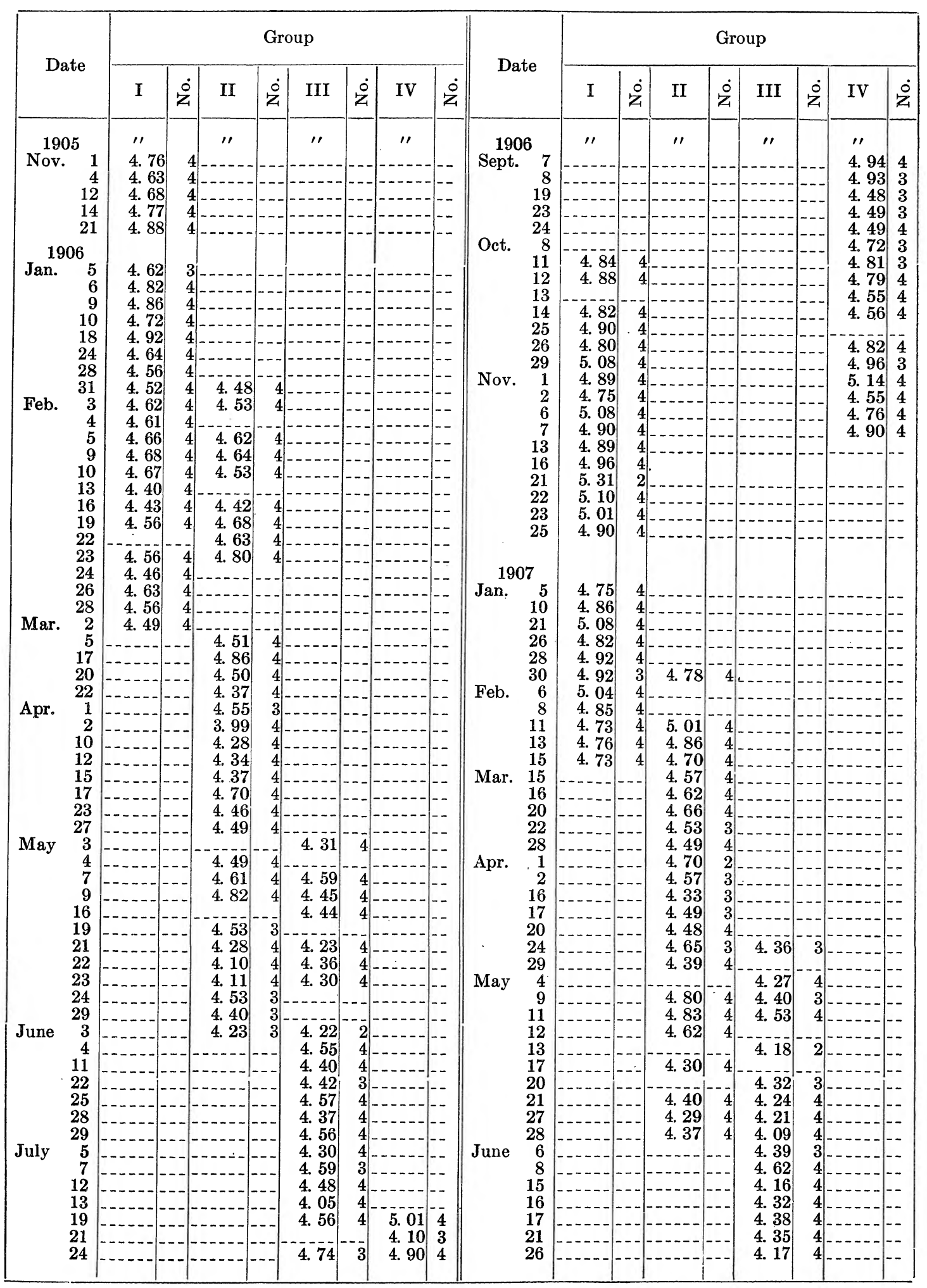


TABLe XXV.-Daily Mean Latitude, by Groups-Continued

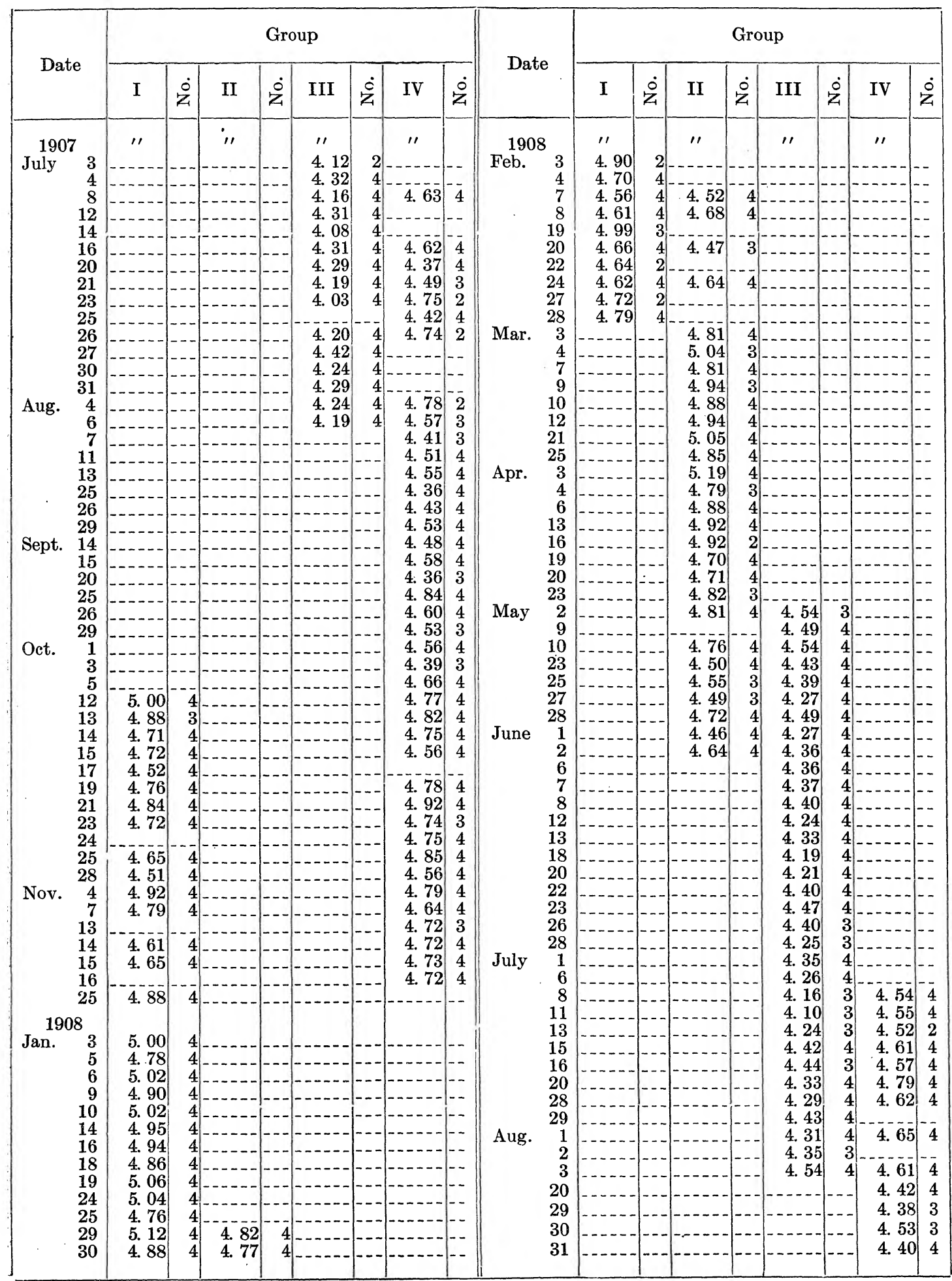


A ClixXXil Prime vertical transit instrument.

TABLE XXV.-Daily Mean Latitude, by Groups-Continued

$\varphi=+38^{\circ} 55^{\prime} 10^{\prime \prime}+$

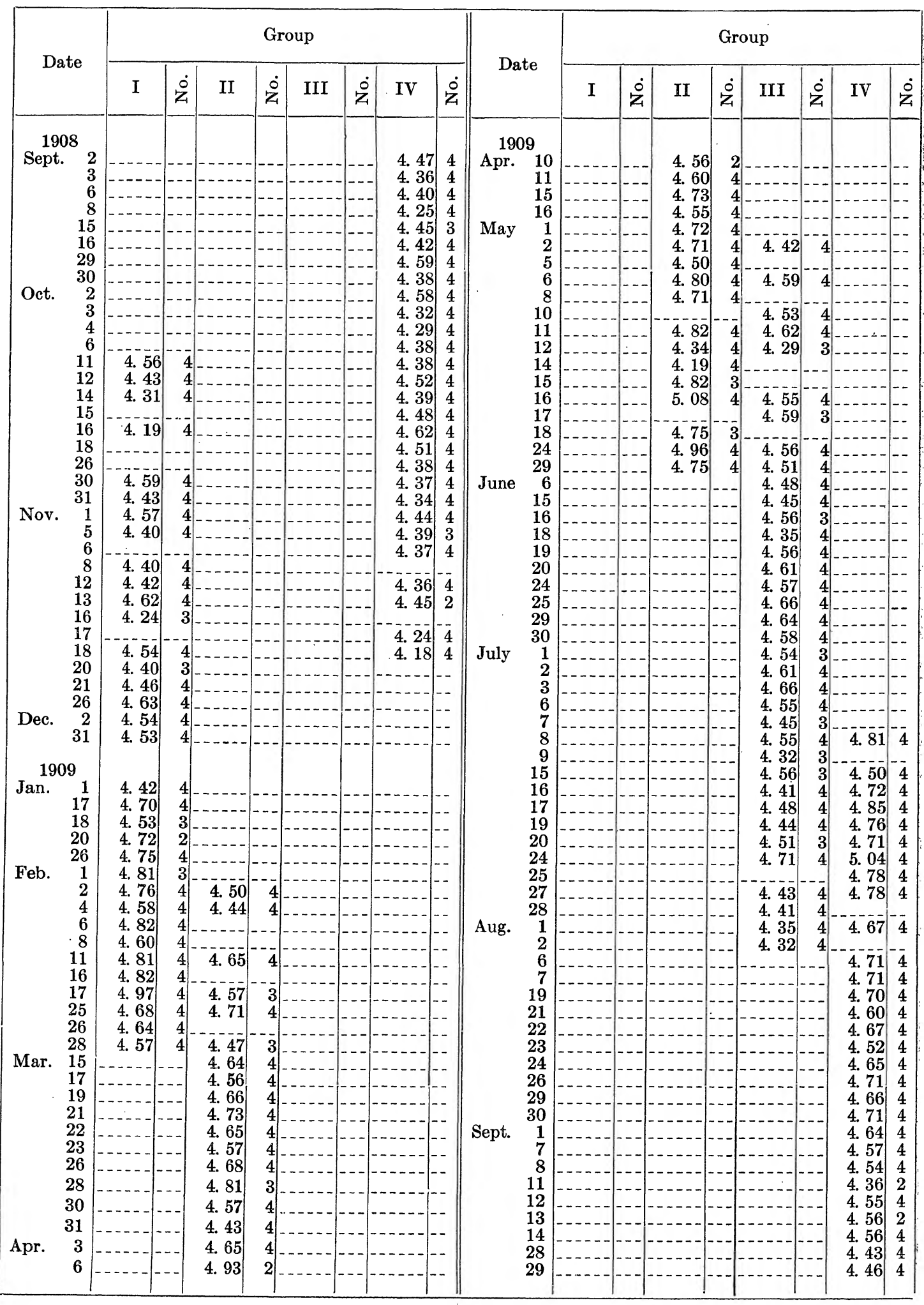


TABLe XXV.-Daily Mean Latitude, by Groups-Continued

$\varphi=+38^{\circ} 55^{\prime} 10^{\prime \prime}+$

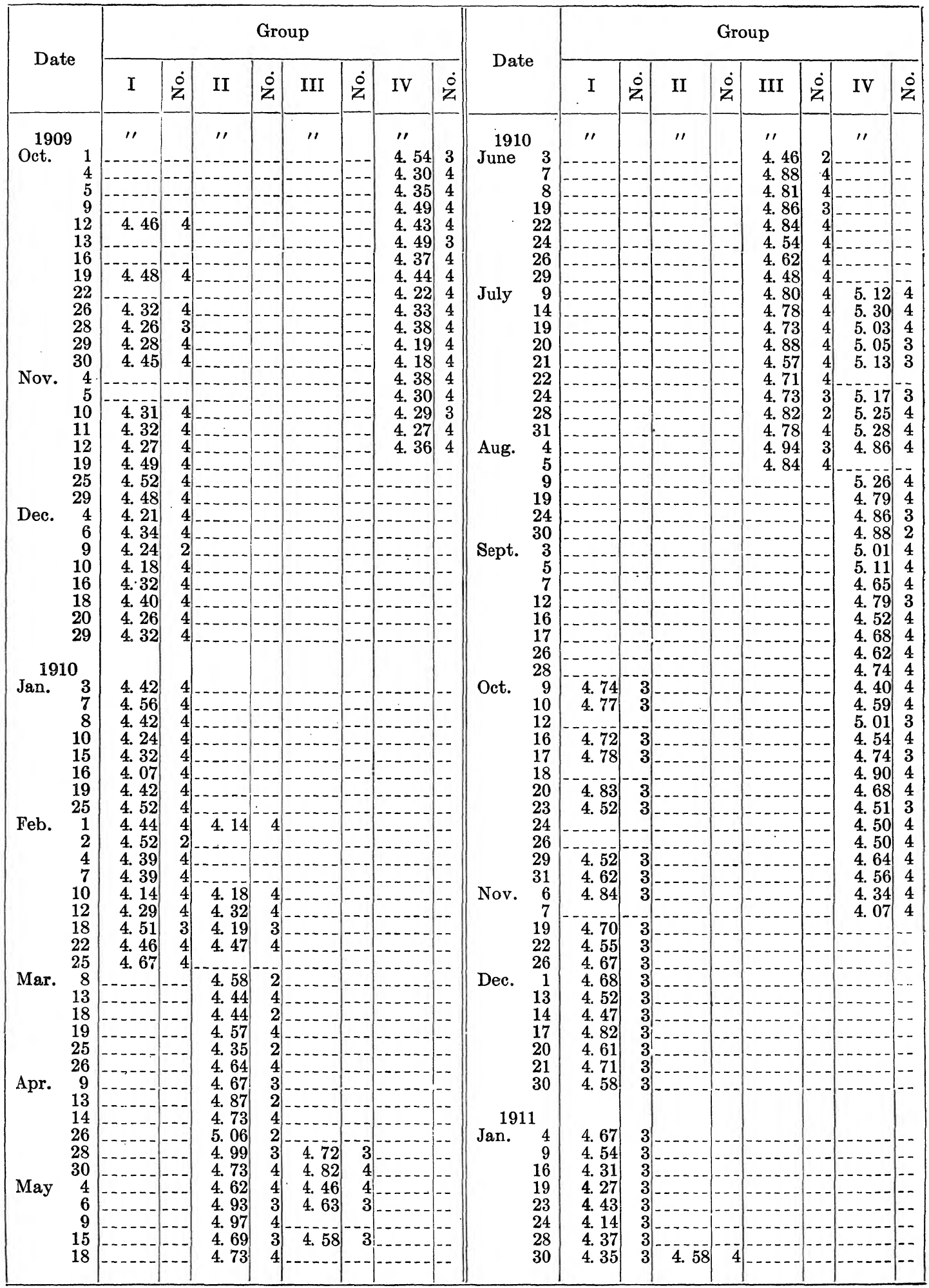


TABLe XXV.-Daily Mean Latitude, by Groups-Continued

$\varphi=+38^{\circ} 55^{\prime} 10^{\prime \prime}+$

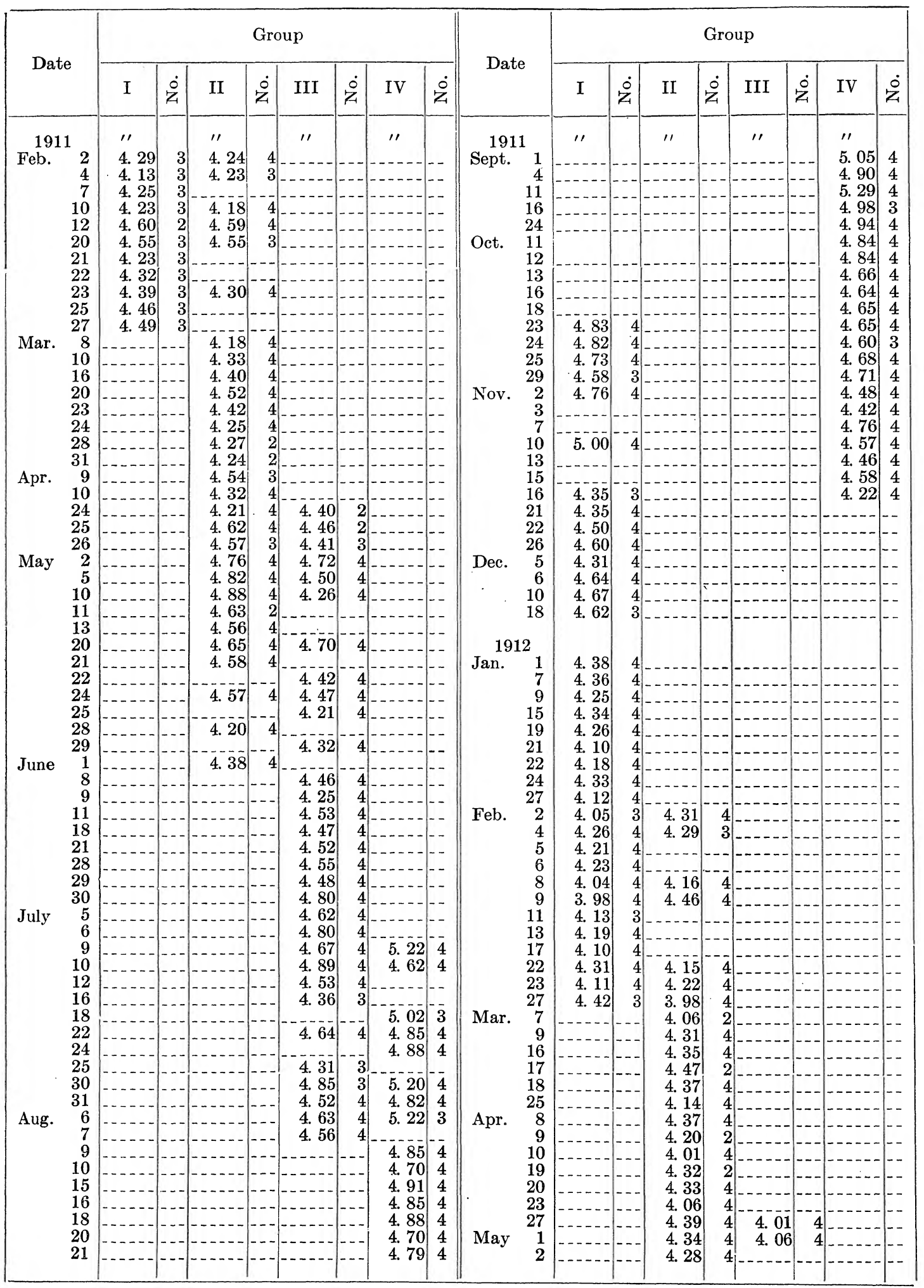


TABLe XXV.-Daily Mean Latitude, by Groups-Continued

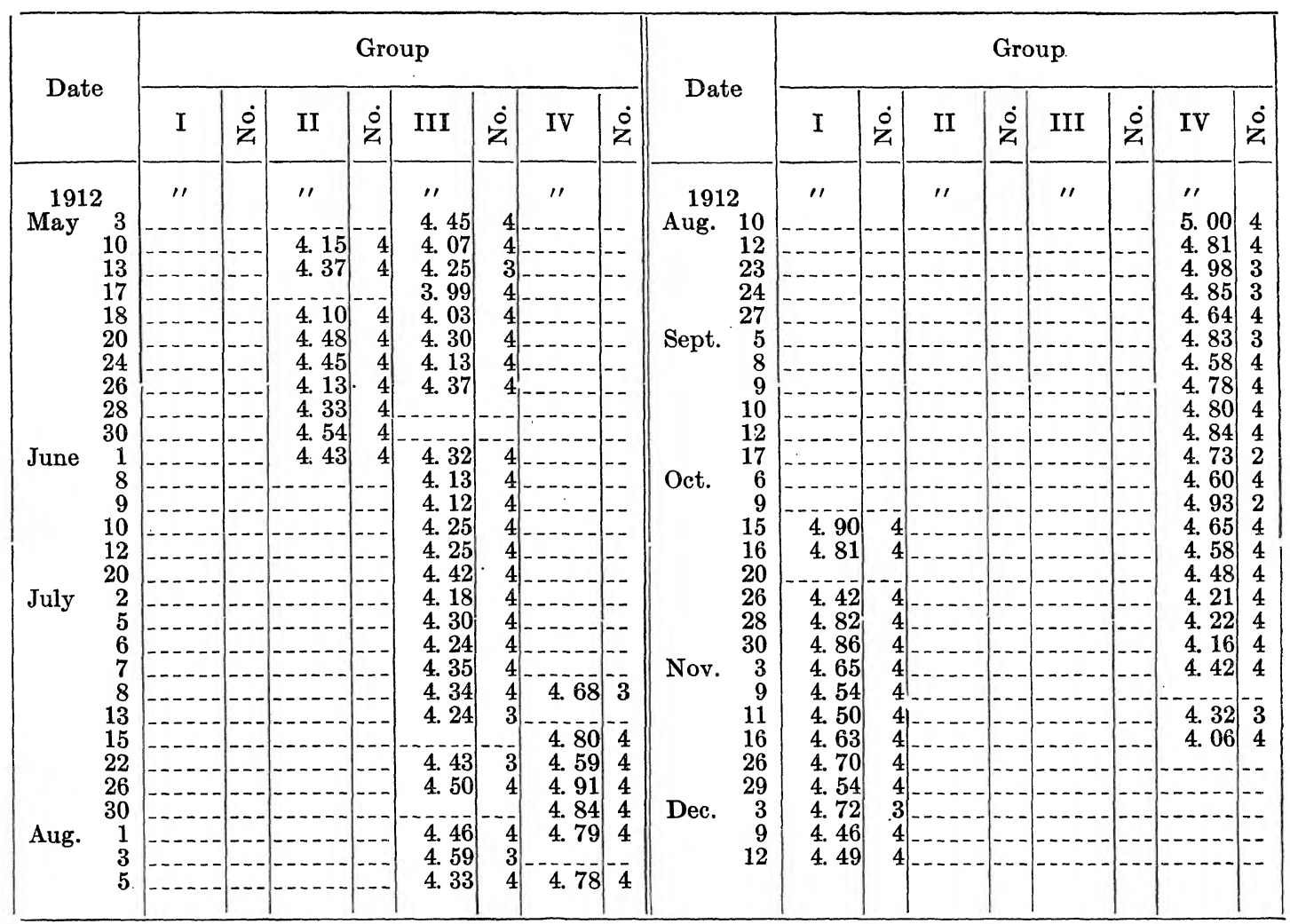

With the data contained in Table XXV we are prepared to proceed to solve for the correction to the adopted aberration constant.

\section{EXPLANATION OF FORMULE}

In the American Ephemeris the terms in the reduction of a star from its mean to apparent place, namely, $c^{\prime} C+d^{\prime} D$, are those, which include the correction for aberration. The values of $c^{\prime}$ and $d^{\prime}$ are,

$$
\begin{aligned}
& c^{\prime}=\tan \omega \cos \delta-\sin \alpha \sin \delta, \\
& d^{\prime}=\cos \alpha \sin \delta,
\end{aligned}
$$

in which $\alpha$ is the right ascension of the star, $\delta$ its declination, both at the beginning of the Besselian fictitious year, $\omega$ the obliquity of the ecliptic at the same epoch.

In the discussion here presented,

$$
\begin{aligned}
& \mathrm{C}=-20.5^{\prime \prime} \cos \omega \cos \odot \\
& \mathrm{D}=-20.5^{\prime \prime} \sin \odot \\
& \omega=\text { the obliquity as defined above. } \\
& \odot=\text { the sun's true longitude. }
\end{aligned}
$$




\section{A ClXXXil PRime Vertical transit instrument.}

Let $\kappa=20.5^{\prime \prime}\left[-c^{\prime} \cos \omega \cos \odot-d^{\prime} \sin \odot\right]$ and assume that $20.5^{\prime \prime}+y$ is the true value of the aberration constant, and $\kappa+\delta \kappa$ the corresponding correction; then

$$
\kappa+\Delta \kappa=\left(20.5^{\prime \prime}+y\right)\left[-c^{\prime} \cos \omega \cos \odot-d^{\prime} \sin \odot\right] .
$$

By division, $\frac{\kappa}{\kappa+\Delta \kappa}=\frac{20.5}{20.5+y}$, from which $\Delta_{\kappa}=\kappa . x$ when $x$ is written for $\frac{y}{20.5}$.

Let $\varphi_{1}, \varphi_{2}, \varphi_{3}, \varphi_{4}$ be the values of the latitude given by Groups I, II, III, and IV and let $\Delta_{1}, \Delta_{2}, \Delta_{3}, \Delta_{4}$ be the constant parts of the correction which these values require. The true values of the latitude will be,

$$
\begin{aligned}
\varphi & =\varphi_{1}+\Delta_{1}+\kappa_{1} x \\
& =\varphi_{2}+\Delta_{2}+\kappa_{2} x \\
& =\varphi_{3}+\Delta_{3}+\kappa_{3} x \\
& =\varphi_{4}+\Delta_{4}+\kappa_{4} x .
\end{aligned}
$$

If we take values of the latitude derived from two groups which have been observed on the same night, one before and the other after midnight, and subtract one from the other, consecutively, we have, after the cycle is completed,

$$
\begin{aligned}
& O=\varphi_{1}-\varphi_{2}+\left(\Delta_{1}-\Delta_{2}\right)+\left(\kappa_{1}-\kappa_{2}\right) x \\
& =\varphi_{2}-\varphi_{3}+\left(\Delta_{2}-\Delta_{3}\right)+\left(\kappa_{2}-\kappa_{3}\right) x \\
& =\varphi_{3}-\varphi_{4}+\left(\Delta_{3}-\Delta_{4}\right)+\left(\kappa_{3}-\kappa_{4}\right) x
\end{aligned}
$$

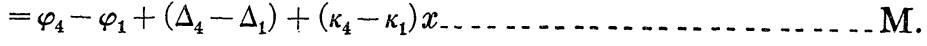

By addition we find,

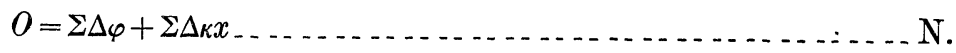

The above method seems to be one of the simplest by which a correction to the adopted constant of aberration can be secured from a series of observed declinations obtained with the prime vertical transit instrument. Its development in the above form is after the plan presented by the late Prof. Charles L. Doolitrie in Part II, Volume I, of the Publications of the University of Pennsylvania. 
TABLE XXVI.-Aberration

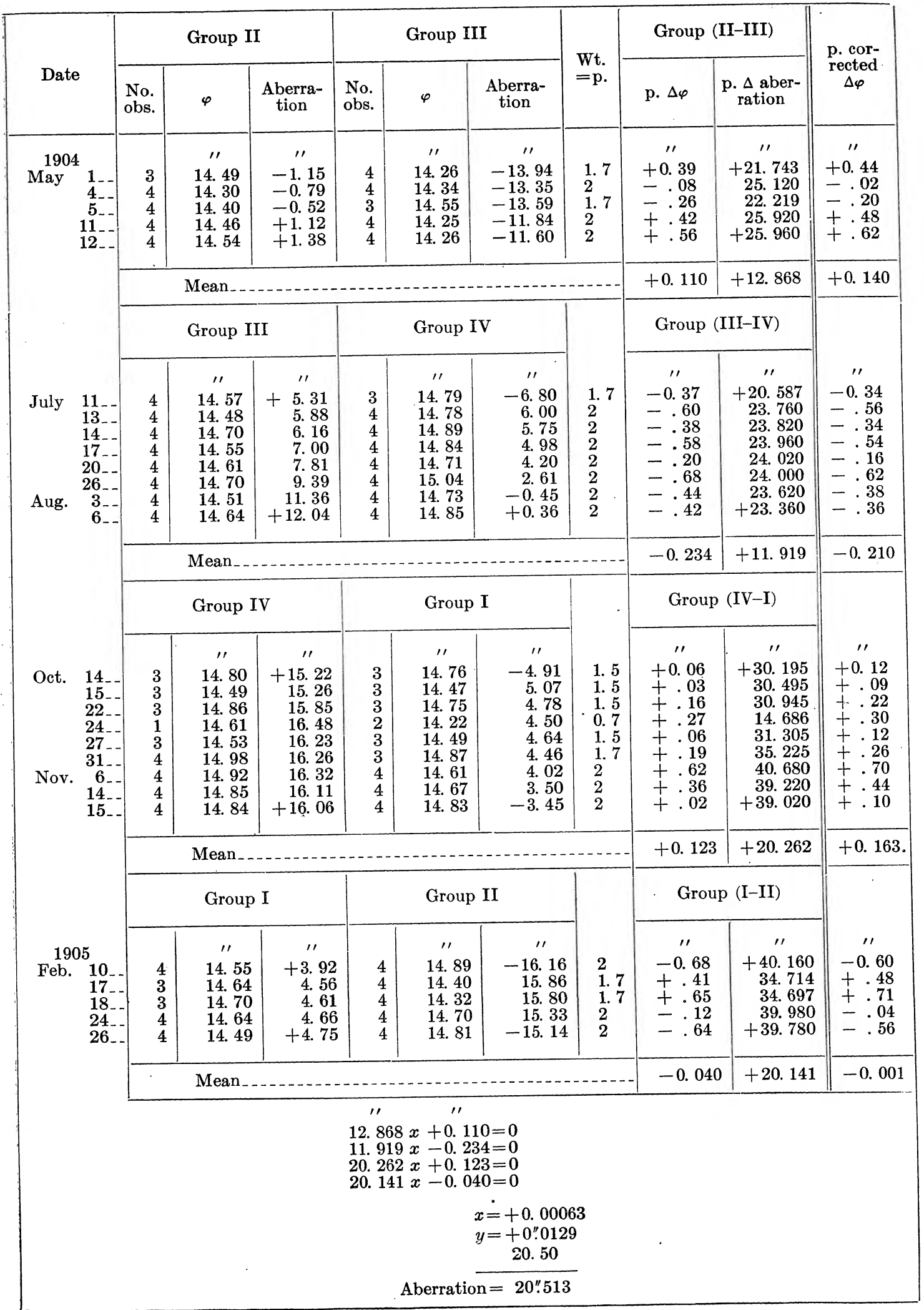


PRIME VERTICAL TRANSIT INSTRUMENT.

TABLE XXVI.-Aberration-Continued

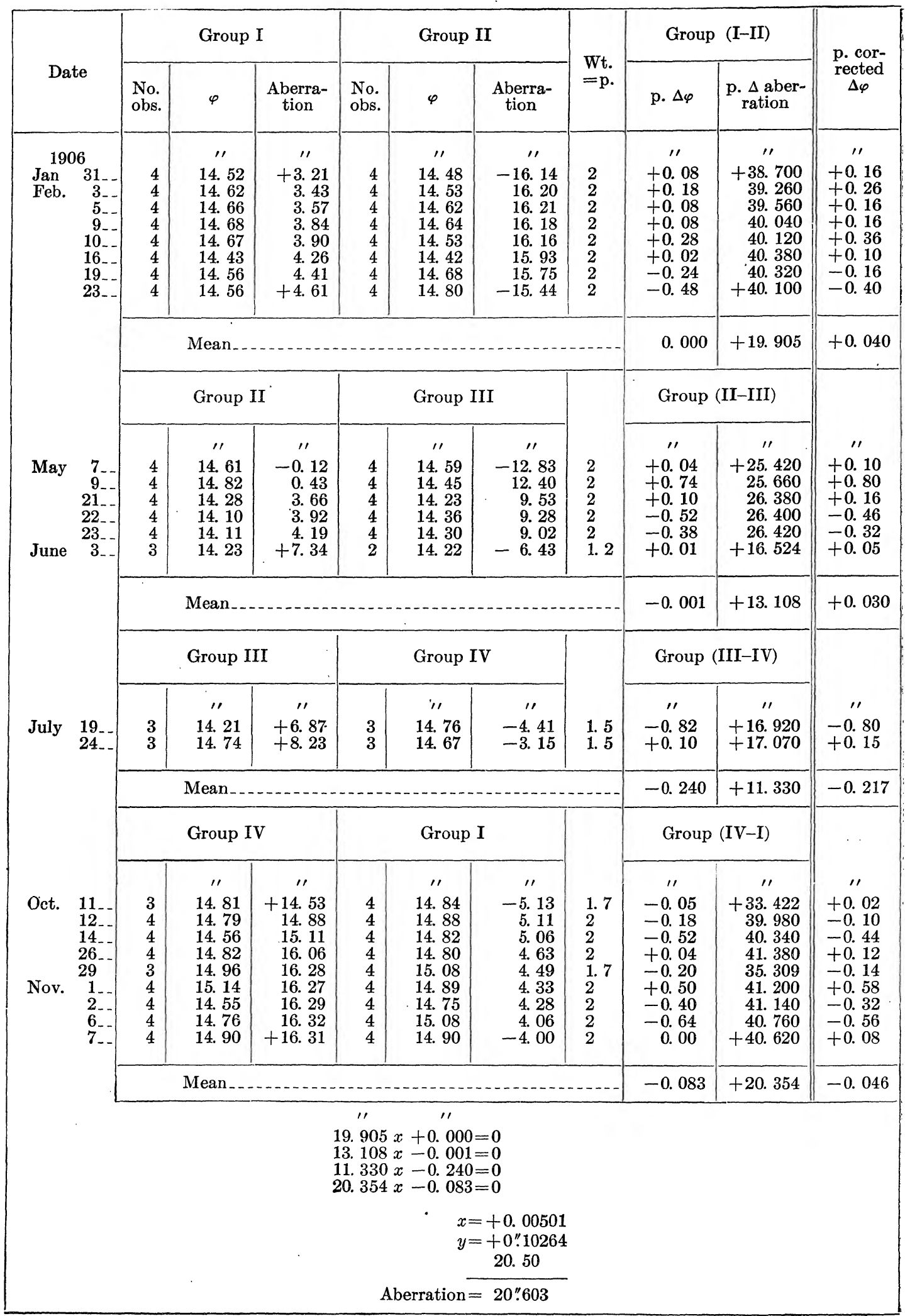


INTRODUCTION.

A ClXXXix

TABLE XXVI.-Aberration-Continued

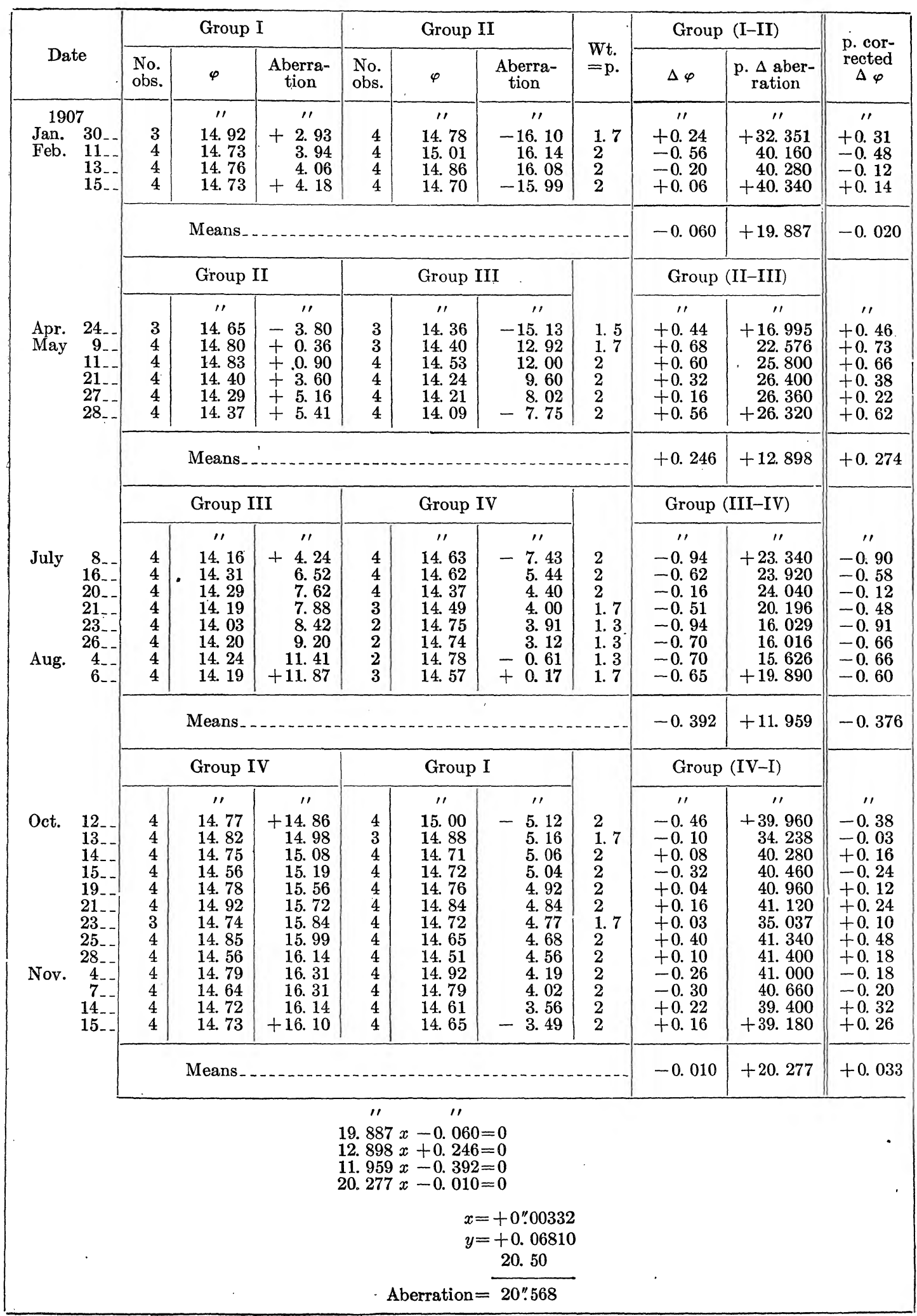


PRIME VERTICAL TRANSIT INSTRUMENT.

TabLe XXVI.-Aberration-Continued

\begin{tabular}{|c|c|c|c|c|c|c|c|c|c|c|c|}
\hline \multirow{2}{*}{\multicolumn{2}{|c|}{ Date }} & \multicolumn{3}{|c|}{ Group I } & \multicolumn{3}{|c|}{ Group II } & \multirow{2}{*}{$\begin{array}{l}\text { Wt. } \\
=\text { p. }\end{array}$} & \multicolumn{2}{|c|}{ Group (I-II) } & \multirow{2}{*}{$\begin{array}{c}\text { p. cor- } \\
\text { rected } \\
\Delta \varphi\end{array}$} \\
\hline & & $\begin{array}{l}\text { No. } \\
\text { obs. }\end{array}$ & $\varphi$ & $\begin{array}{c}\text { Aberra- } \\
\text { tion }\end{array}$ & $\begin{array}{l}\text { No. } \\
\text { obs. }\end{array}$ & $\varphi$ & $\begin{array}{l}\text { Aberra- } \\
\text { tion }\end{array}$ & & $\Delta \varphi$ & $\begin{array}{l}\text { p. } \Delta \text { aber- } \\
\text { ration }\end{array}$ & \\
\hline \multirow{3}{*}{\multicolumn{2}{|c|}{\begin{tabular}{rr}
\multicolumn{2}{c}{1908} \\
Jan. & 29 \\
& $30-$ \\
Feb. & $7-$ \\
8 & \\
& 20 \\
24 & \\
& $24-$
\end{tabular}}} & $\begin{array}{l}4 \\
4 \\
4 \\
4 \\
4 \\
4\end{array}$ & $\begin{array}{l}\prime \prime \\
15.12 \\
14.88 \\
14.56 \\
14.61 \\
14.66 \\
14.62\end{array}$ & $\begin{array}{r}\prime \prime \\
+3.01 \\
3.09 \\
3.67 \\
3.74 \\
4.44 . \\
+4.62 . \\
\end{array}$ & $\begin{array}{l}4 \\
4 \\
4 \\
4 \\
3 \\
4\end{array}$ & $\begin{array}{l}\text { " } \\
14.82 \\
14.77 \\
14.52 . \\
14.68 \\
14.47 \\
14.64\end{array}$ & \begin{tabular}{r}
\multicolumn{1}{c}{ ' } \\
-16.06 \\
16.10 \\
16.21 \\
16.20 \\
15.80 \\
-15.39
\end{tabular} & $\begin{array}{l}2 \\
2 \\
2 \\
2 \\
1.7 \\
2\end{array}$ & $\begin{array}{c}\prime \prime \\
+0.60 \\
+0.22 \\
+0.08 \\
-0.14 \\
+0.32 \\
-0.04\end{array}$ & $\begin{array}{r}1 \prime \\
+38.140 \\
38.380 \\
39.760 \\
39.880 \\
34.408 \\
+40.020\end{array}$ & $\begin{array}{c}1 \prime \\
+0.68 \\
+0.30 \\
+0.16 \\
-0.06 \\
+0.39 \\
+0.04\end{array}$ \\
\hline & & \multicolumn{7}{|c|}{ Mean } & +0.089 & +19.708 & +0.129 \\
\hline & & \multicolumn{3}{|c|}{ Group II } & \multicolumn{3}{|c|}{ Group III } & & \multicolumn{2}{|c|}{ Group (II-III) } & \\
\hline $\begin{array}{l}\text { May } \\
\text { June }\end{array}$ & $\begin{array}{r}2-- \\
10-- \\
23-- \\
25-- \\
27-- \\
28-- \\
1-- \\
2--\end{array}$ & $\begin{array}{l}4 \\
4 \\
4 \\
3 \\
3 \\
4 \\
4 \\
4\end{array}$ & $\begin{array}{c}11 . \\
14.81 \\
14.76 \\
14.50 \\
14.55 \\
14.49 \\
14.72 \\
14.46 \\
14.64\end{array}$ & $\begin{array}{r}1 \prime \\
-1.34 \\
+0.84 \\
4.32 \\
4.66 \\
5.74 \\
5.61 \\
6.61 \\
+6.86\end{array}$ & $\begin{array}{l}3 \\
4 \\
4 \\
4 \\
4 \\
4 \\
4 \\
4\end{array}$ & $\begin{array}{l}\text { '" } \\
\text { 14. } 54 . \\
14.54 \\
14.43 \\
14.39 \\
14.27 \\
14.49 \\
14.27 \\
14.36\end{array}$ & \begin{tabular}{r}
\multicolumn{1}{c}{$" \prime$} \\
-14.17 \\
12.06 \\
8.88 \\
8.35 \\
7.82 \\
7.54 \\
6.44 \\
-6.16
\end{tabular} & $\begin{array}{l}1.7 \\
2 \\
2 \\
1.7 \\
1.7 \\
2 \\
2 \\
2\end{array}$ & $\begin{array}{c}\prime \prime \\
+0.46 \\
+0.44 \\
+0.14 \\
+0.27 \\
+0.37 \\
+0.46 \\
+0.38 \\
+0.56\end{array}$ & $\begin{array}{r}\prime \prime \\
+21.811 \\
25.800 \\
26.400 \\
22.117 \\
23.052 \\
26.300 \\
26.100 \\
+26.040\end{array}$ & $\begin{array}{c} \\
\quad \prime \prime \\
+0.51 \\
+0.50 \\
+0.20 \\
+0.32 \\
+0.42 \\
+0.52 \\
+0.44 \\
+0.62\end{array}$ \\
\hline & \multicolumn{7}{|c|}{ Mean $\ldots$} & +0.204 & +13.087 & +0.234 \\
\hline & & \multicolumn{3}{|c|}{ Group III } & \multicolumn{3}{|c|}{ Group IV } & & \multicolumn{2}{|c|}{ Group (III-IV) } & \\
\hline \multirow[t]{3}{*}{$\begin{array}{l}\text { July } \\
\text { Aug. }\end{array}$} & \multirow[t]{3}{*}{$\begin{array}{r}8-- \\
11-- \\
13-- \\
15-- \\
16-- \\
20-- \\
28-- \\
1-- \\
3--\end{array}$} & $\begin{array}{l}3 \\
3 \\
3 \\
4 \\
3 \\
4 \\
4 \\
4 \\
4\end{array}$ & $\begin{array}{l}\text { "I } \\
14.16 \\
14.10 \\
14.24 \\
14.42 \\
14.44 \\
14.33 \\
14.29 \\
14.31 \\
14.54\end{array}$ & $\begin{array}{r}1 . \\
+4.33 \\
5.64 \\
5.31 \\
6.44 \\
6.16 \\
7.82 \\
9.90 \\
10.88 \\
+11.35 \\
\end{array}$ & $\begin{array}{l}4 \\
4 \\
2 \\
4 \\
4 \\
4 \\
4 \\
4 \\
4\end{array}$ & $\begin{array}{l}\prime \prime \\
14.54 \\
14.55 \\
14.52 \\
14.61 \\
14.57 \\
14.79 \\
14.62 \\
14.65 \\
14.61\end{array}$ & $\begin{array}{r}\prime \prime \\
-7.24 \\
6.51 \\
5.74 \\
5.50 \\
5.25 \\
4.21 \\
2.08 \\
1.00 \\
-0.46 \\
\end{array}$ & $\begin{array}{l}1.7 \\
1.7 \\
1.2 \\
2 \\
1.7 \\
2 \\
2 \\
2 \\
2\end{array}$ & $\begin{array}{c}\prime \prime \\
-0.65 \\
-0.76 \\
-0.34 \\
-0.38 \\
-0.22 \\
-0.92 \\
-0.66 \\
-0.68 \\
-0.14\end{array}$ & $\begin{array}{r}\prime \prime \\
+19.669 \\
20.655 \\
13.260 \\
23.880 \\
19.397 \\
24.060 \\
23.960 \\
23.760 \\
+23.620\end{array}$ & $\begin{array}{c}\prime \prime \\
-0.61 \\
-0.73 \\
-0.31 \\
-0.34 \\
-0.19 \\
-0.88 \\
-0.60 \\
-0.62 \\
-0.08\end{array}$ \\
\hline & & \multicolumn{7}{|c|}{ Mean } & -0.291 & +11.795 & -0.267 \\
\hline & & \multicolumn{3}{|c|}{ Group IV } & \multicolumn{3}{|c|}{ Group I } & & \multicolumn{2}{|c|}{ Group (IV-I) } & \\
\hline \multirow[t]{2}{*}{. } & \multirow[t]{5}{*}{$\begin{array}{r}11-- \\
12-- \\
14-- \\
16-- \\
30-- \\
31-- \\
1-- \\
5-- \\
12- \\
13-- \\
18--\end{array}$} & $\begin{array}{l}4 \\
4 \\
4 \\
4 \\
4 \\
4 \\
4 \\
3 \\
4 \\
2 \\
4\end{array}$ & $\begin{array}{l}\text { '" } \\
14.38 \\
14.52 \\
14.39 \\
14.62 \\
14.37 \\
14.34 \\
14.44 \\
14.39 \\
14.36 \\
14.45 \\
14.18\end{array}$ & $\begin{array}{r}\prime \prime \\
+14.83 \\
14.94 \\
15.16 \\
15.36 \\
16.24 \\
16.26 \\
16.29 \\
16.23 \\
16.19 \\
16.15 \\
+15.88\end{array}$ & $\begin{array}{l}4 \\
4 \\
4 \\
4 \\
4 \\
4 \\
4 \\
4 \\
4 \\
4 \\
4\end{array}$ & $\begin{array}{l}\text { 'I } \\
\text { 14. } 56 \\
\text { 14. } 43 \\
14.31 \\
14.19 \\
\text { 14. } 59 \\
14.43 \\
14.57 \\
14.40 \\
14.42 \\
14.62 \\
14.54\end{array}$ & $\begin{array}{r}11 \\
-5.12 \\
5.10 \\
5.05 \\
4.99 \\
4.42 \\
4.37 \\
4.32 \\
4.10 \\
3.65 \\
3.58 \\
-3.22\end{array}$ & $\begin{array}{l}2 \\
2 \\
2 \\
2 \\
2 \\
2 \\
2 \\
1.7 \\
2 \\
1.3 \\
2\end{array}$ & $\begin{array}{c}\prime \prime \\
-0.36 \\
+0.18 \\
+0.16 \\
+0.86 \\
-0.44 \\
-0.18 \\
-0.26 \\
-0.02 \\
-0.12 \\
-0.22 \\
-0.72\end{array}$ & $\begin{array}{r}\prime \prime \\
+39.900 \\
40.080 \\
40.420 \\
40.700 \\
41.320 \\
41.260 \\
41.220 \\
34.561 \\
39.680 \\
25.649 \\
+38.200\end{array}$ & $\begin{array}{c}\prime \prime \\
-0.28 \\
+0.26 \\
+0.24 \\
+0.94 \\
-0.36 \\
-0.10 \\
-0.18 \\
+0.05 \\
-0.02 \\
-0.16 \\
-0.62\end{array}$ \\
\hline & & \multicolumn{7}{|c|}{ Mean } & -0.053 & +20.143 & -0.011 \\
\hline - & & & & & $\begin{array}{l}\prime \prime \\
\text { 19. } 708 \\
\text { 13. } 087 \\
\text { 11. } 795 \\
\text { 20. } 143\end{array}$ & 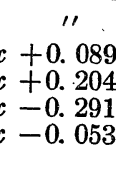 & $\begin{array}{l}=0 \\
=0 \\
=0 \\
0\end{array}$ & & & & \\
\hline . & & & & & & & $\begin{aligned}= & +0.00079 \\
= & +0.01620 \\
& 20.50\end{aligned}$ & & & & \\
\hline & & & & & & erration $=$ & $=20 " .516$ & & & & \\
\hline
\end{tabular}


TABLE XXVI.-Aberration-Continued

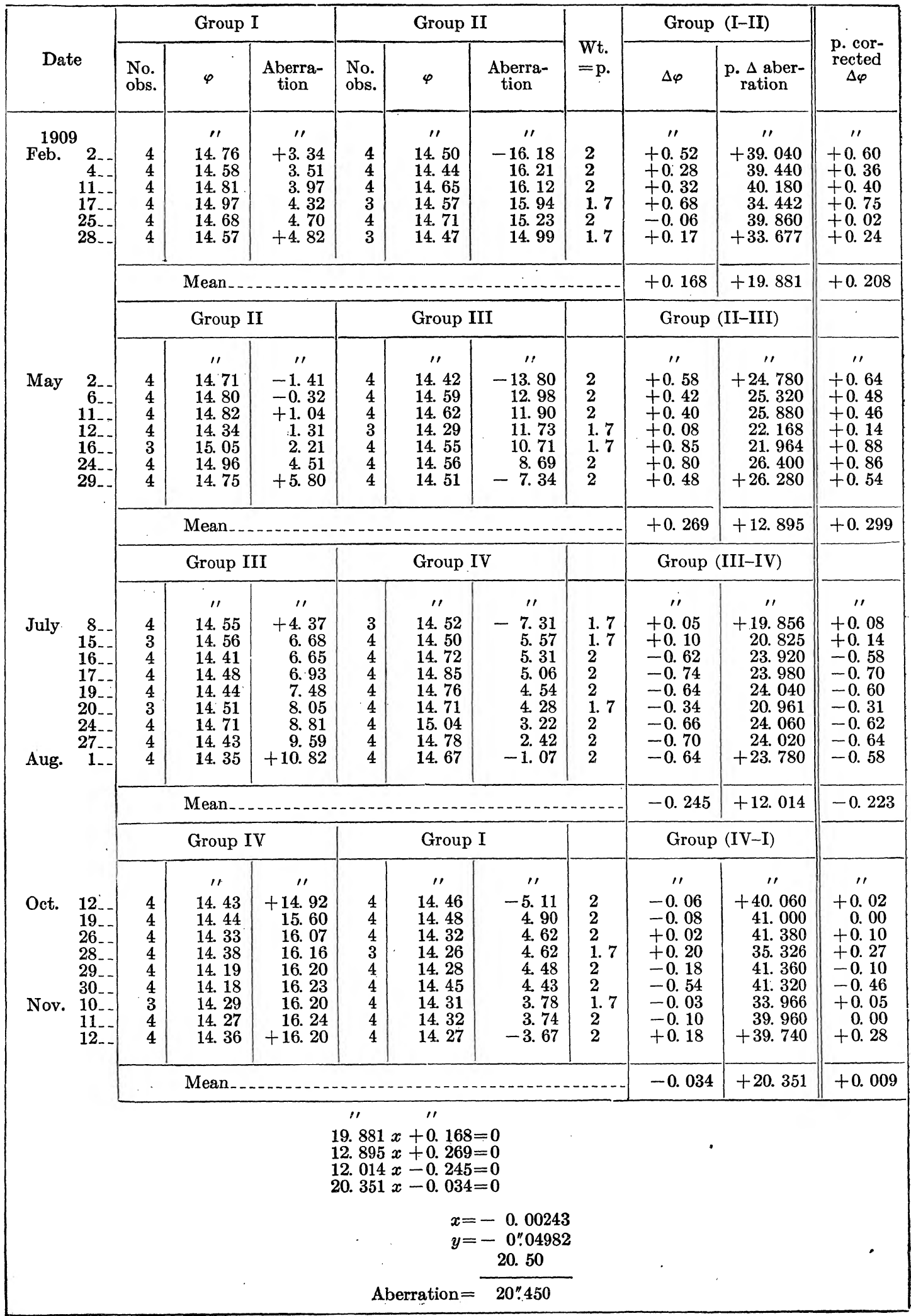


A CXCII

PRIME VERTICAL TRANSIT INSTRUMENT.

TABLE XXVI.-Aberration-Continued

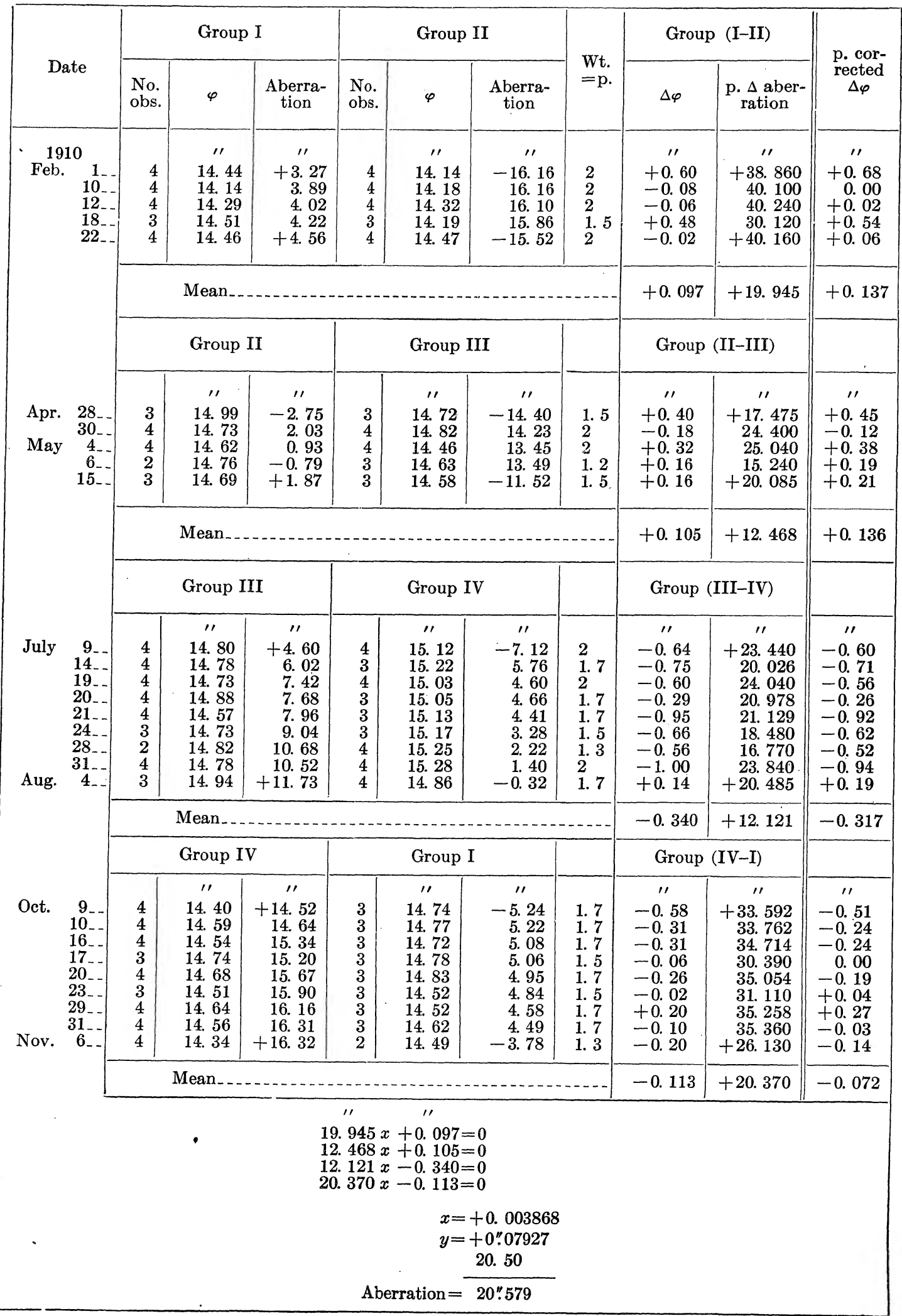


INTRODUCTION.

A cXCIII

TABLE XXVI.-Aberration-Continued

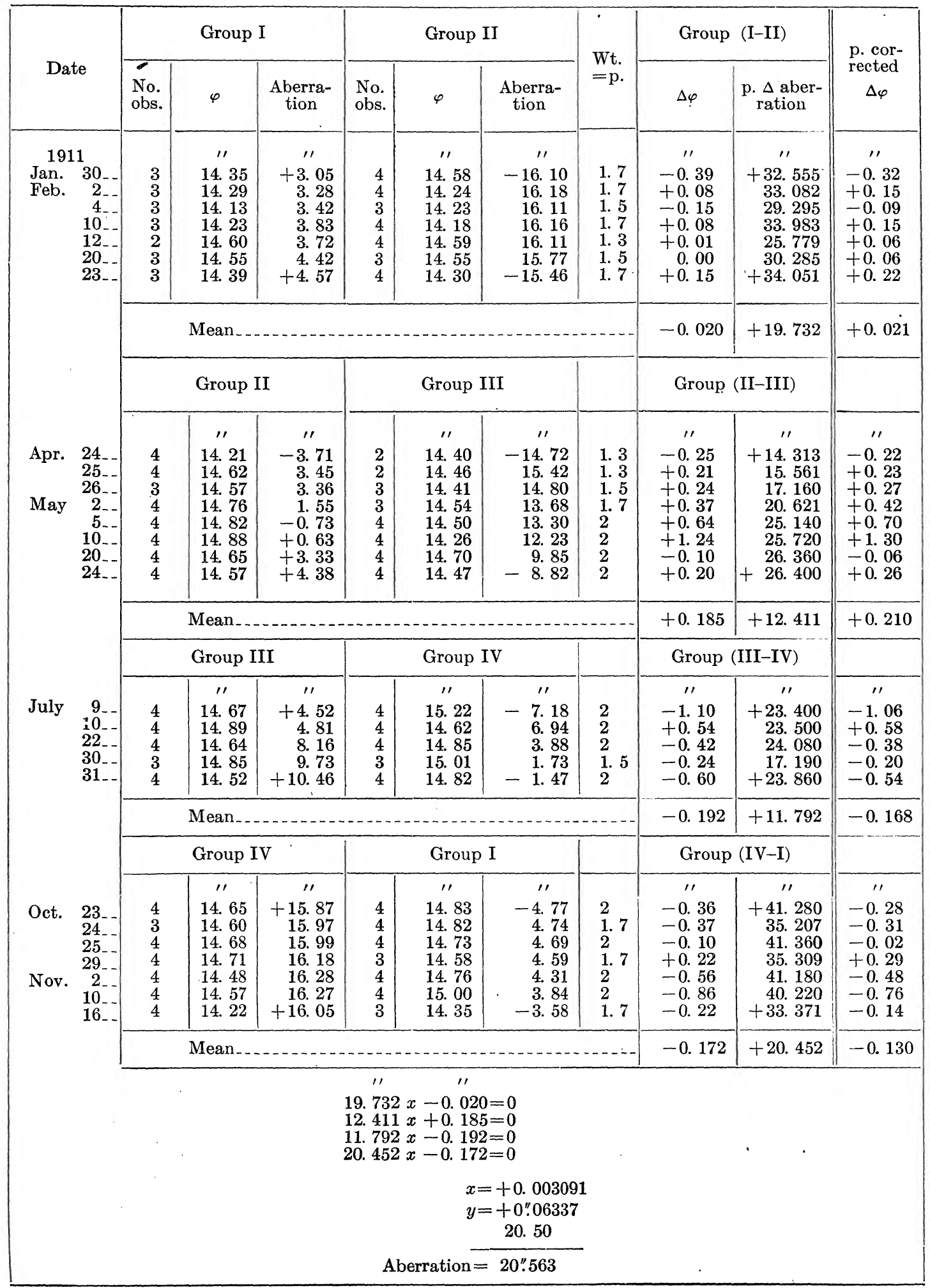

$101141^{\circ}-26 \dagger-P T I-13$ 
A CXCIV

PRIME VERTTCAL TRANSIT INSTRUMENT.

TABLE XXVI.-Aberration-Continued

\begin{tabular}{|c|c|c|c|c|c|c|c|c|c|c|c|}
\hline \multirow{2}{*}{\multicolumn{2}{|c|}{ Date }} & \multicolumn{3}{|c|}{ Group I } & \multicolumn{3}{|c|}{ Group II } & \multirow{2}{*}{$\begin{array}{l}\text { Wt. } \\
=\mathrm{p} .\end{array}$} & \multicolumn{2}{|c|}{ Group (I-II) } & \multirow{2}{*}{$\begin{array}{c}\text { p. cor- } \\
\text { rected. } \\
\qquad \Delta \varphi\end{array}$} \\
\hline & & $\begin{array}{l}\text { No. } \\
\text { obs. }\end{array}$ & $\varphi$ & $\begin{array}{l}\text { Aberra- } \\
\text { tion }\end{array}$ & $\begin{array}{l}\text { No. } \\
\text { obs. }\end{array}$ & $\varphi$ & $\begin{array}{l}\text { Aberra- } \\
\text { tion }\end{array}$ & & $\Delta \varphi$ & $\begin{array}{l}\text { p. } \Delta \text { aber- } \\
\text { ration }\end{array}$ & \\
\hline \multirow{3}{*}{\multicolumn{2}{|c|}{$\begin{array}{cr}1912 \\
\text { Feb. } & 2 \\
& 4 \\
& 4 \\
8 & \\
9 & - \\
22 & \\
23 & -- \\
27 & \end{array}$}} & $\begin{array}{l}3 \\
4 \\
4 \\
4 \\
4 \\
4 \\
2\end{array}$ & $\begin{array}{l}\text { '’ } \\
\text { 14. } 05 \\
\text { 14. } 26 \\
\text { 14. } 04 \\
\text { 13. } 98 \\
\text { 14. } 31 \\
\text { 14. } 11 \\
\text { 14. } 37\end{array}$ & $\begin{array}{r}\prime \prime \\
+3.13 \\
3.45 \\
3.73 \\
3.79 \\
4.53 \\
4.58 \\
+4.85\end{array}$ & $\begin{array}{l}4 \\
3 \\
4 \\
3 \\
4 \\
4 \\
2\end{array}$ & $\begin{array}{c}\prime \prime \\
14.31 \\
14.29 \\
14.16 \\
14.39 \\
14.15 \\
14.22 \\
14.08\end{array}$ & $\begin{array}{r}\prime \prime \\
-16.18 \\
16.23 \\
16.20 \\
16.20 \\
15.56 \\
15.48 \\
-14.86\end{array}$ & $\begin{array}{l}1.7 \\
1.7 \\
2 \\
1.7 \\
2 \\
2 \\
1.0\end{array}$ & $\begin{array}{l}\prime \prime \\
-0.44 \\
-0.05 \\
-0.24 \\
-0.70 \\
+0.32 \\
-0.22 \\
+0.29\end{array}$ & $\begin{array}{r}\prime \prime \\
+32.827 \\
33.456 \\
39.860 \\
39.983 \\
40.180 \\
40.120 \\
+19.719\end{array}$ & $\begin{array}{l}\prime \prime \\
-0.37 \\
+0.02 \\
-0.16 \\
-0.63 \\
+0.40 \\
-0.14 \\
+0.33\end{array}$ \\
\hline & & \multicolumn{7}{|c|}{ Mean } & -0.086 & +20.342 & -0.046 \\
\hline & & \multicolumn{3}{|c|}{ Group II } & \multicolumn{3}{|c|}{ Group III } & & \multicolumn{2}{|c|}{ Group (II-III) } & . \\
\hline $\begin{array}{l}\text { Apr. } \\
\text { May }\end{array}$ & $\begin{array}{r}27- \\
1-- \\
10 \\
13 \ldots \\
18 \ldots \\
20 \ldots \\
24 \ldots- \\
26 \ldots \\
1 \ldots\end{array}$ & $\begin{array}{l}4 \\
4 \\
4 \\
4 \\
4 \\
4 \\
4 \\
4 \\
4\end{array}$ & $\begin{array}{l}\text { 1' } \\
14.39 \\
14.34 \\
14.15 \\
14.37 \\
14.10 \\
14.48 \\
14.45 \\
14.13 \\
14.43\end{array}$ & $\begin{array}{r}\prime \prime \\
-2.70 \\
-1.62 \\
+0.84 \\
1.65 \\
3.00 \\
3.53 \\
4.58 \\
5.10 \\
+6.61\end{array}$ & $\begin{array}{l}4 \\
4 \\
4 \\
3 \\
4 \\
4 \\
4 \\
4 \\
4\end{array}$ & $\begin{array}{c}\prime \prime \\
14.01 \\
14.06 \\
14.07 \\
14.25 \\
14.03 \\
14.30 \\
14.13 \\
14.37 \\
14.32\end{array}$ & $\begin{array}{r}\prime \prime \\
-14.68 \\
13.94 \\
12.06 \\
11.87 \\
10.16 \\
9.66 \\
8.62 \\
8.08 \\
-6.43\end{array}$ & $\begin{array}{l}2 \\
2 \\
2 \\
1.7 \\
2 \\
2 \\
2 \\
2 \\
2\end{array}$ & $\begin{array}{l}\prime \prime \\
+0.76 \\
+0.56 \\
+0.16 \\
+0.20 \\
+0.14 \\
+0.36 \\
+0.64 \\
+0.48 \\
+0.22\end{array}$ & $\begin{array}{r}\prime \prime \\
+23.960 \\
24.640 \\
25.800 \\
22.984 \\
26.320 \\
26.380 \\
26.400 \\
26.360 \\
+26.080\end{array}$ & $\begin{array}{l}\prime \prime \\
+0.80 \\
+0.62 \\
+0.22 \\
+0.26 \\
+0.18 \\
+0.42 \\
+0.70 \\
+0.42 \\
+0.28\end{array}$ \\
\hline \multirow{2}{*}{\multicolumn{2}{|c|}{$\cdot$}} & \multicolumn{7}{|c|}{ Mean } & +0.145 & +12.934 & +0.173 \\
\hline & & \multicolumn{3}{|c|}{ Group III } & \multicolumn{3}{|c|}{ Group IV } & & \multicolumn{2}{|c|}{ Group (III-IV) } & \\
\hline \multirow[t]{3}{*}{ Aug. } & $\begin{array}{r}8 \\
22_{--} \\
26 \\
1-- \\
5_{--}\end{array}$ & $\begin{array}{l}4 \\
3 \\
4 \\
3 \\
4\end{array}$ & $\begin{array}{c}\text { 'I } \\
\text { 14. } 34 \\
\text { 14. } 43 \\
\text { 14. } 50 \\
\text { 14. } 54 \\
14.33\end{array}$ & $\begin{array}{r}11 \\
+4.45 \\
7.82 \\
9.40 \\
10.41 \\
+11.82\end{array}$ & $\begin{array}{l}2 \\
4 \\
3 \\
4 \\
4\end{array}$ & $\begin{array}{c}\prime \prime \\
14.60 \\
14.59 \\
14.81 \\
14.79 \\
14.78\end{array}$ & $\begin{array}{r}11 \\
-7.67 \\
3.68 \\
2.96 \\
-1.00 \\
+0.09\end{array}$ & $\begin{array}{l}1.3 \\
1.7 \\
1.7 \\
1.7 \\
2\end{array}$ & $\begin{array}{c}\prime \prime \\
-0.34 \\
-0.27 \\
-0.53 \\
-0.42 \\
-0.90\end{array}$ & $\begin{array}{r}\prime \prime \\
+15.756 \\
19.550 \\
20.012 \\
19.397 \\
+23.460\end{array}$ & $\begin{array}{c}\prime \prime \\
-0.31 \\
-0.22 \\
-0.48 \\
-0.36 \\
-0.84\end{array}$ \\
\hline & & \multicolumn{7}{|c|}{ Mean } & -0.293 & +11.687 & -0.263 \\
\hline & & \multicolumn{3}{|c|}{ Group IV } & \multicolumn{3}{|c|}{ Group I } & & \multicolumn{2}{|c|}{ Group $(\mathrm{IV}-\mathrm{I})$} & \\
\hline \multirow[t]{4}{*}{$\begin{array}{l}\text { Oct. } \\
\text { Nov. }\end{array}$} & $\begin{array}{r}15 \ldots \\
16_{--} \\
26_{--} \\
28_{--} \\
30_{--} \\
3 \ldots \\
11{ }_{--} \\
16 \ldots\end{array}$ & $\begin{array}{l}4 \\
3 \\
2 \\
2 \\
2 \\
3 \\
2 \\
3\end{array}$ & $\begin{array}{c}\prime \prime \\
14.65 \\
14.62 \\
14.36 \\
14.36 \\
14.31 \\
14.50 \\
14.21 \\
14.41\end{array}$ & $\begin{array}{r}\prime \prime \\
+15.26 \\
15.50 \\
16.26 \\
15.98 \\
16.06 \\
16.33 \\
16.17 \\
+16.05\end{array}$ & $\begin{array}{l}4 \\
3 \\
4 \\
4 \\
4 \\
4 \\
3 \\
4\end{array}$ & $\begin{array}{c}\prime \prime \\
14.90 \\
14.77 \\
14.42 \\
14.82 \\
14.86 \\
14.65 \\
14.60 \\
14.63\end{array}$ & $\begin{array}{r}\prime \prime \\
-5.02 \\
5.04 \\
4.62 \\
4.52 \\
4.42 \\
4.21 \\
3.83 \\
-3.38\end{array}$ & $\begin{array}{l}2 \\
1.5 \\
1.3 \\
1.3 \\
1.3 \\
1.7 \\
1.2 \\
1.7\end{array}$ & $\begin{array}{l}\prime \prime \\
-0.50 \\
-0.23 \\
-0.08 \\
-0.60 \\
-0.72 \\
-0.26 \\
-0.47 \\
-0.37\end{array}$ & $\begin{array}{r}\prime \prime \\
+40.560 \\
30.810 \\
27.144 \\
26.650 \\
26.624 \\
34.918 \\
24.000 \\
+33.031\end{array}$ & $\begin{array}{c}\prime \prime \\
-0.42 \\
-0.16 \\
-0.03 \\
-0.55 \\
-0.66 \\
-0.19 \\
-0.42 \\
-0.31\end{array}$ \\
\hline & & \multicolumn{7}{|c|}{ Mean } & -0.269 & +20.311 & -0.228 \\
\hline & & $\cdot$ & & & $\begin{array}{c}\prime \prime \\
\text { 20. } 342 \\
\text { 12. } 934 \\
\text { 11. } 687 \\
\text { 20. } 311\end{array}$ & $\begin{array}{r}11 \\
-0.086 \\
+0.145 \\
-0.293 \\
-0.269 \\
x= \\
y=\end{array}$ & $\begin{array}{l}=0 \\
=0 \\
=0 \\
=0 \\
+0.00771 \\
\quad 0.1580 \\
20.50\end{array}$ & & & . & \\
\hline & & & & & & rration $=$ & $20 " .658$ & & & & \\
\hline
\end{tabular}


In the following text is an explanation of the contents of Table XXVI. For the purpose of deducing values of $y$ those determinations of latitude were used when both an evening and a morning observation was made on the same day.

The values given to the weights which are shown in column 8 were computed by the following formula,

$$
\text { weight }=\frac{n n_{1}}{n+n_{1}},
$$

where $n$ and $n_{1}$ are the number of separate latitudes in the groups whose differences are to be taken; $n$ representing those observed before, and $n_{1}$ those observed after midnight.

It will be noted that the designated numbers for each pair of groups have been placed just above the observational and computed data pertaining thereto. The dates upon which pairs of groups were observed are shown in column 1. The first designated group was observed before and the second after midnight. The number of observed stars included in each group is shown in the second and fifth columns.

In columns 3 and 6 there will be found the mean daily latitude for each group. The means thus expressed are based upon the number of stars in a group which were observed. To save space, only the seconds of latitude are printed. In both columns these latitudes are designated by the heading " $\varphi$."

In column 9 of the table there are shown the differences between the mean latitudes of a pair of groups, in the sense evening minus morning group. These weighted differences are designated by the heading "p. $\Delta \varphi$. ."

In columns 4 and 7 will be found the mean values of the expression $C c^{1}+D d^{1}$. These means are based upon the sums of the individual values of $C c^{1}+D d^{1}$ for a group divided by the number of stars observed. These mean values are denoted in each of the two columns by the word "Aberration."

In column 10 will be found a tabulation of the differences between these two quantities just mentioned. Those differences are indicated by the heading, "p. $\Delta$ aberration."

Directly below the tabulation of the material for each pair of groups there will be found the weighted mean values of both "p. $\Delta \varphi$ " and "p. $\Delta$ aberration."

The numerical quantities thus expressed are in proper form from which to deduce values of $y$. The method of computing that quantity is shown at the bottom of the table for each of the eight sets of polygons. Directly below that statistical matter, in the eight instances, will be found the resulting values of the aberration constant determined.

In column 11 of the table will be found the quantities which have been designated by the heading, "p. corrected $\Delta \varphi$. ." They are the differences in latitude between pairs of groups after the aberration with which each latitude had been reduced was multiplied by 1.002 . The details of how that quantity was derived are given on page $\mathbf{A}$ cc.

Values of " $p$. corrected $\Delta \varphi$ " have been included in this table, so that an intercomparison might be made between them and the values of "p. $\Delta \varphi . "$

After the solution had been made for values of $y$ the probable error of each determined aberration was computed. From the weighted latitude differences, 
evening and morning, as shown in Table XXVI, the probable error was also ascertained of the group differences in each polygon. These were derived from individual discordances, using the following formula,

$$
\epsilon= \pm 0.674 \sqrt{\frac{\left[p v^{2}\right]}{(m-1) \Sigma p}}
$$

and the assigned weights are justified by them.

In Table XXVII there are assembled, for all polygons observed, the resulting closing sums based upon group differences. In the table they are designated by D, and are shown in next to the last column on the right-hand side of the page with the probable error of each in the last column.

TABLE XXVII.-Group Differences

\begin{tabular}{|c|c|c|c|c|c|c|c|c|c|c|c|c|c|c|}
\hline \multirow{3}{*}{$\begin{array}{c}\text { Groups_..... } \\
\text { Limiting } \\
\text { dates..... } \\
\text { Year. }\end{array}$} & \multicolumn{3}{|c|}{ I-II } & \multicolumn{3}{|c|}{ II-III } & \multicolumn{3}{|c|}{ III-IV } & \multicolumn{3}{|c|}{ IV-I } & \multirow{2}{*}{\multicolumn{2}{|c|}{ Closing sum }} \\
\hline & \multicolumn{3}{|c|}{ Jan. 29-Feb. 28} & \multicolumn{3}{|c|}{ Apr. 24-June 3} & \multicolumn{3}{|c|}{ July 8-Aug. 6} & \multicolumn{3}{|c|}{ Oct. 9-Nov. 18} & & \\
\hline & $\mathrm{D}_{1}$ & p.e. & Wt. & $\mathrm{D}_{1}$ & p.e. & Wt. & $\mathrm{D}_{1}$ & p. e. & Wt. & $\mathrm{D}_{1}$ & p. e. & Wt. & $\mathrm{D}$ & p. e. \\
\hline $\begin{array}{r}1904-5 \\
1906 \\
1907 \\
1908 \\
1909 \\
1910 \\
1911 \\
1912 \\
1904-12 \\
D_{0}\end{array}$ & $\begin{array}{r}1 \prime \\
-0.040 \\
0.000 \\
-.060 \\
+.089 \\
+.168 \\
+.097 \\
-.020 \\
-.086 \\
+.027 \\
+.067\end{array}$ & $\begin{array}{c}\prime \prime \\
\pm .097 \\
.029 \\
.060 \\
.038 \\
.040 \\
.055 \\
.029 \\
\pm .056 \\
-.- \\
-.-\end{array}$ & \begin{tabular}{r|}
1.1 \\
11.9 \\
2.8 \\
6.9 \\
6.2 \\
3.3 \\
11.9 \\
3.2 \\
\hdashline- \\
\hdashline-
\end{tabular} & $\begin{array}{r}11 \\
+.110 \\
+.001 \\
+.246 \\
+.204 \\
+.269 \\
+.105 \\
+.185 \\
+.145 \\
+.193 \\
+.222\end{array}$ & $\begin{array}{r}{ }^{\prime \prime} \\
\pm .056 \\
.062 \\
.031 \\
.016 \\
.036 \\
.041 \\
.058 \\
\pm .041 \\
. . . \\
. . .\end{array}$ & \begin{tabular}{r|}
3.2 \\
2.6 \\
10.4 \\
39.1 \\
7.7 \\
5.9 \\
3.0 \\
5.9 \\
.-- \\
.-
\end{tabular} & $\begin{array}{r}1 \prime \\
-.234 \\
-.240 \\
-.392 \\
-.291 \\
-.245 \\
-.340 \\
-.192 \\
-.293 \\
-.269 \\
-.245\end{array}$ & $\begin{array}{r}\prime \prime \\
\pm .018 \\
.209 \\
.046 \\
.031 \\
.036 \\
.044 \\
.092 \\
\pm .035 \\
-.- \\
\end{array}$ & \begin{tabular}{r|}
30.9 \\
0.2 \\
4.7 \\
10.4 \\
7.7 \\
5.2 \\
1.2 \\
8.2 \\
--- \\
--
\end{tabular} & $\begin{array}{r}1 \prime \\
+.123 \\
-.083 \\
-.010 \\
-.053 \\
-.034 \\
-.113 \\
-.172 \\
-.269 \\
-.047 \\
-.005\end{array}$ & $\begin{array}{r}1 \prime \\
\pm .027 \\
.039 \\
.024 \\
.043 \\
.025 \\
.030 \\
.045 \\
\pm .038 \\
-.- \\
\end{array}$ & \begin{tabular}{r|r}
13. & 7 \\
6. & 6 \\
17. & 4 \\
5. & 4 \\
16. & 0 \\
11. & 1 \\
4.9 & 9 \\
7. & 0 \\
\hdashline & -
\end{tabular} & $\begin{array}{r}1 \prime \\
-.041 \\
-.324 \\
-.216 \\
-.051 \\
+.158 \\
-.251 \\
-.199 \\
-.503 \\
.096 \\
+.039\end{array}$ & $\begin{array}{r}11 \\
+.117 \\
.223 \\
.085 \\
.067 \\
.069 \\
.087 \\
.121 \\
\pm .086 \\
. .-\end{array}$ \\
\hline
\end{tabular}

In the table under the headings Group I-II, II-III, III-IV, and IV-I, are given the limiting dates in each year over which two adjacent groups were observed. The columns headed $\mathrm{D}_{1}$ give the differences between groups as observed in each polygon by years, followed by the probable errors of the differences and their weights.

In the next to the last horizontal line at the bottom of the table are given the weighted means of these group differences for the eight years. Directly under these, designated by $\mathrm{D}_{0}$, are the resulting group differences after the latitudes had been corrected with the aberration obtained from the material.

The expression called the closing sum, which is equal to the sum of the quantities designated by " $p$. corrected $\Delta \varphi$ " for any cycle of observing by the polygon method, is that numerical value which in the discussion of these group latitudes has disclosed itself, as it does in similar pieces of work after each individual latitude in a group has been corrected to the aberration determined. In these several closing sums there are conditions which are influencing the correctness of these latitudes the nature of which still remains unexplained.

The theory of the polygon method of observing, whatever might be the form of astronomical instrument used to obtain the latitudes, is based upon the hypothesis that the value of the closing sum is the result of the adoption of an erroneous aberration. 
It has just been shown that by adding together the quantities in equation $\mathrm{M}$ we obtain equation $\mathrm{N}$, which is that

$$
0=\Sigma \Delta \varphi+\Sigma \Delta \kappa \cdot x .
$$

From this it follows that in each cycle of observing by the polygon method there should be obtained a value of $\Sigma \Delta \kappa$ which when multiplied by $x$ shall equal the numerical value of $\Sigma \Delta \varphi$, but with an opposite sigr.

If such a value of $\Sigma \Delta \kappa$ is not obtained, then either it or $\Sigma \Delta \varphi$, or both, are under the influence of certain causes which will not permit the sum of those two quantities to become equal to zero.

The mean of the right ascensions of the four stars in each group represents in the heavens the meeting points of the four sides of this imaginary form of a polygon. These sides when expressed in time correspond to the differences between the mean right ascensions of each group. The mean right ascensions of the stars included in each group have the approximate values of 6 hours, 14 hours, 18 hours, and 22 hours, respectively. Hence each of the four sides of the polygon represents an approximate sidereal time interval of $8,4,4$, and 8 hours, respectively.

If the assumed declination of each star in a group was known to be absolutely correct and each observed position from which was determined a latitude was also strictly correct, then the differences between the mean latitude of a group observed in the evening and another in the morning of the same day, would be equal to that quantity which had resulted from the use of an erroneous aberration in the reduction; with the proviso, however, that the other constants used in the mean place reduction are themselves true values, and also that none of the stars have a parallax.

Equation $M$ page A cLxxxvi shows that erroneous values of the latitude which are caused by errors in the assumed declination of each star in a group disappear when the summation is made as shown in that equation.

In this connection the real purpose of the polygon method of observing may be overlooked. It has been proven that the polygon method of observing is the only one available by which an observer can with certainty separate from a determined latitude the variation of latitude and errors in the declinations of the stars which have been observed. If, however, there exists a daily variation of the latitude that effect will not be eliminated.

If an investigator has access to values of the variation of the latitude which are the result of observations made contemporaneously with determined latitudes, and if those variations in the latitude are strictly correct, he would then have the material with which to obtain from the observed positions of each star a correction to the aberration used.

To carry out that idea we have in the case of $\alpha$ Lyræ applied the variation of latitude to the observed declinations of that star, and from declinations thus corrected there was obtained an aberration of $20.580^{\prime \prime}$, which differs by only $0.03^{\prime \prime}$ from that found by the polygon method.

Up to the present time there has not been published a series of observations in which the polygon method of observing has been used that does not indicate that the closing sum has included in it other conditions than those caused by the 


\section{A CXCVIII}

PRIME VERTICAL TRANSIT INSTRUMENT.

adoption of an erroneous value of the aberration. Such observations have been made with a number of different forms of astronomical instruments, using both the visual and the photographic method, and in each case the closing sum resulting from observations so made shows the condition above mentioned.

In these instances a number of supposed causes have been investigated. The closing sum may be due to some personality in the method of observing. It may be due to anomalous refractions affecting the results more in one portion of the year than in another, or perhaps differently in different portions of a night. It may also be due to a daily variation in the latitude.

In bringing forward from one year to another the adopted declinations upon which the latitudes are based if there is included in the annual variation an erroneous proper motion of any of the stars observed, that fact would ultimately be revealed.

This would cause a progressive change between the mean latitude of two adjacent pairs of groups, and these changes would have opposite signs for the two pairs. To investigate this an examination has been made of these differences arranged by years. These are shown in the two tables below.

The first table contains these differences based upon an aberration constant $20.5^{\prime \prime}$ used in the mean place reductions. The differences shown in the second table are based upon latitudes derived by the use of an aberration constant $20.542^{\prime \prime}$ in the mean place reductions.

First Adopted Aberration, 20.5"

\begin{tabular}{|c|c|c|c|c|}
\hline Year & $\underset{\text { I-II }}{\text { Group }}$ & $\begin{array}{l}\text { Group } \\
\text { II-III }\end{array}$ & $\underset{\text { III-IV }}{\text { Group }}$ & $\underset{I V-I}{\text { Group }}$ \\
\hline $\begin{array}{l}1904.5 \ldots \ldots \\
1906 \ldots \ldots \ldots \\
1907 \ldots \ldots \ldots \\
1908 \ldots \ldots \\
1909 \ldots \ldots \\
1910 . \ldots \ldots \\
1911 \ldots \ldots \ldots \\
1912 \ldots \ldots \ldots\end{array}$ & $\begin{array}{r}\prime \prime \\
-0.040 \\
.000 \\
-.060 \\
+.089 \\
+.168 \\
+.097 \\
-.020 \\
-.086\end{array}$ & $\begin{array}{c}\prime \prime \\
+0.110 \\
+.001 \\
+.246 \\
+.204 \\
+.269 \\
+.105 \\
+.185 \\
+.145\end{array}$ & $\begin{aligned} & \prime \prime \\
&-0.234 \\
&=.240 \\
&=.392 \\
&=.291 \\
&=.245 \\
&=.340 \\
&=.192 \\
&-.293\end{aligned}$ & $\begin{aligned} & \prime \prime \\
&+0.123 \\
&=.083 \\
&=.010 \\
&=.053 \\
&=.034 \\
&=.113 \\
&=.172 \\
&=.269\end{aligned}$ \\
\hline
\end{tabular}

New Aberration, $20.542^{\prime \prime}$

\begin{tabular}{|c|c|c|c|c|}
\hline Year & $\underset{\text { I-II }}{\text { Group }}$ & $\begin{array}{l}\text { Group } \\
\text { II-III }\end{array}$ & $\begin{array}{l}\text { Group } \\
\text { III-IV }\end{array}$ & $\underset{\text { IV-I }}{\text { Group }}$ \\
\hline $\begin{array}{l}1904.5 \ldots \ldots \\
1906 \ldots \ldots \ldots \\
1907 \ldots \ldots \ldots \\
1908 \ldots \ldots \ldots \\
1909 \ldots \ldots \ldots \\
1910 \ldots \ldots \ldots \\
1911 \ldots \ldots \ldots \\
1912 \ldots \ldots \ldots\end{array}$ & $\begin{array}{r}\prime \prime \\
-0.001 \\
+.040 \\
\pm .020 \\
+.129 \\
+.208 \\
+.137 \\
+.021 \\
-.046\end{array}$ & $\begin{array}{c}\prime \prime \\
+0.140 \\
+.030 \\
+.274 \\
+.234 \\
+.299 \\
+.136 \\
+.210 \\
+.173\end{array}$ & $\begin{aligned} & \prime \prime \\
&-0.210 \\
&=.217 \\
&=.376 \\
&=.267 \\
&=.223 \\
&=.317 \\
&=.168 \\
&-.263\end{aligned}$ & $\begin{array}{c}\prime \prime \\
+0.163 \\
-.046 \\
+.033 \\
\pm .011 \\
+.009 \\
-.072 \\
-.130 \\
-.228\end{array}$ \\
\hline
\end{tabular}


From a study of these two tables it is safe to assert that group differences in the intervals of time they cover do not indicate such a progressive change. However, there may be such an indication in differences between Groups IV and I and possibly between Groups I and II.

The usual practice has been to distribute the residual remaining after the latitudes have been reduced with the value of the aberration found, as a correction to the mean latitudes of each group by a method which will be expalined later.

In such a procedure there is probably a fundamental fault. The increasing accuracy with which individual latitudes are being observed leads to the belief that the parallaxes of the stars used are measurable quantities in these differences. The method of observing as outlined does not permit of removing from the mean daily latitude, based upon the number of stars observed, the mean of their parallaxes. If any of them are near enough to the earth to indicate a parallax it is included in this closing sum that is distributed equally among each of the groups. In fact, its effect would be shown in these differences as a varying quantity, depending upon the time in the year when it was a maximum.

The polygon method could be used in ascertaining parallax displacements by selecting eight groups instead of four. In adjusting this method to that case it would be necessary to have a good many more clear nights per year than obtains in the vicinity of Washington; there should be at least 250 clear nights per year, and two observers would be needed.

When the maximum displacement for Groups I, III, V, and VII was occurring, Groups II, IV, VI, and VIII would be observed for aberration, and vice versa.

Referring to Table.XXVII it will be seen that in each of the eight years of observing the closing sum is negative, except in one instance. As was shown in the theory of this method a negative closing sum indicates that the adopted aberration is too small.

The probable errors of the closing sum for each year have been obtained in accordance with the following: The probable error of the sum of any independent quantities is equal to the square root of the sum of the squares of the probable errors of the individual quantities.

There are several methods by which the probable error of the aberration constant resulting from observations made in accordance with the polygon scheme can be derived. One is defined as follows: The probable error of the closing sum for each completed polygon, divided by the aberration factor, will give the probable error of the aberration constant secured. . The aberration factor is the difference of the quantities $C c^{\prime}+D d^{\prime}$, corresponding to the dates upon which each star included in each of two groups was observed.

Another method, suggested by the late Professor Doolitrle, and in the opinion of the writer somewhat more elegant, is as follows:

Let $\epsilon_{\varphi}$ be the probable error of a single determination of latitude. It is assumed to be $0.09^{\prime \prime}$.

Let ${ }_{1} \epsilon_{2},{ }_{2} \epsilon_{3},{ }_{3} \epsilon_{4}, \epsilon_{4} \epsilon_{1}$ be the probable errors of the differences, Group I-II, II-III, III-IV, IV-I. In general this is written ${ }_{i} \epsilon_{j}$. Similarly ${ }_{i} m_{\mathrm{j}}$ is the number of differences of $i-j$. Then

$$
{ }_{i} \epsilon_{j}{ }^{2}=\frac{2 \epsilon_{\varphi}^{2}}{{ }_{i} m_{j}} .
$$


If we represent the probable error of the cyclical or closing sum in the polygon by $\epsilon_{\Delta}$ we have

$$
\epsilon_{\Delta}^{2}=\frac{2 \epsilon_{\varphi}{ }^{2}}{m_{\mathrm{j}}}, \quad \epsilon_{x}=\frac{\epsilon_{\Delta}}{\Sigma \Delta \kappa}, \quad \epsilon_{y}=20.5 \epsilon_{x}
$$

There are tabulated below the values of the aberration constant which have been derived from the eight sets of polygons, as shown in Table XXVI, with the values of the probable errors and weights computed by the two methods.

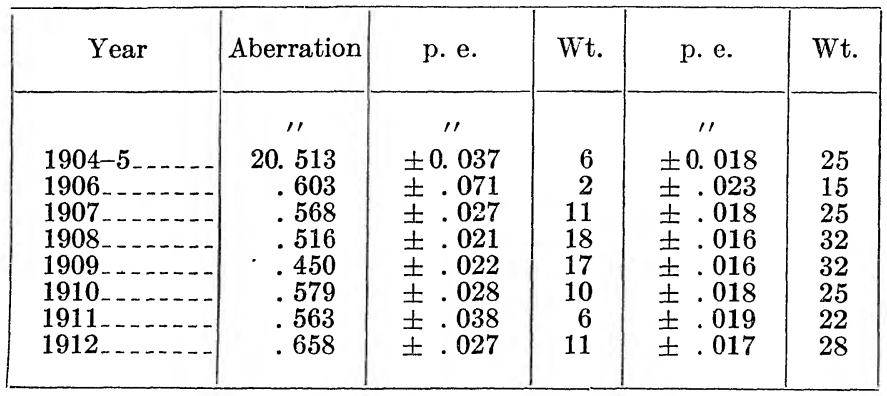

Using the first method, the weight given to each of these determinations is based upon the following:

We have chosen $e_{\mathrm{o}}=0.090^{\prime \prime}$ as the probable error of a fictitious standard determination of the aberration constant, which practically corresponds to the probable error of a single latitude. Then if $e_{\mathrm{o}}$ equals the probable error of a single determination, that of the mean of $m$ determination will be

and $m=\frac{e_{\circ}^{2}}{e^{2}}$, from which we have

$$
e=\frac{e_{0}}{\sqrt{m}}
$$

$$
w_{1}=\frac{e_{0}^{2}}{e_{1}^{2}}, w_{2}=\frac{e_{0}^{2}}{e_{2}^{2}}, w_{3}=\frac{e_{0}^{2}}{e_{3}^{2}}, w_{4}=\frac{e_{0}^{2}}{e_{4}^{2}} \ldots \ldots w_{\mathrm{n}}=\frac{e_{\mathrm{o}}^{\circ}}{e_{\mathrm{n}}^{2}} .
$$

From these were found the weights given adjacent to each determination of the aberration. The probable error of the weighted mean was found from $e=\frac{e_{\mathrm{o}}}{\sqrt{w}}$, in which $w$ is the sum of the weights.

The weighted mean of the aberration constant, and its probable error, computed as above explained is,

$$
20.542^{\prime \prime} \pm 0.010^{\prime \prime}
$$

The weighted mean and probable error computed by the plan suggested by Professor Doolittle is,

$$
20.550^{\prime \prime} \pm 0.006^{\prime \prime}
$$

After the final aberration constant had been obtained the aberration with which each latitude had been reduced in the first instance was multiplied by the ratio $20.542 \div 20.05=1.002$. The results are given in Table XXVIII.

The sums of the differences between adjacent groups, on nights when both were observed, were then formed. They are shown under the caption $D_{1}$ in Table XXVII. Before correcting for the final aberration $\left(20.542^{\prime \prime}\right)$ the weighted mean of the differences between Groups I and II was $+0.027^{\prime \prime}$. After the latitudes had been corrected it was increased to $+0.067^{\prime \prime}$. 
This latter quantity, on purely theoretical grounds, is the sum of two quantities which is necessary to reduce the mean of the declinations of the stars in those groups to a declination system which is valid for both. In this instance, the corrected aberration has increased the numerical value of the sum of the two corrections. Likewise, in the case of Groups II and III, the sum of the two quantities necessary to bring the mean declinations of those groups to a common system has been increased.

Referring to Table XXVII it will be noted that the application of the final aberration to the observed latitudes has changed the closing sum from $-.096^{\prime \prime}$ to $+0.039^{\prime \prime}$. The following example will illustrate how the corrections to reduce the means of the groups to a common system are determined. The data are taken from Table XXVII for the years 1906-7.

On page A CLXXXVI it has been shown that $\Sigma \Delta \varphi+\Sigma \Delta \kappa . x=0$. In substituting the final aberration for the adopted one, as has just been done, we have removed from this equation its second term. However, in the table below $\Sigma \Delta \varphi\left(+0.193^{\prime \prime}\right)$ does not equal zero.

\begin{tabular}{|c|c|c|c|}
\hline Group & $\Delta \phi$ & $\Sigma w$ & $\frac{1}{\Sigma w .}$ \\
\hline $\begin{array}{l}1906-7, \text { III-II } \\
1906-7, \text { IV-III } \\
1906-7, \text { I-IV } \\
1906-7, \text { II-I }\end{array}$ & $\begin{array}{l}\prime \prime \\
-0.030 \\
+.217 \\
+.046 \\
-.040\end{array}$ & $\begin{array}{r}11.2 \\
3.0 \\
17.4 \\
16.0\end{array}$ & $\begin{array}{r}0.089 \\
.333 \\
.057 \\
.062\end{array}$ \\
\hline & +0.193 & $\ldots .$. & 0.541 \\
\hline 1907, III-II $\ldots$ & -0.274 & 11. 2 & 0.089 \\
\hline
\end{tabular}

These differences between pairs of the four groups are residuals. Therefore, let ${ }_{3} v_{2}+{ }_{4} v_{3}+{ }_{1} v_{4}+{ }_{2} v_{1}$, represent the corrections which are necessary to satisfy the condition that the sum of the residuals shall equal zero.

Then we have

$$
\begin{aligned}
& { }_{3} v_{2}+{ }_{4} v_{3}+{ }_{1} v_{4}+{ }_{2} v_{1}=+0.193^{\prime \prime} \\
& { }_{3} v_{2}-{ }_{3} v_{2}=+0.244
\end{aligned}
$$

From these two correlative equations, in accordance with the method suggested by Prof. C. L. Doolittle on page 89, Part II, Vol. I, Publications of the University of Pennsylvania, we have,

and

$$
\begin{aligned}
& 0.541 k+0.089 k^{\prime}=+0.193^{\prime \prime} \\
& 0.089 k+0.178 k^{\prime}=+0.244,
\end{aligned}
$$

$$
\begin{aligned}
k^{\prime} & =+1.299 \\
k & =+0.142 \\
{ }_{3} v_{2} & =0.089\left(k+k^{\prime}\right) \\
{ }_{4} v_{3} & =.333 k \\
{ }_{1} v_{4} & =.057 k \\
{ }_{2} v_{1} & =.062 k \\
-{ }_{3} v_{2} & =-.089 k^{\prime}
\end{aligned}
$$


Therefore,

and

$$
\begin{aligned}
\text { III- II } & =-0.158^{\prime \prime} \\
\text { IV-III } & =+.170 \\
\text { I- IV } & =+.038 \\
\text { II- I } & =-.049 \\
\text { III- II } & =-.158,
\end{aligned}
$$

$$
\begin{aligned}
\mathrm{II} & =\mathrm{III}+0.158 \\
& =\mathrm{IV}-.012 \\
& =\mathrm{I}-.049 .
\end{aligned}
$$

\begin{tabular}{|c|c|c|c|c|}
\hline Year & Group I & Group II & Group III & Group IV \\
\hline $\begin{array}{l}1904-5 \\
1906-7 \\
1907-8 \\
1908-9.19 \\
1909-10 \\
1910-11 \\
1911-12 \\
1912\end{array}$ & $\begin{array}{l}\prime \prime \\
+0.024 \\
-.073 \\
-.069 \\
-.111 \\
-.123 \\
-.144 \\
-.100 \\
-.111\end{array}$ & $\begin{array}{r}\prime \prime \\
0.000 \\
-.024 \\
-.038 \\
-.027 \\
+.004 \\
+.019 \\
-.053 \\
-.071\end{array}$ & $\begin{array}{l}\prime \prime \\
+0.100 \\
+.134 \\
+.227 \\
+.219 \\
+.198 \\
+.213 \\
+.145 \\
+.161\end{array}$ & $\begin{array}{l}\prime \prime \\
-0.124 \\
-.036 \\
-.119 \\
-.081 \\
-.079 \\
-.088 \\
+.008 \\
+.021\end{array}$ \\
\hline Mean ....... & -0.088 & -0.024 & +0.175 & -0.062 \\
\hline
\end{tabular}

To make the sum of the corrections zero, we add $-0.024^{\prime \prime}$ to each, and we have as the corrections to the respective groups from data secured in this polygon,

$$
\begin{aligned}
\mathrm{I} & =-0.073^{\prime \prime} \\
\mathrm{II} & =-.024 \\
\mathrm{III} & =+.134 \\
\mathrm{IV} & =-.036 .
\end{aligned}
$$

\begin{tabular}{|c|c|c|c|c|c|c|c|}
\hline \multicolumn{2}{|c|}{$\begin{array}{c}\text { Group I } \\
\text { Star }\end{array}$} & \multicolumn{2}{|c|}{$\begin{array}{c}\text { Group II } \\
\text { Star }\end{array}$} & \multicolumn{2}{|c|}{$\begin{array}{l}\text { Group III } \\
\text { Star }\end{array}$} & \multicolumn{2}{|c|}{$\begin{array}{c}\text { Group IV } \\
\text { Star }\end{array}$} \\
\hline $\begin{array}{l}1 . \\
2 . \\
3 . \\
4 .\end{array}$ & $\begin{aligned} & \prime \prime \\
&-0.030 \\
&=.092 \\
&=.298 \\
&+.067\end{aligned}$ & $\begin{array}{l}5 . \\
6 . \\
7 . \\
8 .\end{array}$ & $\begin{aligned} & \prime \prime \\
&- 0.116 \\
&=.116 \\
&=.130 \\
&+.265\end{aligned}$ & $\begin{array}{r}9 . \\
10 . \\
11 . \\
12 .\end{array}$ & 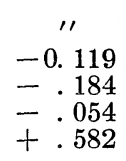 & $\begin{array}{l}13 . \\
14 . \\
15 . \\
16 .\end{array}$ & $\begin{array}{c}\prime \prime \\
-0.062 \\
=.246 \\
-.152 \\
+.212\end{array}$ \\
\hline
\end{tabular}

The group corrections for the several sets of polygons observed are given in the following table:

The Group Corrections.

In Table XXIII are tabulated the corrections necessary to reduce an individual latitude in a group to the mean of the group. Having now determined both the correction to reduce an individual latitude in a group to the mean of the group, and also the group correction, the combination of these two will give the corrections needed to each of the adopted declinations of the 16 stars to bring them all to a common system.

The following table contains those corrections:

An inspection of the list of corrections presented in the above table will bring to the attention of the reader the fact that the adopted declination of $\alpha$ Lyræ which was used in this portion of the discussion, and which was taken from the Prelim- 
inary General Catalogue of Professor Boss (the fourth star in Group III), needs a relatively large plus correction to reduce it to the system to which the other 15 stars were reduced.

In the last column to the right of Table XXI there will be found the adjusted declinations, seconds only, of each of the 16 stars used in the groups. In that adjustment the declination of $\alpha$ Lyræ is based upon observed declinations which were secured when it was included in Group III and not when it was observed outside of that group.

\section{MEAN DAILY LATITUDE}

The mean group corrections which were secured from the eight polygons observed and which are to be found in the table on page A ccII, have been applied to the latitudes by groups, tabulated in Table XXV, and the daily mean taken. These latitudes have also been corrected to the aberration $20.542^{\prime \prime}$, determined from the eight polygons. Those results are shown in Table XXVII.

After those corrections had been applied to the daily latitudes they were combined into general means, each including about 35 observed latitudes and embracing approximately eight nights' work. The values of these latitudes and the limiting dates are shown in Table XXIX. There are included in these several means 3,957 individual latitudes, which were obtained on 822 nights of observing. The general mean latitude derived from the above data, and based upon the adjusted latitudes, is,

$$
+38^{\circ} 55^{\prime} 14.567^{\prime \prime} \text {. }
$$

If that value is transferred from the position of the instrument to the center of the clock house it gives as the latitude of the latter,

$$
+38^{\circ} 55^{\prime} 14.049^{\prime \prime} \text {. }
$$

TABLe XXVIII.-Daily Mean Latitude, All Corrections Applied

$\varphi=+38^{\circ} 55^{\prime} 10^{\prime \prime}+$

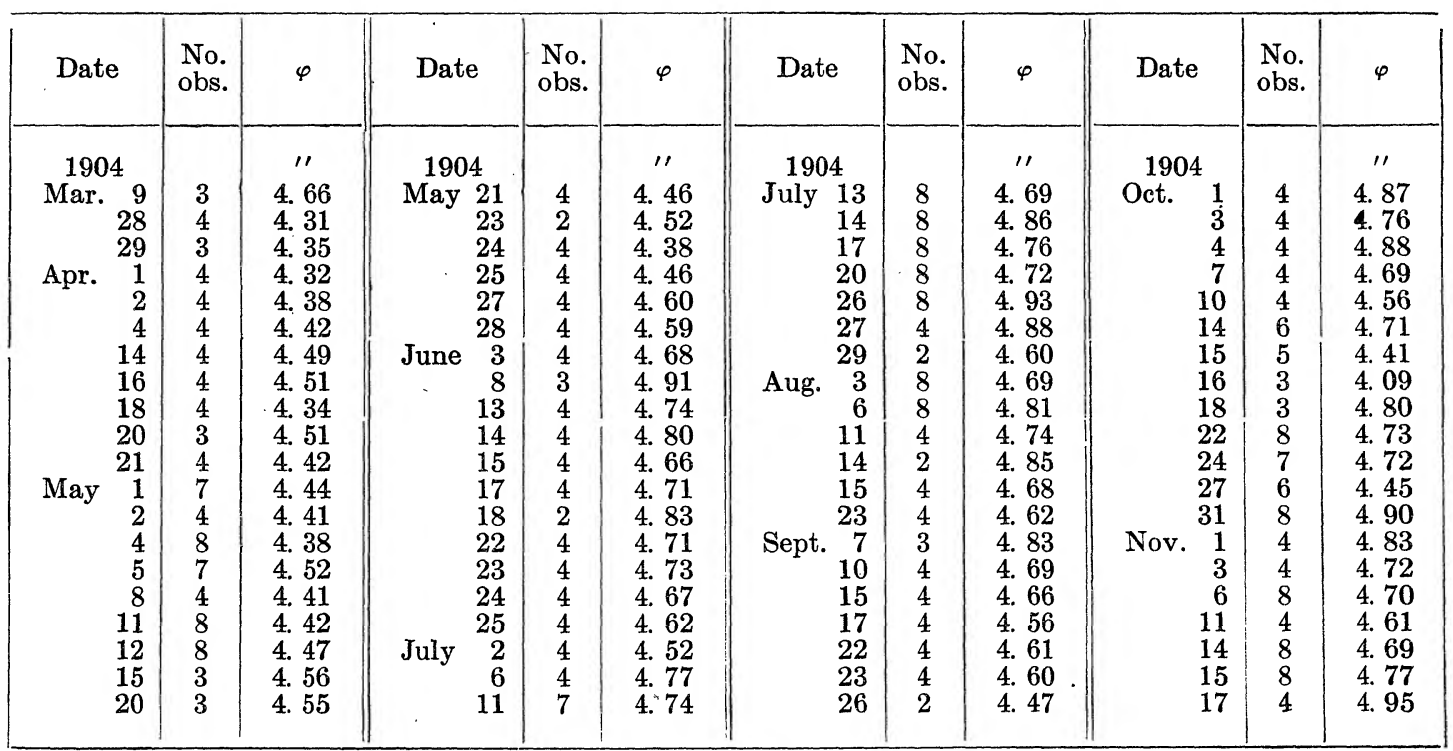


TABLe XXVIII.-Daily Mean Latitude, All Corrections Applied-Continued

\begin{tabular}{|c|c|c|c|c|c|c|c|c|c|c|c|}
\hline Date & $\begin{array}{l}\text { No. } \\
\text { obs. }\end{array}$ & $\varphi$ & Date & $\begin{array}{l}\text { No. } \\
\text { obs. }\end{array}$ & $\varphi$ & Date & $\begin{array}{l}\text { No. } \\
\text { obs. }\end{array}$ & $\varphi$ & Date & $\begin{array}{l}\text { No. } \\
\text { obs. }\end{array}$ & $\varphi$ \\
\hline 1904 & & & 1906 & & & 1906 & & & 1907 & & \\
\hline Nov. 19 & 4 & 4. 70 & Feb. 9 & 8 & 4. 59 & Nov. 22 & 4 & 5. 00 & Sept. 14 & 4 & 4. 44 \\
\hline $\begin{array}{l}\text { Dec. } 29 \\
\text { De }\end{array}$ & 4 & 4. 66 & & 8 & $\begin{array}{l}\text { 4. } 53 \\
49\end{array}$ & $\begin{array}{l}23 \\
25\end{array}$ & 4 & $\begin{array}{l}\text { 4. } 91 \\
4.80\end{array}$ & 15 & 4 & 4. 54 \\
\hline Dec. 30 & $\begin{array}{l}3 \\
4\end{array}$ & $\begin{array}{l}\text { 4. } 36 \\
\text { 5. } 08\end{array}$ & $\begin{array}{l}13 \\
16\end{array}$ & $\begin{array}{l}4 \\
8\end{array}$ & $\begin{array}{l}\text { 4. } 32 \\
\text { 4. } 35\end{array}$ & & & 4. 80 & $\begin{array}{l}20 \\
25\end{array}$ & $\begin{array}{l}3 \\
4\end{array}$ & $\begin{array}{l}\text { 4. } 32 \\
\text { 4. } 80\end{array}$ \\
\hline & 4 & 4. 84 & $\begin{array}{l}19 \\
22\end{array}$ & $\begin{array}{l}8 \\
4\end{array}$ & $\begin{array}{l}4.55 \\
4.58\end{array}$ & 1907. & 4 & 4.66 & $\begin{array}{l}26 \\
29\end{array}$ & $\begin{array}{l}4 \\
3\end{array}$ & $\begin{array}{l}4.57 \\
4.50\end{array}$ \\
\hline 1905. & & & 23 & 8 & 4. 61 & Jan. $\begin{array}{r}0 \\
10\end{array}$ & $\begin{array}{l}4 \\
4\end{array}$ & $\begin{array}{l}\text { 4. } 00 \\
\text { 4. } 77\end{array}$ & Oct. $\quad 1$ & $\begin{array}{l}0 \\
4\end{array}$ & $\begin{array}{l}\text { 4. } 50 \\
4.53\end{array}$ \\
\hline $\begin{array}{ll}\text { Jan. } & 1 \\
8\end{array}$ & 3 & 4. 53 & 24 & 4 & 4. 38 & 21 & 4 & $\begin{array}{l}4.99 \\
4.74\end{array}$ & $\begin{array}{l}3 \\
5 \\
5\end{array}$ & $\begin{array}{l}3 \\
4\end{array}$ & $\begin{array}{l}\text { 4. } 36 \\
463\end{array}$ \\
\hline $\begin{array}{r}8 \\
14\end{array}$ & $\begin{array}{l}4 \\
4\end{array}$ & $\begin{array}{l}\text { 4. } 67 \\
\text { 4. } 52\end{array}$ & $\begin{array}{l}26 \\
28\end{array}$ & $\begin{array}{l}4 \\
4\end{array}$ & $\begin{array}{l}\text { 4. } 55 \\
\text { 4. } 48\end{array}$ & $\begin{array}{l}26 \\
28\end{array}$ & $\begin{array}{l}4 \\
4\end{array}$ & $\begin{array}{l}\text { 4. } 74 \\
\text { 4. } 84\end{array}$ & $\begin{array}{r}5 \\
12\end{array}$ & $\begin{array}{l}4 \\
8\end{array}$ & $\begin{array}{l}4.63 \\
4.82\end{array}$ \\
\hline & 4 & 4. 75 & Mar. 2 & 4 & 4. 41 & 30 & 7 & $\begin{array}{l}4.78 \\
48\end{array}$ & 13 & 7 & 4. 77 \\
\hline 16 & 4 & 4. 55 & 5 & 4 & 4. 46 & Feb. 6 & 4 & 4. 96 & 14 & 8 & 4. 67 \\
\hline & $\stackrel{4}{4}$ & $\begin{array}{l}\text { 4. } 83 \\
4.76\end{array}$ & 17 & $\frac{4}{4}$ & $\begin{array}{l}\text { 4. } 82 \\
446\end{array}$ & 8 & 4 & $\begin{array}{l}\text { 4. } 77 \\
4.81\end{array}$ & $\begin{array}{l}15 \\
17\end{array}$ & $\begin{array}{l}8 \\
4\end{array}$ & $\begin{array}{l}4.57 \\
4.42\end{array}$ \\
\hline 28 & $\begin{array}{l} \pm \\
4\end{array}$ & $\begin{array}{l}\text { 4. } 80 \\
\text { 4. } 80\end{array}$ & 22 & $\begin{array}{l}4 \\
4\end{array}$ & $\begin{array}{l}\text { 4. } 40 \\
4.33\end{array}$ & 13 & $\begin{array}{l}8 \\
8\end{array}$ & $\begin{array}{l}\text { 4. } 81 \\
4.75\end{array}$ & 19 & 8 & $\begin{array}{l}\text { 4. } 71 \\
\text { 4. } 71\end{array}$ \\
\hline 30 & 4 & 4. 69 & Apr. $\quad 1$ & 3 & 4. 51 & $\begin{array}{l}15 \\
15\end{array}$ & 8 & 4. 65 & 21 & 8 & 4. 81 \\
\hline Feb. $\begin{array}{r}4 \\
10\end{array}$ & $\begin{array}{l}4 \\
8\end{array}$ & $\begin{array}{l}\text { 4. } 63 \\
\text { 4. } 65\end{array}$ & $\begin{array}{r}2 \\
10\end{array}$ & $\begin{array}{l}4 \\
4\end{array}$ & $\begin{array}{l}3.95 \\
4.25\end{array}$ & Mar. ${ }_{16}$ & $\begin{array}{l}4 \\
4\end{array}$ & $\begin{array}{l}\text { 4. } 52 \\
\text { 4. } 57\end{array}$ & $\begin{array}{l}23 \\
24\end{array}$ & $\begin{array}{l}7 \\
4\end{array}$ & $\begin{array}{l}\text { 4. } 66 \\
\text { 4. } 72\end{array}$ \\
\hline 14 & 4 & 4. 83 & 12 & 4 & 4. 31 & $\begin{array}{l}10 \\
20\end{array}$ & $\begin{array}{l}4 \\
4\end{array}$ & $\begin{array}{l}\text { 4. } 62 \\
\text { 4. } 62\end{array}$ & 25 & $\begin{array}{l}4 \\
8\end{array}$ & 4. 69 \\
\hline 17 & 8 & 4. 37 & 15 & 4 & 4. 34 & 22 & 3 & 4. 49 & 28 & 8 & 4. 47 \\
\hline 18 & 8 & 4. 35 & 17 & 4 & 4. 67 & 28 & 4 & 4. 45 & Nov. 4 & 8 & 4. 79 \\
\hline 24 & 8 & 4. 61 & 23 & 4 & 4. 43 & Apr. 1 & 2 & 4. 66 & 7 & $\begin{array}{l}8 \\
2\end{array}$ & 4. 65 \\
\hline Mar. $\begin{array}{r}26 \\
2\end{array}$ & $\begin{array}{l}8 \\
4\end{array}$ & $\begin{array}{l}\text { 4. } 59 \\
4.54\end{array}$ & May $\begin{array}{r}27 \\
3\end{array}$ & $\begin{array}{l}4 \\
4\end{array}$ & $\begin{array}{l}\text { 4. } 46 \\
\text { 4. } 46\end{array}$ & $\begin{array}{r}2 \\
16\end{array}$ & $\begin{array}{l}3 \\
3\end{array}$ & $\begin{array}{l}\text { 4. } 53 \\
\text { 4. } 30\end{array}$ & $\begin{array}{l}13 \\
14\end{array}$ & $\begin{array}{l}3 \\
8\end{array}$ & $\begin{array}{l}\text { 4. } 69 \\
4.60\end{array}$ \\
\hline $\begin{array}{l}10 \\
15\end{array}$ & $\begin{array}{l}4 \\
4\end{array}$ & 4. 57 & & 4 & 4. 47 & 17 & $\begin{array}{l}0 \\
3 \\
\end{array}$ & 4. 46 & 15 & $\begin{array}{l}8 \\
4\end{array}$ & $\begin{array}{l}\text { 4. } 63 \\
4.69\end{array}$ \\
\hline 25 & 4 & 5. 07 & 9 & $\begin{array}{l}8 \\
8\end{array}$ & $\begin{array}{l}\text { 4. } 67 \\
\text { 4. } 71\end{array}$ & $\begin{array}{l}20 \\
24\end{array}$ & $\begin{array}{l}4 \\
6\end{array}$ & $\begin{array}{l}\text { 4. } 45 \\
\text { 4. } 56\end{array}$ & $\begin{array}{l}10 \\
25\end{array}$ & $\begin{array}{l}4 \\
4\end{array}$ & $\begin{array}{l}\text { 4. } 69 \\
4.78\end{array}$ \\
\hline $\begin{array}{l}27 \\
29\end{array}$ & $\begin{array}{l}4 \\
2\end{array}$ & $\begin{array}{l}\text { 4. } 95 \\
4.60\end{array}$ & $\begin{array}{l}16 \\
19\end{array}$ & $\begin{array}{l}4 \\
3\end{array}$ & $\begin{array}{l}\text { 4. } 60 \\
4.52\end{array}$ & 29 & 4 & 4. 37 & 1908 & & \\
\hline 31 & 4 & 4. 54 & 21 & 8 & $\begin{array}{l}4.32 \\
\text { 4. } 33\end{array}$ & May $\quad 4$ & 4 & $\begin{array}{l}\text { 4. } 42 \\
467\end{array}$ & Jan. 3 & 4 & 4. 91 \\
\hline Apr. 7 & 4 & 4. 74 & 22 & 8 & 4. 30 & 11 & 8 & 4. 75 & 5 & 4 & 4. 69 \\
\hline $\begin{array}{l}14 \\
17\end{array}$ & $\begin{array}{l}4 \\
4\end{array}$ & $\begin{array}{l}\text { 4. } 69 \\
4.67\end{array}$ & $\begin{array}{l}23 \\
24\end{array}$ & $\begin{array}{l}8 \\
3\end{array}$ & $\begin{array}{l}4.28 \\
4.52\end{array}$ & 12 & 4 & 4. 60 & $\begin{array}{l}6 \\
9\end{array}$ & 4 & $\begin{array}{l}\text { 4. } 93 \\
4.81\end{array}$ \\
\hline $\begin{array}{l}17 \\
19\end{array}$ & $\frac{4}{4}$ & $\begin{array}{l}\text { 4. } 54 \\
\text { 4. } 54\end{array}$ & $\begin{array}{l}24 \\
29\end{array}$ & $\begin{array}{l}5 \\
3\end{array}$ & $\begin{array}{l}\text { 4. } 32 \\
\text { 4. } 39\end{array}$ & 13 & 2 & 4. 34 & 10 & $\begin{array}{l}4 \\
4\end{array}$ & $\begin{array}{l}\text { 4. } 81 \\
\text { 4. } 93\end{array}$ \\
\hline 24 & 4 & 5. 04 & June 3 & 5 & 4. 29 & $\begin{array}{l}17 \\
20\end{array}$ & $\begin{array}{l}4 \\
3\end{array}$ & $\begin{array}{l}\text { 4. } 28 \\
4.48\end{array}$ & 14 & 4 & 4. 86 \\
\hline $\begin{array}{l}27 \\
30\end{array}$ & $\begin{array}{l}3 \\
7\end{array}$ & $\begin{array}{l}\text { 4. } 72 \\
4.77\end{array}$ & 4 & $\begin{array}{l}4 \\
4\end{array}$ & $\begin{array}{l}\text { 4. } 72 \\
4.57\end{array}$ & 21 & $\begin{array}{l}3 \\
8\end{array}$ & $\begin{array}{l}\text { 4. } 48 \\
\text { 4. } 40\end{array}$ & 16 & 4 & $\begin{array}{l}\text { 4. } 85 \\
477\end{array}$ \\
\hline May 1 & 2 & 4. 76 & $\begin{array}{l}11 \\
22\end{array}$ & $\begin{array}{l}4 \\
3\end{array}$ & $\begin{array}{l}4.57 \\
4.60\end{array}$ & 27 & 8 & 4. 33 & $\begin{array}{l}18 \\
19\end{array}$ & $\begin{array}{l}4 \\
4\end{array}$ & $\begin{array}{l}\text { 4. } 77 \\
\text { 4. } 97\end{array}$ \\
\hline & 6 & 4. 84 & 25 & 4 & 4. 75 & & 8 & 4. 31 & $\begin{array}{l}19 \\
24\end{array}$ & $\begin{array}{l}4 \\
4\end{array}$ & $\begin{array}{l}4.95 \\
4.95\end{array}$ \\
\hline$\overline{7}$ & 6 & 4. 60 & 28 & 4 & 4. 55 & $\begin{array}{ll}\text { June } & 6 \\
& 8\end{array}$ & 3 & 4. 56 & 25 & 4 & 4. 68 \\
\hline 8 & 7 & 4. 85 & $\begin{array}{r}29 \\
5\end{array}$ & 4 & $\begin{array}{l}4.74 \\
4.40\end{array}$ & $\begin{array}{r}8 \\
15\end{array}$ & $\frac{4}{4}$ & $\begin{array}{l}\text { 4. } 79 \\
4.33\end{array}$ & 29 & 8 & 4. 91 \\
\hline $\begin{array}{l}12 \\
19\end{array}$ & $\begin{array}{l}3 \\
7\end{array}$ & $\begin{array}{l}5.20 \\
4.63\end{array}$ & 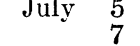 & $\begin{array}{l}4 \\
3\end{array}$ & $\begin{array}{l}4.49 \\
4.78\end{array}$ & 16 & $\begin{array}{l}4 \\
4\end{array}$ & $\begin{array}{l}\text { 4. } 50 \\
\text { 4. } 50\end{array}$ & Feb. $\begin{array}{r}30 \\
3\end{array}$ & $\begin{array}{l}8 \\
2\end{array}$ & $\begin{array}{l}\text { 4. } 76 \\
\text { 4. } 82\end{array}$ \\
\hline 20 & 4 & 4. 55 & 12 & 4 & 4. 67 & ${ }_{21}^{17}$ & $\begin{array}{l}4 \\
4\end{array}$ & $\begin{array}{l}\text { 4. } 56 \\
4.53\end{array}$ & $\begin{array}{l}0 \\
4\end{array}$ & 4 & $\begin{array}{l}\text { 4. } 62 \\
\text { 4. }\end{array}$ \\
\hline $\begin{array}{l}23 \\
24\end{array}$ & 7 & 4. 51 & 13 & 4 & 4. 24 & $\begin{array}{l}21 \\
26\end{array}$ & $\begin{array}{l}4 \\
4\end{array}$ & $\begin{array}{l}\text { 4. } 53 \\
\text { 4. } 35\end{array}$ & 7 & 8 & 4. 47 \\
\hline 27 & $\begin{array}{l}4 \\
4\end{array}$ & $\begin{array}{l}4.75 \\
4.52\end{array}$ & $\begin{array}{l}19 \\
21\end{array}$ & 8 & $\begin{array}{l}4.85 \\
4.03\end{array}$ & July 3 & 2 & 4. 31 & $\begin{array}{r}8 \\
19\end{array}$ & 8 & $\begin{array}{l}\text { 4. } 58 \\
\text { a1 }\end{array}$ \\
\hline June 3 & $\begin{array}{l}x \\
4\end{array}$ & 4. 73 & $\begin{array}{l}21 \\
24\end{array}$ & $\begin{array}{l}0 \\
7\end{array}$ & $\begin{array}{l}4.00 \\
4.87\end{array}$ & 4 & 4 & 4. 51 & $\begin{array}{l}19 \\
20\end{array}$ & 7 & $\begin{array}{l}\text { 4. } 51 \\
\text { 4. } 51\end{array}$ \\
\hline Oct. ${ }_{29}^{28}$ & 3 & 4. 94 & Sept. 7 & 4 & 4. 90 & 8 & 8 & 4. 46 & 22 & 2 & 4. 56 \\
\hline Nov. $\begin{array}{r}29 \\
1\end{array}$ & $\begin{array}{l}8 \\
4\end{array}$ & $\begin{array}{l}4.63 \\
4.66\end{array}$ & $\begin{array}{r}8 \\
19\end{array}$ & $\begin{array}{l}3 \\
3\end{array}$ & $\begin{array}{l}\text { 4. } 89 \\
\text { 4. } 44\end{array}$ & $\begin{array}{l}12 \\
14\end{array}$ & $\begin{array}{l}4 \\
4\end{array}$ & $\begin{array}{l}\text { 4. } 50 \\
\text { 4. } 27\end{array}$ & 24 & 8 & $\begin{array}{l}\text { 4. } 57 \\
464\end{array}$ \\
\hline 4 & 4 & 4. 53 & 23 & $\begin{array}{l}0 \\
3\end{array}$ & 4. 45 & 16 & 8 & $\begin{array}{l}\text { 4. } 52 \\
\text { 4. }\end{array}$ & $\begin{array}{l}21 \\
28\end{array}$ & $\begin{array}{l}2 \\
4\end{array}$ & $\begin{array}{l}\text { 4. } 64 \\
4.71\end{array}$ \\
\hline 12 & 4 & 4. 58 & 24 & 4 & 4. 45 & 20 & 8 & 4. 39 & Mar. 3 & 4 & 4. 76 \\
\hline 14 & 4 & 4. 67 & Oct. 8 & 3 & 4. 69 & 21 & 7 & 4. 41 & & 3 & 4. 99 \\
\hline 21 & 4 & 4. 78 & & 7 & 4. 76 & $\begin{array}{l}23 \\
25\end{array}$ & 6 & 4. 38 & 7 & 4 & 4. 76 \\
\hline & & & 12 & $\begin{array}{l}8 \\
4\end{array}$ & $\begin{array}{l}4.77 \\
4.52\end{array}$ & $\begin{array}{l}25 \\
26\end{array}$ & $\begin{array}{l}4 \\
6\end{array}$ & $\begin{array}{l}\text { 4. } 35 \\
4.49\end{array}$ & 9 & 3 & 4. 89 \\
\hline Jan. 5 & 3 & 4. 53 & $\begin{array}{l}10 \\
14\end{array}$ & 8 & $\begin{array}{l}\text { 4. } 52 \\
4.63\end{array}$ & 27 & $\begin{array}{l}0 \\
4\end{array}$ & $\begin{array}{l}\text { 4. } 49 \\
\text { 4. } 62\end{array}$ & $\begin{array}{l}10 \\
12\end{array}$ & $\begin{array}{l}4 \\
4\end{array}$ & $\begin{array}{l}\text { 4. } 83 \\
4.89\end{array}$ \\
\hline & 4 & 4. 73 & 25 & 4 & 4. 80 & 30 & 4 & 4. 44 & 21 & 4 & 5. 01 \\
\hline 9 & 4 & 4. 77 & 26 & 8 & 4. 75 & 31 & 4 & 4. 49 & & 4 & 4. 81 \\
\hline 10 & 4 & 4. 63 & 29 & 7 & 4. 96 & Aug. 4 & 6 & 4. 53 & Apr. 3 & 4 & 5. 15 \\
\hline $\begin{array}{l}18 \\
24\end{array}$ & $\begin{array}{l}4 \\
4\end{array}$ & $\begin{array}{l}\text { 4. } 83 \\
\text { 4. } 56\end{array}$ & Nov. $\frac{1}{2}$ & $\begin{array}{l}8 \\
8\end{array}$ & $\begin{array}{l}4.95 \\
4.59\end{array}$ & $\begin{array}{l}6 \\
7\end{array}$ & $\begin{array}{l}7 \\
3\end{array}$ & 4. 44 & 4 & 3 & 4. 75 \\
\hline & 4 & 4. 48 & 6 & 8 & 4. 85 & 11 & $\begin{array}{l}0 \\
4\end{array}$ & $\begin{array}{l}\text { 4. } \\
\text { 4. } 45\end{array}$ & $\begin{array}{r}0 \\
13\end{array}$ & $\begin{array}{l}4 \\
4\end{array}$ & $\begin{array}{l}4.84 \\
4.89\end{array}$ \\
\hline & 8 & 4. 43 & 7 & 8 & 4. 83 & 13 & 4 & $\begin{array}{l}\text { 4. } 49 \\
\text { a }\end{array}$ & $\begin{array}{l}10 \\
16\end{array}$ & 2 & 4. 89 \\
\hline Feb. $\quad 3$ & 8 & 4. 51 & 13 & 4 & 4. 79 & 25 & 4 & 4. 31 & 19 & 4 & 4. 67 \\
\hline & $\begin{array}{l}4 \\
8\end{array}$ & $\begin{array}{l}\text { 4. } 53 \\
\text { 4. } 57\end{array}$ & $\begin{array}{l}16 \\
21\end{array}$ & $\begin{array}{l}4 \\
2\end{array}$ & $\begin{array}{l}\text { 4. } 86 \\
\text { 5. } 21\end{array}$ & $\begin{array}{l}26 \\
29\end{array}$ & $\begin{array}{l}4 \\
4\end{array}$ & $\begin{array}{l}\text { 4. } 38 \\
\text { 4. } 48\end{array}$ & $\begin{array}{l}20 \\
23\end{array}$ & $\begin{array}{l}4 \\
3\end{array}$ & $\begin{array}{l}4.68 \\
4.79\end{array}$ \\
\hline
\end{tabular}


TABLE XXVIII.-Daily Mean Latitude, All Corrections Applied-Continued

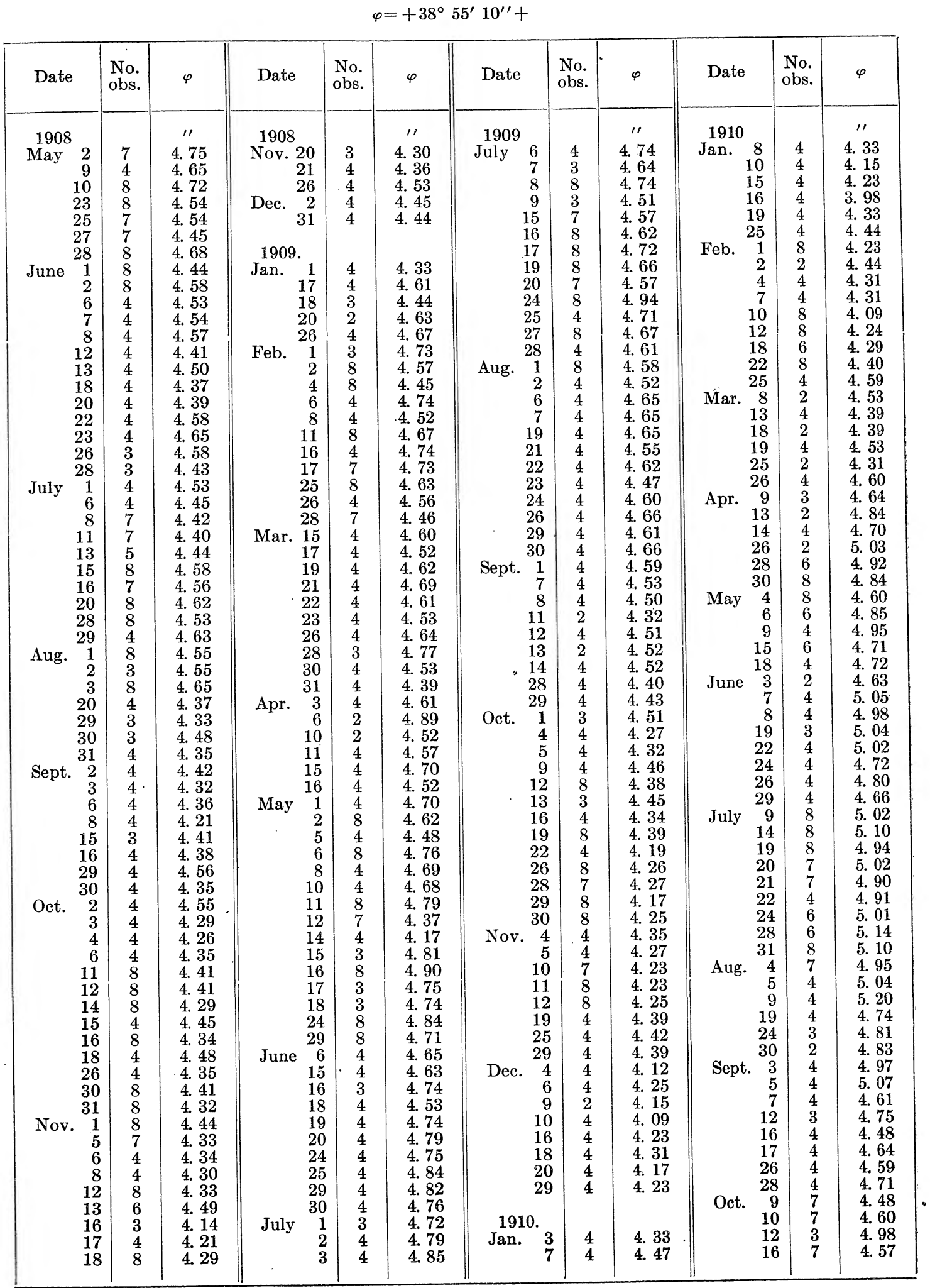


TaBle XXVIII.-Daily Mean Latitude, All Corrections Applied-Continued

$\varphi=+38^{\circ} 55^{\prime} 10^{\prime \prime}+$

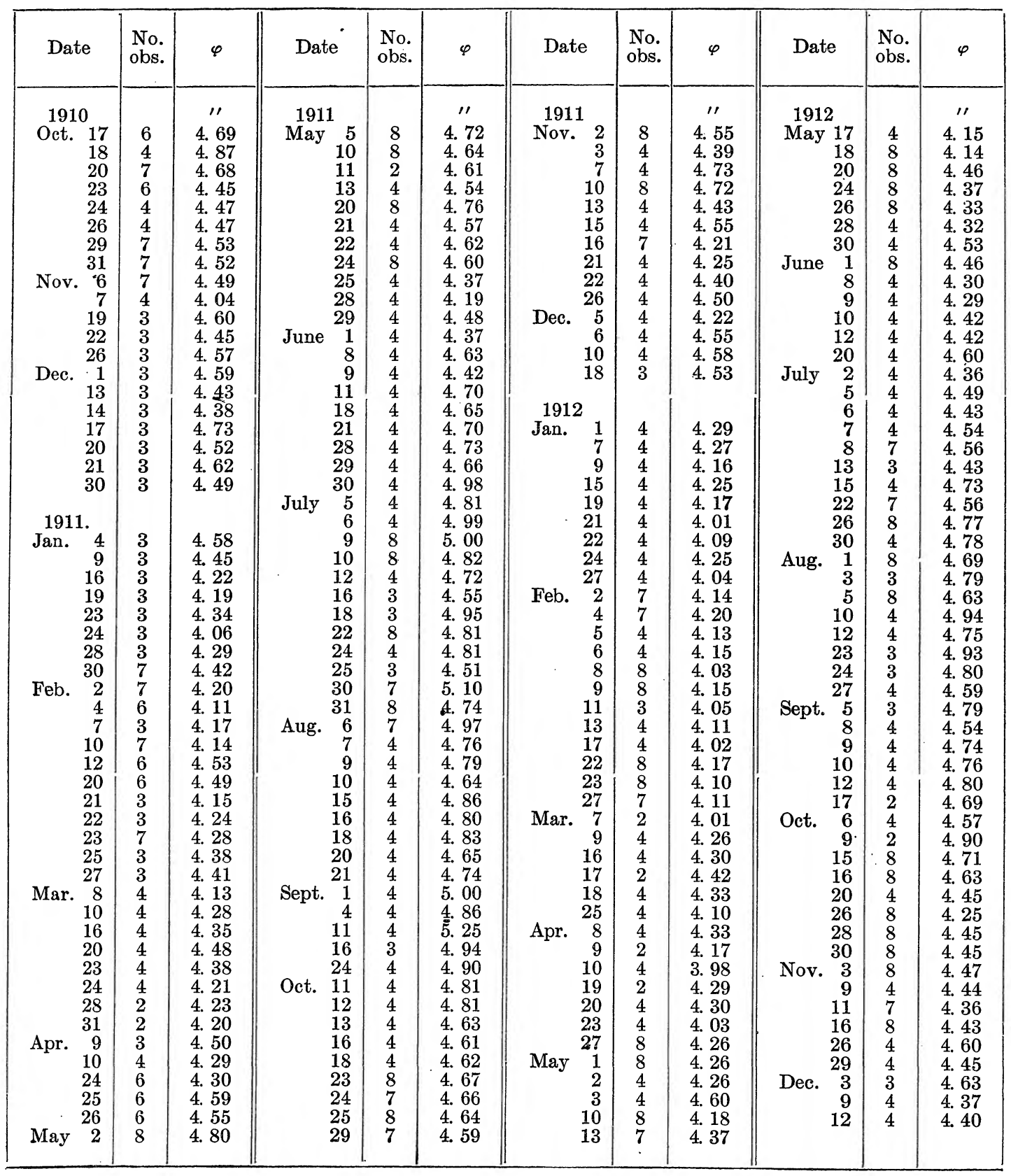


INTRODUCTION.

A CCVII

TABLE XXIX.-Final Values of Latitude

$+38^{\circ} 55^{\prime} 10^{\prime \prime}+$

\begin{tabular}{|c|c|c|c|c|c|c|c|c|c|c|c|}
\hline \multicolumn{2}{|l|}{ Limiting dates } & $\tau$ & \multirow[t]{2}{*}{$\begin{array}{l}\text { No. } \\
\text { nights }\end{array}$} & \multirow[t]{2}{*}{$\begin{array}{l}\text { No. } \\
\text { obs. }\end{array}$} & \multirow[t]{2}{*}{$\varphi$} & \multicolumn{2}{|l|}{ Limiting dates } & \multirow[t]{2}{*}{$\tau$} & \multirow[t]{2}{*}{$\begin{array}{l}\text { No. } \\
\text { nights }\end{array}$} & \multirow[t]{2}{*}{$\begin{array}{l}\text { No. } \\
\text { obs. }\end{array}$} & \multirow[t]{2}{*}{$\varphi$} \\
\hline & & & & & & & & & & & \\
\hline $\begin{array}{l}\text { Mar. 9-Apr. } \\
\text { Apr. 21-May }\end{array}$ & 20 & $\begin{array}{r}1904.261 \\
339\end{array}$ & 10 & 37 & 4. 422 & Nov. 20-Feb. & 1 & 1908. 902 & 11 & 39 & 4. 493 \\
\hline $\begin{array}{l}\text { Apr. 21-May } \\
\text { May 12-June }\end{array}$ & 11 & $\begin{array}{r}339 \\
392\end{array}$ & 7 & 42 & 4. 429 & Feb. 2-Feb. & 16 & 1909. 108 & 6 & 36 & 4. 598 \\
\hline $\begin{array}{l}\text { May } \text { 12-June } \\
\text { June 8-July }\end{array}$ & $\begin{array}{l}3 \\
2\end{array}$ & $\begin{array}{l}.392 \\
.466\end{array}$ & $\begin{array}{l}10 \\
11\end{array}$ & $\begin{array}{l}40 \\
41\end{array}$ & $\begin{array}{l}\text { 4. } 502 \\
4.708\end{array}$ & Feb. 17-Mar. & 19 & .174 & 7 & $\begin{array}{l}38 \\
35\end{array}$ & 4. 594 \\
\hline 6-July & 20 & .533 & 6 & $\begin{array}{l}41 \\
43\end{array}$ & $\begin{array}{l}\text { 4. } 708 \\
\text { 4. } 756\end{array}$ & $\begin{array}{l}\text { Mar. 21-Apr. } \\
\text { Apr. 11-May }\end{array}$ & $\begin{array}{r}10 \\
8\end{array}$ & $\begin{array}{l}.242 \\
.320\end{array}$ & $\begin{array}{r}10 \\
8\end{array}$ & $\begin{array}{l}35 \\
40\end{array}$ & $\begin{array}{l}\text { 4. } 604 \\
\text { 4. } 642\end{array}$ \\
\hline July 26-Aug. & 15 & .595 & 8 & 40 & 4. 798 & May 10-May & 17 & .367 & 7 & 37 & 4. 655 \\
\hline Aug. 23-Oct. & 1 & .710 & 9 & 33 & 4. 663 & May 18-June & 20 & .437 & 9 & 42 & 4. 719 \\
\hline Oct. 3-Oct. & 18 & .780 & 8 & 33 & 4. 598 & June 24-July & 8 & .500 & 10 & 42 & 4. 767 \\
\hline Oct. 22-Nov. & 6 & .829 & 7 & 45 & 4. 724 & July 9-July & 20 & .540 & 6 & 41 & 4. 622 \\
\hline Nov. 11-Dec. & 29 & 1904. 894 & 7 & 35 & 4. 698 & July 24-Aug. & 6 & .576 & 7 & 40 & 4. 687 \\
\hline Dec. 30-Jan. & 30 & 1905. 038 & 11 & 43 & 4. 731 & Aug. 7-Aug. & 29 & .639 & 8 & 32 & 4. 601 \\
\hline Feb. $\quad 4$-Feb. & 24 & .123 & 6 & 40 & 4. 542 & Aug. 30-Sept. & 28 & . 694 & 9 & 32 & 4. 516 \\
\hline Feb. 26-Apr. & 14 & .224 & 10 & 42 & 4. 685 & Sept. 29-Oct. & 16 & .768 & 8 & 34 & 4. 388 \\
\hline - Apr. 17-May & 7 & .320 & 8 & 36 & 4. 678 & Oct. 19-Oct. & 29 & .816 & 5 & 35 & 4. 263 \\
\hline May 8-June & 3 & .384 & 8 & 40 & 4. 734 & Oct. 30 -Nov. & 12 & .852 & 6 & 39 & 4. 248 \\
\hline Oct. 28-Jan. & 6 & 1905.887 & 9 & 38 & 4. 665 & Nov. 19-Dec. & 20 & 1909. 932 & 10 & 38 & 4. 255 \\
\hline Jan. 9-Feb. & 3 & 1906. 060 & 7 & 36 & 4. 569 & Dec. 29-Jan. & 25 & 1910. 030 & 9 & 36 & 4. 277 \\
\hline 4-Feb. & 16 & .112 & 6 & 40 & 4. 493 & Feb. 1-Feb. & 18 & .106 & 7 & 40 & 4. 240 \\
\hline Feb. 19-Mar. & 5 & .156 & 8 & 40 & 4. 568 & Feb. 22-Apr. & 13 & .210 & 10 & 35 & 4. 506 \\
\hline Mar. 17-Apr. & 23 & .259 & 10 & 39 & 4. 404 & Apr. 14-May & 15 & .331 & 8 & 44 & 4. 797 \\
\hline Apr. 27-May & 19 & .350 & 7 & 35 & 4. 587 & May 18-July & 9 & .458 & 10 & 41 & 4. 884 \\
\hline May 21-June & 11 & .406 & 8 & 43 & 4. 487 & July 14-July & 24 & .550 & 6 & 40 & 4. 986 \\
\hline June 22-July & 24 & .515 & 11 & 48 & 4. 643 & July 28-Aug. & 24 & .601 & 7 & 36 & 5. 018 \\
\hline Sept. 7-Oct. & 12 & .735 & 8 & 35 & 4. 694 & Aug. 30-Sept. & 28 & .699 & 9 & 33 & 4. 733 \\
\hline Oct. 13-Nov. & 1 & .812 & 6 & 39 & 4. 786 & Oct. 9-Oct. & 18 & .783 & 6 & 34 & 4. 650 \\
\hline Nov. 2-Nov. & $2 \overline{2}$ & 1906.867 & 7 & 38 & 4. 821 & Oct. 20-Oct. & 31 & .817 & 6 & 35 & 4. 518 \\
\hline Nov. 23-Feb. & 6 & 1907.106 & 9 & 39 & 4. 822 & Nov. 6-Dec. & 20 & 1910.912 & 10 & 35 & 4. 469 \\
\hline Feb. 8-Mar. & 16 & .145 & 6 & 36 & 4. 696 & Dec. 21-Jan. & 30 & 1911. 037 & 10 & 34 & 4. 372 \\
\hline Mar. 20-May & 4 & .275 & 11 & 40 & 4. 482 & Feb. 2-Feb. & 21 & .114 & 7 & 38 & 4. 266 \\
\hline May 9-May & 27 & .371 & 8 & 44 & 4. 504 & Feb. 22-Mar. & 23 & .179 & 9 & 36 & 4. 320 \\
\hline May 28-July & 4 & .459 & 10 & 41 & 4. 465 & Mar. 24-May & 2 & .281 & 9 & 41 & 4. 474 \\
\hline July 8-July & 21 & .537 & 6 & 39 & 4. 433 & May 5-May & 22 & . 369 & 7 & 38 & 4. 661 \\
\hline July 23-Aug. & 6 & .576 & 8 & 41 & 4. 463 & May 24-June & 18 & . 421 & 9 & 40 & 4. 501 \\
\hline Aug. 7-Sept. & 20 & .658 & 9 & 34 & 4. 423 & June 21-July & 10 & .500 & 8 & 40 & 4. 851 \\
\hline Sept. 25-Oct. & 13 & .754 & 8 & 37 & 4. 604 & July 12-July & 31 & .556 & 8 & 40 & 4. 806 \\
\hline Oct. 14-Oct. & 21 & . 792 & 5 & 36 & 4. 660 & Aug. 6-Aug. & 20 & .614 & 8 & 35 & 4. 803 \\
\hline Oct. 23-Nov. & 4 & .820 & 5 & 35 & 4. 660 & Aug. 21-Oct. & 12 & . 710 & 8 & 31 & 4. 913 \\
\hline Nov. 7 -Nov. & 25 & 1907.873 & 6 & 35 & 4. 657 & Oct. 13-Oct. & 25 & .802 & 6 & 35 & 4. 644 \\
\hline Jan. 3-Jan. & 19 & 1908. 030 & 9 & 36 & 4. 856 & Oct. 29-Nov. & 13 & .848 & 6 & 35 & 4. 585 \\
\hline Jan. 24-Feb. & 7 & .081 & 7 & 38 & 4. 731 & Nov. 15-Dec. & 10 & 1911. 903 & 8 & 35 & 4. 391 \\
\hline Feb. 8-Mar. & 3 & .146 & 8 & 38 & 4. 626 & Dec. 18-Jan. & 24 & 1912. 030 & 9 & 35 & 4. 216 \\
\hline Mar. 4-Apr. & 6 & .216 & 10 & 37 & 4. 893 & Jan. 27-Feb. & 9 & .096 & 7 & 42 & 4. 121 \\
\hline Apr. 13-May & 10 & .316 & 8 & 36 & 4. 742 & Feb. 11-Mar. & 7 & .141 & 7 & 36 & 4. 101 \\
\hline May 23-June & 1 & .404 & 5 & 38 & 4. 532 & Mar. 9-Apr. & 23 & 253 & 11 & 38 & 4. 218 \\
\hline June 2-June & 22 & .447 & 9 & 40 & 4. 505 & Apr. 27-May & 13 & .345 & 6 & 39 & 4. 298 \\
\hline June 23-July & 13 & .506 & 8 & 37 & 4. 471 & May 17-May & 28 & .392 & 6 & 40 & 4. 307 \\
\hline July 15-Aug. & 1 & .560 & 6 & 43 & 4. 523 & May 30-July & 5 & .453 & 9 & 40 & 4. 433 \\
\hline Aug. 2-Sept. & & .637 & 9 & 37 & 4. 448 & 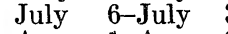 & 30 & .541 & 8 & 41 & 4. 615 \\
\hline Sept. 8-Oct. & 6 & .738 & 9 & 35 & 4. 372 & 1-Aug. & 27 & .618 & 8 & 37 & 4. 736 \\
\hline Oct. 11-Oct. & 16 & .786 & 5 & 36 & 4. 372 & Sept. 5-Oct. & 15 & .721 & 9 & 35 & 4. 711 \\
\hline Oct. 18-Nov. & 5 & .828 & 6 & 39 & 4. 384 & Oct. 16-Nov. & 3 & .818 & 6 & 44 & 4. 450 \\
\hline Nov. 6-Nov. & 18 & .870 & 7 & 37 & 4. 317 & Nov. 9-Dec. & 12 & 1912.903 & 8 & 38 & 4. 443 \\
\hline
\end{tabular}



A CCVIII
PRIME VERTICAL TRANSIT INSTRUMENT.
A DETERMINATION OF THE CONSTANT OF NUTATION FROM OBSERVED DECLINATIONS OF $\alpha$ LYRAE, 1893-1912

One of the primary purposes of observing the declinations of $\alpha$ Lyræ over so long a period of time was to continue them through a Dracontic cycle. The total motion of the moon's node in the interval of time covered by the observed positions is $366^{\circ}$.

The plan mentioned above was carefully considered just after the remodeled prime vertical transit had been installed at the new Naval Observatory, in a conference between the superintendent (Capt. F. V. McNaIR, United States Navy) and the writer. In that conference the latter volunteered to observe $\alpha$ Lyræ through the above period, and he was assigned to the work by order of the superintendent.

Just at this point it may be well to mention several circumstances involved in such a long program of observing. Except in a few instances all observed positions of $\alpha$ Lyræ were secured by the writer.

In the interval of time between 1893.5 and 1912.9 the form of the instrument, as well as the manner in which it is mounted on the piers was not changed, except as follows: In the fall of 1904 the instrument was dismantled in order to have the pivots refigured, to repaint the cube and the tubes, to clean the setting circles and the object glass.

In 1910 a new micrometer was substituted for the old one. In the new micrometer there was introduced a different spacing of the transit threads.

The mounting which supports the instrument upon the piers; the apparatus by which the telescope is reversed in its Y's; the means by which the level frame is reversed, and the method of illuminating the transit threads have not been changed from the commencement of the observations to the time when they were finished. The same level tube was used. The manner of reading the ends of the bubble in the tube and the number of readings made each time a star was observed have in each case been the same throughout the work. One method of recording transits has been used, that is by registering the signals of a "break circuit key" on a chronograph.

The above statement concerning the instrument, its auxiliary, apparatus, and the method of observing is repeated here to bring clearly to the attention of the reader that one plan of operating the instrument was adopted and followed.

In connection with the observed positions of $\alpha$ Lyræ it is emphasized that the whole mass of material is based upon the adoption of a constant value for the latitude; the use of the same constants of precession and nutation (STRUVE-PETER's), aberration $\left(20.5^{\prime \prime}\right)$ and yearly proper motion $\left(+0.275^{\prime \prime}\right)$.

These facts are presented to point out that practically all the observations which are included in the determination of the nutation constant were made by one observer, and therefore personal errors which might be due to several observers engaging in the work are not involved. Moreover, all the observations have been reduced to mean and epoch places with the same set of constants and necessary secular changes.

Before we consider the observed declinations which are to be used in obtaining absolute terms in the equations of condition, we again refer to the circumstance 
that after these observations had been continued for a short period, an examination of the results which were obtained at or near midnight when compared with those secured near midday, plainly indicated that the night declinations were systematically larger than the noon values.

Later, when all declinations had been corrected by a more accurate value of the yearly proper motion of the star, it was evident that the first value was in error by at least $+0.02^{\prime \prime}$ per year. The individual declinations for all years were collected together by days in a year. These were formed into 31 group means, each of which covered a period of six days. When these groups were tabulated, there was revealed very markedly the existence of what has been termed the daylight effect, by an intercomparison of the declination observed in the middle of the day and during the night.

For that reason it became necessary to study carefully whether these daylight declinations so affected could be used both in determining a correction to the proper motion of the star and also to the nutation used.

A number of theories may be suggested for the cause of this effect upon declinations which have been obtained with a prime vertical transit. The theory might be advanced with some possibility of its correctness that this effect is due entirely to the form of the house in which the instrument is mounted.

In the section in which this matter has been touched upon we have considered the other probable causes for the anomaly, but at this point in the discussion we are to examine whether day declinations thus affected should be combined with the night declinations, from which to obtain yearly or semi-yearly means for the purposes just mentioned.

We therefore ask these questions:

1. Should the presumption be made that an observed declination of a star which has been secured in the daytime can be reduced to what it would have been had the position been observed when the sun was below the horizon, by the application of a correction to the day observation?

2. Is the application of such a correction fundamentally correct?

3. Should daylight observations thus corrected be combined with the night observations for the purpose of obtaining a yearly mean in which both will be included?

We will now consider these three questions. The declinations of $\alpha$ Lyræ were plotted, using as reference points the positions based upon these six day means. The hourly latitudes given in Table XI were also plotted. In the first instance it appears that this variability in the values of the declinations of $\alpha$ Lyræ very roughly approximate to a cosine curve varying with the hour angle of the sun, but this is only an approximation. As the curve approaches the time of sunrise or of sunset, with the star in the meridian, the deviations are too great to assume that the variability is represented by this curve.

A trial was also made of plotting these declinations and comparing the plotted points with a curve based upon the cosine of the sun's azimuth when $\alpha$ Lyræ was observed in day light. In the writer's opinion neither of these curves shows with reliability that these changing values are following either law. When it is under$101141^{\circ}-26 \dagger-P T$ I -14 
stood that the actual value of the correction to the nutation constant will be a quantity of the order of a few hundredths of a second of arc, it may be stated with confidence that to apply a correction to the day declinations, the nature of which may be due to other causes than those which have been assumed, would not be advisable.

In this discussion we are considering a type of astronomical instrument in which the method of observing is such that it has always been assumed that the transit times, and the deduced declinations or latitudes, do not need corrections for refraction. The observer is not supposed to be concerned with the necessity of measuring either the density or the temperature of the air, as they are not used in the reduction of the observed declination.

We have expanded this subject quite fully, because in a search through publications containing declinations observed with a prime vertical instrument, when the observations were made both in the day and at night, we have been unable to find a discussion of a similar variability in any long series of observations which might be compared with our results and from which a criterion might be established upon which to construct a proper theory.

In Astronomische Nachrichten, Band 201, No. 4811, Dr. E. Przybyllok discusses the subject of house refraction in latitude determinations. With the aid of data compiled from observed latitudes, all of which were determined with prime vertical transit instruments, he shows by charts upon which those latitudes have been plotted this varying condition in the latitude which he calls house refraction. The observations which he has used were made at Pulkova in 1840-1842 and in 1890-1892; Washington, 1862-1867; Christiania, 1910-1911; and Pino, near Turin, Italy, 1912-1913.

The observations which were used in investigating this house temperature effect at Pino were of the stars $\alpha$ and $\delta$ Cygni, $\psi$ Urs. Majoris, and $\beta$ Aurigæ. These observations extend over a short period, namely, the years 1912-1913.

When latitudes which were obtained from observed positions of $\alpha$ and $\delta$ Cygni are plotted they both show a more accordant curve indicative of the change in the value of the latitude in different parts of the day than do similar latitudes when plotted, which are based upon observations of $\psi$ Urs. Majoris and $\beta$ Aurigæ. The differences of the latitudes derived from the two stars in Cygnus, as between midnight and midday, is approximately $0.6^{\prime \prime}$. This is a larger variation than has been found in the case of $\alpha$ Lyræ which was observed with our instrument.

The Pino Observatory is most fortunate in its location in latitude $\left(+45^{\circ} 2^{\prime}\right)$, to have available for a study of this anomaly four stars so well spaced in right ascension, whose magnitudes will permit of their being observed at any time in the day with an object glass whose diameter is about the same as that of our instrument.

The four stars used at Pino had the following magnitudes and positions:

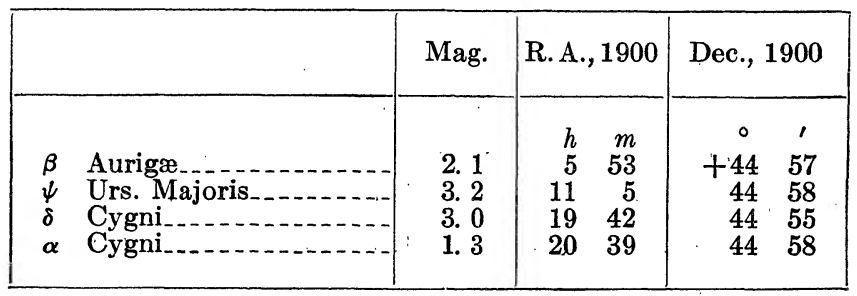


At the present time it is understood that the observers at Pino are carrying on a continuous series of observations of the above stars.

It is the opinion of the writer that until more extended data have been secured concerning this anomaly as between day and night declinations, and until the observed positions of all stars thus compared have been corrected for the variation of the latitude as well as any parallax each might have, it will be difficult to make an accordant comparison of this daylight effect in any two or more sets of observations which have been made at different observatories.

Therefore it was decided not to use the day declinations in combination with those observed after the sum was below the horizon in the nutation determination, and the same plan was followed as is outlined under the discussion of the parallax of $\alpha$ Lyræ.

Hence all declinations of that star which were observed between April 7 and October 7 in each year were utilized in forming the yearly means to be used in the proper motion and nutation discussion. Those made prior to April 7 and after October 7 were not used. The above dates correspond to the time when it is sunrise or sunset, respectively, with the star on the meridian. It should be remembered, however, that on April 7 in each year the transit of the star across the east vertical occurs about 30 minutes before sunrise, and the west transit 30 minutes after sunrise. On October 7 in each year that condition with respect to sunset would be reversed.

To prepare the data to be used in this discussion all observed night declinations were corrected for variations of latitude taken from Table XIII; for the parallax of the star, using the value $+0.123^{\prime \prime}$; for a proper motion of $+0.301^{\prime \prime}$; and for an aberration of $20.580^{\prime \prime}$, the value resulting from the parallax determination.

General means of these yearly declinations were then formed; in some years in two groups and in others only one. These yearly or half-yearly means are shown in Table XXX, in the fourth column. The differences between the mean of each group and the individual declinations therein were taken, and from them were computed the probable error of each general mean, and also that of a single declination. Those quantities are shown in columns 5 and 6 of the same table.

An assumption was then made of the probable error of a fictitious standard mean, to which was assigned a weight of one, as follows:

Let $e_{0}$ equal the value of this fictitious probable error, $e_{1}$ that of each general mean, and $w$ the weight; then

$$
w=\frac{e_{0}^{2}}{e_{1}^{2}}
$$

The values of the logarithms of these different weights are shown in column 11 of Table XXX. 
TABLE XXX.-Computation of a Correction to Peters' Constant of Nutation from Night Declinations of a Lyræ, Observed from 1893.6 to 1912.9

Assumed declination, $1900.0+38^{\circ} 41^{\prime} 25.800^{\prime \prime}$

\begin{tabular}{|c|c|c|c|c|c|c|c|c|c|c|c|}
\hline Year & $\begin{array}{c}\text { Day in } \\
\text { year }\end{array}$ & $\begin{array}{l}\text { No. } \\
\text { obs. }\end{array}$ & $\begin{array}{r}\text { Obs } \\
\text { declir } \\
190\end{array}$ & $\begin{array}{l}\text { erved } \\
\text { cation, } \\
0.0\end{array}$ & $\begin{array}{c}\text { p. e. } \\
\text { single } \\
\text { obs. }\end{array}$ & $\begin{array}{l}\text { p. e. } \\
\text { year } \\
\text { mean }\end{array}$ & $n$ & $\begin{array}{l}\text { Long; } \\
\text { Moon's } \\
\text { node }\end{array}$ & $\begin{array}{l}2 \text { Sun's } \\
\text { long }\end{array}$ & $\begin{array}{c}\text { Moon }+ \\
\text { Sun } \\
\text { terms }= \\
\frac{d \delta_{0}}{d \nu}\end{array}$ & $\begin{array}{l}\text { Log. } \\
\text { weight }\end{array}$ \\
\hline & & & $\circ \quad 1$ & ' & 11 & $\prime \prime$ & 11 & & $0 \quad 1$ & & \\
\hline $\begin{array}{l}1893.686 \\
1894.378\end{array}$ & Sept. 6 & 20 & +3841 & 25. 676 & \pm 0.147 & \pm 0.032 & +0.124 & 2121 & $\begin{array}{ll}328 & 09\end{array}$ & -.862 & 0. 36489 \\
\hline $\begin{array}{l}1894.378 \\
1894.626\end{array}$ & May 17 & 28 & & .883 & .153 & .029 & -.083 & 757 & 11304 & -1.029 & .47477 \\
\hline $\begin{array}{l}1894.626 \\
1895.410\end{array}$ & Aug. 16 & 29 & & .758 & 207 & 039 & +.042 & 308 & 28708 & -.972 & 22781 \\
\hline $\begin{array}{l}1895.410 \\
1895.701\end{array}$ & May 29 & 26 & & .824 & 134 & 026 & -.024 & $347 \quad 59$ & 13538 & -1.024 & 55730 \\
\hline $\begin{array}{l}1895.70 \\
1896.39\end{array}$ & $\begin{array}{l}\text { Sept. } 12 \\
\text { May } 24\end{array}$ & $\begin{array}{l}26 \\
31\end{array}$ & & .803 & .127 & 025 & -.003 & 34222 & 33854 & -.797 & 60355 \\
\hline 1896 & $\begin{array}{l}\text { May } 24 \\
\text { Aug. } 17\end{array}$ & $\begin{array}{l}31 \\
31\end{array}$ & & 78 & 2 & . 036 & +.003 & $\begin{array}{l}328 \quad 52 \\
294\end{array}$ & 12730 & -.855 & . 27825 \\
\hline 189 & May 27 & $\begin{array}{l}01 \\
27\end{array}$ & & $\begin{array}{r}.658 \\
.792\end{array}$ & .151 & .024 & $\begin{array}{l}+.142 \\
+\quad 008\end{array}$ & $\begin{array}{l}324222 \\
309\end{array}$ & $\begin{array}{l}29002 \\
13248\end{array}$ & -. 713 & $\begin{array}{r}52894 \\
62271\end{array}$ \\
\hline 189 & Aug. 16 & 26 & & 874 & 147 & 029 & -.074 & 30506 & 28738 & $\begin{array}{r}-.619 \\
-.457\end{array}$ & $\begin{array}{r}62271 \\
47763\end{array}$ \\
\hline & June 11 & 27 & & 85 & . 120 & 023 & -.058 & $289 \quad 16$ & 16102 & $\begin{array}{r}.108 \\
-.339\end{array}$ & $\begin{array}{r}47.03 \\
67128\end{array}$ \\
\hline & Sept. 3 & 28 & & .8 & .173 & 033 & -.033 & $284 \quad 49$ & 32156 & -.059 & .36652 \\
\hline 189 & May 20 & 35 & & .949 & .118 & 020 & -.149 & 27106 & 11826 & +.043 & 79504 \\
\hline & Aug. 21 & 36 & & 91 & .09 & 016 & -.112 & 26610 & 29620 & +.215 & 96525 \\
\hline & July 28 & 20 & & .81 & .18 & 042 & -.018 & 24807 & 24948 & 409 & 15672 \\
\hline 190 & May 27 & 12 & & .67 & . 148 & 043 & +.124 & 23204 & 13058 & 623 & 13358 \\
\hline & May 20 & 17 & & .76 & 13 & 032 & +.037 & 21307 & 11702 & 845 & 38334 \\
\hline & Aug. 29 & 17 & & .926 & .127 & 031 & .126 & 2C? 46 & 31022 & 996 & 42042 \\
\hline & May 7 & 19 & & .81 & 12 & 029 & -.016 & 19428 & 9130 & + & \\
\hline & July 8 & 19 & & .72 & .170 & 039 & +.075 & 19111 & 21016 & +.873 & 21523 \\
\hline & May 27 & 29 & & .911 & .10 & 020 & -.111 & $174 \quad 02$ & 13130 & +.901 & 81689 \\
\hline & Aug. 30 & 28 & & .78 & 12 & 023 & +.011 & 1690 & 31318 & +1.025 & 66156 \\
\hline & May 17 & 11 & & .630 & .135 & 041 & 170 & 15546 & 9230 & +.871 & 17909 \\
\hline & June 27 & 34 & & .7. & 14 & 025 & +.084 & 13344 & 18948 & +.476 & \\
\hline & June 8 & 24 & & .85 & .11 & 023 & -.055 & 11524 & 15304 & .220 & 0. 68834 \\
\hline & Aug. 27 & 23 & & .873 & .075 & 016 & -.073 & 1111 & 3060 & 316 & 1. 01196 \\
\hline & June 6 & 28 & & .830 & .09 & 019 & -.030 & 960 & 15042 & -.105 & 0.85966 \\
\hline & Sept. 4 & 29 & & .695 & .13 & 024 & +.105 & 912 & 32304 & +.005 & .62921 \\
\hline & June 8 & 33 & & .90 & .12 & 022 & -.100 & 764 & 15404 & -.441 & .72490 \\
\hline 648 & Aug. 24 & 32 & & .71 & 099 & 018 & +.084 & 723 & $\begin{array}{lll}301 & 18\end{array}$ & 349 & 91145 \\
\hline & June 3 & 22 & & .74 & .09 & 020 & +.054 & 57 & 14402 & 714 & 79921 \\
\hline & Aug. 27 & 22 & & .81 & 15 & 033 & -.010 & 530 & 30638 & .619 & \\
\hline & May 30 & 21 & & .77 & .12 & 028 & 030 & 383 & 13554 & 922 & 50319 \\
\hline & Aug. 15 & 21 & & .76 & . 139 & 030 & +.031 & 342 & 28304 & -.866 & 43524 \\
\hline & June 1 & 20 & & .880 & .103 & 023 & -.080 & 1902 & $141 \quad 12$ & -1.059 & .67355 \\
\hline & Aug. 14 & 19 & & .735 & \pm .126 & \pm .029 & +.065 & 1507 & 28236 & -.972 & 0.47549 \\
\hline
\end{tabular}

Total number of observed declinations, 870 .

The numerical value adopted for this fictitious standard probable error was $\pm 0.05^{\prime \prime}$, corresponding to about $\pm 0.07^{\prime \prime}$ mean error. The mean date in each year of each of these several mean declinations, as well as the day in the year, are also shown in the table. Then follow the numerical expressions for the longitude of the moon's node and twice the sun's longitude, both of which have been taken from the American Ephemeris for days in a year corresponding to the mean date of each of these general means.

An examination of the probable error of each of the 35 means, and also that of a single observation included in each, leads to the propriety of the statement that these declinations should yield an accurate correction to the adopted nutation (Peters). It will be noted that the probable error of a single observation does not exceed $\pm 0.22^{\prime \prime}$ and for a mean the largest is $\pm 0.043^{\prime \prime}$.

We will now write the formulæ by the aid of which was computed the coefficient in an equation of condition for solving for $\Delta \mathrm{N}$ the correction to the adopted nutation. 
Let $\delta=$ the mean declination of the star at the given time,

$\delta^{1}=$ the true declination of the star at that time,

$\Omega=$ longitude of the Moon's node,

$\odot=$ longitude of the Sun,

$\alpha=$ right ascension of the star ( $a$ Lyræ).

We then have the following to express the difference between $\delta^{1}$ and $\delta$ as affected by this correction.

$\frac{d\left(\delta^{1}-\delta\right)}{d \nu}=-0.744 \sin \Omega \cos \alpha+1.000 \cos \Omega \sin \alpha+0.119 \sin 2 \odot \cos \alpha-0.129 \cos 2 \odot \sin \alpha$.

The sum of the numerical quantities which are expressed in the above equation will give the coefficients of $\Delta \mathrm{N}$. This latter quantity represents the correction to the adopted nutation. Moreover, the nutation is itself the coefficient of the cosine of the longitude of the moon's node in the expression for the nutation of the obliquity.

If we denote by $\delta_{0}$ an assumed value of the declination of the star ( $a$ Lyræ) at a certain epoch, which declination has been reduced to that epoch by the use of the adopted nutation (PETERs), and by $\delta^{\prime}$ the observed apparent declination, we can write $n=\left(\delta_{0}-\delta^{\prime}\right)$. In the values of $n$ thus formed there are involved three unknown quantities. They are the correction to the assumed declination, the correction to the adopted nutation as above expressed, and also the correction to the proper motion which has been used. The limits of value in $n$ of $\Delta \mathrm{N}$ are a function of $\frac{d\left(\delta^{\prime}-\delta\right)}{d \nu}$. This latter quantity we will now call $\frac{d \delta_{0}}{d \nu}$.

If we denote by $\Delta \delta$ the correction to the assumed declination $\delta_{0}$ then $\Delta \delta$ will be one of the unknowns to be determined. It $t$ represents the mean date of these observed declinations which have been formed into general means, and which have been reduced from date of observation to the one designated as $t_{0}(1900)$, with an assumed proper motion, then the third term of the equation of condition is, if $\Delta$ p. m. represents the correction to be determined to this assumed proper motion $\left(t-t_{0}\right) \Delta$ p.m.

Therefore each of the 35 equations of condition which have been used in solving for the values of the three unknowns mentioned, has the following form:

$$
\Delta \delta+\frac{d \delta_{0}}{d \nu} \cdot \Delta \mathrm{N}+\left(t-t_{0}\right) \Delta \text { p. mi }+n=0 .
$$

In computing values of $\frac{d \delta_{0}}{d \nu}$ the following method was used:

Let $u \sin U=+1.000 \sin a$

$u \cos U=-0.744 \cos a$

$v \sin V=-0.129 \sin a$

$v \cos V=+0.119 \cos \alpha$

then,

$$
\frac{d \delta_{0}}{d \nu}=u \sin (U+\Omega)+v \sin (V+2 \odot),
$$

in which $\Omega$ represents the longitude of the moon's node and $\odot$ the sun's longitude, for dates corresponding to each of the group means. 
By the aid of the 35 equations of condition which were formed as above explained, and which were based upon the data to be found in Table XXX, a least square solution was made to determine values of $\Delta \delta, \Delta \mathrm{N}, \Delta$ p. m., respectively.

From that solution there resulted the following normal equations:

$$
\begin{aligned}
& +140.909 x-17.584 y+583.049 z-2.433=0 \\
& -17.584 x+60.927 y-54.492 z-1.174=0 \\
& +583.049 x-54.492 y+6908.221 z-.655=0
\end{aligned}
$$

From the above normals were formed the following elimination equations in which the numbers in brackets are logarithms:

$$
\begin{aligned}
x+\left(9.096179_{n}\right) y+(0.616766) z+\left(8.237203_{n}\right) & =0 \\
y+(9.492761) z+\left(8.400792_{n}\right) & =0 \\
z+(7.342157) & =0
\end{aligned}
$$

With the aid of the above data the following values were found for each of the three unknowns, their probable errors, and relative weights:

$$
\begin{array}{llr}
x=\Delta \delta & =+0.0296^{\prime \prime} \pm 0.0116^{\prime \prime} & 88.9 \\
y=\Delta \mathrm{N} & =+.0258 \pm .0143 & 58.7 \\
z=\Delta \text { p. m. }=-.0022 \pm .0016 & 4490.0
\end{array}
$$

Applying the nutation correction found to the Peters' value for 1903, namely, $9.2240^{\prime \prime}$, we have

$$
9.2498^{\prime \prime}
$$

as the resulting value of the nutation from the observational data which was obtained with the prime vertical transit instrument.

Also applying the correction found to the adopted proper motion which was used in this part of the discussion $\left(+0.301^{\prime \prime}\right)$ we have as the yearly value of the proper motion in declination of a Lyræ,

$$
+0.2988^{\prime \prime} \text {. }
$$

In Table XXXI there is shown the substitutions of the values of $\Delta \delta, \Delta \mathrm{N}$ and $\Delta$ p. m. in each of the equations of condition, and in column 10 of that table will be found values of the residuals $v$.

From these residuals the probable error of each of the group means was found to be $\pm 0.110^{\prime \prime}$, and from this the probable error of each of the unknown quantities was obtained, as is shown above.

The value of the nutation constant which was adopted by the Paris Conference is

$$
9.21^{\prime \prime} \text {. }
$$

It is now used in practically all national ephemerides. This value of the nutation was suggested to that conference by Prof. S. Newcomb, United States Navy. On page 130 of his book ${ }^{2}$ Professor Newcomb presents 27 value of the nutation which have been determined by a number of astronomers. It was from those data that he derived the value of the nutation above mentioned.

${ }^{2}$ Astronomical Constants: Supplement to the American Ephemeris, 1897. 
TABLE XXXI.-The Substitution of the Values of $\Delta \delta, \Delta \mathrm{N}$, and $\Delta p$. m. into the Equations of Condition and Resulting Residuals

\begin{tabular}{|c|c|c|c|c|c|c|c|c|c|}
\hline No. & Year & $N$ & $\left(t-t^{0}\right)$ & $\Delta \delta+$ & $\frac{d \delta_{0}}{d \nu} \cdot \Delta \mathrm{N}+$ & $\begin{array}{c}\left(t-t^{0}\right) \\
\Delta \text { p. m. }\end{array}$ & $=$ sum & $+n .=$ & $v$ \\
\hline $\begin{array}{r}1 \\
2 \\
3 \\
4 \\
5 \\
6 \\
7 \\
8 \\
9 \\
10 \\
11 \\
12 \\
13 \\
14 \\
15 \\
16 \\
17 \\
18 \\
19 \\
20 \\
21 \\
22 \\
23 \\
24 \\
25 \\
26 \\
27 \\
28 \\
29 \\
30 \\
31 \\
32 \\
33 \\
34 \\
35\end{array}$ & $\begin{array}{l}1893.686 \\
1894.378 \\
1894.626 \\
1895.410 \\
1895.701 \\
1896.397 \\
1896.632 \\
1897.406 \\
1897.628 \\
1898.446 \\
1898.677 \\
1899.385 \\
1899.639 \\
1900.572 \\
1901.402 \\
1902.382 \\
1902.659 \\
1903.346 \\
1903.517 \\
1904.404 \\
1904.664 \\
1905.347 \\
1906.487 \\
1907.435 \\
1907.653 \\
1908.421 \\
1908.678 \\
1909.437 \\
1909.648 \\
1910.421 \\
1910.653 \\
1911.411 \\
1911.620 \\
1912.418 \\
1912.621\end{array}$ & $\begin{array}{r}-0.862 \\
-1.029 \\
-.972 \\
-1.024 \\
-.797 \\
-.855 \\
-.713 \\
-.619 \\
-.457 \\
-.339 \\
+.059 \\
+.043 \\
+.409 \\
+.623 \\
+.845 \\
+.996 \\
+.999 \\
+.873 \\
+.901 \\
+1.025 \\
+.871 \\
+.476 \\
+.220 \\
+.316 \\
. .105 \\
+.005 \\
-.441 \\
-.349 \\
-.714 \\
.619 \\
.922 . \\
-1.059 \\
-.972\end{array}$ & $\begin{array}{r}-6.31 \\
-5.62 \\
-5.37 \\
-4.59 \\
-4.30 \\
-3.60 \\
-3.37 \\
-2.59 \\
-2.37 \\
-1.55 \\
-1.32 \\
-\quad .62 \\
+.36 \\
+\quad .57 \\
+1.40 \\
+2.38 \\
+2.66 \\
+3.35 \\
+3.52 \\
+4.40 \\
+4.66 \\
+5.35 \\
+6.49 \\
+7.44 \\
+7.65 \\
+8.43 \\
+\quad 8.68 \\
+9.44 \\
+9.65 \\
+10.42 \\
+10.65 \\
+11.41 \\
+11.62 \\
+12.42 \\
+12.62\end{array}$ & +0.030 & $\begin{array}{c}\prime \prime \\
-0.022 \\
-.027 \\
-.025 \\
-.026 \\
-.021 \\
-.022 \\
-.018 \\
-.016 \\
-.012 \\
-.009 \\
.002 \\
+.001 \\
+.006 \\
+.011 \\
+.016 \\
+.022 \\
+.026 \\
+.026 \\
+.023 \\
+.023 \\
+.026 \\
+.022 \\
+.012 \\
+.006 \\
+.008 \\
-.003 \\
-.000 \\
.011 \\
.009 \\
.018 \\
-.024 \\
-.022 \\
-.027 \\
-.025\end{array}$ & 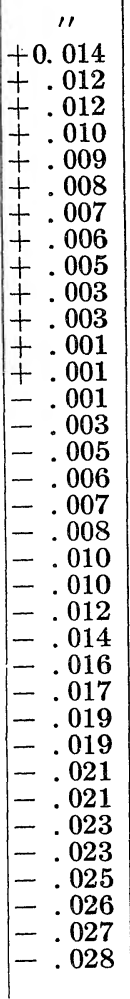 & $\begin{array}{r} \\
+0.022 \\
+.015 \\
+.017 \\
+.014 \\
+.018 \\
+.016 \\
+.019 \\
+.020 \\
+.023 \\
+.024 \\
+.031 \\
+.032 \\
+.037 \\
+.040 \\
+.043 \\
+.047 \\
+.050 \\
+.049 \\
+.045 \\
+.043 \\
+.046 \\
+.040 \\
+.028 \\
+.020 \\
+.021 \\
+.008 \\
+.011 \\
-.002 \\
-.000 \\
-.011 \\
-.009 \\
-.019 \\
-.018 \\
-.024 \\
-.023\end{array}$ & 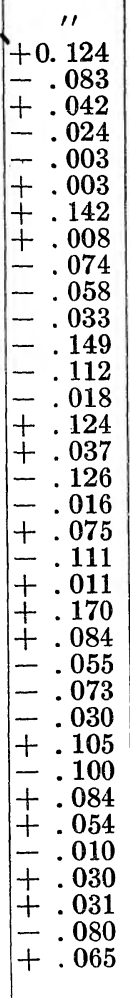 & $\begin{array}{r} \\
+0.146 \\
+.068 \\
+.059 \\
.010 \\
+.015 \\
+.019 \\
+.161 \\
+.028 \\
\pm .051 \\
-.034 \\
-.002 \\
-.117 \\
+.075 \\
+.022 \\
+.067 \\
+.076 \\
+.033 \\
+.120 \\
.068 \\
+.057 \\
+.210 \\
\pm .112 \\
.035 \\
.052 \\
.022 \\
+.116 \\
+.102 \\
+.084 \\
+.043 \\
+.019 \\
+.011 \\
+.013 \\
+.042\end{array}$ \\
\hline
\end{tabular}

$\Sigma w=140.91$

$\Sigma w v \nu=0.84782$

In that list there are four determinations whose values are larger than the one found in this discussion. There are 23 smaller values. Three of the larger values are based upon observations made at Pulkova, and one on observations made at Greenwich.

On page 129 of the above publication Professor Newcomb says relative to these 27 determinations, the "weights are assigned on the supposition that weight unity should correspond to a mean error of about \pm 0.07 ", or to a probable error of $\pm 0.05^{\prime \prime}$; this probable value being not entirely a matter of computation from the discordances of the separate results, but to a certain extent, a matter of judgment."

In this connection an examination of the data indicates that an unweighted mean of the 27 different values of the nutation which are shown on the page above mentioned will give the same value which was obtained by weighting the different determinations, namely,

$$
9.21^{\prime \prime}
$$


Moreover, the mean error which results when an unweighted mean is taken of those 27 values is $\pm 0.047^{\prime \prime}$. When those several values are weighted, as was done by Professor Newcomb, their mean error is $\pm 0.068^{\prime \prime}$.

Professor Newcomb subsequently derived another value for the nutation constant, namely,

$$
9.214^{\prime \prime} \text {, }
$$

based upon his adjustment of the mass of the moon. This latter value was not adopted by the Paris Conference. ${ }^{3}$

Dr. E. Przybyllok has published ${ }^{4}$ a discussion of the determination made by him of a correction to the nutation constant, based upon the observed latitudes which have been secured at the five astronomical stations which are under the control of the International Geodetic Association. The material used extended over a period of 15 years and from it he obtained a nutation constant of

$$
9.2069^{\prime \prime} \text {, }
$$

with a mean error of $\pm 0.0030^{\prime \prime}$ and a weight of 538 , based upon a mean error of $\pm 0.07^{\prime \prime}$ for weight unity.

In his memoir ${ }^{5}$ Prof. William Harkness, United States Navy, gives, on page 133, the value of the nutation constant which he derived from an adjustment of related astronomical constants, a list of which appear on that page.

He finds from a discussion of the material the value of the nutation constant for 1850.0

$$
9.2205^{\prime \prime} \pm 0.00859^{\prime \prime} \text {. }
$$

He also finds as the reciprocal of the mass of the moon

$$
81.068 \pm 0.238 \text {. }
$$

Professor Newcomb gives the results of determinations of the correction to the nutation of PeTERs which are based upon observations made at Greenwich and Washington. ${ }^{6}$ In that discussion he obtains the following corrections with the probable errors indicated:

$$
\begin{gathered}
\text { Greenwich southern stars, } 1851-1869, \Delta \mathrm{N}=-0.108^{\prime \prime} \pm 0.037^{\prime \prime} \\
\text { " } 1870-1887, \Delta \mathrm{N}=-.023^{\prime \prime} \pm .043^{\prime \prime} \\
\text { Circumpolars, } 1851-1869, \Delta \mathrm{N}=-.020^{\prime \prime} \pm .029^{\prime \prime} \\
\text { " } 1870-1887, \Delta \mathrm{N}=-.001^{\prime \prime} \pm .026^{\prime \prime} \\
\text { Washington southern stars, } 1866-1886, \Delta \mathrm{N}=-.006^{\prime \prime} \pm .023^{\prime \prime} \\
\text { northern " } 1866-1886, \Delta \mathrm{N}=-.047^{\prime \prime} \pm .037^{\prime \prime}
\end{gathered}
$$

In the collected Mathematical Works of the late George W. HILL ${ }^{7}$ there is a paper entitled, "On the Connection of Precession and Nutation with the Figure

3 Professor Newcomb's Compendium of Spherical Astronomy, p. 249.

4 (No. 36) Zentralbureau der Internationalen Erdmessung.

${ }^{5}$ The Solar Parallax and its Related Constants: Appendix III, Washington Observations, 1885.

${ }^{6}$ Astronomical Papers prepared for the use of the American Ephemeris and Nautical Almanac, Vol. II, Part VI, p. 482-484.

${ }^{7}$ The Collected Mathematical Works of George William Hill, published by the Carnegie Institution of Washington, 1907, Vol. IV, p. 11. 
of the Earth." In that paper Mr. HiLL discusses the reasons why the formulæ upon which the conclusions depend should be made more nearly rigorous.

In the problem of determining the mass of the moon and the moments of inertia of the earth with respect to two axes, there are involved two quantities which are derived from astronomical observations, $N$, the constant of nutation as defined by $\Delta \epsilon=N \cos \Omega$, and $P$, which is explained below.

If $P_{1}$ is that part of the precession of the equinox on the fixed ecliptic of the date, in seconds of arc and in a Julian year which is due to the action of the moon, and if $P_{2}$ is that part of the same precession which is due to the action of the sun, then the luni-solar precession $P$ equals $P_{1}+P_{2}$.

Let $A$ equal the mean moment of inertia of the earth relative to axes passing through the equator,

$C$, the same moment relative to its polar axis,

$M$, mass of the earth,

$m$, mass of the moon.

Without repeating all the steps necessary Mr. HuLL writes the formulas for $P$ and $N$ as follows:

$$
\begin{aligned}
& P=(3.6876097) \frac{C-A}{C}+(5.9375945) \frac{m}{M+m} \cdot \frac{C-A}{C} \\
& N=(5.3654318) \frac{m}{M+m} \cdot \frac{C-A}{C} .
\end{aligned}
$$

The numbers in brackets are logarithms, and these expressions give the quantities immediately in seconds of arc.

When it is desired to obtain $\frac{C-A}{C}$ and $\frac{m}{M+m}$ from given values of $P$ and $N$ the following formulas serve:

$$
\left.\begin{array}{rl}
\frac{C-A}{C} & =(6.3123903) P-(6.8845530) N \\
\frac{m}{M+m} & =\frac{(8.3221779) N}{P-(0.5721627) N}
\end{array}\right\} \text { Epoch 1850.0. }
$$

We would call to the attention of the reader that the logarithm in the denominator of the last formula, as printed on page 21 of the volume referred to, is incorrect. It should be as above, and not (0.05721627).

\section{RECIPROCAL OF THE MASS OF THE MOON.}

In ascertaining what would be the best modern determination of the value of the luni-solar precession to substitute in the above equation we have adopted the mean of the iollowing values of the general precession as given by DE SiTTER: ${ }^{8}$

$$
\begin{aligned}
& \text { Newcomb (with corrections by Hough and Hatm) }{ }^{9} \ldots \ldots \ldots \ldots \\
& \text { Boss }{ }^{10} \ldots \ldots \ldots \ldots \\
& \text { Drson and Thackeray }{ }^{11} \ldots \ldots \ldots \ldots \ldots \\
&
\end{aligned}
$$

${ }^{8}$ Koninklijke Akademie van Wetenschappen te Amsterdam, vol. 23, p. 1351.

$\because$ Monthly Notices, vol. 70, p. 587. Observatory, vol. 36, p. 299.

10 Astronomical Journal, vol. 26, p. 118.

11 Monthly Notices, vol. 65, p. 443. 